UC-NRLF

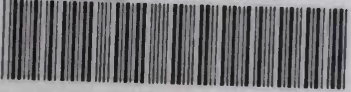

B 3300944 


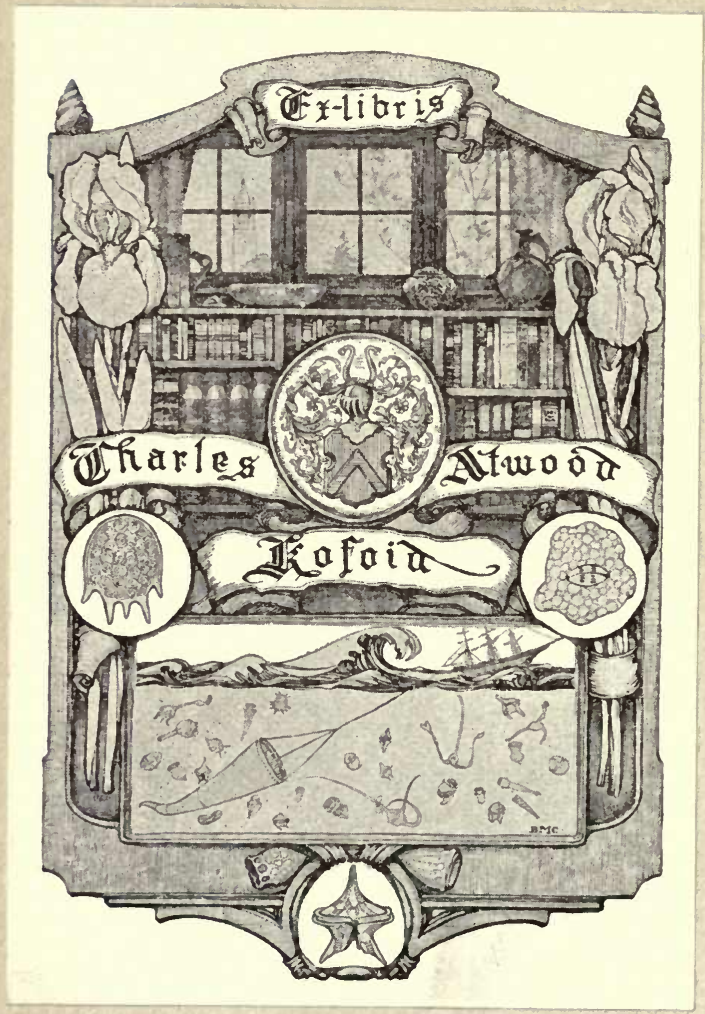




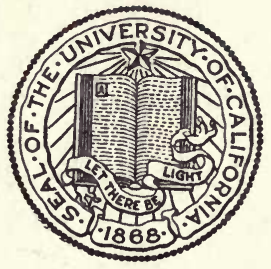

THE LIBRARY OF

THE UNIVERSITY OF CALIFORNIA

\author{
PRESENTED BY
}

PROF. CHARLES A. KOFOID AND MRS. PRUDENCE W. KOFOID 



\section{THE NATURAL HISTORY OF THE}

\section{BRITISH ISLANDS}






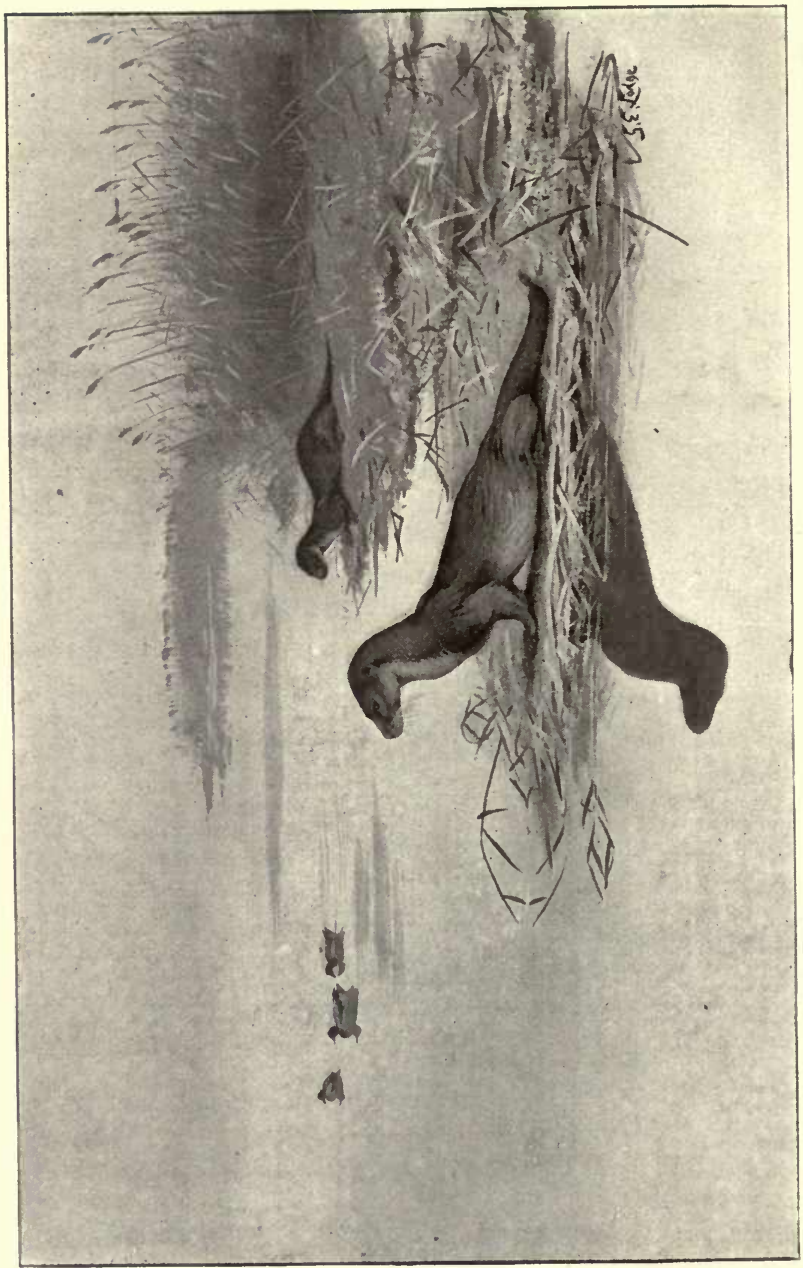

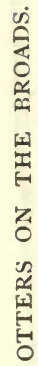




\section{A SKETCH OF}

\section{THE NATURAL HISTORY (VERTEBRATES)}

\section{OF THE \\ BRITISH ISLANDS}

WITH A

CONCISE BIBLIOGRAPHY OF POPULAR WORKS RELATING TO

THE BRITISH FAUNA

AND A LIST OF

FIELD CLUBS AND NATURAL HISTORY SOCIETIES

IN THE UNITED KINGDOM

BY

F. G. AFLALO, F.R.G.S., F.Z.S.

AUTHOR OF 'A SKFTCH OF THE NATURAL HISTORY OF AUSTRALIA,' ETC

WITH ILLUSTRATIONS

WILLIAM BLACKWOOD AND SONS

EDINBURGH AND LONDON

M DCC CX C III 

from a perusal of the bibliography given hereafter. Let me endeavour to express the unambitious aim of this little book. It is offered as no more than the merest outline, an introduction to the many excellent handbooks to county fauna enumerated in the bibliography, from which I may perhaps, without incurring the charge of making invidious distinctions, be allowed to indicate as admirable models the series prepared by Messrs Harvie-Brown and Buckley. What these and other county chroniclers have been able to give in detail, it has been my duty only to outline. The physical peculiarities of the various zoological divisions have, except in the introduction, been dealt with but incidentally; those of counties, which in no way conform to the natural boundaries, have been all but ignored. The great difficulty throughout, of course, has been compression; but it is hoped that, since it has been found impossible to give the whole truth, there has at any rate been included nothing but the truth. It will probably be noticed that slightly different methods of description have been adopted in the several cases of the mammals, birds, and fishes; but these have been thought to offer the most convenient aid in each case to identification. In short, the object of the following pages is to give some clue to the appearance and life-history of the 700 odd verte- 
brates which still, after generations of extermination, protection, and acclimatisation, either reside in or visit these islands. Their anatomy, their synonymies, and their range outside the British Islands, are all to be found elsewhere. The bibliography and list of field-clubs are added in the hope of assisting all who may desire to supplement the information here given by either reading or correspondence with local experts. Neither is offered as in any way complete; indeed, unavoidable delays in printing, of which this book is one of many victims, have conspired to prevent my including at least one fieldclub inaugurated since the list was closed, not to mention a number of later works, such as $R$. and C. Kearton's attractive book, 'With Nature and a Camera,' and Dr Laver's 'Mammals, Reptiles, and Fishes of Essex.' The Right Hon. Sir Herbert Maxwell has most kindly read the proof-sheets, and to both him and Mr J. E. Harting I am under obligation for a number of suggestions made while the book was passing through the press. To Dr Arthur Stradling I am also indebted for much assistance with the notes on reptiles, as well as for two very effective photographs of British snakes.

F. G. A.

Bounnemouth, December 1897. 



\section{CONTENTS.}

PAGE

INTRODUCTORY

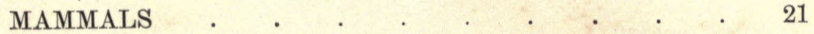

LIST OF BRITISH MAMMALS . . . . . . . 27 CHAP.

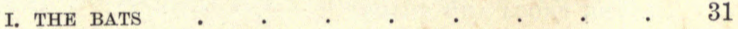

II. THE INSECTIVORA

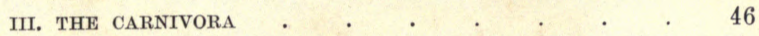

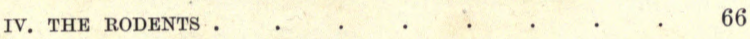

V. THE DEER

VI. THE WHALES AND PORPOISES . . . . . . 86

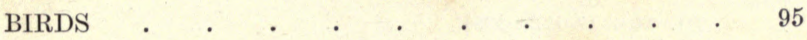

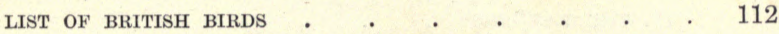

I. THE PERCHING BIRDS • . . . . . . . . 132

II. THE SWIFTS, WOODPECKERS, ETC. • . . . . 189

III. THE OWLS • • • • . . . . . 205

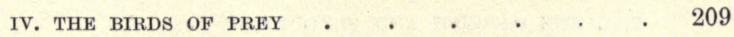

v. THE CORMORANT, SHAG, AND GANNET • . . 219

VI. THE HERONS, BITTERNS, AND STORKS . . . . 223

VII. THE FLAMINGO

VIII. THE GEESE, SWANS, AND DUCKS . . . . 230

IX. THE DOVES . . . . . . . . . . 244 
X. PALLAS'S SAND-GROUSE . . . . . . . 246

XI. THE GAME-BIRDS . . . . . . . 247

XII. THE RAILS AND CRAKES . . . . . . 256

XIII. THE CRANES AND BUSTARDS . . . . . 260

XIV. THE WADERS $. \quad . \quad$. $\quad . \quad$. $\quad . \quad$. 260

XV. THE TERNS, GULLS, AND SKUAS • . . . . 276

xVI. THE ALBATROSS, PETRELS, AND SHEARWATERS . 285

XVII. THE GUILLEMOTS, DIVERS, AND GREBES . . . 288

REPTILES . . . . . . . . . 297

LIST OF BRITISH REPTILES $\quad . \quad$. $\quad . \quad$. . . 301

I. THE LIZARDS . $\quad . \quad$. $\quad$. $\quad$. $\quad$. 302

II. THE SNAKES . $\quad . \quad$. $\quad . \quad$. $\quad . \quad$. $\quad$. 304

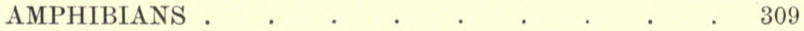

LIST OF BRITISH AMPHIBIANS (AND BATRACHIANS) . . 312

I. THE FROGS AND TOADS . $\quad . \quad$. $\quad . \quad$. 313

II. THE NEWTS . . . . . . . . . . 315

FISHES .

LIST OF BRITISH FISHES

I. THE PERCHES AND SEA-BREAMS . . . . 340

II. THE BULLHEADS AND GURNARDS . . . . 347

III. THE ANGLER-FISH $\quad$. $\quad$. $\quad$. $\quad$. $\quad$. 352

IV. THE WEEVERS . $\quad . \quad$. . . . . . . . 353

v. THE MACKEREL FAMILY . . . . . 354

VI. THE CORYPHENES AND THEIR ALLIES . . . 358

VII. THE HORSE-MACKERELS AND THEIR ALLIES . . 359

VIII. THE GARFISH AND FLYING-FISH . . . . 364

IX. THE GOBIES AND SUCKERS . . . . . . 365

x. THE BLENNIES AND BAND-FISHES . . . . 369

XI. THE ATHERINES AND GREY MULLETS . . . 372

XII. THE STICKLEBACKS $. \quad . \quad$. $\quad . \quad$. 374

XIII. THE WRASSES . $. \quad . \quad . \quad . \quad$. 375 


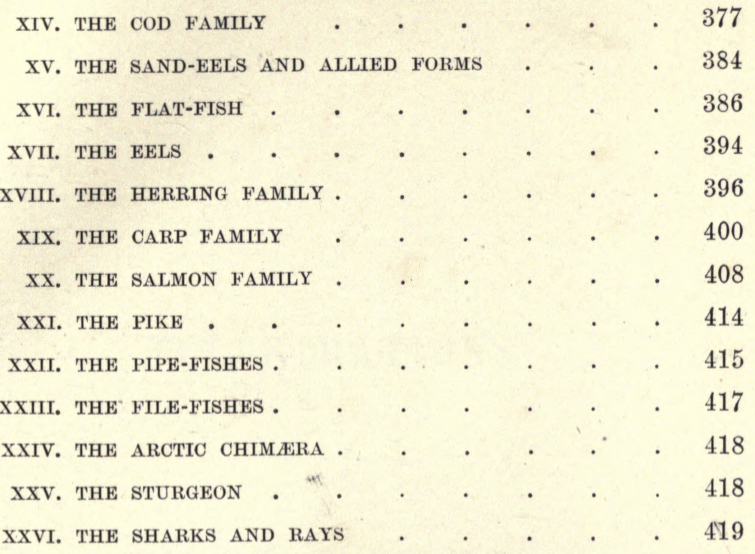

THE LOWEST VERTEBRATES . . . . . 435

APPENDIX I. MATERIALS FOR A BIBLIOGRAPHY OF BOOKS ON THE BRITISH VERTEBRATE FAUNA • . 441

" II. A LIST OF NATURAL HISTORY SOCIETIES AND FIELD-CLUBS IN THE UNITED KINGDOM, WITH THEIR SECRETARIES • . $\quad$. $\quad$. 460

INDEX . . . . . . . . 469 



\section{ILLUSTRATIONS.}

FULL-PAGE ILLUSTRATIONS.

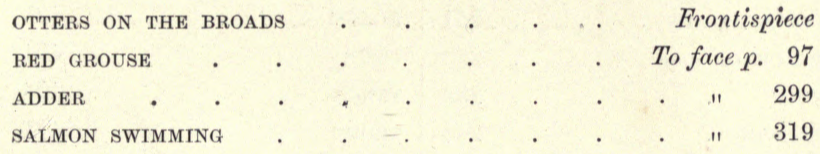

ILLUSTRATIONS IN THE TEXT.

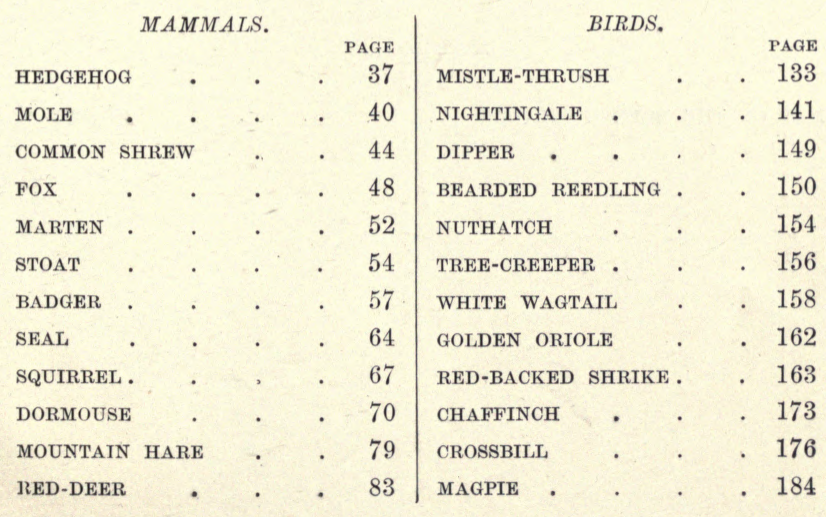




$$
\text { xiv }
$$

ILLUSTRATIONS.

\begin{tabular}{|c|c|c|c|c|c|c|c|c|}
\hline $\mathrm{Y}$. & & · & 186 & \multicolumn{5}{|c|}{ REPTILES } \\
\hline SWIFT & . & . & 190 & RINGED $\mathrm{S}$ & SNAKE & & & 307 \\
\hline NIGHTJAR & . & . & 192 & \multicolumn{5}{|c|}{ FISHES. } \\
\hline GREEN WOODPE & ECKER & . & 196 & PERCH & . & . & . & 34 \\
\hline KINGFISHER & . & . & 198 & BASS & . & . & & 34 \\
\hline CUCKOO • & . & . & 202 & RED MULI & LLET & . & & 34 \\
\hline LONG-EARED OV & WL & . & 207 & MACKEREI & & . & & 54 \\
\hline GOLDEN EAGLE & . & . & 212 & JOHN DOI & $\mathrm{RY}$ & . & & 362 \\
\hline PEREGRINE & . & . & 215 & GARFISH & - & . & . & 36 \\
\hline OSPREY • & . & . & 218 & GREY MU & JLLET & . & & 373 \\
\hline CORMORANT & . & . & 220 & COD & . & . & . & 377 \\
\hline GANNET & . & . & 222 & POLLACK & . & . & . & $38 c$ \\
\hline HERON & . & . & 224 & TURBOT & . & . & . & 38 \\
\hline BITTERN . & & . & 227 & PLAICE & . & . & . & 390 \\
\hline MALLARD & . & . & 236 & CARP & . & . & . & 401 \\
\hline RED-BREASTED & MERG & ANSER & 243 & BARBEL & . & . & . & 402 \\
\hline CAPERCAILZIE & . & - & 251 & $\mathrm{ROACH}$ & . & . & . & 40 \\
\hline BLACK GROUSE & . & . & 253 & CHUB & . & . & . & 404 \\
\hline$O T$ & . & . & 259 & TENCH & . & . & & 40 \\
\hline IPWING . & . & . & 264 & TROUT & . & . & & 411 \\
\hline WOODCOCK & . & . & 267 & PIKE & . & . & & 41 \\
\hline ITTIWAKE & . & . & 283 & BLUE & ARK & . & . & 42 \\
\hline GUILLEMOT & . & - & 290 & SPUR-DOG & & . & . & 42 \\
\hline BREAT CRESTH & & & 293 & THORNBA & & . & & \\
\hline
\end{tabular}

MAP OF THE BRITISH ISLANDS at page 1 



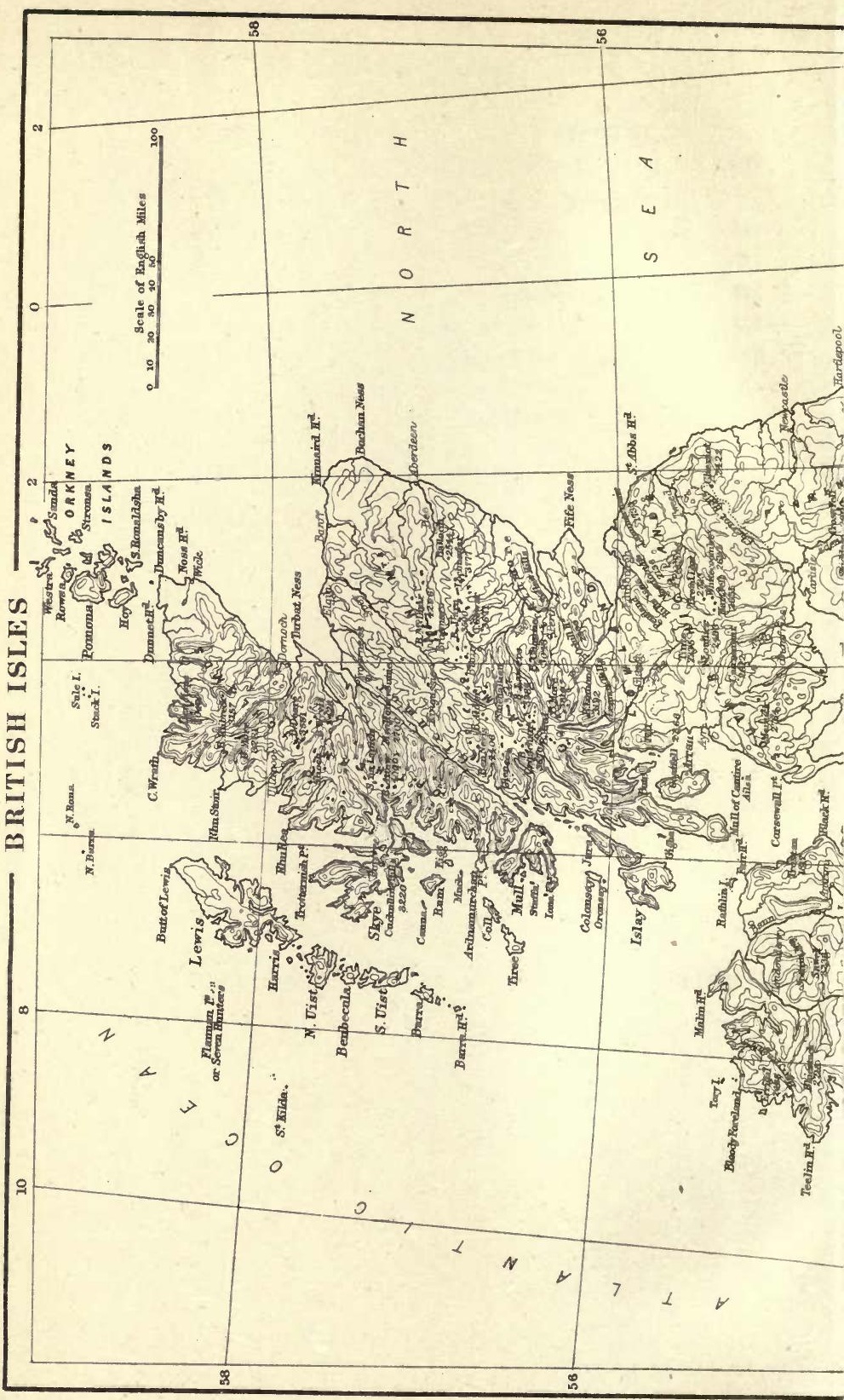




\section{A SKETCH OF THE NATURAL HISTORY OF THE BRITISH ISLANDS.}

\section{INTRODUCTORY.}

IT was a fancy of Richard Jefferies, ${ }^{1}$ and one which, without being pushed beyond certain limits, had in it many elements of truth, that the British Islands afforded the student of animal distribution an epitome of the greater world without. Quite apart from the poverty of our fauna in the mere number of species, it is significant that of the eleven recognised orders of quadrupeds, five only are wanting; of the twenty-three living orders of birds, our list includes, if we count the stragglers, examples of no fewer than seventeen; of the fishes, of which science recognises five existing orders, our seas, streams, and lakes provide in greater or less abundance typical representatives of three.

There is, however, with the exception of the restricted distribution of one bird (the red grouse) and about halfa-dozen non-migratory varieties of the trout and char, nothing actually peculiar about the vertebrate fauna of this archipelago anchored off the north-west coast of the European continent, a group consisting of two principal islands and several thousand islets, some of them mere rocks. Thus, in the Scilly Islands alone there must be

1 Life of the Fields. 
nearly one hundred and fifty such rocks, and in the Orkneys there are sixty-seven.

The area of the islands under consideration is, for all practical purposes, about I20,000 square miles, of which

Area and England and Wales, with their islands, are coast-line. roughly the one half, or rather less, while Scotland and Ireland, with their islands, are roughly the other half, or rather more. The coast-line is proportionately enormous-probably, if we take into consideration all the deep inlets on the west coasts of both Great Britain and Ireland, not far short of ro, ০০০ miles. This will be better appreciated when we recollect that of Ireland it has been said that no inland town is more than fifty miles from salt water, or when we compare our coastline with the 8000 miles of coast-line in Australia to $3,000,000$ square miles of area. Of these 120,000 square miles it should, however, be remembered that, at the lowest possible computation, one-third at the least is composed of mountain, bog, and moor-wild nature, in fact; while of the 5०,000,000 acres that approximately remain, little more than $35,000,000$ are in all probability under cultivation, three-quarters under grass, the rest under oats and other crops. Market-gardening and the cultivation of orchards usually occupy attention on the outskirts of our larger towns. Space will not admit of dwelling at greater length on these important considerations as factors in the animal life of different parts of the country: it must suffice to leave them with this bare enumeration.

A few words must now be said on the subject of our climate. It is customary to speak of this in terms of de-

Climate. rision, and without a doubt it is subject to extraordinary and unlooked-for developments of such a nature as to interfere seriously with private arrangements for outdoor excursions. Climate is not, however, measured by considerations of this kind. As a matter of fact, these islands enjoy, thanks to the surrounding water, the genial influence of the Gulf Stream, and the prevalence 
of south-west winds surcharged with moisture, a climate in many respects unique, certainly more temperate by far than that of any other, taking it all the year round. Of the great changes that have of necessity passed over these islands, then mainland, since the days when elephants crashed through vast forests long since turned to coal, while the hippopotamus basked in our streams, the huge moose browsed on the forest-trees of Ireland, and graceful palms and tree-ferns waved over the northern lochs, there is here no need to speak. It is sufficient to note that Great Britain is to-day the summer resort of tropical birds, the winter-quarters of Polar waterfowl, all repairing hither, year after year, those to reproduce their kind, these to enjoy the food denied them in their natural home. So, too, people who have resided in lands where the annual extremes of mean temperature lie $150^{\circ}$ apart, where even day and night show a difference of $75^{\circ}$, learn with the birds to appreciate the much-abused British climate. As might, however, be expected, there are not inconsiderable variations within the limits of these islands, the damp southwest of England, and, still more, the rainy west of Ireland, contrasting unmistakably with the drier eastern counties, which, hotter in summer and colder in winter, possess a climate far more closely approaching that of the Continent.

In addition to the chief islands of the group-to wit, Great Britain and Ireland-there are a dozen other groups of special interest to the naturalist, the Orkneys, Shetlands, Inner and Outer Hebrides, St Kilda, the Bass Rock, the Farne Islands, the Channel Islands, the Scillies, Rockyll, Lundy Island, the Isle of Wight, the Duke of Buccleuch's gull-preserve on Walney Island, and, lastly, the Isle of Man. Heligoland now lies, politically if not zoologically, outside the region; but all who are interested in its capabilities as an observatory for the study of bird-migration will find an excellent account in the late Dr Gaetke's book, ${ }^{1}$ a translation of which has appeared in the English language.

1 Heligoland as an Ornithological Observatory. 
As little more has been attempted in the, following pages than to treat the British Islands as one tzoological area, it seems desirable to say a word in this place of the subdivisions that might, in a more pretentious contribution to the literature of their fauna, have been followed.

These are two, the zoological and the political. Of the former, examples are found in the fens, moors, and forests ; the latter are of course the counties, and may Areas, coun- be easily dismissed, since they in no way corre-
ties, \&c.

spond with the zoological divisions. With the great Australian colonies the case was, and is, different. Their boundaries are, for the most part, natural, a lofty range, a broad river, a deep strait; and, as might be expected, corresponding differences are to be observed in their animal life, as, for instance, where the diamond-snake of New South Wales is replaced in the other colonies by that species, sub-species, or variety, the carpet-snake. In England, however, we are confronted with few such natural boundaries. The task of detailing the physical peculiarities of each and every county-its soil, its hills and valleys, its water-courses, moors, marshes, and forests-has devolved upon the authors of those handbooks to county fauna, particulars of which will be found in the bibliography. It would, no doubt, have been easy to gather from my own notes, easier still to have compiled from the works in question, supplemented by the Ordnance Survey maps, some account of most shires in the kingdom. To take an example. Sussex might have been contrasted with low, sandy, pineclad Hampshire on the one hand, and high, chalky, hopgrowing Kent on the other; and some account must have been taken of its three or four mentionable rivers, its four harbours, the 500-feet fall of Beachy Head, the lowlands near Pevensey and Pagham, the great oak-woods scattered over the western half of the county, and the beeches of Charlton and Goodwood. I have my own ideas, however, of the function of the present sketch, an introduction or supplement, not a substitute, and I have therefore 
abstained from including such detail as is given elsewhere at far greater length than I could spare in these pages.

Coming for a moment to the zoological divisions, which are of considerably greater interest and importance, the task of establishing fixed rules whereby fieldZoological naturalists learn to associate peculiar types of divisions. animals with certain physical conditions opens up a wealth of fascinating study, and still more fascinating, because more daring, deduction. Let us take an example in the birds and fishes found to frequent rocky or sandy coasts. In either class we find well-marked distinctions. Thus, the ornithologist knows that he will find on a bold rocky coast, like, say, that of Cornwall, such fowl as puffins, guillemots, cormorants, and gannets, birds that find their food in deep water, the majority by diving; whereas on the low sandy shore of Essex, on the other hand, he will look for long-legged wading dotterels and sandpipers, all of which seek their molluscan and insect food in the shallows. Nor is the contrast in the legs of the birds in these two groups more striking than that afforded by their bills, the waders being armed with long slender bills that they can thrust into the mud, the divers having short stout bills, usually hooked, to assist in the capture of the slippery fish on which they feed. In like manner, the student of fish knows well enough that along with the puffins and their kind he will find conger, pollack, and wrasse; with the waders, flat fish and whiting.

These principles admit of almost infinite extension, and if an occasional exception to the rule should be sprung upon the investigator-and it must be confessed that Nature holds some strange surprises in store for those who are so bold as to pry into her secrets-he will, after the first shock has worn off, cheerfully accept it as.the one thing necessary to prove the rule he has laboured so hard to establish.

Thus, he will look for certain types in each district, the 
ruff and reedling among the least drained parts of the fens and the quieter retreats of the broads; the grouse, short-

Typical eared owl and harrier on the bleak moors; birds. the mountain-hare and ptarmigan among the hills and stony plateaux of the Highlands of Scotland; and the woodcock, snipe, and quail on the edge of the peat-bogs of Ireland. The student of birds will recognise-nay, expect-that a certain influence should be exerted on their course in migration by headlands that bid the weary rest, and muddy estuaries that stay those that hunger. Indeed, one estuary or one promontory is not to him as another, and he will not deem as of slight moment the difference between the chalk of Shakespeare Cliff or Beachy Head and the shingle of Dungeness. $\mathrm{He}$ will notice, too, that the mountains of Ireland fringe the coast, leaving the interior, by comparison, lowland.

All these matters appeal so differently to the casual reader and to him who takes an interest in them. How

Fauna of many would find food for reflection in the pecuIsle of liarities of the denizens of the Isle of Wight?

Wight. Yet it is surely not quite devoid of interest that in that little outpost of England, separated from the New Forest ${ }^{1}$ and the most fishful rivers in the south country by a mere ditch, the woods should afford shelter to but few owls and woodpeckers, the streams hold neither pike, nor perch, nor chub, nor gudgeon; that the ring-ousel should abstain from breeding there; that the toad should be commoner than the frog, the viper in excess of the more harmless snake.

To the few, however, the bare enumeration of such facts as the impossibility of inducing certain birds to take kindly to island or even mainland districts, offering to all appearance the identical conditions of their not far-distant home,

1 It must be admitted that, save for Mr Witherby and others blest with exceptional opportunities for exploring it, this most attractive of our forests is not an ideal bird-resort. I recollect Mr Lascelles attributing this to lack of suitable food. 
the quest of the whys and the wherefores which Nature is often so reluctant to answer, discloses a prospect of engrossing research. As a homely example of how little such reasons are understood, a lady was deploring to me a short while ago that the stupid nightingales, which were in such abundance just then round Christchurch, not more than Nightingale five miles distant, would not sing of an evenin Hamp- ing within earshot of her house, a short way shire. out of Bournemouth. I endeavoured to explain that their preference for Christchurch, or, for that matter, for Parkstone, equally close in the opposite direction, might lie in the presence of retreating waters and muddy banks that possibly furnished them, in addition to their staple caterpillars, with some kind of soft food, whereas the Bournemouth valley, lying between, was, on account of a deficiency in this respect, passed by. This explanation contented the lady, who seemed quite reconciled to the absence of nightingales as soon as she was able to realise that it did not arise from mere lack of judgment on their part. ${ }^{1}$ A book that should do no more than collect a number of such cases in the apparently capricious distribution of some of our resident and visiting birds would, I am convinced, command a large audience.

Frankly, however, that is not among the objects of this book, in which, as already set forth, the British Islands are dealt with almost as one area. Adhere to this plan, however, as we will, it is impossible to ignore two interesting pictures, a comparison and a contrast, that constantly recur during our studies of British vertebrates, and these are the strong resemblance between our fauna and that of neighbouring Continental countries, and the still more remarkable deficiencies in the Irish list.

The former points unquestionably to the union, at no

1 I think it right to mention that both Sir Herbert Maxwell and Mr Harting take exception to my explanation of the distribution of nightingales around Bournemouth, but I prefer letting the suggestion stand, for want of a better. 
very remote zoological date, of these islands and the northwest coast of Europe. The latter-examples of which

Irish

fauna.

are found in the wild cat, polecat, weasel, ${ }^{1}$ roebuck, mole, dormouse, harvest mouse, two shrews, voles, and snakes-would appear to indicate the earlier isolation of the western island. Or, as A. R. Wallace puts it: "This may be accounted for by the smaller and less varied surface of the latter island; and it may also be partly due to the great extent of lowland, so that a very small depression would reduce it to the condition of a cluster of small islands capable of supporting a very limited amount of animal life." 2

Of the above Irish absentees, the mole, which occurs in abundance as far west in these islands as Holyhead, is in one respect the most interesting, since there are, in spite of its never having occurred in the island, several old Celtic names for it. There are also Celtic names for the roebuck (Earbog), but that animal, though not indigenous, has been introduced on private estates. Mr Harting, of whom I once asked an explanation of this, suggested that my so-called Celtic names for the mole may possibly have been introduced by immigrants from Scotland, who would have known the creature in their own country. This explanation, which is probably the correct one, brings me to the consideration of the present confusion in the local names of beasts and birds.

Together with the subordination of county distribution above alluded to, I have found it necessary to pay but little attention to such provincial vernacular.

Local names. As regards the birds, at any rate, whole volumes have been devoted to the subject. Moreover, in these days of cheap and easy railway travel, great inducements are offered to young keepers to better their condition elsewhere, and these men carry into the new home the names they have used from childhood, so

1 The weasel has been freely claimed as an Irish quadruped (see p. 55).

2 Geographical Distribution of Animals, i. 197. 
that we find nowadays that such creatures at any rate as come within the ken of these gentry, "vermin" and the like, are very often called by the same name in counties far apart and with vastly different dialects. This, while it tends in course of time to simplify matters and facilitate intercourse, detracts vastly from the interest, philological or otherwise, of these same local names.

I come for a moment to what is perhaps the most inter- . esting aspect of the contemplation of any country's fauna,

Extinct mammals. the comparison of its condition at the present day with what it was five-and-twenty, fifty, or five hundred years ago. In the case of most British mammals, this comparison becomes doubly interesting in view of the impossibility, on account of their isolation, and leaving out of account private efforts towards reintroduction, of the reappearance of any species that has once become extinct. In Continental countries, whatever the practical probabilities and improbabilities may be, this impossibility has, theoretically at any rate, little force. To us, however, the boar and bear, the wolf, beaver, and reindeer, can of their own accord never more return. To our islands they are as dead as are the rhytina ${ }^{1}$ and great auk to all the world. Polar bears may occasionally be sighted, from the bridge of some transatlantic steamer, drifting on ice-floes far south of their natural range; but it will require a miracle indeed to restore these vanished Britons. According to Mr Harting, ${ }^{2}$ the last British bear died in the ninth century; the last boar in the seventeenth century; the last wolf in Ireland was killed as late as the middle of the eighteenth century; the last beaver and reindeer had gone about the twelfth century. In like manner, the last survivor of the old native stock of bustards was bagged in 1829, though this striking bird has visited these islands

1 For the causes of extinction of the rhytina, more commonly known as Steller's sea-cow, see an interesting article in the 'American Naturalist' for December 1887.

2 Extinct British Animals. 
on many occasions since, notably when its Continental haunts were shaken by the cannon of 1870-71; and a hen bustard met the usual fate, if I remember rightly, only two or three years ago. So too, we are told, the old stock of capercailzie died out in the middle of the eighteenth century, to be reintroduced over fifty years later by Lord Fyfe and Sir T. Fowell Buxton. These lost islanders, a fuller list of which will be found in the interesting chapter on paleontology in Lydekker's volume on 'British Mammals,' ${ }^{1}$ will, there seems reason for supposing, be joined at no remote future by the polecat, wild cat, marten, and black rat, among quadrupeds, and by the ruff and bearded reedling, bittern and chough, among birds.

These recent changes would seem, with the exceptions of the vanishing black rat and chough, to be the work of man, the direct outcome of his improvements on the face of the earth. The discomfiture of the two exceptions seems to have been rather the work of their own kindred.

It is the order of things that the children of man shall increase and supplant the wilder children of nature. The transformation that is being achieved under the eyes of the present generation in other continents more recently exploited has long since reached the climax in these islands. Gone are the vast herds of mixed game that but yesterday roamed the African veldt, evoking the admiration of even such hunters as Cornwallis Harris and Gordon-Cumming; gone too are the great herds of bison that, within the memory indeed of Mr Roosevelt and other living American sportsmen, thundered over the boundless prairies. Populous capitals stand on land just reclaimed from the kangaroo and dingo; and I have occupied quarters on the outskirts of Buitenzoorg, in Java, where a few years ago tigers prowled among the affrighted villagers, but where nowadays one can lie at ease in the cool verandah and imagine oneself in the respectable security of a London suburb. These changes are not all matter for rejoicing, 1 Allen's Naturalist's Library. 
but they are inevitable. 'There is not room for the children of man and the children of nature; and as the former have called in the rifle to help them, the latter must soon disappear, with the exception of those which man may, for purposes of his own, choose to domesticate and keep about him. The larger beasts will inevitably go first, nor will those that are swift of foot necessarily survive the longest, for difficulty is as essential to the pursuit of sport as danger, and the hunter is far more attracted by the flying herds of antelope and deer than by the sluggish hippopotamus or crocodile. That something of this may be due to the consideration of the trophy, it would be impossible to deny; but the readiness of the beasts to escape must, as in the case of the fox and hare, have aroused the instinct of pursuit. Man is not, after all, unlike his favourite dog, which will invariably run after those who show the inclination to run away.

In these islands, the process has been slower than abroad. For one thing, the weapons were less precise Extermination and less far-reaching. All our larger quadof species. glance at the above dates, exterminated long before the use of firearms had become general. In the remote Highlands of Scotland, or in equally wild districts in this country and Ireland, a very few may have lingered to meet their death by gunpowder, but the chief work of destruction was achieved with the arrow and the spear. More recently, however, the extermination of many of our most interesting beasts and birds has been furthered by means less direct than the gun and snare. These have of course played their part, and the gamekeeper and farmer have doubtless much to answer for. It is, in any case, useless to bring a general indictment against gamekeepers: on the part of any but their employers, it is not far from an impertinence. The ignorance and destructiveness and wanton cruelty of this class are themes which, to my way of thinking at least, are worn threadbare. That there are 
offenders among them, as among any other class, is not improbable; but, whether or not their attitude towards the beasts and birds of prey is always a judicious one, it is surely within the bounds of possibility that they are acting, according to their lights, conscienBy game-
keepers. interests. It is possible even that the conduct of keepers as a class may in this respect be open to some fair criticism; but it is, I think, impossible that their prejudices, the growth of generations of close touch with Nature, whom they learn to know more intimately than any other class of men except, perhaps, the poachers, can be utterly without foundation. I, for one, should be reluctant to pin my faith unconditionally to the teachings of the class-room as opposed to such downright assertions as are, for example, to be found in Speedy's 'Sport in the Highlands.' Nor may we hope in a little while to soften the still more merciless creed of the farmer. Jesse told By farmers. him that he would find the rook following the ploughshare and not the sower; but such an assurance would, even if beyond denial, appeal with little force to men whose finer perceptions of these matters are pardonably blunted by the bitterness of succeeding years of depression, and who, in their despair, are not unnaturally prepared to lay the mischief at any door but the right one. ${ }^{1}$

There are others engaged in this work of slaughter, some of them with less excuse. There are the bird-catcher and the naturalist-collector. The former By bird-
catchers. empties all the music of Surrey into the catchers. purlieus of Little St Andrew Street-and small blame to him: it is his living. The latter commits his depredations in the cause of science; and these, indeed, sometimes almost pass belief. They are scarcely less shocking than the evils perpetrated in the name of re-

1 When ladies disagree, indeed, as they have in the recent sparrow controversy between Miss Ormerod and Miss Carrington, the farmers may well keep their own counsels. 
ligion. As an instance, the late $\mathrm{Mr}$ Seebohm, whose four volumes are the delight of all who care to read about our birds, owns in one place to having robbed in one day upwards of $45^{\circ}$ egg:3 (not, be it remarked, in
By collectors. these islands), including nearly I50 of one species and over 80 of another. In another account he mentions $25^{\circ} \mathrm{eggs}$ of the lesser tern as the gleaning of one week. After these confessions, it is surely intended for humour when he complains at yet another page of the "hard-hearted" peasants of Siberia, who habitually take quantities of these eggs for food. Worse than all these is the wanton pot-hunter, who, without any rational interest in game, crops, or science, loafs abroad at all times and blazes at any oriole, hawk, or other bird that may chance to cross his path. Boys are among the worst offenders, and it is not without regret that one finds the editor of an excellent school magazine delivering himself thus : "School arrangements may limit them, irate farmers and keepers may rage, and Acts of Parliament thunder, but eggs and bugs will still be sought and acquired wherever there be boys." That our four-footed animals have not by such means been long since reduced to the level of those of New Zealand, that our song-birds are not as scarce as on the great plains of Italy, ${ }^{1}$ is owing less to any measures taken for their protection than to the sacred rights of ownership in land, against which the lover of nature is not likely, whatever his politics, to raise his voice. But the museum-men! As Ruskin says of the birds: "One kills them, the other writes classifying epitaphs."

As above remarked, however, it is by less direct means that our mammalian and bird fauna has become gradually impoverished, not alone in variety, but rather in actual numbers. Here and there, perhaps, the keeper's gun may have told. We learn, for instance, that in parts of the North

1 In the 'Times' of July 10 of the present year (1897) appeared a letter from a lady deploring the well-known spoliation of Italian wild birds for the London table! 
Country he has practically exterminated the jay and magpie. ${ }^{1}$ The buzzard, kite, and hen-harrier have likewise in many parts of these islands been driven to the verge of extinction.

But it is by cultivation and draining, the latter more especially, that our smaller birds have been most powerBy draining fully affected. The reclaiming of carseland and cultiva- has been the death-warrant of the bittern tion. and ruff, of the bearded reedling and Savi's warbler. The Scots cut down their great forests in olden time to rid them of the wolf, and with it they lost the capercaillie. One of the most remarkable and sudden of recent changes in the face of a country is to be found in some of the Channel Islands, where, since gin took the place of cider as the national beverage, the orchards have been abandoned, and the whole country is under vegetables for the early London market. ${ }^{2}$ The effect of such a transformation on the number of the migratory species that formerly stayed to breed in those islands can scarcely be overestimated. The draining of the fens, with the accompanying cutting down of the dense reeds that had for all time afforded shelter and nesting-sites to many fen-birds, has perhaps been the most important factor of all. The actual spread of bricks and mortar, though doubtless a condition to be reckoned with, is not of such paramount importance as might at first sight appear. In the first place, there must always be very large tracts which,

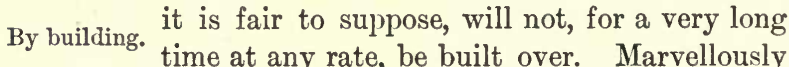
as the population of these islands has increased during the past century, having already passed that of France, a country of considerably more than half again the area, it is to be remarked that the tendency has been to crowd more closely into those centres of population which were cities and towns at the beginning of the century, in many

1 Muirhead, Birds of Berwickshire, pp. 200, 202.

2 Smith, Birds of Guernsey, vol. viii. 
cases within almost the old limits, rather than to start new townships in waste parts of the country. If a new town does now and again spring up, it is certain to be a watering-place, the mushroom rise of which is not infrequently followed by sudden decay. As an instance of this, I may cite Southbourne-on-Sea, a new speculation which was, we were told a very few years ago, to rival Bournemouth and eclipse Boscombe; but the venture has to all appearance come to nothing, and the whimbrel and dotterel and redshank are left in possession of the sandflats below Christchurch, laying their eggs peacefully on the sands and shingle which should, in the fertile imagination of investors, have been thronged ere now with children and nursemaids. Thus rapidly does Nature reclaim her own. Secondly, it is notorious that a large number of beasts and birds, so far from shunning his presence, follow man into new districts.

But man not only exterminates, both directly and indirectly; he also acclimatises and protects. It is not so easy as might be expected, when sketching the fauna of a highly civilised country like ours, to draw the

Acclimatisation. line strictly between the indigenous and the imported. In the case of Australia, the distinction was far simpler, the placental dingo presenting the only difficulty. As for the horse, cattle, sheep, and dog, the camels, oxen, buffaloes, poultry, and the like, all these had obviously no place among the rightful owners of that remarkable island. With us, however, it is different. The palpably domesticated animals are easily reckoned with. The horse, ass, goat, sheep, dog, cat, hog, poultry, guinea-pig, and foreign cage-birds-these are ignored in the following pages, as also the semi-domesticated remnant of our wild oxen. But what shall be said of our fallowdeer, pheasants, capercailzie, red-legged partridge, edible frog, and carp? or who would have the courage to omit all notice of these from an account, however slight, of our natural history? This tinkering of an impoverished fauna 
has indeed gone on for so many years, that it is hard to know where to begin and where to leave off. The case of both our rats, the black and the larger brown, misnamed Norway or Hanoverian, illustrates the difficulty. We have, by contrast with the more recent introduction of the latter, come to regard the weaker species as a much older resident of these islands, which, in point of fact, he is. But this has become so strong in the minds of some, that a recent writer on the subject of ferrets alluded to the black rat as "the oldest inhabitant of this country," and this too when it was introduced from the East in all probability not earlier than the fourteenth century! Thus, in addition to the species introduced by man, the classification is complicated by others that have arrived in ships or otherwise, but not under his auspices. This is a difficulty which it is important to grasp, because we shall more than once be confronted by it in the following pages.

To make this still clearer, I will give one instance. It will be observed that I have, contrary to the usual practice, omitted the turtles from the list of British vertebrates. I think I should scarcely have ventured, on my own responsibility, to do so, had it not been for a trivial episode that I shall relate as my justification. My ship was nearing the end of a long voyage. We had covered i 5,000 miles of sea, and had brought successfully through every degree of climate, from a tropical summer to a British winter, two leather-back turtles, which were allotted private quarters in the long-boat, and played on with the hose under my supervision twice a-day. Thus they thrived exceedingly, until, not a hundred miles south-west of the Eddystone, one got washed overboard. The captain, to whom they had been tendered as an advance Christmas gift by one of the Company's agents, raved and stormed in language suitable to the occasion; but my own regret at his discomfiture was largely tempered by curiosity as to whether the creature might perchance get washed ashore alive, in which case nothing would, if we may 
judge by the analogy of some of the British-North-American birds that figure in our list, have prevented its being temporarily recorded as a British turtle. I do not, be it understood, take upon myself for one moment the responsibility of criticising the validity of examples previously recorded. I prefer relating what did happen, and suggesting what might have happened but that, fortunately for British zoology, the precious morsel was evidently carried away into the broad Atlantic by westering currents, and thus lost to our fauna. I hope it is unnecessary to add that I fully intended, perhaps after duly enjoying the humour of the situation, to set matters right. This is why I have ignored the turtles; and if I had only the evidence of my own eyes, my own opinion is that the bird-list might in like manner have been considerably curtailed, as I fancy that if the spars and sheets of the Atlantic liners bound for Liverpool could speak, they might tell strange tales of stowaway birds. ${ }^{1}$

Nor have the factors that have united to make our fauna what it is been quite exhausted in the foregoing remarks, for it would be impossible to overestimate the effects of protection. Man has not only exterminated, or in some cases kept under, indigenous beasts Protection. and birds; not only has he introduced and acclimatised foreign species; but he has also, almost entirely for sporting purposes, extended his protection to both beasts and birds that would otherwise have disappeared long since from our countryside. Such are the fox, hare, otter, red- and roe-deer, and grouse, which were at any rate among the early inhabitants of these islands. The fallow-deer, as also the various breeds of pheasants, come under another category, for they were introduced, and not indigenous. It has been shown that the preservation of

1 A turtle of very large dimensions has at various times during the past summer (1897) been sighted-and more than once harpooned-off the Cornish coast. I have reason to believe that it is still at large in those waters. 
game is responsible for a deal of destruction; but it should not be forgotten that it is at the same time acting in an opposite direction, and that, but for the landowner and preserver, our country rambles would never be enlivened with the sight of the passing fox or flying deer, our meditations never broken by the sudden whir of the grouse or the soft splash of the otter. For the latter, although undoubtedly much harassed by the riparian owner, would perhaps have been exterminated were it not that many an owner of a trout-stream has a soft corner in his heart for an occasional day with the otter-hounds. It would seem, indeed, as if the best chance of survival lies, anomalous as it may appear, in being prized for the chase; and it may well be asked, Where will the wild cat and marten be in another fifty years unless some kindly soul discovers, ere it be too late, that there is legitimate sport to be had out of them? This will be a more laudable venture than the more ambitious, though less successful, efforts which are from time to time directed towards the reintroduction of the beaver and boar, or the acclimatisation of zebus and musk-rat.

There will always be this about the study of natural history in these islands, though to many it will appear but a poor recommendation, that it may be pursued without risk, from either climate or the creatures themselves. Our climate, subject though it is to sudden changes, is neither too hot nor too cold to put a stop to field natural history throughout the year. In this we are singularly blest, for there are few other lands of which as much could be said. Even on those portions of the Continent that lie at our door there are, as more than one ill-fated expedition of other days learnt to its cost, great dangers in the seasonal changes. Those who have, as I have, gone in search of birds' nests in the Roman Maremma, will appreciate what we have to be thankful for. Nor are the beasts of these islands any more fearsome than the climate. Our existing carnivora would, save on rare occasions the 
weasel, make off on the approach of a child; our only poisonous reptile, equally fond of making itself scarce, causes little more than temporary inconvenience by its bite, unless, indeed, the patient be in a bad state of health already; the sharks of our seas are mostly infants ; even our insects are to be dreaded less than those of any other country I know of.

This little volume may, perchance, prove an incentive and a help to such outdoor study. I hope, indeed I might dare expect, so much of it. For there is much to be gained, by both the individual and the nation, not to speak of the benefit accruing to the beasts and birds themselves, if only this taste for natural history become more general. There is a large and ever-increasing class of readers. These are well in their way, and it is not for writers of books, at any rate, to deny their usefulness. But this reading of natural history should be the prelude to observation at first hand, not its substitute. The book of nature is in many chapField-work. ters, and most of its pages are as yet unturned by man. The book is free to all who will open it. None are privileged, and the deepest secrets are revealed at a moment's notice to professor or ploughman. The interpretation is another matter; and what is fraught with meaning for one, causing him, no matter what his creed, to stand amazed, baring his head in presence of that which not all his poor book-learning can explain, another will pass by with a shrug, the even tenor of his thoughts not for one instant disturbed. It is the old story of "Eyes and no Eyes." The boy is father to the man; and he who, as a truant from morning school, regards the hedge-sparrow as designed for no more than a butt for swan-shot, whose acquaintance with his country's beasts and birds is strictly limited to the fitness of each species for the table, will in riper years make no secret of his creed: The earth is the Anglo-Saxon's, and the fulness thereof! 

M A M M A L S 



\section{A M M A L S.}

THE mammals of these islands are surpassed in poverty only by the reptiles. New Zealand is the only land, exPoverty of cepting perhaps the Polar regions, of considerliterature on able size with a poorer list of four-footed inour mammals. habitants; and, compared with the doubtful rat and various bats of that region, our quadrupeds make quite a formidable list. They have failed, however, to arouse that interest that has ever attached to our birds, fishes, and insects, as witness the literature of the subject. There are not many more than half-a-dozen works of any standing, as against over two hundred treating of our birds. For this lack of interest in the quadrupeds many reasons might be assigned, but none operates perhaps more powerfully than the great difficulty of observing them, second only to that of studying living fishes. Birds live under our eyes : they are, with few exceptions, creatures of daylight, and we can watch them obtaining their food and rearing their young. Our beasts are, with equally few Difficulties of exceptions, creatures of twilight and darkness, observing. and those that come abroad in the glare of day are careful to keep far from the haunts of man. How far this love of darkness is natural, and how far it is the result of a proper appreciation of man's peculiarities, who shall say? The fact remains; and the discomfort, often impossibility, of nocturnal excursions has, I think, 
much to answer for in the paucity of books on the subject. That there is need of a new and up-to-date account of our mammals no one will doubt, for the standard work on the subject is nearly a quarter of a century old, and some progress has been made since its appearance, more particularly in our knowledge of the distribution of the smaller rodents, which wants collecting. Such a volume is more than half completed by Mr Harting-as mentioned indeed in his valedictory remarks when resigning the editorship of the 'Zoologist'; and the name of the author of 'Extinct British Animals' should be a guarantee that the work will be all that is required.

Meanwhile, then, Bell remains the handbook on the subject, though some later information is to be found in the Bell's

'British volume in the 'Naturalist's Library,' in which, Quadrupeds.' tinct Mammals " will probably have attracted most readers. Examined critically in the light of an additional quarter of a century's investigation, Bell's second edition (1874) has no doubt its faults, and in the Irish list more particularly, as also in the old error of the beechmarten, needed some correction; but, for careful attention to detail, it stands alone.

Of the six orders that find representatives among the seventy-one mammals on the British list (I exclude the so-called wild cattle and the domestic beasts), two only, the bats and cetaceans, and a sub-order, the seals, present much difficulty, since they alone can, like the birds, move freely between these islands and the neighbouring mainland. This does not imply that there is not yet a great deal to be learnt about the habits and distribution of the smaller land mammals; but the older errors-as, for instance, the presence of two martens, the inclusion in the Irish list of the wild cat, dormouse, and others, as well as the long-lived fable about the alpine hare not changing its coat in that island-are confusions that belong to an age of imperfect communication. 
These and other deficiencies in the Irish fauna, as well as their probable explanation, have been alluded to on

Irish

mammals.

a previous page; and it may be added that mammals. made to differentiate the Irish stoat, otter, and long-tailed field-mouse. These have not as yet, however, been generally accepted as more than varieties. Formerly too, before the appearance of the second edition of Bell's work, the Irish hare was distinguished on account of the above-mentioned error respecting the permanent colour of its coat.

I have already enumerated the animals which have become extinct in these islands in comparatively recent times. Protection The wild cat and the polecat will probably be versus ex- next to go; and in truth very few of those termination. who have most right to a voice in the matter will miss them. Extreme views are never more to be deprecated than in this question of protection; and the keeper who shoots and traps indiscriminately without thought of the mischief he may be doing, is scarcely more to blame than are those dwellers in cities who, without any concern, direct or otherwise, in such matters, raise their voice in pious ejaculation whenever they read in the 'Field' or elsewhere of the death of a polecat or other vermin. Our noxious mammals are, though small, many and active. True, there is no danger to man, for our woods harbour no beast that could not with address be despatched with a spade; but the damage done, one way with another, by the fox, wild cat, polecat, marten, stoat, weasel, ${ }^{1}$ otter, seals, and all the rodents with the exception of the largely insectivorous dormouse, is simply inInterfering calculable. It would not, of course, answer to with the exterminate any one of these; for if the car"balance." nivora were gone, the rodents would multiply into a plague, and even if the latter could be annihilated,

1 Sir Herbert Maxwell informs me that he preserves weasels, being persuaded that their staple food consists of mice, voles, and rabbits. 
the larger beasts would be forced to turn their attention exclusively to the hen-house and the game-preserve. The balance has been upset so often, and with such dire results, that the present generation should be chary about experiments of this kind, though even lately "lady-birds," as we call them, have been introduced into a tropical island to devour certain noxious native aphides, and there is a still more recent movement afoot for acclimatising the nightingale in America, as a pleasant change from the mockingbird. It would seem fair, however, to suppose that an island without either rodents or carnivora would be an ideal one for the agriculturist and farmer; and New Zealand, indeed, is a case in point. In the ordinary course, however, an island incapable of supporting so much wild life has little in its soil to recommend it for such purposes.

It is, above all things, important that we should not harbour any false notion that there is nothing more to be learnt about our few mammals. From time to time we hear the same plaint about the birds, yet book after book appears; and though it would be wide of the mark to say that each new contribution to our bird-lore is full of original matter, it is at least safe to aver that there is something new, some trifling addition to our knowledge of the birds, in almost every one. The food and reproduction of many of our mammals are still matters of argument; and if an opening for original investigation is sought, we need not look further than the remarkable and still unexplained mortality to which our shrews are subject at the end of summer. 


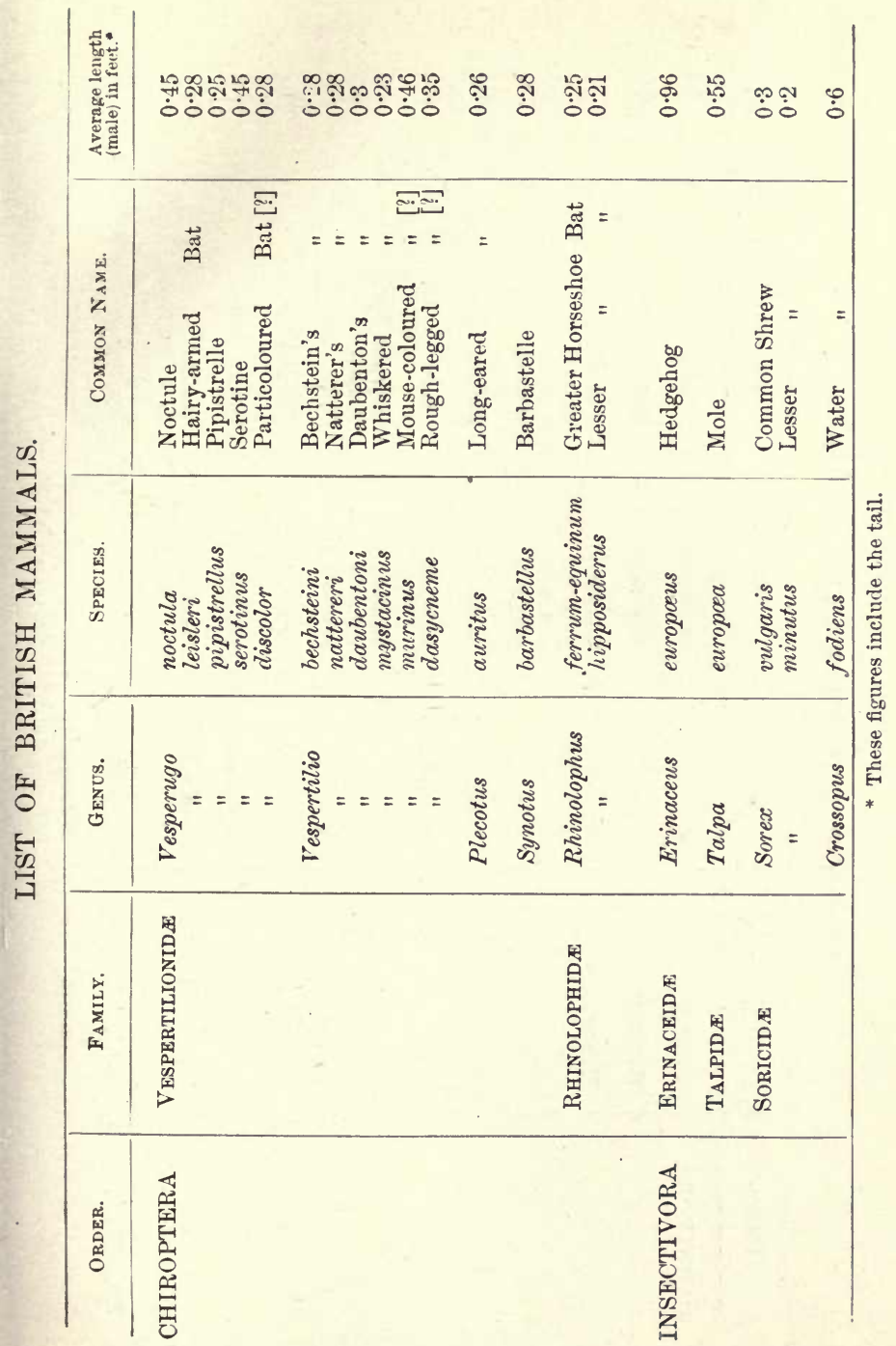




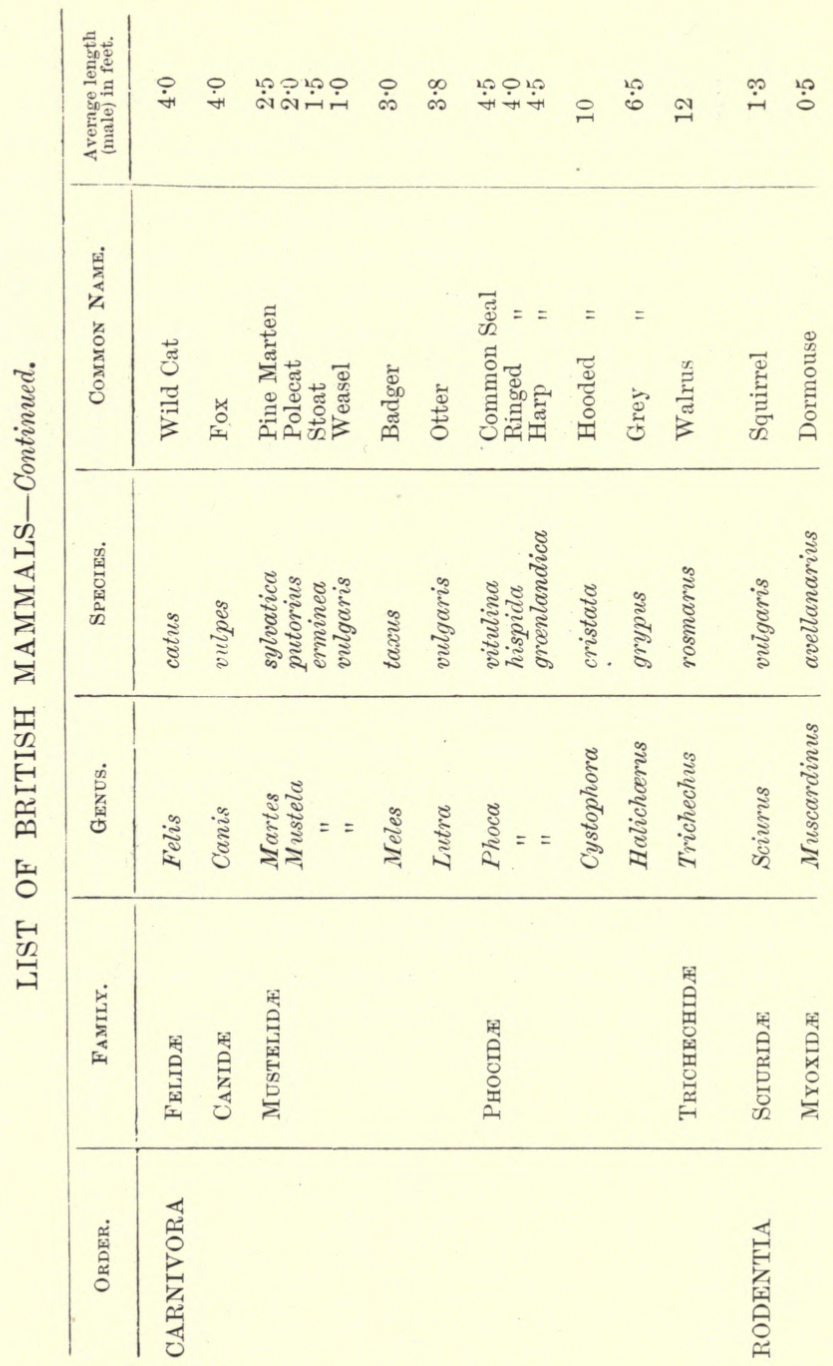




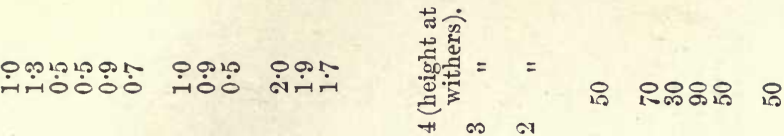

$\underset{\tilde{O}}{\stackrel{0}{*}}==$

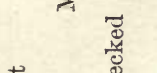

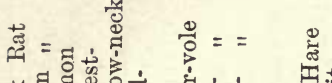

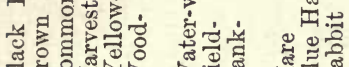

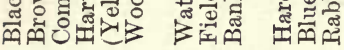

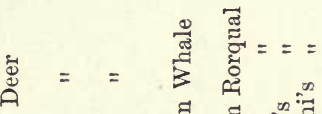

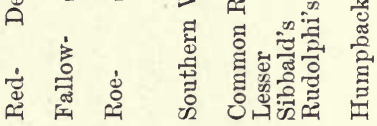
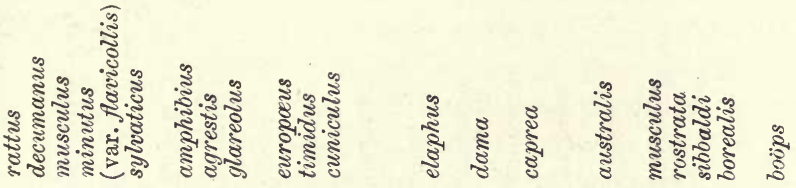

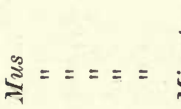

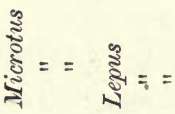

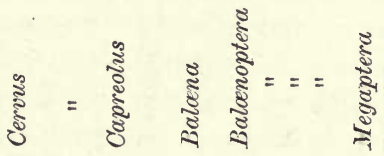

量

和

蝢

究

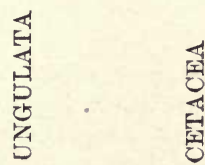

受 


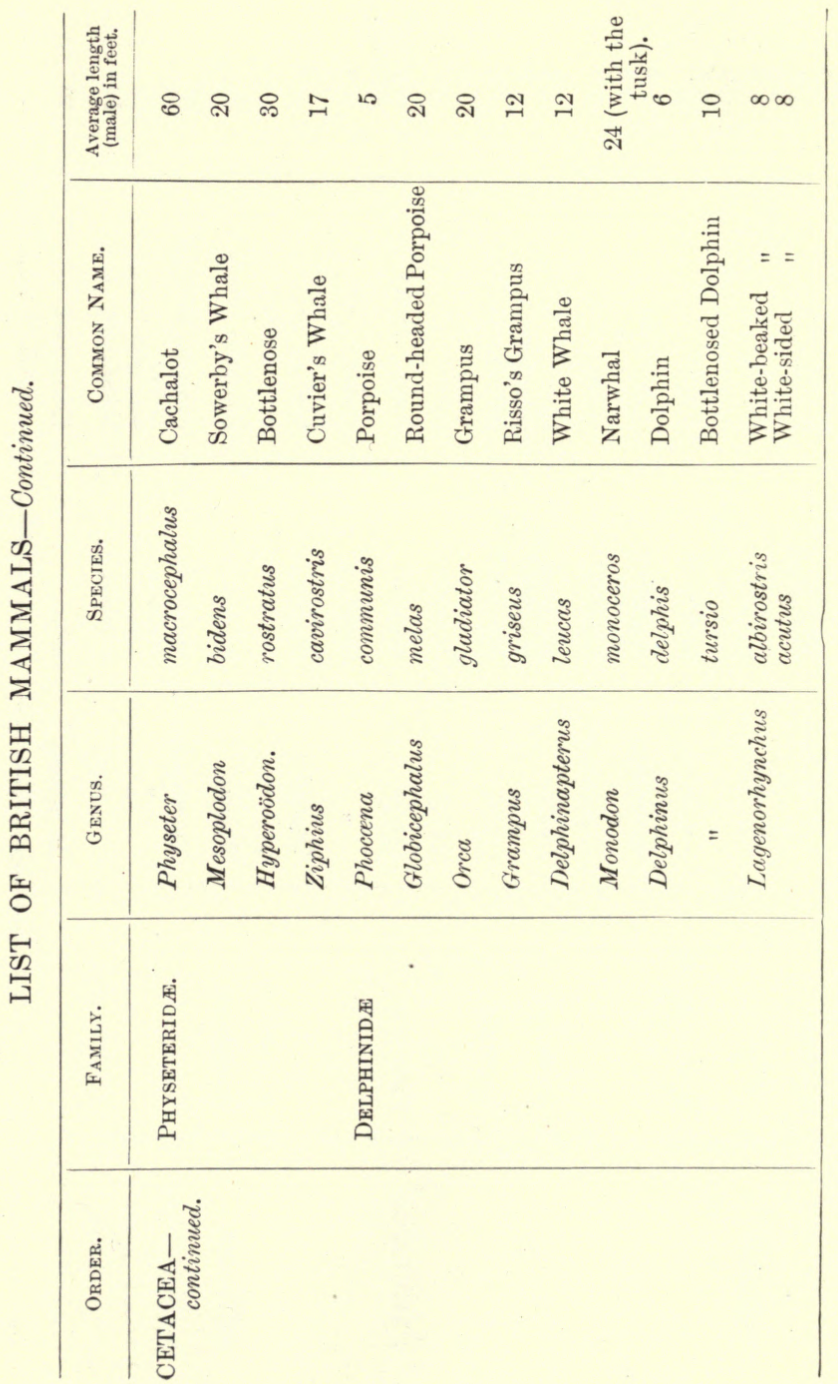




\section{CHAPTER I. THE BATS.}

ThE list of Bats as given by the older writers on British zoology now requires some revision; and we find the

Number of species. present number to be at the outside fourteen, while a fifteenth, the particoloured bat, is included on slender evidence. Their position, too, has undergone change, for while the older naturalists regarded them as the link between mammals and birds, they are now more correctly placed between the lemurs and insectivora. All British bats are truly insectivorous, the large fruit-eating kinds, so common in India, Australia, and Madagascar, being absent from this part of the world. ${ }^{1}$ They are particularly fond of moths. Their teeth are therefore cusped, and vary in number from thirtytwo to thirty-eight. It is also believed that they drink regularly. The hairless membrane that joins the tail and fingers is worked by powerful muscles, so that these creatures are virtually winged and fly much as birds, their steering, which is remarkably sharp, being achieved by the aid of the inter-femoral membrane that encloses most of the tail.

1 Roughly speaking, the bats of temperate regions are almost exclusively insectivorous, whereas tropical kinds ('Peropus, \&c.) live on fruit, and some of the larger species suck the blood of sleeping mammals. From some islands where winged insects are not conspicuous (Iceland, Kerguelen, \&c.) there are no bats. 
So extraordinary is the sensibility of this entire membrane that several naturalists, Spallanzani among them, A sixth sense. have attributed to these animals the possession of a sixth sense, a hypothesis that rests for the most part on the fact that, when artificially blinded, they have been known to fly clear of threads suspended in a darkened room. Other observers have testified to the remarkably keen sense of smell possessed by them.

All bats are without doubt seen to greatest advantage on the wing. On the ground, they shamble for the most part very awkwardly, the long-eared bat by alternately hooking on with the curved nail of the fore-thumb and raising itself on its hind-legs, the rest running along with bent head. Most bats can swim, though they do not take to the water by preference, nor can they leave it without some difficulty.

Without exception, they suffer much from parasites, numbers of small ticks, not unlike those associated with house-martins, being found beneath the fur. They are also preyed on by stoats and owls, and occasionally by the hobby and kestrel. ${ }^{1}$

It is a mistake to regard bats as creatures of darkness, for although the majority of species do not come abroad until, at all events, the twilight, it is not by any means uncommon to find a stray one or two about, especially in early summer, at midday.

They hibernate for various periods, some kinds in solitude, others in pairs, but the greater part in colonies, in Hibernating. which each sex often keeps to itself, in old ruins, caves, church-towers, or hollow trees. In this winter sleep they are usually found hanging head downwards. Mild days will, however, tempt them forth

1 It is a remarkable fact that a number of dogs show the greatest reluctance to pick up a bat, the scent apparently affecting them; and Sir R. Payne-Gallwey records a similar objection in respect of dogs retrieving snipe and woodcock. 
at all seasons, and I have seen the pipistrelle abroad within a fortnight of Christmas. When disturbed and dragged forth against their will, they usually become very active for an hour or two, but rarely survive this unwonted energy.

In breeding, the different species vary somewhat; but, as a rule, the female brings forth one, or at most two, at a birth in early summer, wrapping the young in a fold of her membrane.

It will now suffice to enumerate briefly the fourteen species referred to.

The Great Bat, called by White the "high-flier," is found in hollow trees, its presence being often betrayed Great Bat by its fetid-odour. It is this bat that has or Noctule. been found hibernating in pairs. The membrane starts above the ankle. There is a line of hair along the forearm, in which it resembles the next species. It appears not to have occurred in either Wales or Scotland, but has been noticed in Ireland.

The Hairy-armed Bat, a smaller species that closely rosembles the last, save for certain differences in the teeth, Hairy- is apparently confined to our south-western armed Bat. counties, and to a few districts of Ireland. It is at most but a rare wanderer.

The Pipistrelle is the commonest of our bats, and is the more in evidence inasmuch as it rarely hibernates for more Pipistrelle. than three months, and is consequently seen at a time when most other species are in hiding. Though insectivorous by preference, devouring even the hard wing-cases of beetles, it will also, in captivity at any rate, feed readily on flesh. Save for a tuft of black hair over the eye, the face is almost naked. The fur is reddish brown at the surface, but much darker, almost black, at the roots. The ears are conspicuously lobed and notched on the margin. Over the mouth are large glands. The membrane starts below the ankle.

The Serotine (the $V$. noctula of St Hilaire, whose $V$. serotinus is our $V$. noctula) is a solitary bat met with in 
the home counties, and in the immediate neighbourhood of the Metropolis. Its name implies that its activity commences only in the evening, and few bats are

Serotine.

less frequently seen abroad by day. Its torpor lasts for at least six months, as it is rarely seen before the early days of May, and disappears again in September or October. Its flight, especially when it first returns to life, is laboured, though at all times easily distinguished, by those who know both, from the more deliberate movements of the last species, to which it has in this respect been compared. In other particulars there is considerable resemblance. This bat does not, however, give birth to more than one at a time, while the pipistrelle has been known to produce two.

The Mouse-coloured Bat is the largest, as it is also one of the rarest, of British bats; indeed its claim to a place Mouse- in our fauna is, like that of the next, very coloured slight. It is described as a quarrelsome, unBat. sociable species, feeding largely on moths, as well as on smaller insects. The membrane, which includes all but the tip of the tail, is dark yellow, and partly covered with hair. There are also conspicuous tufts over the eyes, and there is some hair elsewhere on the face.

[Once recorded from the New Forest, Bechstein's bat Bechstein's has been admitted into our fauna, which is as Bat. unsatisfactory as the inclusion of a number of so-called " British" birds."]

Natterer's Bat is a smaller allied species, and lighter in colour. It is the most hairy of all British bats. The

Reddishgrey or Natterer's Bat. fur is long and soft; in colour reddish grey and white. The membrane, which has a grey shade, includes the ankle. Ears very long and pointed. This species, which is widely distributed throughout the British Islands, though less

1 The Rough-legged and Particoloured Bats are also admitted to the British list on the strength of the capture of a single example of each ! They do not therefore invite description in the present outline. 
partial to forest districts than the last, may be distinguished by the conspicuous fringe on the interfemoral membrane.

Daubenton's Bat is not infrequently seen hawking Dauben- over water. On the face are two prominent ton's Bat. swellings. The ears, nearly as long as the head, are oval in shape, lobed and notched on the outer margin. It occurs throughout these islands, though nowhere is it very common.

The Whiskered Bat is a small, solitary, and swift-flying bat, not uncommon in Hampshire and the neighbouring whiskered counties, but gradually rarer farther north, Bat. and not indeed recorded from Scotland until comparatively recently. In Ireland its occurrences would also appear to be few and far between. This species hibernates for a short period only in ruins, caves, or hollow trees. The face is thickly furred, hence the trivial name. There are a number of transverse bands on the membrane, which is devoid of lobe and starts from the base of the foot. The tail is long and curved.

The Long-eared Bat is one of the commonest kinds indigenous to these islands, easily distinguished by the great Long-eared length of its ears and tail, the former being Bat. flexible and semi-transparent, and almost as long as the body. When the animal is asleep they are observed to fold downwards. The voice of this bat is particularly shrill and high-pitched-so much so, indeed, that many folks are quite unable to distinguish it. Bell and some older writers described a smaller species, in which the ears were proportionately less and the tail longer. It is now, however, referred to the present species.

The Barbastelle is a rare bat of remarkable appearance Barbastelle. and restricted distribution, being found chiefly,
though nowhere in abundance, in our southeastern counties, scarcer as we proceed northward, and 
apparently wanting in Scotland and Ireland. More than one writer has noticed its absence from apparently suitable districts. The expression imparted by the position of the nostrils in a hairless depression over the muzzle is grotesque in the extreme, the effect being heightened by the tufts of black bristles on the cheeks. The face and ears are black, the latter being short, broad, and notched on the margin. This bat undergoes long retirement.

The group to which our two Horseshoe Bats belong is characterised by the presence of a hairy, leaflike hood over Greater the snout, the exact purpose of which has Horseshoe not, so far, been satisfactorily determined. St Bat.

Hilaire regarded it as a valve to the nostrils, but Bell considered it rather in the light of a highly developed organ of smell, a view that has been more or less accepted by later writers.

The Greater Horseshoe Bat is fairly common in the southern counties of England, becoming rarer farther north, and absent altogether from Scotland and Ireland. Its food consists largely of chafers, and it is essentially a forest bat.

The nose-leaf is in three sections, that in front being in the form of a horseshoe, the second flat and bent at the sides, and the hinder one pointed. There is a conspicuous groove in the lower lip. The ears are pointed and the tail short.

Long regarded as a variety of the last, the Lesser Horseshoe Bat is distinguished by its inferior size, the position

Lesser of its lower teeth, and the depression in the Horseshoe hinder portion of the nose-leaf. Like the Bat.

larger, it is found only in the southern counties, but, unlike it, it is recorded from Ireland, where it has been taken in caves. It is not so fond of forests, and its flight is more powerful. 


\section{CHAPTER II. THE INSECTIVORA.}

\section{The Hedgehog.}

The Hedgehog is among the creatures generally reckoned as vermin of the farm. If any one has just cause of complaint against the hedgehog, it is not the farmer but the gamekeeper, as it has often been taken in traps baited with game-birds or their eggs.

Its chief food, however, consists of worms and insects, and, when domesticated in the kitchen, it subsists largely Food. on cockchafers. It is also known to attack adders, which lacerate themselves against its armour of spines. At any rate its diet is entirely animal, and White was in error when he endowed it with vegetarian tastes. Its worst offence is a rare raid on the hen-house.

The most familiar habit of the

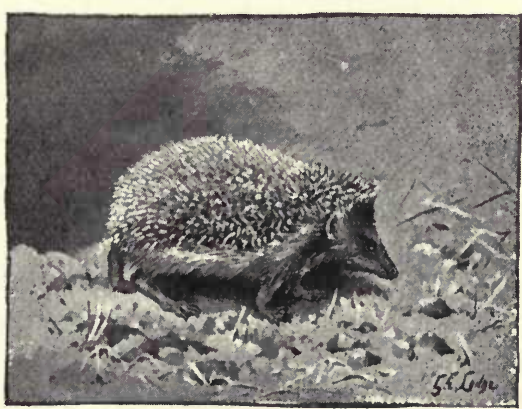
hedgehog is that of rolling in a ball when threatened by danger, a special arrangement of the muscles enabling it to assume this re-

Enemies. markable position. In this way it is able to keep off most of its enemies, including even dogs specially trained for its pursuit, but the fox is said to possess the secret of making it unbend by ducking it in some swamp, or by a disgusting process which it is undesirable to describe in detail. The badger is also said to be 
a sworn foe of this animal. ${ }^{1}$ Another advantage of the coat of spines is that its elasticity is sufficient to break any fall. This it was that formerly lent weight to the slander that the hedgehog was given to climbing fruit-trees and bearing off the fruit impaled on its spines. It has a curious habit of taking up its quarters in particular gardens, where, if unmolested, it will remain for many months. A young hedgehog had taken up its residence in this way in the garden of a house in Cornwall where I was recently staying, and it would run about the gravel walks all night, lying in hiding during the day. At last the owner of the house bought some poultry, and it was all I could do to prevent his throwing the unfortunate hedgehog into a neighbouring stream. I managed, however, to persuade him to deposit it in a market-garden close by, where I have no doubt it did good service.

Early naturalists were pleased to weave romance round the birth and nourishment of young hedgehogs, which are, needless to say, as those of other mammals. The hedgehog pairs for life, and the young-five, six, or, according to $\mathrm{Mr}$ Harting, even seven in number-are born early in August in a roomy nest of dead leaves.

When first born they are blind, the spines being, moreover, white and soft, but soon assuming the colour and

As food. hardness of maturity. Save by gipsies, who roast it "in its jacket," the flesh of the hedgehog is not eaten in this country, though it is a favourite dish in the French provinces, where, according to some writers, two species are recognised.

The appearance of the hedgehog is unique among British mammals, nor is any one likely to confuse it with any other beast, unless it be with the Australian Appearance, echidnas, to which it certainly bears some
\&c. superficial resemblance. Rather less than a foot long, the arched body is covered with dull white, sharp spines, an inch or more in length, and having a dark

1 See the 'Zoologist,' January 1889, p. 10. 
ring at the centre, from which they taper to either end. On the head and belly these spines are replaced by coarse yellow bristles. In colour, hedgehogs show considerable variation, and perfectly white examples are on record. The ears and neck of this animal are short, as are also the legs, the feet having five toes armed with strong curved claws The weight of a live grown hedgehog now in possession of a friend of Mr Harting's is $\mathrm{r} / 2 \mathrm{lb}$. Being unable to find any record of the hedgehog's weight, I persuaded Mr Harting to have this one weighed specially.

\section{The Mole.}

Although partial to the interesting little Mole, which, like the Californian black ant among insects, is for its size

As an

offender. about the strongest of its class, I have always been careful not to spoil its case by pretending that its offences are altogether imaginary. They are at any rate light. From February onward it may undermine the potato-bed, and later in the year it may even disturb the even surface of the cricket-pitch or tennis-court, or, worse still, chase grubs through the drills of young turnips. Nor can it claim to be the friend of the gardener by reason of its destruction of myriads of earthworms, for gardeners of the present enlightened age know well that the erst-despised worm has its uses in nature's economy. At the same time, much of their work, which consists for the most part in turning over the clogged soil, is accomplished by their devourer, which also consumes vast quantities of such noxious creatures as the wireworm and larva of the "daddy long-legs," known in England as "leather grub," in Scotland as "pout."

The mole also devours mice, shrews, small reptiles, and frogs, but is said to draw the line at the toad. It has also

Food.

been described as laying up a store of worms for the winter in an underground pit, a statement which is, however, open to considerable doubt, as 
the mole works throughout the year, its casts in winter often showing through the snow. ${ }^{1}$ This lean animal dietfor, like the hedgehog, the mole eats no vegetable foodinduces continuous thirst, to quench which the mole is known to sink deep shafts for water. Its enormous appetite is partly attributable to its constant exertion, but I have once or twice had captive moles, that had no work to do, die overnight for want of worms. It seems indeed as if this animal must

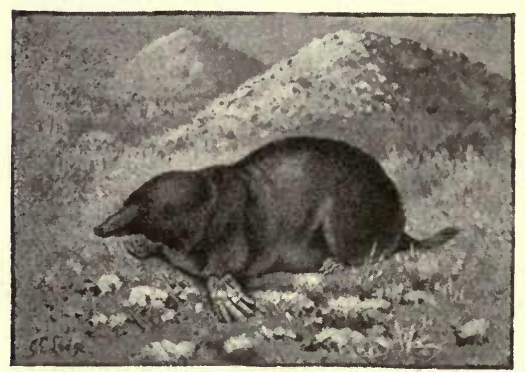

be ever feeding, and certainly no other starves more easily.

Though it seems to do most of its engineering and bunting by night, the mole is not by any means inactive in the daytime, and it is observed to be in motion at certain fixed hours, which it appears to keep with great precision. It works near the surface, almost above it when there is snow on the ground; and Mr Lydekker has happily compared its progress to that of a porpoise in a smooth sea, which recalls the curious fact, already mentioned, that, though unknown, both now and formerly, in Ireland, there are several Irish names for this creature, and one of these denotes "porpoise." 2

The distribution of the mole is not devoid of interest. In many apparently suitable districts, where it would

1 I do not intend calling in question the existence of such stores of worms, for these are not uncommon; but their ultimate object, to provide food in winter, or, as is also alleged, to feed the new-born young, seems at least very questionable.

2 Sir Herbert Maxwell points out that the common Irish equivalent for porpoise is muc mara (sea-pig); but the word I have in mind, but caunot recall, may be a provincialism. 
find food in abundance and soft soil to work in, it is wanting altogether. Very abundant throughout England and the Lowlands of Scotland, it becomes very rare in the Highlands, and is absent from many of the islands.

The question is asked from time to time, What becomes of the moles in flood-time? and I fancy the solution of the riddle is to be sought in the instinct that prompts them to tunnel in sloping ground in the neighbourhood of rivers. This is at any rate the case in the Dover valley, where last February (1897) I found hundreds In floods. of runs in the soft soil of either cliff, but not a single one down on a level with the stream.

Of the structure of the mole and its marvellous adaptation to its conditions of existence, little remains to be said. Built essentially for progress, always Physical peculiarities. hungry and always tunnelling into fresh hunting-grounds, all the strength of the "moudiewarp" is concentrated, as is apparent from a casual examination of the skeleton, in the fore-limbs, the others being comparatively weak. The fur, growing perpendicular, lies equally well in any direction, thereby offering little resistance to the narrow walls against which it brushes. The mole can run rapidly, as Le Court proved by placing little sticks with flags in its run and noting the rapidity with which it displaced them. ${ }^{1}$ It is also something of a swimmer, though it is not known to take to the water unless pursued by the weasel, its worst enemy after man. As in the hedgehog, the senses of smell and hearing are acute, and it is owing to this that the traps of the professional mole-catchers often make large catches on the most windy nights. There is, for all the mole's keen sense of hearing, no external ear, but merely an orifice hidden by coarse hairs.

1 The value of this historic experiment has been called in question, for a horn was inserted in the run and sounded to frighten the mole, and the displacement of the flags has been attributed to the sudden air-pressure. 
The sense of sight is, however, practically in abeyance, though the eyes are not, as in its cousin of the Mediterranean countries, totally enveloped in the skin, but may be seen by any one who will take the trouble to blow aside the fur that normally conceals them.

The elongated muzzle, which is the most sensitive part of the mole's anatomy (especially in the North American genus, on the snout of which is a starlike growth, recalling the nose-leaf in some bats), is thought to give assistance in tunnelling, though the powerful back-turned claws would appear to need little help.

The engineering works of the mole have been so often described that a very brief notice of its wondrous under-

Molehills. ground establishment will here suffice. What we know as a molehill is nothing more than the earth thrown up by the creature as it forages into fresh feeding-grounds, its course being along a kind of highroad, also clearly discernible at the surface. It is in this main track that the traps are set. The actual fortress of the mole, a circular abode reached by a number of passages converging from this highroad, is not thrown up in the exposed part of a field like the hills, but is generally in a natural hummock, or I have found them in hedges. It has a circular gallery, into which run the paths from the highroad. The mole works at various depths according to the nature of the soil and the scarcity of worms, and it is by this that its mischief to the farmer is reckoned. As already mentioned, when snow lies thick on the ground, it works almost at the top. When, however, worms are scarce, as in periods of drought, it sinks its shafts to a much greater depth, and is at such times incapable of doing any damage whatever. On occasion, these animals will obtain their food above ground, where they often feed on certain larvæ. This is observed most frequently in the early part of the year.

The females, being in the minority, have a number of lords, and great fights are held in their honour, it being 
impossible for two males to pass one another in the pairing season without a desperate fight a l'outrance.

The nest, distinct from the fortress, is likewise beneath some hillock; and as the moles use it but once, the Breeding. deserted dwelling is usually appropriated by field-mice. The number of the litter would seem to average five, and personally I never found more, though six, and even seven, are recorded. They appear to be born about the end of July, at least I have found them still blind the first week in August.

The appearance of the mole is too familiar to need detailed description; in fact, as the characters given in this little book are only such as may enable the reader to distinguish the species under notice, it is Appearance, scarcely necessary to enumerate the features
\&c. of one that could scarcely be confused with any other. In colour the mole is, as a rule, glossy black, but grey, yellow, and even albino examples are not rare. When first born, the young are pale brown or grey, their snout being of a delicate pink. The average weight of an adult mole is just under 4 ounces.

It has attracted the attention of more than one writer on the subject that so interesting a creature as the mole, White and one, too, sufficiently common in his part of Buckland. Hampshire, should have been mentioned but once, and that incidentally, in White's 'Selborne.' This reminds me of the drawing of a mole's hand with six fingers, which embellishes Buckland's (1875) edition of that work.

\section{The Shrews.}

In the Shrews, we come to the least of our mammals, smallest of all being the Lesser Shrew, which holds the same position in its class as the goldcrest among our birds. Though frequently confounded with the rodent mice, they have no more in common with them than have the so-called 
"pouched mice" of the Australian region. Indeed they bear, especially in the peculiarly sensitive snout, considerably more resemblance to their near ally, the mole. Being, however, still more exclusive in their preference for insect diet, though their pugnacity leads them to attack with zeal small birds, lizards, frogs, and the like, they are even less mischievous, though the Water-Shrew makes an occasional raid on fish and their spawn. They are normally of dark colour, but albinos have been recorded from time to time in the columns of the 'Field,' both of the Common species in Great Britain and of the Lesser in Ireland.

The Common Shrew is widely distributed throughout Great Britain and some of the Scottish isles, but is not Common found in Ireland. It has the fighting instincts Shrew. of its race; and the quantities of dead shrews found in country lanes in late summer might easily be attributed to this cause, were it not that they bear on them no outward signs of violence. As it is, this singular Mortality. mortality remains without satisfactory explanation. The shrew has many enemies. By man, curiously enough, it is but little troubled, which may in part be due to its retiring habits, though formerly a

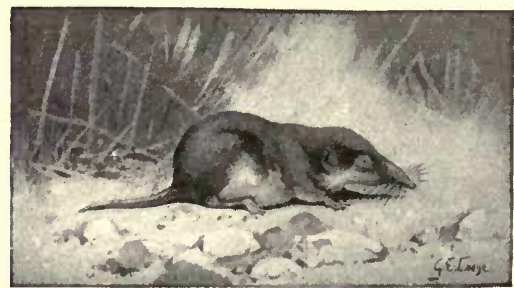

"shrew ash," in which the offender was buried alive, imparting to the wood, so it was said, marvellous healing

Enenies. qualities. It is, however, largely consumed by owls and moles, while cats kill but do not eat it, a habit that has been thought by some to account for the dead shrews aforementioned. 
The shrew breeds in the spring, the young, which number from five to eight, being born in July or August in an unBreeding. derground nest made of dry grass and leaves. ${ }^{1}$ The shrews are all of more or less nocturnal habits, but, unlike the mole, they find their food at the surface, and consequently, instead of displacing the soil, their runs are made in the grass, much as those of fish and Hibernation. waterfowl in the reeds in Broadland. They become torpid in winter, their sleep being more perfect than that of bats, and rarely, if ever, disturbed by any unusual rise in temperature.

The colour of the Common Shrew is usually reddish above and grey beneath. Its most distinctive Appearance, feature is the short, bristly, four-sided tail.
\&c. Like all the group, it secretes an unpleasant odour in lateral glands concealed by long hairs.

Of the Lesser Shrew little need be said beyond the interesting fact in its distribution that, while less common

Lesser in England, it replaces the larger shrew in

Shrew. Ireland and the Hebrides. The forearm is Distribution. relatively shorter than in the latter, the teeth being also more minute.

The Water Shrew is a rapid swimmer and powerful Water diver, the fur keeping comparatively dry when shrew. immersed. It does not occur in Ireland.

Its food consists, like that of the others, chiefly of insects, caddis among the rest; but it seems admitted that Food. it has occasionally been caught in the act of devouring the spawn and fry of game fish. In turn, it is much persecuted by the weasel, which overtakes it in the water with ease, and also by pike and, in Continental rivers, wels.

The female, considerably the smaller of the two, gives

1 The nest is usually in a depression of the ground, but Mr Harting tells me that it is sometimes found in a clover field, ball-shaped, like that of the harvest-mouse. This shrew is thought by some to.rear a second litter (see the 'Zoologist,' November 1896, p. 432). 
birth to a litter of from five to eight young in May, rearing them at the end of a long burrow of her own digging in a nest of moss and dry grass.

This is the largest of our shrews. The body is broader, the snout less tapering, the tail more slender than in the common species, and fringed with white hairs. Appearance, The teeth, of reddish hue at the tips, are
sc. slightly recurved. The fur is black above, white beneath, as also within the ears.

[The older writers described a fourth shrew, a variety, as is now well known, of the present species.]

CHAPTER III. THE CARNIVORA.

I. The Wild Cat.

Of the now narrow distribution of the Wild Cat, fiercest of our surviving carnivora, much has been written, while its European range is the subject of a most interesting volume. An additional interest formerly attached to it by reason of its having been long regarded as the progenitor of our domestic breeds; but this view is now generally rejected. Nevertheless, the wild and domesticated cats are known to interbreed.

That the wild cat still holds its own, though in diminishing numbers, in the wilder districts of Argyllshire, in Lochaber, and the extreme north-west of ScotPresent land generally, is beyond all doubt, though
range. considerable caution is necessary before accepting every reported wild cat as genuine, so many examples having proved on investigation to be the domestic animal run wild. Apart from this, there has been confusion, as 
Harvie-Brown ${ }^{1}$ points out, between this creature and the marten. The same writer refers to its absence from the Hebrides. Not so many years ago the wild cat survived farther south. Roebuck ${ }^{2}$ gives the year i 840 as the date of its extinction in Yorkshire. Major Fisher ${ }^{3}$ saw one in very bad condition in North Wales. I recollect Sir Herbert Maxwell telling me of one said to have been caught less than fifty years ago in Oxfordshire, and now in a glass case at Middleton. He has not, however, been able to verify the date of its capture. From the Lake district it seems to have vanished half a century ago; and as it is undoubtedly a very great nuisance to the farmer and gamekeeper, it would not be surprising if its extinction in these islands were to follow closely on the dawn of the twentieth century. Such folks have no time to devote much thought to the less practical consideration of the impoverishment of our mammalian fauna, nor, it must be confessed, is there much to be said on behalf of this fierce and voracious beast. It is almost a blessing that it is so easily trapped, showing very little suspicion of any baited fall, a little valerian root being, according to Speedy, sufficient to attract any game-hunting cat. The wild cat, it is now generally agreed, never occurred in Ireland.

Breeding. The young, five or six in number, are born in early summer, the lair being either in a hollow tree or in some deserted badger-earth.

Seen in the museum-and few have nowadays any opportunity of seeing it elsewhere-it is a striking animal, bearing a strong resemblance to the lynx. Appearance, The body gives the impression of combined
\&c. strength and immense activity, and is well balanced by the bushy tail, which is proportionately far shorter than in the domestic cat. In colour it seems from all accounts to vary considerably, the type being yellow

1 Fauna of Argyll, p. 11.

2 Yorkshire Vertebrata, p. 5.

3 Outdoor Life in England, p. 4. 
with darker bands, and having black rings on the tail and a black line along the back. The soles of the feet are black.

\section{The Fox.}

In the Fox we have a beast of peculiar interest, which is chiefly due to the fact that the amusement afforded by its pursuit has invested it in this country with an altogether disproportionate importance, in consequence of which it is Protection. strictly protected at the expense of the farmer and game-preserver, whose birds it destroys wholesale. But for this artificial protection, there is every

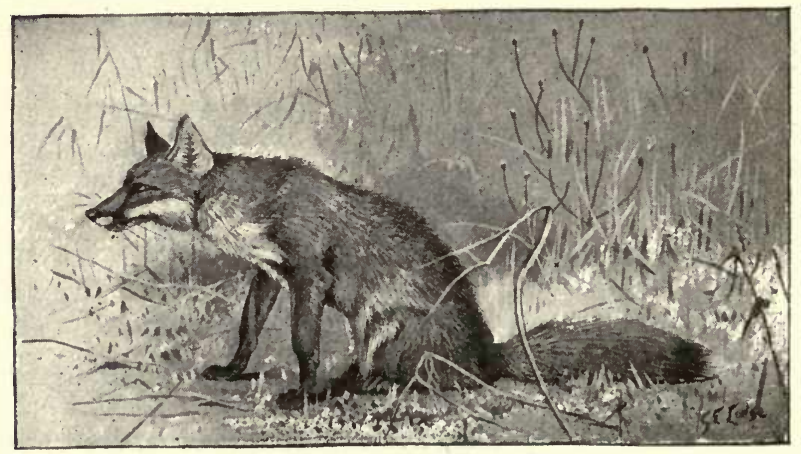

reason to suppose that it would have followed the wild cat, and survive only in the waste mountains of North Britain.

As its pace and endurance endear it to the hunting-man, so does the naturalist find much to interest him in its sagacity. It is not easy, indeed, to be quite sure where this sagacity stops short; in literature, at

Sagacity. any rate, it goes great lengths, and the fox is represented in the folk-lore of all nations as invariably getting the better of other creatures, both weaker and stronger than itself. Among the many dodges by which 
it has been alleged to outwit its more powerful adversaries is that of feigning death (hence known as "foxing"), a habit commonly observed in the Australian dingo; but few hunting-men appear to believe this, none to have seen it.

The accomplishments of this much-hunted animal in making good its escape are many and varied. It is swift of foot, can on very rare occasions clamber up a tree out of reach of the hounds, and will even, when hard pressed by them, take to the water and swim with great ease and at considerable speed. It also fouls the scent, and is even said to roll in manure with this object. In the recent floods in the Fen Country (1897) foxes were, however, reduced to such straits, more especially on the various temporary islands, as to become quite tame. This shows that these animals are not by nature fitted for long distances in the water, choosing it only in preference to the more certain death behind. A case was, however, not long since reported in which a vixen reared a litter on an islet, traversing several hundred yards of water every few hours to procure food for the family. A good deal of this so-called cunning in seeking sanctuary, some interesting examples of which were enumerated in a recent issue of the 'English Illustrated Magazine,' may in fact be attributed to the desperation to which the terrified beast is reduced. It would be too much to think that it stopped to argue to itself whether or not the hounds would follow it into that favourite and oft-quoted asylum, the old woman's applecart.

Though known to excavate now and again the earth in which, curled up like all dogs, it passes the day, and in the hills frequenting heaps of fallen rocks, it more often

"Earths." appropriates the burrow of the badger, so fouling it that the real owner has-being, for all the popular estimate of its offensive odour, a fastidious beast-no more taste for it. Were the intruder not to adopt some such plan, indeed, it would probably be 
evicted, making a very poor show against the teeth of the badger.

An interesting contrast is furnished between the sleek red fox of the hunting counties and the finer grey race of the Highlands. In England, the shooting of a fox is regarded as an act of heresy, and excites obloquy such as falls on the man who in riding country in India shall dare to shoot a wild boar. Sport has its unwritten laws, and they are respected a deal more than some others enacted in less uncertain phrase. In Scotland, however, these sturdy In Scotland. "greyhounds" are shot and trapped without mercy. Attempts have from time to time been made to transplant them to the low countries; but they show to greater advantage amid their native hills, giving but a poor run on the flat, and showing an irrepressible tendency to get back to the hills. Attention has also been called quite recently to the large introduction of German foxes into Bedfordshire, and the farmers have been loud in their condemnation.

The food of the healthy fox is very varied, in fact it is almost omnivorous, readily accommodating itself to circum-

Food. stances. Where furred game is available, it undoubtedly prefers it; but poultry is always acceptable ; and hedgehogs, rats, mice, and even beetles, are often made the best of. On the sea-shore, foxes are known to prowl, especially after a storm, for the crustaceans and molluscs thrown up ; and among other jetsam, ambergris is said to be highly appreciated. Mangy foxes, which feed more on poultry than on rabbits, are most harmful in a district, and are greatly dreaded by huntsmen on account of infection. The mange spreads to the badgers, and even to the rabbits, of the neighbourhood.

From three to five cubs are born in the latter part of April; but the most interesting question in connection with the breeding of this animal is its relations

Breeding. with domestic dogs. That crosses (known as "cocktails") do occur there can be little doubt, but the 
subject is one that requires considerable investigation before the extent of their breeding can be satisfactorily estimated. The cubs remain blind for some days after birth.

Little need be added as to the appearance of so familiar an animal. Few creatures alter their appearance more under different conditions. The lithe, snakeAppearance, like body gives, when seen sneaking away along the ground, a very different impression from its appearance when flying before the hounds, where the observer can appreciate the use of the slender legs and the steering power of the bushy tail, which has sometimes a conspicuous white tip. Unlike the larger grey fox of the Highlands, our race is of an almost uniform reddish hue with variable grey markings, underparts white, as also the extremity of the tail, some black on the head and legs. The pointed muzzle, oblique eyes with elliptical pupils, and tapering ears, always erect, are all sufficiently familiar features. The characteristic scent ${ }^{1}$ is secreted in a gland beneath the tail. The white "tag" is no indication of sex.

\section{The Marten and its Allies.}

The Pine Marten, another of our rapidly diminishing beasts, is still known to breed in the Peak country and in Pine parts of Wales, and one was said to have been

Marten. obtained in Leicestershire as recently as last year. It also holds its own in a few wild parts of the Highlands, and was seen in Argyllshire last year, though of late years it has sensibly diminished, and Present has disappeared altogether from some of the
range. islands where it was formerly not uncommon. In parts of Ireland, especially in Kilkenny, the "marten cat" is not scarce.

1 Lord Coventry, in the course of his article on Fox-hunting in the 'Encyclopædia of Sport,' points out an interesting fact known to hunting-men, and that is, that the scent is certain to be poor on days when gossamer is observed floating in the air. 
Essentially, for all its partly webbed feet, a tree-hauntFood. ing species, the marten feeds almost entirely, save for an occasional relapse to such humble fare as wild honey, on birds and squirrels, which it pursues among the

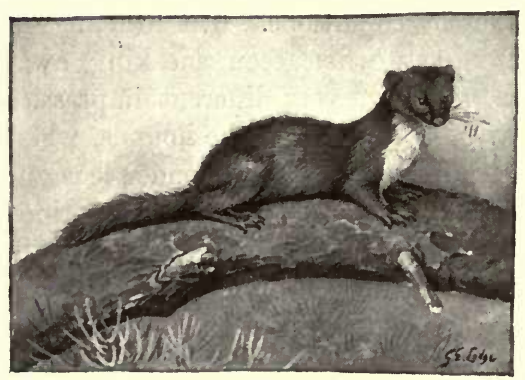

branches. Though it is known to descend periodically to the ground to vary its diet with game and rabbits, there is reason to believe that its offences in this direction are exaggerated.

Like all its tribe, it can get over the ground very rapidly, advancing with sidelong leaps.

More than one litter is brought forth in the year, the

Breeding. first, numbering three or four, appearing some time in April, in an old squirrel's dreyeappropriated for the purpose.

The brown fur is long and glossy, the ears round and hairy. The underparts are of yellowish hue, and there is a conspicuous patch of the same on the throat. Appearance, The colour becomes deepest on the tail, which
\&c. \&c. terminates in a brush. This species lacks the offensive odour of some of its relatives.

[The Beech, or Stone, Marten never existed in these islands, save in books and menageries.]

The Polecat is the largest and the worst smelling of our weasels, the scent being secreted in an anal pouch, and at Polecat or once impregnating everything with which it Foumart. comes in contact. The foumart (foul marten), as it is therefore appropriately called in the North Country, is of somewhat restricted distribution, it having become 
rarer and rarer throughout these islands, until neighbourhoods where it was till comparatively recent years not uncommon, now know it no longer. Accord-

Range. ing to Messrs Harvie-Brown and Buckley, it never occurred in the Hebrides. To Ireland it is not indigenous.

Any kind of live food seems acceptable to this voracious beast, among its favourite items being poultry, ducks,

Food. rabbits, and young game-birds, frogs, toads, and even eels, a picture of a polecat with a large eel in its jaws figuring in the "Naturalist's Library," in Mr Lydekker's volume on 'British Mammals.' There would be nothing remarkable in its taking eels, since they will often wriggle through the wet grass from one water to another, besides which the polecat is a powerful swimmer. Most of its hunting is done by night, but one was shot in broad daylight when pursuing something in a hedge on a private property (July 1893 ) in Suffolk.

The female brings forth five or six young in early summer, rearing them in some rabbit-burrow.

In colouring, this animal is of a uniform dark brown, some of the longer fur being almost black. White markings are present on the sides of the head and near the mouth. The bushy tail is shorter than that Appearance, of the marten. Maximum weight, about
\&c. $6 \mathrm{lb}$.

[The Ferret is merely a domesticated variety of the polecat, from which it is easily distinguished by its inferior

size and the lighter colour of the fur. Never-
Ferret. theless, escaped ferrets are continually reported as genuine polecats. The ferret, as is the case with most domesticated races, multiplies much more rapidly than its wild relative, the litter numbering as many as eight or nine, and a second litter being frequently produced.]

The Stoat, or Ermine, is not more than two-thirds the 
size of the last, yet often confounded in parts of Yorkshire. ${ }^{1}$

The most interesting point in connection with this member of the tribe is its seasonal change of coat. In

Stoat or summer-time, when it is known in the Fen Ermine. Country as "lobster," its coat is reddishbrown; in winter, however, this is replaced (whether by fresh growth or by actual colour-change in the fur itself was long a disputed point) by almost uniform Change of white, only the extreme tip of the tail retain-
coat.

ing its blackness. It is now generally admitted that this protective colouring is brought about by the growth of new fur, and not, as formerly averred, by the effect of the

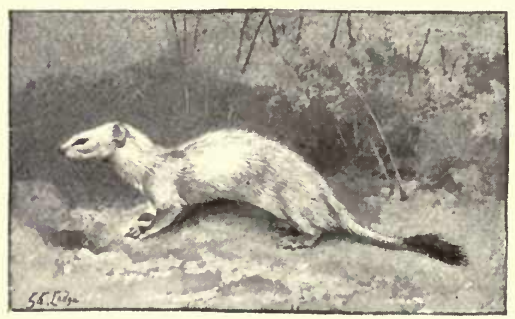
fall in temperature on the colour of its summer coat. The change is observed to be less complete in the milder winters of our southern counties, there being permanent dark patches about the head and back. In autumn, there is an intermediate pied stage.

Unfortunately for the beast, the mingled black-and-white fur has long been in special demand for the linings of State robes; and though the fur, even in Highland Fur. examples, of our ermines is not of sufficient beauty for the market, in Northern Europe and Asia the little animals are persecuted wholesale, their pursuit having led to the opening up of a deal of the interior of Siberia.

The stoat is an unmitigated nuisance in the hen-house

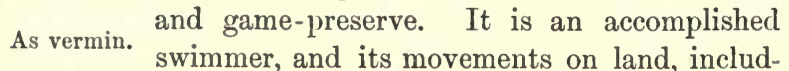
ing the sideling leaps so characteristic of the family to which

${ }^{1}$ Eagle-Clarke and Roebuck, Yorkshire Vertebrata, p. 7. 
it belongs, are exceedingly rapid, so that it can run down a rabbit, as I have more than once seen it do, without difficulty. It is said to leap on its victim's back; but I never saw this, my experience being rather that the rabbit, half stupefied by fear, was easily dragged down Pursuit of by the ear after a very short chase. The
prey.

squeals of the unfortunate rabbit on such occasions are piercing, and seem different from its ordinary voice. The stoat is also known to ascend trees after birds and their eggs. In the fall of the year, stoats wander in packs, and are then said to attack even man, but I do not remember ever coming across an authenticated instance of this.

Five or six young (as many as eight have been recorded) are born in spring.

The stoat is widely distributed in these islands, its range extending to the Hebrides. Some naturalists preRange. fer to distinguish the smaller Irish stoat, which is said to exhibit some slight variation in colouring.

In appearance it is not unlike its larger relative, the polecat, though its length is, with the tail, fully one-fourth less. In connection with the aforementioned winter change of coat, it is of interest to note that stoats have been found in the southern counties in their winter Appearance, coat at mid-summer. At considerable alti-
\&c. tudes they retain, as might be expected, the white coat throughout the year.

The Weasel is the smallest British member of the group. Of wide distribution throughout the mainland of Great

Weasel. Britain, it is apparently unknown in Ireland and the smaller isles. The so-called "weasel" of Ireland is the stoat. " In the North, the weasel is known

1 The absence of the true weasel from Ireland has been denied by many gentlemen in the 'Field' and 'Zoologist'; but, as the then editor (Mr Harting) of the last-named magazine once had occasion to remark, the promised skins of Irish weasels were never forthcoming. 
as the "Whittret" (=Whitethroat). The food of this species consists chiefly of the brains of rats, mice, and moles,

all of which are seized by the head, the brains sucked, and the body left. The alleged habit of blood-sucking is discredited by many. When hard pressed, these animals will eat carrion, and are at times partial to eggs, though these belong for the most part to wild birds that nest in trees and not to game-birds. They are also known to swim in pursuit of water-voles.

These animals, though mostly feeding at night, are frequently met with in daylight; and I came across two in the same week a few miles out of Winchester.

The greatest enemies of the weasel are the larger birds of prey; and it is said to get the better of even the largest occasionally, clinging to their throat and

Enemies. bringing them back to earth faint from loss of blood. I have seen one carried up by a partridge, but the ascent was brief, the descent rapid, and the death of the stoat, brought about by a keeper who had no respect for the fact that "nature is one with rapine," the immediate sequel.

The weasel nests in some bank or hollow tree, and is prolific, the litter numbering from four to six. The

Breeding, alleged rearing of a second, or even third, litter appears to rest on scanty evidence.

The weasel is less striking in appearance than its British relatives. The tail, more particularly, is inconspicuous, head small, neck long and muscular, body Appearance, slender and arched. In colour, it is usually
\&c. reddish above, white below. A winter change of coat is occasionally observed, but the phenomenon is of irregular occurrence.

[Bell and other early writers alluded to a smaller species, an error apparently arising from the great variation in size to which the female is especially liable.]

If appearance went for much in zoological classification, 
we might well be tempted with the older naturalists to press the relationship of the Badger with the extinct

Badger. British bear. The heavy gait, short legs, and hairy body, all lend it at least as much resemblance to the true bears as that possessed by the so-called bear of Australia. Appearances, however, go for very

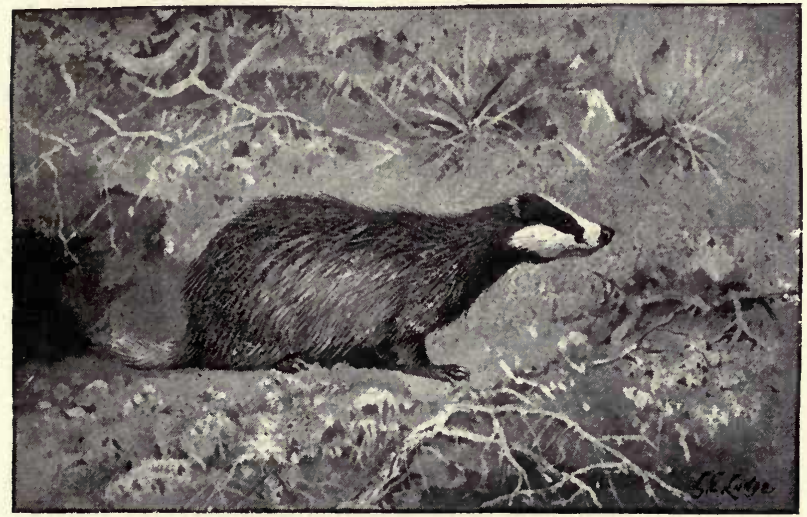

little, and more reliable characters link the badger with the weasels and otter, though the resemblance be externally slight.

The "brock," or "grey," as it is called in the provinces, where the former survives in a number of place-names, is often spoken of as on the verge of extinction, a notion Mistaken partly due to its nocturnal and retiring habits. scarcity. Were it in the habit of seeking its food by day, so large a beast-an old dog-badger may weigh anything up to $40 \mathrm{lb}$.-could not long escape observation and the persecution that invariably accompanies it. As it is, it suffers a good deal of unnecessary cruelty. Persecution. Not many years ago, the sport of baiting the badger, otherwise exposing it in a greased barrel to the onslaught of rough terriers and mongrels, which eventually, and after undergoing much punishment 
from its terrible jaws, worried it to death, was a recognised diversion. This pastime is believed by some to be obsolete. Others are curious to know what becomes of the large number of badgers openly caught on moonlight nights by bolting with the help of trained dogs into a sack placed in the entrance to its earth. The great care exercised in taking it alive may well arouse suspicion as to the unhappy beast's ultimate destination.

Another modern method of taking the badger is that of digging it out with the aid of small dogs sent into its earth, and gripping it, as soon as it appears

Mode of capture. at the entrance, in a pair of blunt tongs made for the purpose. Here, again, the extreme solicitude with which I have observed it on these occasions to be transferred to a roomy sack has suggested ultimate possibilities. There has been at least one badger club engaged in its pursuit.

The food of this burrowing and undoubtedly carnivorous beast is exceedingly varied, and includes roots of bracken,

Food. nuts, fruit, more especially blackberries, small mammals (especially hedgehogs), and reptiles, grasshoppers and other insects, eggs and honey, wasps' nests being also a favourite dish. With the exception of an occasional leveret, its damage in the game-preserve may be generally dismissed as imaginary. Thus, Sir Herbert Maxwell has with no unsatisfactory results re-established it in Wigtownshire, where it had become extinct. Speedy, ${ }^{1}$ however, in his interesting book, declares it to be "the most formidable and difficult of ground vermin to deal with," but very sensibly advocates, instead of its wholesale destruction, its being caught alive and conveyed to those parts of the country where game-preserving is not the paramount consideration. It is, however, too often killed at sight. Only this spring (1897) a Yorkshire farmer killed with a blow from his stick a fine vixen weighing $20 \mathrm{lb}$. 
The strong scent of the badger is secreted in a large glandular pouch beneath the tail.

For so heavily built an animal, it is singularly swift of foot, though it has not, as some aver, legs of unequal length to enable it to run uphill. When escape from the dogs is out of the question, its strongly articulated lower

Gentle disposition. at bay and give a very good account of itself. It is nevertheless extremely gentle by nature, and is, when taken young, capable of great affection for the hand that feeds it. A friend and myself kept one for nearly a year, which preferred young rats to any other food. At the end of that time it died, and I remember we thought at the time that its decease was due to the absence from its diet of some necessary corrective root of which we unfortunately did not know the secret. The badger is as a rule a silent beast, but it will occasionally utter piercing cries without apparent cause.

The distribution of the badger in these islands is somewhat local. As already remarked, its burrowing and nocturnal habits have caused it to be regarded as rarer than it really is. In the Lake district, however, it cerPresent range. tainly does appear to have diminished of late years, though correspondingly extending its range in other directions. According to Roebuck, ${ }^{1}$ it is also dwindling in Yorkshire. By no means rare in the Highlands, where it hibernates, it is apparently unknown on most of the islands, though introduced into Jura. ${ }^{2}$ It is common in parts of Ireland, where the peasantry cure its flesh.

It breeds in the spring, four young being born in March Breeding, or April as a rule, though litters are recorded hiberna- in the summer. The period of gestation is tion, and said to vary. Its hibernation is no more appearance. than a broken sleep, for, although it stores a quantity of moss and grass in its so-called winter

1 Yorkshire Vertebrata, p. 7.

2 Harvie-Brown and Buckley, Fauna of Argyll, p. 18. 
quarters, yet at no season is it torpid, in this country at least, in the true sense of the word. The prevailing colour of the badger is reddish-brown, with white streaks and white stripes on the face. Unless, however, the observer is close, the animal looks uniform grey.

We have in the Otter another much persecuted member of the family, for which, although perhaps the most beautiful of our surviving quadrupeds, even its

Otter. admirers cannot in fairness claim innocence of the charges brought against it. In the fox we had a beast preserved, notwithstanding the hatred of the farmer, for the sake of sport. In the otter we find a curious contradiction, for whereas it affords sport to a limited number of enthusiasts, it equally spoils the prospects of many a good salmon-stream. In consequence, it is mercilessly slaughtered, and the most one can hope for is, that it shall be killed in a manner worthy such a sporting beast, and not trapped or poisoned. To those who have no such direct interest in the stock of the rivers, few creatures lend more enchantment to the scene ; and there is that in the otter's flute-like whistle that makes the angler, if he be not the veriest pot-hunter, pause and listen.

The distribution of the otter throughout these islands is universal. Pollution has driven it from some rivers where it was formerly plentiful, and the draining of the fens has sent it to the Broads; but it still flourishes in most parts of Great Britain and Ireland, on the wilder coasts of which, especially down in the west, otters remain altoDistribution. gether, seldom reverting to the inland waters. These must not, of course, be confused with the larger (and generically distinct) sea-otter of the North Pacific. Otters are particularly abundant in the lochs and streams of the Scotch isles, in writing of which HarvieBrown and Buckley ${ }^{1}$ give a spirited account of the animal's "holt," as its lair in the bank is called.

\footnotetext{
1 Fauna of Argyll, p. 17.
} 
Though a fish-eater by preference, most of its poaching being done at night, it is occasionally driven by the scarcity

Food. of its favourite food to levy toll on rabbits and poultry; but such raids are comparatively rare, and it is in its character as fish-poacher that the otter is detested. Among the other creatures on which it feeds with avidity are moorhens, which it captures by ambush, frogs and crayfish. Of all these it is particularly fond ; and when its native stream ceases to furnish it with any of these in sufficient quantity, it migrates elsewhere, even finding its way down to the sea-coast, where, much like the fox, it picks up a living on crabs and other jetsam. I know of several caves down near the Lizard where these animals have made a temporary home. In one instance, several years ago, I recollect a prolonged storm causing the death of one of these refugees; but whether it was starved to death, or whether an unusually high wave dashed it against a sharp rock, I never discovered. At any rate, my boatman picked its emaciated body up on a little beach just within the entrance, and its remains were respectfully lowered in a crab-pot, where they did good service for many days.

Like so many of our wild creatures which in earlier days found their proffered confidence sorely abused, the otter, having grown shy, is regarded as much rarer Alleged scarcity. than is really the case. Few people, comparatively speaking, unless they live beside some stream, have watched this singularly beautiful creature catching or devouring its prey, or, better still, gambolling with its young. The crown of its head disappearing at the apex of diverging ripples, as the wary creature swims rapidly away to the other bank, is the utmost that is vouchsafed to many a patient watcher. Nor are the In captivity. opportunities for studying it in captivity very much better, for it is, in most zoological gardens, kept in a half-starved condition, its slender dole of fish being seized and devoured in hasty and unnat- 
ural fashion, so that the impression that the visitor carries away with him is that of a restless, cat-like, somewhat noisome creature, with even less claim to beauty than a skunk. In reality, however, whether reclining on its unsavoury lair with a half-devoured fish between its forepaws, ever on the alert for danger, or hunting up the fish beneath the surface, the air-bubbles imparting a beautiful silvery appearance to its fur, not unlike their effect on the plumage of diving-birds, the otter presents

In nature. a most fascinating picture. The lithe form, smooth fur, rudder-like tail, short legs, and large webbed feet, all have their part to play. Though seen to greatest advantage in the water, the otter is by no means an ungraceful animal on land, and the pace at which it can run over the earth, be it hard or swampy, is marvellous. It is not many years since a large otter was run over by a passing train near Market Drayton.

The worst habit of this creature, and one which has doubtless gained more enemies for it than Destructive- any other, is its mischievous practice of kill-
ness.

ing more than it can eat, a wanton spirit of destructiveness that recalls the Australian dingo in its palmy days. The otter has not many natural enemies, though a recent Continental writer ${ }^{1}$ gives a graphic account of a combat between two otters and a sea-eagle.

The "holt" of the otter is in some convenient hole in the bank, and the young, four or five in number, are born in

Breeding.

the summer, not, as frequently stated, in early spring, at which season the dam has not even thought about making ready the bed for the coming family.

The otter is a larger beast than would seem to be comAppearance, monly supposed. In weight the dog, or male,
\&c. lb.; $28 \mathrm{lb}$. is scarcely an exceptional weight, while one of $40 \mathrm{lb}$. has been recorded. The body of the

1 Von Mosjvar, Das Thierleben der österr-ungar Tiefebenen (1897), p. 228 . 
otter is elongated and sinuous, the head flattened, as is also the tail, the latter being thickest at the root, and having beneath it two fetid glands. The eyes are small and exceedingly bright, the ears short and rounded, the muzzle broad and ornamented with sensitive whiskers, the latter typical of the carnivora. Further, the nostrils are narrow, and close hermetically under water. The snout is so sensitive that a smart tap on it will kill or stun the animal. In colour the soft under-fur is pale grey, shading at the tip to brown; the longer, coarser fur is of darker hue. The narrowness of the gullet has also attracted notice, and is thought to aid the otter in keeping under water without too frequently rising to breathe.

\section{The Seals.}

Our coasts are visited by five seals and the walrus, the latter differing in the position of the hind-limbs and the possession of tusks, overgrown canines without root. The horrors of the Behring Sea butchery, still fresh in the public mind, roused considerable interest in these furPersecution bearing, fin-footed amphibians. The commercially useless seals of British estuaries are slain whenever occasion offers, out of regard for their destruction of salmon. For the greater part of the year they subsist on flounders.

Though separated from the true carnivora, there are many points of outward resemblance between these creatures and the otter, the chief difference lying in the limbs, which in the seals are modified as flippers to suit the requirements of an aquatic existence. Of the breeding season of this group, writers and travellers give various Young. accounts, some species apparently bringing forth their young in the early spring, others in late autumn. One point there seems, however, to be in common between the young of all seals, and that is the whiteness of their fur in the early days or weeks of their 
existence, and the curious reluctance with which many of them take to the water until driven to it by their parents. No British seal has either external ears or under-fur, and it is in consequence of the latter deficiency that none has any commercial value whatever.

The Common Seal is nowadays confined for the most part to the northern estuaries, though I have twice come across

Common solitary examples on the Cornish coast. Not Seal. in the ordinary course a strictly migratory species, it nevertheless occasionally finds its way up the river Thames, where it is promptly shot by some riverside

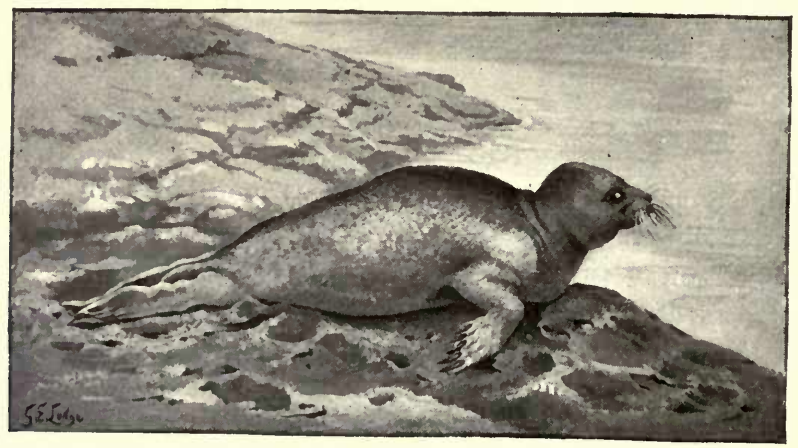

loafer, and reappears a few weeks later grinning against an unnatural background from the farther side of a glass case. A similar fate befell one a year or two ago above Conway Bridge in Wales. Harvie-Brown and Buckley ${ }^{1}$ mention the occurrence of this seal in Loch Awe, and quote a case in Loch Suinart in which one took a small coal-fish off a hook. ${ }^{2}$

The common seal breeds on our northern coast in the Breeding. summer; one, or at most two, would seem to be produced at a birth, and some females are said to breed only in alternate years. This species is of gregarious habits.

1 Fauna of Argyll, p. 21.

2 Ibid., p. 24. 
The head and face are small, the molar teeth growing Appearance, obliquely for want of room. In colour brown-

\&c. ish grey with dark-brown spots; belly lighter and without spots.

The Ringed Seal is a rare visitor on our coasts, though sufficiently common among the Norwegian fjords, where Ringed its blowhole is often seen in the young ice.

Seal. This species is said to have occurred on our east coast within the last ten years. It does not breed on our coasts. The teeth do not lie obliquely as in the last.

The Harp Seal, a large, migratory, and gregarious species, is one of the worst destroyers of salmon. It oc-

Harp casionally enters our rivers, having been taken

Seal. in the Thames and the Severn, and has been once at least recorded from the Irish coast. In colour it is of a dark grey, having on the back a curious black mark, to the supposed form of which it owes its trivial name.

The Hooded Seal is named from the bladder-like process over the snout of the male, which, when inflated by the

Hooded animal, in either anger or fear, assumes the

Seal. form of a hood. This species, which is said to be of polygamous habits, finds its way but rarely to our coasts.

The Grey Seal is easily distinguished from the foregoing by its flat skull, and is fairly common on the less frequented tracts of the north-British and south-Irish coasts, being well known to breed at the present day among the Hebrides, but not on the mainland. ${ }^{1}$ I have seen one or

Grey two of these seals in the Baltic (Christmas

Seal. I890), but they kept at a safe distance from the boat from which we were shooting wildfowl.

The Grey Seal is considered to lack the intelligence that

1 Harvie-Brown and Buckley, Fauna of Argyll, p. 27. 
characterises the rest of the family, a deficiency that is chiefly interesting by reason of its association with the flat skull and expressionless face. The intelligence. grinding teeth are without tubercles.

In colour this seal is grey, with numerous small black markings.

The Walrus, Morse, or Sea-Cow, has only been recorded in British waters on two or three occasions, yet, like a

Walrus. number of our birds, it is freely claimed as a British subject. Its food consists largely of crustaceans. Its fierce disposition, the theme of so many travellers' tales, must be subject to moods, for Nansen tells of walruses so gentle that he had to strike them on the snout with his stick before they would move. Doubtless Nansen's walruses had not yet benefited by the educating influence of contact with man. The appearance of the walrus is certainly suggestive of ferocity, especially the long tusks and bristling moustache.

\section{CHAPTER IV. THE RODENTS.}

This large and important group, of which four families are represented in our fauna, is easily distinguished from

Teeth. any other by the presence of a pair of curved enamelled incisors in either jaw. These teeth are ever growing and ever wearing down by friction. Cases are recorded in which, owing to either accident or malformation, one pair has grown unchecked into the opposite jaw, soon causing the death of the animal from As vermin. starvation. These creatures are, from the nature of their food, among the worst enemies of the agriculturist and planter, the squirrel ring-barking 
the young trees, ${ }^{1}$ the rats and voles devastating the crops. Plagues of the latter occur periodically, when the reprisals are enormous, tens of thousands paying the penalty.

\section{The Squirrei.}

The Squirrel is certainly the most pleasing of our rodents, its antics in the higher branches of beech or fir Range. tree being extremely fascinating. It appears of these islands, and is extending its range in Scotland,

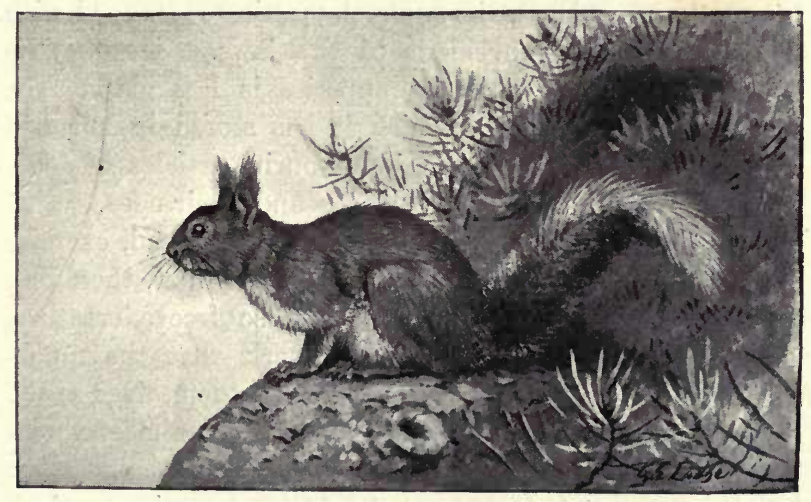

from parts of which it had temporarily disappeared. In the New Forest it is particularly plentiful, and I have more than once seen it in gardens and on bypaths in the very heart of Bournemouth.

Unlike its distant connection, the dormouse, the squirrel never falls into a state of torpor, though it is compara-

1 The damage done to trees by squirrels was discussed at some length in the 'Times' this year (1897), some correspondents giving evidence of their girdling the trunk several feet from the top, while others stated. that their gravest offence was eating out the buds, letting the twigs fall to the ground. 
tively inactive in very severe cold. The food of this animal is, more especially in the warm months, exceed-

Food. ingly varied, including cherries and other stone fruits, nuts, beech-mast, certain toadstools, and, according to one authority, daffodils, though I never came across an instance of this. True, I once succeeded in inducing a captive squirrel to eat one of these flowers, having read of this strange preference; but the success of this experiment goes for little, as the animal would in all probability have accepted with equal readiness a. blossom of the Australian lily, such as neither it nor its forebears had ever in the natural course had the chance of tasting. Like all the rodents, the squirrel masticates its food with a peculiarly free movement of the jaws. During the winter, at which season its appetite is less active, the squirrel subsists on nuts which it has stored in holes in trees. In addition to these, its favourite articles of food, the squirrel will also feed on birds and their eggs. This is one of our most active quadrupeds, and, indeed, exercise seems to be essential to its wellbeing. Without, therefore, In captivity. advocating the caging of so free a creature, it is permissible to remark that the muchcondemned revolving cages are not in themselves cruel, since without some such arrangement the animals would in all probability get seriously out of condition. It is, however, essential that there should be a stationary dark box, for there are times when, like all beasts and birds in captivity, the squirrel finds the glare of daylight unbearable.

The breeding of the squirrel has been the subject of some errors. In point of fact, it presents no great diffiBreeding. culty. Its "drey" or "cage" is built in a hole, or in a fork, in some beech or fir, and a number of these bulky structures are found in an unoccupied, half-finished condition. The young, three or four in number, are brought forth in summer, and in a comparatively short time they appear to mate and breed in their turn. 
The external features of this little animal are sufficiently familiar to render any description unnecessary. The arched body, bushy tail, rounded head, and Appearance, prominent eyes, the ears surmounted by tufts
\&c. of hair, the long, curved claws in which the animal grasps the refractory nut,-all these are unmistakably the squirrel's. In colour, which is subject to considerable variation according to season, it is usually reddish above and white on the underparts. In winter there is a good deal of grey in the coat. The tail has in some cases been observed to be of a creamy yellow at all seasons, and not, as Bell had it, in late summer only. During the breeding season the ear-tufts are shed, and are not renewed until the late autumn. The Squirrel is a rapid swimmer, and $\mathrm{Mr} \mathrm{J}$. G. Millais has in his latest work $^{1}$ given a striking picture of its action in the water.

\section{The Dormouse.}

The dormouse is widely distributed over the south of England, though apparently unknown in the Highlands and in Ireland. Though physically far nearer the mice, this little animal bears in its general mode of existence, in its choice of food and methods of eating and storing it, a marked resemblance to the squirrel, the chief differences in habit being found in the nocturnal activity of the dorHibernation. mouse and in its regular hibernation. For, unlike the squirrel, it slumbers intermittently for almost six months out of the twelve, though the first mild day suffices to awaken it, when it promptly feeds on its stored nuts, and slumbers again. Though October is the season at which most dormice fall asleep, it is observed that those of the year go into retirement somewhat later. When awakened artificially from its slumber, the dormouse becomes very active for a short period, then relapses into slumber, nor does such interference usually have fatal

1 British Deer and their Horns, p. 44. 
results, as in the case of bats. The two degrees of torpor are in fact quite different.

Physically, save in colour, the dormouse bears but slight resemblance to the squirrel, the most striking difference being in the poverty of its tail. It is, however, in more

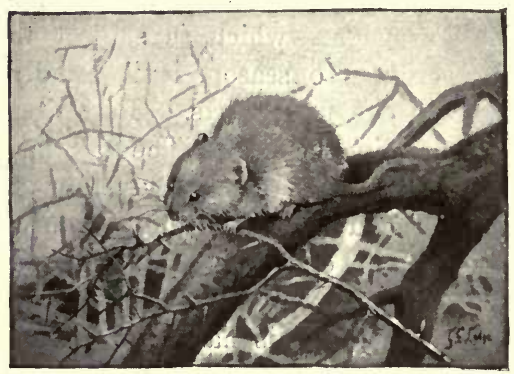
reliable characters that the student has to seek the distinction between them and the affinity which the members of the present family have with the mice.

The food of the dormouse resembles, as already stated, that of the squirrel, but Mr Harting has noted an interesting difference in the fact that it is in addition insectivorous. Although it con.

Food. sumes, as implied by its specific name, large quantities of hazel-nuts, other nuts of various kinds seem to be equally acceptable.

The nest is made in a hole in the ground or in some tree; and dormice are known to have appropriated the

Nest and breeding. nests of jays and like birds, and to rear their young in them, using the nest at a later date for the winter slumber, in which, however, the animal is thickly enveloped in a covering of dry grasses. The young, three or four in number, are born in spring, and some writers are of opinion that a second litter is produced in the autumn, at which season the dormice are very fat previous to their retirement.

In colouring, the dormouse is not unlike the squirrel, being reddish above and white on the underAppearance, parts. The ears, proportionally smaller than
\&c. in the squirrel, are never tufted. 


\section{The Rats, Mice, and Voles.}

The Black Rat is frequently spoken of as the "British " rat, implying that it occurred in these islands from the Black Rat earliest times. Such, however, is far from or Ratton. the truth, as this species was undoubtedly, as geologists are able to tell us, of comparatively late introduction. It would appear to have come, like its more Introduction powerful antagonist, from the East, travelling into these vid the Continent, the period of its arrival islands. in these islands being in all probability about the end of the fourteenth century. Its stay has been short, indeed, for within little more than five hundred years of the date commonly assigned for its introduction it was already becoming scarce, disappearing before the superior strength of its brown relative. NowPresent adays, it only lingers in a comparatively few
range. towns, and, so at least it is said, in some London cellars in the neighbourhood of St Paul's, where one was taken, I believe, as recently as I895. It is also said to hold its own in Sark and others of the Channel Islands; Stockton-on-Tees is, according to Roebuck, one of its last strongholds in Yorkshire; and Sir Herbert Maxwell has caught it in Galloway farmyards.

Though associated, like all vermin, in the popular mind Cleanliness. with all that is dirty and offensive, few animals are of cleanlier habits, for, like other rats, the present species is always combing its fur and keeping itself sweet.

The black rat is prolific like the rest of its family, the female producing during the year an aggregate of from thirty to fifty young, each litter numbering Breeding. seven or eight. The roomy nest of leaves and débris is used as the nursery of successive families, the first of which are themselves parents ere their younger brothers of the same year have seen the light. 
The food of the black rat is varied, though its preference is unquestionably for vegetable matter.

The rats need little description, their typical appearance being too familiar. In colour the present species has a good deal of grey in its fur, though its common name Appearance, serves to distinguish it from the other species.
\&c. The short lower jaw of the black rat gives the face a shrew-like expression. The ears are large and naked. The tail, longer than the head and body, is nearly naked and ringed with scales. The feet are plantigrade, the hindfeet with five well-developed toes, the forefeet with four toes and a rudimentary clawed thumb.

The Brown Rat, easily distinguished by its superior size, is the rat commonly met with in this country, where it has Brown Rat. all but ousted its smaller black relative, just as, in the Antipodes, it has driven to extinction the possibly apocryphal Maori rat of New Zealand. It is wrongly called the Hanoverian or Norway rat, and would appear to have been introduced at the end of the seventeenth century.

Its food is still more varied than that of the last species, as it is not only carnivorous at certain seasons, but is also

Food. known to relapse on very slight provocation into cannibalism. Game, fish, young birds, eggs, frogs, snails, truffles, and grain, are among the articles on which it commonly feeds; and it is also known to gnaw hard substances from which it could not possibly derive any nourishment, in the endeavour, possibly, to keep its teeth worn to the proper level. It is a powerful swimmer, and I remember seeing one night in Sydney Harbour a large number of these rats leaving a ship, having in all probability exhausted the food supply.

If anything, this species is even more prolific than the Breeding. last, as many as twelve having often been recorded in one litter, though the number of 
litters in the year has not, so far as I know, been satisfactorily determined.

This rat is widely distributed in these islands, there being a black race from the east coast of Ireland. It is this race (M. hibernicus) that occurs, according to HarvieBrown and Buckley, ${ }^{1}$ in the Hebrides, where the true black rat is unknown. This race has a conRange. spicuous white patch on the chest.

Besides its superior size, this rat is easily distinguished from the last by its lighter fur, broader Appearance, muzzle, shorter ears, and shorter, more hairy
\&c. tail.

The Common Mouse needs but a brief mention, since it is still more familiar than the brown rat. Easily tamed,

Common like the white variety kept as "pets" by boys,

Mouse. the mouse will grow bold with very little encouragement; and I well recollect how, ten years ago at Bexley, a tiny mouse used to sit on my foot night after night as I sat reading late in an outhouse. So bold is this animal, indeed, as to attack, even in the daytime, large cage-birds, which it has been known to overcome and devour. It is prolific, like most noxious creatures, and probably increasing in spite of owls, cats, traps, and poison. In former times the Welsh used to roast mice alive over a slow fire, but this pastime is no longer in favour.

In colour, the mouse is subject to considerable variation, for all that its typical shade has passed into a household Appearance, word, and ladies would probably be able to \&c.

describe, or at any rate distinguish, mousecolour to their own satisfaction. The typical colour is between a grey and a brown. The tail is long and curling; the muzzle is tapered; the ears large and sensitive, and fringed with long hairs; the feet furred and of a delicate pink tint.

1 Fauna of the Outer Hebrides, p. $36 a$. 
The Harvest-Mouse, the smallest of the family, is widely distributed over the southern counties of England, but

Harvest- rarer in the Midlands, and practically absent

Mouse. from the Lake Country. In Scotland it is very rare, and in Ireland is all but unknown, though it has from time to time been reported.

Like the squirrel and dormouse, it burrows, usually underground or in hay-ricks, sometimes breeding in the latter. Its diminutive nest is, however, more

Breeding. often hung among the wheat or thistles, the long dry grasses of which it is composed being plaited in a very neat manner round the corn-stalks. Several litters, each numbering from five to eight, are produced during the year, the young being blind and less red in colour than their parents.

The harvest-mouse feeds on grain and insects, and

Food lays up stores of the former for the winter months.

It is one of our smallest mammals, only the lesser shrew being inferior. In colour, reddish brown, with white underparts. The tail, rather less than the body, is Appearance, prehensile, and the little creature continually
\&c. winds it around any convenient object in order to steady itself, as may be observed by taking it in the hands. It is a curious fact that, like snakes, mice and rats are, if held by the tip of the tail, head downwards, unable to recover the upright position, or bite the captor's hand.

[The Yellow-necked Mouse was added to the British Yellow- fauna by De Winton in 1894. This variety necked is distinguished by the yellow band on the Mouse. chest; is reddish above and white beneath.]

The Wood-Mouse is a large species, of wide distribution in these islands, where attempts have been made to distinguish more than one variety, notably the small dark race 
from Ireland, and another from the Outer Hebrides. The name wood-mouse is not entirely satisfactory, for Wood- the species is more commonly met with in Mouse or corn-fields and among the ricks, and has Field-tailed even been recorded in dwellings. Like the Mouse. squirrel, this animal becomes inactive, but not actually torpid, during the cold weather.

The wood-mouse feeds principally on grain, and is one of the farmer's worst enemies. It also lays up vast stores

Food. of grain in underground granaries. Humblebees are said indeed to form a favourite article of food, but it is improbable that this animal is to any extent anything but a vegetable-feeder. It has, however, been known, in common with others of the family, to eat considerable quantities of putty without apparently suffering any ill effects. On occasion, too, it has been known to develop cannibal tastes and to devour its own offspring - a tendency oftenest observed in the buck shortly after the young are born.

The wood-mouse is prolific above most of its prolific race. Some years ago Mr Barrington made a calculation in the 'Zoologist,' by which he showed that Breeding. a doe could produce from fifteen to twenty young in the course of four or five months. Were it not that this mouse is a favourite article of food with owls, weasels, and foxes, its increase would be an alarming problem for the farmer. As it is, its numbers are kept well under, and it rarely makes its presence felt as do the voles. It nests for the most part, like its fellows, in the ground, but is also known to rear its young in deserted nests in high trees.

The hind-feet are slender and white, as are all the lower parts, including the under-surface of the tail, the last named being about the same length as the Appearance, body, or a trifle less. Ears, with a projecting
\&c. lobe, not much shorter than the head. In colour, reddish above, with a dark patch on the white breast. 
In the voles we have a group distinct from the rats and mice, and outwardly distinguished by their clumsier water-Vole. build and shorter ears and tail. Being almost entirely vegetarian in their feeding, they are even worse enemies of the farmer.

The Water-Vole is often misnamed "water-rat," though, as I had occasion to point out in a previous work, waterMisnamed rats, so common in Australia, have no place "Water-rat." in the British fauna. This false analogy has possibly been heightened by the fact that the black race of this vole, common in our eastern counties and in parts of Scotland, is often reported as a genuine black rat. Like the other voles, this animal is unknown in Ireland and on some of the Scottish isles.

For all that its toes (of which the fore-feet have four, the hind-feet five) are not webbed, this vole is a remarkably good swimmer, striking out with its hind-legs after the fashion of a frog. It is also a diver, and will, as I have often timed it, remain below the surface for more than a minute.

It makes its nest usually in the neighbourhood of Breeding. water, but sometimes far from it; and the female appears to bring forth a litter of six or seven in early summer. A nest of seven dead voles was found by me this summer on the banks of the little stream at Felpham in Sussex.

The food of this vole consists almost exclusively of aquatic plants and insects, principally the former. It is accused of destroying fish-spawn and water-

Food. fowl, but this is untrue. I watched one quite recently through my glasses rooting up the gravel in the bed of the Hampshire Stour, and it was easy to see from its rapid movements beneath the surface that it was pursuing water-larvæ of some description, as it turned and doubled in a manner totally unnecessary had it been merely picking up spawn. As for an animal of such comparatively sluggish habits catching water-fowl, it seems difficult to credit. 
In colour, this vole is dark brown or black above, grey beneath. A pied vole of this species was recorded in the 'Field' for June 5, 1897. The head is short, Appearance, the eyes small, the ears almost hidden in the fur. The tail is tapering and of moderate length only. The toes are not webbed; the soles are pink, and the claws have a reddish tinge. The teeth are yellowish.

The Field-Vole, otherwise the Short-tailed Field-Mouse, is the most destructive of all, as in the famous "voleField-Vole plagues," the subject of parliamentary inquiries (of which Lydekker gave a useful summary in his 'British Mammals' in the "Naturalist's Library"); and the I892-93 Commission, of which Sir Herbert Maxwell was chairman, brought home most of the mischief to one species only. Though also found near water, it is particularly partial to damp localities at some little distance from any river. It is a great burrower, and the mischief done by it is almost incalculable, though, being a most prolific creature, it is by no means easy to get rid of. Its best friend is the keeper who traps weasels and shoots owls, as these natural enemies are far more efficacious in the long-run than any device of man. Although a powerful and rapid burrower, the field-vole does not hesitate to appropriate the deserted run of the mole, though the latter, should they meet, is known to attack, rout, and even devour the intruder.

This vole hibernates much in the same way as the

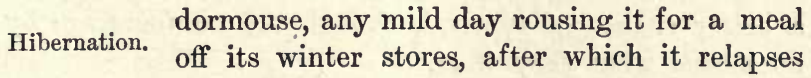
into its long slumber.

It nests underground, several litters, each numbering four or five, being produced during the warm Breeding. months.

A considerably smaller species than the last, the field- 
vole is distinguished by its shorter tail and by the possession of six pads on the sole of the hind-foot Appearance, in lieu of five, as in the water-vole. The
\&c. colouring is very similar.

The Bank-Vole, or Red Field-Vole, as it is often called, is another destructive product of our fields and forests. It seems exceedingly rare in our northern counties, and Bank-Vole. is absent from Ireland and probably from Bank-Vole. the extreme north of Scotland. It is distinguished by the tail being nearly black above and white beneath, and covered with hair. The rudimentary thumb Appearance, of the fore-foot is also more conspicuous. In \&c. many parts of the country this species is scarcely distinguished from the field-vole. In colour reddish above, white beneath.

\section{The Hares and Rabbits.}

The chances of the Hare increasing beyond bounds are slight. For although it is exceedingly prolific, although it Hare. is swift of foot, quick to scent danger, gifted with eyes so placed as almost to see behind as well as before, and, more important than all, protected to some extent, though all too little, for purposes of legitimate sport, yet its natural enemies are so many and so voracious that its numbers are always certain to be kept under. At the same time, the foregoing influences cannot but work powerfully in its favour; and when all is said and done, no beast, after the fox, has a better chance of survival, though the numbers are by no means what they were.

Yet its distribution is interesting by reason of the almost

Range. unaccountable rate at which its numbers are,
in some districts like the New Forest, steadily decreasing.

Except for their general form and affinities, few animals 
so closely allied could well present more points of difference than the hare and rabbit, from their birth and life Contrasted habits to the time when they figure at length with the rabbit. on the table, and the flesh is so different in of totally distinct orders.

In the first place, the young of the hare, or "leveret," as it is called, is born in a comparatively advanced state,

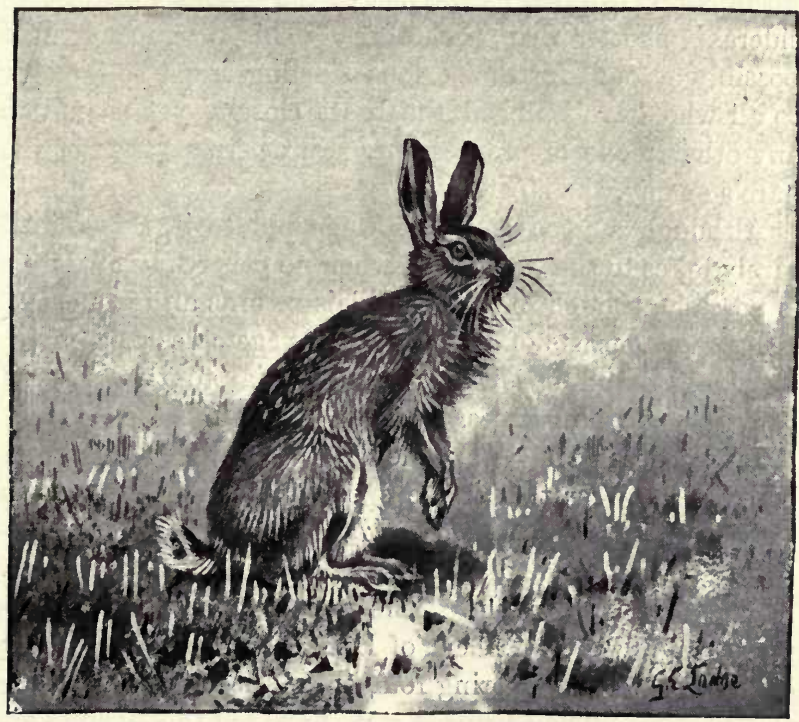

its eyes being open and its body sparsely furred, whereas that of the rabbit is born blind and naked. Again, the hare is a larger beast, and its ears have conspicuous black tips rarely found in those of the rabbit. Lastly, while the weaker, slower rabbit is forced to pass the greater part of its life underground in burrows of its own digging, the hare crouches close on a "form" or shallow depression in the ground, in which position it may, with some little practice, be closely approached. 
The hare has also several peculiar habits which are not observed in its smaller relative. For instance, it has a Curious foolish trick of doubling back to its form, habits when or starting-place, when pursued, which does pursued. not avail it in the least when two greyhounds are after it, the one driving it into the jaws of its rival.

Another instinct observed in the hare is that of escaping uphill, a performance in which, especially for very short distances, it is aided by the fact of the fore-legs being considerably shorter than the others. This discrepancy may possibly account for the curious sideling leaps, so familiar to all who have watched the beast closely, yet so unlike any other mode of progression except perhaps that of the hare's enemy, the stoat.

Although a good swimmer when put to it, this animal rarely takes to the water save when no other way of escape is possible, though Mr J. G. Millais records an instance. ${ }^{1}$

Its food consists of all manner of vegetables and grain,

Food. and it is said to be partial to the bark of young trees.

It is generally held that the common hare will not interbreed with either the Alpine species, which replaces it in Breeding. Ireland, as well as in some of the higher portions and islands of Scotland, or the rabbit. So far, however, as the former is concerned, this view is rejected by a correspondent of Harvie-Brown. ${ }^{2}$ More than one litter, each numbering four or five, is produced during the summer. The advanced state in which the leverets are born has already been alluded to.

In addition to the characters incidentally given above, the following may be noted: The ears are longer than the head; the upper lip is cloven; the claws are Appearance, long and curved; there are long bristles over
\&c. the eyes and mouth. In colour, greyish-brown or reddish, with some black on the back and ears, white beneath. Black hares have been recorded, also uniformly

1 British Deer and their Horns, p. 44. 2 Fauna of Argyll, p. 42. 
white examples, some of the latter having the eyes of the normal brown, not pink as in albinos. The hare is covered with hair all over, even to the soles of its feet. Mr Harting fixes the average weight at $8 \mathrm{lbs}$.

The Blue Hare (otherwise, Varying, Alpine, or Irish hare) is found chiefly in Ireland (where it replaces the preceding species), in the Highlands and isles of Scotland, and in the Lake Country, though it is not uncommon in Yorkshire and Cheshire and a few
other counties.

The interest chiefly attaching to this rather smaller species is in its winter change of coat, a metamorphosis whinter coat. like the stoat, it undergoes in greater
or lesser degree throughout its range, although older writers denied, for some reason or other, that this change took place in Ireland. The process is now held to be similar to that observed in the stoat, and not, as was also alleged in the case of the latter, through any actual change in the colour of the old fur. The common hare is said to undergo a similar change in the colder portions of its range. The black tips of the ears never change colour. The food of this species consists largely of pine-seeds and hill-grasses. It has no "form" like the common hare, but it has the same habit of lying close. Like the hill-fox, its pace is far inferior to that of the hare of the plains.

This hare is said to produce but two litters during the Breeding. year; and if this is indeed the case, then it the family.

is the least prolific of the British members of

The chief differences, in addition to the winter whitening of the coat, between this and the common hare, are as follow: The hind-legs are shorter, Appearance, approaching the others in length; the ears
\&c. are also shorter, and the fur is softer. In colour greyish, the tips of the ears black. 
Something has been incidentally said above of the appearance and habits of the Rabbit, and a very short account will here suffice. It is widely dis-

Rabbit. tributed throughout these islands, though, owing doubtless to the presence of natural enemies unknown in the Southern Hemisphere, it has never become so serious a trouble here as in Australia, where the problem of dealing effectually with this imported plague costs the colonial Governments millions sterling. Even in these islands, however, farmers have periodically suffered from its increase, particularly from the plantdeath caused by its bite.

As an article of food it is, save with Jews and Shetlanders, in almost general use.

Like the hare, this animal multiplies with alarming rapidity, breeding at the age of six months, and proBreeding. ducing in her underground warrens several litters in the year, each numbering from five to twice that number. The naked, blind condition of the new-born young has been alluded to above. Colonies of rabbits are in some parts known to inhabit hedges in lieu of the underground burrow.

Like the hare, the rabbit, though an excellent swimmer, takes to the water only as a last As a resource; indeed, it takes quite as readily swimmer. to a tree, in which, when pursued, it can climb with ease.

The ears of the rabbit lack the black tip that distinguishes those of the hare. The white Appearance, under-surface of the erect tail is very con-
\&c. spicuous. 
CHAPTER V. THE DEER.

The Red-Deer only occurs wild in the Highlands of Scotland, in at least a few wild districts in Ireland, in Red-Deer one wood in the Lake Country, at two spots Red-Deer. in Devon and Somerset, in parts of Mull and the Hebrides. In addition to these, there are still

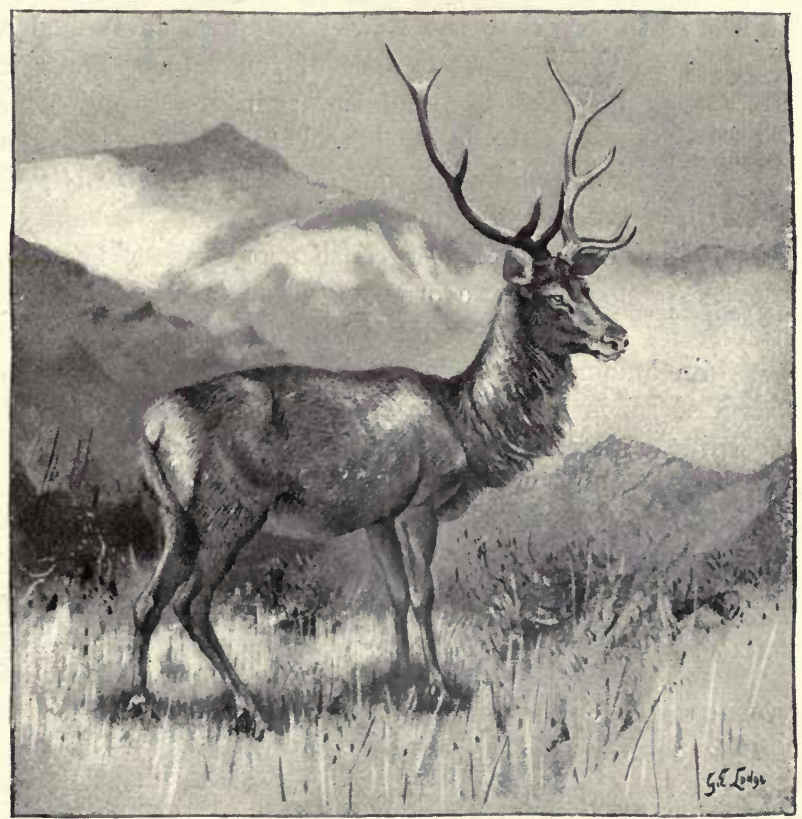

a few head in the New Forest; and tame herds are Range. kept in some eighty parks, an account of which is to be found in Whitaker's 'Descriptive List of the Deer Parks and Paddocks of England' (r892).

The male, otherwise stag or hart, is, as in other deer, 
distinguished by the possession of solid branched antlers, which are shed each year after the breeding season, and Antlers. occasionally eaten by the hinds. These antlers, which in the young stag are intersected by the circulating blood, are, at a later stage, without blood and not sensitive to pain, and the skin gradually peels off, leaving the horn bare.

It is unnecessary to go into the technical terms which have, as in most sports, sprung up around stag-hunting. Suffice it to say that the new-born fawn is termed a "calf"; on the first appearance of the velvety horns it becomes a "knobber"; in its second year Names at dif- the male is a "brocket"; in the third a

"spayad"; in the fourth a "staggard"; in the fifth a "stag"; in the sixth a hart.

The food of the red-deer consists of grasses, heather, Food, \&c. toadstools, acorns, and like fare. It drinks a certain amount of salt with its food. Except when in search of hinds in the autumn, at which season they are exceedingly quarrelsome, the stags keep apart, feeding on the higher ground, the hinds and young keeping to the lowlands. All deer are subject to epidemics of great virulence.

A single fawn, spotted at first, is produced in early Breeding. summer, the period of gestation being rather over eight months. Instances are known of two at a birth, but one is the rule.

The red-deer has the typical appearance of its family. That is to say, arched back, long neck and legs, taper Appearance, naked muzzle, large expressive eyes with a \&c. tear gland or furrow beneath them. The tail, the lower surface of which is white, is short. In colour, reddish along the back and sides, becoming lighter, with more grey, in winter. A light patch on the rump. A yellowish-white race is also known. Weight between 15 and 30 stone. 
The Fallow-Deer is not, like our two other deer, indigenous to these islands, though the date of its introducFallow- tion is uncertain. From the last it is dis-

Deer. tinguished by its inferior size and palmated horns. It is this deer that is said to supply the finest venison.

Fallow-deer are kept in a number of parks; and there are large herds in the New Forest, differing, according In the New Forest. to $\mathrm{Mr}$ Lascelles, in the narrow palmation of the antlers and in the spring and autumn change of coat.

Where they occur, as in the New Forest, together with the larger species, it is remarkable how hounds, laid on to the red-deer, are nowise diverted by the scent of the smaller animal. ${ }^{1}$ When alarmed, these deer bunch together, and when escaping, the bucks bring up the rear. ${ }^{2}$

The doe gives birth to one or two (very rarely, if ever, Breeding. three) in early summer, the middle of June
being the usual time. When the horns first appear in the second year, the young male is known as a "pricket."

Fallow-deer suffer intensely in cold weather, and during one severe winter some hundreds were found dead in one Food. part of the New Forest.

The fallow-deer crops the grass, and is particularly fond of acorns and chestnuts.

In addition to its smaller size, it is easily distinguished by the palmate antlers and longer tail. In Appearance, colour it is light brown with white spots.
\&c.

There are two races of this deer, a lighter and a darker.

The Roe-Deer, smallest of our deer, though formerly widely distributed in these islands, is, with Roe-Deer. the exception of a number of reintroductions,

1 De Crespigny and Hutchinson, The New Forest, p. 158.

2 Millais, British Deer and their Horns, pp. 145, 149. 
now restricted to the northern counties and Scotland. It is, like the chamois, an alpine species. From Ireland it Range. appears to have been always absent. In the New Forest it is scarce, and the few that are there found are said to be of comparatively recent introduction.

Two, in very rare cases three, spotted fawns are born in

Breeding. May or June; and a remarkable phenomenon, known as suspended gestation, is observed in the reproduction of this species.

The food of the roe-deer is much the same as that of the rest, though it has a special weakness for fungi.

The antlers of the adult show three points, each the Appearance, growth of a year. The tail is very short. $\& c$. In colour, the roe-buck is brown, lighter in winter; rump and under-side of tail white. The buck utters a loud bark in presence of danger. Roedeer are fond of running in circles, and $\mathrm{Mr}$ Millais ${ }^{1}$ gives a most interesting account of their so-called "playing-rings."

\section{CHAPTER VI. THE WHALES AND PORPOISES.}

When the unscientific world regarded the bat, after its kind, as a bird, it also considered the cetaceans in the Formerly light of fishes, - a view confirmed by their regarded watery surroundings, their mode of getting as fishes. about, their generally fish-like outline, and the nature of their food. It needed the research of Linnæus and others to assign them to their true class as warm-blooded creatures, breathing by lungs and bearing and nourishing their young in true mammal fashion.

The food of these cetaceans is very varied, and presents

1 Millais, British Deer and their Horns, p. 188. 
one singular anomaly in the fact that the largest of the order, the right or whalebone whales, are toothless, and Food. consequently manage to support their huge bulk on a diet consisting exclusively of $\mathrm{mi}$ nute crustaceans, tiny organisms known to the crews of whalers as "whale-feed," and often encountered in midocean covering several acres of the water's surface. I have noticed that it possesses a peculiar aroma, and I recollect our ship passing, off the coast of Sumatra, through a considerable tract of it, which gave forth a most unpleasant stench. The method of feeding adopted by these toothless whales is well known. They engulf a mouthful of this feed, then expel the water, and leave the foreign matter stranded on the plates of baleen, or "whalebone," as we call it, which thus forms a convenient sieve. It lies in plates in the upper jaw, and the term "bone," as applied to it, must not be taken too literally, as in point of fact it is not exactly bone.

The great toothed whales, on the other hand, consume vast quantities of squid and cuttlefish, which they swallow whole, a greedy habit to which we are indebted for that exceedingly valuable product ambergris.

The external characters of whales do not need to be very closely studied before they show how superficial is the External characters. supposed resemblance to fishes. The X-rays and the dissecting-knife soon show the socalled "fins" to be more of the nature of gloved hands. The whales - most of them at any ratehave five fingers like ourselves, only, needing their hands for swimming purposes, and having no use for the separate action of the fingers, they have been permitted to grow flesh gloves, thus transforming the useless hand into the useful flipper. The tail, again, though forked somewhat after the manner of that organ in some fishes, is attached horizontally, not vertically, a few strokes of this powerful propeller being sufficient to bring the whale up from the great depths at which it passes its life, whenever it wants 
to breathe. The skin is not scaly like that of fishes, but perfectly smooth, having, moreover, beneath it an elastic cushion of fibrous blubber, - a wonderful provision against the heavy pressure under which, for the most part, these animals live. Again, the whales have no gills, but in their place are endowed, like ourselves, with lungs, by the aid of which they breathe the air direct; and, in order that they may remain for considerable periods beneath the surface, they are further provided with a marvellous means of aerating the blood. The blowhole, through which they breathe or "spout," closes hermetically with a powerful valve whenever they dive. In short, it would be difficult to find another order of living creatures better adapted to the peculiar conditions under which they have elected to live. Their mental standard cannot be very easily judged, but it is probably low. Indeed, as their brain does not amount to much more than three per cent of their total bulk, some of the larger whales should be more stupid than most creatures.

Their reproduction is slow, indeed cynical folks have some cause for remarking that this is the case with most Breeding. valuable creatures, only the rats, sharks, and other vermin multiplying with rapidity. The possible explanation of this discrepancy is that nature did not plan everything beforehand for the comfort of man. At any rate, the whale only produces a single "calf" at a birth, carrying it for over a year, and, after its appearance, tending it with a devotion almost rare in some higher mammals. She never hesitates, for instance, to place herself between it and any danger that may threaten.

Of the three most valuable products yielded by these creatures - the fourth is the oil run down from their blubber-it will be well to say a few words. Of these, Whalebone. the first is the so-called whalebone, to which passing allusion has already been made. This is put to a variety of uses, the chief being in the manufacture of corsets, while a less important function is in the 
rings of landing-nets. I have used a landing-net with the ring of whalebone for upwards of eight years of sea-fishing, the sport that above all others tries the angler's tackle, and it is still as good as new ; indeed, as the market price has, after many fluctuations, risen above that at which I bought it, its value has increased. The value of this product varies considerably, and was at one time over $£ 2000$ per ton. At the time of writing I believe it stands at rather more than half this figure.

Spermaceti comes from the cachalot, being contained in fluid form in the "box" within the forehead. This fluid Spermaceti. hardens on cooling, and, after a simple treatment with alkalis, is of use in ointments. The spermaceti from a large whale will fill over a dozen barrels. Sperm-oil is better than the commoner train-oil.

The third of these commodities is unquestionably the most interesting of all. It also has its origin in the cachalot, and a passing strange origin it is. In the courtAmbergris. ing season, that huge cetacean repairs with its mate, or maybe in search of her, to the warmer waters of the Gulf Stream, where together they gorge on the cuttlefish that swarm in those waters. In its great haste, the whale swallows these cephalopods whole, an indecent greed that is punished by the accumulation of the beaks, the least digestible portion of the cuttlefish, in the creature's inside. Here they presently set up so severe an irritation as to give rise to the secretion of ambergris in great masses, which are usually vomited in mid-ocean and subsequently carried ashore, largely in the Bahamas, by the tides. Less frequently the whale retains the ambergris, which then accumulates by the time of its death to an enormous bulk weighing many hundreds of pounds - a very acceptable addition to the marketable value, when it is remembered that the price of this insignificant, greyish, half-greasy substance is something like $£ 5$ per ounce. Some curious finds of this secretion are on record. On one occasion an old negress 
found an enormous mass on the foreshore of one of our West Indian possessions, broke off a moiety weighing about 500 ounces, and thrust the remainder under a bush. A fellow-countryman subsequently advised her to throw the evil-smelling "rubbish" away, which she did. As a result the fragment fell into the hands of a more sophisticated European, who disposed of it in London for close on $f 3000$ !

The use of ambergris is for the most part confined to the manufacture of perfumes. Ground up with sand and treated with alcohol, in which it slowly dissolves, it is effectual in intensifying and fixing certain essential perfumes. In the East, and notably by the Moors, it is also drunk in tea, on which, greasy as it is, it floats. Its flavour, taken in this way, is peculiar, but not unpleasant, and Orientals value it chiefly as a stimulant. According to Milton, it was formerly used in English cookery. It is desirable to point out that, save as part of the ocean's flotsam, this substance has nothing in common with amber. The latter is a vegetable, not an animal, product; it comes largely from the Baltic, not from the warmer Southern seas; and its value is 5 s. an ounce instead of $£ 5$.

It will now be necessary to enumerate very briefly the score of whales and allied dolphins and porpoises which wander, rarely for the most part, to the coasts of these islands, though, as their collective points of interest have been given above, the notice may in each case be restricted to a few words only.

The Right or Whalebone Whale is a great toothless species. The head is large and flat, the baleen, or whaleSouthern bone, lying within the upper jaw in some six Whale. hundred plates. This species, which has been recorded from the east coast and Orkneys, was confused by the older writers with the allied Greenland whale. In colour it is black above, lighter beneath. Head large and flat. 
Of the four Rorquals, or Finners, recorded from British waters, only two, the common and lesser, visit these Rorquals. islands with any regularity. I have seen the latter, which rarely exceeds a length of 30 feet, rounding up the pilchards off the Dodman near Mevagissey. The Common Rorqual is said to attain to a length of 70 feet, and the rarer Sibbald's Rorqual, the largest of them all, grows to 9o. It has, however, occurred on our coasts less than a dozen times. The fourth, Rudolfi's Rorqual, which rarely exceeds 50 feet in length, has also not strayed to our waters more than half-a-dozen times, having occurred mostly on the east coast of England.

The Humpback Whale is found in summer on the Humpback. northern coasts. It is distinguished by the hump on its back and by the fold of skin along the throat. In colour this whale is black.

The Cachalot is the toothed whale. It has no baleen; indeed, as already mentioned, it feeds chiefly on squid and Cachalot cuttlefish. It is but a rare straggler to these or Sperm islands. The head and body are of almost Whale. equal length. In the lower jaw are some twenty pairs of well-developed teeth, and some rudimentary teeth are discernible in the upper. This whale is recognisable by the swelling over the snout. It has a rudimentary back-fin.

Sowerby's Whale is easily distinguished by its long beak, Sowerby's dorsal fin, and the two short teeth in the lower whale. jaw. It has been recorded a score of times in the waters around these islands.

The Bottlenose is not uncommon, especially on the Bottlenose. ${ }^{1}$ north coast, and may be recognised by the
truncated forehead and beak-like snout. It

1 The "Bottlenose" of our south-coast watering-places is neither this nor the true bottlenosed dolphin, but the common $D$. delphis. 
has, like the last, two teeth in the lower jaw. The dorsal fin lies back near the tail.

Cuvier's A rare beaked whale allied to the last. Whale.

The Porpoise, or Sea-Hog, is a familiar object on our coasts, where its appearance in numbers is locally, and Porpoise, with some reason, regarded as the prelude to a spell of east wind. It feeds entirely on fish, herrings more especially, and when the shoals of the latter break up, it ascends rivers after the salmon. Its fate is usually a rifle-ball, and it has always seemed to me matter for regret that it should not be more systematically hunted for its superb oil, which is worth at the least half-asovereign the gallon, as also for its hide, excellent material for shooting boots. The female bears one calf only at a time. This cetacean is too common to need description; its triangular back fin is often seen cleaving the water, and the arched backs have, when several proceed in single file, given the impression of a sea-serpent. The blowhole is crescent-shaped. In colour our porpoise is black above, white beneath.

The Round-headed Porpoise, "Black fish," or "Pilotwhale," rarely encountered in English waters, is seen in Round- herds, often driving along at high speed, headed among the northern isles. It is the "ca'ing Porpoise. whale" of the Shetlanders, who kill it for its oil. Its food is said to consist largely of cod, flounders, and cuttlefish.

This cetacean has a short dorsal fin, the flippers being short and narrow. On the forehead is a conspicuous swelling. Some twenty conical teeth lie in either jaw. In colour it is black above, white beneath; a heart-shaped white patch is situate below the head.

The Grampus, or "Killer," is the most voracious of the 
sub-order, and feeds on large fish and cetaceans, the porpoise being a favourite meal. The dorsal fin is long and high. There are sharp teeth in either jaw. Grampus. The grampus is not uncommon in the Channel. In colour it is, like the rest, black above, white beneath; a white patch is conspicuous over the eye.

Generically distinct from the last, Risso's Grampus 'has Risso's no teeth in the upper jaw. It has not been Grampus. recorded in these waters more than a dozen times. In colour this grampus is black above, lighter beneath, with irregular spots.

The "Beluga," or White Whale, is, like so many of our White whales, met with only in our more northern

Whale. waters. It has no dorsal fin, and the flippers are short. The head is also short, and there are small blunt teeth in either jaw. In colour the beluga is almost pure white, streaked in some cases with yellow.

The Narwhal is the most singular in appearance of all the sub-order, and has occurred but three times off the

Narwhal. coasts of these islands. It is unmistakable by reason of the single enormous tooth, or tusk, that protrudes from the left corner of the upper jaw to a length of as much as 8 feet. There is in the right corner a second tooth, which, however, save in very rare cases, remains undeveloped. This strange twisted tusk is developed in the male only. In place of a dorsal fin, this genus has a ridge along the back. In colour this species is greyish white with darker spots.

The Dolphin, next to the porpoise the commonest cetacean in the Channel, is in that sea known, on account of

Dolphin. its beak-like snout, as the "bottlenose," a name that should more properly be given to the far rarer species that follows. It is not known to ascend rivers, like the porpoise. (On the other hand, 
there are dolphins in the Ganges that never go down to the sea.) There are numerous teeth in either jaw. The dorsal fin is high. In colour, the dolphin is black with yellowish stains.

Bottle- The Bottlenosed Dolphin is a member of a nosed Dolphin. rarer genus.

The rare White-beaked Dolphin has occurred about a dozen times in our waters, chiefly on the east coast, white- but also in both Scotch and Irish inbeaked shore waters. The white beak and lips Dolphin. contrast strangely with the black of the back and sides.

White- The allied White-sided Dolphin has the sided sides yellowish white. It occurs at long Dolphin. intervals among the Orkneys. 
B I R D S 


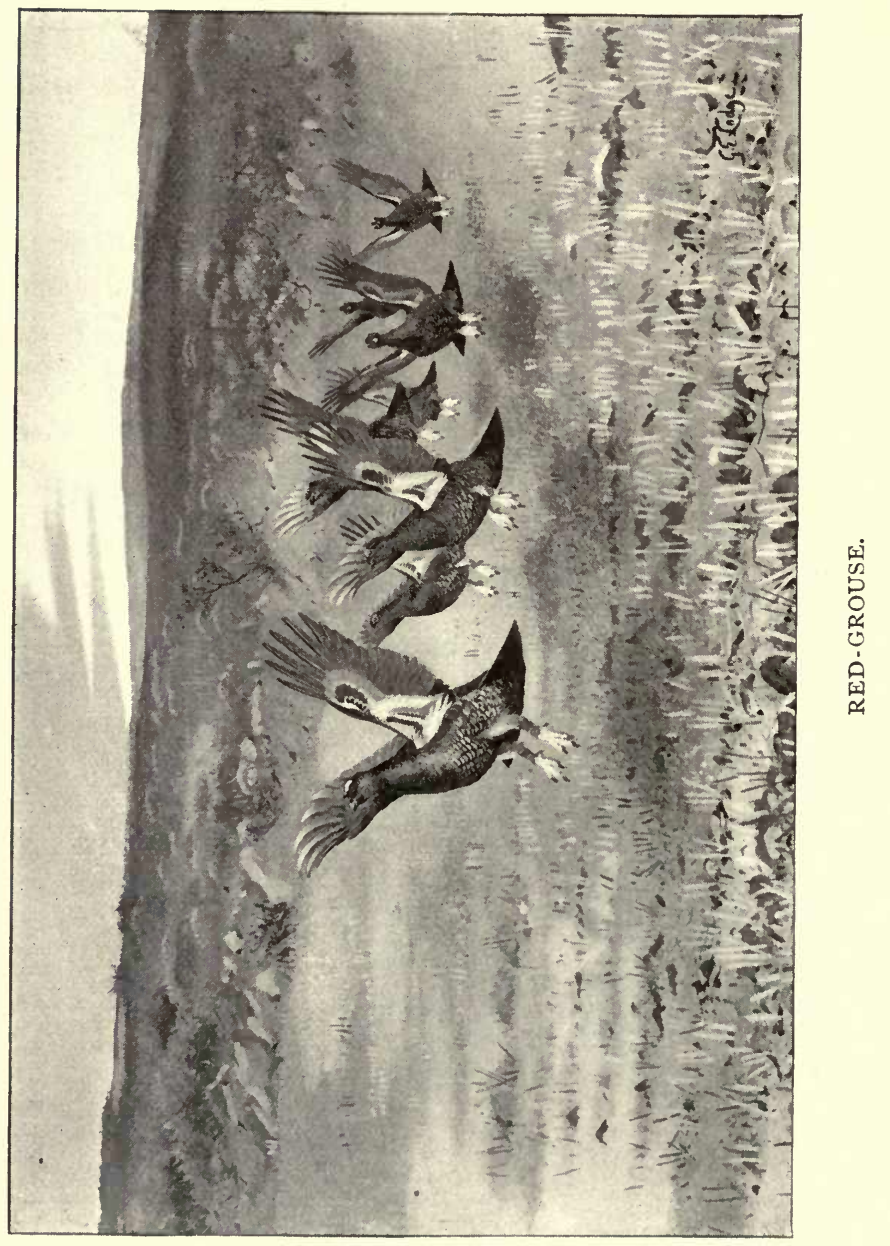




\section{B I R D S.}

Since the days of Aristophanes, at any rate, man has been the recognised foe of the birds, but his affection for them Persecu- is a tender plant of modern growth, rearing its tion and head only in a few highly civilised lands, and protection. even there in constant danger of being killed. For the tendency of the present day trends dangerously on that exaggeration that is certain to provoke the charge of maudlin sentimentalism. It is perfectly right to endeavour, even, as in Massachusetts, by legislation, to restrain the senseless fashions that have resulted in feathered women. It is equally laudable to attempt to bring home to the farmer, ay, and game-preserver, the wholesome fact that nature's balance was established before the dawn of farming or preservation; that limits had already been put to the untoward increase of bird-life, the egg-eating mammals and reptiles, the terrific winds to thin the ranks of migrants, and the late frosts to kill the early broods. Man's arrival on the scene was a bad day, indeed, for the birds, and a bright one for the insects on which they fed. Bird-protecting societies have plenty of excellent work to do if they can only stamp out the catapult ; if they can but persuade the agriculturist that a single wagtail, or swallow, or nightjar may be worth a ton of vermifuge. They need not go beyond their strength and protest against the shooting of game-birds reared, even imported, for the pur- 
pose. It may, or may not, be cruel, but it has simply nothing to do with the case. The business of bird-protection societies in this country is with our wild birds; and, but for the people who shoot them, the pheasant and capercaillie would not be here. Even the partridge and red-grouse, though indigenous, would, it is fair to assume, have disappeared long since but for the preserver.

One outcome of the modern movement in favour of wild-bird protection has unquestionably been an enormous

Increase increase of late years in the literature of the of books subject. It is difficult, indeed, to distinguish on birds. the precise extent to which the movement has evoked the literature, and that to which the literature has furthered the movement. It is, in fact, one of those cases of continuous action and reaction. At any rate, the books are a reality. The old errors began to lose ground. Doubts arose as to the cuckoo sucking eggs in summer to clear his voice, and changing in winter into a merlin; soon folks came to ridicule the notion of the wren hibernating, the nightjar sucking cows' milk, the siskin building an invisible nest, the heron hatching her eggs, like the flamingo of books, astraddle, and catching eels with the aid of an attractive oil exuded from her foot. Common-sense began to ask how the race of nightingales could be perpetuated if, as averred, the mother reared only those (males) that gave promise of good voice. The swallow was no longer believed to pass the winter at the bottom of frozen lakes, to know the healing properties of celandine, to have in its crop a magic stone like the equally apocryphal jewel of the toad. Folks were told that the skin of a dead kingfisher was an infallible protection in a thunderstorm, but they grew so matter-of-fact as to prefer the ordinary lightning-conductor. One naturalist revealed the truth about the halcyon's noisome nest; another ridiculed the simple old faith in its suspended body foretelling the quarter of the wind, and suggested that any live bird perching in a tree-top 
was a far better guide, since it would at least arrange itself head to the wind, so that its feathers might not be unduly ruffled, just as waterfowl can only rise from the water head to wind. The greed for knowledge so characteristic of the nineteenth century has made itself felt in no direction more than that of natural history. If the old beliefs had to go, the sooner they were replaced with the bare truth the better for all concerned. And so, as knowledge grew from more to more, the natural history of their fathers went piecemeal.

Hence the books. Elaborate monographs, illustrated by what were then costly processes, of the various orders and families ; minute county records ; popular life-histories of sea-birds, moor-birds, forest-birds, London birds, and the rest; volumes on their eggs and nests, their migrations, their voice; treatises on the birds of the classics, of the Bible, of Shakespeare, of heraldry: in short, the changes have been rung on the bird theme until any original addition to the shelf would seem impossible. Yet, for all the fifty works on British birds, many of them running into several volumes, that have, as may be seen from the bibliography appended hereto, been either completed or commenced during the past ten years, students of the subject are looking forward with the greatest interest to the appearance of the new edition of $\mathrm{Mr}$ Howard Saunders' 'Manual,' or, more locally perhaps, to the long-expected volume on Hampshire birds from the pen of Mr Hart of Christchurch. The summary of British birds given in the following pages has of necessity been compressed until it is little more than a list. But little has there been said on the subject of the external features of birds, and on one or two other points of interest, upon which I therefore venture to preface a few notes.

Some of the reasons why these islands should, under certain conditions, prove peculiarly attractive to birds of passage have already been indicated on a previous page. At any rate, of the birds known to science, probably not 
short of ten thousand, quite four hundred are alleged, and seven-eighths of them probably with justice, either to reside in or to visit the British Islands.

British birds. These are found on analysis to fall, roughly speaking, under five categories: (i) The residents (which may or may not perform certain considerable migrations within these islands); (ii) the regular summer (breeding) visitors; (iii) the regular winter visitors (from the Northern seas); (iv) those which are with us for a short time only on passage to and from remote breeding-grounds (in spring or autumn, or both); and (v) the casual migrants, including rare stragglers. (These various categories are indicated by types and signs in the following pages.) It is found convenient for some purposes to subdivide these still further, but the above will suffice for the purpose of this book. It will be noticed that the line is not drawn very rigidly in the case of the so-called "residents." This lenient interpretation is, in fact, necessary in each case. Thus, not alone are our residents continually recruited from the Continent, but many so-called summer visitors have stayed through mild winters, just as winter visitors, and even more commonly spring visitors on migration, have stayed the summer. Many of our seafowl which breed in the northernmost lochs are really and to all practical purposes winter visitors to the rest of these islands. A word is said on the subject of migration on a subsequent page.

Ornithologists are by no means quite agreed as to what exactly constitutes a title to rank as a British bird, some among them being more cautious than others in dealing with evidence. The candidates for this honour that excite the keenest controversy are, as might be expected, those American stragglers which, it is very properly objected, are likely to have travelled a considerable part of the journey in the rigging of some swift liner. Those of us who have made the passage of that mournful cemetery the Red Sea know well how the hawks, finches, and wagtails 
cling about the sheets during that trying and dangerous run. Of the thirty or more "doubtful" birds given at the end of the section-they might easily have been doubled, had I included many that Mr Saunders and others have shown to be too preposterous-it will be observed that over half hail from the other side of the Atlantic. As it is, one occurrence, properly authenticated, suffices to add a bird to the British list. Only last autumn, Mr Keulemanns showed me the skin of "a new British warbler," which he had just drawn for the British Museum.

Of the external features of the bird it lies not within the scope of a small and unscientific book like this

External features. to give any detailed account, the subject being but little less foreign to its purpose than its anatomy. A few remarks of an elementary nature may not, however, be out of place.

Feathers, of which there are several categories, including the so-called "down," are the distinctive character of the class. No other living creature has a cover-

Feathers. ing of this sort; no bird is without it. The colouring of this plumage is, as a rule, the first aid to identification. It is of importance to bear in mind the seasonal changes, most noticeable in the male, which, save in the dotterel and phalaropes, is always more gaily clad than his mate. If it were possible to lay down a general rule, it would be that the male puts on brighter garments during the breeding season, resuming in winter a duller plumage closely resembling, if not identical with, that of his mate. To this, the ducks offer a striking exception. This seasonal change of plumage reaches its climax in the well-known instance of the ptarmigan, which has three moults in the course of the year, turning, all but the black eye-stripe, completely white in winter. In some birds, as the ruff and grebes, this breeding dress includes not only brighter colours, but also the development of some extra collar or tippet of feathers, which are dropped again as soon as the courting-time is over. Of the relation between 
the plumage of the parents and that of the young bird, as well as the broader questions of the origin, development, and shedding of feathers, there is no space to treat, further than to point out that the young of birds in which the two sexes differ little in plumage themselves resemble the parents; the rest follow, broadly speaking, the colouring of the adult female. The brief hints given in the following pages for identification have reference to the adult male, in either breeding or winter plumage, according to the season at which he is most conspicuous in these islands. For the transitional plumage, as for that of the female and young, I had no space. Before quitting the subject, however, there is another point of interest about these feathers which cannot fail to strike the most casual observer of bird-life, and that is the marvellous way in which they resist water or shot, the former more especially. The smallest bird shields with thatch-like back her precious eggs from the rains or snows of April without danger to herself; and still more remarkable is the imperviousness of waterfowl. Though birds unquestionably preen their feathers with their own oil, yet wildfowlers know well that the great secret of this waterproofing lies not wholly in the action of the oil, but rather in some muscular action of the bird itself, in proof of which they can show that dead or badly wounded fowl are in a very few moments damaged by the water, and even one wing which is broken will take in water to the detriment of the feathers, while the rest of the bird is yet healthy and dry.

Evidence of nature's wonderful workmanship is nowhere more apparent than in the bill of birds, whether we con-

Bill. sider the curved bill of the creepers, the chisel of the woodpeckers, the scissors of the crossbill, the serrated mandibles of the fish-eating goosander, the sensitive sucker of the woodcock, the bristles on the bill of the moth-hunting nightjar, or the absence of open nostrils on that of the plunging gannet.

The foot has four toes, normally, instead of our five. 
There are never more, and in many birds the fourth, or hind-toe, is either so small as to be obsolete or else want-

Foot. ing altogether. It will be found, I have noted, that the swiftest runners (e.g., the ostrich and $\mathrm{emu}$ ) have fewest toes, a rule that, with few exceptions, holds true of the mammals as well. The adaptations of birds' feet are not less striking than those of their bills. There is the grasping foot of the perching birds, slightly modified in the case of owls and woodpeckers; the webbed toes of waterfowl, supplemented in the rapacious skuas by powerful claws; the curious lobed membrane on the toes of the grebe and coot; the comb-like claw of the night-jar and heron.

Since birds dropped the lizard-like tail of their early days they have little left; indeed, what we call the tail is

Tail. in reality the feathers that cover it, and they are undoubtedly of more practical use than the real article. In all birds, they serve to some extent as rudders, and to the woodpecker and tree-creeper they are climbing-spurs. Few indigenous British birds have brilliant feathers beneath the tail, which must be a consideration when flying silently before a keen-sighted enemy.

When I lived in the country, I knew the note of most birds; but I cannot, try how I will, convey what appears

Voice. to me a satisfactory equivalent on paper. Many there are who have made a study of the subject, who write learnedly on the cuckoo's "minor third," and who are content to express the note of each bird by something like "zick-zack," "fink-fink," "churrwit," \&c. Of the nightingale one gives the note as "jug-jug," another as "wit-wit," while Tennyson, who gave us nature with as little editing as possible, rightly caught the spirit of one portion at any rate of its carol as "bubbling." Another word eminently suggestive of bird-song is "shivering."

I must confess, however, that these attempted interpretations of bird-song appear to me scarcely more satis- 
factory than the "little bit o' bread and no cheese" attributed to the yellow-hammer, or the still worse "in another week will come a wheatear," which is said at a certain season to constitute the daily remark of the chaffinch. (The German chaffinch, by the way, says "Fritz, Fritz.") A few birds, such as the skulking corncrake, the nightingale, the cuckoo, and the lapwing, are as unmistakable in their voice as in their appearance; but in the great number of cases, identifying a bird by its note, as by its flight, requires much practice and long residence in the country. To add to the difficulty, many of our birds, like the small woodpeckers, which warble quite agreeably in the breeding season, are devoid of voice, other than a harsh grunt, in winter; and, worse still, many others, as the starling, thrush, sedge-warbler, jay, and magpie, are such accomplished mimics as to make the confusion worse than ever. In some cases, the study of bird-voice is of course both interesting and profitable. Thus, one ornithologist is said to have recognised in the crow over a score of distinct notes, each conveying a different meaning, which I believe he also translated; while it is notorious that old wildfowlers learn from the voice of the birds up to which they are punting whether they are in suspicious mood.

It seems to me, however, that this subject is one rather for close study than careless handling; therefore I have made but few references to it in the following pages. I leave the subject, at any rate, in many zealous hands; and there will always be observers to tell of the whitethroat's confession of "I did it, I did it"; of the "tzac, tzac" of the shrike; or the "glock, glock" (see Crockett's 'Raiders') of the raven.

A ready means of identifying many of our commoner Flight. birds, though one requiring observation at first hand, is by their flight. Country folk know at a glance the dash of the peregrine, the gliding of the kite, the hovering of the kestrel, the soaring of the 
skylark; and gunners recognise the curved neck of the flying heron, and the drooping head of the woodcock.

One episode in bird-life has, their breeding excepted, attracted more attention than any other, and has formed the subject of voluminous works by Gaetke, Migrations. Dixon, and other writers. Much has yet to be learnt with reference to their wondrous organised movements, and the obstacles that lie in the way of systematic observation are scarcely less formidable than those which beset the investigator of marine life. So much is hidden, for the wandering birds move often at great altitudes, mostly at night. This preference for travelling at a great height means, in all probability, that the birds find the higher atmosphere clearer and less disturbed by currents. Their movements by night are, as may be imagined, much influenced by lighthouses, and, to a lesser extent, by the bright lights, mostly electric nowadays, of our harbour and other seaside towns. The lighthouses cause the destruction of thousands that dash themselves against the glass, sometimes right through it.

Regular migrants, as the swallow, must be guided to a great extent by transmitted instinct, for they will fly straight north and south, and are known to follow the shortest route over the sea, the track maybe of a former isthmus. The swallows, type of birds of passage, will cover over one hundred miles in the hour, will return year after year to the same eaves, and, strangest of all, will, on the wane of summer, and when the insect food is giving out, feel the returning instinct so strong within them as to leave a third brood to perish of starvation. Of these summer visitors these islands are the native land; many of them remain for more than half the year. Of the waterfowl, however, those wondrous hordes that rear their young in the glow of the midnight sun, far from the disturbing presence of man, they are but a winter feeding-ground.

With the casual migrants and stragglers, again, the case 
is different. They must have a hard time of it, and very many must perish by the way. As a sort of compromise between the two classes, we have the case, in many ways unique among animal migrations, of Pallas's sand-grouse, that remarkable little Asiatic wanderer, of which five irruptions have found their way to these islands, the last (1888-89) extending to their westernmost limits. Intervals of from five to twelve years elapsed between these invasions, whole generations in fact of sand-grouse that never straggled to the Western continent. Here, then, was clearly no case of transmitted instinct, but the thousands that came so far from their native tundras were evidently the children of circumstance, driven forth by some sudden and unlooked-for alteration in the conditions of life in those parts, some lack of food or maybe some fall in temperature. The difficulty of drawing a hard-and-fast line between the residents and the visitors has already been indicated. It is only possible to lay down certain principles, leaving room for numerous exceptions. Summer visitors are occasionally tempted to stay the winter; winter birds will bide with us in spring. The divers and the fulmar and many others, residents in the north of Scotland, are winter visitoris only to the coasts of England; the whinchat breeds freely in the north of Ireland, but is a winter visitor to the south. And, before quitting the subject of migration, it is of importance to mention the wanderings of many birds within these islands. The robin is a case in point. Other kinds, too, which in winter are found only on the sea-shore, resort in the breeding season to inland moors and bogs. Of such are the curlew and dunlin.

Under normal conditions, the various groups of birds affect a certain class of food. So much it is safe to say, and the anatomist can, as a rule, make a Food. close guess from the form of the bill. Openair observation soon leads us, however, to supplement the creed of the text-book, the ethics of the hard-billed and 
soft-billed birds, with a broader belief in the almost unlimited capacity shown by birds in adapting themselves to any diet that offers. They are, in fact, like many mammals, omnivorous; though this does not of course preclude them from having special fancies. Nor is there any need to seek such far-away instances as the muchquoted carnivorous kea of New Zealand. It is only necessary to suspend a lump of suet or half a cocoa-nut from a tree and watch how in a little every titmouse within call will soon be clinging to it and pecking eagerly at what can scarcely be its natural food. ${ }^{1}$ So, too, the so-called insectivorous birds devour at certain seasons great quantities of grain and fruit; and gulls, that live normally on fish and flotsam, are seen hawking after mice and insects, and will, if kept inland, kill and devour every small bird that comes within reach. Some birds swallow certain substances, grit usually, to assist digestion. The habit of swallowing its own feathers, noticed, among others, in the grebe, is probably a case in point.

Birdnesting has at all times been a favourite recreation with schoolboys, and not a few of their elders have, from

Nest. more scientific motives, also amassed considerable collections of eggs. In these days of decrease of wild birds, it is just as well that laws should be enacted and enforced against the practice; but, for the benefit of those who may find themselves in newer lands with no such restrictions, it may be as well to point out that there is birdnesting and birdnesting; and in earlier days I got together a collection of over three hundred representative British eggs without, I am perfectly certain, causing a single bird to desert, and without disturbing a single open nest. The collection was the result of several years' work in very different localities-in Kent, Hampshire, Cornwall, North Germany, and Tuscany. One egg

1 White pointed out a parallel case in the fondness of the cat for fish, which it could not catch for itself. This gave his numerous editors an opening for anecdotes. 
was taken from each nest, rarely two, and I always took every care not to frighten the sitting bird. There are critics of this kind of pastime who admit of no distinction in the matter of degree, and to them I prefer not to excuse myself. It is possible, however, that they may extend their mercy in consideration of my never having shot a single song-bird, all my stalking in that direction having been done with binoculars. The study of nests is an interesting one, but unfortunately it is among those that cannot be pursued in the armchair; and the existing regulations preclude the necessity of my entering into the subject as fully as I might otherwise have been inclined to do. What will at once strike the observer, however, is that this architecture is surely the result of instinct, and not of memory or imitation. One writer has objected to what he is pleased to call the "loose" employment of the word "skill" in connection with this performance. Skill, he says, is the result of education. But skill is, in my humble opinion, too old a word for any gentleman to begin playing tricks with now; and it is almost as applicable to the nest-building bird as to the human mechanic and engineer. The great difference in merit shown by various nests is another fact which soon makes itself felt. Not alone do we note the difference between the beautiful dwelling of the goldfinch and the mere platform of the dove or bullfinch, but even in birds that nest in different situations there is a perceptible difference in the amount of care lavished by the same bird. Thus, it is generally conceded that the nests of birds that rear their young in darkness build a very careless nest; and in the common instance of the house-sparrow, it is notorious that the nest when built in open tree-tops is a more elaborate domed structure than the mass of grass, paper, and rubbish that suffices it in our roofs. There are certain orthodox sites for the nests of each group of birds, but these are open, like everything else in the ordering of their lives, to exceptions. Thus the wood-pigeon nests, as a rule, amid the topmost branches of firs and beeches, but I have seen 
many a nest in low bushes within a couple of feet of the ground, more especially on well-wooded slopes. On the other hand, game-birds deposit their eggs on the ground; but Mr J. G. Millais ${ }^{1}$ gives instances of the nests of both pheasant and capercaillie high in trees. The doubtful point is how the parents convey the young in safety to the ground. Perhaps the most remarkable instance, however, of deviation in this respect is to be found in one of the sandpipers (Helodromas ochropus), which is known on its Continental breeding-grounds (it does not breed in these islands) to lay its eggs in the deserted nest of thrush or magpie, instead of building a primitive nest, like the rest of the group, on or near the ground. From the elaborate nest of the goldfinch or oriole, we find every grade of workmanship, good, bad, and indifferent, down to the work of the waders and game-birds, whose nests are often mere depressions in the earth, and the seafowl that simply deposit their eggs on a ledge, the nightjar that rears her young on the bare earth, the cuckoo who billets her eggs on other nests and leaves the duty of incubation, and subsequently of rearing the chicks, to the owners.

Of eggs, their shape and colouring, their size as compared with that of the bird, their resemblance to their

Eggs. surroundings, much has been written. Their protective colouring more particularly has been the subject of some learned treatises, and in no case more than that of the cuckoo. One has it that the bird can colour the coming egg to suit certain surroundings; another claims, with more probability, that, having laid the egg, she flies along with the same in her bill until she comes to some clutch to which it bears some sort of resemblance. Personally, I have had the misfortune to take so many dark-brown eggs of this bird from among the azure eggs of the hedge-sparrow that these rival theories have lost much interest for me.

Another striking feature of the cuckoo's egg is its small size compared with that of the bird, in which it furnishes 1 Game-Birds, p. 17. 
a marked contrast with that of the guillemot. The egg of the latter recalls yet another consideration, that the pyriform shape of the eggs of certain seafowl minimises the danger of their rolling off the narrow ledge on which they are deposited, although a great many undoubtedly get destroyed in this manner, some even finding their way. into the trawl. Mention of the colour of eggs reminds me of the "light" egg found in most clutches of the treesparrow and in some of the house-sparrow. This egg is generally unfertile. I have given only general descriptions of the various eggs, their average number, length, and markings, relying for the commoner kinds on specimens in my own collection, on standard text-books for the rest. Not the least interesting aspect of the study of the nests and eggs of birds is the discovery of new and strange sites, some amusing examples of which were cited in a recent article in the 'Pall Mall Magazine,' including sparrows nesting in a cannon-box (the cannon being fired twice daily) and in a growing fungus; titmice rearing their young in a lamp-post and a letter-box; wrens nesting in an old bonnet that had been converted into a scarecrow; and thrushes appropriating a gardenroller.

The identification of a living bird that crosses our vision one moment and is gone the next is not always an easy Identification matter; and I fear that I have succeeded but indifferently in my endeavour throughout the descriptions which follow to give the character, whether it be a patch on the wing-coverts, a line over the eye, a crest or a collar, most likely to be arrested in a snapshot with the binoculars. No bird is difficult to identify in the museum, where there is leisure to take account of the exact number of feathers in the tail, the number of toes, or the shape and nature of the nostrils. Identifying the specimen is, however, a very different matter from recognising the living bird; and I have purposely omitted the details given in every text-book in order to lay stress on what to look for at the short notice usually available. 
A longer acquaintance with the birds will put us in a position to identify them in a number of indirect ways, by their nest and egg, their flight or voice. At first, however, it is essential to note at a glance some such slight peculiarity as those enumerated above. The impressionist instinctively notes the yellow bill of the blackbird, the bald forehead of the coot, the grey collar of the jackdaw, the coloured proboscis of the puffin; nor, trifling as may appear these often ephemeral characters, is the practice of taking note of them with, or still better without, the binoculars, an unimportant factor in the training of the eye to that rapid, unpremeditated, and accurate observation which, whether inborn or acquired, is a part and parcel of the field naturalist.

In all ways, then, birds are perhaps the wild creatures that most repay study, nor is it a small matter that they are the easiest of observation. Those who take the trouble to observe them in nature are always finding some new and hitherto unsuspected feature of their lives. At one time, they note with interest the limits to their instinct, which seems to have no inkling of those late snows that, year after year, make April fools of the old birds and corpses of the young. The sportsman learns to distinguish between the solitary and the gregarious; and the mutual advantages derived from this sociability soon occur to him when he finds how much harder are the latter to stalk, whether they mount sentinels, as is sometimes their practice, or not. The book-student, it is true, brackets the exquisite kingfisher and the hideous lizard. The quadrate bone between lower jaw and skull, the single condyle in the neck, the oval blood-corpuscles, as well as the origin and development of the two, all stamp them the "sauropsidan" progeny of a common reptilian ancestor. And if the bird-lover should recoil from thinking of his favourites as feathered reptiles, let him give the library and dissecting-room a wide berth, and wander in blissful ignorance along the forest ridings or beside the stream. 
BIRDS.

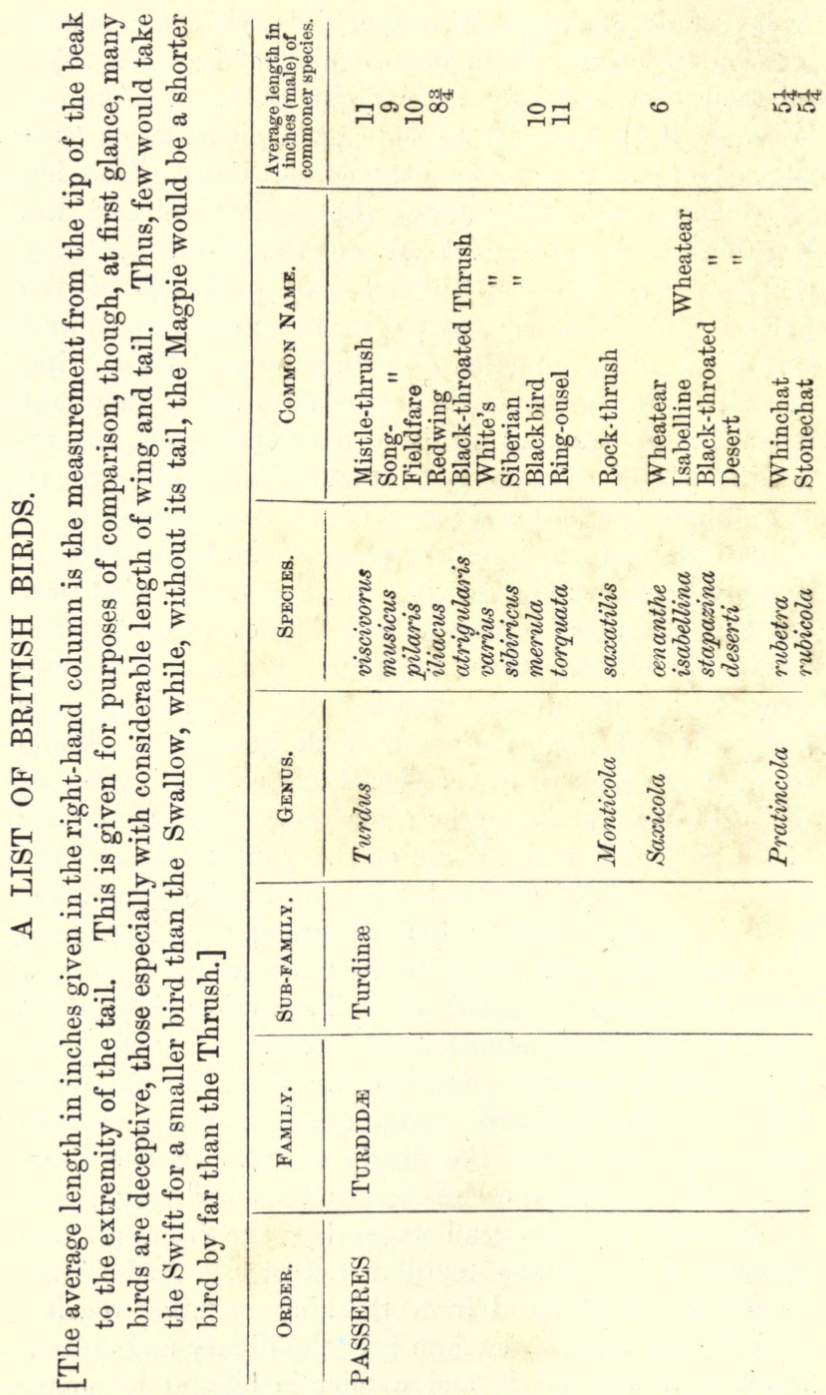


A LIST OF BRITISH BIRDS.

iै

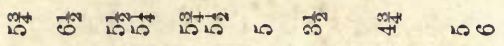

2.

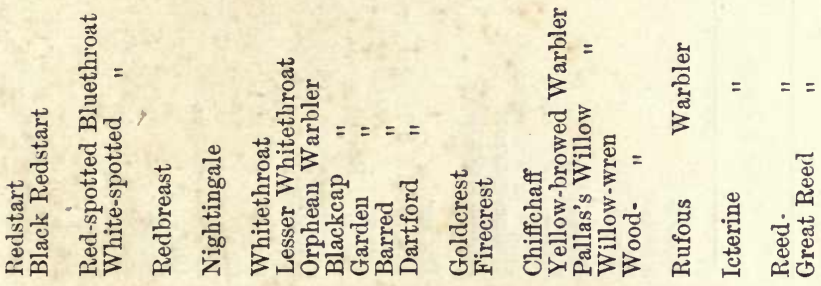

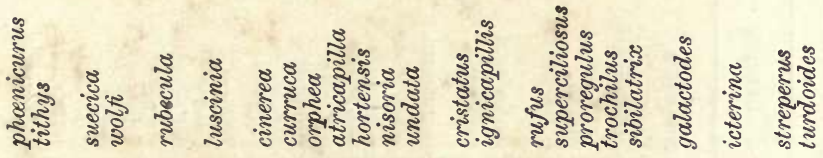

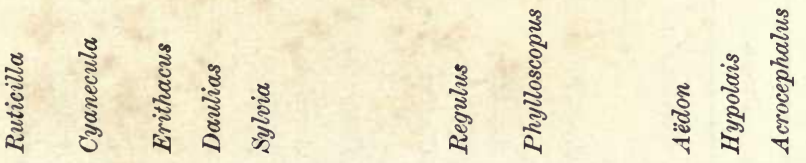

运 


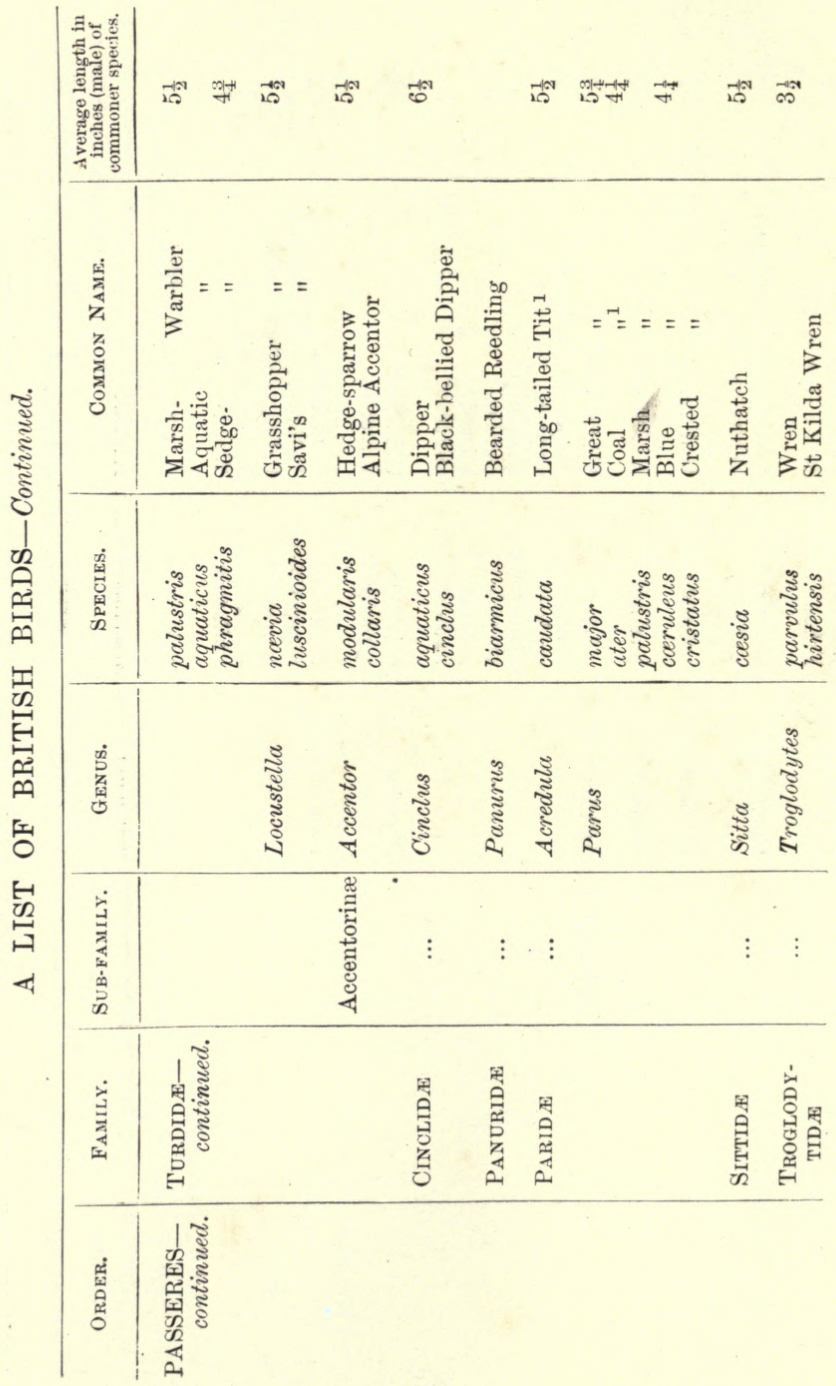


\#
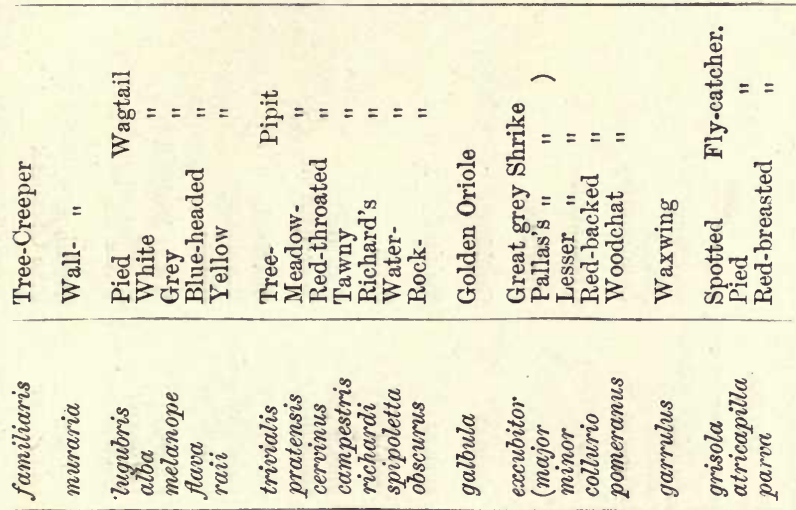

\begin{tabular}{|c|c|c|c|c|c|}
\hline 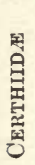 & 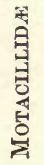 & $\begin{array}{l}\text { 用 } \\
\text { 芯 } \\
\text { 今. } \\
\text { 号 }\end{array}$ & 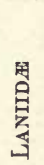 & $\begin{array}{l}\text { 图 } \\
\text { 藏 } \\
\text { 娄 }\end{array}$ & 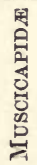 \\
\hline
\end{tabular}




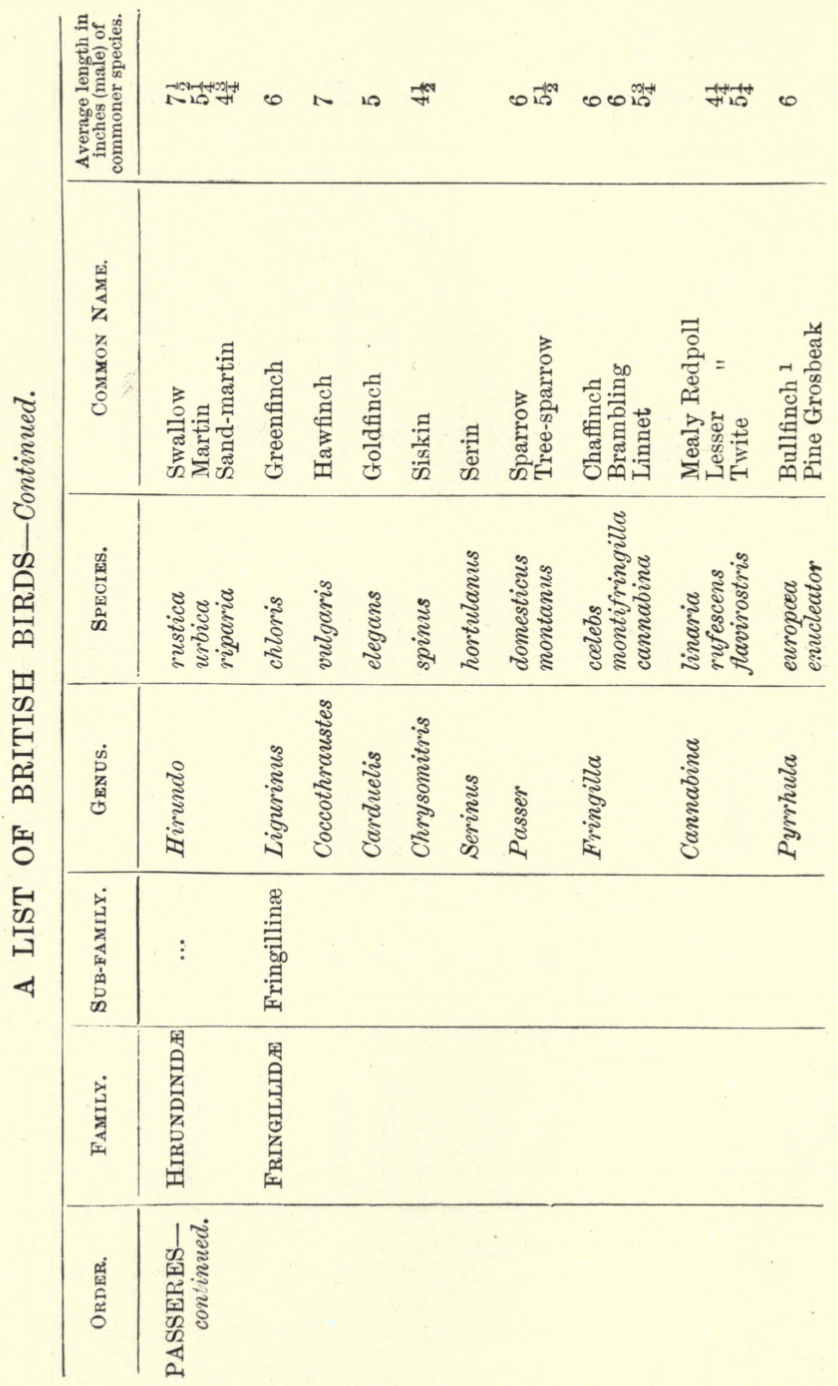


A LIST OF BRITISH BIRDS.

๘

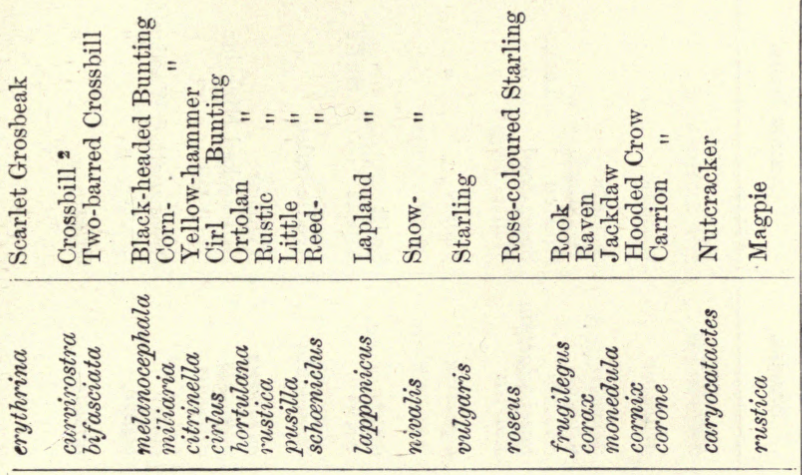

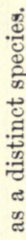

푤

تี⿻

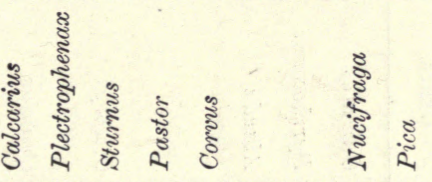

赵

$\Phi$

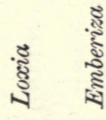

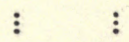

要

牙

क्ष

.020

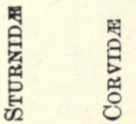


BIRDS.

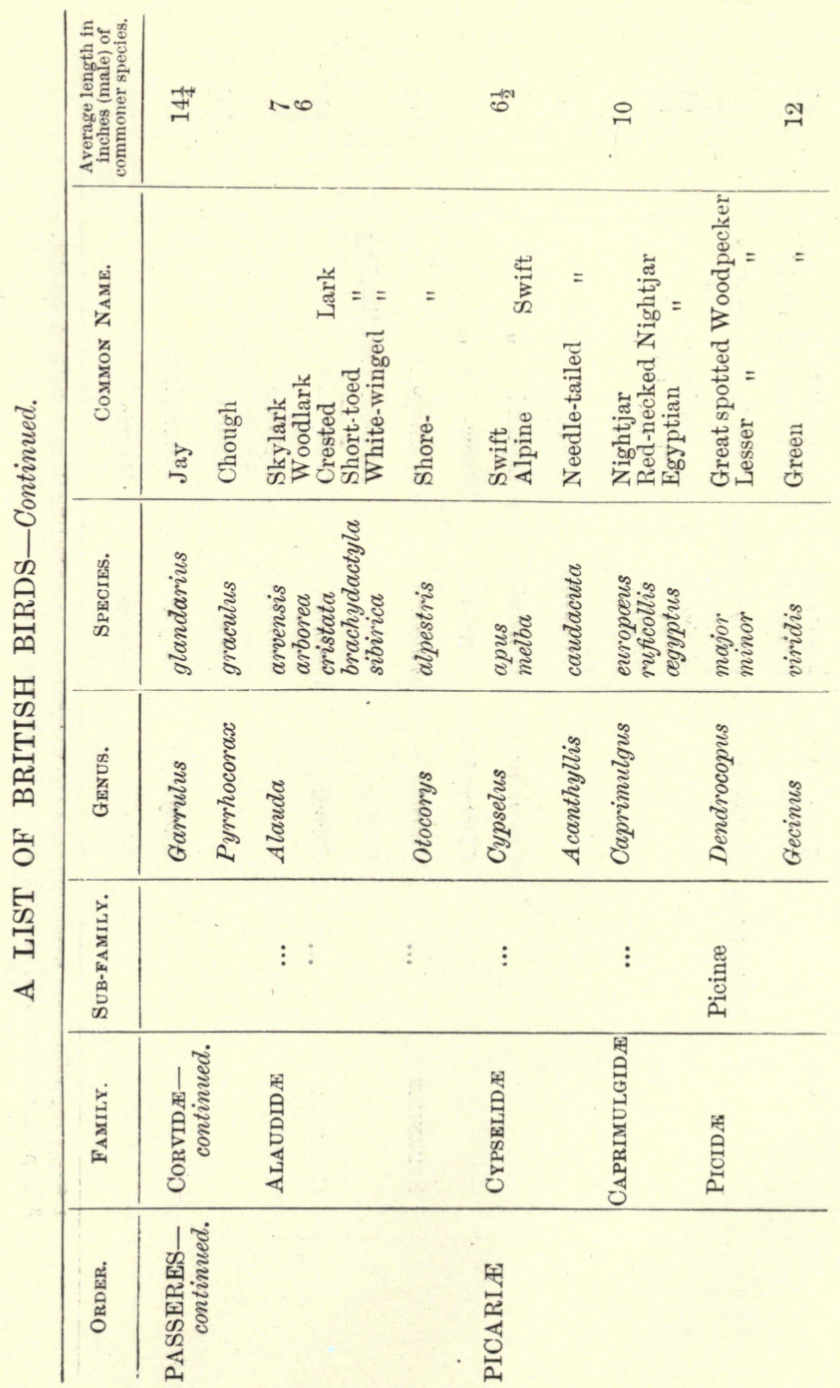


*

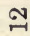

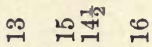

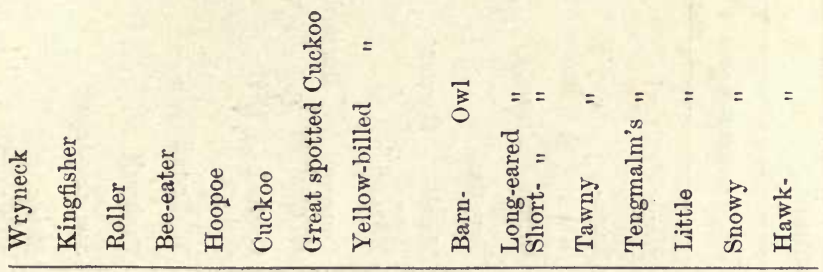

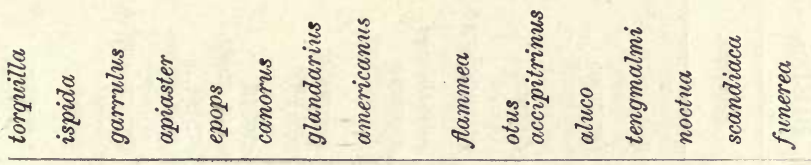

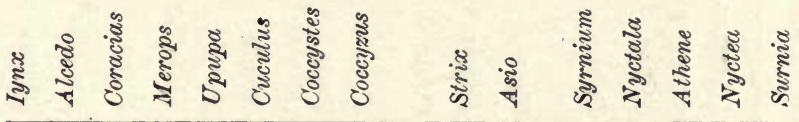

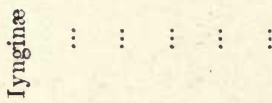

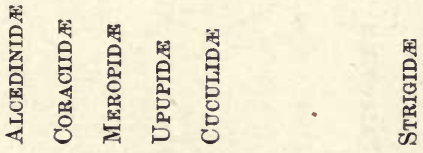

造 


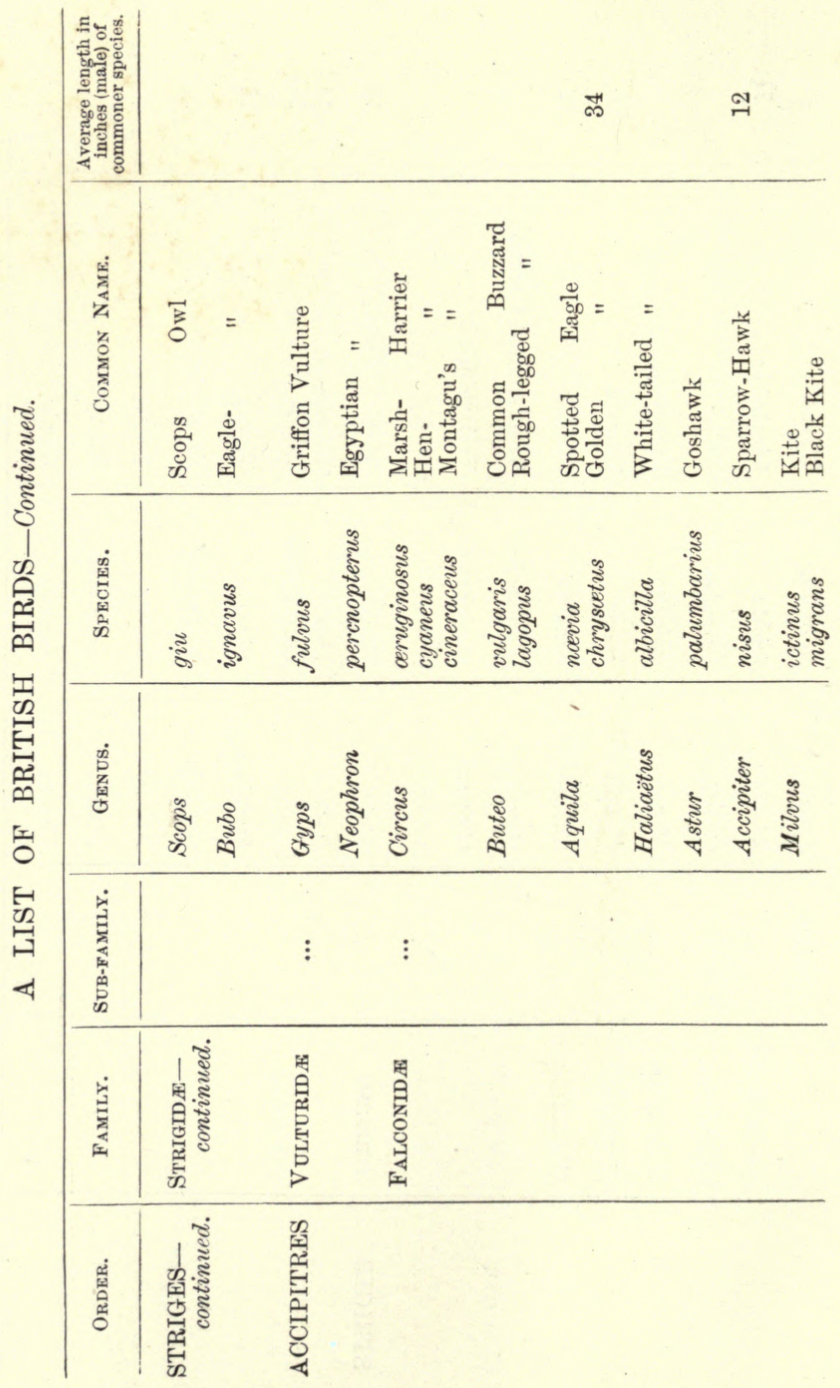




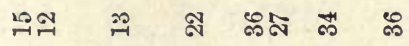
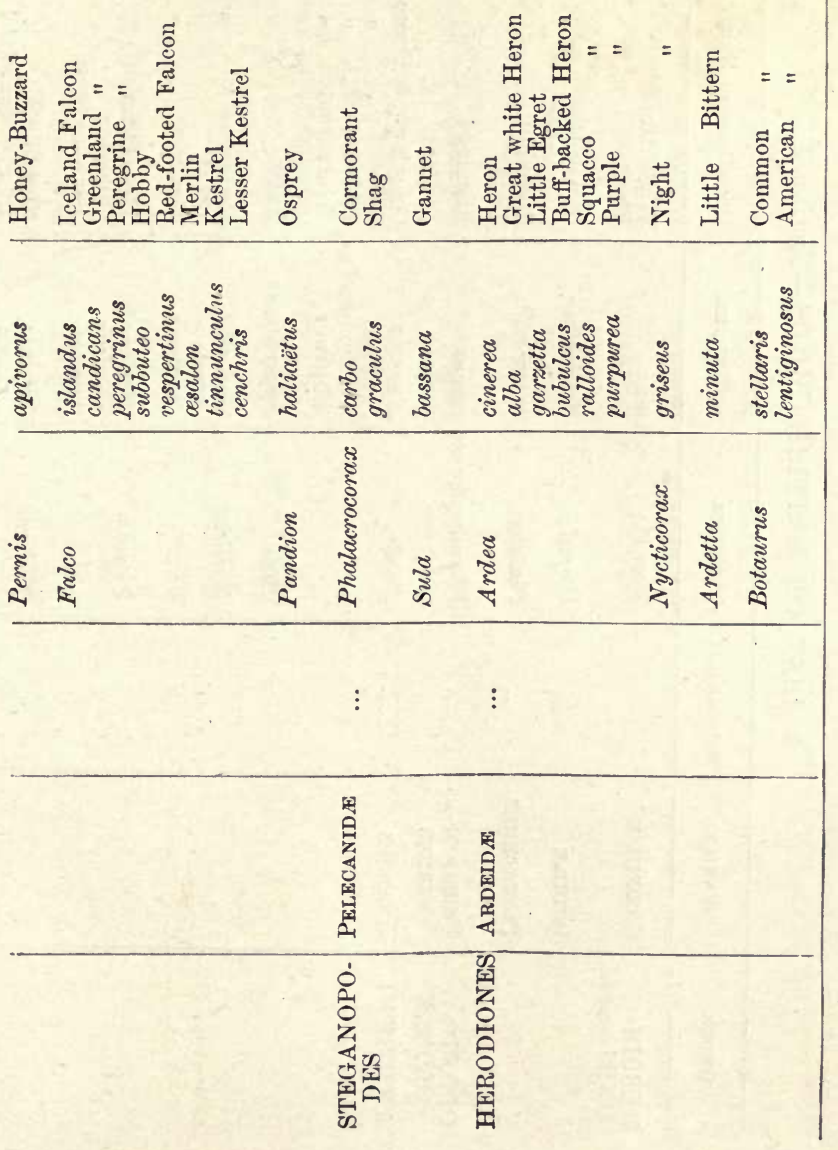


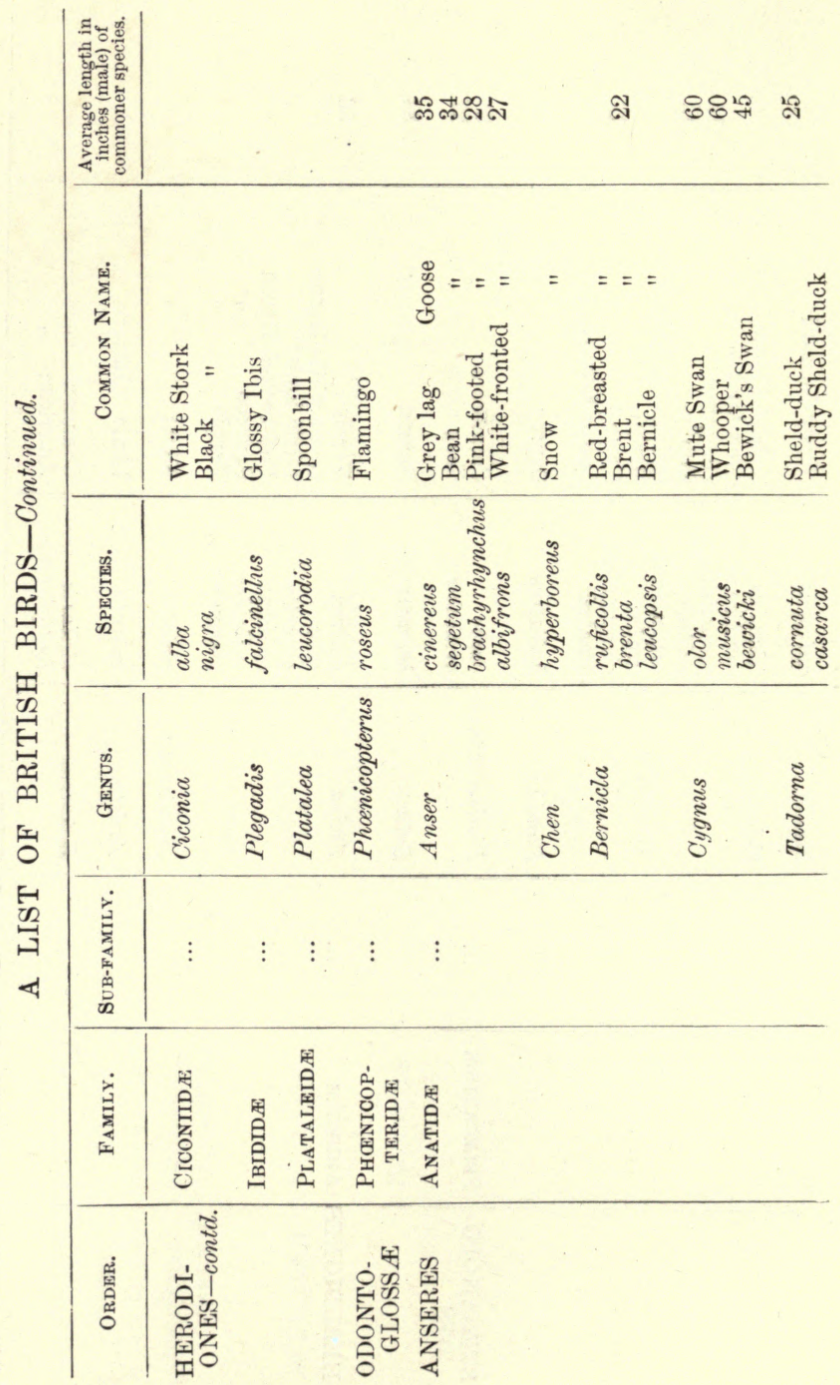




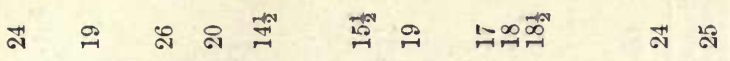
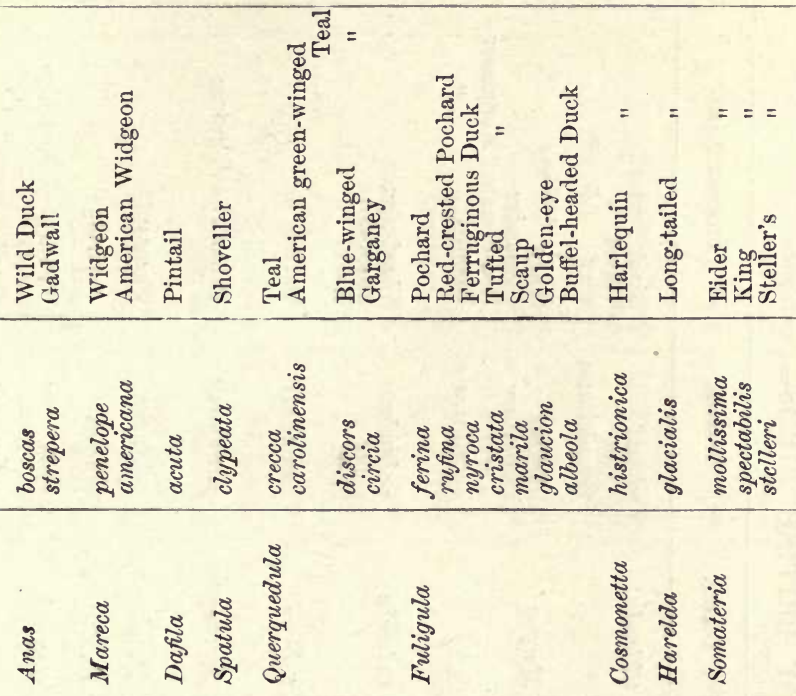
BIRDS.

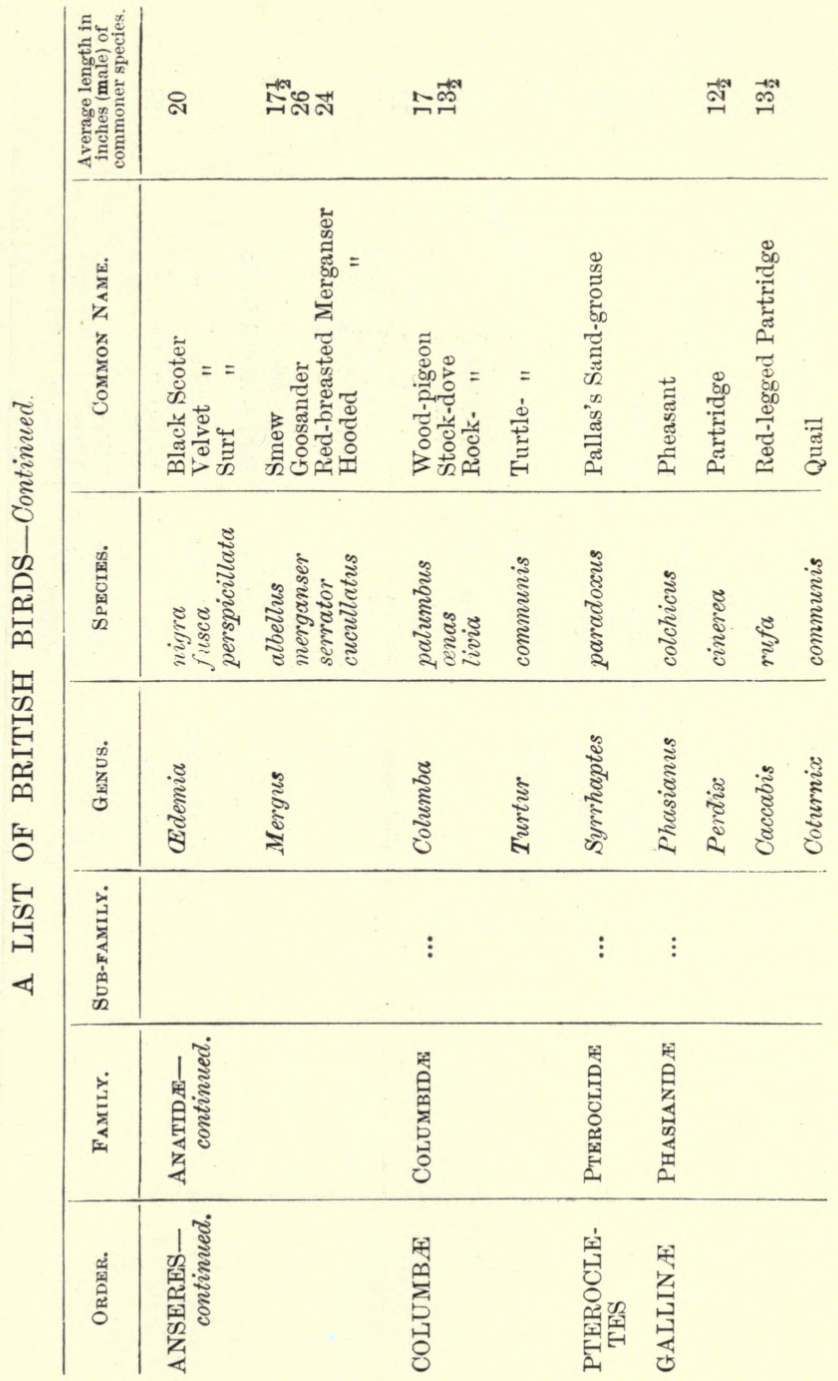




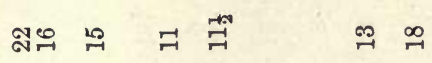

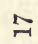

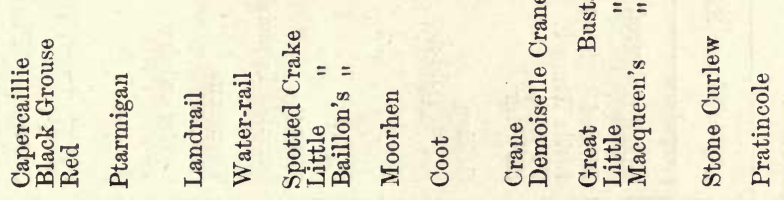

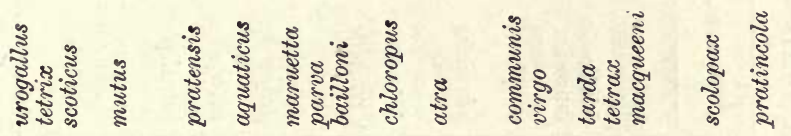

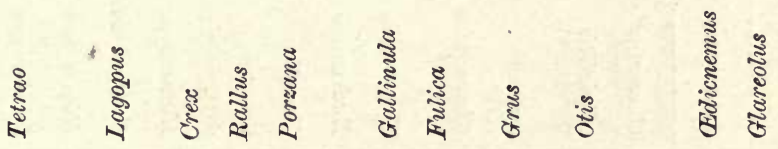

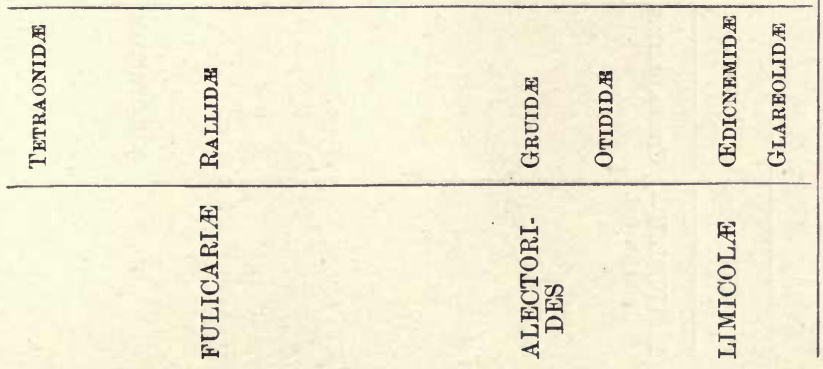


BIRDS.

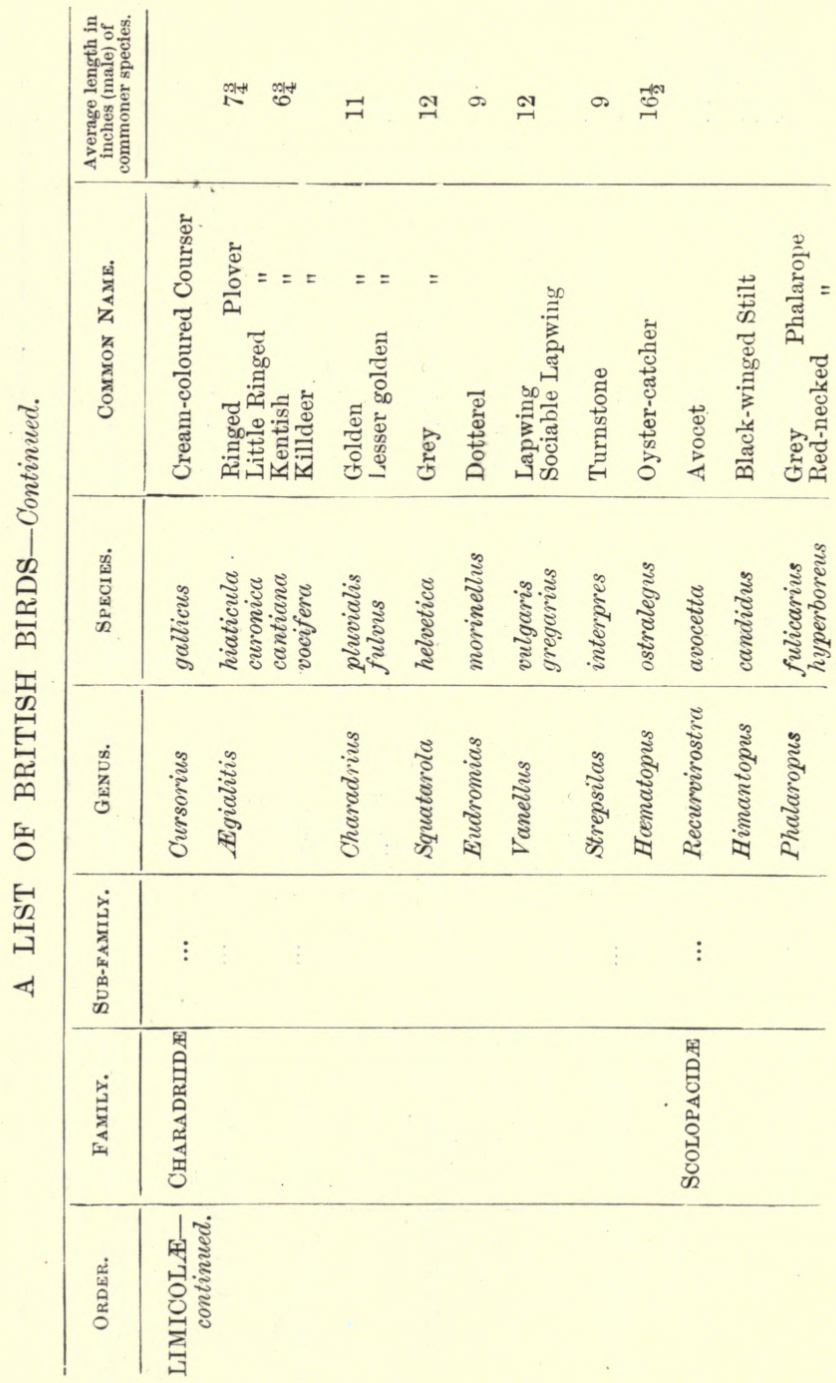


تn $\quad \infty 00$

$\infty$

कீ)

$\infty$

$\infty$ का

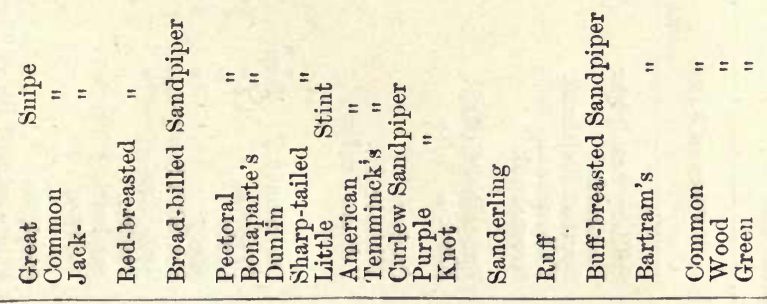
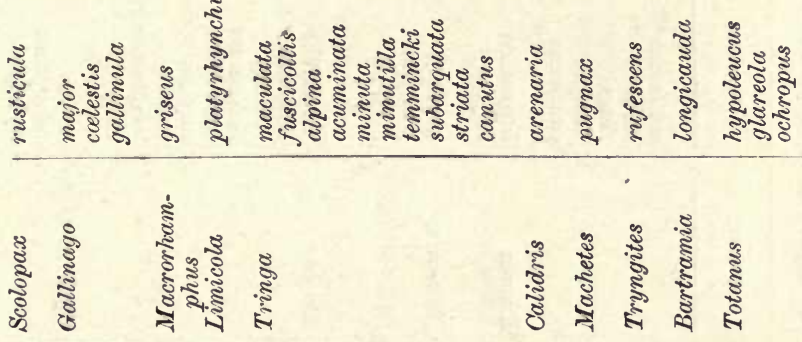


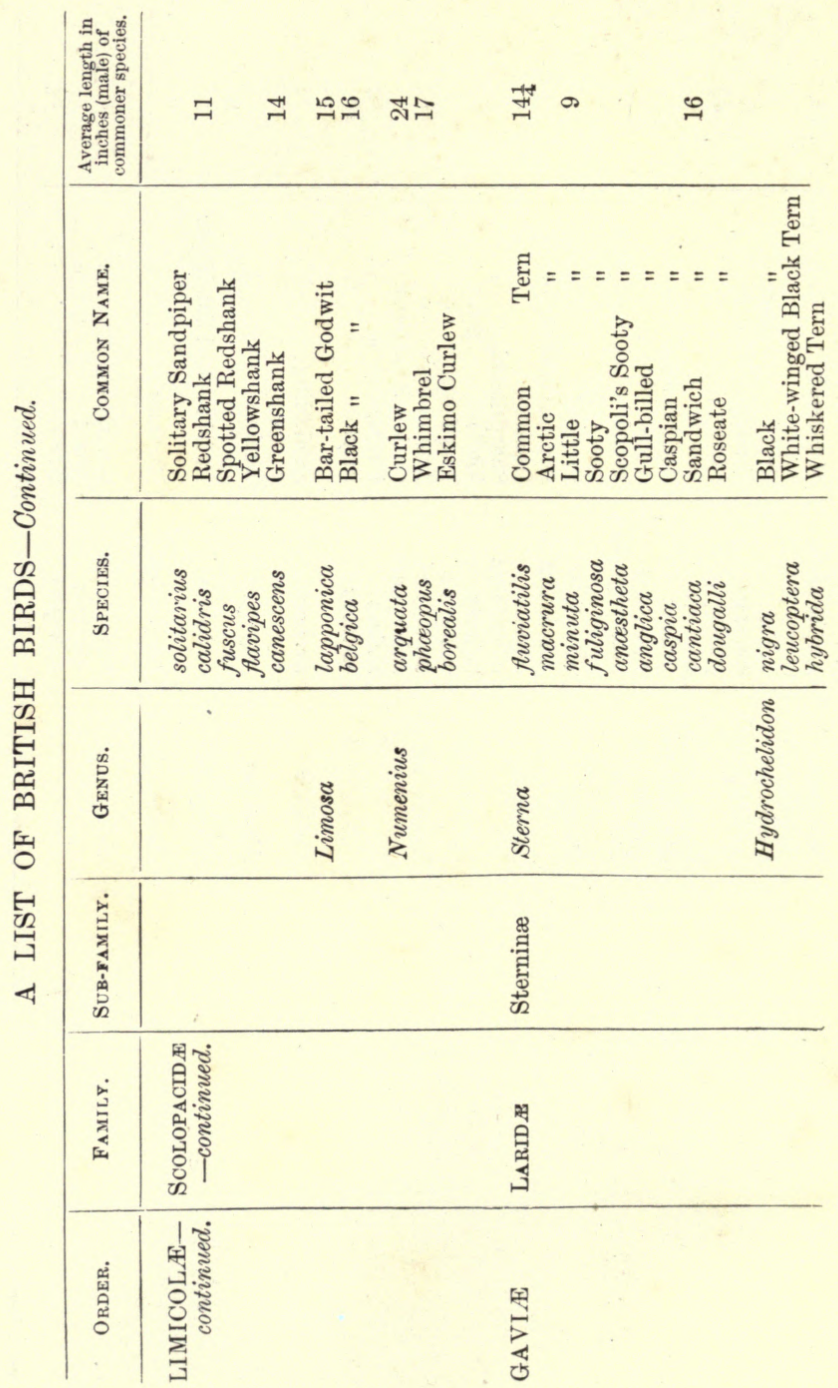




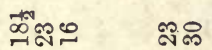

สี่ง สล

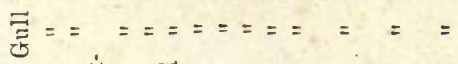

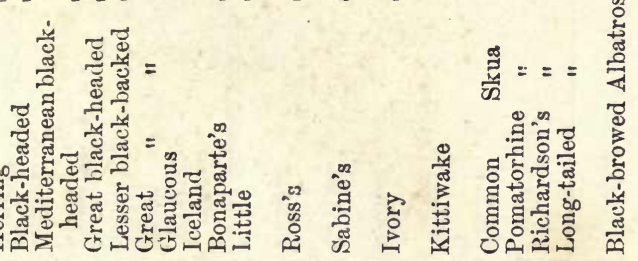

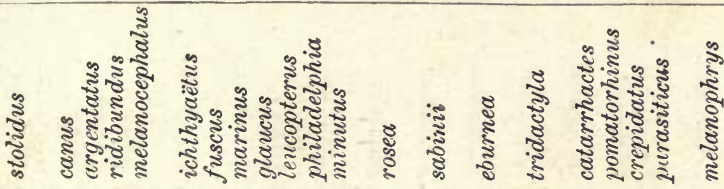

స్

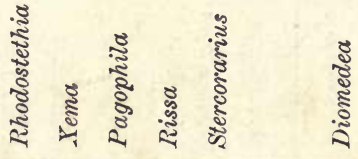

氖

竞




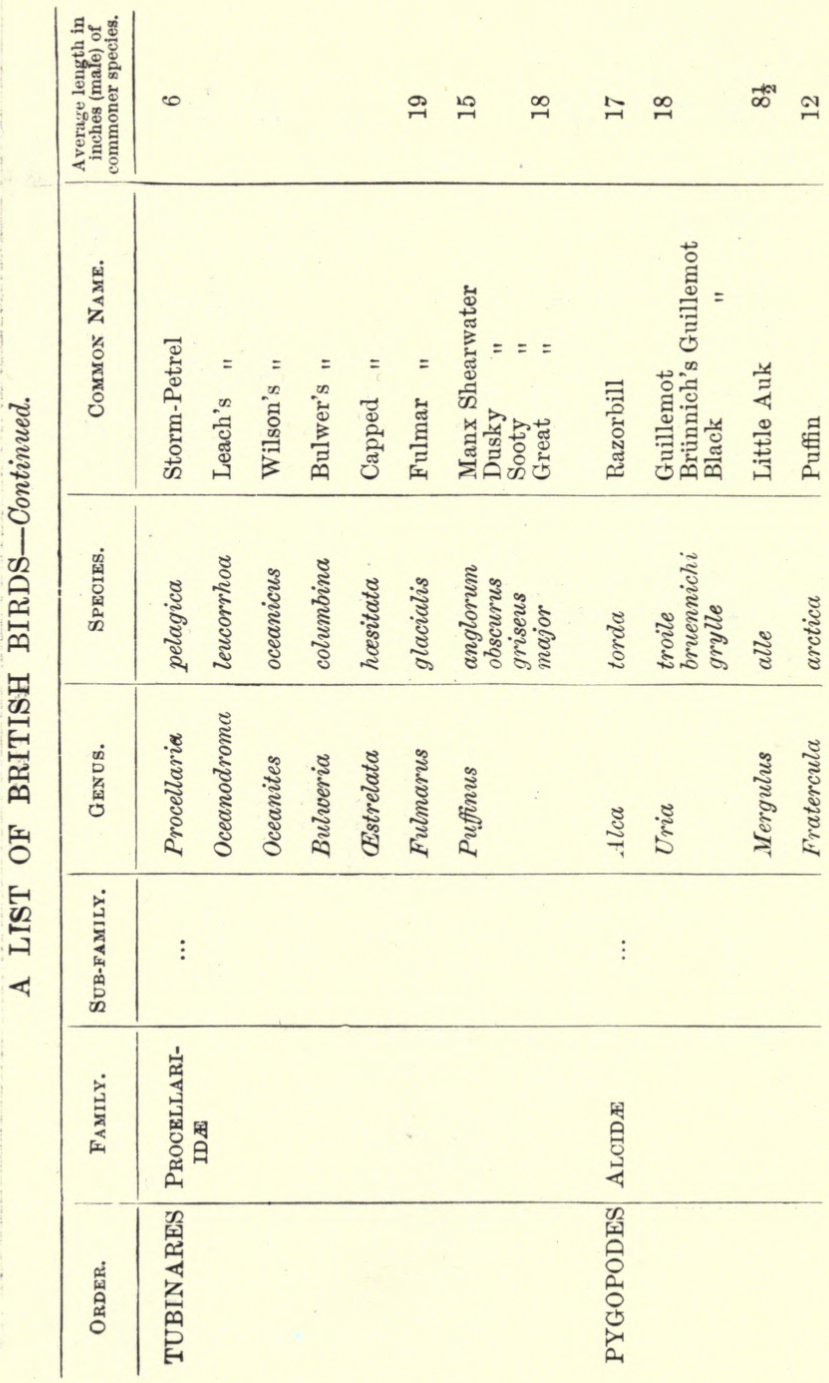


A LIST OF BRITISH BIRDS.

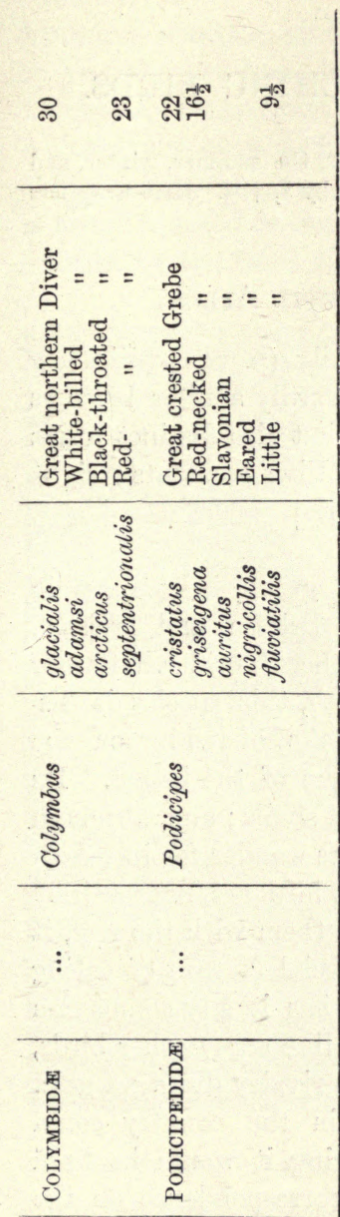




\section{CHAPTER I. THE PERCHING BIRDS.}

[Throughout the following pages on birds, the summer, winter, and migrational visitors are denoted respectively by ${ }^{*},+, \S$. Rare stragglers are in italics. The rest are residents.]

\section{The Thrushes aisd their Allims.}

[A GLANCE at the Turdina sub-family (p. I I 2) will show that it includes not alone such outwardly similar birds as the thrush, fieldfare, and ring-ousel, but also distinct forms like the redbreast and nightingale. Five residents; eight regular visitors ; ten irregular visitors.]

The Mistle-thrush, largest of the group, is common in all the wooded districts of Great Britain and Ireland, its range extending to the Hebrides. Larger

Mistlethrush or than the common thrush, this species is disStorm- tinguished by the streaks of white on the thrush. wings and the lighter hue of the breast. Its favourite food consists of berries and snails; and, although no migratory bird, it will nevertheless wander far in search of these. The trivial names of this bird are not entirely satisfactory, since, although fond of them with the rest, it does not at any season make a special feature of eating the berries of the mistletoe. ${ }^{1}$ Nor has it any connection with storms, though it is true that, like many other birds, Voice. it will raise its voice in rivalry during a gale. How any one living in the country could question the fact of this bird singing it would be hard to say, yet not only did a lively correspondence on the subject fill many columns of a north-country paper as recently as last February (1897), but a similar controversy evidently engaged the attention of the naturalists of a

1 In the south-western counties it is known as the "holm thrush" (holm =holly). 
bygone generation, since Brown has a note on the subject in his (1833) edition of White's 'Selborne.' It all depends, I suppose, on the exact distinction between song and noise, which would seem to be more or less a matter of taste.

The mistle-thrush nesta early in the year, the nest, which is usually placed in the fork of an oak, being in most years finished by the third week in February, if not sooner. At

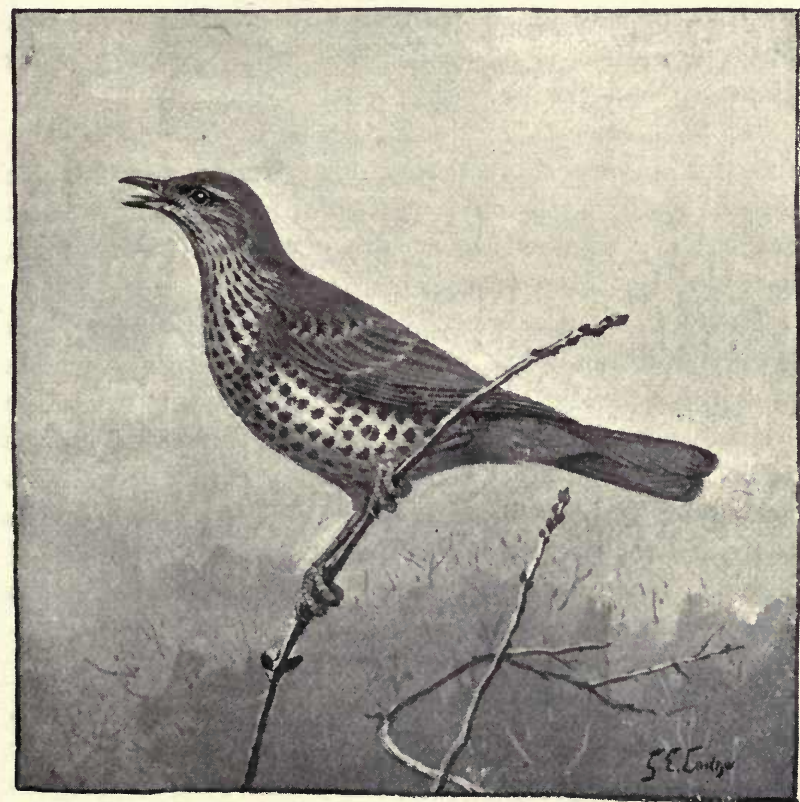

this season the bird becomes shy and silent. Lined with grass and mud, and placed, as a rule, Io or 12 (I have found them at only 4) feet from the ground, few nests of the size are more easily overlooked. Eggs, 4, rather over I inch; greenish, with red spots and lines. Two broods are reared in exceptionally fine seasons-rarely, however, in Scotland. 
By no means a very timid bird, and allowing close observation, the Common Thrush is familiar to most, and, though of inconspicuous plumage, save for the speckled

Songbreast, is easily distinguished on the lawn by

thrush. its curious hopping gait when after worms, and the long low flight for covert when flushed. Only the blackbird, distinct by reason of his black back and yellow bill, has such antics, indeed he runs more like a starling, and has in addition a peculiar way of cocking his tail. The song-thrush is of darker hue, with less grey in its plumage, than the preceding species.

Its food consists of worms, snails, seeds, wild berries, and, for a very short period, ripe fruit. I watched a thrush break snails on a particular stone near its nest beneath my window almost every evening for nearly a fortnight last May (1897).

The familiar nest is cup-shaped, lined or plastered with mud and rotten wood, and is placed at varying heights in a hedge. The bird has also been known, when the original nest is disturbed, to lay in a depression in the earth. Eggs, 4 or 5, about I inch; bright blue, with small spots of black or dark brown. Two or three broods are reared each year, the first being hatched by the end of March. When disturbed, the female glides away from the nest without a sound.

Both the Fieldfare and Redwing arrive early in October, and leave again late in March or early in April, the fieldtFieldfare fares being last to go. They come from the and north of Europe. The redwing feeds almost †Redwing. exclusively on insects; the fieldfare varies its insect diet with juniper, rowan, and other berries and grain. The redwing is easily distinguished by the pale streak over the eye; the fieldfare by the conspicuous white of the belly. Neither bird has ever been known to breed in this country.

Black-throated Thrush.-A rare visitor from Siberia, 
recorded twice (1868, 1889) only. The belly is of a spotless white.

White's Thrush.-Another rare straggler from northern Asia to most of our southern and eastern counties.

American Robin.-This is the migratory thrush of North America. Its occurrence in these islands is considered by many to rest on insufficient evidence.

Siberian Thrush.-Another doubtful visitor.

The Blackbird is one of the handsomest and sweetest of our song-birds. The body and legs of the male are of Blackbird. greyish black, his bill bright orange, I recently saw a cinnamon-coloured British blackbird at the Zoological Gardens, and believe this to be a not very rare variety. The female is dark brown, bill and all. The note varies in quality, being most mellow in the spring. Of wide distribution throughout these islands, in several districts of which it is yearly extending its range, the bird, although resident, undertakes considerable inland migrations, like those of the mistlethrush. It feeds on worms, snails, seeds, fruit, and hawthorn berries; and it drinks regularly. This spring, I observed a blackbird constantly drinking from the gutter beneath the eaves of a house, a trick which I believe it caught from a pair of jackdaws that had their nest there. The shallow nest is ready by the end of March. It is lined with grass, and almost invariably placed in a hedge 3 or 4 feet from the ground. Eggs, 5 or 6, about I inch; pale green, with reddish spots, either at the larger end only or over the whole surface. This bird rears a third, or even a fourth, brood. It is also known to interbreed with the thrush; and I took two blue, unspotted eggs from a nest at Bexley (1886) that were, I believe, the product of this union, though I only saw the hen, a blackbird. These birds sit very close, and, when the intruder is upon them, fly silently from the nest.

A bird of the moors, the Ring-Ousel arrives from the 
Continent in March or early in April. It rears, as a rule, but one brood, then leaves these islands in October, though

* Ring- a few remain the winter both in the Midlands

Ousel. and in Ireland. It is easily distinguished by its conspicuous white collar. It feeds on worms and snails, also on fruits and berries. Its voice is inferior to that of the thrush or blackbird. The ring-ousel breeds in the higher districts of Great Britain and Ireland, not much south of the Thames, save in the south-western counties. The nest, placed on or near the ground, is not unlike that of the blackbird, and the same resemblance applies to the eggs, which are 4 or 5 in number.

Rock-thrush. - A very rare visitor from Asia. Has been recorded but once (1843).

The Wheatear arrives from the Continent in March, and leaves again in September or October. Only a portion of * Wheatear the vast flocks that visit these islands on migration remain to breed, the majority, a larger race, passing on to more distant breeding-grounds. The wheatear is easily distinguished from the other small migratory species with which it congregates by the black ear-coverts and lores. It feeds exclusively on insects, and, like the wagtail, has a habit of continually jerking its tail to the accompaniment of a short sharp utterance. The nest, lined with finer grass or fur, is of coarse grass, and is usually placed in rabbit-burrows or under similar cover. $E g g s, 5$ or 6 , nearly I inch; pale blue, with or without a few specks.

Isabelline Wheatear.-An African straggler. Recorded once (1887) only.

Black-throated Wheatear.-A straggler from the Continent. Occurred but once (I875).

Desert Wheatear.-A straggler from Africa. Has occurred three times (1880, 1885, 1887).

The Whinchat, one of our latest visitors, arrives from 
the Continent late in April, and leaves again early in October. It is easily distinguished from the stonechat * Whinchat. and sundry other small birds, with which on occasion it foregathers, by the white spot on each wing and the white line over the eye. This bird is very partial to the noxious wireworm. The nest, built of fine grasses and moss, is placed at the foot of a furze-bush, on or near the ground. Eggs, 5 or 6, considerably under I inch; greenish blue, with a zone of reddish spots. The first brood is reared in May, and there is usually a second early in July. This bird does not appear to breed in Cornwall, but is widely distributed over the rest of these islands.

Not unlike the last, the Stonechat is distinguished by its uniformly black head and the white bars on its wings. A Stonechat. common resident in parts of Great Britain and Ireland, its range extends to the Hebrides and Orkneys : in the latter, rare. In some districts it is migratory, uncertain and capricious in its comings and goings. Its food consists almost entirely of insects, which it captures on the wing. Its nest is not unlike that of the last, only somewhat more carefully lined. It is usually on the ground. It used to nest abundantly on Dartford Heath and round Chiselhurst (1886-87). Eggs, 5, about $2 / 3$ inch; two types in my collection both greenish blue, one with a narrow belt of spots, the other with the larger end thickly spotted with red. A second brood is sometimes, but not invariably, reared.

Arriving from Eastern Europe in March, leaving again in September, the Redstart, an insectivorous bird, is far * Redstart. more common in Great Britain than in Ireland, where, save in a few districts on the north and east, it is extremely rare. It is also rare in Cornwall. The redstart is easily recognised by its white forehead and black throat. It nests, at no great height 
from the ground, in holes in trees or walls, and, like almost all builders in holes, constructs a bulky nest of grass lined with feathers. Eggs, 6, 3/4 inch; very pale blue and usually without spots.

The Black Redstart, a regular, but never common, visitor to the southern counties of England and Ireland, rarely tBlack reaches Scotland. It is said to have bred in

Redstart. one or two counties, Essex among them; but this appears by no means certain. I have taken its nest in old walls in Mecklenburg, the eggs being pure white. The bird is distinguished from the last by its black forehead and the white patch on the wing.

The Red-spotted Bluethroat wanders from Northern

† RedEurope and Asia, as a rule, to only our east spotted coast, but a few are recorded from Scotland. Bluethroat. The throat is blue. with a dull red patch in the centre.

[ + White-spotted Bluethroat, possibly a race only of the last. The throat-patch is white.]

The Robin is one of the most familiar of our resident birds. I found an almost identical bird (Petroïca) in AusRedbreast. tralia, its voice as pleasing, its ways as pert. The redbreast is at all times, save perhaps in the autumn moult, a bold bird, and one easily observed. The precise extent of its migrations, as well as the question of its pairing for life, seem still undecided. I believe personally that it does mate for life, as, having taken from a robin's nest near Crayford (April I886) a remarkably beautiful type of egg, of coffee colour and without spots or markings of any kind, I tried the experiment of abstracting two eggs, the rest of the clutch being of the commoner type with red spots, to induce the female to make up the proper number before sitting, a habit noticed so far only in the life-pairing birds. My attempt was so far success- 
ful that the hen deposited some ten or eleven eggs, I forget which; but here my success ended, as the newcomers were none of the coveted type. At last I gave up the attempt, and left her the normal half-dozen to sit on.

As regards the migrations of this bird, they are, it is generally believed, confined for the most part to seasonable journeyings for favourite food from one part of the Migrations. country to another. It is also known, however, Channel. Human brutality has for some reason or othera relic maybe of earlier superstitions - stayed its hand at the robin, the result being that the bird is trustful and slow to take alarm. There is every reason to suppose that the other birds might have given us their friendship in exchange for kind treatment in lieu of small-shot and bird-lime.

The food of the redbreast varies with the season, and few birds adapt themselves more readily to whatever is

Food. handy. Worms and flies, fruits, wild or cultivated, seeds and grain, each have their turn. Then at length, when the ground is snowbound, the bird reaps the benefit of its familiarity with man, and gets crumbs from the table. As it is quite the most quarrelsome and pugnacious of our smaller birds, not even the bully sparrow cares about crossing it. Its conspicuous red breast, as well as the low undulating flight, render it impossible to confuse this with any other British bird. The young, which the parents soon drive off to cater for themselves, are speckled like thrushes.

The nest of the redbreast is usually in the ground, preferably half-way up the side of a grassy bank. I have Curious also found it in another very common position Curious
nesting-sites. -namely, the thickest part of faggot-heaps; and it is a curious fact that it generally selects those most recently stacked. The eccentric choice of situation often shown by this bird is so well known, and has been the theme of so many writers, that it needs but 
passing mention. As an instance, I found one nesting in a disused rat-trap which the gardener had pitched over the hedge; and in this dungeon, still occupied by a large piece of dried bacon, a pair of robins reared four young ones. A similar instance, in which a pair nested in an old tin can, is quoted by Mr Barrett-Hamilton. ${ }^{1}$ The nest is also found in holes of trees and old walls. In form it varies little, the outside being of dead leaves, sometimes with moss, the lining of hair or feathers. Eggs, 6 to 7 , $\frac{4}{5}$ inch; usually white or greyish, with numerous red spots. I had three pure white. As a rule, the texture of the shell is coarse and rough, but the creamy egg alluded to above was highly polished. Two or three broods are reared.

Writers who must at any cost show that singing-birds are invariably dressed in sober hues, are fond of describ-

* Nightin- ing both the Nightingale and the linnet as exgale. tremely plain creatures. As a matter of fact, the cock-linnet is, in the breeding season at any rate, a handsome bird; and it can hardly be denied that the nightingale has a pleasing appearance, the brown and red of the tail and upper parts contrasting sharply with the dull white beneath. The distribution of this migratory

Range. bird, which is with us, as a rule, from the middle of April until the middle of September, the males being the first to arrive, is regulated by suitable conditions of climate and food, which are not easy to assign. Thus, it has not yet occurred in either Scotland or Ireland, and is extremely rare in Wales. Yorkshire is one of the most northerly counties included in its range in these islands, and it is unknown in West Devon and Cornwall. Within a short radius, too, it may be capricious in its fancies. Thus, taking the west of Hants, I have heard numbers this year behind Poole, and again near Ringwood, whereas in the apparently suitable (and strictly enclosed)

1 Harrow Birds, p. 4. 
woods and coppices in and around Bournemouth, immediately between these two districts, I heard or saw never Popular a one. From its habit of singing loudly on fallacies. moonlight nights, many people seem to imagine that the bird is silent throughout the day, whereas in reality it sings the spring through from soon after daybreak until about an hour before noon; then, after a silence during the hottest hours, again through the after-

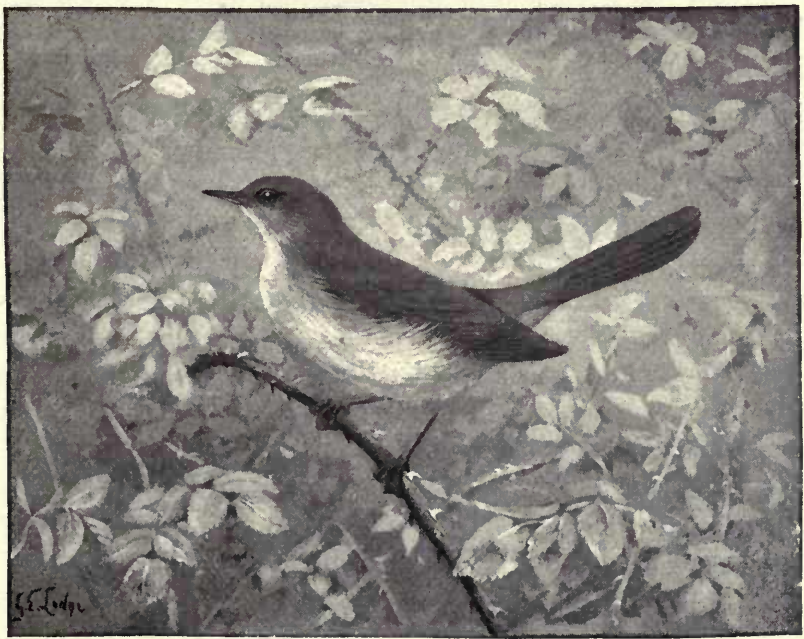

noon into the darkness. Another fancy is that this is the only bird that sings after darkness has set in, whereas the song-thrush, and in some parts the sedge-warbler, also sing, and the wood-pigeons coo, during the warm summer nights. The song of the nightingale, the curious sustained gurgling and shivering of which is unlike that of most birds, the nearest being the blackcap's, is admirably described in Hudson's 'British Birds.'

The food of the nightingale consists almost entirely of insects and worms, largely of caterpillars and elderberries, rarely of soft orchard fruit. 
The nest, made of leaves and lined with horse-hair and rootlets, is placed close to the ground at the foot of a clump in the thickest and most tangled part of a hedge. Eggs, 5, about $\frac{4}{5}$ inch; resemble small olives, being unspotted greenish brown.

\section{The Warblers.}

[With the exception of the foregoing, most of our songbirds are included in this group, though they vary greatly in the quality of their voice. Two residents; twelve regular visitors; eight irregular visitors and stragglers.]

The Whitethroat is widely distributed from April to September, save in parts of the Highlands. The note *White- is sweet, but neither loud nor sustained. The

throat. bird feeds on insects and grubs, with an occasional meal of fruit. The nest, built early in May, is of dry grasses and bents, lined with hair, and is placed, not far from the ground, in bushes. Eggs, 5, about 3/4 inch; there are several types; and in the summer of 1886 I took eleven distinct varieties from the furze-bushes of Dartford Heath and the neighbouring park. They go through every shade from palest yellow to deep green, some spotless, but the majority profusely speckled with pale brown.

Also with us in the southern counties from April to September, the Lesser Whitethroat is rarely found in

* Lesser Wales or Scotland, never reaches the HighWhite- lands, and is unknown in Ireland. It bears

throat. considerable resemblance to its larger relative in appearance, being distinguished by the absence of red from the wings. In habits and food there is little difference. The nest, similar but smaller, is found in the same situations. The egg, also smaller, is of lighter hue with similar markings. A second brood is usually reared.

Orphean Warbler.-A rare straggler from the South. 
Has occurred only twice, once in Yorks, the other time in Middlesex.

Yearly with us from April to September, the Blackcap has often been shot in the southern counties in winter; so that some, at all events, remain through *Blackcap. the year. Except in the extreme north of Scotland, and to those islands which it passes only on its autumn wanderings, the bird breeds throughout the United Kingdom. Easily distinguished by the contrast of the black head with the uniform grey of the rest of the plumage, this warbler has a song which, though not the theme of many poets, is at its best little inferior to that of the nightingale. It feeds on insects, fruits, mostly wild, and berries. A most interesting habit has been noticed in connection with its capture of insects, which it is said to effect with the aid of the intoxicating juice of the hibiscus, pricking the flower with its bill and returning anon to feed on the helpless insects that lie around. The nest, of dried grasses lined with fine bents, is placed in thick bushes 3 or 4 feet from the ground. Eggs, 5, 3/4 inch; stained white, with dark brown or reddish spots and blotches at the larger end. Two broods are usually reared. It is curious how densely, given suitable conditions, these birds will nest, almost in colonies. In May r886 I took, in one morning, an egg from each of five nests in a hedge not 500 yards long on the banks of the Cray in Kent. I have generally found the nest of this warbler in the immediate neighbourhood of running water.

The rarer, duller brown-and-white Garden Warbler is with us for five months only, not arriving until the second week in May. Though not uncommon in our * Garden
Warbler. south-eastern counties, it is rare in most parts of Scotland, Ireland, and Wales, and Cornwall is almost beyond its usual range. Like the last, it feeds on 
insects and fruit. Its nest, a large edition of the blackcap's, is found in similar places, more often in gardens. The eggs, also a trifle larger, are otherwise nearly identical.

Barred Warbler.-A rare autumn straggler, distinguished by the white bars on the wings and tail and the dark bars on the chest. Only about half-a-dozen occurrences are recorded-one in Ireland, a second in Skye, the rest in our eastern counties.

The collector of eggs finds a solemn interest in the Dartford Warbler akin to that which the entomologist might experience after a week's hunt for the Dartford chimerical and coveted "skipper" in and around the sleepy little cove at Lulworth. Judging from my own experience of three summers spent right on Dartford Heath, I should think that the type from which in 1773 the species was named must have been the first and last ever seen in the neighbourhood. I have taken the eggs in Richmond Park and in the Isle of Wight, but not within ten miles of Dartford. Though comparatively scarce north of the Thames, it has been found breeding in Yorkshire. It is a much darker bird than the other warblers. It feeds on insects and berries. The nest is usually found in furze-bushes (hence called " Furzechat"), and is a slightly more compact structure than that of the whitethroat. Eggs, 5, rather smaller than those of the blackcap; brownish white, with many brown spots. Two broods are reared.

The Goldcrest, smallest of British birds, is, owing to its wanderings from one part of the country to another, known in some parts, notably at the coast,

Goldcrest. as the "Woodcock-pilot," presumably from its arriving just before the Woodcock. It has a black-andyellow crest, and the wings are barred with black and white. With the exception of the Outer Hebrides and some other of the isles, it breeds throughout the kingdom. 
It feeds entirely on insects. Its nest, perhaps the most beautiful of British nests, is of moss, lined with wool and feathers and hair, and is often hung beneath the horizontal branch of a yew. Eggs, 8 or 10, 1/2 inch; dull white, with red spots.

Distinguished by the deeper orange of the crest, the †Firecrest.

Firecrest is an irregular winter visitor to the Channel counties, and has been recorded from Yorkshire. Some reported firecrests have turned out to be old male goldcrests. It has occurred in Scotland, but is not yet recorded from Ireland.

With us from March to October, the Chiffchaff has also been shot in winter. Except in the Highlands, its dis*Chiffchaff. Tribution is wide throughout these islands. It feeds on insects. The nest, dome-shaped, is of moss and grasses, lined with feathers, and placed near the ground. $E g g s$, 5, rather over I/2 inch ; dull white, with red spots.

Yellow-browed Warbler.-A rare autumn straggler from Asia. Has occurred on the east coast four times, and once in Ireland.

Pallas's Willow-warbler has been once recorded (1896). ${ }^{1}$

The Willow-wren is with us from April to September. There is much yellow in the plumage, especially a line over the eye and along the edges of the *Willow- wings. The song is pleasing, but of no very
wren. high order. Its food consists almost entirely of insects. The nest, domed and placed on or near the ground, is of grass and lined with feathers. Eggs, 4 to 8, $\frac{3}{5}$ inch; dirty white, with pale red spots.

Distinguished from the last by the white feathers in the tail, which is proportionately shorter, the Wood-wren

1 See Mr Southwell's notes in the 'Zoologist' for January 1897. 
also seeks these islands from April to September, though considerably more local in its occurrence and very rare in Ireland. It feeds on insects; occasionally on

* Wood- fruit. The nest is domed and placed on or
wren. near the ground. It is lined with fine grasses. Eggs, 6 to 7 , about $2 / 3$ inch; white, with brown spots. The wood-wren used to nest in great abundance near Doberan, Mecklenburg, in May 1890.

Rufous Warbler.-A rare straggler from the South. Only three have been obtained-in Sussex and Devon.

Icterine Warbler.-A rare straggler from the Continent. Five have been obtained-one in Ireland, the rest on our east coast.

The Reed-warbler is with us from April to September, chiefly in the southern counties; rare in Scotland and * Reed- Ireland. Song, loud rather than sweet. There warbler. is a conspicuous yellow streak above the eye. The underparts are white. This is among the birds that sing during the summer nights, a performance credited by some to the nightingale only. It feeds entirely on insects. The deep nest, hung in the reeds, or, more rarely, in trees, is of grass lined with feathers or wool. Eggs, 5, nearly $3 / 4$ inch ; bluish white, with dark spots.

A very short stay is made by the Marsh-warbler, since it does not arrive till late in May and leaves again in

* Marsh- August. This bird closely resembles the last, warbler. and its song is pleasant. Its food, like that of the rest, consists almost entirely of insects. Its distribution is local. It has nested near Taunton, Banbury, and Bath. The nest. is of grass lined with hair, and placed in low bushes in the neighbourhood of water. Eggs, 5 to 7 , about $3 / 4$ inch ; white, with brown spots.

Great Reed-warbler.-A rare straggler from the Continent. May have bred.

Aquatic Warbler.-A rare straggler. Three occurrences, 
two of which were on the south coast, the third in Leicestershire.

lare in northern Scotland and the isles, the Sedgewarbler is found in most parts of these islands from April * Sedge- to the end of September. It has a yellowish warbler. streak over the eye, the crown is buff and the throat white. It feeds on aquatic and other insects. The nest, of moss lined with hair, is perhaps less often hung among the sedges than among bushes close to the water's edge, though I have taken eggs from both situations, early in June, not far from Ringwood. Eggs, 5 or 6, 2/3 inch; yellow, with black spots and streaks.

Fairly common in Great Britain, save in the extreme north of Scotland, from April to September, the Grass* Grass- hopper Warbler is very local in Ireland. The hopper underparts are very pale brown. The name Warbler. has reference to the curiously vibrating song, which, like that of the reed-warbler, is often heard in the stillness of a summer night. Its food consists of insects. The nest is of grass lined with finer grasses, and placed near the ground. Eggs, 5, nearly 3/4 inch; pinky white, with brown spots. A second brood is reared.

[Savi's Warbler, which formerly bred in the eastern counties, has, singularly enough, not been seen in this country for the last forty years.]

\section{The Hedge-Sparrow.}

The Hedge-Sparrow is one of the commonest of our country birds. In order to emphasise its distinction from the true sparrows, most naturalists have preferred to give it the somewhat cumbersome name of Hedge-Accentor, which seems hardly necessary so long as the distinction is borne in mind. Another of its many aliases is "Shufflewing," by which it is widely known. The song, which is 
exceedingly sweet, is heard in some parts of the country throughout the year. I have repeatedly found this bird abroad in the late evening, after other small birds are gone to roost, though at such times it is silent. It feeds in summer on worms and winged insects; in hard weather on seeds. The neat moss nest, a favourite with the cuckoo, is ready by the middle of March, if not sooner. It is lined with hair or feathers. Eggs, 5, 3/4 inch; spotless blue. Several broods are reared.

Alpine Accentor. - A rare allied straggler from the South, distinguished by the white bars on the wings. It has not been obtained more than about a dozen times.

\section{The Dipper or Water-Ousel.}

The attractive little Dipper, which follows every bend of the mountain-stream and carols forth its wild song beneath the very waterfall, is a familiar sight on the river-bank, less timid too and easier of observation than the more showy kingfisher, whose name it borrows in the north. It has been associated with the poaching of trout-eggs, but, Alleged apart from the fact that its feeding-grounds damage are often far from the "redds," where the ova to ova. lie hid in their shingle hummocks, the bird feeds very largely on caddis and other water-insects. Let us therefore spare the dipper and confine our attention to that wholesale culprit, the swan. The dipper is not easily mistaken for any other bird, for no other, save perhaps the wagtail, is seen standing on the slippery stepping-stones, flirting its tail and nodding its wren-like head. Its white breast, too, is conspicuous at some distance, as are also the short round wings. The dipper's plunge is all but noiseless; and it walks, so we are told, over the bottom with or against the current, and, like the water-vole, chasing the larvæ and water-beetles. I give these particulars from other accounts, for, though I have watched the bird through glasses by the hour, I was never yet so fortunate as to 
take up a position whence I could examine its movements below the surface; nor, though we are gravely assured that it is so, have I ever heard its song from that submerged region. The dipper is a favourite with travellers and naturalists, and there are many charming accounts of its In literature. interesting ways, among the brightest of which are perhaps the tribute paid it by the author of 'Autumns on the Spey,' and the chapter in Muir's 'Mountains of California,' the gem of a delightful book, for my introduction to which I was indebted to $\operatorname{Dr}$ A. R. Wallace.

The nest of the dipper, a domed structure of moss lined

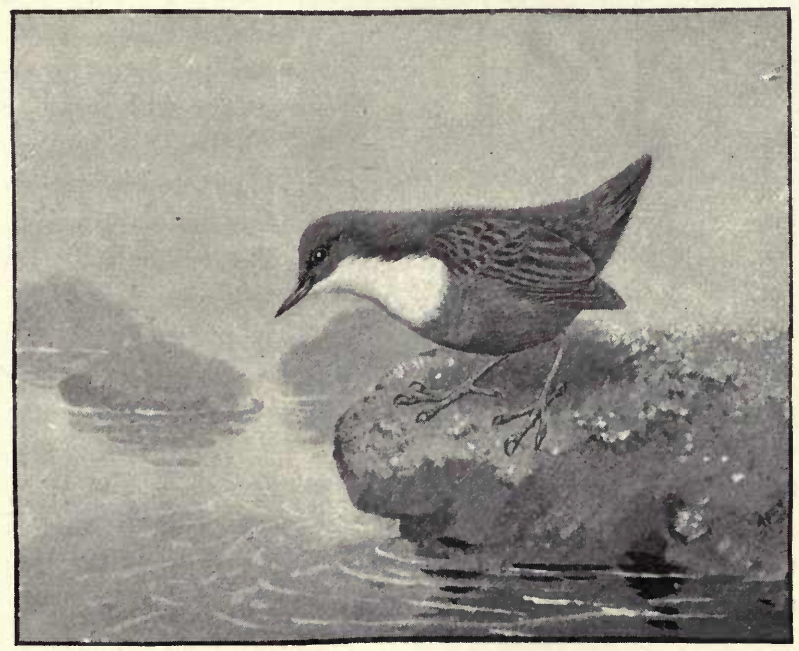

with dead leaves, is usually placed in some hole in the rocky bank near its feeding-grounds, occasionally in trees. Eggs, 5, I inch; pure white. Two or three broods are reared.

+Black-bellied Dipper. - A rare visitor to the eastern counties. It is held by many to be a race only of the last, and not specifically distinct. 


\section{The Bearded Reedling.}

The Bearded Reedling, more generally known perhaps as the Bearded Tit, and erroneously classed by many with the next family, is rare nowadays, confined, so far as its range in these islands is concerned, to the south of England, while its breeding is restricted to the district of

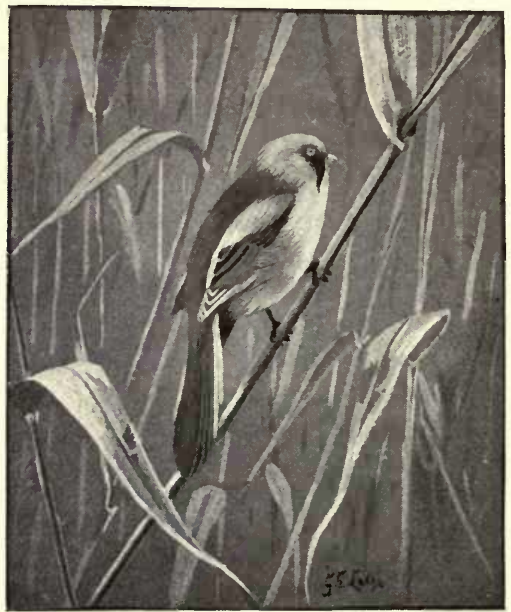
the Norfolk Broads. There the marshmen know it as the "reed-pheasant," in allusion to its great length of tail. The bird is easily distinguished by its prominent whiskers, or "beard," which are black-and-white in the male, brown in the female. Its food consists chiefly of molluses and the seeds of waterplants. In April, it weaves its cupshaped nest among the decayed reeds. Eggs, 5 to $7,3 / 4$ inch; cream-coloured, with brown lines. Though this is one of our resident birds, a number are suspected to cross and recross the Channel each year.

\section{The Tits or Titmice.}

[These active little birds are, in their movements, aptly compared with mice, and have no song worth the name. They are easily attracted to the garden in the winter months by a lump of suet or half a cocoa-nut suspended from a tree. Six residents; two rare visitors.] 
The Long-tailed Tit, often confused with a closely allied Continental species that is but a rare wanderer to these Long-tailed islands, has the smallest body and proportionTit. ately longest tail of the group. It is further distinguished through the glasses by the white on its crown, together with the broad white margin (and outer tips) of the tail. The bird occurs throughout these islands, and its food consists of insects and seeds. The flask-shaped nest, from the appearance of which the bird is widely known by the name of "Bottle-tit," is finished, as a rule, by the first week in April. They had eggs in them in the New Forest this year (1897) on the I 2 th of that month. It is of moss, lined with feathers, and is placed in high bushes or in the lower forks of trees; it is also large for the size of its occupant, and has but one opening. Eggs, 7 to $12,1 / 2$ inch ; white, with or (more rarely) without reddish spots and lines. The bird will sit close, her tail projecting from the opening, until the intruder is right upon her, when she flies off without a sound.

Continental Long-tailed Tit.-A rare straggler from Northern Europe, distinguished by the absence of black from the head.

The Great Tit may be distinguished from the rest by its superior size, the white cheeks, and the black stripe down Great Tit, the breast; and the species is common in most parts of these islands. Though, like most of the rest, resident, strictly speaking, there is nevertheless a large autumn arrival from the Continent, and probably, though less accurately recorded, a counter-departure. The note of this bird is piercing. Though its food consists for the most part of nuts, seeds, and insects, which last it digs out of the tree after the manner of woodpeckers, the great tit is known to attack small birds, and bats too for that matter, for the sake of their brains. In hard winters it will, with the rest of the family, approach our dwellings for such scraps as are available. 
The nest, ready by the end of March, is placed in any convenient hole in trees or walls, or even in squirrels' "cages" or old crows' nests. It is of moss, lined with hair and feathers. Eggs, 5 to 9, 3/4 inch; white, with red spots. A second brood is reared.

Often confused, as the long-tailed tit, with the closely allied grey variety from the Continent, the white cheeks

Coal Tit. and nape and the white bars on the wings serve to distinguish the Coal Tit from the rest. Common in parts of England and Ireland, it becomes less so in northern Scotland, and exceedingly rare in most of the isles. A shy bird, it is mostly met with in the wooded margins of moors and commons. It feeds on seeds and insects. The nest, also in holes of trees and walls, or in the ground, is, though smaller, like that of the last. Eggs, 5 to Io, $\frac{3}{5}$ inch; white, with a few spots of red.

Continental Coal Tit.-A rare visitor to the eastern counties.

The best way of recognising the Marsh Tit is to know the rest, for in truth, beyond having their general apMarsh Tit. pearance and antics, it has very little about tailed and coal tits, there is a distinct Continental race. The resident flocks, local in distribution, are augmented by autumn migrants, and their wanderings inland are considerable. This bird is quite unknown in many English districts, and is rare in Scotland and Ireland. It feeds on insects; also, to a lesser extent, on seeds and fruits. Although it occasionally selects a hole ready made to its purpose, this bird more often excavates a hole in some alder in damp situations, being, unlike the woodpeckers, careful to remove most of the tell-tale chips from the ground, near which the nesting-hole is usually made. The nest, a careless structure, like those of most birds 
that rear their young in darkness, is ready early in May. Eggs, 5 to 8, $\frac{\pi}{5}$ inch; white, with pale red spots.

The Blue Tit is easily known by its bright blue crown, the feathers of which are sometimes raised, and by the Blue Tit. white line on its forehead. Like the rest, and perhaps even more than some, it is seen to greater advantage balancing, often head downwards, on some slender branch than on the wing. It appears to be found throughout the British Islands. Although nominally insectivorous, the blue tit will, like the rest, eat almost anything. The nest, a loose structure of moss and hair, is found early in April in holes in trees or old walls, more rarely in the earth. Both sexes incubate. Eggs, 6 to 12 , about $1 / 2$ inch; white, with red spots.

Confined to the Highlands, or at any rate rarely met with in England, the Crested Tit has a prominent crest of Crested Tit. black and white, the throat and breast also being of deep black. It excavates a hole in Scots firs near the ground or in decayed stumps, the nest being warmly lined with fur. Eggs, 5 to $8, \frac{3}{5}$ inch; white, with deep red spots.

\section{The Nuthatch.}

That remarkable and interesting bird, the Nuthatch, fairly common in the woods of the southern counties, where it appears to be extending its range westward, is very rare in Scotland, and unknown in Ireland. It cannot easily be mistaken for any other bird, for when running up and down and around the trunk of some beech in search of food, it looks rather like a large brown mouse, while the reddish sides of the underparts and the white bars on the tail are enough to distinguish it from other birds-the woodpeckers, for instance, or the tree-creeper-likely to be found in such situations. It is one of the most pugnacious of forest birds. 
The food of the nuthatch is varied, consisting of grubs, beech-mast, nuts, and the like. The nuts are wedged in Method of a fork and hammered with the bill until the feeding. shell breaks, a proceeding I have witnessed many a time in the New Forest and elsewhere; and the bird throws its whole force into each blow.

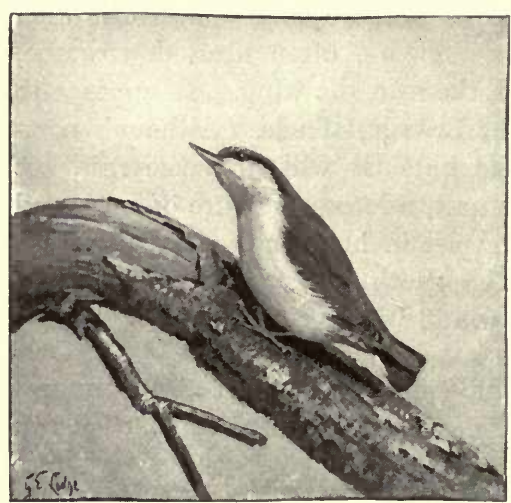

Now and again an unusually refractory nut is seized in the bill and dashed repeatedly against the trunk.

Perhaps, however, the most interesting habit of this bird is to be found in its notions of architecture. It is, ${ }^{1}$ in fact, a compromise between the woodpecker that excavates its own nesting-hole and the lazier starling that appropriates one ready made. For the nuthatch, though not taking the trouble to hew Nesting- the wood, casts about until it lights on a hole that will serve its purpose, and then proceeds to effect improvements in the front-door, which it plasters with mud and stones until only just wide enough to admit its body. The object of this has not been, so far as I know, ascertained; if it be done with the idea of making the smaller hole less conspicuous, we have here one of the instances in which bird-instinct is at fault. The "nest" consists for the most part of such bark and rubbish as may be within the hole. Eggs, 5 to $8,3 / 4$ inch; white, with brown blotches. 


\section{The Wren.}

The Wren is commonly distributed over these islands. The name of this little bird is, in most European languages, significant of royalty, and tradition has linked its name with that equally quarrelsome bird the robin, like which it utters its somewhat monotonous note throughout the year. Though more thickset, it is of about the same size as the goldcrest, from which it is at once distinguished by the white line over the eye and the absence of crest. It also carries its square tail erect, while that of the other bird usually droops. The food of the wren consists of insects when available, of autumn fruits and seeds in winter. The nest, built in April, is a bulky domed structure of moss and dead leaves lined with feathers. Few birds desert

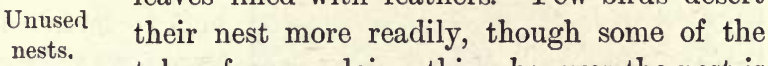

tales of wrens doing this whenever the nest is touched require confirmation. In consequence, a number of finished nests, some without the final lining of feathers, are found throughout the summer, for which various reasons have been offered, among others that they serve as domiciles for the male birds. These are, however, mere suppositions. Similar spare nests, it may be noted, are recorded of the squirrel and swan. In the ordinary course the wren shows some aptitude for suiting the colour and material of its home to its surroundings; but $I$ found (1886) in Baldwyn's Park, Dartford Heath, a number of exceptions to this in the shape of nests of dead yellow fern reposing in low green bushes. Eggs, 5 to 9, $\frac{3}{5}$ inch; glossy white, with red spots at the larger end. A second brood is reared.

St Kilda A species, sub-species, or race, found only Wren. on the island of that name. It is slightly larger than the common type. 


\section{The Creepers.}

The little Tree-Creeper is usually seen running zigzag up the trunks of trees, against which press the twelve Tree- stiff tail-feathers. By these, as well as by the Creeper. white spots and bars on the back and wings, it may easily be recognised. It never descends trees like the nuthatch, but having reached the top of the bare trunk, flies off to the base of a neighbouring tree. The long curved bill assists it in its search for grubs, of which

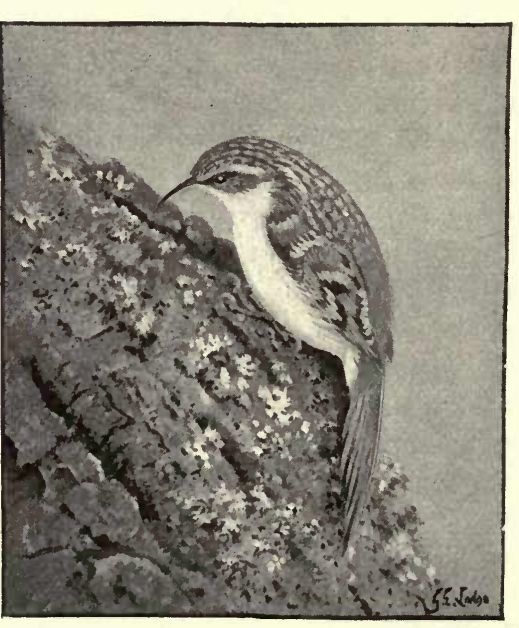

its entire food consists. The only pretence to song is a twitter. The nest, laced between the trunk and some loose portion of the bark, is ready early in May. Curiously enough, it is attached, as a rule, to the loose bark, though I have more than once found it fast to the trunk. It consists of straw and bark lined with feathers. $E g g s, 6$ or 8 , $\frac{3}{5}$ inch; white, with reddish spots at the larger end. The distribution of this bird varies in successive years. In I886, for instance, I found seven nests within a mile of Dartford Heath; but I do not know of one taken in that immediate neighbourhood in either 1887 or 1888 .

Wall-Creeper.-A rare straggler from Southern Europe. I knew of eggs in three nests in a crumbled wall outside Pisa (r89r), and the old birds used to feed on the large 
spiders that abound in every ruin in Tuscany. The wings are conspicuously marked with crimson.

\section{The Wagtails and Pipits.}

[These birds nest on the ground, often near water, and feed on insects. It is hard, in dealing with this group, to distinguish the residents and migrants. Three (partially migratory) residents; three regular visitors, six irregular visitors.]

Though many stay throughout the year, it is more satisfactory to regard the Pied Wagtail as a summer migrant. *Pied Known in many parts as the "water-wagtail," Wagtail. this bird is widely distributed over these islands, where it is often seen in much the same situations as those affected by the dipper, though commonly found in gardens far from water. Its call-note is loud and sharp. It does not plunge, but trips among the shallows, seizing aquatic insects from the water. By no means an exceptionally shy bird, this wagtail is easily stalked with binoculars so long as the observer keeps moving, but a moment's halt is sufficient to rouse its suspicions, and away it goes, its undulating flight clearing the crests of imaginary waves. It is a black-and-white bird, with white face.

Besides aquatic insects and molluses, it is said to feed on glowworms.

The nest, large for a bird of its size but withal neat, is built in April in the bank of its favourite water or in a stump hard by. It is of moss or soft grasses, lined with hair and feathers. In suitable localities many nest in close proximity, and I knew of five nests, all with young birds, within 50 yards of a bend in the little stream that runs through Buckland, behind Dover. A nest of the pied wagtail was found this summer (1897) in a truck of coal that had just arrived at Poole from the north country. It 
contained four eggs, three of which were broken. Eggs, 4 or 5 , $\frac{4}{5}$ inch; dirty white, with faint grey spots.

The White Wagtail, a rare visitor from Northern * White. Europe, is scarce in Scotland, still more so Wagtail. in Ireland. But for the white shoulders of the present species, it might easily be confused with the

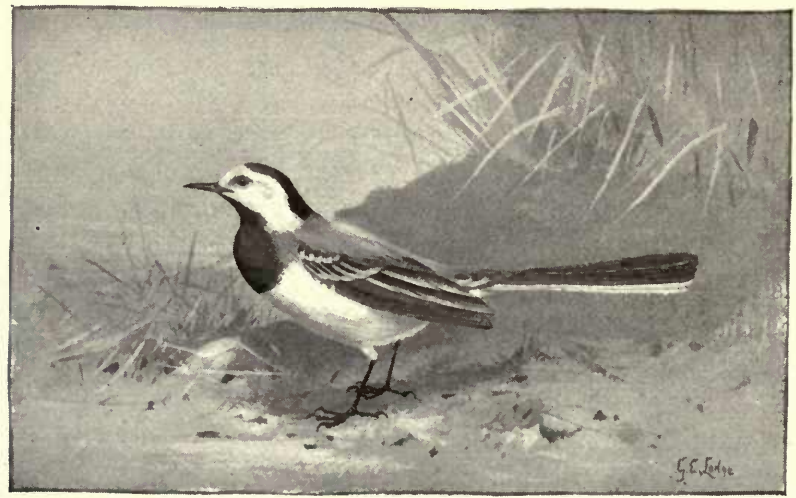

last. It has bred in several counties near the Thames. The typical nest and eggs closely resemble those of the last.

The Grey Wagtail is essentially the wagtail of Devon and Cornwall, and, though it has bred in almost every Grey county in these islands, its occurrences in the Wagtail. south-east are comparatively rare, as also in many parts of Scotland and Ireland. Its habits and food are those of the rest, save that it is more often seen seeking its insect food in trees. It is recognised by the white lines round the eyes, by the pale shade of the legs and feet, which in other wagtails are black, by the pale blue of the back, black throat, and yellow breast. The nest, built in 
April in the steep banks of swift streams, is of grass and roots lined with hair. Eggs, 5, 3/4 inch; dirty white, with pale-brown spots and sometimes a few black lines.

A spring and summer visitor to our east coast, the Blueheaded Wagtail is distinguished by the blue tint of the * Blue- head and a white streak over the eye. Besides headed this, there is a race, of far rarer occurrence, Wagtail. lacking the characteristic eye-streak. This bird appears to find the immediate presence of water less indispensable, as its nest is not seldom found in corn-fields at some distance from any river. The nest, not ready until the middle of May, and placed on the ground, is of fine grasses lined with hair or feathers, or both. Eggs, 5, $3 / 4$ inch; yellowish, with pale spots and black lines, the latter often absent.

Mostly with us from April to September, not a few Yellow Wagtails remain through mild winters. In the * Yellow Highlands and Ireland this species is rare. Wagtail. The eye-streak is yellow, and there is a good deal of yellow in the under-plumage generally, while the prevalent shade of the back is green. Its food consisting chiefly of molluses and insects, there seems little reason for the name "Seed-bird," by which it is widely known, unless it is that the bird, which often chases insects near the droppings of cattle, is supposed to be feeding on the undigested seed. The nest, commenced almost immediately on arrival in April, is placed on the ground, and is of fine grasses lined with feathers and hair. Eggs, like those of the preceding in number and size, and differing little in appearance.

The Tree-Pipit arrives from the Continent in April, and leaves these islands about the end of September. It breeds in most English counties, but is very scarce in Wales and 
the Highlands, and quite unknown in Ireland. On Octcber 2, I892, I saw flocks of these birds, with other small

* Tree- birds, on the cliffs east of Dover. Like many

Pipit. migrants, the tree-pipit is exceedingly capricious in its change of breeding-area. Thus I did not find a single nest near Dartford Heath in either I 886 or 1888 , whereas in the intervening summer I took no fewer than seven. The meadow-pipit, on the other hand, was plentiful in 1888, but I found one nest only, and that deserted, in 1886 . These details seem almost too trivial to insert without apology; but I cannot help thinking that the laws of migration might, for the summer visitors at any rate, be worked out more satisfactorily by carefully compiled records of the nests in each season than by the more rough-and-ready method of powder and shot.

The tree-pipit is, even after its partial spring moult, no striking bird, the long tail suggesting, especially when the bird is on the wing, the appearance of a lark, an impression strengthened by the habit of trilling while in the air. It feeds on insects and seeds, and, according to Dixon, on wheat. The nest, built on arrival, is placed on the ground. It is of grass lined with fine grass and hair. Sometimes it is in a shallow depression smoothed by the birds. Eggs, 6 , about $\frac{4}{5}$ inch; dull blue or grey, spotted all over with brown. I found one year two clutches with a zone of spots round the larger end only, and two cloudy blotches near the centre.

A partly resident, partly migratory pipit, the MeadowPipit is often spoken of as restricted and local in its disMeadow- tribution, though I have taken its eggs near Pipit. Bexley, Dover, Richmond, and Bournemouth. It is widely known as the "Titlark," and is characterised by a peculiar smell. Its distinguishing marks are a white line over the eye and some light spots or patches on the tail. Its food consists of insects, snails, and seeds. The 
nest, found on the ground early in April, is usually not far from water of some kind, if only a pond, and is large and deep, of grass lined with bents and roots. Eggs, 5, $\frac{4}{5}$ inch ; grey, with brown spots and lines. I took in one year seven eggs of the cuckoo out of the nests of these birds, and indeed the vagrant must find it placed more conveniently than most.

Red-throated Pipit.-A rare straggler from Northern Europe, which has occurred twice in Sussex and Kent.

Tawny Pipit.-A rare straggler, mostly to the Sussex coast, on autumn migration.

Richard's Pipit.-An irregular autumn straggler to this country and Scotland, distinguished by the great length of its hind-claw.

Water-Pipit. - A rare straggler to the Sussex coast, on which four examples have been taken.

Resident on all our rocky coasts, the little Rock-Pipit may be seen, especially down in Cornwall, tripping over

Rock- the decayed seaweed in search of insects

Pipit. and molluscs. It is a sober-coloured creature, lightest on the breast. The hind-claw is long and curved. Two races are known, of which the lighter-hued northern form is by many authorities regarded as specifically distinct. On the flat east coast the bird does not breed, and is rare even on winter migration. The nest, of seaweed or cliff grasses, and lined with soft bents or feathers, is placed among the rocks Two broods are, as a rule, produced. Eggs, 5, $\frac{4}{5}$ inch; greyish white, with redbrown spots. 


\section{i I. The Golden Oriole.}

The male of the rare and beautiful Golden Oriole that visits us from the Continent is conspicuous by reason of his bright yellow plumage and black wings and tail. The oriole's food consists of insects, and it makes occasional raids on the orchard. It has bred in Surrey, Kent, and

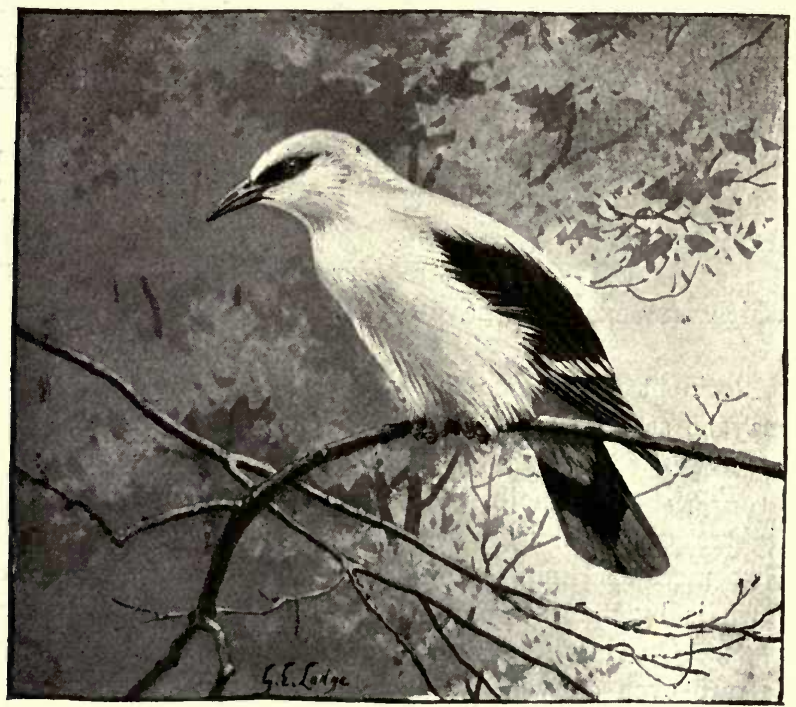

the Fen Country, and occurs annually in the south-west, but appears not to breed there. It might probably do so if less molested by the collector and his emissaries. The deep cup-shaped nest, cunningly made of fine grass and strips of bark, is suspended in trees. Eggs, 4 or 5 , rather over I inch; white, with reddish blotches.

\section{2. The Shrikes.}

[Carnivorous and insectivorous birds. Two regular and two irregular visitors.] 
With us every winter, a few Great Grey Shrikes have stayed the summer, but not to breed. In Ireland the tGreat Grey species is very rare, and it appears not to Shrike. have reached the Hebrides. The shrikes are, as a group, easily distinguished by the hooked bill, their neighbourhood being betrayed by the small birds, frogs, lizards, and chafers spiked on the thorns near their favourite feeding-perch. The present species has an inconspicuous white line over the eye and two white bars on the wings, besides which the white of the underparts is purer than in the rest.

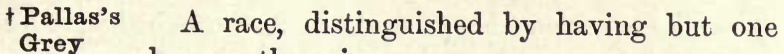 Shrike. bar on the wings.}

Lesser Grey Shrike.-A rare straggler from Central Europe, which has reached these islands but four times.

The Red-backed Shrike is common from May to August south of the Thames, but increasingly rare farther north

*Red- and in Ireland. A smaller bird than the rest, backed it is distinguished, apart from the fact that Shrike. it is the only shrike known to breed in these islands, by its red-and-grey plumage. A nearly white variety from Essex was recently recorded in the 'Field.' It has the family habit of impaling its victims on thorns ; but, singularly enough, though I have watched them

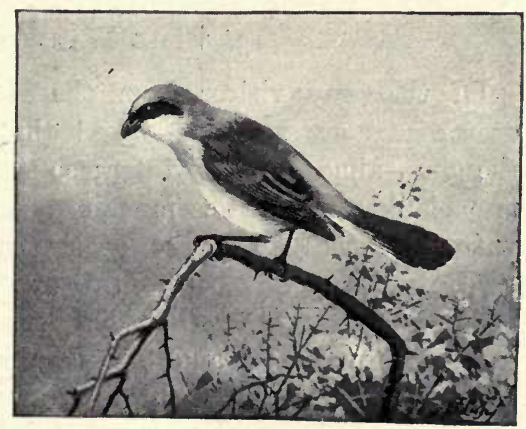

by the hour in my garden at Bexley, where they used to arrive late in May, and through strong glasses, I never 
once saw this done, the birds merely leaving their perch, after the fashion of the flycatchers, darting after some large winged insect and returning to the perch, upon which the genial couple would, so far as I could see, fight vigorously over the prize. Sir H. Maxwell tells me, however, that in 1895 he watched a pair in a chalk-pit near Winchester impale a young mouse. The harsh chatter of these "butcher-birds," varied by an occasional note of purer quality from the male, was heard continually to the middle of July, after which, up to their departure, they were comparatively silent. The nest, a large and clumsy structure of moss, hairs, and feathers, is placed, 7 or 8 feet from the ground, in a thorn-hedge. Eggs, $6, \frac{6}{7}$ inch; greenish grey, with brown and purple spots at the larger end.

Woodchat.-A rare visitor from the South to most English counties, but not to Scotland or Ireland. Under forty occurrences have been recorded, but there appears to have been some slight evidence of the bird having bred in the Isle of Wight. The breast is yellowish, the crown reddish-brown, and there is a conspicuous white line before the eye. The woodchat has the hooked bill of all the shrikes.

\section{The Waxwing.}

Of that gay visitor from the North, the Waxwing, occurrences are recorded-alas! through the medium of the gun-almost every winter; so that, in spite of one or two blank seasons, it seems fair to regard it as a regular visitor, especially to the north-east portion of Great Britain. In Ireland it rarely occurs, nor has it, curiously enough, been recorded from the Hebrides. Its distinguishing points are the brown crest and the black round the eyes. The general colour is reddish brown, and the wings (hence the name) are curiously tipped with bright red the colour of sealing-wax. The end of the tail is yellow. It feeds on insects. 
14. The Flycatchers.

The Spotted Flycatcher is an inconspicuous bird with spotted white breast and the characteristic bristles at the * Spotted base of the bill. From May to September, its Flycatcher. range seems to extend throughout these islands. It has been known to breed, according to Mr Harting and others, in London parks. The insects on which it feeds are captured on the wing and, after the style of the shrikes, devoured on the perch. The nest, a compact structure of moss, grass, and hair, sometimes lined with feathers, is placed in holes in trees, or in more exposed situations, as, for instance, in wall plum-trees or on beams; and the bird is known to return, like the nightingale and swallow, to its old nesting-haunts, and also to avail itself of the old nests of other birds. Eggs, 5, 3/4 inch; greenish white, with red and purple spots.

With us from April to September, the Pied Flycatcher breeds mostly in the northern counties, less in Scotland, and * Pied Fly - has only occasionally found its way to Ireland. catcher. The back and legs are black, breast and forehead white. This bird feeds almost entirely on winged insects, but it captures them by preference on the ground or amid the branches. It has a more powerful and pleasing song than the last. The nest, similar though less compact, is found in holes in trees. Eggs, 5 to 9, over $\frac{3}{5}$ inch; pale blue, sometimes speckled with brown.

Redbreasted Flycatcher. - A small and rare winter straggler that has occurred but nine times, chiefly in the south-west.

I5. *The Swallow and Martins.

[The three birds that come under this group (the swift, popularly associated with them, is not even remotely connected, belonging, indeed, to a different order) are all 
summer visitors from the South, whither they duly return at the end of summer, often, in their fear of being left behind, leaving a late brood to die of starvation. They have no very sustained song, though a low sweet twittering is heard in the breeding season.]

Common throughout England and Wales from April to October, the Swallow is rare in the northern Highlands

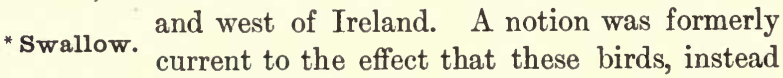
of migrating, passed the winter at the bottom of lakes and ponds, reappearing in early spring. In the present year (1897) a gentleman wrote to the papers announcing an early swallow (March 26), and hinting at the possibility of the bird having wintered in the neighbourhood, though it is fair to add that no allusion was made to the local pond. The swallow is easily distinguished from the swift and martins, in whose company it flies, by its reddish throat and deeply forked green tail. There are also metallic reflections in the plumage that differ from those in the house-martin. Its food consists largely of gnats, which it chases early and late, catching them, eating them, and digesting them during its rapid flight. Few birds take less rest, and when the swallow does alight on the ground, which it does rather more often than some imaginative chroniclers would have us believe, it must be admitted that its movements sadly lack that grace that it exhibits on the wing. One cannot have everything; and these birds, so symbolic of the poetry of motion in the air, are little better than geese on the ground. The flight, however, is unique; and it has been known to cover over I 20 miles in an hour. Its favourite perch seems to be the telegraph wire; indeed one wonders what swallows did before the introduction of this useful but unsightly feature in the landscape. The fact is, that on a perch of that kind the short legs and long wings do not place the bird at so great a disadvantage as elsewhere. The deeply forked tail must, to judge from 
the marvellous turns, be a wonderfully efficient steering gear. The swallow commences building its remarkable nest under the eaves of houses on arrival. Mud, its principal ingredient, is incorporated with hair and grass, and the familiar nest is lined with soft grasses or feathers, and has a single opening above. When black clay is used, such a nest will last for years. The bird has also, though rarely, been known to nest in trees and on the sea-cliffs; and it has been shown, by the simple expedient of marking them, that these birds will return year after year to the same nest. Eggs, 5 or $6, \frac{4}{5}$ inch; white, speckled and spotted with brown. A second-some say even a thirdbrood is reared.

The Martin is another of the birds spared by schoolboys, not wholly, let us hope, because its rapid flight renders it * Martin. particularly difficult to shoot. It arrives soon after the first swallows, leaving again early in October, and is a sociable bird. Its food consists entirely of insects, which it chases, with flight somewhat inferior to that of the swallow, high and low. The notion that these birds act as barometers, forecasting fine weather when they hawk at a height, and vice versa, is no fanciful one, the explanation being that their insect prey flies close to the ground when the glass is low. In Europe this bird is little persecuted by man, but Michelet gives an instance in which its virtual extermination in the Isle de Bourbon brought down on the farmers a plague of grasshoppers that went near to ruin them. I do not, of course, vouch for the truth of his statement.

The martin nests in the eaves of houses and in steeples, its nest differing from that of the swallow in its rougher surface and in the position of the opening, which is here at the side. The bird itself is distinguished from the swallow by the slighter forking of the tail, the white throat, and the white feathers on the legs and feet. Eggs, 5 , 告 inch; pure white. Like the swallow, this bird rears 
at least two broods, and returns to its old quarters year after year.

So called from its habit of nesting in colonies in sandstone cliffs, the Sand-martin differs from the larger species * Sand. in having a smaller patch of feathers on the martin. legs and none on its feet. The back is much lighter in hue than in the swallow or martin. Like the rest, it feeds entirely on insects, in catching which it is said to receive assistance from a thick secretion within the mouth. Its nest, a careless mass of grass and feathers, is placed at the widened end of a tunnel which the birds excavate, claws and bill uniting in the work, to a depth of a couple of feet in the face of some sandstone or other cliff. The burrow slopes upwards, so that the overhead drainage has no chance of damaging the eggs or young, and is invariably swarming with small vermin. Eggs, 5 or $6,3 / 4$ inch; pure white.

\section{I6. The Finches.}

[This large and important group of hard-billed birds has several subdivisions (given more accurately on p. I I6), the chief being the Finches proper and the Buntings. The former include, besides the common sparrow, a number of favourite cage-birds. At the same time, it would be unfair to weaken the case of a few more deserving birds of other groups by denying that the greater number of them would have some difficulty, during a part of the year at any rate, in posing as friends of the farmer. Fifteen residents ; four regular, and ten irregular and rare, visitors.]

The Greenfinch (extending its range in Scotland, but not in the isles) is known by the yellow stripe over the Greenfinch. eye and the yellow on the wings and tail, Greenfinch. the extremities of which are almost black. From its prevailing colour it is also known as the "Green 
Linnet." Its food consists of grain and seeds. The song is tuneful, but not of any great power. It has a habit, not generally noted, of roosting in ivy. The nest, built about the second week of April, is placed in high hedges, and is of twigs and wool lined with hair. Eggs, 5 or 6, $\frac{4}{5}$ inch; with reddish spots. Two broods are reared.

A larger bird than the last, the Hawfinch is recognised by its powerful short bill, as well as by the black markings Hawfinch. on the face and throat, the reddish feathers breeds in the counties round London, less frequently farther north, and never in Wales, Scotland, or Ireland, in all of which it occurs in winter only. Besides seeds and berries, particularly those of the yew and hornbeam, it is partial to the stones of fruits, which it easily cracks with its sturdy bill. The nest, not of any great depth, is of twigs and roots, lined sparingly with hair. Eggs, 5, I inch; greenish, with black spots and lines.

The beautiful Goldfinch, unmistakable by reason of the bright red on its face and throat, the yellow on the wings, Goldfinch. and the black on the crown, is, as the result of persecution, becoming rarer. Its food consists largely of thistle-seeds and groundsel, and its song is very pure. The slight nest, of moss lined with wool and feathers, is found in May, orchards being a favourite situation. Eggs, 4 or 5, rather over $\frac{3}{5}$ inch; bluish white, with red spots. There is a second brood.

Breeding regularly amid the dense plantations of Scots firs, as well as in Cumberland and sparingly in the eastern

Siskin. counties of Ireland, the Siskin nests but rarely in the southern half of this country, where it is seen mostly in winter. It may be recognised by the black chin and crown, and the yellow stripe behind the eye. Its white breast is streaked with black. The nest 
is not unlike that of the last, and the eggs, somewhat smaller, are of a more pronounced blue.

Serin.-A rare straggler from the South. It has occurred about a dozen times in England and once in Ireland.

The House-Sparrow resides in most countries of the civilised world, and where nature had mercifully omitted

it from the programme, as, for instance, in

Sparrow. Australia and New Zealand, man had the good sense to introduce it and temper the pleasures of colonising to an extent which the present generation has no difficulty in recognising, and for which it duly respects the judgment of the pioneers. Nature is often best left alone, and this introduction of the $\begin{array}{ll}\text { Artificial } & \text { sparrow into continents in which nature had }\end{array}$ provided no efficient check, was even more culpable than the other extreme of exterminating it in others where it may have had its sphere of usefulness in the scheme. Not only is it a scavenger which some teeming cities could ill spare, but it may at times be of use even in agricultural districts where the conditions would, without it, be favourable for the undesirable multiplication of insect life. At the same time, it may possibly keep away other preferable fowl. It is an old story, but an instructive one, how Frederick the Great once offered a reward of Persecution. one halfpenny a head for dead sparrows, a bait to be considered in so poor a country as his; but the orchards were ere long overrun with grubs, and the great one had to own his error, and to take the bird under his own royal protection. On another occasion, the Hungarians exterminated the bird, which their Government had to restore at a cost of thousands of pounds. And it is within the memory of the present generation in Ireland how the sparrow mercifully came on the scene thirty years ago and put an end to the plague of cockchafers.

Without, however, going to either extreme, a moderate 
policy should be found productive of good results, the birds being neither unduly encouraged nor ruthlessly exterminated, but judiciously kept under. It must not be forgotten that, although the grown bird has little fancy for anything but grain and fruit, the food of the young consists entirely of caterpillars and all manner of noxious grubs; so that, without perhaps making up for the very considerable damage they do during the rest of the year, there are yet several months of parenthood in which the sparrows render not unimportant services by way of reparation. The means of keeping them under are various, much work being done in this direction by the organisations known as "sparrow-clubs"; and if these crusaders confined their attentions to the heads of the infidel only, they would be less to blame than is the case, for they also destroy numbers of other interesting and harmless birds. These notes will have gone to press before the appearance of Miss Carrington's promised pamphlet, but we have heard much said on both sides of the question. The domestic cat is another valuable agent in the sparrow death-rate, preferring its oily flesh to that of any other wild bird. The sparrow is, as already mentioned, essentially the companion of man and the bird of cultivation; and the only portions of these islands in which it does not occur are a few wilds as yet untouched by the ploughshare. Description of so familiar a bird seems superfluous, although the smoke of cities often obscures the distinctive bluish crown, black chin, and light brown chest. Its favourite nesting-place is in the roofs of our dwellings, and too often in some drain-pipe, which its nest chokes, with unpleasant consequences. It also nests, usually in solitary pairs, in holes in trees, and I have found its nest in the hen-house, close to the sitting hens. Swallows' nests under the eaves are also appropriated for the later broods. I have also taken the nest in trees, but never in company with the tree-sparrow, though the latter was breeding in neighbouring trees. The nest 
when in trees is far more elaborate and better finished than the heap of noisome rubbish that contents the birds that nest in house-tops. On one occasion in Hampshire, I found a nest with four young in the deserted "cage" of a squirrel.

Eggs, 5 or 6, nearly I inch ; very variable, but generally greyish white, with few or many brown spots, though I had some in my collection without spots. The shape is also subject to variation, and I have taken them of elongated form like those of the swallow, or perfectly round like some of the robin's. Two or three broods are reared.

The sparrow is an interesting bird in spite of, perhaps by reason of, its power for evil. Not the least difficulty in the way of its repression is its remarkable indifference to extremes of temperature, and I have found it equally impudent and pugnacious in the midday heat of a Queensland October and the short grey dawn of a Baltic Christmas.

Common in the south of England, less so as we go north, and unknown in the Orkneys and, according to Tree- report, over the greater part of Ireland, the sparrow. Tree-Sparrow is distinguished from the more familiar bird by the bars on the wings, the black patch on the cheek, and the lighter hue of the legs and feet. The nest of this bird is by no means found only in trees, for it is also known to nest in the roof of thatched cottages, and I have myself taken the eggs from nests in old barns. It is more compact than that of the other, but also consists of grass and feathers. Egys, 4 to 6, 3/4 inch; white, with brown spots, and, in most clutches, one with fewer spots than the rest, known as the "odd" egg, and often infertile. Several broods are reared.

The Chaffinch, considerable numbers of which cross and recross the Channel, appears to breed throughout these islands, save in the Shetlands. It is a most attrac- 
tive type, easily distinguished by the white tail-feathers, the yellow in the wings, and the reddish breast; and the somewhat harsh call-note of the male is occaChaffinch. sionally varied by a more musical outburst. The food of the chaffinch consists largely of grubs and winged insects, though it certainly does some damage among imperfectly protected newly sown seed. The nest, one of the most compact and beautiful of those found in this country, is of moss

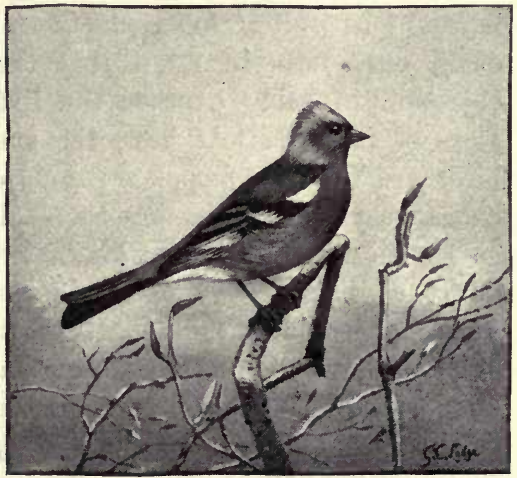
lined with hair and down, and is usually placed in orchardtrees at a height of 4 or 5 feet. $E g g s, 5, \frac{4}{5}$ inch; greenish, with purple spots and smears. An unspotted variety of the egg is also known, but I never found one. A second brood is reared in June.

Now a regular winter visitor to parts of Scotland, and an occasional wanderer to almost every county in England and Ireland, the Brambling was once found
breeding in Perthshire. It is also known as the Mountain Finch. The breast is of reddish hue, and there is some yellow about the wings.

The Linnet, or "lintie," is a common resident in these islands, except in the north of Scotland, where it is rare,

Linnet. and the Shetlands, where it seems to be unknown. As the sparrow is a bird of cultivation, so is this a bird of waste ground. Not a very handsome species, the male has just sufficient red in his 
crown to make him, especially when the tail grows its white edges, at least attractive, while the song is superior to that of any other member of the group. For this reason the linnet is a favourite cage-bird, and it must be admitted that few take more kindly to captivity, only it would be well if folks who keep these little prisoners could only bear in mind that they have the greatest objection to being exposed the livelong day to the full glare of the sun. At best, the surroundings of captive birds are the most hopeless parody of natural conditions, but a very slight attention to detail of this nature may go far to minimise their discomfort. The food of the linnet consists largely of oily seeds, also charlock, with some berries in autumn. Its nest of twigs and moss, lined with wool and hair, sometimes feathers, is found by the middle of April in trees and bushes surrounding commons and other open land. Eggs, 4 to 6, 3/4 inch; dirty white, with a belt of brown spots around the larger end.

The Mealy Redpoll is a winter visitor to Scotland, less often met with in England, and only twice recorded from † Mealy Ireland. The breast is reddish, striped with

Redpoll. brown, the forehead is crimson, the throat black, and there is some white in the wings. A larger race, regarded by Dr Sharpe as a sub-species, has been taken twice in Norfolk.

The Lesser Redpoll, the smallest British member of the family, is a resident in most parts, but becomes local in

Lesser the breeding-season, absenting itself from the

Redpoll. south-west and from parts of Scotland. In the home counties it breeds regularly. It is a smaller and darker bird than the last, and lacks the white markings on the wings. Dr Sharpe recognises a sub-species in the larger Greenland straggler, one occurrence of which was recorded many years ago in Northumberland. It feeds on seeds. The nest, placed at no great height in bushes and 
small trees, is of twigs and grass, with a soft downy lining. Eggs, 4 to 6, $\frac{3}{5}$ inch; bluish grey, with brown spots.

Living in the hills and mountains of the north, and more especially in Scotland and Ireland, visiting the

Twite lowlands and southern counties in winter, the Twite is a duller bird than the foregoing, having little or no red about its plumage, save on the rump. The food of the "Mountain Linnet," as it is also called, consists largely of seeds, as does indeed that of all the group. It nests in May in low bushes, or close to the ground in tufts, often near the sea-shore, and the nest is of grass, with a soft lining. Eggs, 3 to 6, 3/4 inch ; greenish, with red spots and lines.

The Bullfinch is widely distributed over the British Islands, and is continually extending its range in Scotland Bullfinch. and Ireland, in parts of which, especially on the islands, it was, up to a few years ago, almost unknown. The bird is a favourite both on account of its handsome plumage and for those imitative faculties that atone for any weakness in its tuneful song. The bullfinch has a glossy black head, red throat and breast, while the rump, as well as some feathers in the tail and wings, are white. The female is, both in voice and appearance, an improvement upon most of her sex in the bird world. The food of the bird consists of insects in the warm months, supplemented by fruit and buds, as well as by the seeds of various weeds. The nest, a shallow platform of twigs, which, but for its spare lining of hair and roots, would be a miniature of that of the ringdove, is placed about 5 feet or more from the ground in bushes in the midst of woods. Eggs, 4 to 6, 3/4 inch; pale blue, with a belt of reddish spots at the larger end. A larger race, or sub-species, a rare wanderer from Scandinavia, has been obtained in Yorkshire.

Scarlet Grosbeak, the "Rosy Bullfinch" of some author- 
ities, is a rare straggler from the North, and has occurred but twice in England-in Sussex and Middlesex.

Pine Grosbeak.-An exceedingly rare straggler from the far North, the validity of even the few that have reached these islands being questioned.

A local resident, though more commonly seen in winter, the Crossbill is distinguished from every other British

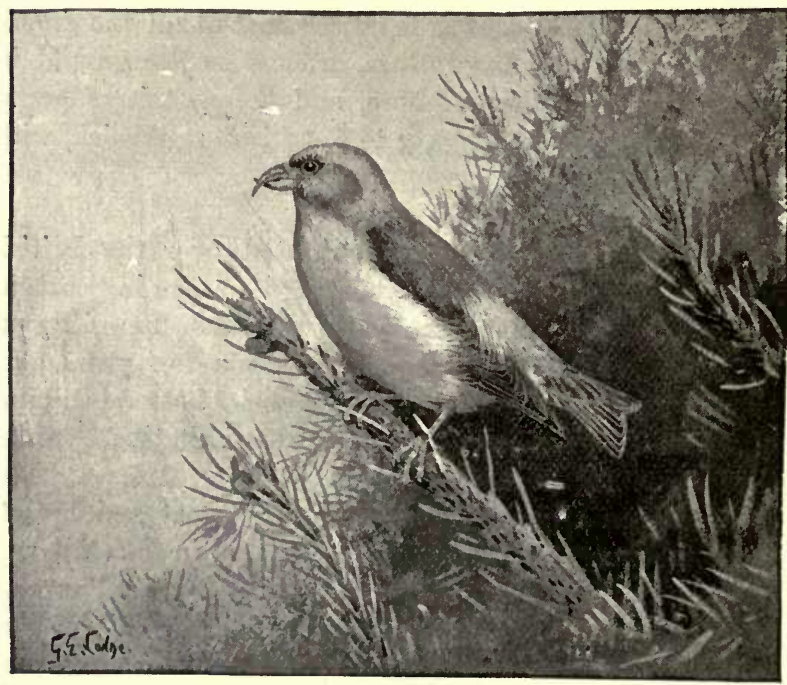

bird, except its rare congener, by the scissors-like bill, the mandibles of which cross at the tip. Its plumage is dull Crossbill. crimson. It breeds regularly in some Scottish pine-forests, but its breeding in England and Ireland is exceedingly irregular. Crossbills were unusually plentiful in Shropshire during the winter 1894-95. ${ }^{1}$ The food of this bird consists of the seeds of the fir, spruce, larch. and kindred trees, its bill being

' Caradoc and Severn Valley Field Club 'Record,' 1895. 
admirably adapted for extracting them from their hard covering. The "Parrot Crossbill," a larger race with stouter bill, has wandered to Great Britain and Ireland at long intervals. The nest, ready by the end of February, is of twigs lined with grass, and is placed among the boughs of fir-trees. Eggs, 4, nearly I inch ; grey, with red spots.

Two-barred Crossbill.-A rare straggler from the north of Europe, a slightly different American race having also occurred 'but a few times. In the winter of $1894-95$, one was killed in Somersetshire and another near Enniskillen. There are two white bands on the wings.

Black-headed Bunting.-A rare straggler from Southern Europe, which has occurred three times.

The Corn-Bunting, or "Bunting Lark," as it is often called, is widely distributed throughout the British Islands,

Corn- though little known in many districts, especially

bunting. in Ireland. The breast of this bird is yellowish white, with brown spots, and there is a not very distinct whitish line over the eye. The food of the corn-bunting consists of insects and grain, chiefly, it is to be feared, the latter; though there is compensation in the fact that when fattened on this diet it is, like its still better relative the ortolan, excellent eating. The nest, placed on the ground, is of grass and straw lined with hair. It is built late in May. Eggs, 4 or 5 , $\frac{4}{5}$ inch; greenish white, with purple and brown spots and streaks.

The Yellow-"Hammer" nests throughout these islands, save in the Shetlands. This bird is the handsomest of the

Yellow- buntings, and may be at once recognised by Hammer. the bright yellow of its head and breast. The crown is spotted. It feeds on insects, berries, and seeds. The nest is usually on or near the ground, but I have taken it in bushes quite 2 feet above it. It is of grass lined with hair. Eggs, 4 or 5, $\frac{4}{5}$ inch ; brownish white, with curious violet or purple scribblings (hence "Writing Lark"). 
The Cirl Bunting, distinguished by the yellow collar, black throat, and yellow lines round the eye, breeds south Cirl of the Thames, but is a straggler only to ScotBunting. land and Wales, and is unknown in Ireland. It feeds on grain. The nest is not unlike that of the last, but is placed a trifle higher. Eggs, 4 or $5, \frac{4}{5}$ inch ; greyish, with very dark markings.

Ortolan.-An irregular visitor on migration to the south of England, twice recorded from Scotland, and once from Ireland.

Rustic Bunting.-A rare straggler from Northern Europe, which has been recorded only three times.

Little Bunting. - A rare straggler from Northern Europe, recorded once.

A common resident, breeding everywhere in the British Islands except in the Shetlands, the Reed-bunting is dis-

Reed. bunting. tinguished by its black head and throat and white breast and collar. It is also known as the "reed-sparrow"; while in some parts it goes by the name of "Black-headed bunting," which is to be regretted on account of the confusion risked with the straggler properly so called. It feeds on aquatic larvæ and molluscs; in winter, on seeds. The nest, placed low down in the reeds, is of dry reeds lined with hair and down. Eggs, 4 or 5, 3/4 inch; grey, with deep brown spots. Two or more broods are reared.

Lapland Bunting.-An irregular wanderer from the Arctic regions to the south of England. It has occurred twice in Scotland and once in Ireland.

The Snow-bunting must be regarded as a winter visitor to the northern portions of the British Islands, although it has long been known to breed in the Shet+ Snow- lands and on the mainland in Sutherland and Banffshire. Large flocks visited Highgate in February 1895. It is a handsome black-and-white bird 
with strikingly long wings, and feeds on insects and corn. It breeds only on the sides of the higher mountains, the nest being of grass lined with hair and feathers. Eggs, 4 to $7, \frac{4}{5}$ inch; grey, with brown and purple markings.

\section{i7. The Starling.}

The Starling is one of the comparatively few birds that have been, and are still, steadily increasing their range in these islands, especially in Scotland. It is at all seasons a familiar bird, whether on the chimney-stack, raised to its full height, flapping its wings and shrieking at high pitch; or, again, running (not hopping like the thrush) over the lawn, tugging at the retreating worm, or, in harder weather, sharing the crumbs with the sparrows. Viewed casually, the starling is no striking bird, but the glasses reveal much beauty in the steely sheen of the brown-tipped green plumage, the bright yellow bill, and reddish-brown legs and feet. The female is spotted, and is generally seen running in the wake of her lord. The voice of the starling, though not out of keeping with the grey dawn, cannot be described as more than a shriek, followed by a spell of chattering in a half whisper. Always a wary bird, for which reason the bird-catchers call it "Jacob," the starling is particularly difficult of approach when in company with its fellows, and the flocks which feed together in cold weather move off simultaneously on the least sign of intrusion. This is even noticeable in summer, when they find agreeable insect food on the back of each grazing cow, and even draw leeches from its nostrils. If any one approaches that part of the field, the birds at once leave their feeding-grounds and fly shrieking to the nearest tree, from which, when all is quiet again, they descend to resume their favourite occupation. Though its food con-

Food. sists for the most part of insects, there seems little doubt that the starling does at one season commit much havoc among the fruit-trees, though the notion of its sucking game-birds' eggs, a charge pre- 
ferred with more reason against the magpie and jay, is probably fanciful. At times, especially towards the end of summer, these birds are observed to fly at a great altitude, and we are told on respectable authority that their object is to course certain high-flying insects. I have no means of denying this, though it would be of interest to learn how the information, unless acquired from a balloon, was arrived at; but I have repeatedly watched these lofty starlings through powerful glasses without observing any of the somersaults and other antics that usually accompany the capture of winged insects. It seems therefore more reasonable to assume, in the absence at any rate of stronger evidence, that the birds prefer performing their considerable journeys in the purer, lighter medium above. The starling is a hardy and not unpopular cage-bird, its imitative faculty and occasional soft notes compensating for the more usual shrillness of its voice; and it is also used, by those who have a fancy for so remarkable a form of sport, as a substitute for the more costly trap-pigeon. The nest, which is often stowed away in eaves or in the top of a drain-pipe, but is also found in holes in the earth or in trees, less frequently open to the sky, is not, as a rule, an elegant structure, being loosely put together with grasses, paper, string, wool, and any other débris that is available. I never found one with an elaborate lining, though such are recorded. Eggs, 5 or 6, I inch; pale blue, glossy, and elongated.

Rose-coloured Starling.-A rare autumn visitor from the South. It is a gaily-coloured bird with a large black crest ; and is also known as the "Rose-coloured Pastor."

\section{The Crow Tribe.}

[Somewhat large birds, mostly of gregarious habits, and almost omnivorous. Eight residents ; one straggler.]

The Rook, already widely distributed in Great Britain and Ireland, is extending its range in Scotland, where it 
was by no means common a few years ago, and breeds, save in the Shetlands and Outer Hebrides, everywhere.

Rook. On account, perhaps, of the readiness with which the rook dwells in the midst of cities, it is the best known of the family. There have been rooks at Haverstock Hill and in Kensington Gardens and elsewhere in London for many generations ; and there is a considerable colony in the centre of Dover town, where I saw the elders repairing their old nests. on February $\mathrm{I} 2$ th of the present year (1897). I understand, from Mr W. N. Wilson, honorary secretary of the "Rugby School Natural History Society," that the members of the Zoological section always made a feature of annually recording the number of rooks' nests in the Close. Unfortunately the great storm of March 1895 destroyed twenty of the old elms, so it has been useless to continue the record. The adult rook is at once distinguished from the rest of the tribe by the featherless patch of white skin at the base of the bill. This has been attributed to the action of the earth into which the latter is plunged in search of grubs; but this method of seeking food is also employed by other members of the family in which the face remains thickly feathered. The young bird retains the face-feathers or bristles until the second moult. The rook is a fowl of sociable habits, both in the nesting-time and during the winter migrations in search of grain. Its morals are those of all the crows, and any falling off in the supply of wireworm and other noxious grubs, of which (being for the greater part of the year the farmer's friend, as it is unquestionably his enemy for a month or so) it destroys vast quantities, is promptly made up for by a raid on the nearest grain, while even the game-preserver has learnt to dread the bird's taste for eggs and young birds. Dr Sharpe includes walnuts among its favourite food. The nest is, as a rule, completed early in March, but I have noticed that the birds settle down to their duties somewhat earlier where the old nest is refurnished. Occa- 
sionally, where there are no trees, the rook is known to breed near the ground. Liggs, 3 to $5, \mathrm{I} / 2$ inch ; brownishgreen, with dark spots.

The Raven, the largest of the family, is diminishing yearly owing to persecution on the part of keepers, to

Raven. whom, it must be admitted, the bird is an unwelcome neighbour. It is only in the hilly parts of Scotland and the isles that the raven is nowadays at all plentiful, though it breeds in isolated districts of England and Ireland. It is a pugnacious bird, not hesitating, in defence of its young, to attack those of twice its size, and even men have to proceed warily after the eggs. The raven is a destroyer of young lambs and weakly ewes, but it also destroys large numbers of rats. It is easily recognised by the long throat-feathers. It nests in cliffs or trees, preferably on or near the coast. The nest, always large, becomes huge in time unless destroyed, as the bird adds to it year after year. It is of twigs and heather lined with lamb's-wool. Eggs, 3 to 5, near 2 inches; much as those of the rook save for their greater size.

Like many of its tribe, the Jackdaw has a liking for the sea-coast, where it may always be seen to advantage by Jackdaw. those who walk along the top of the cliffs in which it nests. The dull grey collar dis-
tinguishes it from the rest of the family. Those who have visited the quieter glades of Sherwood Forest will not soon forget the large colony of jackdaws which are, or were, one of the sights of the place. There was a large colony, too, in the white cliffs not far out of Ramsgate; but the cliffs are continually crumbling in those parts, and the birds consequently desert freely. This small member of the crow family is an insect-destroyer on a large scale, one of its favourite feeding-grounds being the backs of sheep and cattle. It is, however, a poacher as well, for in addition to its taste for fish it has a fancy, not altogether rare, for eggs. The long wings 
of this bird enable it to wheel with rapidity. The nest, a careless mass of sticks and feathers, is placed in some hole in the cliffs, or in steeples, hollow trees, or chimney-stacks. It has, though rarely, been recorded in the open. Eggs, 3 to $6,1 \mathrm{I} / 2$ inch or less; greenish, with grey spots. I had two or three in which the spots were all but invisible.

The Hooded, or "Royston," Crow breeds commonly in Scotland and Ireland, but to the greater part of England

Hooded and Wales it is only a winter visitor, though

Crow. a few are known to breed. It is distinguished from its closely allied relative the carrion-crow by the grey mantle and breast, though the birds breed so freely, the hybrids being to some extent fertile, that the number of intermediate forms makes identification no easy matter in every case. The name given to the other crow, by the way, does not point to any gentler tastes on the part of the present species, for it will eat carrion with any of them, and is among the worst offenders of the whole robber gang, being very partial to the eggs of grouse. It also eats molluscs. The hooded crow is perhaps less partial, on the whole, to the sea-shore than the rest. It nests mostly some way inland; the nest is of sticks, with a lining of wool. It is placed indifferently in high trees or rocks, or on the ground. Eggs, 3 to $5, \mathrm{r} 3 / 4$ inch; green, mottled with brown.

Unlike the last, the Carrion Crow is commoner in England than in either Scotland or Ireland. It lacks the lighter

Carrion plumage of the last bird, and the long bristles

Crow. at the base of the bill are always conspicuous. In addition to its love for carrion, preferably in an advanced stage of decay, the bird is a great poacher of game and poultry, and will even attack lambing ewes. It nests late in spring, not, like the rook, in colonies, but singly. The nest is softly lined, otherwise resembling that of the rook. Eggs, 3 to 5, r 3/4 inch ; pale green, with dark spots. 
Nutcracker.-An irregular visitor from the North. It is easily recognised by the brownish white spots with which the plumage is thickly covered. Its food is not, like that of the nuthatch, even chiefly nuts, as it poaches game and eggs like the rest of the group. The seeds of pine and fir trees are also largely eaten.

Though lacking the brighter colouring of the jay, the Magpie is, perhaps by reason of the sharp contrasts afforded

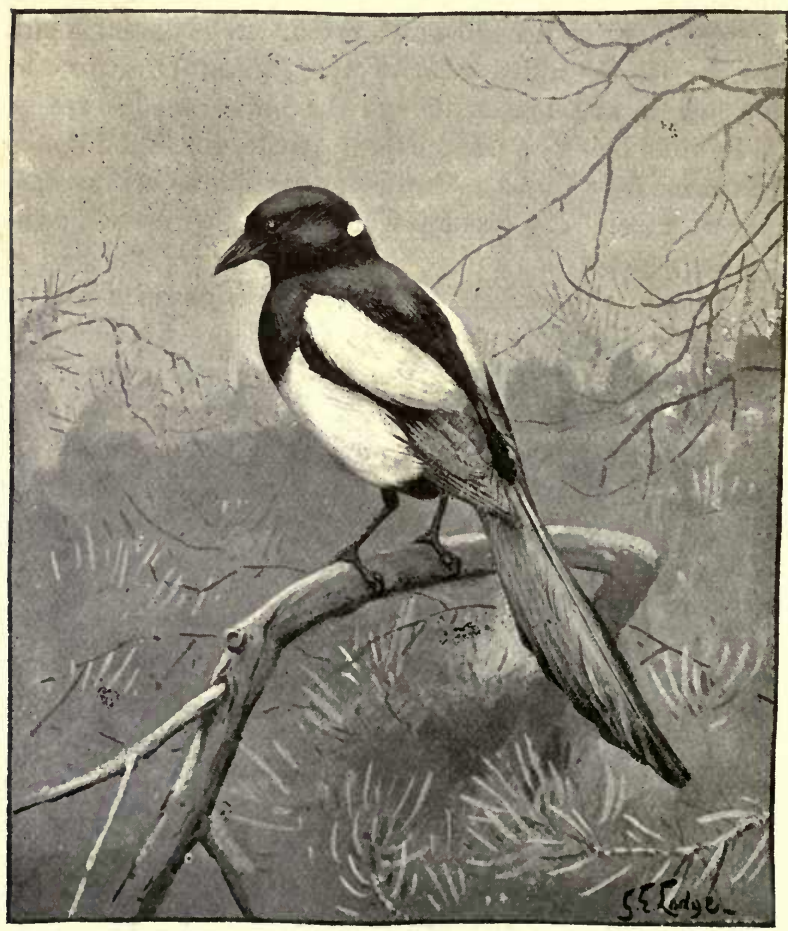

by the black and white of the plumage, the most attractive, as well as the most conspicuous, of our Corvida. 
Unfortunately, it is also an abandoned poacher, and besides its fondness for young birds and eggs, it delights in a meal of carrion, knowing well when the

Magpie. deer is getting near the end of its wind. It has also been observed to feed on a dead donkey, and the observer of this spectacle, no other than the late Lord Lilford, was doubly privileged, for it has been said that few men have ever seen a dead donkey. The voice of our magpie is, except for an occasional but very brief improvement during the courting weeks, the reverse of pleasing; but in Australia the so-called magpie, an even greater cage-favourite than the genuine bird at home, has a beautiful voice. The long tail of the magpie is much in evidence, especially when the bird is on the wing, its flight being laboured. The magpie, though all but exterminated by its enemy the keeper in some parts of these islands, is, in those districts at any rate where gamepreserving is not the one end and aim of life, extending its range. This is particularly noticeable in Ireland. Although, as already mentioned, a robber in the gamepreserve, it is on the whole more correct, as well as certainly more charitable, to regard worms, slugs, and snails as its staple food. The nest, placed according to circumstances in high trees, in bushes, or on the ground, is of sticks and clay lined with grass. Eggs, 6, $1 \frac{1}{3}$ inch; pale green, speckled with brown.

Like the magpie, the beautiful Jay with the bluebarred wings and black-and-white crest, black moustaches and pale-brown legs, has been very sternly Jay. dealt with by the gamekeeper; and it would be mere folly to deny that those whose interest or duty it is to preserve have few worse enemies. Though energetically kept under so far as actual numbers go, it seems to be spread over a much larger range in Scotland ${ }^{1}$ than was the

1 Sir H. Maxwell informs me that he has reintroduced it in the south-west. 
case a few years ago, while in Ireland the reverse is taking place, and it is diminishing in range as well as in numbers.

In Northern Germany the jay is exceedingly common, and in the Rostocker Heide, in Mecklenburg-Schwerin, I frequently had opportunities in the spring of 1890 of witnessing the remarkable assemblies of courting birds, which are rarely to be seen nowadays in this country.

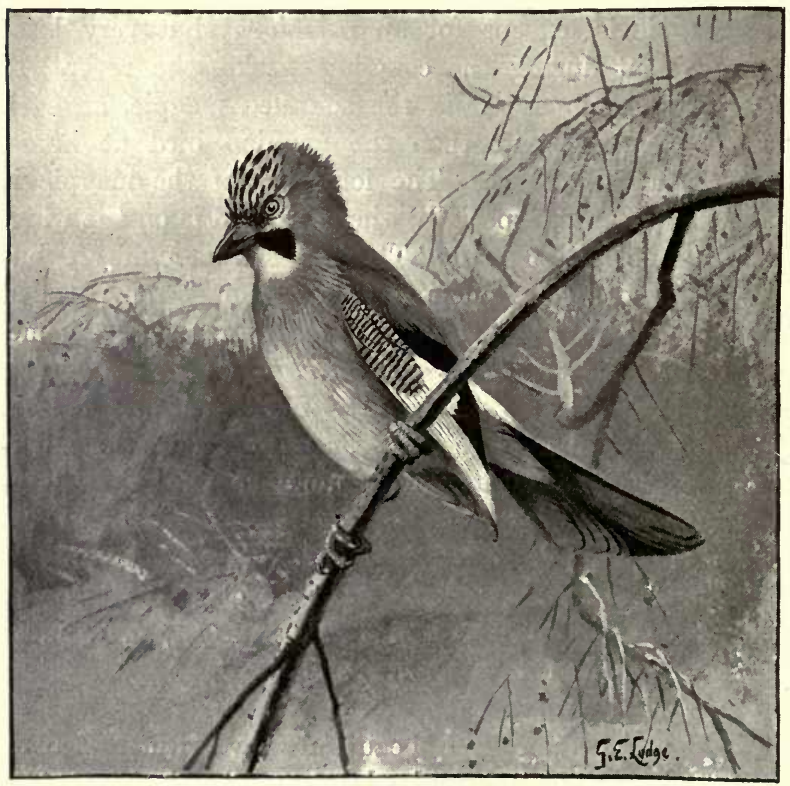

The birds would chase one another, almost oblivious of intrusion and with some of the abandonment noticed in the love-sick black grouse, hopping, too, unlike the rest of the group. There was also a sweeter note than is usually uttered by the bird-an effort, doubtless, of the suitor. During the actual breeding-season the jays were comparatively silent, being once more at their noisiest in July. The bird will, true to its scientific name, take 
acorns whenever they can be had in sufficient quantity and with little labour, but eggs are almost equally relished, and it will kill and eat young birds. The nest, of twigs lined with grass, is placed in the forks of trees from io to 20 feet from the ground, or even in bushes. I took several nests in Germany not 3 feet from the ground. Eggs, 4 to 6, $1 \frac{1}{6}$ inch; grey or greenish, speckled with black.

Recognised by the red of its legs and curved bill, as also by its remarkable antics and cries in the air, the Chough is not only not confined, as is some-

Chough. times alleged, to the duchy after which it is often called, but is even less common there than in many other parts of these islands. It is popularly supposed that the tourist has no sooner crossed the Brunel bridge west of Plymouth than he will see this handsome bird on every rock and tree. Nothing of the kind happens. I know something of Cornwall, both of its coast and its interior, and I have only seen four of these birds there in the course of my wanderings. On the other hand, it is not uncommon in parts of Devon, on Lundy Island, throughout the coast districts of Wales and the Scottish isles, the west coast of Ireland, and several places in the Channel Islands whence the pugnacious jackdaws have not expelled it. It breeds regularly on the Galloway coast. Indeed its own tribe are its worst enemies, for, being the only one of them not classed by the willing keeper under the head of vermin, it is little troubled by any one save the collector and his familiars. It is rarely found at any great distance from the coast, and it feeds chiefly on insects, less on grain. Its nest, placed in cavities and holes in the cliffs, is of twigs and heather lined with wool. Eggs, 3 to $5, \mathrm{I} / 2$ inch; greyish white, with brown spots.

[The single Alpine Chough, a species from Central Europe, in which the bill is yellow, taken in Oxfordshire in $\mathrm{r} 88 \mathrm{I}$, is commonly regarded as escaped from confinement.] 


\section{I9. The LaRKs.}

[Two residents (partially migratory); one regular, three irregular visitors.]

The Skylark, or "Laverock," is, though partially migratory in cold weather, a strictly resident bird. Different

skylark. races are recognised by ornithologists, but the amount of red in the speckled plumage seems the only mark of distinction. The white tail-feathers and the great length of the hind-claw distinguish it from the smaller woodlark, the only bird with which it is likely to be confused. Already widely distributed, it is even extending its range and increasing in numbers wherever its enemies the hawks are kept under. This lark is most familiar as, in spring, it soars up into the blue, voice vibrating, wings beating, tail stretched out like a fan, the bird ascending rapidly, not straight but obliquely. At last it is a mere speck; then, after a motionless pause, slowly descends the singer, with jerky progress, a last halt, and, with wings folded and voice stilled, down like an arrow into the long grass. Not straight into the nest either, but some little distance away, reaching its treasures by rapid running. It has been observed to perch; and it occasionally sings on the ground. It feeds on insects and seeds, and is said to do some damage among the clover and corn. The nest, a simple affair of grass lined with finer grass or hair, is placed on the ground, usually beneath some tuft in open fields. I have also found many on the sea-shore only a few yards above highwater mark. Eggs, 3 to 5 (second brood only 3), nearly I inch; dark brown or grey, with numerous spots and mottlings.

The smaller Woodlark is easily distinguished by the more conspicuous white stripe over the eye and the shorter tail. It is more local in its distribution than the last, being 
exceedingly rare in parts of Scotland and Ireland, and most numerous in the south of England. It perches more Woodlark. commonly, and its sweet song, little inferior to that of the last, is heard both from its perch and on the ground. The nest is a more elaborate establishment than that of the skylark, being usually made of twigs and bents lined with grasses and hair. It is found in similar situations. Eggs, 5, $\frac{4}{5}$ inch; greenish, with reddish and violet spots.

Crested Lark.-A rare straggler from the Continent, of which seven examples only are authenticated - two in Sussex, the rest in Cornwall.

Short-toed Lark. - A rare straggler from Southern Europe, of which about eight have been taken in the south of England and one in Ireland.

White-winged Lark.-A rare straggler from Asia, one example of which was taken many years ago near Brighton.

The Shore-lark is a spring and autumn visitor on migration to and from the North. It is distinguished by its \&Shore-lark. yellow throat, black crown and collar, and black crest, and is rarely seen away from the sea-shore, where it sings as it trips among the pools, looking for molluscs. It has not yet been noticed in Ireland.

\section{CHAPTER II. THE SWIFTS, WOODPECKERS, ETC.}

[In this, the next order after the Passerine birds, we have a somewhat motley group, their feet being the common point wherein most of them differ from the foregoing. In some we find all four toes directed forward, enabling 
the birds to cling to perpendicular surfaces; in others two toes point forward and two behind - thus we find some of these birds perching lengthwise. With the exception of the cuckoo (whose song is hallowed by association) they lack tune.]

\section{The Swifts.}

[One regular visitor; one irregular visitor; one rare straggler.]

Popularly associated with the swallow and martins, the Swift is in reality allied to the group under notice. Appar-

* Swift. ently larger, the swift, uniform black, save for the grey chin, is easily distinguished from these other birds, with which it hawks. Last to arrive, it is also

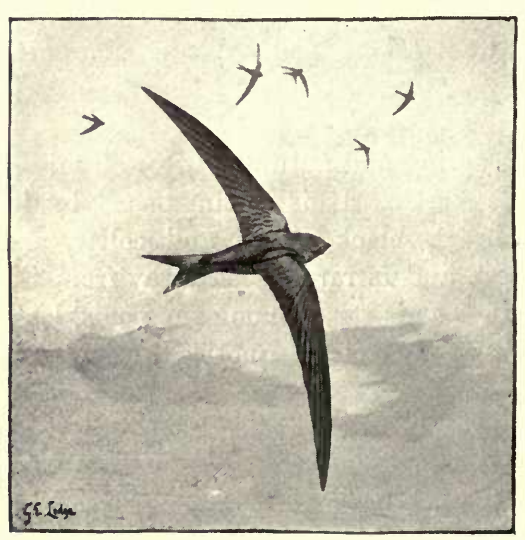

the first to leave us for its African winter quarters, and May and $\mathrm{Au}$ gust are the periods of its migrations. The shrill note of the swift as it dashes overhead is not easily mistaken for that of any other bird. It is not often seen to alight, though I have caught a few, a very few, in the act of dusting themselves in Kentish lanes, from which, in spite of the length of their wings, they can rise without quite so much difficulty as some chroniclers would have us imagine. The length of wing does not hamper them much in getting clear of the side of a cliff, to which, thanks to the distribution of their toes, they are able to cling firmly, even in a high 
wind. The food of the swift consists entirely of insects. The height at which it flies varies considerably : in company, they are observed to move at a great altitude, but when hunting alone the bird seems to prefer dashing along within a few feet of the earth. The nest, a loose, flat bed of grasses, is placed in any convenient hole in cliff or church tower, and, like those of the swallow and martins, is infested, as is the swift itself, with parasites. Eggs, 2, I inch; spotless white.

Alpine Swift. - A larger, white-bellied bird that has wandered on about four-and-twenty occasions from Southern Europe, thrice to Ireland, but not yet recorded from Scotland.

Needle-tailed Swift.-A very rare straggler from Siberia. It has occurred once in Essex and once in Hampshire.

\section{The Nightjars.}

[One regular visitor; two stragglers.]

A straggler only to Shetland and the Outer Hebrides, the Nightjar is from May to September widely distributed * Nightjar. over the rest of these islands. A bird of heaths and commons, it is, like the British cuckoo, a nestless bird; but it lays its eggs on the bare earth. The unfortunate creature is the victim of unfounded suspicions, in consequence of which it suffers the same persecution at the hands of the rustic as does its ally the morepork at the hands of the Australian stockowner. Most of its Australian cousins, by the way, build a nest, as do some Australian cuckoos. Its supposed offence is sucking the milk of goats and cows, hence the name goatsucker, which has descended on it from olden time. Most often seen on the wing or on the ground, it is nevertheless no very uncommon sight to see the bird perching on some old fence, and it does so, not as most birds, but lengthwise. The nightjar, not being abroad much before sundown, 
though not exclusively a bird of the half light, is among the least familiar of our summer visitors. During three years, in a part of Kent much affected by these birds, I met but one in broad daylight, and it seemed to be chasing small winged insects round a quantity of dead bracken. Indeed only on one other occasion have I ever seen the bird abroad by day, and that was in the Bournemouth Gardens, not a hundred yards from a busy street, about four o'clock on a September afternoon. A singular fact which I have noticed on many occasions is the frequency with which one comes across a single egg of this bird (the full clutch is two) in the ridings of small unfrequented

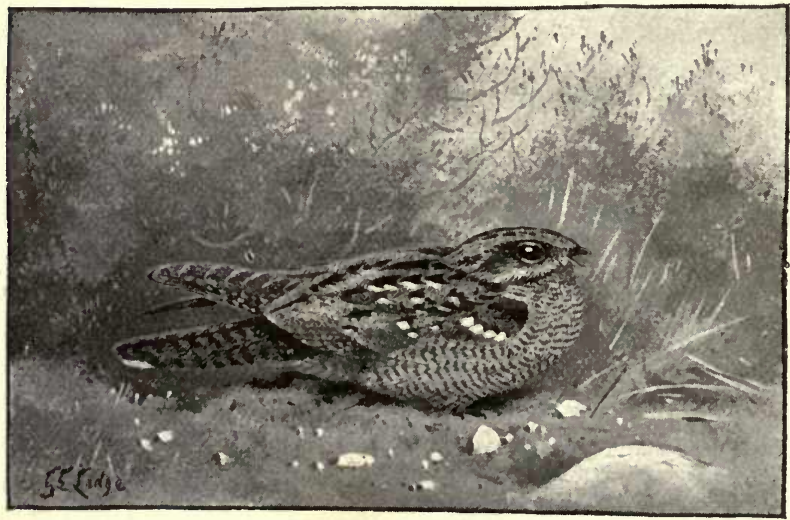

woods. Twice in 1886 , once in 1887 , and once again in the following year, I all but trod upon an egg in this manner not a hundred yards from the house near Dartford Heath in which I was then living, and in each case the egg was right in the path, its strong resemblance to the earth making recognition difficult until I was almost of moths. flying open-mouthed among the moths of the upon it. Eyewitnesses describe the bird as gloaming and catching the yellow underwings in its bristled gape. This may be so; but $I$ have 
watched many of these birds with great care, by no means a difficult business once the eye grows accustomed to the half light in which they conduct their operations, and, as their slow flight hid no movement from me, I could be certain the bill was closed. I certainly never witnessed the actual capture of a moth; so that, for all I know to the contrary, the bristles at the base of the bill may assist in delaying the moth for a moment until the bird swallows it. The note of the nightjar is a low vibrating "churr," and the bird has some slight power of ventriloquism. There is also a louder, harsher note that sets the hearer's teeth on edge. It seems hardly necessary to devote any space to the description of a bird that could not by any possibility be mistaken for any other; but the nightjar may always be recognised by the white spots on the reddish wings and tail, and the remarkable head. The bird has a jagged claw, the precise use of which, like the spur of the beaver and platypus, has not been satisfactorily determined. The food of this bird consists of insects, chiefly moths; and it is in the habit, like the owls, kingfishers, swifts, and cuckoo, of ejecting the hard and undigested portions in the form of pellets. As already said, the nightjar makes no nest, but lays its eggs in a slight depression in the earth, usually near a clump of fern or heather. Eggs, 2, I I/4 inch; yellowish white, with brown spots.

Red-necked Nightjar.-Has straggled once to Newcastle from Southern Europe.

Egyptian Nightjar.-Has straggled once from Africa to Notts.

\section{The Woodpeckers.}

[Three residents; one summer visitor.]

The Great Spotted Woodpecker, a rare bird nowadays, is but a winter visitor to the greater part of Scotland and to Ireland; indeed it is not known to breed in the latter 
country, and its breeding in Scotland is extremely uncertain. In this species the crown is black, the tail being

Great conspicuously marked with white. It feeds Spotted on insects, berries, and acorns ; and is wonderwood- fully armed, like the rest of its tribe, for huntpecker. ing the grubs out of their retreat in trees. They all have the low-keeled breast-bone, enabling them to hug the trunk closely; the stiff, pointed tail-feathers to support them, although the claws are already specially modified to that end; the powerful wedge-shaped bill for exploring; and, lastly, the wonderful extensile tongue, that works, as it were, on a powerful spring from the back of the skull, and that is further connected with a salivary gland and armed at the tip with recurved hooks. Of a truth the insects have but a poor chance against such odds, and the woodpecker is not likely to go short of a meal wherever there are trees. These remarkable features are common to all three woodpeckers, so that it will be unnecessary to allude to them again. This woodpecker usually hews the hole for its nest in some half-rotten trunk, but occasionally spares itself some of the labour by adapting to its requirements a hole already in existence. Unlike the marsh-tit, it rarely takes the trouble to remove the telltale chips from the foot of the tree. Eggs, 5 to 7, I inch; creamy white, without spots of any kind.

The Lesser Spotted Woodpecker is a much smaller species than the last, which it otherwise greatly resembles Lesser in both appearance and habits. Though by Spotted no means uncommon in the south of England, Wood- in the home counties more especially, and pecker. scarcely rare in the Midlands, it is rare in Scotland and a straggler to Ireland, there being at most half-a-dozen authenticated records of its occurrence in the latter country. It has the undulating flight of all the woodpeckers, and, like them, is to be seen by the experienced stalker who, guided by the tapping on the bark 
rather than by the low monotonous note, makes his way noiselessly to the foot of a neighbouring tree, whence he can watch the little black-and-white bird dodging round the trunk, over which it appears to glide, often with head downwards. It is then that a strong field-glass reveals to perfection the marvellous equipment of these birds alluded to above. Like the rest, it feeds on the larvæ of woodboring insects, as well as on the perfect insects themselves. Any one who has watched this bird clinging to a tree and the swift clinging to a cliff, will be at no loss to understand why the latter bird is no longer placed among the passerine birds next the swallows. The lesser woodpecker excavates a hole for its nest similar to that of the last species, but oftener near the ground; and I have taken the eggs not more than 3 feet from the root. Eggs, 5 to $7,3 / 4$ inch; creamy white.

The Green Woodpecker or "Yaffle," the largest and perhaps least shy of all, is common in most wooded Green districts south of Durham, very rare. in ScotWood- land and Ireland. It is most capricious in its pecker. movements, suddenly taking a violent fancy to a neighbourhood apparently unsuitable hitherto, as instances of which there was, not many years since, a great influx into West Cornwall and a still more recent immigration into Ireland, where, previous to the appearance of the last edition of $\mathrm{Mr}$ Saunders's admirable Manual, but two examples had been recorded. This bird, which is about a foot in length, is one of the handsomest of our feathered carpenters, the bright green-andyellow plumage, with the crimson crown and moustache (the latter black in the female), making its identification a simple matter. Like its smaller fellows, it feeds chiefly on wood-insects, but I have often come across it digging insects, presumably ants, out of the ground; and acorns are included among its makeshifts for insect food. 
Woodpeckers have often proved a nuisance to telegraphpoles, into which they peck, deceived by the humming of the wires into the belief that insects lurk within; and there is even an American species that uses these poles for its winter stores of nuts.

The nesting-hole, larger than those of the others and somewhat more perfectly circular, is made by the bird,

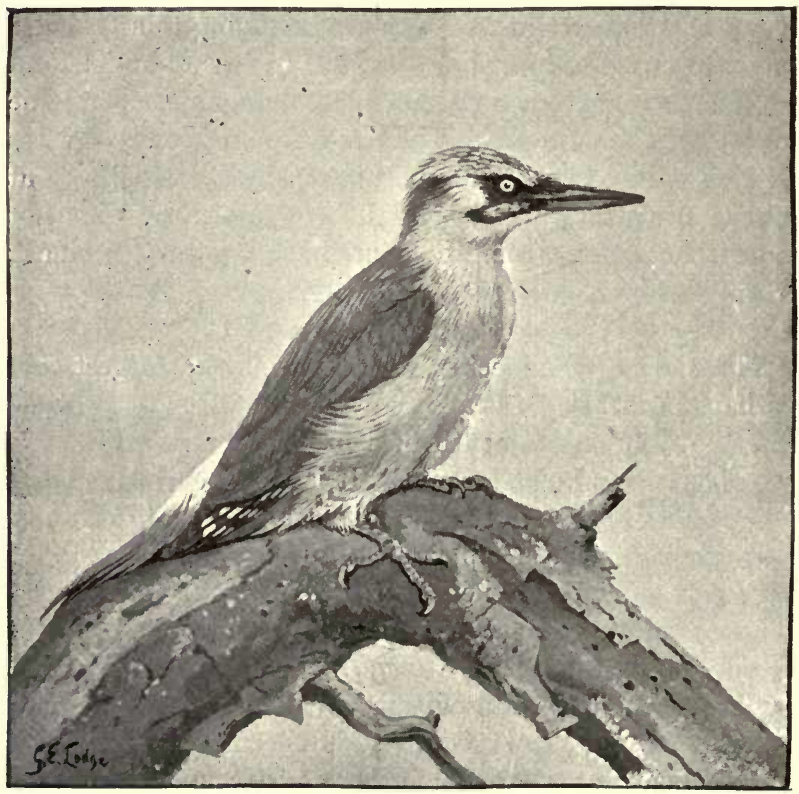

and, after running straight into the tree, turns abruptly downwards to a wider cavity, wherein the eggs repose on the sawdust and chips that have accumulated there. Eggs, 5 to $7, \mathrm{I} 1 / 3$ inch; creamy white.

[Several other woodpeckers-Americans for the most part-have been included in the British list, but all on unsatisfactory evidence.] 
Associated in some parts with the cuckoo, ${ }^{1}$ presumably because they come and go about the same season of the *Wryneck. year, the Wryneck is not uncommon in parts of Kent and Surrey, but is rare in the north and west, and but an occasional straggler to Scotland and Ireland. Its habits are not unlike those of the woodpeckers, only, being in some respects less perfectly equipped for tree-climbing, as, for instance, in the absence of stiff tail-feathers, it feeds more on the ground, its worm-like sticky tongue making short work of the ants. It also eats fallen berries at times when ants are scarce. I have also seen it feeding on trees, though never with head downwards. Both birds take part in incubating the eggs, and a loud hissing is at once set up if they are disturbed, so suggestive of snakes that the intruding hand is, as a rule, rapidly withdrawn by the tyro unaccustomed to the ways of this dweller in darkness. The wryneck is no true carpenter, for it makes the best of any hole deserted by woodpecker or tomtit or sand-martin. In appearance it differs from the woodpeckers in the erectile crest and in its curious habit of twisting its neck. It is also an adept at feigning death, a trick known to few of our birds. The glass reveals black bars on the tail and throat, and a black patch in the centre of the back. Eggs, 6 to Io, $\frac{4}{5}$ inch; pure white, with thin shell.

\section{The Kingfisher.}

The kingfisher, loveliest of British birds in plumage, one of the meanest of voice, and certainly one of the dirtiest in its dwelling-place, is to be found along most of our inland waters, where it gives plenty of occupation to those whose business it is to look after the young trout, on

1 The "impressionist" has strange flights of fancy. Quite recently a writer spoilt an otherwise excellent picture by pressing the comparison between the cuckoo and corncrake, because, forsooth, each has a double note! 
which, it were maudlin sentimentality to deny, the bird levies terrible toll. Even those who are bound to keep it under cannot but admire the great beauty of its plumage, the blue-and-green body, the white throat, and the reddish patch at the side of the head; but even admiration cannot, or should not, blind us to faults, and water-bailiffs have a perfect right in their masters' interests to shoot or trap the kingfisher. The only hope is that the gun may miss

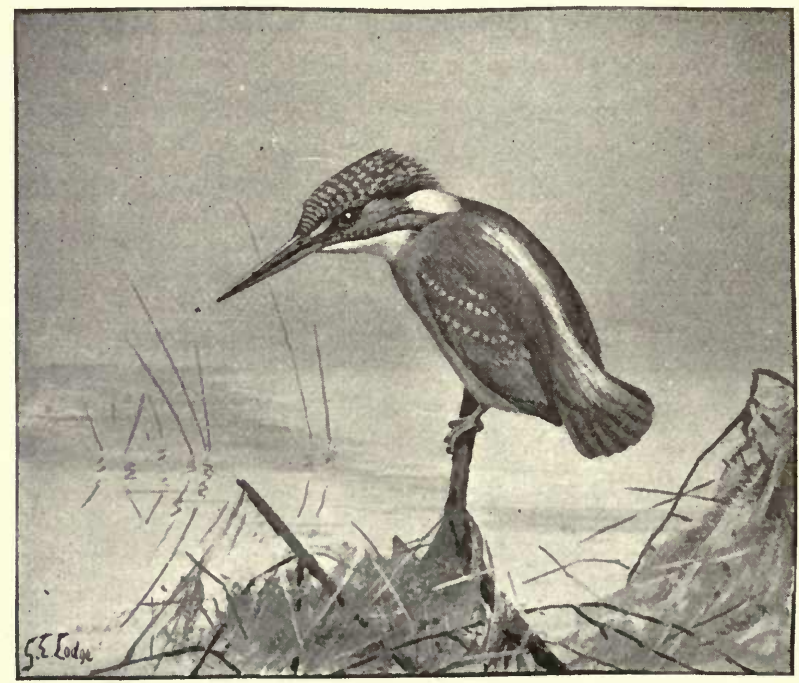

fire as often as possible, and that the traps may at least be humane and constructed with due regard to the fact that, whereas four-footed vermin are usually caught by the head or body and crushed outright, birds are as often as not caught by the leg, and may thus linger through hours of horrible pain. The trapper should also be at least merciful enough to do the round of his traps every few hours, so as to put his victims out of their pain as soon as possible. If writers in general would only have the goodness to regard 
keepers as a very intelligent and often high-minded class of men, instead of assuming them to be bloodthirsty ogres, their diatribes against cruelty to the children of nature might bear more fruit than it can be said to do at present. The keepers are in possession, that is certain ; and it is for the advocates of the furred and feathered delinquents to make of those in possession allies and not enemies.

To return to the kingfisher, the cause of this unpardonable digression. Fairly common, as already said, in this country, it is scarce in the north of Scotland, and, though resident in many counties, but a straggler to some parts of Ireland. It is, however, a bird of such rapid flight and such retiring habits, as to be comparatively unknown in many districts where it is in reality not scarce. The wings beat rapidly like those of the starling. Indeed, the dense foliage of the river-bank conceals it from our gaze during the warmer weather when we are most likely to pass near its haunts; and from the fact of the kingfisher being for this reason so much more in evidence during the winter months, they call it "Ice-bird." in Mecklenburg the "Ice-bird." It must not, however, be forgotten that it is by no means a hardy winter-bird, for numbers are found dead in the Thames valley every hard winter. A greater recluse, save perhaps the owls, does not exist among birds; and it is observed to beat its own particular stretch, where no other appears to intrude. It is, however, undeniable that, in spite of an occasional meal, for want of better, of water-insects and molluscs, small fish, preferably troutlets, form its principal food. The kingfisher also feeds on the foreshore near estuaries, and there is generally one throughout the summer perched of early mornings on the west works of the Arun estuary at Littlehampton. Its nest, which takes remarkable forms in poetry-books, is in reality no more than some hole, bored or borrowed, in the bank, or in some wall near the water. Here, at the end of an up-sloping tunnel some 
2 or 3 feet in length, its eggs are laid and its young reared on a dirty bed of fish-bones and excrement. The bird rears two broods, and it has been said, though I never found them so myself, that the second clutch is laid before the first brood of young are fledged. Eggs, 6 to 8, I inch; glossy white, and globular in shape.

[The Belted Kingfisher, a North-American bird, is said to have occurred twice in Ireland, but few authorities seem satisfied with the admission of this species to the British list.]

\section{The Roller.}

The Roller is a rare and irregular visitor to these islands. Its home is in Africa. It is a beautiful bird, the prevailing colours of its plumage being light and dark blue. [Two Abyssinian Rollers were said to have been obtained in Scotland many years ago, but their claim to rank as British birds is rejected.]

\section{6. § The BeE-Eater.}

The Bee-eater is but an occasional wanderer on migration to the British Islands, chiefly to the southern counties of England and Wales. Quite recently it was reported in the 'Field,' as far north as Caithness, in the month of May. I have taken its white eggs from holes in the hills round Florence. It is easily known by its long green tail with black tips, and the yellow throat with black cravat.

\section{7. *The Hoopoe.}

The Hoopoe, a remarkable-looking bird, with reddish, black-tipped crest and conspicuous white bars on the wings and tail, breeds sparingly where it is not immediately shot on its arrival in our southern counties in spring. More often, alas! its beauty rouses the greed of the local pot- 
hunter; and the papers even reported, let it be hoped in error, that one of the last examples noted in this country was shot only last February (1897) by a Yorkshire parson, who might have been better employed in ministering to his flock. Besides the small numbers that arrive in the Channel counties in spring, there is often a larger influx in autumn. The bird is, however, only a rare straggler to Scotland and the north of Ireland. Its flight is graceful, as are also its stately movements on the ground, at least where I have seen it on the Continent. The nest, more offensive than even that of the kingfisher, is in some hollow tree, the hole being found, not made. The bird feeds entirely on insects, and is therefore quite harmless. Eggs, 4 to 7, I inch; pale green.

\section{The Cuckoo.}

The Cuckoo, that reaches us in spring, - the spring is only a make-believe until the familiar note has echoed through the woods, - is always on the move. In March you may see it among the grey hills of Morocco: northward it flies, however, for its remarkable breeding operations; and even when it has reached its goal in these islands, there is no time for building a nest like other fowl, but it must needs wander on from county to county, laying an egg, now here, now there, in the nests of smaller birds, the eggs of which bear in some cases a resemblance to its own. That this protective instinct does not, however,

Protective carry it very far, may be gathered from the colouring fact that the brown egg is commonly found of egg. reposing among the blue eggs of the hedgesparrow,-I have, at one time or another, seen over thirty eggs of the cuckoo in the nest of this bird,- - to which it can bear but the slightest resemblance. The egg has also been taken from the nests of the blackbird and swallow. Those who have no opportunity of making the comparison out of doors may see the approximate effect in the 
frontispiece to Dixon's 'Rural Bird Life.' I have often wondered-and I ask no credit for the originality of a fancy that must have struck hundreds of others-what on earth the cuckoo would have done if her egg had been large in proportion to herself. She would have built a nest, unquestionably, like some of her relatives in distant continents, for, not being by any means a fighting bird-you may see even the male driven out of the neighbourhood by a

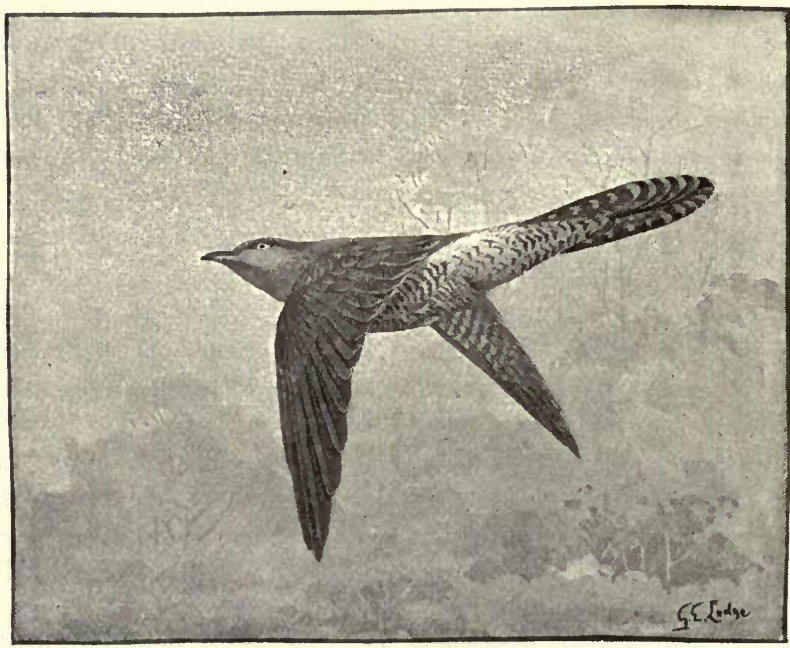

few small finches that mob him, probably under the impression that he is a hawk ${ }^{1}$ - she would never dare to intrude her unwelcome eggs and young on foster-parents strong enough to warn her off the premises. As it is, the young stowaway grows so rapidly that it is able in three or four days to edge the other young out of the nest and

1 The cuckoo bears, on the wing at any rate, a slight resemblance to a hawk, which is thought by some, added to the fact of its leaving these shores at the season when birds of prey are much in evidence, to account for the rustic notion that the cuckoo turns into a hawk in winter. 
monopolise the attention of their bereaved parents. It is aided in this nefarious murder, so strangely does nature sometimes work out her own ends, by a cavity between the shoulders; nor can there be any doubt as to the purpose for which this deformity was intended, since it disappears soon after the deed is done. Truly, "Nature is one with rapine"! The remarkable fascination exercised by the young interloper over its foster-parents is the subject of endless speculation. They need only leave the ungainly little brute to die of hunger, and the shrivelled corpses of their callow chicks that lie beneath would be avenged. But they tend the ogre with unflagging care, feeding it every hour, until, able to go out worming on its own account, it deserts them without a pang, and flies over the narrow sea to the fair Southern lands whither its parents journeyed many days since. A case was recently recorded in the 'Field' of a young cuckoo being found dead in the nest of a sedge-warbler, together with a chick of the latter species. The parent warblers had evidently deserted both. The note of the cuckoo has been the subject of considerable dis-

Voice. cussion; and even musical authorities have discoursed in erudite fashion on its minor third, and so forth. What is, however, worth noting is, that the male has, in addition to the more familiar and, to my mind at any rate, singularly wearisome note uttered both on the wing and from some hidden perch, a low hissing or grating noise, which I heard in the New Forest not more than three days previous to the time of writing. The orthodox note has also been strangely distorted by those whose fancy is to know nature better than she knows herself. In the first place, it surely requires a lively imagination to supply the consonants commonly supposed to have part in it; and again, it is scarcely correct to describe it as a bird of two notes, for I have more than once heard semitones in its cry, especially when, towards the days of its silence, it reiterates its cry as much as six times in close succession, often 
when fighting with another of its kind, for, like rnost cowards, it is pugnacious on occasion.

The food of the cuckoo consists almost entirely of insects, more especially in the caterpillar stage, hairy caterpillars

Food. being preferred. It is also stated on good authority to be fond of sucking the eggs of thrushes and similar birds, but I have never got any evidence of this at first hand.

Its habit of deputing to other birds the hatching of its eggs and the rearing of its young has already received mention. It only remains to add that the egg is first laid on the ground, and then carried in the bill to some suitable nest close by. I have seen it stated somewhere that the mouth of the female is provided with a membraneous pouch for the safer transport of the egg, but this would appear to be superfluous, as the egg is so small and the mouth so large. It is in these contrasts, as between the disproportionate egg of the cuckoo and those, equally disproportionate, of the apteryx and guillemot, that nature's forethought is ever apparent. About an inch or less in length, the egg is of varying pattern, and my own collection included a series ranging through many shades of grey and brown, always deeply spotted and mottled.

Much that is marvellous has been recorded of this bird, which I have, for reasons that are obvious, omitted. A Frenchman asserted that there was that in the bird's breast-bone that precluded the possibility of her incubating her eggs; but White proved the error, and more recently the cuckoo has been reported as sitting on her own eggs. A German declared that she possessed the secret of colouring each coming egg to match that of the intended foster-parent. This theory bears such a stamp of reality as to invite no criticism. After all, we may hear worse folly than that of the little girl who defined the cuckoo as a bird that does not lay its own egg !

Great Spotted Cuckoo.-A rare straggler from the South, 
that has occurred twice-once in Northumberland, once in Ireland.

Black-billed Cuckoo.-An American straggler, reported to have occurred once.

Yellow-billed Cuckoo.-An American bird that has been shot on five occasions on the western shores of these islands.

\section{CHAPTER III. THE OWLS.}

[The owls commonly admitted to the British list include three residents, two regular and six irregular visitors. They were formerly reckoned as a group among the birds of prey, but their distinctiveness is now generally recognised. Another ornithologist placed them next to the parrots. All are birds of the gloaming, remaining throughout the day in a half-sleepy condition, and being ill at ease in the glare of the sun. The female is always the larger of the two, though the difference is not great in the majority of cases. Their food consists entirely of small mammals, birds, and reptiles, and they ought therefore to be encouraged instead of, as is too commonly the case, persecuted by the keeper and farmer. Three residents; two regular, four irregular visitors, and one doubtful.]

The Barn-Owl, smallest of our resident owls, is common throughout these islands, except in the Orkneys and Barn. Shetlands, where it is rare. Its disappearance

Owl. from neighbourhoods where it once was plentiful is doubtless due to the short-sighted policy of persecution meted out to the unoffending bird by gamekeepers. As rats, shrews, and voles are among its favourite articles of food, a few of these voracious birds on an estate should be worth a ton of poison. Besides these, it devours bats 
and fish. There is more white about this little screecher than in most of our owls, and even the bill is almost white, in which it resembles only that of the tawny owl, easily distinguished by the absence of orange from its plumage and the thicker feathers on its feet.

Like all the owls, this bird perches with two toes on each side of the branch, and not, as in most birds, three before and one behind. This fact is not, however, invariably borne in mind by the taxidermist, who is frequently pleased to edit nature gratuitously. It is a remarkable fact that even in some recent manuals on birds the illustrations deliberately give the taxidermist's version in preference to the true one. The silent flight of the owls has been much written about and not a little exaggerated. Between flying more silently than other birds and making absolutely no noise whatever, there is a gap, though, to the casual rambler in the country, the flight of all birds is practically noiseless. This owl roams about our dwellings, and is especially common in parts of Kent. I well remember some fifteen or twenty years ago staying in a little cottage opposite the Walmer barracks, where these "screech-owls" would fly in of a night at the open windows. At first they earned a cheap reputation as ghosts, until one sultry night a sudden chance swoop with a fishing-rod brought one to book and set the matter at rest. The way in which gardener, farmer, and gamepreserver unite in persecuting this owl has been mentioned, and it is to be doubted whether they would achieve a far different result were they actually to breed and turn down rats and voles, of which this bird must annually destroy hundreds of bushels. What prompts the small birds of the neighbourhood to turn out in force and mob any belated owl who may not have regained the security of its dark retreat ere the sun is high, it would be difficult to say. The professional bird-catcher is at any rate content to use the blinking bird, dead or alive, as a decoy.

The nest of this owl, if nest it can be called, is in some 
hole in a tree or ruin. I have found it less than 3 feet from the ground. The eggs in a clutch number but two, but the clutches follow so closely where the bird is not subject to interruption, that it is not uncommon to find on the uncleanly bed of vomited pellets two or three clutches of eggs and a brace or two of young birds. Eggs, 2 to 6, laid in pairs, $I I / 2$ to $I 3 / 4$ inch ; round and white, and not very glossy. Owls' eggs are found almost throughout eight months of the year.

The larger Long-eared Owl is common, though rarely much in evidence, all over these islands. It is easily Long- distinguished by its prominent ear-tufts with eared Owl. dark centres, and the fawn-tinted feathers on its feet and toes. The food of this species is as that of the last, with perhaps more insects. It is one of the most silent of our owls, neither hooting nor shrieking with any regularity. This is the only owl that nests exclusively in the deserted nests of magpies and other birds, or in empty squirrel - dreys.

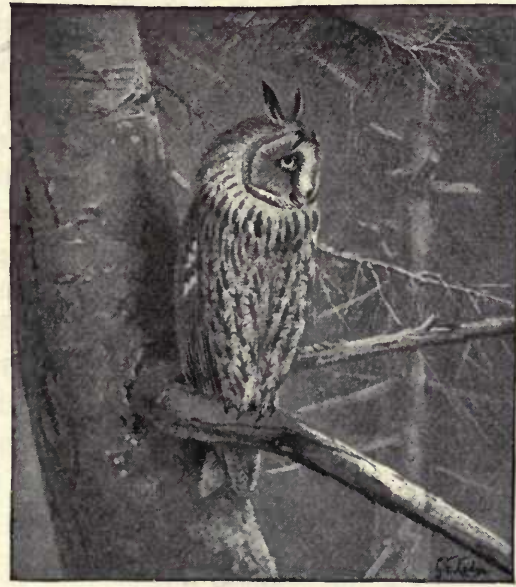

Sometimes the interior is relined, sometimes not; I have come across instances of both. Eggs, almost identical in size and whiteness with those of the last, like which, too, they are found during the greater part of the year.

The Short-eared, or "Woodcock," Owl is for the most 
part, and at any rate to the southern counties, a winter visitor. A comparatively few pairs breed in the Fen + Short- Country, and a few more farther north, especieared Owl. ally in Scotland, where there is a supply of voles. The ear-tufts in this species measure only half those of the last, being less than $3 / 4$ inch. Often seen abroad by day, the bird, which, as already indicated, breeds with us only in the fens or on the moors, lays her eggs in a clump of sedge or heather on or near the ground. Eggs, 4 to 6, I I/2 inch; creamy white, and smoother than those of most owls.

Resident over the major part of Great Britain, the Tawny Owl is extending its range northward, but has

Tawny not yet been recorded from Ireland. Its toes

Owl. are feathered to the claws, the tail, white at the tip, is barred with brown, and there are white spots on the wings. The bird has no ear-tufts like the last. There are two phases, a red and a grey, the latter being the more common in our southern counties. This is the hooting owl of our woodlands, and Wordsworth's famous line about the wandering voice never seen (though scarcely, perhaps, "longed for"!) would apply to it with greater force than to the cuckoo, in honour of which it was penned, for few birds shun intrusion or hate the light of day more than this owl. Though no offender in the ordinary course, an instance is quoted by Mr Witherby (in 'Knowledge,' June 1897) in which one of these birds killed a full-grown rabbit. It nests, as a rule, in hollow trees; but occasionally its eggs are found in the deserted nests of crows and other birds, in squirrels' dreys, or even in rabbit-burrows. Eggs, 4, I $\frac{4}{5}$ inch; white, round and smooth.

Tengmalm's Owl.-A very rare winter visitor from the North. Has occurred sixteen times in England and twice in Scotland.

[Little Owl has occurred in most English counties, and has bred in some, but has not yet been recorded from 
either Scotland or Ireland. As so many are yearly brought over from the Continent, many being turned loose, it is unusual to treat it seriously as a British bird. The late Lord Lilford established it in Northamptonshire.]

The large and handsome Snowy Owl, which comes from the North, is a regular winter visitor to the north of Scot-

+ Snowy land, though of its visits to England less than Owl. a score have been reported, and to Ireland eight only. The plumage is white, with black spots. This owl is not perhaps a very welcome visitor to the gamepreserve, though even there its choice will fall most readily on the sick or wounded birds. It also fishes, much after the fashion of the osprey.

Hawk-Owl.-A rare straggler, of which there are two recognised forms-the American, which has occurred some half-dozen times, mostly in Scotland. The other, or European, form has been recorded (by Dr Sharpe) but once.

Scops Owl.-A rare straggler from the South, which has been recorded many times in England, once in Scotland, and five times in Ireland.

Eagle-Owl.-A handsome eared owl from the Continent that visits the Orkneys and Shetlands, where it once probably bred at long intervals, but rarely occurs farther south, never in Ireland.

\section{CHAPTER IV. THE BIRDS OF PREY.}

[The group under notice embraces birds of very various habits and appearance, some being pronounced carrioneaters, others, the smaller more usually, disdaining all food that they have not killed themselves. As in the owls, the 
female is the larger bird. The enmity of keepers bids fair to remove the greater number from the British list. They all have the distinguishing "cere," a membrane over the nostrils and upper mandible. Eleven residents (mostly rare); five regular, eleven irregular, visitors.]

Griffon Vulture.-One only has occurred-in Ireland.

Egyptian Vulture has been obtained twice only-in Essex and Somerset.

Though to all intents and purposes an indigenous bird, the Marsh-harrier is so rare nowadays as to call for passMarsh- ing mention only. It is thought that a few harrier. breed in undisturbed parts of Norfolk, but this seems to require confirmation. It still straggles to Scotland, but is no longer to be found breeding freely in Ireland, as it did comparatively recently, though it may still do so in one or two counties. According to $\mathrm{Mr}$ Saunders, it uses the nest of the coot.

Distinguished by its grey-and-white plumage, and now known to breed only in comparatively few districts in

Hen- Great Britain (chiefly in the Scottish isles and

harrier. Highlands) and Ireland, the Hen-harrier is the enemy of the game-preserver rather than the farmer, its food consisting of small mammals and birds, for which it quarters the open moors like its congeners. The nest, placed among the heather, is on or near the ground, and is composed of twigs and grass. Eggs, 4 to 6, 13/4 inch ; bluish white, rarely spotted. Like most British birds of prey, the bird lays early in May.

Also far less common than formerly, Montagu's Harrier is still known to breed sparingly in the Channel counties, * Montagu's still more rarely as far north as Yorkshire. Harrier. To Scotland, save in the extreme south, it is a very rare straggler, as also to Ireland. It is far less destructive than most birds of prey, for its food consists 
largely of reptiles and large insects, as grasshoppers. It is also known to devour the eggs of wild birds. A smaller and darker bird than the last, it has the wings proportionately longer, the tail being also barred. The nest is on the ground among the heather or sedges. Eggs, somewhat smaller and paler than those of the last.

Rarer every year, the large and handsome Buzzard still breeds in a few western districts of Great Britain and Ireland. The district of the Broads was once Buzzard. its favourite haunt in these islands, but it has been sacrificed to the preservation of game. As, however, it is by no means one of the most active, and as it is certainly among the least courageous, of our raptorial birds, there is some reason to doubt whether it does much damage among the pheasants. This buzzard is of large size, some examples being dark, others much lighter, all having bars on the tail. Nests of this bird are found in lofty trees or cliffs, and consist of twigs and leaves. They are very bulky. Eggs, 3 or $4,2 \mathrm{~T} / 4$ inches ; dull white, with reddish spots and blotches. Both sexes incubate.

The Rough-legged Buzzard, in which the legs are feathered to the toe, occurs every winter, its visits being †Rough- measured by the number shot, for it is of legged those visitors never recorded as observed. Buzzard. Quite recently (March 1897) one was shot in Yorkshire by one of Lord Feversham's keepers. Not more than half-a-dozen have been recorded from Ireland, and the various reports that have at one time or other been credited are disposed of by Mr Saunders and others as impositions.

Spotted Eagle.-A rare straggler from Southern Europe, four examples of which have occurred in England and two in Ireland. The smaller Continental form is not known to visit these islands. 
The Golden Eagle is perhaps the only one of our birds of prey of which it can be said that protection, tardy Golden yet not too late, is causing it to extend its Eagle. breeding-range in the Scottish Highlands and isles, where it is known as the "Black Eagle." It is almost certain that this splendid bird, the largest of our eagles, is more numerous to-day in parts of North Britain than it was ten years ago; and this is the work of the

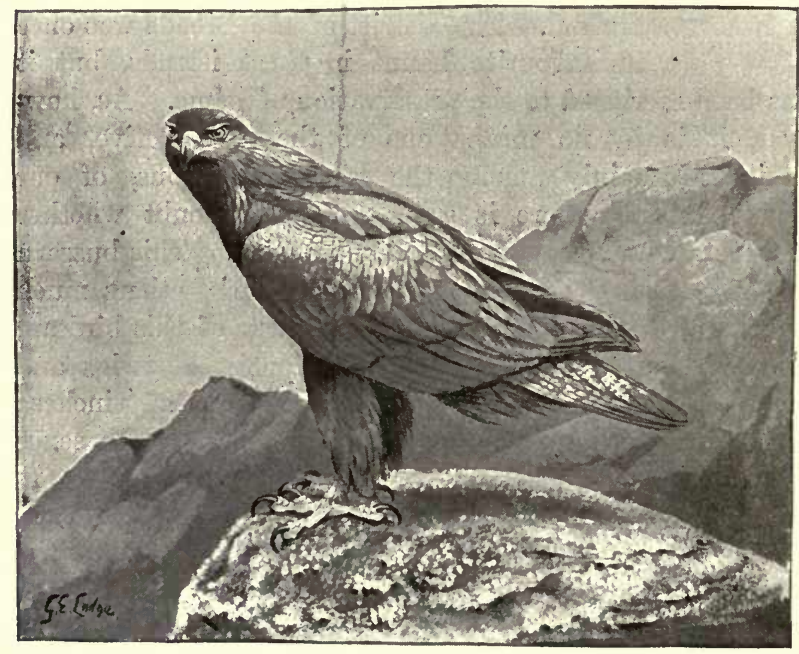

landowner. It also breeds in a few isolated localities in Ireland. The bird feeds on mountain-hares and grouse; but it also snatches an occasional lamb from the fold, and will even eat carrion. The legs are thickly feathered to the toes. Examples have been shot of a length of 3 feet. The nest, in some high tree or inaccessible rock, is a large platform of sticks with some softer lining. To this the bird adds every year, so that, as do those of the raven, old nests grow to unwieldy dimensions. Eggs, 2 or 3, nearly 3 inches; greyish, with red spots. 
The White-tailed Eagle, distinguished by the absence of feathers from the lower half of the leg, and by the White- broad scales on the toes, is commonly (imtailed mature visitors to the South more particuEagle. larly) reported as the Golden Eagle. It is also known as the "erne," and breeds nowadays only on the more northerly coasts of Scotland, among the Shetlands, and here and there on the wild west coast of Ireland. The bird feeds on fish and any carrion. Its nest, sometimes found inland, is like that of the last, as are also the eggs, though rather smaller, and without spots.

Goshawk.-A rare straggler nowadays that has not bred in these islands since the beginning of the century. It may be recognised by the short wings and the white line over the eye.

American Goshawk.-A closely allied species, said to have occurred once in Scotland and twice in Ireland, but whether it arrived unaided as a genuine visitor seems uncertain.

The small Sparrow-Hawk is fairly common in all wooded districts, and recognised by its short wings, the sparrow- dark reddish bars on the breast, and the great Hawk. length of the legs. Though the smaller wild birds and mammals form its principal food, there is no doubt but the sparrow-hawk can, especially when there are young to feed, be a great trouble in the farmyard, and also among partridges. It feeds on the ground, and one may often come upon small heaps of blood-stained feathers in the clearings of woods, showing plainly where the bird has had a recent meal. The female is much larger than the male, and Mr J. Steele-Elliott ${ }^{1}$ points out that this is the origin of the common error of regarding them as birds of different species. As a rule, the sparrow-hawk builds a large nest of sticks and twigs, which is placed near the top of high trees; but it is also known to adapt

1 The Vertebrate Fauna of Bedfordshire, p. 11. 
to its requirements the deserted nests of crows and other birds. Eggs, 4, 5, or 6, $\mathbf{1}_{5}^{3}$ inch; pale blue, with red blotches.

The Kite is very rare nowadays, and only known to breed in a few spots in Wales and Scotland, the precise

Kite. locality of which those who are in the secret wisely conceal. In Ireland it is still rarer. Its long forked tail and exceedingly graceful gliding flight distinguish it from others of its size. Its destructiveness is probably on a par with that of the last, the damage being confined for the most part to the time when there are young in the nest. The nest, found in lofty trees, is not unlike that of the last, but a considerable quantity of rags and other rubbish is usually found in its lining. Eggs, 3, $2 \frac{1}{4}$ inches; bluish white, with red spots and blotches.

Black Kite.-A rare straggler from the South, which has been recorded once only-in Northumberland.

Swallow-tailed Kite.-An American bird, said to have visited these islands (Harting) on five occasions. $\mathrm{Mr}$ Saunders, however, discredits all but one, and regards even that as a bird escaped from confinement.

It is doubtful whether the Honey-buzzard, known by the three dark bars on the tail and the white, brown${ }^{*}$ Honey- spotted breast, breeds any longer in these buzzard. inhospitable islands, where collectors are as thick as thieves. It visits us, however, every May, and it is possible that a few, a very few, remain to nest under the protection of those for whom the high prices offered have no charm. Let us hope so. To Ireland it finds its way but rarely, though it has been recorded from there on several occasions of late years. Wild bees and honey are the staple food of this inoffensive bird during the warm weather, after which it eats small mammals, reptiles, birds, and even worms. Colonel Butler recently reported one in the 'Field,' which was shot in Suffolk as late as July 1, 
1897. Eggs, 2, 3, or 4, 2 inches; cream, with brown blotches.

Gyr Falcon, Iceland Falcon, and Greenland Falcon, three closely allied species, rare stragglers from northern regions.

The Peregrine, boldest and perhaps handsomest of our smaller birds of prey, is the species chiefly used in the Peregrine sport of falconry; and those who have seen Falcon. it lift a rabbit or a partridge in its dashing course are not likely to forget the suddenness of the action.

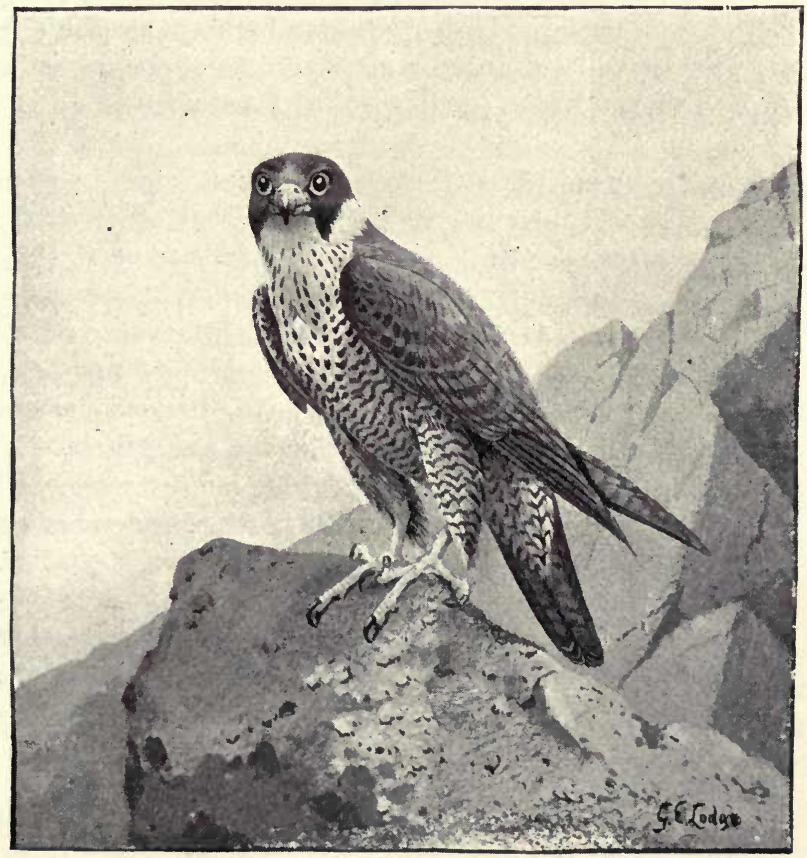

By no means very superior in size to the kestrel and sparrow-hawk, though a somewhat heavier bird, it does not hesitate to attack them, and invariably comes off victor ; 
indeed it is said to eat the vanquished now and again. The resident peregrines of these islands are temporarily augmented by immature birds on autumn migration. The peregrine still breeds in the cliffs of our south and southwest coasts, and in the North, though many reported cases are partly apocryphal. The bird is easily distinguished from others of the same size by the conspicuous blackness of the head, as well as by the black line on either side the throat; and its "kek, kek," is a somewhat more distinctive cry than that of most of its kind. It nests on the ground among the cliffs, or in the deserted nest of a crow or other large bird. It never builds a nest in any case, but it will return year after year to a suitable site. $E g g s, 2$ to 4, 2 inches; yellowish, with red spots.

The Hobby is with us, though in no great numbers, from May to October, breeding in Hampshire and other south-. ern counties, not, however, farther north than

* Hobby. Yorkshire. It has been taken in almost every part of Scotland, to which country it can, however, be regarded as only a straggler; while from Ireland not more than eight examples have been recorded. Its food consists for the most part of large insects, also of small birds. In many respects, as, for example, the long pointed wings and the black head and throat-stripe, it bears considerable resemblance to its larger ally the peregrine. Like the latter, too, it breeds in the nests of other birds; and a curious habit has been noticed in the female bird-namely, that of brooding, before her own eggs are laid, on those of the kestrel, a freak which has given rise to some curious mistakes. Eggs, 3, 4, or 5, over $1 \frac{1}{2}$ inch; yellowish, speckled with red.

$\S$ Red-footed Falcon.-Practically an annual spring and autumn visitor, though never in numbers. It comes chiefly to the southern counties of England, though in Yorkshire, where it was first added to the British list, ${ }^{1}$ as many as a

1 Clarke and Roebuck, Vertebrate Fauna of Yorkshire, p. 47. 
dozen have been recorded. In Scotland, it has been obtained but three times; in Ireland, but once.

The Merlin is our smallest falcon. Its tail has a broad black band just above the white tip; and it breeds in the Merlin. northern moors of England, as well as in the Merlin. higher districts of Scotland and Ireland. In winter, it may be seen at the coast chasing the smaller waders; but during the breeding season it is noticed, as a rule, perched motionless on some rocky boulder. It is not a rapid flier, so that there may possibly be some foundation for the charge, often preferred against it, of robbing nests of the newly hatched young. Eggs (laid in a depression in the earth), 4 to $6,1 \mathrm{x} / 2$ inch; deep red. The bird has been known, though rarely, to lay in deserted nests.

The Kestrel, distinguished from the smaller merlin by the reddish hue of the back, which is covered with Kestrel or black spots, is our commonest bird of prey, "Wind- and its peculiar motionless hovering is as well hover." known on the country-side as is the far-reaching, not unpleasing, cry. Its food consists almost entirely of mice, so that its persecution is wanton folly. It lays its eggs in old nests of crows or other like birds, or occasionally on the bare earth. Eggs, 4 to 6, 1 $\frac{3}{5}$ inch; yellowish, with deep red spots and blotches.

Lesser Kestrel. - A straggler from Southern Europe, which has been recorded but three times-in York, in Kent, and near Dublin.

The Osprey is practically a winter visitor to the greater portion of these islands, though it still breeds in a few Highland lochs. In the winter months it tOsprey. occurs almost annually on the Broads and other inland waters; and it has been recorded recently hawking over the joint estuary of the Hampshire Stour and Avon, below Christchurch. The breast is white, with a brown band. It feeds almost entirely on mullet, salmon, 
and trout, upon which it pounces with great dash, bearing its victim off lengthwise in its long pointed claws, which are admirably adapted for the purpose. Its nest is an

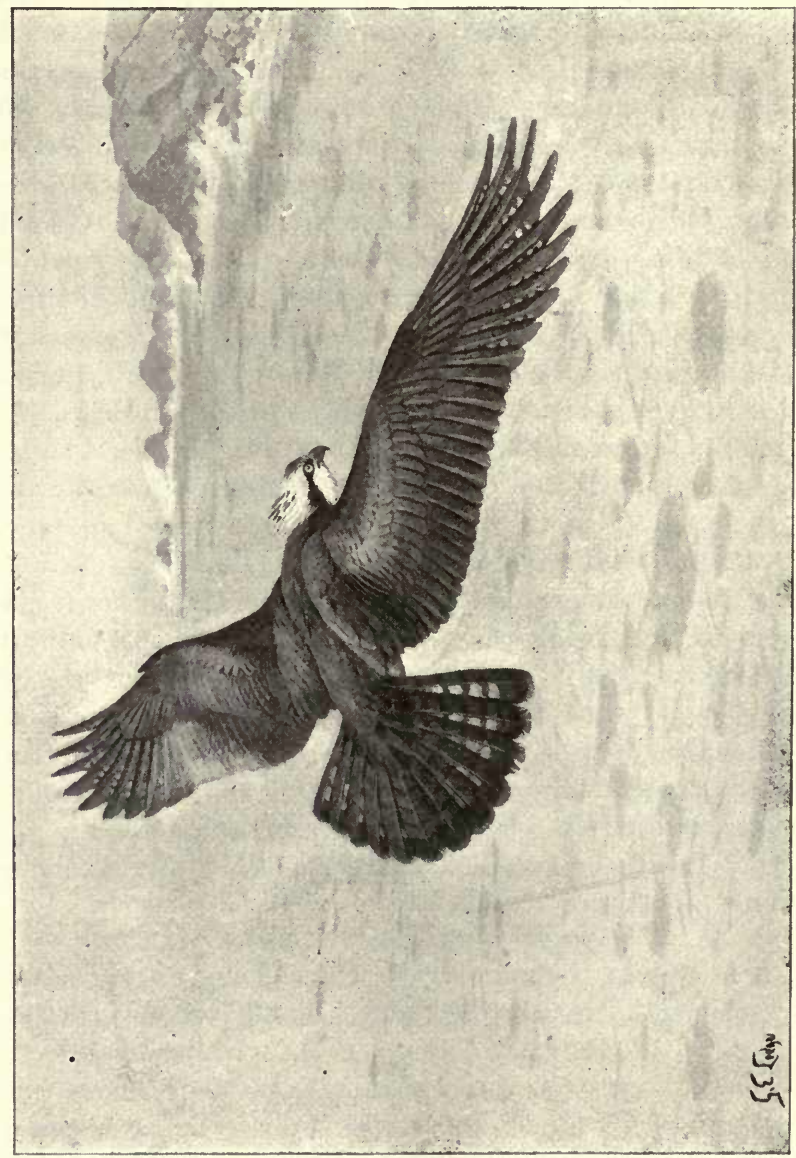

enormous structure of twigs and sticks, with a soft-lined receptacle for the eggs. Eggs, 2 or 3,2 I $/ 2$ inches; white, with deep red blotches. 


\section{CHAPTER V. THE CORMORANT, SHAG, AND GANNET.}

[These three birds, British allies of the pelican, are of great interest on the coast, where their fishing operations, the diving of the first two, and the wonderful oblique plunge of the last, can be watched wherever there are high cliffs overlooking the shallow bays where they seek their favourite food. Though pleasing on the wing, however, they are all grotesque on land, for, the feet lying far back, they walk with difficulty, and their movements are devoid of grace.]

The Cormorant, or "Diver," is a common bird at most Channel ports, where it is seen either flying rapidly over the water, neck and legs stretched out fore and aft, or Cormorant. else perched on some rock, its burnished wings spread to dry in the sun. From its smaller relative the shag it is distinguished by the white feathers on the neck, a large white patch on the thigh, and some yellow skin at the throat. As in the rest of the order, the nostrils are covered by a membrane. The bill is sharply hooked on the lower mandible, the value of which may be seen where, as at Regent's Park, the bird is fed in captivity. In many countries, and by a few amateurs in these islands, ainong them Mr Salvin, the cormorant has been successfully trained to catch fish, which it is prevented from swallowing by a tightly fitting collar. This practice comes from the East. When seen flying rapidly over the water, the cormorant is usually bound for some fixed destination. For several years now there has been a single old male cormorant in Bournemouth Bay, and I have watched it from my boat, when about three miles from shore, day after day and at all seasons, fly every hour or so from Swanage across to Hengistbury Head and back. It is always alone, so I should be inclined to put it down as an old bachelor, as it is well known that a 
number of these birds remain solitary during the breeding season. ${ }^{1}$ When fishing, the cormorant is seen paddling quietly about some sheltered bay, often under the shadow of a pier, well knowing that the small fry congregate in such shelter, and every now and then suddenly diving

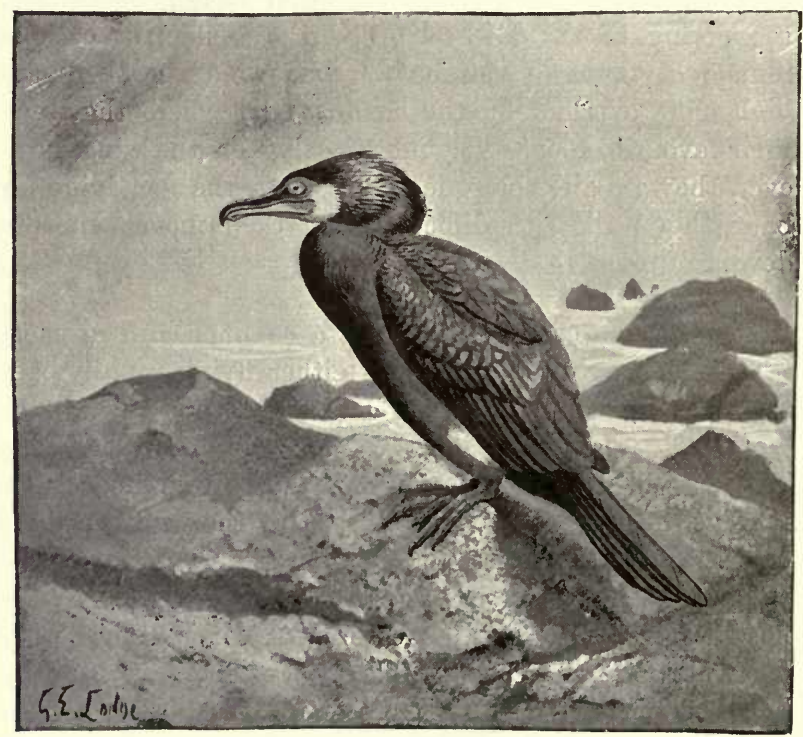

head first and swimming some distance under water. It roosts in the ledges of the cliffs. The large nest is of sticks and seaweed; but it also nests inland, particularly in Ireland. Eggs (laid in May), 3, 23/4 inches; pale blue, incrusted with a chalky coating.

The Shag is a green bird, smaller than the last, but often, though quite unnecessarily, confused with it. In addition

1 A parallel case of a single old cormorant is to be found at Littlehampton, where a fine malo has haunted the west works for some years. 
to the points of distinction already enumerated, we may note the presence of yellow spots on the gape. Like the Shag. last, this is a denizen chiefly of rocky coasts, and it is more numerous on the wilder cliffs of western Scotland and Ireland. In the former it is known as the "scart." In diving after fish it first lifts itself clear of the water, making more of a splash than the cormorant. The nest, seldom at any distance from the coast, is not unlike that of the cormorant, but much more dirty. $E g g s, 3$ to 5, under 21/2 inches; otherwise similar to those of the last.

The Gannet, or "Solan Goose," is a beautiful white bird of large size and striking appearance, which breeds only

Gannet. on the Bass Rock, on Lundy Island, on an island off Pembrokeshire, on Ailsa Craig, at three spots in the Scottish isles, and in the south-west of Ireland at two stations. - The bird is entirely white, except some conspicuous black feathers on the long pointed wings. The tip of the lower mandible lacks the strong hook noticed in the cormorant and shag, though there is a slight depression. There was a fine gannet in the Brighton Aquarium this August (1897), but it looked to me strangely out of condition. The spectacle of a number of gannets fishing in some Cornish bay is one not easily forgotten. On the hottest days, the shoals of smaller pilchards will wander right inshore; and at such times these magnificent "geese" will sail overhead, and, each one soaring to a great height, will fall headlong, wings folded, on the fishes, harried from below by pollack and other scaly allies of the greedy birds above. For greedy the gannet undoubtedly is. I have watched half-a-dozen of them fish in this way for over an hour, killing fish at every plunge, and even then they were on the look out for more. Sometimes they dash obliquely on the fish from a low elevation. A very wonderful provision is observed on examining the bill of this bird, for, as in the 
cormorant, the nostrils are found to lie beneath the membrane, or, roughly speaking, the gannet has no nos-

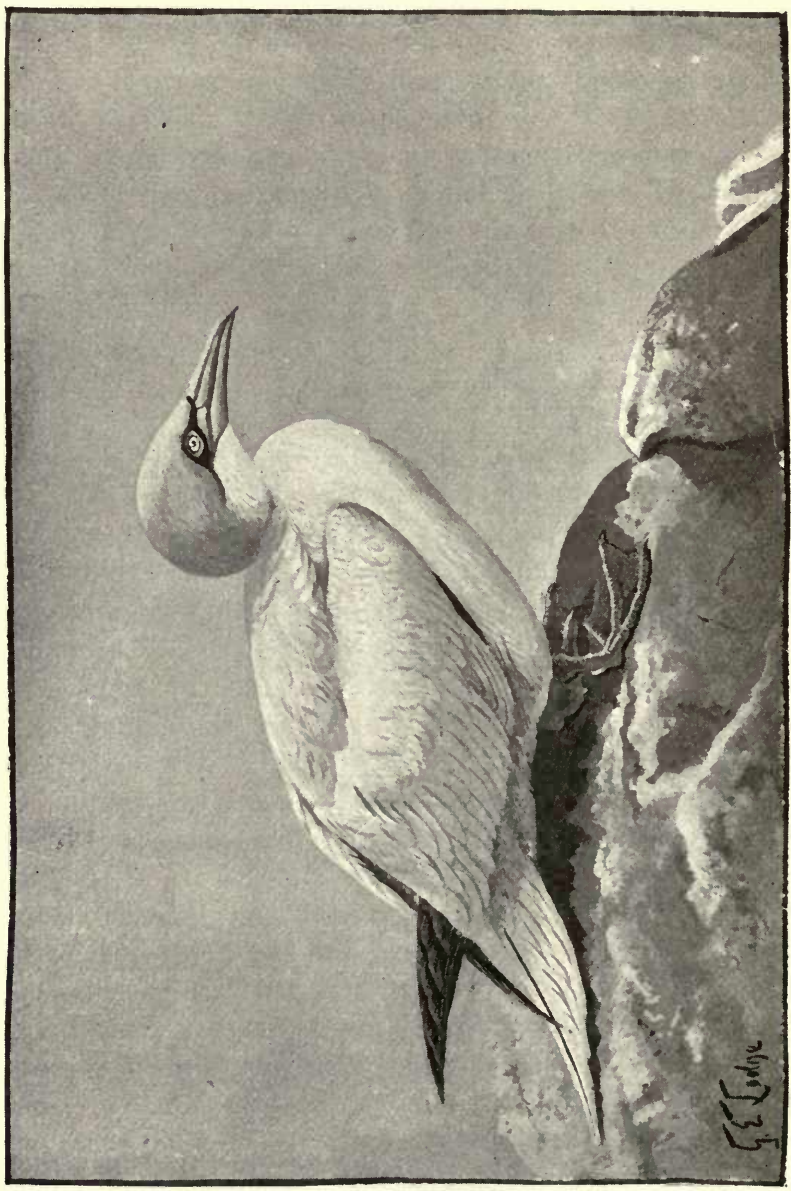

trils, which must comfort it considerably in its high diving. Booth, ${ }^{1}$ who gives a most interesting series of plates of the 1 Rough Notes, vol. iii. 
gannet in various stages of plumage, expresses the doubt of this bird being able to rise from flat ground unless assisted by a high wind. I have also noticed something of the kind; but I came upon three of these birds, or rather of the closely allied Australian species, feeding one still evening in Middle Harbour, Port Jackson, and flying with ease from one flat "beach" to another. Like all waterfowl, the gannets and cormorants cannot rise from the water except head to wind. The nest is of grass and seaweed. Egg, I, 3\%/4 inches; bluish, with a whitish coating of chalky matter, which soon soils.

CHAPTER VI. THE HERONS, BITTERNS, AND STORKS.

[The characters of the present order are long bill, neck, and legs, and the curious comb-like edge of the middle toe. The herons have twelve feathers, the bitterns only ten. All of these birds feed on fish, also on small mammals, reptiles, and even crustaceans, molluscs, and insects. They are for the most part but rare stragglers to these islands, though the bittern has only become so of late years, thanks to the reclaiming of marshland, as it bred and "boomed" among the fens and broads up to within a quarter of a century ago. One resident; thirteen irregular visitors.]

\section{Herons.}

Though the water-bailiff and collector are doing their best to thin the ranks of the grand and stately Heron, it

Heron. is still, especially far from the haunts of man, a familiar figure to fellow-anglers; and it requires no more than ordinary caution to watch the 
BIRDS.

ragged-looking sentinel gazing down unmoved at his own reflection in the shallows, more often on some ditch or tributary than beside the larger rivers. The least false step is, however, enough to break the spell,-down comes the other leg with a snap, and in a trice the graceful form

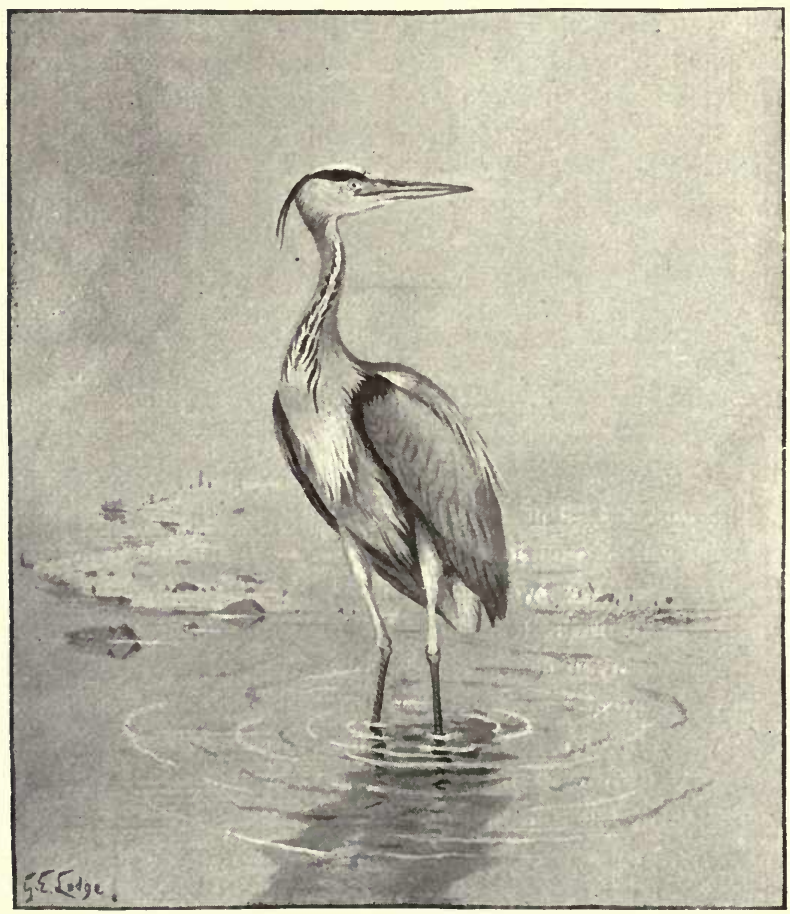

is cleaving the air under the slow and regular beat of long wings, the legs stretched rudder-like behind, the neck in a fold between the shoulders, and the black-crested head held well back after the fashion of a deadly snake about to strike. It is a curious fact, and one which I have noticed all the world over, that those birds which cus- 
tomarily rest on one leg, with the other tucked away in the line of the body, cannot to all appearance take wing without first putting the other foot to the ground. The food of the heron is by no means confined to fish, but includes a variety of small mammals, as moles and water-voles, young birds-especially those of the moorhen-frogs, lizards, and various shell-fish and insects. I know a spot in west Hampshire whither to this day one or more herons will resort of a July evening to sup off young moorhens. As it is not improbable-though the verdict so far is "not proven"-that the moorhen is at times a greedy consumer of trout-ova, it may be conceded in all charity that the heron thus atones in part for his misdemeanours.

I never to my knowledge witnessed a heron on the water, though there is no reason why it should not swim after a fashion, as recorded by some observers from time to time. Herons, although often solitary when on the prowl, are sociable during the breeding-time, which is very early in the year; and they nest in colonies, known as heronries, which are nowadays more or less protected, if only through the fact that their love of seclusion leads them to select spots near private waters. Thus laws framed with a very different object have operated most beneficially for these birds. There are few large heronries in either Scotland ${ }^{1}$ or Ireland, but the number in England is very considerable, some, as the small colony in Richmond Park near the Penn pond, quite near the metropolis; and it is doubtless from these that those occasional herons hail whose bright white figures, sailing high over the chimney-stacks, cause the citizens to stare upward open-mouthed and the evening papers to publish accounts of so unwonted an apparition. Yet, considering the number of colonies within a very few miles of the city boundaries, it is more than probable that a very large number pass unrecorded over the greater colony

1 Muirhead (Birds of Berwickshire, ii. 43) enumerates eight in Berwickshire. 
beneath, the members of which are, as a rule, far too busy with the affairs of earth to trouble about what is transpiring up above. During a high wind, herons may be seen grasping the swaying boughs with their bills in most grotesque attitudes. The nest, often used and enlarged year after year, is at first a mere platform of sticks with some kind of grassy lining, and is placed in the top of high trees. Eggs, 3 to 5, 21/2 inches; pale green.

Purple Heron.-A rare straggler to the east coast, of which only two or three have been obtained in Scotland. and but one in Ireland.

Great White Heron. - A very rare straggler from the South, less than ten having been taken in Great Britain and none in Ireland.

Little Egret.-A still rarer wanderer from the South. Almost all of the supposed occurrences are rejected by Mr Saunders and others.

Buff-backed Heron.-One example only exists, and it was taken in Devon. It is a southern bird.

Squacco Heron.-An occasional straggler from the South to our southern counties. Has also occurred twice in Scotland and half-a-dozen times in Ireland.

$\S$ Night Heron might, so far as the south-western counties go, be regarded as an almost regular spring and autumn visitor, but wanders rarely farther north than Yorkshire, where it occurs only at long intervals. It has been taken half-a-dozen times in Scotland and about a dozen in Ireland. It is only about two-thirds the size of the heron; the plumage is metallic black, the wings and neck grey, the crest white.

\section{Bitterns.}

Almost a regular summer visitor to the eastern counties, this bird has also straggled to Scotland and Ireland. It * Little is supposed to have bred comparatively re-

Bittern. cently in the Broad district, but the nest has never been seen. It is a small bird, about half the size of 
THE HERONS, BITTERNS, AND STORKS.

the last, the crown and tail conspicuously black, the face and neck reddish.

Having a liking for the inoffensive bittern, I stretch a point and treat it as a regular spring visitor, though it is to be feared that the wish is father to

* Bittern. the thought, and that in the greater part of these islands, if not throughout, its visits are nowadays

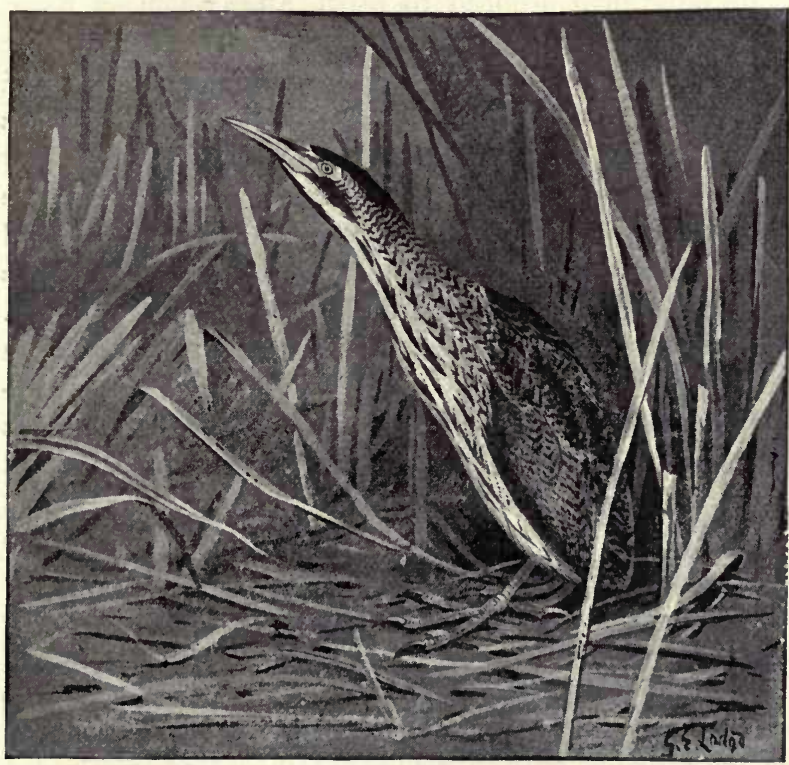

- somewhat irregular, and the hope of its once more establishing itself as a resident is a vain one indeed. So large a bird is such a pleasant mark for the indifferent shot who could not hope to bag smaller fowl. Its long green legs would alone distinguish it from all our other birds, and it has further a conspicuous ruff on the neck. The general plumage is brownish, but the crown is black, and there is a black bar on the wing. The ex- 
istence of the bird in these islands has been shortened not alone by the pot-hunter, but also by the reclaiming of the marshes. I was only once, to my knowledge, within reach of a bittern in this country, and even then I did not see it, for the occasion was an eeling expedition not far from Lowestoft, and the hour was not far short of midnight. Something large rose from out the reeds close to our boat, flew, as we could plainly hear, about a dozen yards only, then dropped to earth, after which we heard it running rapidly away. I had only the word of my attendant (an ex-poacher) for its being a bittern, and such evidence would, in the opinion of the cautious naturalist, "require confirmation." Still, I never knew him pervert the truth when there was nothing to be gained; and at any rate $I$ like to fancy that $I$ did actually put up a bittern so near a large town. It was by far the most pleasant incident of the night's outing. In Australia, however, I have many a time seen an almost identical bittern, and have even heard its extraordinary booming note, uttered, not in the hushed stillness of the night, but in the broad light of day. The last bitterns I saw were running about a deserted estuary in Central Queensland, picking up a living on small snakes and frogs. This food they swallow whole and alive. In uttering the note, which struck me as rather like the howling of a dog, the birds would throw their head back. I shall possibly be disbelieved if I say that on one occasion, when walking near that same estuary after a chance wallaby, with a double-barrelled shot-gun loaded in my hand, I put up two bitterns, not of the common species but almost as large, within half-a-dozen yards, one of which, if not the brace, I could have bagged with ease. But they flapped their way in peace, and it will be a consolation to me, if I should live to see the day when many of Australia's birds, now common, shall have joined the things that were, to reflect that my gun was at any rate used for the most part against creatures 
that, however interesting to the naturalist, mean ruin to the stockowner. When threatened by an eagle or other danger, the bittern does not, like the heron, rely solely on the sharpness of its bill, but throws itself, so eye-witnesses relate, on its back, and strikes out desperately with its claws as well. The bill is not less powerful than that of the heron, though the latter bird is, when winged, by no means to be approached without caution.

+ American Bittern.-A winter straggler to these islands. It is a slighter bird than the last, and lacks the black bars on the wings.

\section{STORKs.}

White Stork.-An irregular spring visitor to the eastern counties, which has never stayed to breed. Has also been recorded rarely in Scotland and Ireland.

Black Stork.-A still rarer visitor to the southern and eastern counties, not up to the present recorded from Scotland or Ireland.

\section{The IBIS.}

Glossy Ibis. - A rare autumn visitor to the south of England, with long curved bill and glossy plumage. It has also occurred in most other parts of the country, and, very rarely, in Scotland and Ireland. It was formerly known as the "black curlew."

\section{Spoonbill.}

The Spoonbill, formerly breeding (seventeenth century) in this country, is now only a straggler to the eastern and southern counties, Norfolk and Cornwall being favourite haunts. It has found its way to the Scottish isles, but only a few have been seen in Ireland, chiefly in the extreme south. It was also known as the "shoveller." The plumage is white and yellow, and the bird is said to have a remarkable mode of feeding, by immersing its bill in the mud under water and walking round and round. 


\section{CHAPTER VII. THE FLAMINGO.}

A short chapter, truly; but, following my plan of enumerating the British representatives of each order in a chapter, I have no option but to devote this one to that rare and handsome straggler, the Flamingo. The home of this tall bird, with the pink-and-scarlet plumage and remarkable curved, pink, black-tipped bill, is in Africa and Southern Europe. It breeds among the salt marshes, and sits on its mud nest, which resembles a small anthill ( $\mathrm{I}$ have in memory countries where anthills of ten feet high are common), with folded legs, and not, as formerly represented, astraddle. It is known to eat a certain quantity of frogs, but its food is for the most part of a vegetable nature. Its occurrences in these islands have up to the present been but four, one of which Mr Saunders regards as possibly escaped from captivity. Another of the four was, I am happy to say, observed only, not shot. It is scarcely to be supposed that so large and conspicuous a bird could have visited us unnoticed.

\section{CHAPTER VIII. THE GEESE, SWANS, AND DUCKS.}

[A large and important order of waterfowl, varying in size from the swans down to the teal, a little bird less than a third of their length. Some of them have been totally domesticated, others resort to inland waters under a kind of tacit protection. The decoys used for taking many of these birds, elaborate accounts of which have been given by Mr Cordeaux, Mr Harting, Sir R. Payne-Gallwey, Mr Southwell, and others, are found 
chiefly in our eastern counties, though there are a few still working in Ireland. The order is represented in these islands by no less than forty-two birds, which analyse as follows: four actual residents; twenty-two regular visitors (many stáying to breed); sixteen irregular visitors.]

\section{The Geese.}

The Grey Lag Goose is a winter visitor to the greater part of these islands, though still breeding in Sutherland t Grey Lag and among the Outer Hebrides. In Ireland Goose. it breeds only in a semi-domesticated state. It is the largest of our geese, being usually regarded as the progenitor of our tame birds, and has the general plumage brown and grey, the under parts white, and the terminal nail of the bill also white. As in all geese, there is no difference in plumage between the two sexes. I recollect on one occasion seeing three flocks, numbering in all not far short of a thousand, as I computed them roughly, flying south over the Baltic in the dawn of a September morning. As I had no gun with me, they were well within shot. The nest, ready by the end of March, is placed on the ground; and it is of interest to note that the lining of her own down is not added by the female bird until she is about to sit on the full clutch of eggs. Eggs, 5 or $6,3^{\mathrm{T}} / 2$ inches; creamy yellow.

The Bean Goose is not known to breed in these islands, but is a tolerably common visitor to the west and south-

†Bean west, comparatively rare on the east coast and

Goose. in Scotland, ${ }^{1}$ but visiting the greater part of Ireland. It is a somewhat darker bird than the last, and the nail at the tip of the bill is black. Like most geese, it is a strict vegetarian.

1 Muirhead (Birds of Berwickshire, ii. 72) enumerates nearly one hundred farms in Berwickshire visited of late years by these birds. 
Like the rest of the family, the Pink-footed Goose has its true home in arctic regions, but it visits our east †Pink- coast in large numbers each winter; to the footed southern and western counties it is but a

Goose. rare straggler only; in Scotland ${ }^{1}$ its appearances vary considerably in different years; while in Ireland it has been obtained but once. It is a smaller bird than the last, the nail on the beak is black, while the legs and feet, though subject to variation, are pink. There are conspicuous white markings on the tail.

The White-fronted or "Laughing Goose" visits the western portions of these islands every winter in large †White- flocks. It is not unlike the somewhat larger fronted grey-lag goose, having the nail on the bill

Goose. white; but it may be distinguished by the white on the forehead and the black bars on the breast. There is also a smaller race, which has more white about the face. This has been obtained but once-on Holy Island.

Snow Goose.-The Snow Goose is a rare wanderer from arctic America, which has been obtained about half-a-dozen times, mostly in Ireland, and which has more recently been reported as wintering in flocks in the northern counties of England. It has not occurred farther south than Yorkshire. There is a larger race from arctic Asia, which has not, however, straggled to these islands.

Red-breasted Goose.-A very rare straggler from Eastern Siberia, which has been obtained seven or eight times, mostly on the east coast.

The Brent Goose visits the east coast every winter in †Brent large numbers, though its haunts are much

Goose. disturbed by shore-shooters. It is easily known by its black head and breast and the white patch on either

1 Muirhead (Birds of Berwickshire, ii. 72) enumerates nearly one hundred farms in Berwickshire visited of late years by these birds. 
side the neck. In one race the lower portion of the breast is much darker, and there is less white on the neck; and both forms, or sub-species, or whatever they are, visit the British Islands. We used to stalk this bird with rifle on the large brackish lagoons that lie close to the Baltic, although the cold was often intense and the birds were usually too shy to afford a shot.

The Bernicle Goose from Greenland visits our western counties with regularity and in considerable flocks. Along

+ Bernicle the eastern seaboard, however, it is rarer. To

Goose. Ireland it is a regular visitor. It differs from the last in the white face, broken only by a black line before the eye. In its food it is more omnivorous than most geese, digging with its short bill in the mud for molluscs and the like. Its note is louder than that of most of our geese; and, like them, it loses its quills so completely in its moult as to be unable to fly, and at that trying period it has to escape by running. It breeds freely in captivity, but its natural resting-place is unknown.

\section{The Swans.}

Practically a domesticated bird, the Mute Swan is every now and again shot in the wild state, to which it easily Mute Swan. reverts. Its most remarkable feature is the shield or "berry" between the eyes, not found in other swans. The name "mute" is unsatisfactory, as the bird has a loud trumpeting note, and will always hiss loudly when provoked. It lacks, however, the call-note of the next species. The swan will undoubtedly pick up a living off water-plants and insects, but there can be little doubt either of its helping itself freely to spawn and young fish wherever these delicacies are available, hence the complaints of London anglers of the misdeeds of the Thames swans, many of which are the property of the liveried companies, others belonging to Eton College. 
One of the largest swanneries, where the birds are regularly farmed and plucked of their down, is not far from Weymouth, and the birds there are a very beautiful sight. Some ornithologists distinguish the so-called "Polish swan," which seems to differ only in the whiteness of the young or cygnet, which in the ordinary swan is grey. As, however, Mr Saunders failed to find the alleged differences (colour of legs, \&c.) in the adult, it seems unnecessary to manufacture even a race out of these abnormal youths and maidens - there are so many races and forms and sub-species as it is. Swans are said to be exceedingly long-lived.

The Whooper, or "Whistling Swan," which nested in the Orkneys at the end of last century, is now but a twhooper. winter visitor, staying on in secluded spots until well into the spring. In his 'Manual,' $\mathrm{Mr}$ Saunders mentions Poole Harbour as one of its favourite resorts; but unfortunately Bournemouth has increased during the eight years that have elapsed since the publication of that unique work, and loafers, of which there must always be a large number during the "slack" months of a watering-place, have not been idle, so that the gunner would have to spend a good deal of time nowadays in watching for a wild swan in Poole Harbour. In this swan, nearly two-thirds of the bill is yellow, the lowest third being black. The note of this species is but indifferently described as "whistling," - a fresh proof of the difficulty of adequately rendering the various notes of wild birds, to which allusion has already been made. It is more like a toy trumpet,-a vulgar comparison, I fear, but at any rate as near the mark as the other.

Bewick's Swan is a rarer visitor, though more common in Ireland. It is a much smaller bird than the last, and †Bewick's is further distinguished by the smaller patch Swan. of yellow (only one-third) on the bill. The note, equally indescribable, is softer. 


\section{The Ducks.}

[These are conveniently divided into two groups, the non-diving, and the sea- or diving, ducks-the former including such familiar species as the Widgeon, Mallard, and teal, while to the latter belong the less known Pochard, Smew, Scoter, and Eider. It is interesting to note that in captivity almost all ducks will interbreed; and they all have a curious habit of adding down to the nest only when the eggs are laid and incubation is about to start.]

\section{(a) The Non-Diving Ducks.}

Although not included in the so-called "sea-ducks," the Sheld-Duck is never met with far from the coast, and I

Sheld- have often observed it in Hampshire on littleDuck. frequented parts of the sandy foreshore. It is a bird of extremely shy habits, and it flies at no great height and at only moderate speed. The female is a very noisy bird. It would be difficult to mistake this handsome bird for any other, with its glossy green head and throat, its deep-red knobbed bill, the white band beneath the green throat, the dark patch on the white belly, and the black tip to the white tail. If only every bird were as conspicuously marked, binoculars would be almost superfluous. The plumage is alike in both sexes. The sheld-duck feeds for the most part on marine plants and small molluses, also on sandhoppers. It breeds in May in some hole, usually a rabbit-burrow, but also in round tunnels of its own excavating, or, very rarely, in natural fissures in the rocks. The nest, at some considerable distance from the light, is of grasses lined with down. Eggs, 8 or 10, $23 / 4$ inches; creamy white.

$R u d d y$ Sheld-Duck.-A wanderer from the South, which has been obtained on several occasions in Ireland, and of which a number were obtained as recently as 1892 . In summer the adult male is unmistakable by reason of the 
narrow black ring which he then wears round his neck. Otherwise he is a bird of sober plumage, in size about the same as the last.

The Mallard is the "wild duck" of the British Islands, the largest of our commoner ducks, and the progenitor of Mallard the domesticated bird. In his full dress, the drake is a very handsome bird, with his green head and neck, narrow white collar, and the four blue

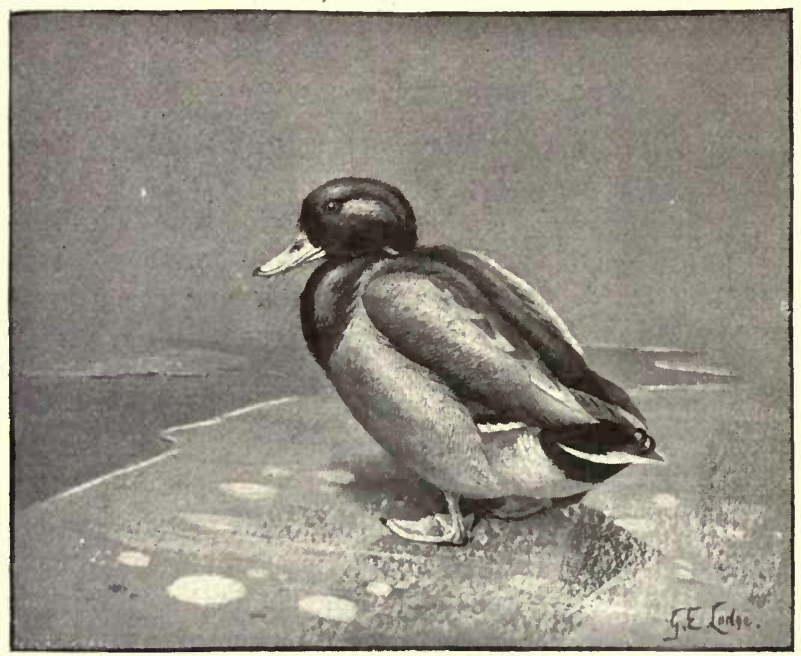

curled feathers in his tail ; but during the summer months he moults to a far quieter looking being, more like his mate. There are two races,- the smaller birds that visit us from the Continent, and the larger home-bred residents. It is interesting to note that, like other domesticated birds, this duck is polygamous only in the tame state, being by nature content with one mate. It is also a much cleaner feeder than its degenerate relatives. The quacking cannot, by the ordinary ear at any rate, be distinguished. 
It nests on the ground, usually near inland waters, but also in hedgerows, and even in the deserted nests of other birds. The nest is of grass lined with down. Eggs, 8 to $\mathrm{I} 2,2 \mathrm{I} / 4$ inches; greenish white.

Breeding in a semi-protected state in parts of Norfolk, the Gadwall must be more correctly regarded as a winter visitor, and by no means a common one. The t Gadwall. plumage of this bird is not striking at any distance, and indeed its most distinctive feature is to be found in the laminæ of the upper mandible of the bill, which project sideways. The white outer webs of the wing are also somewhat conspicuous.

Like the last, the Widgeon, though, strictly speaking, a winter visitor, breeds in a few places in the northern tWidgeon. counties of Scotland and in most of the islands twidgeon. except the Outer Hebrides. Its nesting in Ireland seems a matter of some uncertainty. It feeds entirely on vegetable matter, and only at night. It may always be remembered that all these drakes assume the plumage of the female during the late summer months. In his brighter dress, the widgeon has a creamy-white forehead, the face and neck reddish brown, spotted with green, and the shoulder white. The nest, of grasses lined with down, is placed on the ground among the rushes. Eggs, 7 to Io, 2 I $/ 3$ inches; creamy white.

The American Widgeon has been recorded but once on sufficient evidence. It is distinguished by a green stripe behind the eye.

Another winter visitor, the Pintail breeds in a very few districts, as in the Hebrides. The head and neck of the †Pintail. male are of a reddish brown, the neck being bordered with a white stripe; but the bird is chiefly distinguishable by the two very long tail-feathers, from which it takes its familiar name, as also that of "Sea- 
Pheasant," by which it is often known. It is frequently found in company with widgeon. Its food consists largely of water-insects and shell-fish. It is known to breed somewhat freely with the mallard. The nest, rather deeper than that of most ducks, is otherwise similar. Eggs, 7 to Iо, 2 inches; pale green, and of elongated form.

The Shoveller, or "Spoonbill," may, in both sexes, be distinguished by the spoon-like bill. It breeds in several † Shoveller. ${ }^{1}$ parts of Ireland, also locally in Scotland as far as the Inner Hebrides. Its breeding-places in England are few, and are confined to the eastern sea-board. This duck consumes more insect food than most. The nest is on dry ground near water. Eggs, 8 to I2, 2 inches; pale green.

The Teal, smallest of our ducks, breeds in many parts of the British Islands, chiefly in the northern counties and Scotland, but also as far south as the Thames

Teal. valley. It is easily recognised by the conspicuous green patch behind the eye, the brown stripe down the centre of the forehead, and the numerous black spots on the breast. The food of the teal consists largely of vegetable matter, but insects are also consumed. It is remarkable for a devotion to its young that is by no means characteristic of all ducks. The nest, in the immediate neighbourhood of water, is like those of the rest. Eggs, 8 to I2, I3/4 inch; brownish white.

American Green-winged Teal.-A very rare straggler, which has occurred but thrice-in Devon, Hampshire, and Yorkshire, though the bird is omitted, whether intentionally I do not know, from Clarke's list in his and Roebuck's 'Yorkshire Vertebrata.'

Blue-winged Teal.-Another American straggler, which has occurred once only-in Scotland.

1 Not to be confused with the true Spoonbill, also known as "shoveller." 
The Garganey is a rare spring visitor, a few also reaching these islands in autumn. A somewhat larger bird than the allied teal, the garganey is distinguished \$ Garganey. by the white line that runs behind the eye and down the side of the neck, as well as by the conspicuous black crescent-shaped marks before the rump. The curious grating note of the male has gained for this bird in East Anglia, where it is least rare, the name of "Cricket-teal." It has found its way at irregular intervals to nearly every part of Scotland and the isles, except the Outer Hebrides. Nest, among the sedges. Eggs, 8 to I2, nearly 3 inches; like those of the teal, but lacking the greenish tinge.

\section{(b) The Diving Ducks.}

[Although a number of the foregoing are observed to. feed with their head submerged and the legs and tail waving in the air, yet they cannot be said to get their food by diving, as do for the most part the following nineteen, which have, moreover, a distinct preference for the neighbourhood of salt water.]

The Pochard, or Dunbird, is one of the winter visitors of which, on the slightest encouragement, numbers remain † Pochard. to breed, chiefly in the eastern counties. I knew a case of a single pair breeding on a small private water not far from Poole. The hind-toe of this, as of all the group, is prominently lobed. The bird is at once recognised by the black collar and apron, and by the band of greyish blue across the centre of the otherwise black bill. The pochard feeds, largely at night, on water-plants, also on crustaceans. From its curious cry when flushed, the pochard is also known as "Curre." The nest, not a very elaborate structure, is found on the ground among sedges. I came upon a nest of this bird on one occasion with two out of the three greenish eggs badly broken, the third intact. Eggs of ground-nesting 
birds are not unfrequently found cracked in deserted nests, and it has been suggested that the departing hen does this in despair ; but in the case mentioned, where the third egg was unhurt, some other explanation is wanting. Eggs, 7 to IO, $2 \frac{1}{3}$ inches; greenish grey.

Red-crested Pochard.-A rare straggler from the South, which has occurred over a dozen times in England, and once each in Scotland and Ireland.

$\S$ Ferruginous Duck.-An irregular spring and winter visitor to the east coast. It is also known as the "Whiteeyed" duck, from the white iris, and is further distinguished by a white spot on the chin.

The Tufted Duck is a winter visitor in numbers, though a great many remain to breed, especially in Notts, and in + Tufted other counties, also in parts of Scotland and Duck. Ireland. This bird may be recognised by its glossy black crest and pale blue bill. Like many ducks, it is most active after sunset, and its food consists largely of water-plants. As food, this duck is worthless. The nest is placed among the sedges. Eggs, 8 to $12,21 / 3$ inches; greenish.

The Scaup, a common winter visitor, is said to have bred in Scotland. It lacks the crest of the last, but

† Scaup. otherwise resembles it much in colouring, In uttering the harsh note from which it takes its trivial name, the bird is said to twist its head in a peculiar way, but I do not remember having seen this. It is one of the ducks least esteemed for the table.

The Golden-eye has likewise been said to breed in Scotland, but authorities, Mr Saunders among them, regard the † Golden- statement with extreme suspicion. This handeye. some duck may be recognised by the white patch beneath the eye, black back, white underparts, and 
a sort of rudimentary crest on its green head. Like most of these sea-ducks, the golden-eye is excellent gun practice, for it is exceedingly shy, either diving at the flash or rising at once from the water and flying rapidly away, with audible whistling of the wings.

Buffel-headed Duck.-A very rare straggler from North America, so called from the white patch behind the eye, which has found its way to these islands (not to Ireland) on five occasions.

Harlequin Duck.-A rare straggler from arctic regions, which appears to have been obtained, always in the North, on less than half-a-dozen occasions. Its prevailing colours are black and white, distributed in striking patterns.

The Long-tailed Duck, for the most part a scarce winter visitor, is thought to breed in the Shetlands. It is chiefly † Long- met with in Scotland and Ireland, though it tailed has been obtained in nearly every county of

Duck. England. The male is easily recognised by the brown patch on its white neck and the two very long black tail-feathers; and, unlike most ducks, he has a distinct summer dress.

The Eider Duck, a winter visitor to England, breeds in the Farne Islands, also in the Orkneys, Shetland, and † Eider Hebrides. It is a somewhat striking bird, with

Duck. white back and breast, black crown and tail, and a black line of feathers on the bill. I have seen it occasionally bagged on the Baltic shores in mid-winter; and I noticed that it flew even closer to the water than most ducks, and that it was remarkably silent. It is a valuable bird on account of its soft down. The nest, placed on the ground on the shore, is of sea-weed and grasses, lined with this down as the young are expected. Eggs, 5 or 8, 3 inches; green.

King Eider.-A rare straggler from arctic regions, which has been obtained on but few occasions in England, and 
no farther south than Norfolk, half-a-dozen times only in Ireland, and rather more frequently in Scotland and the isles. It is distinguished from the other by the presence of a large red tubercle at the base of the bill.

Steller's Eider.-A smaller species which has wandered from arctic regions on two occasions only, both to our east coast.

The "common" Scoter, a winter visitor to our east and south coasts, breeds in Caithness, Ross, and elsewhere in † Black the Highlands. It is uniformly black, about

Scoter. its only touch of colouring being the orange line along the top of the bill. Like most ducks, this bird does not breed until late in May. Nest near inland water. Eggs, 6 to 8, 21/2 inches; brownish white.

The Velvet Scoter, a winter visitor from the North, occurring in small numbers on our east coasts, is believed to † Velvet breed in certain spots in the North of Scot-

Scoter. land, but on slight evidence. It has also been observed in the west of Ireland in summer and in breeding plumage. It differs from the last in having a white patch behind the eye, and a more conspicuous white bar on the wings. It has been captured in the salmon-nets.

Surf-scoter.-A North American bird, which has strayed to the Scottish isles on several occasions, and, more rarely, to the English and Irish coasts. There is no white about its plumage, which is deep black, save two patches, one on the forehead, the other on the back of the neck.

The Smew, or "Nun," is a not uncommon visitor to the unfrequented waters near the sea on our south coast,

† Smew. though, as a rule, it is more likely to be met with at some little distance out at sea; and I have steamed near it, forgathering with pochards, in November, about three miles south-west of Plymouth. In his full plumage, the male is a handsome black-and-white 
bird with a green patch on the crown and a white crest. Like the rest of the group to which it and the next three belong, the mandibles are serrated, which must give the fish and frogs and the like, in pursuit of which it dives, a very poor chance of escape.

The Goosander, a very much larger bird than the last, and distinguished by its dark-green head and crest, pink

† Goos- breast and bright-red bill, is not only a ander. winter visitor to Great Britain and, in smaller numbers, to Ireland, but breeds in parts of Sutherland, Argyll, and the neighbouring counties. The nest is in a hollow trunk, or, less frequently, on a ledge. Eggs, 8 to I3, $23 / 4$ inches; brownish white.

The Red-breasted Merganser is a winter visitor to most of our coasts, estuaries, and tidal rivers, breeding in many †Red- loughs in Ireland (known as "Sheld-duck"), breasted as well as in most of the Scottish isles and Merganser. many spots on the mainland. It is a smaller,

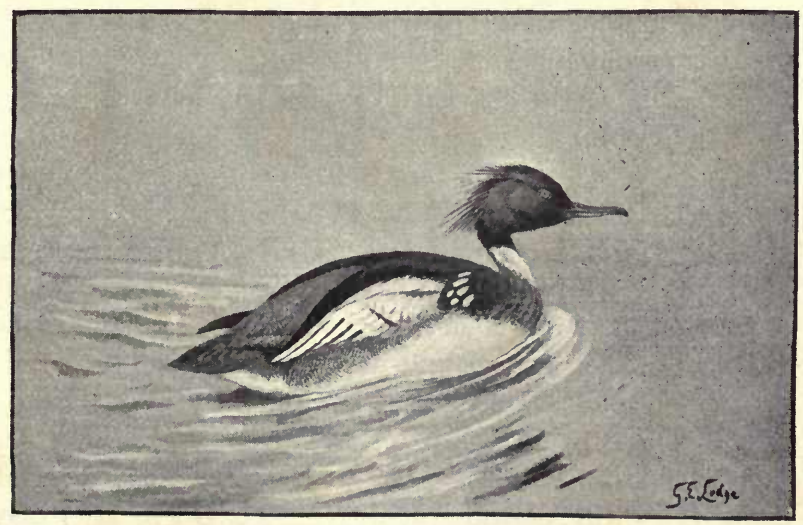

but more striking, bird than the last, having a green crest, white collar, reddish breast, and white belly. Like the Goosander, it is an unmitigated nuisance on the Highland 
trout- and salmon-streams, and its protection has been the subject of a deal of discontent. The nest is either underground or else in the heather or long grass, and is lined, as are those of almost all ducks, with a profusion of down. Eggs, 8 to 10, 2 I $/ 2$ inches; greenish drab.

Hooded Merganser. - A rare straggler from North American waters, which has occurred half-a-dozen times, mostly in Ireland.

\section{CHAPTER IX: THE DOVES.}

Three residents; one summer visitor.

The Wood-Pigeon, Ring-Dove, or Cushat is the largest of our doves, and is familiar, more especially to the farmer

Wood- whose crops it raids, in most parts of these Pigeon. islands. It is one of those birds that have increased and extended their range in our islands, and is common in agricultural districts where but half a century ago it was not known. Being the most abundant of our doves, it is not easily mistaken for any other; besides, it is sufficiently distinguished by the green patch on the neck, below which are the white feathers which, after the second year, form a kind of incomplete collar. The straight flight of this bird, as also its great speed, is appreciated by those who have waited in the woods at sunset for an overhead shot as the birds fly home to roost. They move like arrows, and are as easy to miss as most birds. The note of this pigeon, the low vibrating "cooing," cannot be mistaken for that of any other bird, or, for that matter, any other dove. Like all the family, it is a great drinker, and, in Australia at any rate, it is generally easy to reckon on a bag of the indigenous pigeons, of which that continent has such a variety, by repairing at sundown to the neighbourhood of some water-hole. Its food 
is unfortunately composed for the most part of grain, peas, clover, and various seeds, all of which man has planted for his own use, so that the bird is no favourite. The nest, a platform of sticks, is placed at almost any height, commonly in the tops of the fir-trees; but I have also taken the eggs, especially on wooded hillsides, less than 4 feet from the ground. It is likewise known to lay in the deserted dreys of squirrels or nests of hawks or magpies. Two or three broods are reared, the first eggs being found in the early days of April. Eggs, 2, $1 \frac{3}{5}$ inch; glossy white.

The Stock-Dove is a smaller and more silent bird, and may be distinguished by the absence of the white collaret. Stock-Dove. In the Highlands this dove has extended its range considerably of late years, though it was till comparatively recently found no farther north than the Forth. In Ireland, it appears still confined to parts of the east coast; but along the south and west coasts of England it seems to be extending as rapidly as in Scotland. Its flight is still more rapid than that of the ring-dove. Its food consists largely of charlock and other seeds. The bird makes no nest, but lays its eggs in rabbit-burrows, holes in trees and cliffs, deserted nests of magpies and other birds, squirrels' cages, \&c. Eggs, 2, I I/2 inch; yellowish white.

The Rock-Dove, the wild form of our domestic pigeons, is distinguished best by its white rump and black bars on Rock-Dove. the wing. It is a bird essentially of the ground, among the coast caves of Scotland and Ireland seems to be general, though in England it is exceedingly local, and absent from apparently suitable districts. It is a wellknown resident on the Isle of Man, and Flamborough Head is a favourite breeding-station. The bird feeds, like the rest, on grain and seeds, and it also drinks much and regularly. It nests on ledges in caves, the nest being a very slight structure. Eggs, 2, I I/2 inch; pure white. 
The Turtle-Dove has bred in some of the northern counties, and has recently extended as far north as

* Turtle- Caithness. A bird of more twisting flight Dove. than the rest, it is distinguished by the somewhat longer tail, which is edged with white, and by the black-and-white patches on the neck. It is the smallest of our doves, and in food and habits closely resembles the wood-pigeon, only the nest is generally placed nearer the ground. I have taken the nests, however, in adjoining plantations, and at the same height. Eggs, 2, I $\frac{1}{5}$ inch; white.

\section{CHAPTER X. § PALLAS'S SAND-GROUSE.}

Pallas's Sand-Grouse, which must stand by itself, is a capricious migrant from the steppes of Asia, spring and autumn irruptions passing over Europe to these islands at long and irregular intervals. These arrivals of this curious bird, known by its long tail-feathers, short feathered legs, and the possession of three toes only, united by a membrane, have occasioned a great deal of discussion and learned correspondence, and have even been the subject of more than one monograph. Here it suffices to say that the chief arrivals have been in I859, in the winter $1863-64$, in 1872,1876 , and $1888-89$, the last being also the greatest and in many ways the most interesting, as a large number were kept in confinement, ${ }^{1}$ and many more remained, probably to breed, as eggs were taken in several counties. Moreover, this influx extended over a greater range than its predecessors, reaching even to the extreme west of Scotland and Ireland. The bird feeds entirely on seeds, and its flight has been likened to that of the golden plover. It builds no ${ }^{1}$ Macpherson, Visitation of Pallas's Sand-Grouse, p. 31. 
nest, but scratches a depression in the earth for the reception of the eggs. Eggs, 3, I I /2 inch; buff, with brown or purple blotches; elliptical in form.

\section{CHAPTER XI. THE GAME-BIRDS.}

[Our game-birds include eight species, of which perhaps the most interesting to the naturalist is the red grouse, which occurs nowhere else in the world; while still more interesting in its history is the splendid capercailzie, reintroduced from Scandinavia sixty years ago, after it had become extinct for nearly a century. Several of the rest were artificially introduced. The term "Game-birds" is applied somewhat loosely to this order, for, legally speaking, the snipe and woodcock, though they may be trapped without licence, rank as "game" for the gun. Seven residents; one summer visitor.]

The Pheasant, introduced from Asia at some remote date,-as some say, by the Romans,-now crossed with Pheasant. more recently introduced breeds, is met with throughout these islands, even to the Outer Hebrides, though it would have had a poor chance of survival were it not for the protection extended to it during half the year that it may be better shot during the other half. It is on many estates practically a tame bird for six months, a wild one for the other six. A remarkable bird too in many of its arrangements and instincts, for not only is it said to be common for three or four hens to incubate the same clutch of eggs, but the male is also alleged on rare occasions (not like those birds in which such duties regularly devolve upon his sex) to take his share of incubating the eggs and of looking after the young birds. The natural food of the pheasant consists of berries, grain, and worms, but it has of course learnt 
to look for the food placed in certain spots by the keepers. It is remarkable how oblivious these birds have grown of the passing train. Even in the height of the shooting season, when they might be expected to be shy, both sexes will feed placidly within 20 yards of the track; indeed so little fear does the steaming engine inspire in them, that a cock-pheasant is said to have flown (March I897) into a first-class compartment, closely pursued by a hawk, the latter withdrawing, and its victim soon dying of its injuries. The way in which these birds will, when disturbed, run swiftly under cover, then, rising in a curve, top the nearest hedge and alight in some sheltered place beyond, is well known. The hen bird, whose sober colours certainly bear a close resemblance to those of earth, especially in a ploughed field, is said on good authority to rely somewhat on this protective colouring, crouching where she stands, and only rising reluctantly and at the last moment. Although I have commonly observed this crouching in the partridge, I must confess to having missed it in the larger bird, my idea having been that she behaves very like her lord, but escapes, if possible, by running under cover.

Like most birds of this group, the pheasant passes most of its time on the ground, the shelter of dense undergrowth suiting it better than high trees, though it usually roosts in them, and has been known to lay its eggs in deserted nests at a great height from the ground,-a departure from the normal state of things that recalls the nests of the cushat which I have more than once found on the ground. The cock bird fights gallantly for his establishment of hens, and is, as a rule, prompt to desert them as soon as the young appear. Like all grain-eating birds, the pheasant is a great drinker. The cock-pheasant is too familiar to need description, but it is desirable to draw attention in passing to the remarkable spur at the back of the leg-a spur that recalls that in the beaver, platypus, and chanticleer. Old hen pheasants that no longer busy 
themselves with family affairs assume a plumage not unlike that of the male.

The nest, when on the ground, is a slight structure,

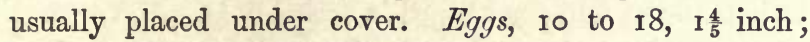
glossy greenish-brown and spotless. When the hen, deserted by her mate, has to leave the nest, usually for water, she is mindful to cover the eggs with leaves or bracken.

The Partridge is a familiar bird in all the more cultivated portions of these islands. It is indeed essentially Partridge. a bird of cultivation, and there are therefore Partridge. untilled districts in Scotland (particularly in the isles) and Ireland where its distribution is local. It was more abundant in Ireland ten years ago than to-day.

Like the other game-birds, the partridge is swift of foot, and to this, as well as to its protective colouring, the bird prefers to trust. When flushed, however, the short wings beat rapidly until the bird considers itself at a safe distance, when it glides for perhaps a hundred yards, alights and runs a very little way, then looks back to see what its disturber is about. But this procedure is perhaps too well known to need mention, since partridges can be observed any day in the fields, though, in the hurry of shooting, many of their most interesting habits go unnoticed. The most distinctive mark on the old partridge is the horseshoe on the breast. These birds roost on the ground, a habit much approved by stoats and foxes. They consume more insects than the pheasant, and snails are a favourite article of food. The partridge appears to have but one mate. The nest, not unlike that of the pheasant, though smaller, is built in April. Eggs, 12 to $\mathrm{I} 8$, nearly $\mathrm{I} \mathrm{I} / 2$ inch; olive brown and spotless.

The French Partridge, introduced towards the end of the last century, is most abundant in East Anglia, but Red-legged occurs in many other southern counties, though, Partridge. for some reason or other, it will not thrive in Scotland or Ireland. It is a wretched bird to shoot unless 
well driven, for it possesses in an exaggerated degree the family objection to rising from the ground, and will run before the dogs. The notion that it is in any way injurious to the indigenous bird is probably an error. They preserve a kind of armed neutrality, rarely interfering, still more rarely interbreeding, though instances of the latter are on record. At the same time, it seems advisable to mention that more than one authority on the subject of game-birds has stated the existence of a sort of blood-feud, much as that existing between the black and brown rats, and with much the same result, the victory of the new-comer.

Unlike the common partridge, this bird frequently perches on stumps and even at a considerable height; and it will even nest at some little distance from the ground, notably in stacks. It is easily distinguished from the other bird, not alone by its red legs and bill and the presence of a blunt spur, not unlike that in the pheasant, only less, but also in the very easily recognised black patch under the throat, and the black and red bars on its sides. The nest is as slight as those of most of the family. Eggs, ro to I8, I $\frac{3}{5}$ inch ; creamy white, with numerous reddish spots.

With us from May to October, the migratory Quail is a small edition of our common partridge, except for the

*Quail.

black patch on the throat. It is a southern bird, and the flocks on migration are immense. A number remain with us through the winter; and this was also the case in Ireland, where, however, the bird has, both as a visitor and as a resident, gradually diminished in numbers of late years. In Scotland its distribution is extremely limited. This is another bird difficult to get off the ground, and even on the wing it rarely rises to any height. Its note is peculiar, but I, at any rate, find it indescribable. Its food consists mostly of seeds, chickweed for preference. The nest is placed in an open field, and is no more than a hollow in the ground sparsely lined with grass. Eggs, 7 to I 2, I inch ; creamy, with brown blotches. 
The Capercailzie, handsomest of our game-birds, if not indeed of British birds irrespective of order, has, as already mentioned, been successfully reintroduced Capercailzie. from the pine-forests of Scandinavia to those of Scotland, after an absence of nearly a hundred years.

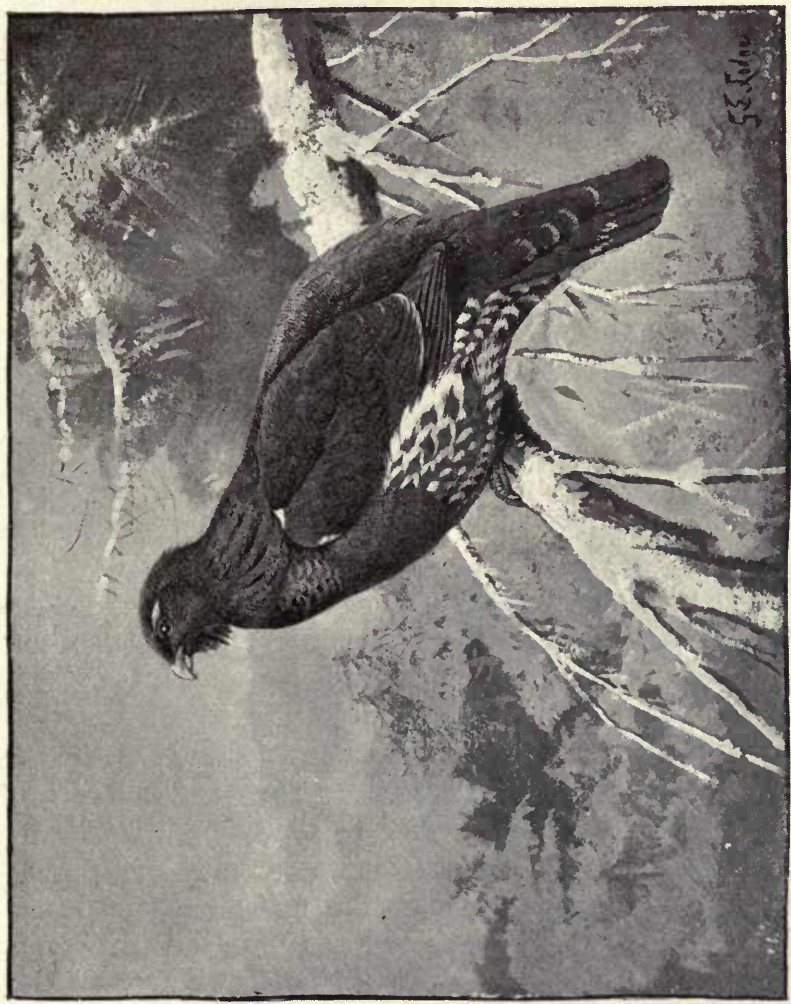

The precise meaning of the name is "horse of the woods." A great deal of interesting information on this and every other point in connection with the bird's distribution and history is to be found in Harvie-Brown's 'Capercaillie 
in Scotland.' In Ireland, where it apparently became extinct about the same time as in Scotland, it has not been reintroduced; in England it may never have occurred, or, if it did, it became extinct at some early period of which there remains no record. The legs of the capercailzie are feathered, but the foot, unlike those of the red grouse and ptarmigan, is bare. The tail is long and rounded, therein differing from the striking lyre-like extremity of the next species. The male, the larger of the two, is a fighting bird; and Sir Henry Pottinger and others who have made a study of it give most interesting accounts of his spring "spel," wherein he performs all manner of antics to engage the attention of the hens. He is a confirmed polygamist, and fights, or makes a great pretence of doing so, for his wives. These birds feed largely on berries and fir-shoots, the latter imparting to their flesh a flavour of turpentine, and the Scandinavian peasantry call it by a name that has reference to this peculiarity. The eggs are laid in a depression scraped in the earth. Eggs, 7 to Iо, $2 \frac{1}{4}$ inches; brownish or pale orange, with brown blotches.

The Black Grouse (the male being known as the "Black Cock," the female as the "Grey Hen") is a smaller bird Black than the last, which it nevertheless somewhat Grouse. resembles in habits. The adult male is at once distinguished by the lyre-shaped feathers in the tail, the underpart of which is white. There is also a conspicuous bar on the wing. The distribution of this bird is somewhat local and subject to unaccountable changes. It seems pretty generally at home throughout Scotland, including the Inner Hebrides, though said to be on the decrease in the Loch Lomond district; in Ireland, it appears to be wanting ; in England, it occurs in many suitable districts, ${ }^{1}$ wherever there is secluded forest, but generally in small numbers. Thus, I have learnt to look on those said to

1 Sir Herbert Maxwell informs me that the bird has almost, if not quite, disappeared from Surrey. 
inhabit the New Forest as apocryphal, though they are doubtless to be found by those enjoying greater opportunities of visiting the more secluded shades of that enchanting waste. As already said, this bird agrees closely in habits with its larger congener, and notably in the curious spring tournaments and "spels," being also, like the capercailzie, both pugnacious and polygamous. Con-

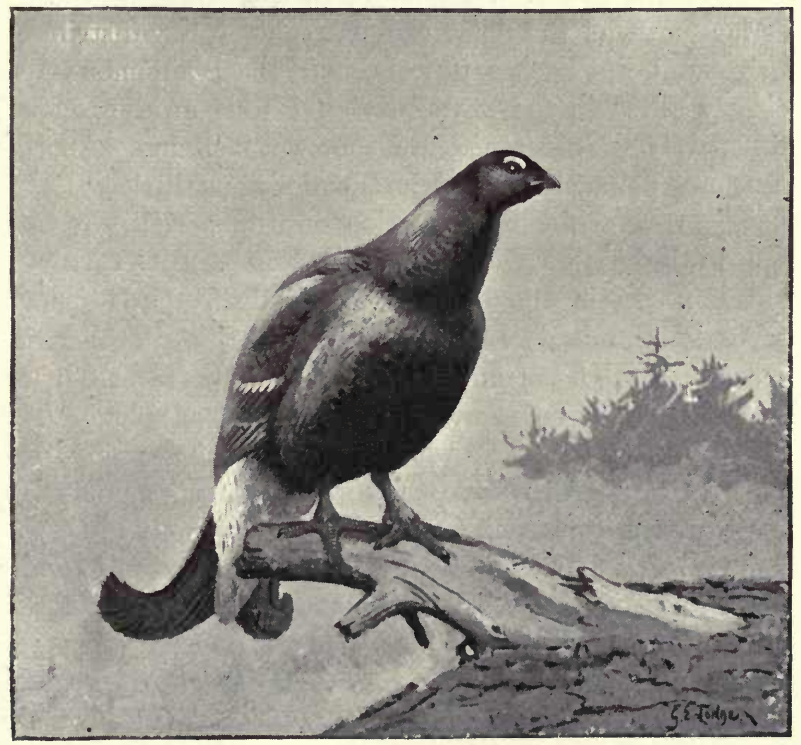

tinental sportsmen take advantage of the love ecstasies of both these birds to shoot them from ambush; and in the case of the capercailzie a good deal of mancuvring seems to be necessary, as the love-song lasts only for a few seconds, and unless engaged in singing or otherwise showing off to the hens, the bird is very alive to danger. Buds, seeds, and grain are the chief food of this bird. The black grouse breeds with almost all our other gamebirds, and some remarkable fertile hybrids are the result. 
The nest is merely scratched in the earth. Eggs, 6 to Io, 2 inches; yellowish white, with reddish-brown spots.

The subject of the full-page plate, the Red Grouse (p. 69), is, as already mentioned, peculiar to these islands, where it is Red practically restricted to the northern portions,

Grouse. being commonest on the Scottish and Yorkshire moors, and even extending to the Midlands, but not as far south as the Thames. It seems widely distributed in Ireland, but it does not thrive in the Shetlands. It is closely allied to the Scandinavian Willow-grouse; indeed the points of difference are somewhat slight. Another bird not distantly related is the delicious little "Hazelhen," to eat which to perfection one must visit a restaurant in its native country or in Northern Germany in autumn. It is one of the most delicate birds for the table in Europe. In the grouse and its congener the ptarmigan, the leg and foot are thickly feathered, and the hind-toe is so short as to be almost obsolete. This national bird passes its whole existence on the soft bleak moors, nesting there and only going on short migrations in very severe weather. It feeds on the sprouts of heather and on corn, berries, and seeds. The dire disease to which the grouse is liable has been the subject of public inquiries and of several books, but the mystery seems to remain unsolved. Besides this remarkable ailment, this bird is the host of a number of parasites, which have also been specially studied by veterinary authorities. The red grouse has all the little peculiarities of its tribe, the vanities when in presence of the hens, and the singular habit of burying itself in snow, also observed in the capercailzie and ptarmigan. The nest is no more pretentious than that of most game-birds. Eggs, 7 to Io, 13/4 inch; pale coffee, with red blotches.

The white Ptarmigan, sometimes seen in English poulterers' shops in early spring, is confined, so far as these 
islands are concerned, to the stony plateaux of the Highlands. It seems, though once found, according to some, Ptarmigan. in Cumberland, to have never occurred in the south of England or anywhere in Ireland; and even in Scotland it steadily refuses to thrive in many apparently suitable spots, both on the mainland and among the islands, into which sportsmen and landed proprietors have repeatedly endeavoured to introduce it. The interesting part of this bird is its habit, like that of the mountain hare and stoat, of changing its brown summer coat to white when the snow is on the ground. Even the conspicuous red swelling over the eye of the male disappears in winter. He, however, retains black stripes before the eyes, which serve to distinguish him at once from the female and from the almost identical willow-grouse in its winter garb. ${ }^{1}$ It is interesting to notice that, while the stripe on the face never loses its blackness, so, on the other hand, the feathers of the tail are white winter and summer alike. The legs and feet of this bird are very thickly feathered, and the hind-toe is exceedingly short. Mr J. G. Millais relates in one of his interesting books ${ }^{2}$ a most ingenious and simple method employed in poaching this bird during snowy weather. The poacher merely presses into the soft snow an inverted champagne-bottle, and fills half the pit thus formed with grain, scattering a little more of the latter around by way of attracting the birds and whetting their appetites. They approach the pits, and, in trying to get at the contents, overbalance and tumble in. Then the frost comes to the aid of the iniquitous, and the hapless bird soon struggles to death in its prison. The ptarmigan has much the same food and habits and disease as the grouse. The nest and eggs are also much the same. Eggs, 8 to 10, nearly $13 / 4$ inch; pale brown, with reddish markings.

1 Most of the white birds sold as "ptarmigan" are in reality willowgrouse in winter clothing.

2 Game Birds, p. 71. 


\section{CHAPTER XII. THE RAILS AND CRAKES.}

[These include seven small and mostly familiar, though not conspicuous, birds. The landrail, indeed, is seen less often than heard. They are all insect-eaters, though not exclusively so. Three residents; two regular and two irregular visitors.]

The Landrail, or "Corncrake," is a bird to which the poet's complaint in respect of the cuckoo might far better *Landrail. apply, for it is often exceedingly difficult to get a glimpse of the owner of the harsh note that sounds at dusk from out of the long grass close by. Any summer evening, often indeed far on into the night, the strange rasping sound may be heard. Swift, however, as it is on foot, it is but a poor performer on the wing, its legs dangling in careless fashion. It is said by most observers to feign death-a trick common to many beasts and birds; but I never had the good fortune to witness this, though I have handled many live birds of this species, and, so far from "foxing," they one and all pecked vigorously.

The landrail is a timid skulking bird, and knows full well how poor it is in the air, for it quits the earth with the greatest reluctance, and it is often only by very patient and careful observation that one is enabled to see the long neck craning over the top of the waving corn, among which the bird finds the insects and seeds on which for the most part it feeds. It is, according to Mr Saunders, also known, when put up by dogs, to climb into bushes. There seems to be some slight uncertainty as to whether the female also utters the "crek-crek." This much I know, that the bird, whatever its sex, almost invariably stands still during the moment of utterance; but I never got more than a passing glimpse of the owner of the voice, and the sexes present no striking differences in plumage. 
They nest soon after arrival, late in May. The nest is of grass lined with softer grasses, and is placed on the ground in the corn or long grass. Eggs, 7 to IO, I I $/ 2$ inch; dull brownish white, with red spots.

Not uncommon in the marshy tracts of these islands, but rarer than formerly, the Water-rail is as shy as the last, Water-rail. even noisier, and still more reluctant to rise on the wing. About the same size, it is easily distinguished by the conspicuous white bars on the wing, as also by its red bill. It passes its life among the sedges, feeding on aquatic insects and molluses, and nesting in March, two broods being reared. The bird is by no means so close a sitter as the last, the nest being of reeds, and therefore admirably concealed among the same material. Eggs, 7 to Io, under II $/ 2$ inch; creamy white, with red and grey spots.

The Spotted Crake breeds during its visit in the east and south of England, in parts of Wales and Scotland, rarely

* Spotted in Ireland. The return migration takes place

Crake. in October, but a few birds are thought to remain through the winter. The small white spots with which the bird is thickly covered distinguish it at once from the rest, which it closely resembles in food and habits. Its nest, placed among the reeds, is a far more artistic structure than those of its relations, consisting of flags, with a soft-lined receptacle for the eggs. Eggs, 7 to Io, I I $/ 3$ inch; greenish brown, with red spots.

\$Little Crake.-A rare visitor from the south, chiefly to the eastern counties, where it has occurred over a dozen times. The bill and legs are green.

§Baillon's Crake.-A very rare straggler, chiefly to the eastern counties. Its home is in Africa. It is said to have nested in this country.

The Moorhen, or Water-hen, is familiar on many of our inland waters, and may be recognised by its red-and-yellow 
bill and the red mark on the leg, which is otherwise greenish. These birds frequent certain waters in numbers, and Moorhen. on a short stretch of the Cray in North Kent I took six or eight nests in two successive years. The birds were by no means shy, being little persecuted, though they were made less welcome at the trout-hatchery close by. It is a good deal molested on account of its supposed destruction of young trout and game-birds. I do not, from what I have been able to observe, believe in the damage done in this respect, though I have more than once detected it, on a certain private water that shall be nameless, feeding, as I believe, on trout-ova. I could plainly see it with the aid of my glasses feeding on something very like spawn; and I admit in all contrition that, having been refused permission to fish the water not long before, I did not feel called upon to warn the owner of the presence of poachers. The swimming and diving of this bird are, considering that the feet are not webbed-differing from those of the landrails only in their narrow marginal membrane-marvellous, nor is it by any means so poor on the wing as some writers make out. It dives at the flash of the gun, and, like some other waterfowl, has a knack of remaining submerged all but the bill. The moorhen is very susceptible to cold, and in the severe winter of I886 I picked up several birds that had obviously died of the cold.

In addition to the aforementioned trout-ova, which are available for a short space only, the bird consumes quantities of insects and grain. The nest is of flags and sedges, and is placed low down by the water, sometimes floating, at others partly submerged, and the bird is said to resort to ingenious methods of keeping both nest and contents dry in flood-time. It is also known to nest in trees at some height above the water, and I have found its nest in the dry bracken a couple of hundred yards from the

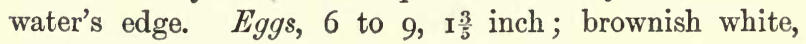
speckled with red. 
The Coot, a fairly common pond-bird, may be easily distinguished by the bald white patch on its forehead. Its

Coot. habits are much those of the last, as it dives when shot at, reappearing several yards away. The feet of the coot have a remarkable lobed membrane along each toe, which may partly assist the bird in its rapid progress over the water-lilies. Each toe has a free flap. To appreciate this palmated foot, as also the slighter membrane of the moorhen, it is absolutely necessary to examine the bird alive if possible, or at any rate im-

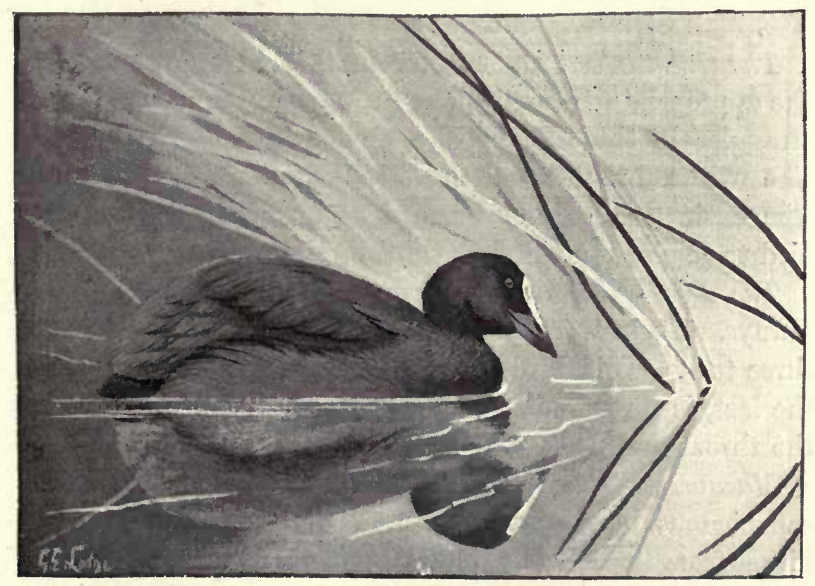

mediately after its death. The museum specimen, no matter how skilful the taxidermist through whose hands it has passed, gives a very inadequate idea of its functions. The coot is a sociable, not over-timid bird. Like the last, it is rarely seen off the water, even roosting on its surface. It feeds on water weeds, snails, insects, and seeds, and perhaps a few small fish. The nest, placed among the reeds, is very large for the size of the bird, being a compact structure of flags and reeds. Eggs, 6 to 1о, 2 inches; greyish, speckled with very dark brown. 


\section{CHAPTER XIII. THE CRANES AND BUSTARDS.}

The Crane.-Nowadays a rare straggler only, though at the end of the sixteenth century it bred in East Anglia. The old male has a red patch on the crown, and is a bird of about 4 feet in length.

[The Demoiselle Crane, another southern bird, is included by some in the British list, but many regard it as doubtful. It has been recorded in Somerset. $\left.{ }^{1}\right]$

The Great Bustard, familiar in the old engraving with the appropriate Stonehenge in the background, is another straggler in the islands where once it reared its young. The white bristles on the neck distinguish the male. The extinction of the bustard as an indigenous British bird took place in the first third of the present century.

The Little Bustard.-A straggler from Africa, now as always. It is worth noting that the bustards have but three toes. This bird, which is less than half the size of the last, is further distinguished by the bands of white on the throat and neck.

Macqueen's Bustard, a large and handsome bird with a conspicuous black-and-white crest and ruff, has wandered hither from its home in Central Asia on, so far as is known, two occasions only.

\section{CHAPTER XIV. THE WADERS.}

[These include the curlews, plovers, snipes, and sandpipers, a large and important group, most in evidence on our foreshores in winter. They are birds of very similar

3 Proceedings Wincanton Field Club (1893). 
habits, wading among the channels left by the receding tide and picking up a living on crustaceans and molluscs. The bill is long and slender; in some it is soft and adapted to sucking. They are mostly visitors on spring and autumn migration. The hind-toe is often wanting. They build no nest, laying the eggs in a depression in the earth. Eight residents, twenty-five regular, nineteen irregular, visitors.]

Also known as "Norfolk Plover" or "Thick-knee," the Stone-curlew breeds freely in the south and east of Eng-

* Stone- land, and a few remain in the warmer portions curlew. of the south-west through the winter, though the majority depart for the south in October. To Scotland and Ireland the bird is a rare straggler only. The underparts are dull white with brown streaks; the bill is black towards the tip, the base yellow. There is no hind-toe. It is a bird of nocturnal habits, feeding, chiefly on small mammals, reptiles, and beetles, after dusk, and not until the moon is up is its singular cry heard to any great extent. Heaths and rabbit-warrens are the favourite resort of the stone-curlew. Like the rest of the group, it lays its eggs in a depression among the stones, which they closely resemble. Eggs, 2, over 2 inches; pale brown, with grey spots.

§Pratincole.-An irregular visitor in spring and autumn, chiefly to the southern counties, though it has occurred as far north as the Shetlands. Its home is in Africa. One occurrence only is recorded from Ireland.

Cream-coloured Courser.-An African straggler to the south of England. One has occurred in Scotland, but none in Ireland.

Otherwise "Ringed Dotterel" or "Sand-Lark," the Ringed Plover is a familiar shore-bird on the east and south coasts, where it breeds in April. There are two 
races, a larger and a smaller, the latter being for the most part visitors on migration only. I know of a number of

Ringed patches on the coasts of Sussex and Hampshire

Plover. where the birds' eggs are to be found regularly every spring, and, curiously enough, they seem to know instinctively how hard the eggs are to pick out from among the surrounding stones, for, unlike many other groundbreeding birds, I have noticed them show but little anxiety when I was close upon the eggs. The latter lie with their points to the centre. The black collar and breastplate scarcely distinguish the bird from some of its relatives, which also affect these ornaments, but there is a conspicuous white stripe behind the eye, which should serve the purpose. The note of the bird is as shrill as that of most of the group, but a softer note is heard from the male during his courtship. The bird feeds on crustaceans (being very partial to sand-hoppers) and molluscs. Eggs, 4 (pear-shaped), I2 inch; grey, with black spots.

The Little Ringed Plover, distinct from the smaller race of the last-named bird, is a very rare straggler from the south, having occurred not more than half-a-dozen times.

The Kentish Plover is a regular visitor to England and a rare one to Ireland, nor does it occur so far north as Scot-

* Kentish land. The black band on the chest is distinc-

Plover. tive in the case of this bird, as its continuity is broken in the centre, and it therefore resolves itself into a patch on either side. The behaviour of this plover is very different from that recorded above of the ringed plover. It manifests the greatest anxiety when any one approaches the eggs or young, performing all the more commonly recorded tricks of the male lapwing, though much of this distress is unnecessary, for its treasures are fully as difficult to find. Nevertheless, collectors have played the mischief with the eggs of this once plentiful bird. They are often, though not invariably, placed with 
the pointed end in the earth, but not to the centre as those of most plovers. They are laid either on the shingle, or, occasionally, in the deserted nest of a tern. Eggs, 3, I I/4 inch; grey, with black spots and lines.

Killdeer Plover.-A very rare American straggler, which has been obtained twice only - in Hampshire and the Scilly Islands.

The Golden Plover, which retires to the inland moors to breed, is known by its black plumage, profusely spotted

Golden with bright yellow. It is found breeding in

Plover. the Hebrides, also in the Orkneys and Shetlands, the breeding-stations being on the moors and on high land. The note of this bird, often heard at nights, is shrill like that of the rest, though there is a more liquid sound about it. Eggs-laid in a depression slightly lined-4, 2 inches; greyish yellow, with dark-brown blotches.

Lesser Golden Plover, of which there are two forms, the American and the Asiatic. Each has occurred not more than twice.

The Grey Plover, a common winter visitor to the coasts of these islands, chiefly on the east side, may be known

t Grey by the white line over the eye, and may be

Plover. further distinguished from the golden plover, a bird of much the same size, by the absence of yellow from the plumage and the presence of a hind-toe. I give its general appearance in the winter plumage in which it visits these islands, for in its Siberian breeding-stations its breast is conspicuously black, the knowledge of which, however, will not greatly assist in its identification while with us.

The Dotterel should more properly perhaps be regarded * Dotterel. as a passing visitor on spring and autumn pas-
sage, but a number breed in the Lake District. According to Mr Saunders, its decrease in this country is 
due to the employment of its feathers in the manufacture of artificial flies. The crown of this bird is very dark, and there is a white curved line behind the eye, as well as a white band, somewhat indistinct, on the chest. It has the reputation of being a very stupid bird. Its food consists of insects. In Ireland its occurrence is exceedingly rare. It breeds up in the mountains, the eggs being laid in a depression in the grass. Eggs, 3, I I/2 inch; yellowish, with brown blotches.

The Peewit, or Green Plover, is easily distinguished by its black crest and breast, the underparts being Lapwing. white. It is found almost throughout these islands, and its curious flight and shrill cry are familiar,

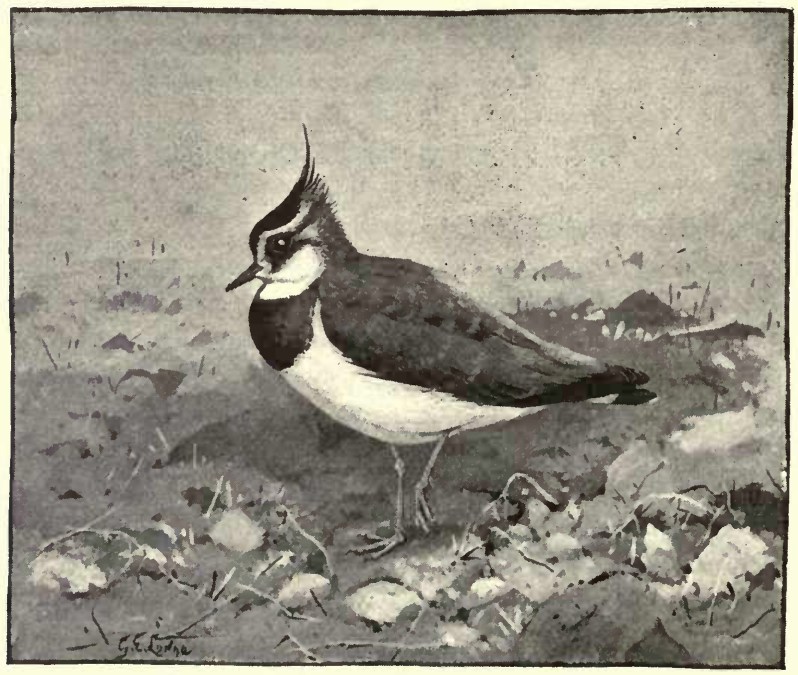

more particularly on the mud flats near the sea, in April after it has paired. Perfectly white lapwings have been recorded. This bird is commonly included among the food of the peregrine, but I was recently witness of the interesting 
sight of one of these fine birds flying rapidly over a large flock of peewits near Christchurch in Hampshire without showing any inclination to molest them. What, however, was even more significant than this-for the bird may of course have been gorged-was that the peewits showed not the least fear in presence of the falcon, as they might surely have been expected to do in the presence of a natural enemy. On the other hand, the wheeling bird seemed to have a business eye on the movements of a number of little white tails that were bobbing among the sandhills close by,-in short, it appeared to be bent on a meal of fur rather than feather, for which its preference is universally admitted. The male lapwing's tricks for diverting attention from his eggs or young have been alluded to; but, even before the breeding season, the evolutions in the air of both sexes are somewhat remarkable, and I have seen in the low land within a mile or two of the Baltic a flock of probably some hundreds of these birds behaving like tumbler pigeons. Mere wanton gambolling evidently, since they would not, even were it the practice of this bird to feed in the air, have been chasing any insects in a temperature several degrees below zero. In that country I have eaten the bird, and very fair it was, though I always believed it was not much eaten in these islands. Sir Herbert Maxwell, however, protests strongly against our wasteful consumption of both the bird and its eggs. The food of the lapwing consists of insects. The so-called "false" nests, which are so common in the vicinity of the breeding-grounds, are said to be caused by the males dancing to the females. The eggs are laid in a shallow depression, often lined with a few grasses. Eggs, 4, $1 \frac{3}{5}$ inch; greenish brown, with black blotches. These are the "Plovers' eggs" of trade, and so important is the industry that special dogs are trained to find them.

Sociable Lapwing.-A rare straggler from the Continent, which has occurred once only-in Lancashire. It has no crest, and there is a white line over the eye. 
The attractive black-and-white Turnstone is with us only on its way to and from its northern breeding-grounds, § Turn- though a few are said to stay the winter. It stone. may be seen in spring running among the seaweed just above the high-water line of late winter storms, and also turning over the shingle (though I have seen this far less commonly) for the little sand-hoppers beneath. It utters a loud twitter during its short flights to new feedinggrounds.

The Oyster-catcher, or "Sea-pie," is a conspicuous blackand-white bird, nearly twice the size of the last, and easily

Oyster- distinguished by the absence of hind-toe, the

catcher. greater length of the bright yellow bill, the upper mandible of which is also distinctly grooved, and the pink feet. It is seen seeking its crustaceans and molluscs on the flat weed-covered rocks, where also it lays its eggs. Like the turnstone, though rather more frequently, it is sometimes observed on the water, but only in still weather. Its double note is even shriller than that of most of the other waders. Eggs, 3 or 4, $2 \frac{1}{4}$ inches; yellowish, with dark spots and lines.

\$Avocet.-A rare spring and autumn visitor from the south, which formerly bred in our southern counties. To Scotland and Ireland its visits are few and far between. The most striking feature of this bird is the black, upcurved bill, with which it scoops crustaceans from the sand. It is an expert swimmer.

Black-winged Stilt. - A rare spring visitor to these islands, chiefly to the south of England.

The Grey Phalarope is an almost regular but usually scarce winter visitor, chiefly to the south of England. +Grey Some winters it arrives in great numbers. Phalarope. Its feet are yellow, and the toes are lobed. The underparts are dull red. 
To the greater part of these islands the Red-necked Phalarope is only a spring or autumn visitor on migra§Red- tion, and in Ireland it has occurred only once. necked A few still breed in the Scottish isles. Like Phalarope. the last bird, than which it is rather smaller, it has curiously lobed toes, and, like it also, the female is the handsomer bird. The bill is proportionately longer and more slender. Eggs, 4, I inch; greenish, with black blotches.

In spite of the fact of the Woodcock breeding, more than ever of late years, in almost every part of these †Woodcock. islands, it seems more desirable to regard it as a winter visitor, so familiar, to all at any rate who

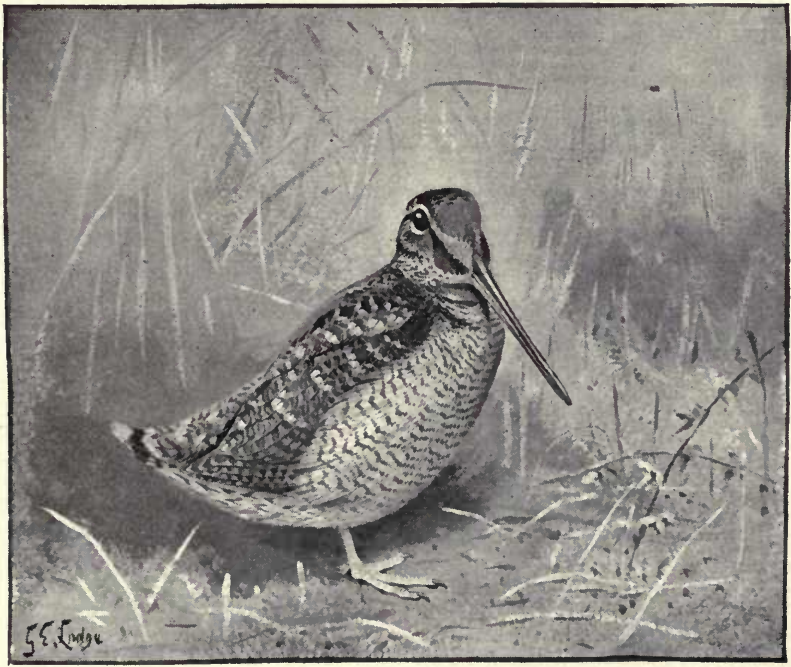

have resided on the north-east coast in autumn, are the return "flights." The birds leave again for Scandinavia in early spring, though, as above mentioned, a large number remain to breed. A number nest annually in Hampshire, 
and their tracks in the New Forest often arrest the attention of picnic-parties who have not the least idea of their meaning. There are many points of interest in connection with this bird, among those most often disputed being the method in which the mother carries her young (between the legs, and pressed with the bill, is, I believe, the actual manner), the precise extent of the bird's migrations, and the exact manner in which it produces the curious sound known in some parts as "roding," which is quite distinct from the "drumming" of the snipe. With regard to its migrations, ornithologists seem on the whole to regard these as very capricious, and Mr Saunders attributes much of the scarcity of the woodcock at certain times to the bird's secretiveness after moulting. In its external features the woodcock is also among the most interesting of our birds, the eye being placed far back, obviously by reason of the way in which the bird obtains the soft worms by thrusting its bill into the mud, the latter organ being, moreover, most sensitive towards the tip, which is curved and wrapped in a membrane. When on the foreshore, the woodcock also devours quantities of small shrimps and sand-hoppers, most of its food being obtained after sundown. It bears some resemblance to the snipes, but may be readily distinguished by the presence of feathers down to the tarsus, which gives it the appearance of being much shorter-legged than the latter. On the wing, the woodcock hangs its head in a fashion unique among birds. The bird lays in April in a depression in the earth lined with dead leaves. It breeds in all the southern counties. Eggs, 4, I3/4 inch; yellowish, with brown blotches.

The Great Snipe, a winter, or, more properly, autumn, visitor to the east and south of England, is rarer in the

tGreat west; while in Scotland and Ireland its re-

Snipe. corded occurrences have been little more than a dozen. It is also known as the "Double " or "Solitary" 
snipe, and is the largest of the three found in these islands, having a good deal of white in the tail; the latter, moreover, has sixteen feathers, being two more than in that of the common snipe, and four more than in that of the Jack-snipe.

The Snipe is one of those partly resident birds, the numbers of which are, after breeding, replaced by autumn

Common visitors. There is a black variety, practically Snipe. confined to these islands, and formerly distinguished as a species under the name of "Sabine's snipe." The bird breeds near bogs, and is perhaps more generally distributed in Ireland than in any other part of these islands. It is a shy bird, and is often surprised tripping about the mud in search of worms and other soft food, but is rarely hard to put up. It squats low, and is occasionally successful in baffling a dog in this manner. The "drumming" of the snipe in the breeding season, as he drops into cover, is among the most extraordinary of bird sounds, and there seems reason to suppose that it is caused by the action of the air rushing through the feathers of the wings. Sir R. Payne-Gallwey gives a very interesting account of this in his 'Letters to Young Shooters' (1896, pp. 348-352). It makes a slight nest. Eggs, 4, I $\frac{3}{5}$ inch ; yellowish, with brown blotches.

The "Half-snipe" is found on our foreshores and among the swamps in the vicinity from October until April. In

† Jack- spite of a few having been, on what appears

Snipe. loose evidence, known to stay the summer year after year, there seems no reason to suppose that it has ever bred in these islands. This is the smallest of our snipes.

Red-breasted Snipe.-A straggler, mostly in autumn, from North America, which has occurred about a dozen times in England, twice in Scotland, and once in Ireland. 
[There is a larger species, sub-species, or variety, which has occurred once-in Ireland.]

Broad-billed Sandpiper.-A straggler from Scandinavia, which has occurred five times in the south and east of England, and once in Ireland.

Pectoral Sandpiper.-A straggler from North America. It has been obtained over twenty times in England, mostly on the east side, and twice each in Scotland and Ireland.

Bonaparte's Sandpiper.-Another American straggler, of which about a dozen, or rather more, have been obtained in England, most in the west, and one in Ireland.

Sharp-tailed Sandpiper.-A Siberian bird that has been obtained once-in Norfolk.

The Dunlin, or "Ox-bird," is common throughout these islands in winter, at which season flocks are seen on all our

Dunlin. low shores; but in the spring, the breeding season being about May, these birds become more local, especially in Ireland, where its breeding-stations are very few. In England it breeds chiefly on the higher moors. In the breeding plumage the breast of the male is conspicuously black, and the great length of the bill is certain to attract attention. The food and habits are the same as those of the rest of the group. It builds a slight nest in the grass or heather. Eggs, $4, \mathrm{I}^{\mathrm{I}} / 3$ inch; greenish, with brown spots.

The Little Stint, a small and noisy bird, bears some resemblance to the dunlin. I have seen numbers on $\$$ Little the Sussex and Hampshire coasts in former

Stint. years, though they seem less plentiful of late; and they are often found in the company of larger waders, which has always suggested to me the parallel of the herds of mixed game that in the old hunting days were, we are told, to be seen browsing together in peace in the South 
African veldt. Its trivial name is unsatisfactory, as it is slightly larger than Temminck's Stint.

American Stint.-A very rare straggler, which has been obtained on three occasions-in the south-west.

A spring and autumn visitor, reported to have wintered $\S \mathrm{Tem}-$ in Ireland, from arctic regions. There is minck's more white in its plumage than in that of Stint. the other stints.

This small visitor on migration, chiefly to the eastern seaboard, may be distinguished by the reddish tinge in the \$Curlew underparts and the white on the back. Its Sandpiper. chief resemblance to the curlew, a bird three times its size, lies in the long curved bill. Its flight is rapid; and its egg and breeding-place were, until the present year (1897), unknown.

An idea prevails among ornithologists that the Purple Sandpiper may breed sparingly in the Shetlands. It is + Purple seen on our shores in winter, seeking its food Sandpiper. on or near the water. The short legs are yellow in colour.

The Knot is a common winter visitor to all our coasts. I have observed that this wader is far less shy when t not. alone, a not uncommon way of finding it, than
when in company; and this is characteristic of all gregarious birds, which probably flock for the double object of finding food and being on the alert for enemies. A hundred pairs of eyes and ears can recognise danger, as a hundred bills can find worms, so much sooner than the number allotted to the individual. The antics of the knot at the edge of the receding tide, where it thrusts its long straight bill after the retreating solen, are often very striking, and when it takes flight the mottled underparts are most conspicuous. The back is black, barred with pale 
brown. The bird's breeding-grounds and egg are a mystery, though the young have been taken but a few days old. The knot is a great traveller, being found as far south as Australia, whither it journeys from a presumably arctic birthplace in incredibly short time.

The northern Sanderling, which is found in numbers on most of our coasts in early autumn (the old and young \$ Sander- birds arriving together), and again in spring, ling. is easily known by the conspicuously black back and white underparts, the absence of a hind-toe, and the straight black bill, slightly swollen at the tip. I have shot the bird on the mud-flats north of Leghorn, and I noticed that, unlike a number of waders, it invariably flew straight out to sea when disturbed. They were the smallest waders on that coast, and were always very fat.

The Ruff (the female is called "Reeve") must be regarded as an autumn visitor nowadays, though a few may still sRuff. breed in East Anglia, where formerly the birds nested in hundreds. Thus the bird is seldom seen with us in the full glory of his many-coloured ruff, which he only wears for a short time during the breeding season, and when flocks pass us in spring the sides of the face are patchy, wearing a half-ragged appearance. The spring "hilling," or sparring, of the males consists for the most part of show, not unlike the similar mock-tournaments observed in some of the game-birds. The ruff feeds on worms and seeds. The nest is in the grass. $E g g s, 4$, I告 inch; greyish, with brown spots.

Buff-breasted Sandpiper. - A straggler from arctic America, which has been obtained about a dozen times in England, chiefly in the south, three in Ireland, but not once, it is thought, in Scotland.

1 In the same way (among fish) the dull female of the Gemmeous Dragonet goes by the name of Dusky Skulpin. 
Bartram's Sandpiper.-Another North American straggler that has occurred less than a dozen times, of which three were in Ireland. Not recorded from Scotland.

The "Summer Snipe" is found in these islands between April and September, though it breeds chiefly in the west, * Common also in most parts of Scotland and Ireland, Sandpiper. near all the great inland waters. The white in the tail-feathers and the indistinct white line over the eye are not so useful in distinguishing this bird from the others as its restless manner. The bird is never still, and will even fly to some low perch and back, if watched. It is also seen on the water. The nest, always in the immediate neighbourhood of water, is a less elementary structure than that of most of the group. Eggs, 4, I I $/ 2$ inch; reddish, with brown spots.

The Wood-Sandpiper is a scarce, though regular, visitor on migration, rarer in Scotland, and reported once only $\S$ Wood- from Ireland. It has conspicuous white spots Sandpiper. on the wings and back, and white bars on the tail. It formerly bred in Northumberland.

Formerly confused with the last, and chiefly distinguished by the broader black bars on the tail and the shorter legs, \& Green the Green Sandpiper is also a slightly larger sandpiper. bird, and in tint is of a more decided green. Although it probably never breeds in these islands, it is interesting to note that, unlike the rest of the group, it is known on the Continent to make use of the deserted nests of thrushes and magpies,-a very remarkable difference from the nesting habits of its fellow-waders. It is the largest of our sandpipers.

Solitary Sandpiper.-An American straggler which has been obtained on three occasions.

The Redshank is found on the coast in winter, going to 
its inland breeding-places early in March. It is one of the noisiest of a noisy family. Its distinctive points are Redshank. the bright red legs and black-tipped yellow bill. It can swim well, and is even known to dive when wounded. Like the lapwing, it is said to throw itself into the most remarkable contortions to tempt the intruder away from its eggs, which are concealed in a tuft of grass. Eggs, 4, 13/4 inch; yellowish-grey, with brown blotches.

The Spotted Redshank is a spring and autumn visitor to the eastern counties; rare north of Yorkshire and across §spotted the Border, and has occurred in Ireland only Redshank. about half-a-dozen times. The legs are darker red than in the last, and the plumage is more mottled. It is also a slightly larger bird.

Yellowshank:-An American straggler that has occurred only once or twice. The legs and feet are bright yellow.

The Greenshank is a visitor on migration to our inland waters, a very few remaining the winter, especially in Ire-

§ Green- land, and others breeding, according to Harvie-

shank. Brown, in the Outer Hebrides and some other of the isles, and also on the mainland in the far north. It is a larger bird than the redshank, the legs and feet are green, and the black bill has a slight upward curve. Water seems somewhat less essential to its comfort than is the case with the rest of the group, for it seeks much of its food in upland fields, and the primitive nest is also found at some distance from water. Eggs, 4, 2 inches; grey, with purple blotches.

The Bar-tailed Godwit is a visitor on migration to every part of the British coasts, but never breeds in these \&Bar- islands. The white bars on the tail, from tailed which it takes its name, are most conspicuous Godwit. in the summer plumage, though discernible even in the duller tints of winter. The bill is slightly 
up-curved, and the toes are partly united by a membrane, the centre one having a comb-like edge. The double note is soft.

Though now only a visitor on migration to the east side of England, rarer in Scotland and Ireland, the Black§Black. tailed Godwit formerly bred in the fens. A tailed slightly larger bird than the preceding, it is

Godwit. distinguished by the black tail and white bars on the wing.

The Curlew is a resident in these islands, but it should be borne in mind that its migrations within their limits

Curlew. are considerable, and it is not to be found in the same district all the year round. Like the next bird, the curlew is conspicuous by reason of its long down-curved bill; the rump is also white, and the underparts are profusely streaked with dark brown. This bird is a great trouble in winter to the shore-shooter, for it is easily alarmed, and its shrill note is enough to alarm everything else within range. So rapid is the flight of this bird with the wind behind it, that one has been known to go through a $1 / 4$-inch plate-glass window. The curlew breeds in almost every part of these islands, except in the south-east of England and the Outer Hebrides. It visits the latter, however, in winter. $E g g s, 4,23 / 4$ inches; greenish-brown, with dark blotches.

The Whimbrel, "May bird," or "Titterel," is a visitor on migration to the mainland of these islands, breeding

\$Whim- only in some of the Scottish isles, as in the brel. Orkneys and Shetlands, and one or two spots in the Outer Hebrides. It is a much smaller bird than the curlew, to which it, however, bears strong resemblance, differing chiefly in the presence of a whitish stripe over the eye. As in the case of the curlew, the female is the larger bird. I have also fancied that I observed less order 
in the passing ranks of whimbrels moving in flocks. It is said to be very bold in defence of its eggs, and is also said to be partial to land berries. Eggs, 4, 21/2 inches; greenish, with brown blotches.

Eskimo Curlew.-A rare straggler from North America to the British Islands, to which it has found its way about half-a-dozen times.

\section{CHAPTER XV. THE TERNS, GULLS, AND SKUAS.}

[An important group, including the majority of our seabirds, most of which are resident, others being mere stragglers. These birds are web-footed, and rapid on the wing. The terns have been termed not inaptly the swallows of the sea, and their swallow-like flight as they skim the waves recalls the little migrants, as does also their awkwardness on land. They lay their eggs on the earth without any approach to a nest. They are, in some localities, great enemies of the gulls, destroying their eggs and young. Nine residents ; twelve regular, eleven irregular, visitors.]

\section{The Terns.}

The Common Tern, with us from May to September, is a grey bird with black crown and white underparts. The * Common tail, as in all this group, is deeply forked. Tern. The bill and tail are orange-coloured. This tern feeds, as do the rest, on small surface fish, and, though no diver, may be seen plunging on the shoals and generally securing a prize. Eggs, 3, I 3/4 inch; grey, with dark blotches. 
Apparently resident on the east side of Scotland (where it breeds on the islands), also on the west in the Hebrides,

Arctic and off the English coast on the Farne group,

Tern. the Arctic Tern is a somewhat darker bird than the last, and the bill and legs are of a more pronounced red. In food and habits, it resembles the last. Eggs, 2 or $3, \mathrm{x}^{2} / 3$ inch; greenish, with red spots.

The Little Tern, with us from May to September, and breeding, somewhat locally, on almost all our coasts, ap-

${ }^{*}$ Little pears to be absent from most of the Scottish

Tern. isles. The bill is bright yellow, tipped with black, while the crown and a line from the eye to the bill are also black. Like the other terns, the bird is bold when near its eggs. It makes no nest. Eggs, 2 or $3, \mathrm{I} / 3$ inch ; grey, with brown spots.

Sooty Tern.-A straggler from the tropics, obtained three times. I have seen large numbers on the islets in the Red Sea.

Scopoli's Sooty Tern.-A very rare straggler from the tropics; has been obtained but once-at the mouth of the Thames.

Gull-billed Tern.-A rare straggler from the south. About a score have been obtained in England, chiefly in the east and south; none in Scotland or Ireland.

The Caspian Tern, the largest of British terns, is a rare visitor to the east and south of England, but has not reached Scotland or Ireland.

Though the Sandwich Tern is a regular visitor to these islands, and, while far less plentiful than formerly, *Sand- still found breeding on the Farne Islands wich and in other spots on the English, Scottish, Tern. and Irish coasts, the breeding-stations of this bird are at the present day few and far between. The male has a black crown, and the long, forked tail, with the rump, is conspicuously white. The bird feeds 
largely on sand-eels, and I once saw a pair of them lifting these little fish from the surface of a sheltered bay in Cornwall early in July, and visiting a ledge of rock not much above high-water mark. I had my suspicions that they were feeding their young, but as the bird is said to have forsaken the Cornish coast and Scillies as breedingstations, this was probably fancy on my part. At any rate, my object was fishing, and not molesting sea-birds, so that I gladly left the matter in uncertainty. Eggs, 2, 2 inches; yellowish, with reddish-brown spots.

The Roseate Tern formerly bred among the Scilly Islands, but now nests only in a semi-protected state on the Farne

* Roseate Islands. The pink tinge on the underparts,

Tern. from which the bird derives its name, is not lasting; the legs and feet are red; crown black; and general plumage on the back silver grey. This tern is rarely if ever seen away from the immediate vicinity of the coast. After the last two, this is about the largest of our terns. Eggs, 2 or 3, I $3 / 4$ inch ; pale brown, with deep brown blotches.

A scarce visitor on migration, the Black Tern formerly bred in East Anglia and in the Solway district. Its occur-

§ Black rence north of the Border seems more frequent

Tern. on the west side, which is the reverse of what obtains farther south. The tail in this (and in the following) species is much less forked than in the preceding terns - the same difference, in fact, as between the tails of the martins and swallows. It is chiefly an insect-eater, dragonflies being among its favourite articles of food.

The White-winged Black Tern is a scarce visitor on migration, chiefly in spring. It appears not

\$ White-
winged to have reached Scotland, and has been Black reported about half-a-dozen times from

Tern. Ireland. 
Whiskered Tern.-A rare straggler from the south. It has been obtained half-a-dozen times only.

Noddy. - A rare visitor from the tropics, which has been reported twice-from Ireland. There were several species of noddy in Australia, handsome birds with uniform dark plumage. They feed on fish, which are picked off the shallows.

\section{The Gulls.}

The trivial name of the Common Gull is an instance of the loose employment of the prefix "common," since the

Common commonest of our gulls, especially during the Gull. summer, when people visit the Channel towns, is the Herring-gull, the so-called common species having flown north to breed. In Ireland, again, as Mr Saunders points out, the commonest gull is the black-headed species, also abundant all the year round on our south coast. In company with both of these, this gull will follow the plough, especially in rough weather, and feed on the worms that it turns up; and it will also wander up tidal estuaries, though those which venture up the Thames regularly as far as Battersea are, so far as I have ever seen, of the black-headed species. I once saw in France, near the coast, several of these gulls following the plough in company with a pair of choughs, and there was a good deal of fighting, though it did not appear that family ties entered very much into the matter, as the gulls were punishing each other severely, as well as shrieking at the red-legged birds. The latter were, however, sworn allies, and this gave them the better chance. At any rate, the gulls presently flew to another part of the field, leaving the choughs to worm in peace. This gull will, when there is nothing more to its taste, eat grain and turnips, but it cannot of course be treated seriously as an offender in this respect; while, on the other hand, its undoubted fondness 
for that curse the wireworm constitutes it undoubtedly a friend and ally of the farmer. In summer the head and neck of this gull are white, but in winter they are spotted or streaked. The bill is yellow at the tip, darker at its base. It makes a large nest of grass and seaweed on some islet, and close to the water. Eggs, 3, 2 I/4 inches; light brown, with black blotches.

The Herring-Gull, a larger bird than the last, is found breeding on all our coasts. I have seen its eggs, sometimes

Herring- from above and in anything but pleasant places, Gull. near Dover, Hastings, and Torquay, and have found the nest with young just outside Lulworth Cove, in Dorset, and west of Polruan, in Cornwall. The name is not a very happy one, for most other gulls will follow and harry the herring and pilchard shoals, besides which this bird feeds a good deal on sloping fields on the downs, and is a great egg-lifter. It is easily recognised by the sharp contrast of the black of the folded wings, the tips having some bright white spots, and by the yellow-and-red bill. The head and neck, pure white in summer, are, as in the last, streaked in winter. Like the other gulls, this bird is no diver. I have had them round my lugger when fishing the whole day eight or ten miles from the Cornish coast. The seafowl in those parts seem to be but little molested by the fishermen, if one can judge at least by the absence of fear. I have had herring-gulls and blackheaded gulls and guillemots (or "murrs") all feeding on whatever I threw them. To the gulls the most suitable offering was a dry fish that had been caught some time, and that would consequently float while they tore pieces from it. Otherwise they liked best a fresh wrasse, which, from the buoyancy of its distended air-bladder, would also float. As soon as I threw a piece of wet fish, however, which immediately sank, the gulls would merely hover over it, seemingly unable to snatch it from even an inch or two beneath the surface. Then came the turn of the 
guillemots, which would disappear on business and return at a safe distance from the larger fowl that might have resented the intrusion. I tried this many days, and always with the same results, for the question of gulls being able or not able to dive has an interest in connection with the harm they are alleged to do the fisheries, a matter to which I may have to allude on a later page. The nest is sometimes near the ground. Those who have seen only casual breeding-sites associate the birthplace of these birds with inaccessible cliffs and crannies; but some of our most famous gulleries-for instance, the Lincoln colonies at Scotton and Twigmore-are in low flat situations in the immediate neighbourhood of ponds. Eggs, 3 , nearly 3 inches; pale brown, with dark blotches.

The Black-headed, or "Laughing," Gull is another of our common species, and is familiar nowadays even to Black- Londoners, as some are generally to be seen headed in the winter months above Waterloo Bridge. Gull. It breeds on several parts of our coasts, more particularly in Scotland and Ireland. I recollect one arm of the Baltic, not far from a large wood inhabited by wild swine, where these birds bred in hundreds, and the eggs were easily obtained, being, in fact, on the ground. The name of this gull is not much nearer the mark than that of the last, for in the first place the head is white in winter, and even in summer it is dark-brown, not black. Nor can its voice be considered more like laughter than that of several other members of the genus. Like many of the rest, it is partial to wireworms, and I saw these gulls on more than one occasion catching mice in some fields east of Bognor. Eggs, 3, $2 \frac{1}{5}$ inches; light brown, with dark blotches.

Mediterranean Gull has been obtained once or twicein the eastern counties.

Great Black-headed Gull.-A southern straggler that has been obtained once. 
In the Lesser Black-backed Gull the back is almost black, the head and neck white (streaked in winter), and Lesser the bill yellow with red tip. It breeds on our Black- northern coasts wherever there are cliffs and backed rocks, also in Cornwall. In the north it does Gull. damage to the eggs of moor-breeding birds, and is on that account kept under. In winter it occurs

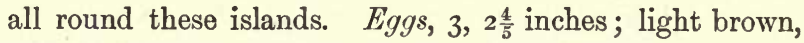
with blotches.

The Great Black-backed Gull, the largest of the gulls that breed in these islands, is not unlike the preceding,

Great

Blackbacked Gull. though a considerably larger bird. I have seen its eggs through glasses down near the Land's End, but they were always in places that did not tempt me farther. It is, like the last, a pest, only much worse on account of its greater size ; and is even known to attack lambing ewes. It does not breed on the east coast, but has a number of stations among the Scottish and Irish cliffs. Eggs, 2 (sometimes I), 3 inches; brownish-grey, with dark blotches.

The Glaucous Gull, a winter visitor only, is a splendid bird with yellow bill and pink legs, the wings white, tGlaucous the back silvery grey. Its visits are chiefly Gull. to the coast of Norfolk and the east of Scotland.

The Iceland Gull is a scarce winter visitor, smaller † Iceland than the last, and having proportionately Gull. longer wings.

Bonaparte's Gull.-A rare arctic straggler, which has occurred half-a-dozen times only.

The Little Gull is an irregular visitor from Northern † Little Russia. The head, black on the breedingGull. grounds, is almost white while the bird is with us. Legs bright red. Wings dark below. 
Ross's Gull.-A wedge-tailed bird, that has wandered from the Polar regions on one occasion only, many years ago.

Sabine's Gull is a rare visitor on autumn migration. The tail is forked. The head and neck are grey while §Sabine's the bird is with us, though in summer quite Gull. black. It is not a regular visitor, and only about a dozen specimens are recorded from Ireland.

Ivory Gull.-A scarce winter visitor from the north. Of the thirty odd examples that have been obtained, most were recorded from Scotland.

The common Kittiwake breeds in Devon and Cornwall,

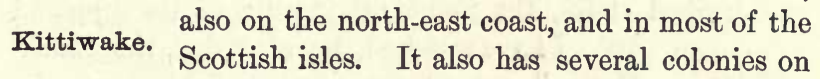
the more precipitous coasts of Ireland. Like the last, it

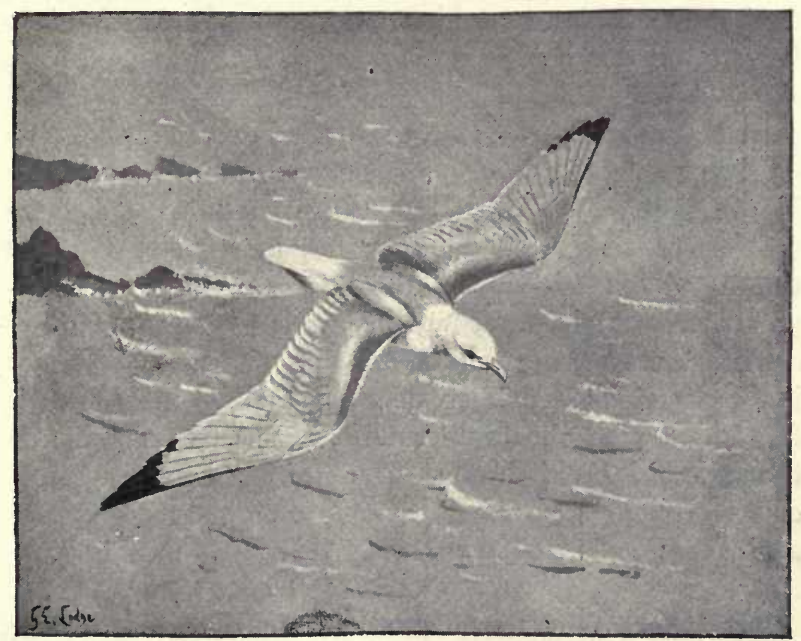

is a short-legged bird, and the hind-toe is absent. The tail is white, the wings long and pointed and tipped with black. It is essentially a sea-bird. I have met with it 
hundreds of miles from land, and its flight is rapid and sustained. I have also observed that its swooping on the fry embraces a nearer approach to diving than is ventured on by most gulls, the bird's head and wings being often completely immersed. The name has of course reference to its grating note, and is about as descriptive as most other bird-names bestowed for similar reasons. The nest is on rocky ledges. Eggs, 2 or 3, 2 inches; greenish-grey, with dark blotches.

\section{The Skuas.}

The Great Skua is a large, dark bird, with powerful bill and hooked claws, the name originating in its supposed Common cry. I have watched, day after day, the "JackSkua. Hurry" out on the Cornish fishing-grounds, as it swooped on the gulls and made them disgorge their food. The fishermen told me that when it attempted to levy toll in this way on a shag, that wily bird would dive, at which the skua was no match for it. There prevails on parts of the coast a notion to the effect that the skua feeds on the excreta of gulls, and the name of "Dung-bird" is in consequence bestowed on it. There must be a large number of non-breeding birds; for, in spite of the fact that it breeds nowhere in these islands save in a semiprotected state in the Shetlands, it is to be found every summer off Cornwall, and I have met it off the Needles in June. Besides making the gulls disgorge their food, it feeds largely on the smaller birds themselves, notably on the young of the kittiwake. The bird nests on the ground on the high waste lands in the Shetlands. Eggs, 2, $2 \frac{4}{5}$ inches; greenish-brown, with very dark markings.

The Pomatorhine Skua is an autumn and winter visitor $\dagger$ Pomator- to our east coast, less frequently to Ireland. hine Skua. The lower parts are white, and the long tailfeathers are twisted vertically. 
Of Richardson's Skua two forms occur on our coast-a light-chested one, known more properly as the Arctic Skua, Richard- and a darker. Both breed in most of the son's Skua. Scottish isles, and intermediate forms are found, which bridge over the differences. The tail is long and tapering. This skua obtains most of its food by violence, but it also feeds on shore crustaceans. Eggs, 2, $2 \frac{1}{3}$ inches; green, with brown blotches.

The Long-tailed Skua is so called from the long brown tail-feathers. It visits our coasts, more particularly on the §Long- east side, in autumn, and less frequently in tailed Skua. spring. Save for the longer tail and some yellow on the neck, this bird is not unlike the somewhat stouter light form of the last.

\section{CHAPTER XVI. THE ALBATROSS, PETRELS,} AND SHEARWATERS.

[A group of sea-birds, mostly of small size, distinguished by their tubular nostrils. They spend most of their time on, or over, the water, and feed entirely on fish. They comprise three residents; two regular visitors ; five irregular visitors.]

\section{The Black-Browed Albatross.}

A specimen of the Black-browed Albatross was taken this summer (July I897) near Linton, in Cambridgeshire. The legs and feet are greyish-blue, the tail blackish, head and underparts white. The occurrence inland of this southern bird, which has more than once been seen hovering in the neighbourhood of the outlying Faroë Islands, created something of a sensation in the press and elsewhere. 


\section{The Petrels.}

Those who know the great albatrosses of the southern hemisphere find its flight wonderfully reproduced in that of

Storm- its tiny black-and-white relative, the "Mother

Petrel. Carey's chicken," or Storm-Petrel, of northern seas. The foolish notion that connects this bird with storms has just so much truth in it as that, knowing instinctively when a storm is nearing, it seeks the company of ships. The albatross does, as a matter of fact, often fly better in a gale than in still weather, and I have seen these birds following the ship for days of very dirty weather heedless of the storm. Not only does the flight of the petrel recall the larger bird, but its features are those of the other in miniature-the tubular nostrils and hooked bill; and, to complete the resemblance, there is the same unpleasant oily smell about the plumage. When a petrel is brought aboard, it is visibly distressed, like its larger relatives, keeping its footing with difficulty and hanging its head, while oil drops from its bill as if it were sea-sick. Like all its kind, the storm-petrel is a true sea-bird, feeding on the floating squid and other surface food, and even roosting on the water. It breeds in the Scilly Islands and on Lundy. The single egg is laid at the farther end of a burrow that smells yet worse than

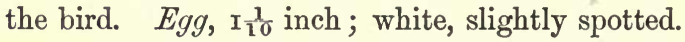

Leach's, or the "Fork-tailed," Petrel, is an irregular visitor to the east coast of England, but breeds on St Leach's Kilda, as well as in parts of the Hebrides and Petrel. elsewhere on the Scottish and Irish coasts. I recollect one of these birds being picked up dead after a three days' gale one November off Ecclesbourne, near Hastings. The bird is somewhat less sombre than the storm-petrel, and the white-barred black tail is forked. Egg, I I/3 inch ; white, with tiny spots.

[An example of an allied species was found on the Sussex 
coast in 1895, another in Colonsay on New Year's Day 1897.]

Wilson's Petrel.-A rare straggler from the southern seas, of which under a dozen have been taken in England, a couple in Ireland, but none in Scotland.

Bulwer's Petrel. - An Atlantic straggler, which has occurred once only-in Yorkshire.

Capped Petrel.-A southern straggler, which was obtained once-in Norfolk.

The Fulmar is known on the English coasts only in rough winter weather, but breeds in the Shetlands, Outer

†Fulmar Hebrides, and St Kilda. It is the largest of

Petrel. our petrels, and has all the family characters. There are two forms, one with darker grey underparts, but it is the whiter race that breeds in the above islands. This bird is closely allied to the great "Mollies" of the South Australian coasts, and, like them, and in fact all the petrels, feeds on the water. I have seen several flying slowly about the herring-boats at the mouth of the Elbe. The egg is laid on a ledge. Egg, 3 inches; white. It has a rough surface and, when first taken, a strong smell.

\section{The Shearwaters.}

Tolerably common-the non-breeding birds at any rate -on most parts of our coasts throughout the year, the Manx Manx Shearwater breeds off the Cornish coast, Shearwater. perhaps on Lundy, and, I am told, among some islets not far from Weymouth. It also nests among the Scottish isles and at several points on the Irish coast. The shearwaters differ from the petrels in the much longer curved bill. The flight is rapid, and is performed just clear of the water; and I have seen the bird riding on 
the water on calm days, but I think it never dives unless it first gets up plenty of way on the wing. Then it will go right through the waves and come up a little way off. Its food consists, however, for the most part of squid and other creatures that it can get without diving. $E g g, 22$ inches; white.

Dusky Shearwater. - An Atlantic bird, which has occurred twice only.

Sooty Shearwater.-An irregular visitor in the cold months, formerly confused with the young of the next.

The Great Shearwater is a scarce visitor on migration, $\S$ Great chiefly in autumn. Its food consists of squid Shearwater. and cuttle. The fishermen use it for bait.

\section{CHAPTER XVII. THE GUILLEMOTS, DIVERS,}

\section{AND GREBES.}

[The three groups of which the order is composed differ widely, for the first have stout short bills for the most part ; the divers are all marked by curious bands on the throat; and the tailless grebes have singular palmated feet, recalling those of the coot. In all, the underparts are white. They all dive, however, for their food, but in their nesting habits they bear little resemblance, one group constructing large floating nests, another making no nest whatever. There are, in all, eight residents, five regular visitors and one irregular visitor.]

The Razorbill is a common bird on our coasts all the year round, breeding in most of our cliffs. Down near LulRazorbill. worth Cove there are inaccessible ledges covered with their eggs and young; and I have noticed that the gulls and other seafowl that breed there 
take up different levels. The bird must occasionally seek congenial food at some distance from its nesting-place, for this summer there was a pair right through June and July every morning under Bournemouth pier just after sunrise. I used to go down at daybreak almost without fail to get smelts and sand-eels for baiting with later in the day, and there were these two diving birds, which had also apparently learned that the small fish congregate in the shelter of the weed-covered greenheart piles when they were not to be found elsewhere in the bay. 'There are, however, no cliffs in which these birds would care to nest nearer than St Alban's Head on the one hand and Hengistbury Cliff on the other, the latter fully three or four miles away, the former indeed considerably more. It is therefore to be presumed that the birds had some means of conveying food to their young, but where they stowed it, unless in their mouth, I do not know. The only other assumption was that there were no young to feed, though, as the birds were of different size, therefore presumably of opposite sex, there seemed, considering the time of year, slight ground for such a supposition. This bird is about the same size as the equally familiar guillemot, but the bill is conspicuously humped at the end, and the back is of a deeper black. It also floats at the surface with its tail cocked, like most of our ducks. In taking wing from their nesting-ledges, all these birds drop sheer from a great height, then suddenly sweep up in a curve just when they seem about to fall into the water. Like the guillemot, this bird lays a single large egg, which it also incubates lengthwise. $E g g, 2 \frac{4}{5}$ inches; brownish-white, with dark blotches.

The Guillemot is an equally familiar bird, with long straight bill and brown plumage. There is a "ringed" Guillemot. variety having conspicuous white lines round the eye. It breeds on rocky ledges, and I have had eggs from every county between Hampshire and the Land's End (including the Isle of Wight), but 
its chief stations are, I believe, in the north-east. In the spring of 1894 I was witness of a somewhat interesting sight, which enabled me to record in the 'Field' a new article of food for this bird, notably large barnacles. I was steaming near the Wight when I saw something on the water, which developed under strong binoculars into

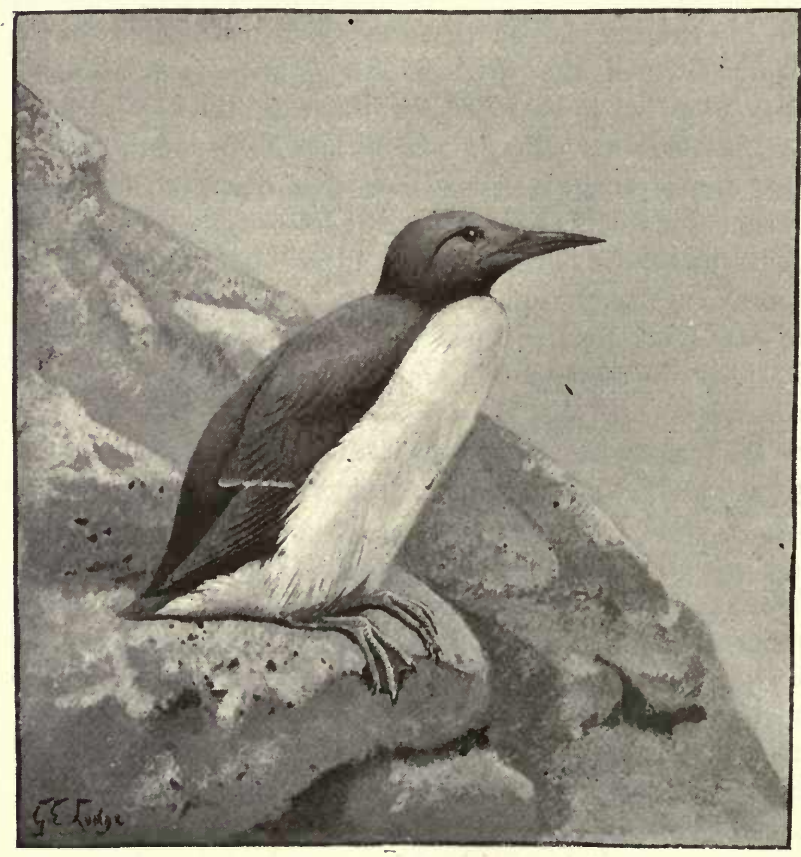

a small plank, evidently a fragment of wreckage, covered with those crustaceans, which two guillemots were busily tearing off and eating-such portions at least as they could manage, for a barnacle is not all eatable. There could be no doubt about their occupation, for I could plainly see them first worrying the creatures off the wood, then throwing up their heads, evidently swallowing some portions. 
This is interesting, as I never knew of any bird before, either north or south of the equator, that tackled a fullgrown barnacle and came off alive. On the Cornish coast, where the guillemot, or "murr," is found in abundance, it will seek the company of fishing-boats for the sake of the scraps of ground-bait (vernacular, "guffin ") thrown overboard; and I have known one paddle round my boat in this way for hours together. It is often caught in the stake-nets, and so many were recently destroyed in this way off the Fowlsheugh, near Stonehaven, that the Government was petitioned to cancel the lease of the nets, and did so. Egg, 3 $\mathrm{T} / 4$ inches (the female is only about 16 inches !) ; pear-shaped and green, white, or stone-colour, with black or brown blotches and lines.

Brünnich's Guillemot. - A rare straggler from Polar regions.

The Black Guillemot, with the conspicuous white patch on the back of the wings, is found breeding on the Isle of Black Man, also among the Orkneys, Shetlands, and Guillemot. Hebrides (where it is known as the "Turtledove"), and on rocky parts of the northern portion of Ireland. In other parts of these islands it is seen only very rarely, in winter. Unlike the other guillemots, this bird lays two eggs. Eggs, 2, 2 I/3 inches; bluish-white, with brown blotches.

† Little The Little Auk, an uncommon winter visitor

Auk. to our north and east coasts, is a small blackand-white bird, with stout bill and a white spot over the eye.

The Puffin, "Sea-parrot," or "Culterneb," is a little black-and-white bird, the most remarkable feature of

Puffin. which is unquestionably the bill, for, instead of putting on smarter courting plumage, it grows a larger bill at breeding-time, and that protuber- 
ance becomes, moreover, brightly streaked with red and gold. In autumn this attraction is shed piecemeal. It is after this bird, which has burrowed there from time immemorial, that Lundy Island is named. It also breeds in the Scilly Islands, among the Hebrides, and in fact among all the wilder cliffs of the Scottish and Irish coasts. Egg, 2 I/4 inches; dirty white (in collections), with small brownish spots. It is said to be pure white at first, but I have not taken it myself.

\section{The Drvers.}

The Great Northern Diver, a large and handsome bird, must be regarded as a winter visitor to these islands, t Great though it is said to breed in the Shetlands. Northern The black plumage is spotted with white; Diver. the underparts are white; and there are two white streaked bands on the throat. It seeks food at considerable depths. This bird is not uncommon off the Cornish coast in early winter. Like the rest, it is awkward on land, and is seen to best advantage in the water.

White- (or Yellow-) billed Northern Diver.-A Polar bird which has been obtained on four occasions only, all on the east coast. It is a slightly larger bird.

The Black-throated Diver, a rare visitor to England in the winter months, breeding in the north of Scotland Black- and among the isles, has the throat conspicuthroated ously black, with a narrow white streaked Diver. band. Eggs, 2, 3 inches; greenish-brown, with black spots.

Red-

The Red-throated Diver, or "Rain-Goose," throated as it is often called, has the throat conspicuDiver. ously red in the spring and summer. Eggs, $2,23 / 4$ inches; marked as those of the last. 


\section{The Grebes.}

The Great Crested Grebe, largest of our grebes, is found on our inland waters throughout the year. These grebes

Great are, to outward appearance, tailless; but their

Crested most distinctive and interesting feature is the

Grebe. remarkably lobed membrane of the toes. The present species is distinguished in summer by the presence of a brown crest and some long black feathers on the throat. It is no very unusual sight in the neighbourhood

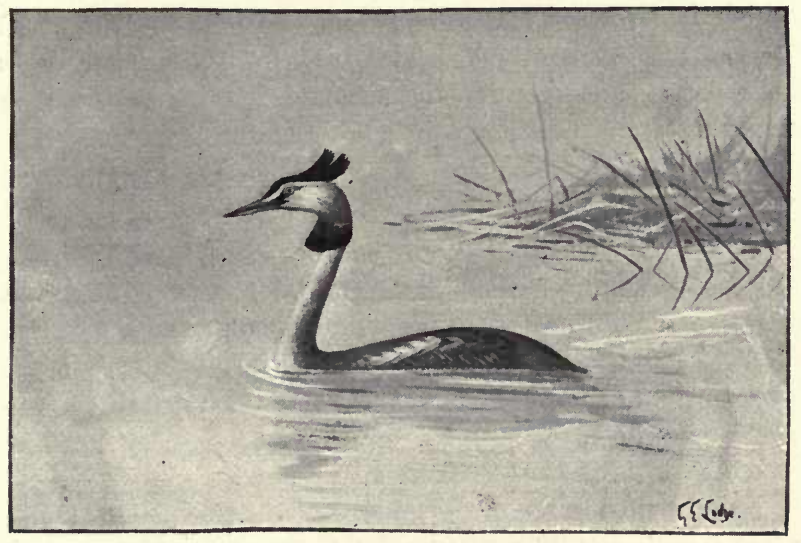

of the Broads to see several of these birds flying at a considerable height. The food consists of fish and frogs, and even aquatic larvæ; and the birds are known, for some reason connected with their digestion, to swallow feathers, a habit noted in several other groups. These feathers are found in the castings. This grebe does not breed in the north of Scotland. The floating nest of sedges is continually added to. Eggs, 4, over 2 inches; dirty white.

The Red-necked Grebe is a smaller bird, with a grey 
patch on the side of the face, a black crest, and the front of the neck red; is a winter visitor only to the east of t Red- these islands, very rarely to Ireland. I have necked seen its nests in some small See or other in

Grebe. North Mecklenburg, I forget exactly where. It constructs a floating nest like that of the last, but invariably makes it fast near a clump of tall reeds. Such at least was the case on the lake in question. Eggs, like those of the last, but slightly smaller.

The Slavonian Grebe is a winter visitor from the north, which is supposed on some evidence to breed in the north + Slavonian of Scotland. The bird in its summer dress Grebe. has conspicuous tufts of reddish feathers on the side of the head, but in winter these are gone. The black bill has a white tip. Eggs, 2 to 4, r $3 / 4$ inch; bluish white.

The Eared, or "Black," Grebe is a rare spring and §Eared autumn visitor. There seems even some idea

Grebe. that it has bred recently in Norfolk. In the summer plumage there is a bright reddish patch on the side of the head.

The Little Grebe, or "Dabchick," is the smallest and most familiar of the group, and has all the antics of its

Little fellows, among them the habit of diving with

Grebe. the young beneath its wing or on its back. In addition, the female covers the eggs with weeds whenever she leaves them. The bird is considerably darker in its breeding-plumage than in winter. It spends a good deal of the colder season at the coast, feeding on small fishes and crustaceans, but it goes inland to breed, when it consumes much insect and regetable food. The dabchick may in spring-time be seen paddling under water with its wings in search of submerged weed wherewith to build its nest. The bird has been held up to ridicule for troubling 
to drag every weed from the bed of the river when there is so much floating around; but I have always preferred to believe that these sunken weeds are so softened and seasoned by immersion as to be particularly suited to the architect's requirements. Its feet are green. The nest, large for the bird, is much like that of the rest. Eggs, 4 to 6, I1/2 inch; dirty white.

\section{ALLEGED (POSSIBLY GENUINE) BRITISH VISITORS}

(Mostly North American).

Bee-eater, Blue-tailed (Merops philippinus).

Buzzard, African (Buteo desertorum).

Cape Pigeon (Duption capensis).

Caspian Plover (Agialitis asiatica).

Crake, Carolina (Porzana carolina).

Crane, Crowned (Balearica pavonina).

Flycatcher, Red-eyed (Vireo olivaccus).

Gallinule, Martinique (Porphyrio martinicus).

Grackle, Rustic (Scolephagus ferrugineus):

Grebe, Pied-billed (Podilymbus podiceps).

Hemipode, Andalusian (Thrnix sylvatica).

Kite, Black-winged (Elanus coeruleus).

Lark, Calandra (Alauda calandra).

Martin, Purple (Progne purpurea).

Myna (Gracula religiosa).

Owl, Saw-whet (Nyctala acadica).

Phalarope, American (Phalaropus wilsoni).

Pigeon, Passenger (Ectopistes migratorius).

Sandpiper, Marsh (Totanus stagnatilis).

" Spotted ( $T$. macularius).

Scops asio.

Serinus icterus.

Sparrow, White-throated (Zonotrichia albicollis).

Starling, Meadow (Sturnella magna).

" Red-winged (Agclceus phoniceus). 
Swallow, Tree (Tachycineta bicolor).

Thrush, Gold-vented (Pycnonotus capensis).

Woodpecker, Black (Picus martius).

" Downy (Dendrocopus pubescens).

" Golden-winged (Colaptes auratus).

" Hairy (Dendrocopus villosus).

Wren, Ruby-crowned (Regulus calendula). 


\section{R E P T I L E S}




$$
\text { है }
$$




\section{R E P T I L E S.}

The poverty of the British Islands in this class is not likely to cause profound regret to any one who has lived Scarcity of in tropical parts. Although the fear of snakes British is much exaggerated in the Colonies, it is reptiles. nevertheless a relief to be able to ramble in the New Forest without the hindrance of heavy top-boots or leggings; and it is pleasant to contrast the six British reptiles, only one of which can ever be mischievous, with the hundred snakes, two-thirds of them poisonous, and the two hundred lizards of the Australian continent. In addition to its slight power for evil, the adder of our woodlands is so easily distinguished from the harmless species that there is no excuse for an accident, nor is it necessary to slay every snake encountered on the chance of its being dangerous. Unfortunately, however, the same policy prevails both north and south of the Line: the snake is killed first, identified afterwards. In the Colonies, where the differences are as often as not internal, and where a fatal bite might be the result of a moment's delay, there is much to commend this destructive policy; but in this country the habit of persecuting these harmless and beautiful creatures should be condemned, though few indeed who cry so loudly against the slaughter of their cousins, the birds, would offer the slightest objection to the murder of ringed snakes.

It is not difficult to define the class of reptiles, parDefinition. ticularly for the present purpose, where it is
not necessary to include alligators and tortoises. Suffice it to say that the animals composing this 
class are scaly and cold-blooded; and that they reproduce their species in one of two ways, either laying eggs much like birds, or else hatching the egg within their own bodies, and bringing forth the young in the perfect state, -a birth which must, however, be regarded as distinct from that of the mammal.

One of the most remarkable functions in reptiles is the periodic casting of the loose skin or slough, which comes

Sloughing. $\begin{aligned} & \text { away entire, - a performance which, in some } \\ & \text { cases, involves considerable rubbing against }\end{aligned}$ any convenient stone or other hard substance. In birds, which may be considered as modified reptiles; we call the process "moulting." After this change the new undercoat is very bright; and the reptile, more especially a snake, is at this time particularly susceptible to cold. I never went so near to losing a 6-foot constrictor that I was bringing home from Australia as after it had cast its slough piecemeal (which is by some considered a sign of bad condition) while we were crossing the Timor Sea. It pulled through, however, and died recently at the Zoo. Dr Stradling, who kindly read this portion of my proof, tells me that young snakes usually cast the slough entire, whereas old snakes rarely do so, quite independent of the condition they are in at the time. Lizards are generally credited with the power of reproducing any limb which they lose, Reproduction more particularly the tail, which frequently of limbs. comes away when a lizard is roughly handled. Miss Hopley ${ }^{1}$ criticises this, however, and is of opinion that the reproduction of the tip of the tail is a very imperfect performance. It is commonly stated that there are no reptiles in Ireland. This is a mistake, as although there are no snakes there,-it is interesting that zoologists should have failed hitherto in finding a creditable explanation of their absence from a soil and climate apparently suited to their requirements,--lizards are abundant.

1 British Reptiles, p. 83. 
LIST OF BLITISH REPTILES.

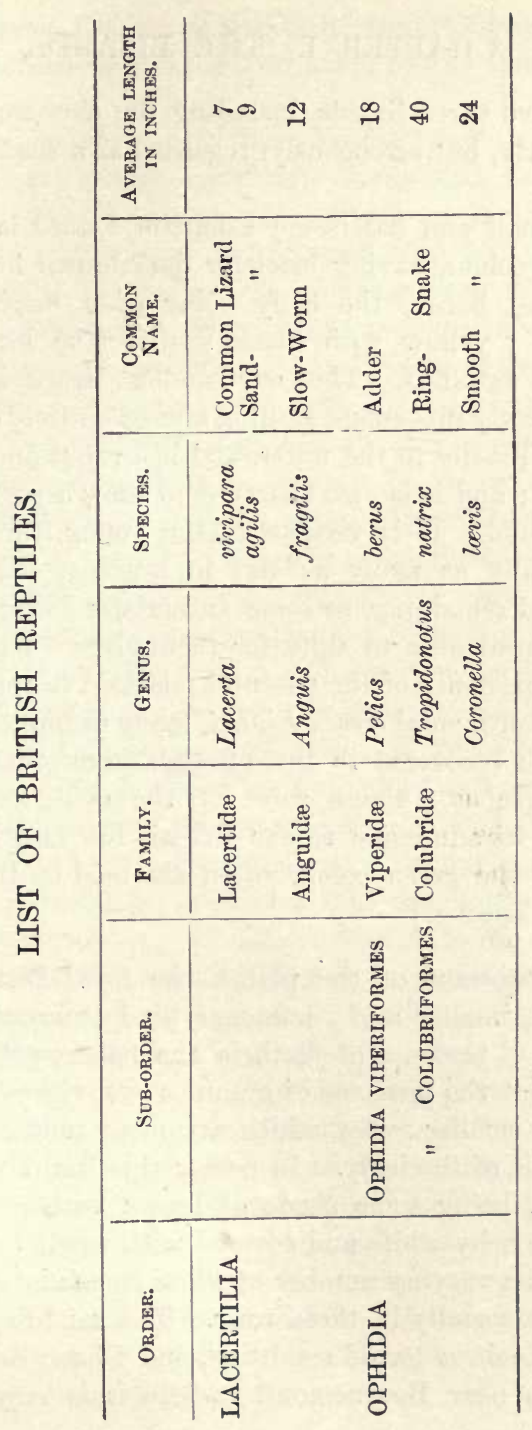




\section{CHAPTER I. THE LIZARDS.}

We have three lizards, including the slow-worm, which is popularly, but erroneously, regarded as a snake.

The small and handsome Common Lizard is greenishbrown in colour, having black or dark-brown longitudinal

Common bands, the belly being of a bright orangeLizard. yellow with black spots. The head of this species is flattened. This, our smallest lizard, is, like the rest, perfectly innocuous, feeding almost entirely on insects. It takes readily to the water, and is a rapid and powerful swimmer; and it is also observed to show a preference for high ground. It is viviparous, the young, three or four (occasionally as many as six) in number, being nearly black, and remaining, so some authorities assert, with the parents until able to shift for themselves. Others question the existence of the parental relations in reptiles.

[The Continental Green Lizard, many examples of which have been recovered in these islands from confinement, is not indigenous, though some of the evidence formerly given for its admission to the British list may have been based on the green colour often assumed by the male of the next species.]

An inhabitant of the plains, the Sand-Lizard differs from the smaller and commoner kind internally by the

Sand- presence of teeth in the palate, externally by

Lizard. the presence of granules over the eyes, as well as by the smaller scales, which are more numerous round the middle of the body. In colour this lizard varies considerably, being some shade of brown with green reflections, the belly white and covered with small black spots. There are a varying number of white spots along the back and sides, usually in three rows. The sand-lizard passes the winter in a torpid condition, and I have dug it up in this state near Bournemouth, where it is very common. 
It is oviparous, the female depositing about a dozen eggs in the sand, where they are left to hatch out by themselves.

In the Slow-Worm, or "Blind-Worm," as it is often miscalled, we have a type outwardly resembling the snakes, Slow- but in reality-as proved by the traces of

worm. rudimentary feet beneath the skin, as well as by the movable eyelids (which it closes when hibernating or asleep), the shoulder-girdle, pelvis, and solid lower jawa lizard. This harmless creature is, like the snakes, absent from Ireland. It grows to a length of over I 5 inches, but the average measurements are considerably under this, and a more common length is ro inches. In colour, it is of a metallic red or grey along the back, dirty white or darker along the belly. The tail, which is about the length of the body, is covered with minute scales; the head and eyes are small; the tongue notched, but not forked, as in snakes. There is a rudimentary third eye, not functional, in this reptile. I have observed as many as a dozen large slowworms on the Downs beyond Clifton, all within a hundred yards ; and in the low land bordering on the Avon beyond, both it and the viper were common in summer, the latter showing the more decided preference for wet spots. The period of hibernation is shorter with the slow-worm than with any other reptile. It casts its slough in the same way as snakes. Its food consists largely of snails and worms. It is viviparous, producing ten or twelve young in July, often in the vicinity of a manure-heap. True to its name, this reptile shows less anxiety than any other I know to get out of the way when disturbed. It lies stiff and motionless in your path, and, if seized roughly, will sometimes, though not invariably, leave the tail in its captor's hand, a habit characteristic of many lizards. The brittleness of this creature, however, to which it owes its specific name, has been grossly exaggerated. Though its teeth are too insignificant to penetrate the skin, the slow-worm is very savage, and bites furiously. 


\section{CHAPTER II. THE SNAKES.}

There are in Great Britain three snakes, one noxious. No snake occurs in Ireland.

As already incidentally mentioned, our only poisonous snake, the Adder, is easily distinguished from the rest.

Adder or Equally unmistakable are the dark zigzag line Viper. along its back and the V-shaped black patch on the crown of its blunt head. On closer inspection, too, the plates on the head are observed to be smaller and more numerous than in the others. In colour, it is true, this snake exhibits considerable variety, examples showing every shade of brown to black. In 188 I I remember catching in Fairlight Glen, near Hastings, a small red kind, which was locally described as particularly venomous. Dr Stradling tells me that the red phase, there regarded as a valid species, is also credited in Herts, Somerset, Devon, and parts of Scotland, with special virulence. The adder, like all snakes, casts its slough regularly, wriggling out of it in such manner that the skin, even to the transparent eyecovers, is turned inside-out. The bite of this snake is instantaneous. The venom lies in a gland above the upper jaw, and when the two fangs strike, it is driven down a canal in the fang into the wound. The fangs are at once withdrawn, and the adder strikes a second time with lightning rapidity. When not in use, the fangs lie back, not unlike a similar arrangement in some sharks; and there is a series behind which are probably ready to take the place of those in active service should the latter get broken, as not infrequently happens, though the second series are often not perforated. The venom is of greenish hue. I knew a herpetologist in Sydney who had dessicated the venom of almost every known poisonous snake of that continent, and who kept the powders in sealed bottles,-poison enough to have rid the capital of the Colonies of its larrikins and Chinamen. 
Wonderful tales are related of Australian snakes jumping backwards to bite, and our own adder has been credited with a similar trick. This, like most zoological fiction, is not without its grain of truth; and the fact is that the adder, like the common snake, does coil and uncoil with such rapidity, its belly touching the ground the whole time, as to give the impression of a spring. But for any snake to leap several times its own length is a sheer impossibility. The average length of the adder may be given at 18 inches, but I have found examples of 24 inches, and have read of others much longer. It is more common in our southern counties, becoming rarer in the north of Scotland, though met with on Jura, Mull, and some other of the isles, especially in the deer-forests. ${ }^{1}$ The forked tongue of the adder, a sensitive organ that aids it in finding its food, has absolutely nothing to do with its bite, which is, by the way, often described as a "sting." Like our other snakes, the adder hibernates, unless disturbed, until the end of spring, though its sleep is lighter than that of the smooth snake. I have found adders lively in the New Forest in the middle of April, rarely before; but Sir Herbert Maxwell tells me that he has seen them in Scotland as early as March. The thinshelled egg is hatched out in the body of the parent, the young varying in number, according to Dr Stradling, from fourteen to forty. On the vexed question of whether the adder swallows her young for safety, I shall not enter. I have never, in spite of much patient watching, seen anything myself that could be construed into such a performance, but, on the other hand, I have met many who, with nothing to gain by lying, declared that they have witnessed it on many occasions. Always prepared for the marvellous in nature, however, a frame of mind induced by even a nodding acquaintance with her, I cannot find sufficient reason to disbelieve the fact, though ocular testimony would of course be welcome.

1 Harvie-Brown and Buckley, Fauna of Argyll, p. 216. 
When feeding, the adder moves its jaws over the surface of its prey, the fangs working independently; and although its bite is rarely fatal, or even productive of serious results, save when the reptile is in unusually good condition and the patient the reverse, it is always best to avoid it. Sheep have been known to die at once from its bite. It is thought that, on the whole, men and monkeys succumb more frequently to snake-bite than other animals. Dr Stradling has record of five fatal cases in this country. The food of the adder consists of mice and various lizards, small birds and their eggs, and insects. It has been denied that snakes eat insects, but Dr Stradling recently watched a green whipsnake in Ceylon taking quantities of ants from an ant-hill.

The Common, or Ringed, Snake, an absolutely harmless creature, is distinguished from the adder by the abCommon, sence of the V-patch; besides which, it has a or Ringed, yellow patch on either side the head, formSnake. ing a kind of collar, as well as some dark blotches on the sides of the body, the general shade of which is greenish. This is the largest of our snakes, growing to a length of nearly 6 feet, though I never managed to obtain one more than about 33 inches. Lord Londesborough had one of 5 feet 8 inches from the New Forest. It feeds on frogs, which are seized by the hindleg and swallowed alive, having been known to survive the passage down the throat, toads, rejected by almost every other living creature, birds and their eggs, mice and newts - the last-named being often captured in the water, but invariably consumed on the bank. Both toads and newts are highly deleterious food. This snake is apparently rare in Scotland. It is oviparous, depositing between two and four dozen leathery-shelled eggs in any convenient manure-heap; and these eggs have been known to remain unhatched through the winter and hatch out the following spring. They absorb moisture, and grow to twice the original size. The young are very dark at first, the collar only being light. 
The Smooth Snake is the rarest of all, especially in the north of Scotland. In colour it is reddish-brown, with a Smooth double row of black spots. From the last-

Snake. named it is easily distinguished by the absence of keel from the scales, and the consequent smoothness of the latter. Its favourite food consists of lizards. Though quick to resent a liberty, its bite is perfectly harmless, and, when excited; this snake also, like the last, emits a strong secretion. It is viviparous.

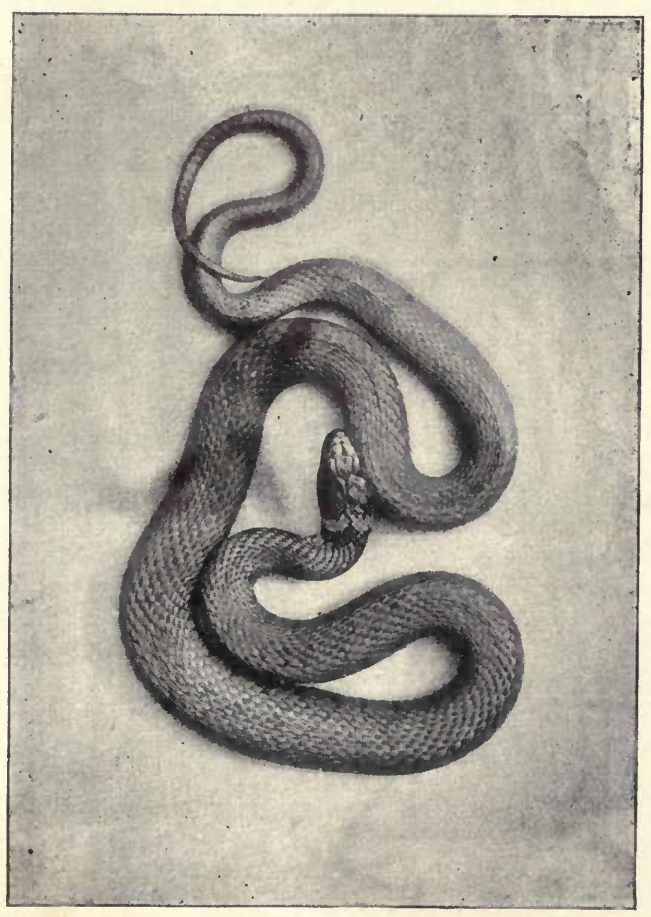

RINGED SNAKE.

From a photograph in the collection of Dr Arthur Stradling. 

A M P H I B I A N S 



\section{A MPHIBIA N S.}

Our amphibians are, like our reptiles, few and small, numbering only seven. From reptiles, the members of Definition of this class may readily be distinguished by the Amphibians. metamorphoses they undergo, resembling, indeed, fishes in their earlier stage; and these changes are undergone, not in a torpid state like that of insects, but in continuous activity. These animals are oviparous, spawning like fish. Like the reptiles, they cast the slough periodically, usually making a meal of it. It is interesting to note that the newts assume during the breeding season, the only time at which they take to the water, certain ornamental crests, often -serrated or festooned, as well as additional webbing on the toes to enable them to hold their own in their temporary abode. All these amphibians are able to breathe through the skin. Of tailless amphibians we have four: the common and edible frogs (the latter an introduction from the ConBritish tinent), the toad, and the natterjack. Of tailed forms we have but three: the common, palmate, and great water newts, Bell's fourth species having been rejected by later authorities. 
AMPHIBIANS.

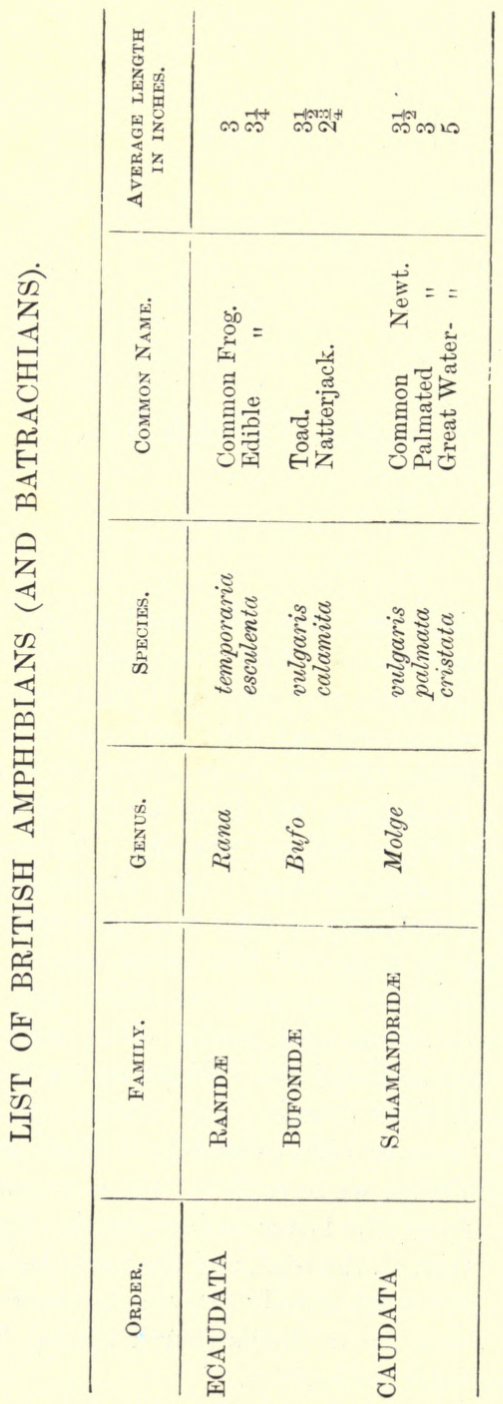




\section{CHAPTER I. THE FROGS AND TOADS.}

The frogs are in their habit more or less aquatic, while the toads, on the other hand, are more or less terrestrial.

The common British Frog was introduced into Ireland a couple of centuries ago. The early metamorphoses of Common this species are those of all the group. The Frog. spawn is deposited in ponds in early spring, floating at the surface in irregular masses. In three or four weeks the tadpoles are hatched out. These remarkable little creatures breathe by gills enclosed in a fold of skin. The mouth is beak-like, the food consisting in all probability of small organisms and water-plants. The tail is long. Gradually this tail is absorbed, the limbs develop, the mouth loses its beak form, and step by step the tadpole emerges into the perfect frog, a being of very different characters, breathing by lungs, and feeding on land- and water-insects. Some tropical frogs are expert climbers, the discs on the toes enabling them to scale perpendicular surfaces, even of glass. The eye, the pupil of which is horizontal, is furnished with a nictitating membrane and two other lids. The frog is able to glance sideways. The characters of the common frog need scarcely be given in detail. In colour it is brownish, with or without spots. The female is larger than the male. The hind-leg is long, and the toes webbed; the forefoot of the male develops a swelling in the breeding season. The frog captures most of its insect food with the aid of its tongue, which is protruded, being tipped with a viscid secretion.

[There has always been some doubt as to the exact claim of this Continental form to a place in the British Edible list, but it appears to me, since it was intro-

Frog. duced at an indefinite date and is now general among the fens, that this claim is at any rate as strong as 
that of some game-birds that found their way into our fauna under like auspices. There are many points of distinction about this frog, chief among them being the black markings on the back, the fold of skin at the throat, the complete webbing of the hind-toes, and the presence of vocal sacs on the sides of the head, which are connected with its croaking and are most in evidence in the breeding season. This frog has a greenish hue, and there are black marblings and white lines on the back.]

A more innocuous creature than the insect-eating Toad would be hard to imagine, yet it has always been reToad. garded with disgust in every age and land. The spitting of the toad is pure fiction, though there is of course a dirty white sticky secretion in the pores of the skin, which is used only in self-defence, and which, with its poisonous, or at any rate irritant, properties, is able to procure the toad immunity from many beasts and birds that do not thus spare frogs. When excited, the toad is observed to puff itself out and exude beads of this secretion. From the frog this animal is easily distinguished by its warty skin, the swellings over its eyes, its clumsier build, and the shortness of its hind-legs. The mouth has no teeth, the tongue, free behind though attached in front, being but slightly cleft at the tip. With this organ, tipped like that of the frog with a gummy secretion, the toad catches insects with lightning rapidity, much after the fashion adopted by the chameleon, the sight of which on the feed is among the most interesting reminiscences of a visit to Regent's Park. Otherwise, it is a sluggish creature. On the stories current about disinterred toads, however, that have survived ages imprisoned in sandstone, the gravest suspicion is usually permitted to rest. In colour, the toad is brown above, with black markings; below, white, with black spots. There are double tubercles beneath the hind-toes. It spawns, like frogs, in the water, the spawn floating in a double row. 
The tadpoles are darker in hue than those of the frog. Save for the purpose of spawning, however, the toad lives little by the water, hiding rather among the stones in damp situations. It hibernates, like frogs, in the ground, and often in companies. Lastly, it casts its transparent slough more than once in the year, often swallowing it.

Somewhat rarer, and apparently altogether wanting in the Highlands, the Natterjack is distinguished from the Natterjack. larger toad by the light line down the centre in some parts as "Golden Back." The hind-toes of this toad, which is of far more active habits than the last, and even indulges in something approaching a run, are not deeply webbed; the hind-leg is short, and has a gland. There are also the same small glands over the eye, which is prominent, being plainly visible within the mouth, and has three lids like those of the frog and toad. The warts on the back are porous in both species. Like the foregoing, this toad feeds on insects, and occasionally on small mice. It is not of aquatic habits except during the breeding season. The tadpoles are small, but develop with remarkable rapidity. For some reason this has been called the "Cornish toad."

\section{CHAPTER II. THE NEWTS.}

Our three newts are of terrestrial habits excepting in the breeding-season, when they deposit their spawn in the crumpled leaves of water-plants, and the young soon start life as tadpoles. During the breeding season, too, as already mentioned, the adults, the male more particularly, put on extra ornaments in the shape of a crest, usually 
serrated, along the back and tail. As in the frogs, the skin is a supplemental breathing apparatus.

The handsome Smooth Newt is of green or brown hue, profusely spotted; below, yellow, with black spots. The Common lower surface of the flattened tail is red in the or Smooth male, with bluish lines and markings; in the Newt. female it is yellow, without markings. In the breeding season the male develops a festooned frill along the back, the female growing a smaller frill. This species seeks the neighbourhood of water in the warm months only, at which time too it sheds the slough.

The Palmated Newt, smallest of the three, has dark spots on the body, and lines along the head, which is Palmated speckled with black. The crest, which is not Newt. festooned as in the last, is black-edged. In the breeding season the male has the toes webbed, and grows a curious filament on the tail.

Larger than either of the foregoing, the Great WaterNewt is in colour black above, yellow beneath, with Great black spots; and the male has during the Water- breeding season, in addition to his high sernewt. rated crest, a light band on the tail. This newt seems to be more common in our southern counties than in the north. Its distinguishing character lies in the warts that stud the skin, and there are curious pores along the head and body. Teeth are present in the palate and jaws. The great water-newt lays its ova in the leaves of water-plants, and the tadpoles hatch out in the course of a month. All the newts feed much on frog-tadpoles. 


\section{F I S H E S}




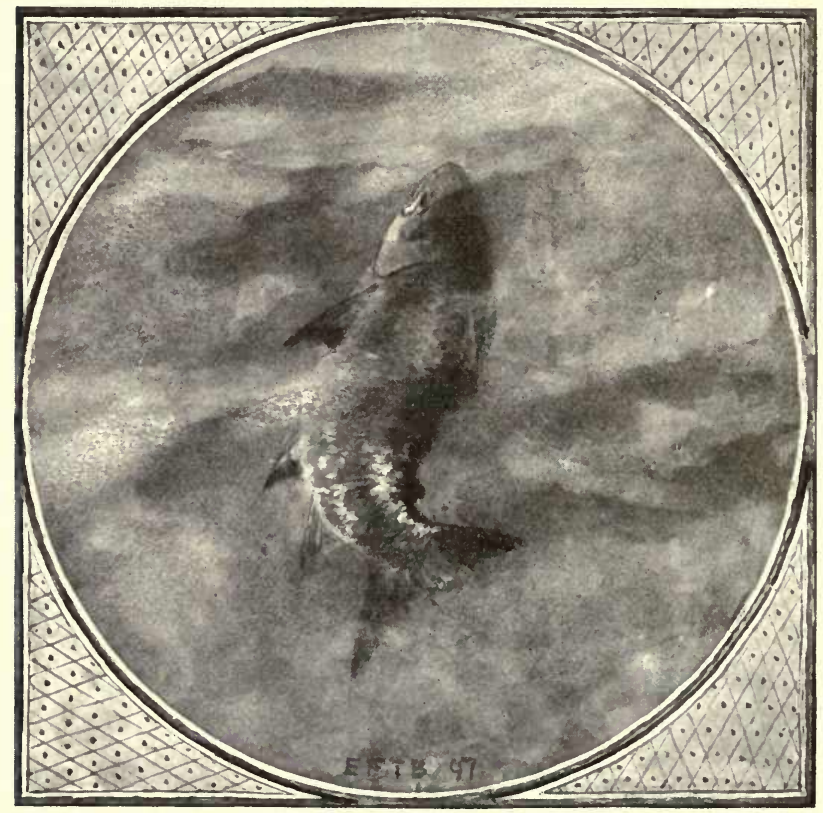

SALMON SWIMMING. 


\section{F I S HES.}

Tris class, lowest but one of the vertebrates, is of great interest and importance. Our British fishes are about two hundred in number, of which, roughly speak-

British species. ing, rather over three-fourths are either marine or anadromous forms, the former passing their whole existence in salt water, the latter entering rivers for the purpose of spawning. A few, like the eel and flounder, go down to the sea to spawn, passing most of their existence in fresh water, and these are termed "catadromous." Of our fifty or more fresh-water fishes, a few, non-migratory members of the salmon family for the most part, have from time to time been introduced. As in the case of birds, several divisions of the subject might have been permissible in a small work of this kind, such as the separation of sea- and fresh-water forms, the commercial and non-commercial fish, or like arbitrary groups. It has been thought best, however, to follow the systematic classification in general use, though an attempt has been made to give some indication, by means of two familiar signs, of the division between the purely fresh-water and purely marine forms, as well as of the third group, embracing members of widely different orders, that are able to exist in both fresh and salt, some entering one or the other at regular intervals and with a fixed purpose, others rather frequenting brackish estuaries at all seasons indifferently.

The definition of a fish, which it is here necessary 
plainly to enunciate, may be given as follows: A vertebrate animal that lives in water, breathes the dissolved air by means of gills, and swims by the aid of fins. Definition In the majority of cases, the body is covered
of a fish.

with scales; in some, however, as the tench and eel, these are minute and embedded; in others, as the conger, they are absent. It will now be desirable to consider briefly some of the chief external characters of fishes.

Though not sufficient in themselves to distinguish them from the class of reptiles, among the most characteristic of

Scales.

these are the scales, which are, as above mentioned, sometimes small and embedded in the skin, sometimes absent and replaced by an arrangement of calcified processes like teeth, as in sharks, in which order we find the skin similar within the mouth. In the sturgeons we find rows of plates along the body. These scales have been denominated according to their form, as ctenoid, those with serrated edges; cycloid, in which the edge is smooth. (See figures in Taylor's 'Half-Hours in the Green Lanes,' cap. ii.)

The shape of fishes is subject to considerable variation, for in addition to the typical tapering, torpedo Shape of form, we find the body flattened, laterally, as
fishes.

in the flat-fish; vertically, as in the rays and skates; elongated, as in eels; spherical, as in sunfish.

The organs of locomotion, or fins, are vertical (lying along the back and belly) and unpaired, or horizontal

Fins.

(lying on the sides) and paired. The vertical fins are called, according to their position, dorsal (along the back), anal (on the belly, just before the tail), or caudal (the tail-fin); the paired fins are the pectoral (behind the gill-covers) and ventral (or pelvic, beneath the last), the latter being either abdominal (immediately beneath the pectorals), thoracic (behind and beneath the pectorals), or jugular (before and beneath the pectorals). The dorsal fins are either soft or spinous, intermittent or continuous, the salmon and its kind having, 
in addition to the front rayed dorsal, an adipose or fatty second dorsal without rays. The caudal, or tail-fin, is usually in two distinct lobes, often, as in the sharks, of unequal length, and usually either forked or fan-shaped, convex or concave. In some of our forms, however, as the rays and chimæra, there is no terminal fin, the tail ending in a whip-like lash. (See fig. of Perch, p. 340.)

The mouth of fishes is subject to more variation, both in position and form, than the same organ in any of the foregoing classes. Its position is normally in Mouth and front of the head, the cleft opening towards
teeth.

the tail, as in the salmon. In sharks and rays, however, we find it beneath the head; in the weevers it is directed, like the eyes, upwards. Its shape is various. In the flat-fish it becomes distorted in the adult, though symmetrical in the larval form. In the sea-horse it is a tube; in the garfish, a toothed beak. In the wrasses, the mouth has thick lips; in the cods, loaches, red mullet, and some of the carp family, it is supplemented by a varying number of feelers or barbels. In the pike, hake, pollack, and some other predatory forms, the lower jaw protrudes. The tongue, which is sometimes absent, is never protruded as in the other classes of animals. The teeth are usually solid, and are continually being shed and renewed. In size and shape they vary much, the two leading types being those which are sharp and adapted to cutting and tearing, and those which are flat and suitable for crushing. The former belong to fishes that feed on other fish, the latter to those which feed chiefly on molluses and crustaceans. In some sharks, there are hinged teeth, which are capable of lying back and preventing the escape of prey; and there are, as in snakes, latent series ready to take the place of those in use when the latter sustain injury. In some rays, too, the teeth slant, with the inner margins cutting.

As in other classes, the eye is, so far at least as shape goes, less subject to variation than any of the foregoing characters. In size, it is true, the eyes show some differ- 
ence, and we learn to associate fishes having very large eyes with residence at considerable depths, at which light

Eye. is scarce and must be economised ; those, on the other hand, with strikingly small eyes, often embedded in the skin, with still greater depths, beyond the range of light altogether. It is in their position, however, in which we find the greatest amount of variation in the eyes of fishes. Normally they are situate on either side of the snout; in the adult flat-fish they are on the same side, both on the upper, or coloured, surface of the fish, the right or left eye travelling round to the opposite side as mentioned under the division in question. In the hammerhead, again, we find the eyes, of large size, at either extremity of the "hammer." In the weevers the eyes are, with the mouth, directed upwards, or, as the inventors of trivial and scientific names have it, towards the stars. In some sharks we find a loose nictitating membrane; and in mackerels and mullets there is present a fatty eyelid.

Without extending the province of this little book to the consideration of internal anatomy, two characters of great interest in the class before us must at any rate Lateral line. be mentioned,-the lateral line and the airbladder. The lateral line, which is to be traced in the majority of fishes as a curved black or white line along the middle of the sides, but which is in many fishes absent altogether, in others interrupted about half-way from the head, is in reality a row of perforated scales through which exudes the secretion from the mucous canal, so important a factor in the free passage of fishes through the water. Their bodies being lubricated with this matter to a still greater degree than the much-discussed similar operation in wildfowl, move through the water with a minimum of friction, and almost, as it were, without (in our sense of the word) getting wet.

In the air-bladder, or, as it is often called, the swimming-bladder, we have nothing more or less than an 
internal gas-bag inflated with a preponderance of nitrogen, its function being to assist fishes in rising or sinking by Air-bladder. alteration of their specific gravity. Sharks and chimæras, as well as a number of bony fishes, are without air-bladders, and it is interesting to note that these include both slow ground-loving forms and rapid surface-swimmers.

We must now consider certain of the more important functions of fishes.

Our British fishes breathe, without exception, the dissolved air by means of gills, in passing over which the Respiration. blood is aërated. These gills are, in adult fishes at any rate, covered with flaps of flesh or gristle, though embryonic sharks show bunches of external gills. In some fish, like herrings and some sharks of great size, we find appendages called gill-rakers, the function of which is, like the baleen of whales, to filter the water and retain the minute floating organisms on which these forms feed. In the sharks, moreover, the gills open as so many external slits, usually five in number, but in one British form six.

Like the higher vertebrates, fish may be classified, with considerable reservation, according to their chief food,

Food. as carnivorous, herbivorous, or insectivorous, though the line of demarcation is perhaps even less exact. They vary, as every angler knows, in their degree of fastidiousness - some, as the conger, habitually rejecting all but the freshest of food; while others, like the bass, show a constant preference for stale offal. The crabbers find this distinction between crabs and lobsters, the latter not objecting to bait a few days old. The sharks are, with the exception of the very large basking forms, exclusively carnivorous, some preferring living prey, others, fewer in number, being content with carrion. Rays subsist, as may be gathered from their flat crushing teeth, largely on crustaceans. It is not necessary to enter in detail into the various foods of the dif- 
ferent orders of fishes, for these have been mentioned in the proper place in the following pages. As examples, however, of widely different tastes, I may mention, in addition to the foregoing, that the grey mullets are, like Girella of Australian waters, partly herbivorous; that flatfish consume sand-worms and other soft food, the sole feeding almost entirely by night; hake, pollack, mackerel, and others pursue living fishes, chiefly sand-eels and mackerelmidge (young rocklings), at or near the surface. Some fish, as the torpedo, swallow their prey whole, and salmon have been recovered from the interior of the ray without bearing any marks of violence.

Fish are either oviparous, as the majority of our fishes, spawning at fixed seasons; or viviparous, as one of Reproduc- our blennies, one or more of our sharks, and tion. the bergylt, bringing forth the young alive, also at a regular season. Some of the sharks and rays deposit the egg in a remarkable receptacle known as a "purse," those of the sharks being furnished with tendrils or filaments, with which they attach themselves firmly to weeds or rocks.

As in the case of birds, much remains to be learnt of the periodic concerted movements among the great fish Migrations. families, which, also like the birds, perform these journeys at a great altitude-in other words, near the surface of the water. The general tendency of the present day, on the strength of the careful observations recorded by Cunningham (whose admirable book, recently published, I have had such frequent occasion to quote in the following pages) and others, is to reject many of the more extensive movements, as those of the Arctic herrings, recorded by the older writers with great minuteness, and to regard the migrations of fishes chiefly as movements of more moderate extent to and from deep water for purposes of spawning or in search of food. Even the so-called "stationary" fish, as an example of which we may take the plaice, move about in some degree-one of 
the most important factors in their arrangements being doubtless those sudden changes in temperature to which, though in a less degree than the atmosphere, the sea is subject.

Lastly, a word must be said of the habitat of our commoner fishes - of the forms that inhabit sandy, and those Habitat. others that frequent rocky, coasts. In the ordinary course it is found that the two divisions rarely overlap. Thus, the flat-fish and silver whiting keep to the sand, while the conger, wrasses, and pouting are found among the rocks. Most fishes within twenty miles of the coast dwell near the bottom, in the lowest third, at any rate, of the total depth, though the garfishes, mackerel, herrings, pollack, mullet, bass, and some others, even some of the flat-fish and eels, are found, more particularly of an evening, feeding or gambolling at the surface. As a rule, however, the flat-fish lie in the sand, only the eyes, which have an extraordinary range of vision, projecting above it.

It will now be necessary to enumerate the orders, families, genera, and species of our British fishes, with some remarks on their characters and life-history; but it must be prefaced in apology for the meagreness of some of the accounts that the scheme of the present little work excluded sternly anything in the shape of anecdote, and the whole has necessarily been drawn up in the spirit of condensation. 


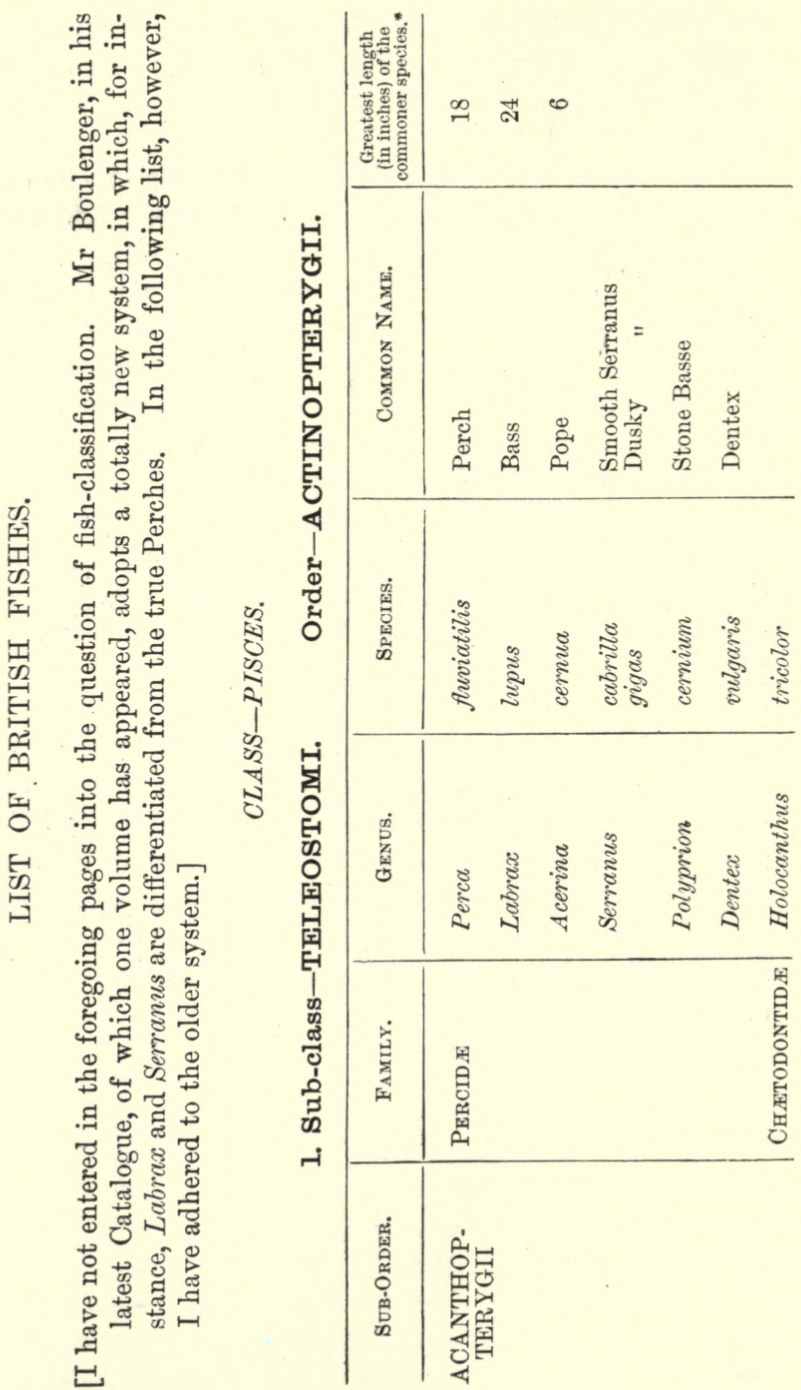




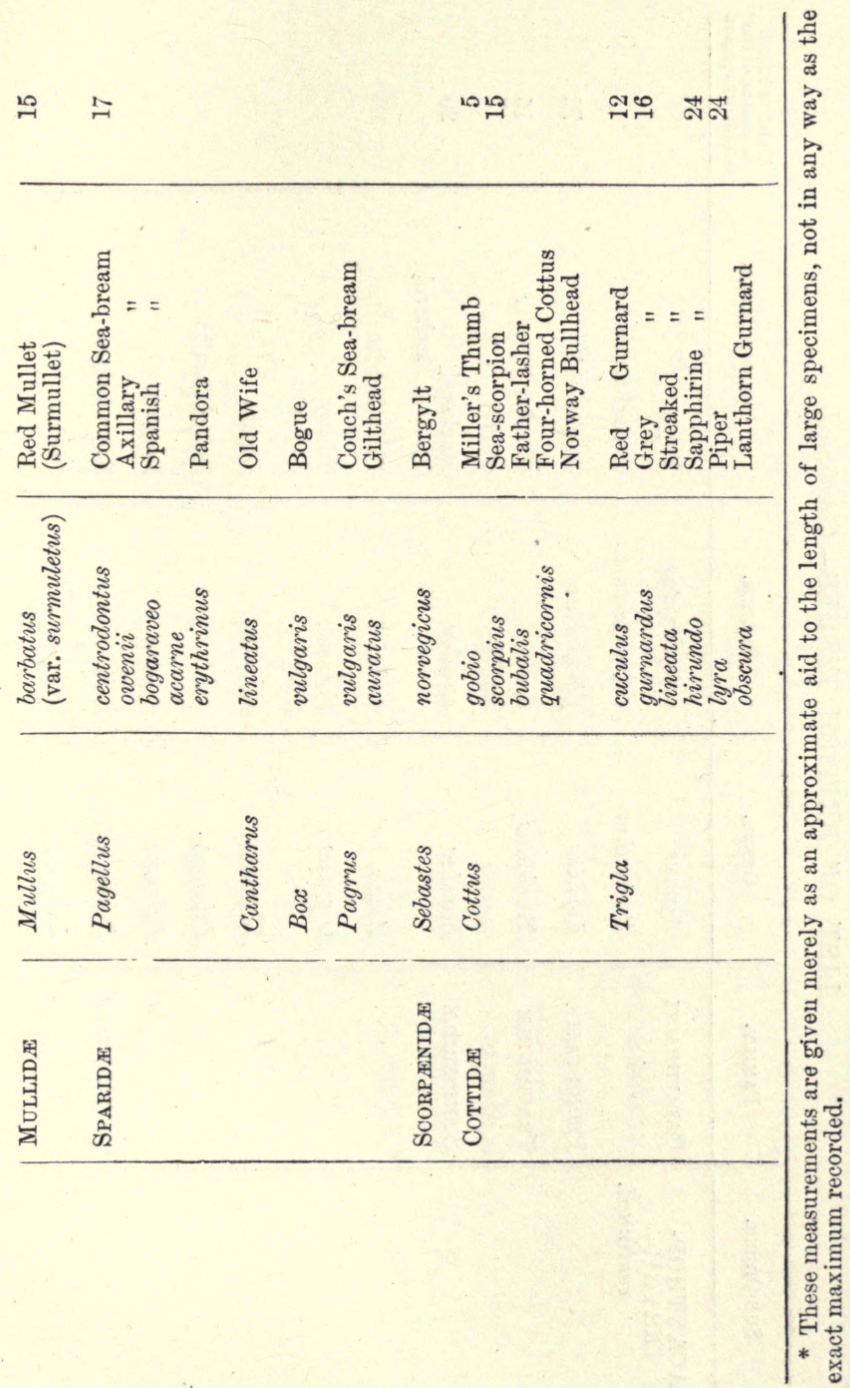


FISHES.

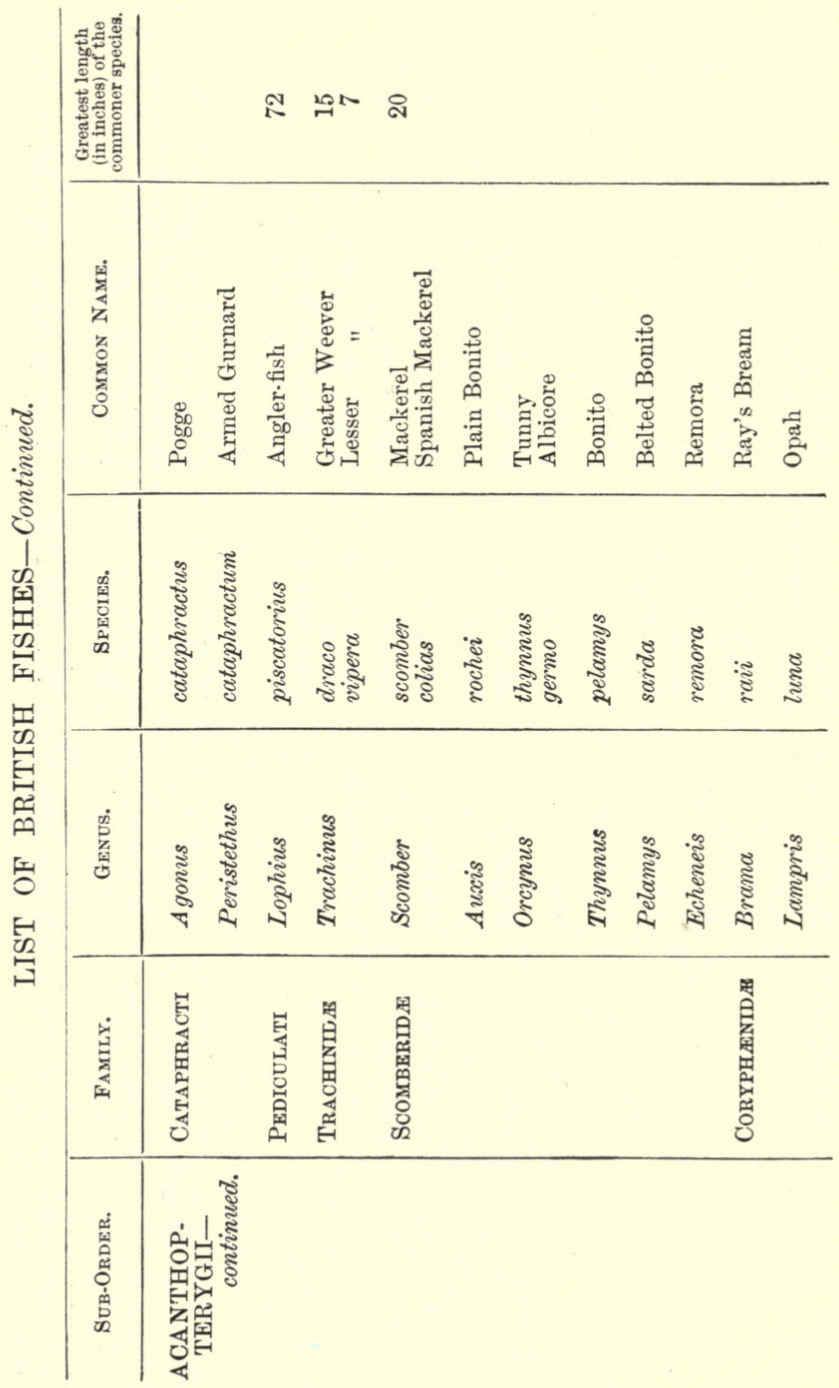


FISHES.

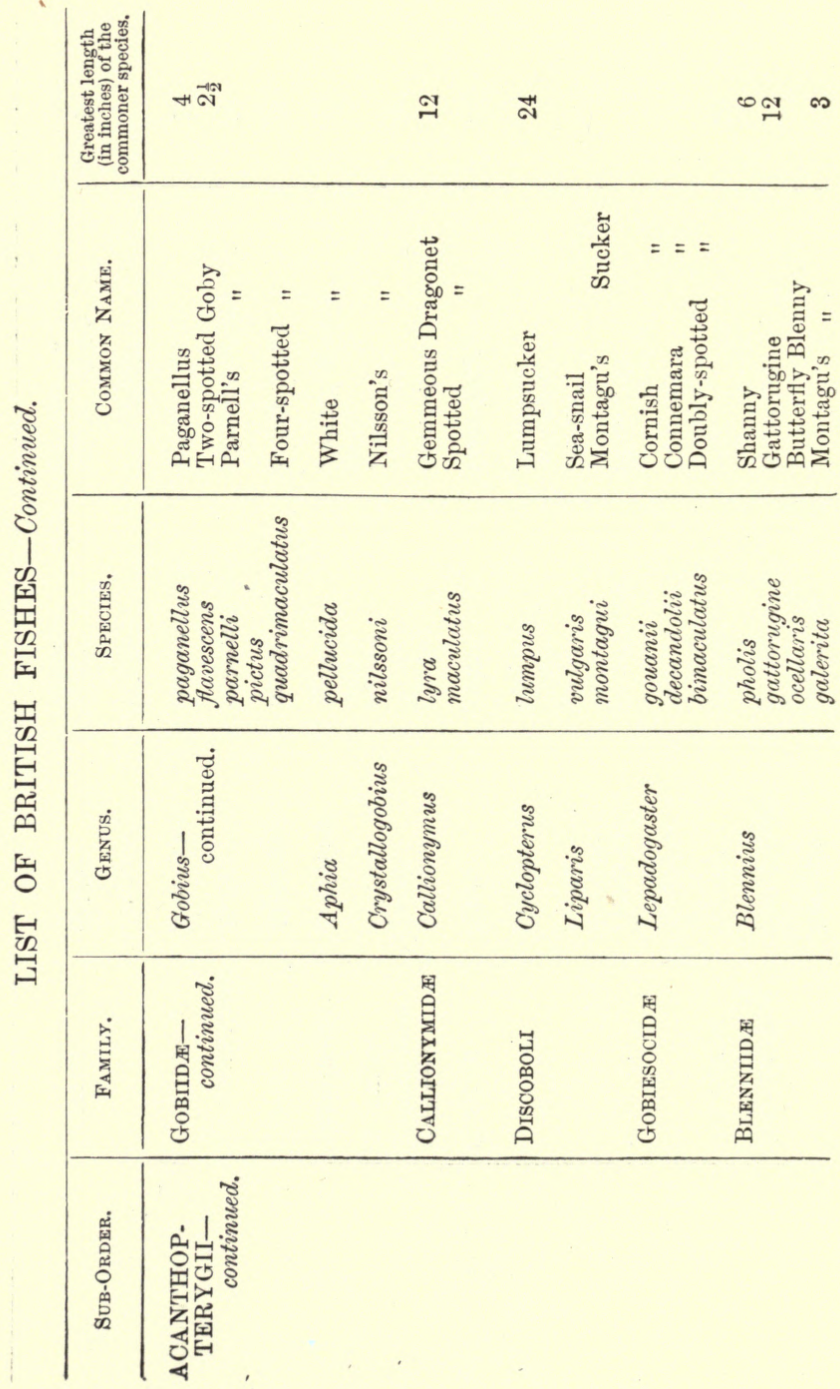


코 - ๓ ตัก
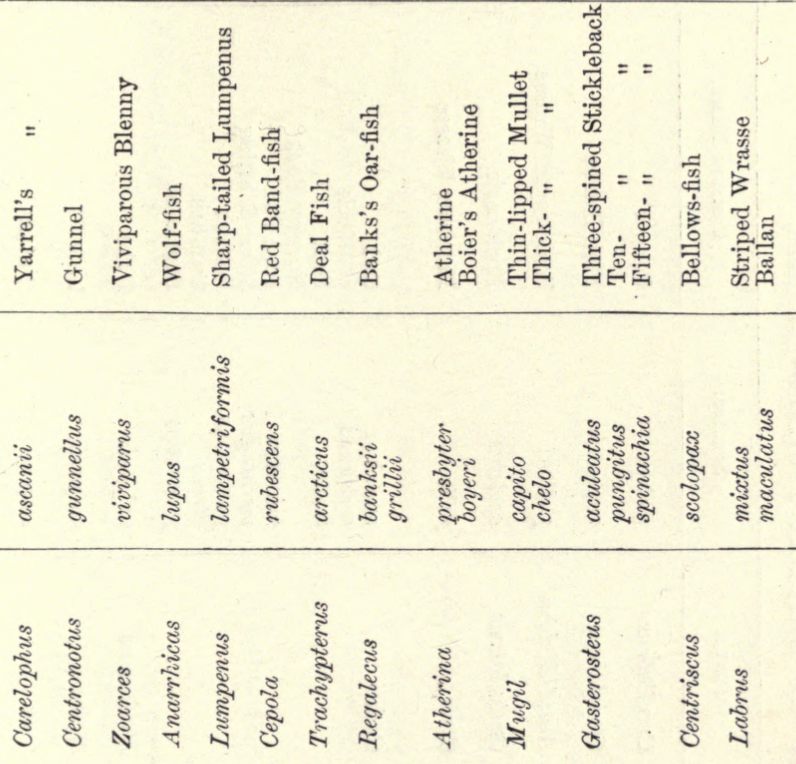

成究


FISHES.

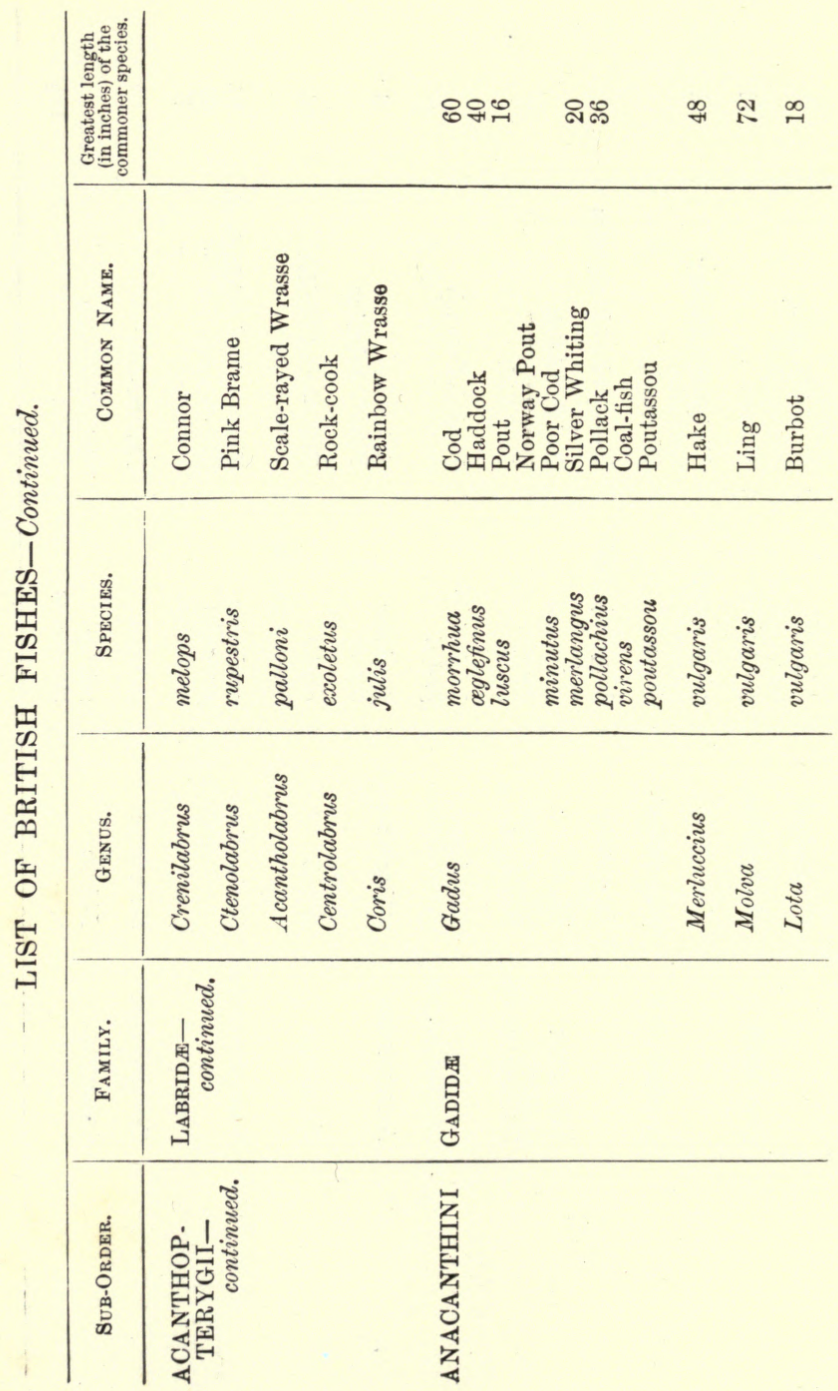



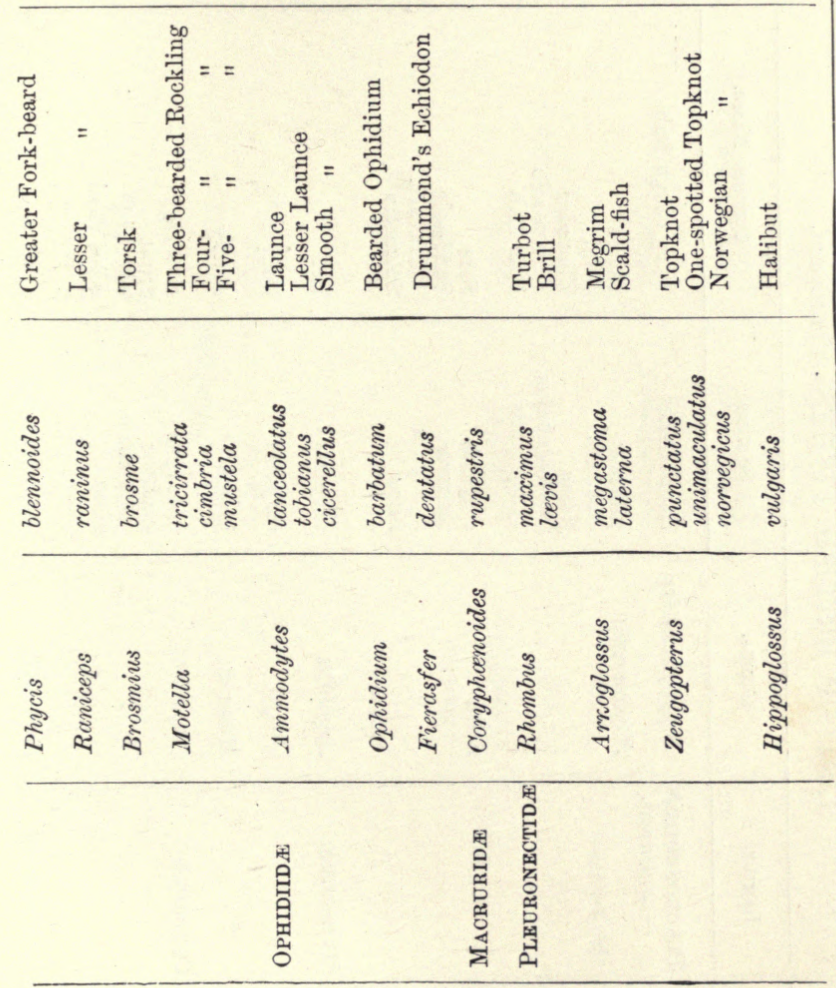
FISHES.

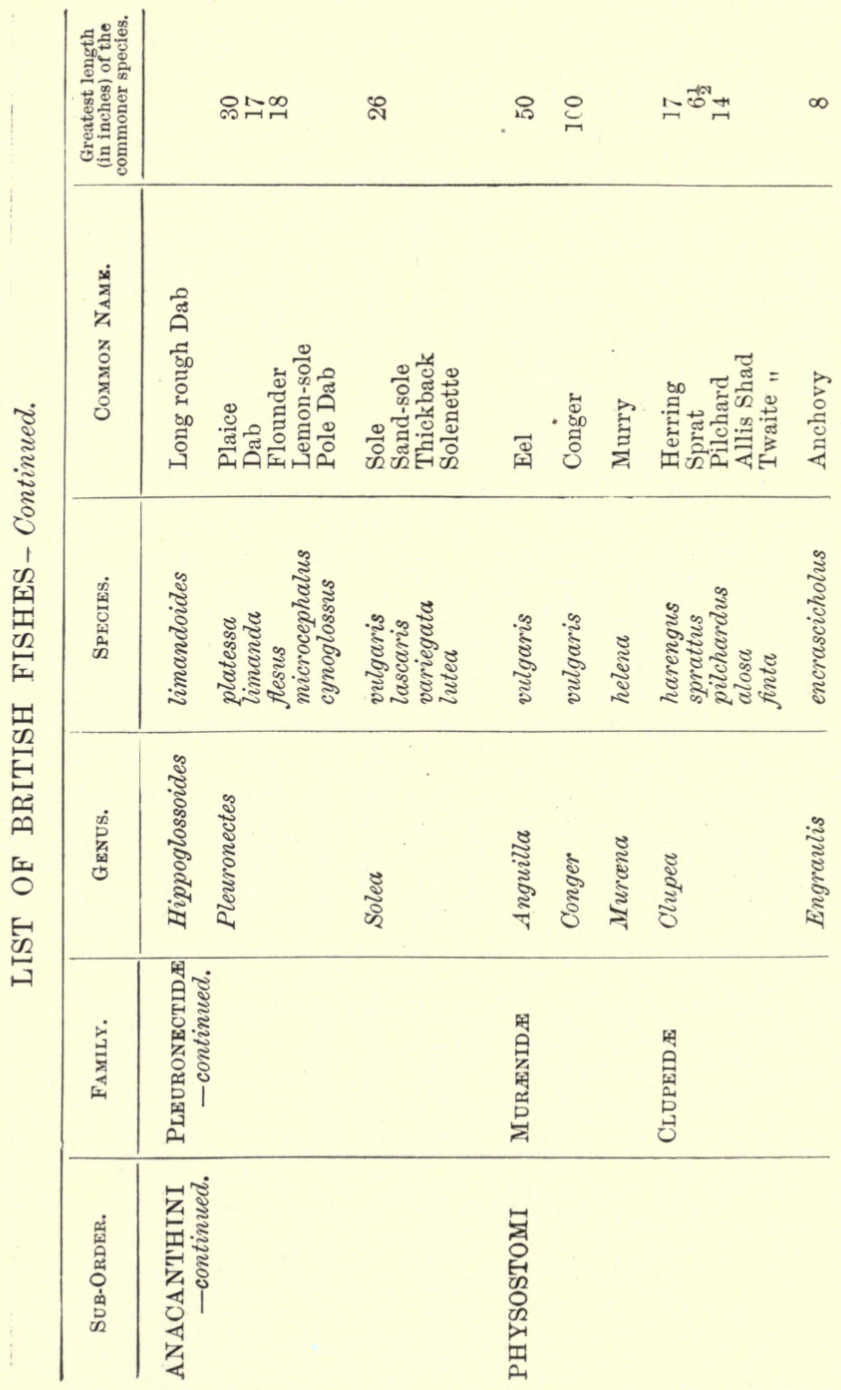


ㅇำ
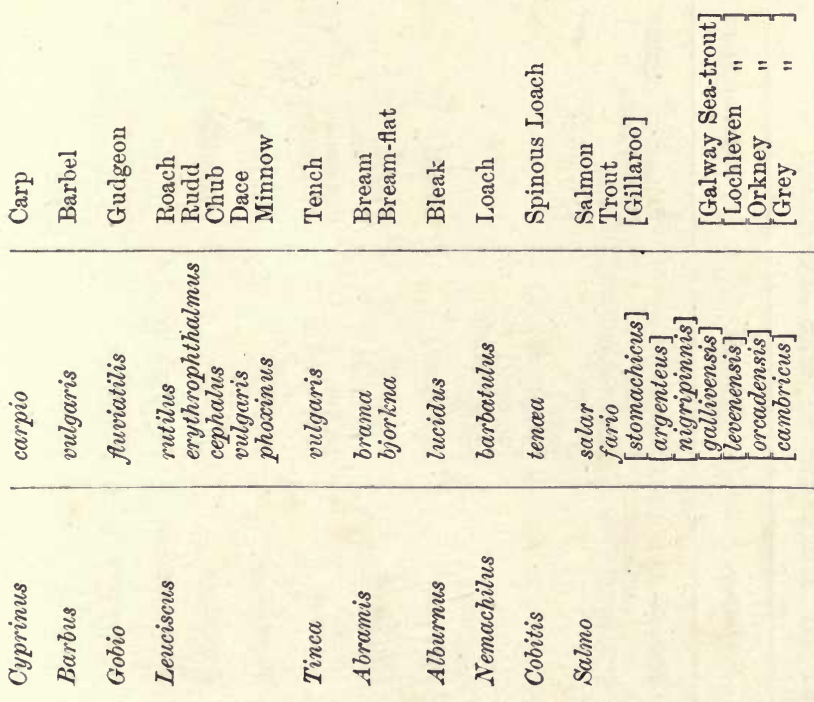

突

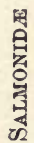




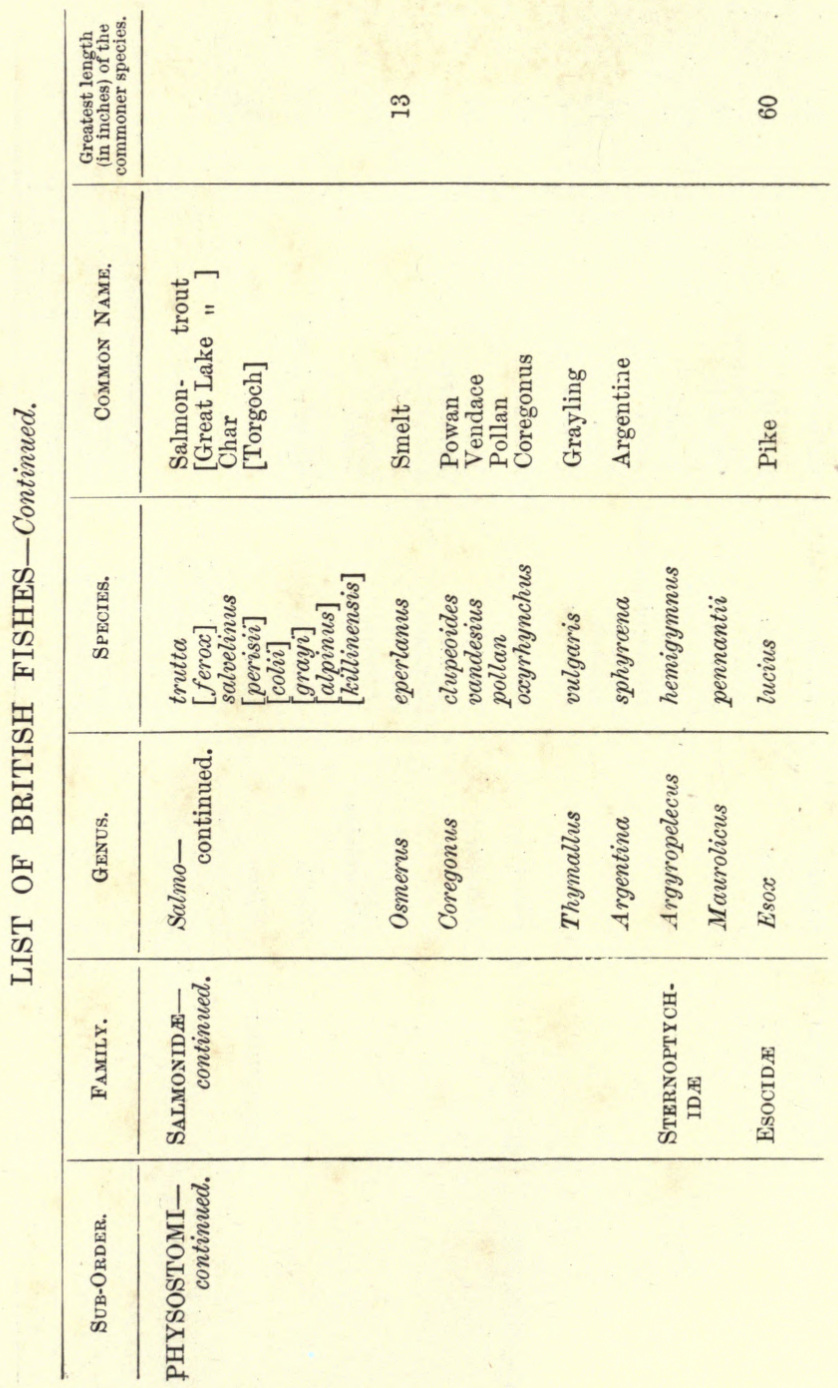


LIST OF BRITISH FISHES.

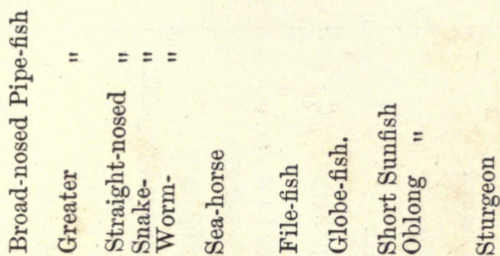

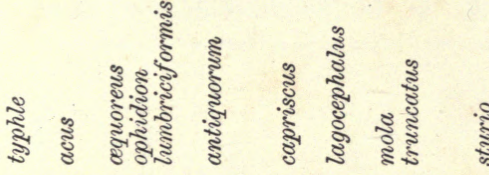
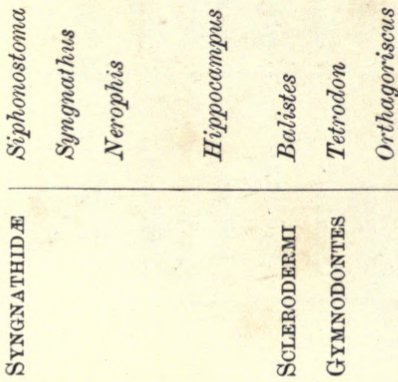

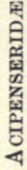

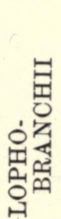

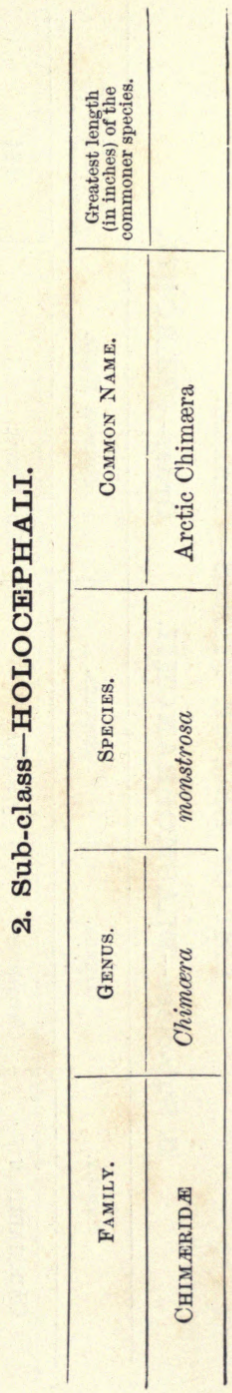




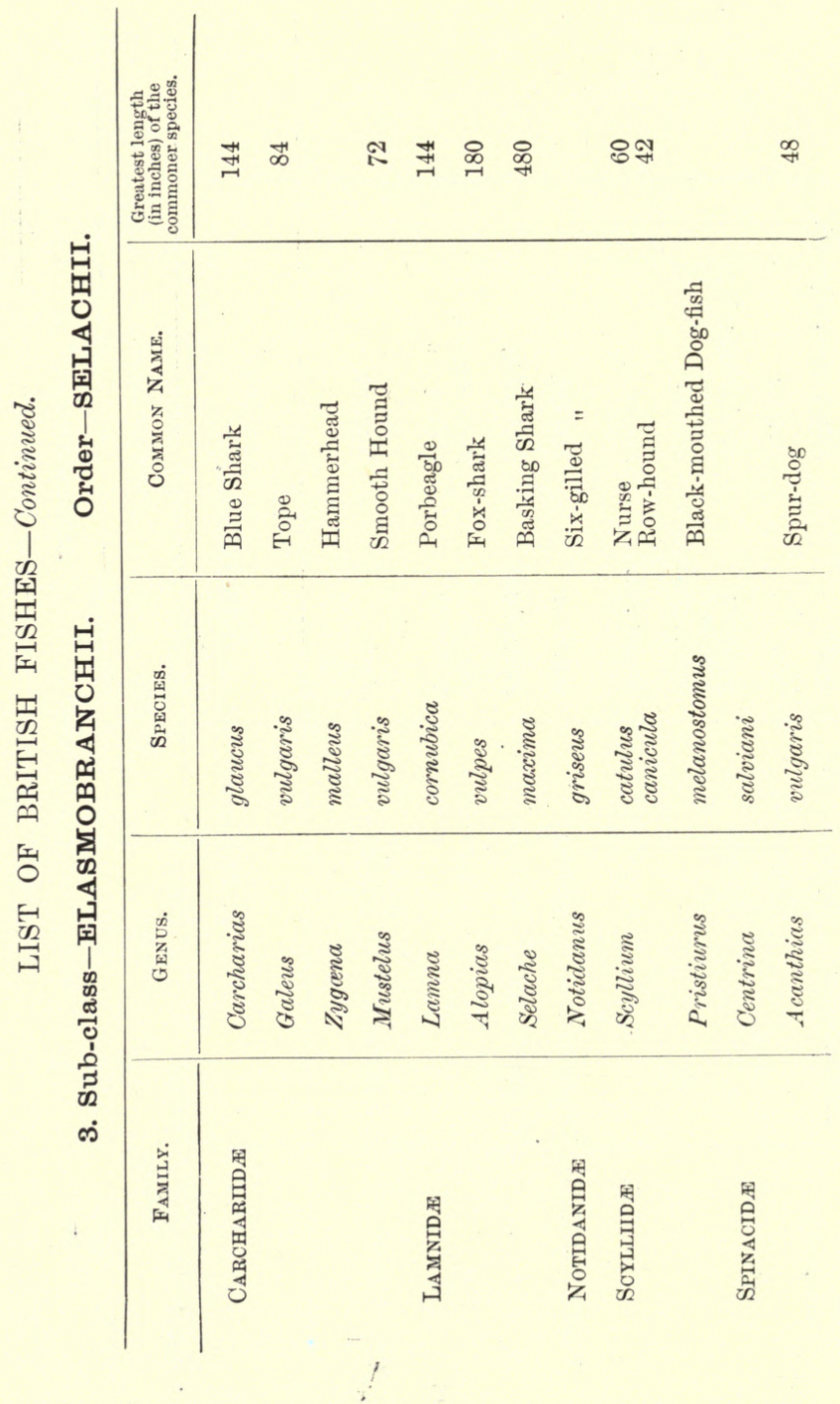



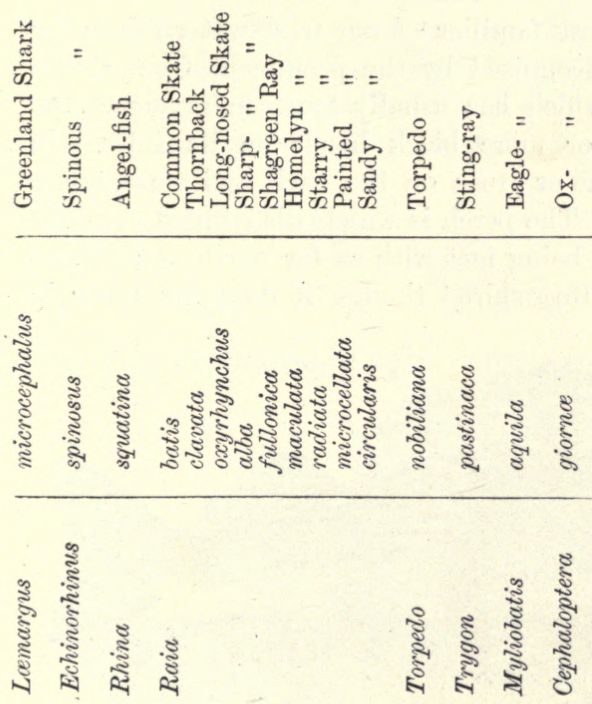

是是

目是夏是 
$\left[{ }^{*}\right.$ Fresh-water fishes; + Fishes found in both fresh and salt ; rare fishes in square brackets.]

\section{CHAPTER I. THE PERCHES AND SEA- BREAMS.}

\section{The Perches.}

One of the most familiar of our fresh-water fishes, the Perch is easily recognised by the prominent front dorsal

*Perch. fin, which has usually fourteen rays, and the five or more black bands on its sides. In colour, it is bronze or green on the back and sides, white below ; fins red. The perch is widely distributed throughout these islands, being met with as far north at any rate as the waters of Ross-shire, ${ }^{1}$ though it does not occur in

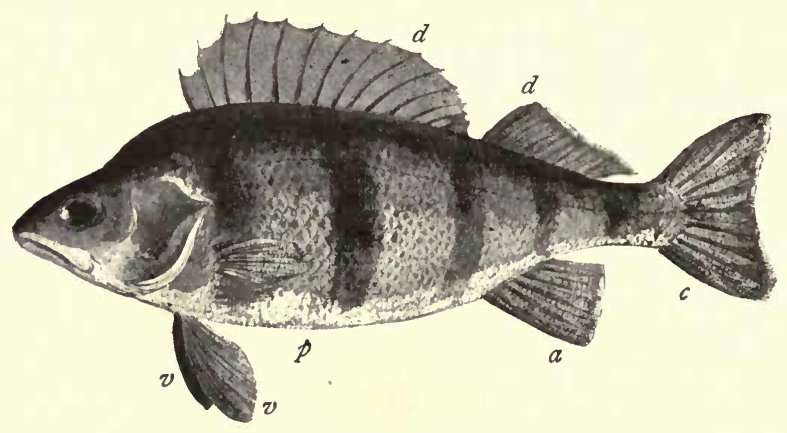

$a$, Anal fin. $\quad c$, Caudal fin.

$d d$, Dorsal (intermfttent ; rst dorsal, spinous).

$p$, Pectoral. $v v$, Ventral (jugular). See p. $32 \mathrm{x}$.

the Isle of Wight. It is not affected by brackish water; and I have caught large perch in the Baltic three or four miles out at sea. The dorsal fin is so sharp that it is

1 Harvie-Brown and Buckley, Fauna of the Outer Hebrides, p. 134. 
customary to remove it before using the fish as bait for pike, but the young fish are greedily devoured by both trout and pike. It is a voracious fish, of catholic appetite, feeding greedily on minnows, small roach and dace, young water-hens, water-voles, also reptiles and insects, and it pays the penalty of its want of discrimination by suffering the attacks of a variety of parasites. It is of gregarious habits, and those of similar size are usually found together in the neighbourhood of sluices, weirs, and dams. In the cold months perch appear to grow sluggish. Anglers are at all times careful not to prick and lose a perch, as the rest of the shoal are easily frightened away. Its maximum weight is about 7 or $8 \mathrm{lbs}$; but a fish of half this weight

The Fish Drawings in this Volume are by C. K. Bennett.

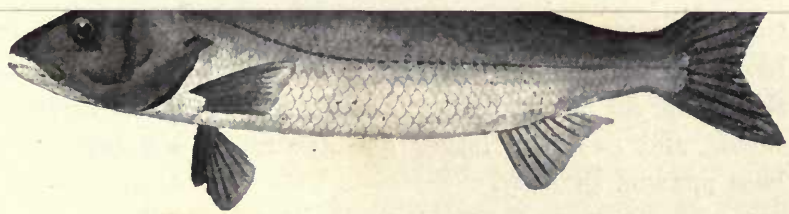

mostly in trammels and crab-pots, in our waters weighing as much as $20 \mathrm{lbs}$., but a fish of half the weight must be regarded as above the average nowadays. Not unlike a chub in general appearance, especially about the head, the bass has the distinguishing percoid dorsal fins; in colour, it is dark green along the back, shading off to silver 
beneath, young fish being much spotted. The bass, though, as aforementioned, uncertain in its goings and comings, may, so far as our seas go, be regarded as a Channel fish; but it is not uncommon off the Scottish coasts, occurring (Buckley) in Loch Carron, in Ross-shire. It is also met with on most parts of the Irish coast. Bass of small size are abundant in summer in such enclosed waters as Southampton docks, and greedily unbait every hook in the vicinity; but the heavier fish are usually driven inshore by a spell of south-west wind, after which they are found feeding for a day or two just behind the break of the waves. They then disappear as suddenly as they came. Though often shy of the hook, the bass is a very foul feeder, and I have taken many from lobster-pots when the latter were baited with stale fish, often too at places where, as at Lulworth, they are not seldom baited with rabbit, or even dead horse, which soon becomes particularly offensive in the water. In addition to its taste for offal, the bass pursues sand-eels and various fry at the surface, hence its popularity with the angler, who judges its whereabouts by the movements of the gulls overhead. Though not regularly anadromous for spawning purposes, the bass, always an estuarine fish by preference, is frequently taken in fresh water, and I have caught one or two above Arundel, while the tide was running out and the water was, for the time being, merely brackish. In like manner bass are, or were when I was there, taken in the Tiber as far up as Rome. Small bass move in large shoals, and even the larger fish are rarely solitary. The bass spawns in July.

Not unlike a small perch, the Pope is characterised by the possession of but one dorsal fin instead of two; *Pope or and in place of the bands that mark the Ruff. perch, the body of this fish is spotted, the spots generally extending to the fins. Of somewhat local distribution even in England-the Thames and Severn are 
both among its native rivers - it is not found in either Scotland or Ireland. I have taken it in the Baltic in company with the perch. A fish of sluggish habits, the pope prefers a muddy bottom. A cruel practice, which I have also observed followed with unfortunate sea-bullheads, obtains in some parts, particularly on midland rivers, which is known as "plugging" the fish, corks being fixed on the dorsal spines and the pope being then cast adrift to die of starvation. This fish spawns in early spring.

The Smooth Serranus is an unfamiliar, thick-set seaperch, which is practically confined, so far as our waters Smooth go, to the coasts of Devon and Cornwall, Serranus where it is taken for the most part in the or Gaper. crab-pots. In colour it is yellow, having dark longitudinal bands. The lower jaw projects considerably, and there is but one dorsal fin. The food of this fish consists of small fishes and crustaceans. It spawns in the month of August.

The Dusky Serranus is a larger species, taken in the same waters. It grows to a weight of $60 \mathrm{lbs}$. (Day), Dusky is darker in colour than the last, and lacks Serranus. its longitudinal bands. It is said to spawn in spring.

One of our largest as well as least familiar fish, the Stone Basse is caught off our south-west coast, and off Stone the south of Ireland, to a weight of $60 \mathrm{lbs}$. Basse. (Day). One example was taken years ago in the mouth of the Clyde, but that is regarded as north of its natural region. A deep-water fish by preference, it is known to follow barnacle-covered planks at the surface, hence called "Wreck-fish." Its capture is irregular, and is usually accomplished with some kind of grains, or spear.

I have caught the Dentex in the Mediterranean weighing 
as much as 12 lbs., but in our seas it is rare, confined practically to the south-west coast, where, however, the nets Dentex. take examples of over 50 lbs. On the Italian coast, we used to fish for it at night, a torch being hung out over the bow, and a hook, dressed with two white feathers and baited with 3 or 4 inches of the tentacle of an octopus, being "dapped" at the surface. In colour, it is bluish, with silver reflections. It has but one dorsal fin; and the mouth is armed with long curved teeth.

[According to a correspondent of Harvie-Brown, an example of Holocanthus tricolor, allied to the Australian coral-fishes, was taken off Stornoway some years ago.]

\section{The Red Mullet.}

The Red Mullet has no connection whatever with the grey mullet, from which it is easily distinguished by its smaller Red Mullet. size, brighter colouring, and stiff "feelers." At first sight it might be taken for a small red gurnard. There are two forms of this fish-the striped,

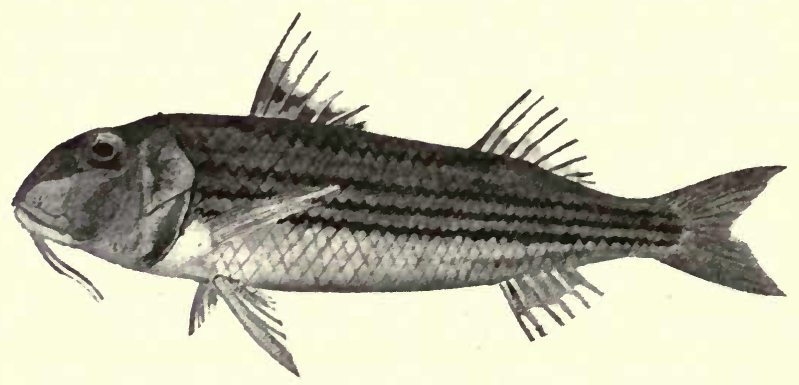

or surmullet, the larger and commoner, and the smaller plain form. Cunningham ${ }^{1}$ has not found the smaller form at Plymouth. This fish-it suffices for present purposes to

1 Marketable Marine Fishes, p. 307. 
treat both forms as one-is of a bright red hue, the colour being fixed, and intensified, to render it more attractive when offered for sale, by the cruel process of scaling the fish before life is extinct. The scales are large and thin, and the commoner surmullet is banded with bright yellow. This fish is usually taken in the trammel, but a number of instances, three of them at Bournemouth, have come under my notice in which it has taken a hook baited with mussel. It grows to a weight of 2 lbs., though the majority weigh nearer $1 / 2 \mathrm{lb}$. It spawns late in the summer, and is rarely caught in the colder months. Red mullet are very rare in north Scottish waters. ${ }^{1}$

\section{The Sea-Breams.}

The Sea-Bream is a gregarious rock-haunting fish which approaches the coast in the warm months, breeding in late Common autumn. Though in greatest abundance in Sea-Bream. the Channel, it is found on every part of the British coasts, where it grows to a weight of 5 or 6 lbs. I have caught many of 3 lbs. off the Lizard, on a favourite ground of mine. In colour bright red, the adult having a conspicuous black spot on the shoulder; the young are known as "chad," the intermediate size, of half a pound or so, being denominated "ballard." 2 Sea-bream are caught in the neighbourhood of reefs; and it is a fact that where chad of the smallest type are on the feed, there is little hope of finding larger fish, which would favour the theory of fish of an age keeping to themselves. Seabreams are known on various parts of the Scottish coast as "Bulgarian (or Barbarian) Haddies."

1 Harvie-Brown and Buckley, Fauna of Sutherland, p. 259.

2 Just as the sea-bream is among our only common fishes with different names according to size, so Australians know three stages of the same fish, to wit, the "red brim," the "squire," and the famous, justly famous, "sehmapper." 
The Axillary Bream is a somewhat similar fish, having the fins and belly of paler hue, and lacking the black spot Axillary on the shoulder. Little appears to be known Bream. of its habits, though from the fact of its having been taken on the coasts of Scotland and Cornwall, its distribution in British waters should not be very limited.

The Spanish Bream is smaller, its greatest length (Couch)

Spanish being about ro inches, and is also taken mostly

Bream. on the south-west coast in the autumn months. It is conspicuously spotted with blue. I caught one this (1897) August at Mevagissey; weight about 2 lbs.

[An allied form, Pagellus acarne, is also taken on rare occasions.]

The Pandora is a red bream with blue spots. Of Pandora or migratory habits, it is taken off the south King of the and south-west coasts of Great Britain and Breams. Ireland, but never in any numbers, though not uncommon.

The Old Wife, to all intents and purposes the popular "Black brim" of Australian fishermen, is not uncommon Olä Wife on our south coast, where it grows to similar or Black dimensions as those of the common sea-bream, Sea-Bream. though examples of 20 inches are recorded. Farther north, and on the Irish coast, it becomes rarer. Like all the breams, it is taken on the rocks, where it finds crustacean food to its taste. In colour, it is silvery grey rather than black, and has longitudinal yellow bands on the body and rows of dark spots on the fins.

The Bogue, which is of a bronze hue with yellow longitudinal lines and a brown spot on the pectoral fin, is not Bogue. common in our waters, but in parts of the Mediterranean there is a regular fishery for it, and I have taken numbers on the rod off Leghorn. 
[Couch's Sea-Bream and the Gilthead are stragglers only to our seas. One of the former, which grows to a weight of Io lbs., was taken off the Cornish coast. The latter is caught in the same waters. It is named after the crescentshaped yellow mark between the eyes.]

\section{The Bergylt.}

The red Bergylt, which grows to a weight of at least 30 lbs., is chiefly interesting because, Jike one of our blennies, Bergyit or it brings forth its young alive, the breeding Norway season being in summer. More properly a Haddock. northern fish, it finds its way to Scottish and Irish waters occasionally, where it is taken on long lines set for cod in deep water. Cunningham gives in the appendix to his recent work an interesting comparison between this fish and that other European marine species, the aforesaid blenny, which bears its young in the same fashion; and he points out their differences,--the blenny being a littoral fish, lurking under stones, the bergylt living out in deep water, where it pursues its food boldly.

\section{CHAPTER II. THE BULLHEADS AND GURNARDS.}

I. The Bullheads.

As the first representative of this group, we have in the Miller's Thumb a prickly little fish, familiar in most of our *Miller's clear running streams, where it lurks beneath Thumb. the stores, a favourite method of dislodging it being to strike the stone sharply, which has the effect of stunning the recluse beneath. In colour this fish is greenish above, lighter on the sides and belly, and marked with 
vertical black bands. The body is practically without scales, and the lateral line is distinct throughout. This bullhead can survive some time out of water. The spines that arm the head have been the death of grebes and kingfishers, as the fish instinctively inflates its head whenever a bird attempts the difficult task of swallowing it. Buckland mentions, indeed, a case in which one of the next species choked a fisherman. Of little account in this country, I have tasted it frequently in German towns, where they convert it into a soup, and it is also in some demand for bait. The miller's thumb is said to be injurious to trout spawn and fry, but its food consists for the most part of larvæ. The male is alleged to defend the eggs and young with great valour, but evidence of this appears to be wanting. In parts of Ireland this fish is exceedingly rare.

The Sea-scorpion is a shore bullhead, and is found more particularly in the vicinity of estuaries and some †Sea-scor- little way up rivers. It is very common in pion or the Baltic; and there were days when, spinSting-fish. ning half a mile above Rostock (or some ten miles from the sea), nothing else could have a chance with the bait, so many sea-scorpions were round it. This fish, which is dark grey, the underparts white with yellow spots and streaks, and often having some white and red markings on the fins, does not in our waters exceed a length of $\mathrm{I}_{5}$ inches, but there is on the coast of Greenland a form, practically identical, which grows to a length of 6 feet. Our fish appears to spawn about December, the spawn adhering to stones and weeds; and the father is, as in the last species, credited with strong parental instincts.

A smaller and more abundant fish than the last, found tFather in the rock pools between the tides, and feed-

Lasher. ing on small fishes and crustaceans, the Father Lasher recalls in general appearance the flatheads that give 
such excellent sport in Australian waters. Our species is especially common in the fall of the year in the mouth of the Thames. In colour it is usually brown with black and white streaks, occasionally deep red. Cunningham ${ }^{1}$ attributes the colour of the carmine examples to the influence of the red seaweed in the midst of which they lurk.

I have also taken in the Baltic the greyer Four-horned Cottus with the red and yellow markings. It resembles

+ Four- the rest in its sluggish movements, occasional

horned activity in rushing at a spoon-bait, and capac-

Cottus. ity for surviving several hours out of water. Its name alludes to the four rough tubercles upon the head.

[The Norway Bullhead, a straggler only to our waters, has been added to the British list comparatively recently, a single specimen having been taken off the Mull of Kintyre.]

\section{The Gurnards.}

The gurnards differ from the foregoing outwardly in the development of a bony armour on the head, inwardly in the presence of an air-bladder. The square head with its fleshy feelers imparts anything but a pleasing appearance; nor is the impression made more favourable by the curious grunts which fresh-caught gurnards are capable of emitting from the air-bladder, a peculiarity to which they owe their trivial name in many tongues (cf. Gourneau, Croonan, Knurrhahn, \&c.) Like the bullheads, they are creatures of sluggish habits, feeding for the most part on or near the bottom, over which they crawl with the aid of their sensitive feelers, but occasionally in warm weather gambolling at the surface. They greedily take any bait that lingers within reach; and $I$ have even caught a fair number on spinning baits when pollack-fishing, usually when, for some reason or other, the bait has been allowed

1 Marketable Marine Fishes, p. 326. 
to sink for a moment among the weeds. The flesh, though much eaten, is not remarkable.

The Red Gurnard, commonest, and with one exception smallest, of our gurnards, is a red fish with silvery belly, Red or the lateral line crossed by plate-like scales. Cuckoo In the Channel it is particularly common,

Gurnard. being found in all rocky localities, where it preys on crustaceans. It spawns in May, the spawn floating at the surface.

The Grey Gurnard, another familiar British fish, lacks the ridge of spines found in the rest of the group, and is Grey grey in colour, having white spots over the Gurnard. back and sides. It is more abundant on the east coast than the last. The females, the proportion of which is, according to Dr Fulton, about 4-I, are slightly larger than the males. ${ }^{1}$ Day ${ }^{2}$ considers this a gregarious fish, but my own experience in the Channel has invariably been to catch at most two or three with as many dozen red gurnards. This, however, has always been in September, and it is quite possible that they are more sociable at the spawning season, about May. On the Galloway coast, I understand, the reverse obtains, and September anglers take a dozen grey gurnards for every red one.

The Streaked Gurnard has raised red bands down the sides, hence the trivial name. In colour it is deep red on streaked the back and sides, white beneath, and with Gurnard. blotches on the fins. It is an exceedingly rough fish to handle, owing to the spines along the back and lateral line. By no means one of our commoner fish, it is taken in the trammels on the south coast, rarely, if ever, on the hook.

The Sapphirine Gurnard is a larger fish. It is easily recognised by the large blue pectoral fins, the lower

1 Marketable Marine Fishes, p. $330 . \quad 2$ British Fishes, i. 63. 
surface of which is bright blue with rows of black spots. Like the rest, it lives at the bottom, and feeds on crusSapphirine taceans and small fishes. Cunningham ${ }^{1}$ Gurnard alludes to a curious habit which this fish has or Tub-fish. of spreading the pectoral fins when alarmed.

A still larger fish is the Piper, so called from the vocal performances to which, like the rest, it is addicted. It is Piper. taken principally in the Channel, though not uncommon farther north. The largest of our gurnards, it grows to a weight of $5 \mathrm{lbs}$. or more. In colour this gurnard is bright red above, white beneath. It is a more slender fish than the last, lacks the distinguishing blue pectoral fins, and has the edges of the bony plates on the snout strongly serrated.

The Lanthorn Gurnard, smallest of our true gurnards, is recognised by its elongated dorsal fin, after which it

Lanthorn is called in some parts the "long-finned Gurnard. gurnard." It is red in colour, and has a bright silver band along the sides. It is said not to take a bait.

In the little Pogge we have a kind of sea-armadillo, clad in a suit of impregnable armour. Like the true Pogge or bullheads, it is destitute of air-bladder. It Armed is regarded as commonest on our east coast, Bullhead. especially in the neighbourhood of estuaries. In colour yellowish grey, with black bands.

The Beaked Gurnard is another armed fish, scarlet in colour. It is but a straggler in our seas, and may at Beaked once be recognised by the pointed bony proGurnard. jections before the head, beneath which there are filaments, and the large plates of bone with which the body is covered. Like the true gurnards, it has an air-bladder. 
FISHES.

\section{CHAPTER III. THE ANGLER-FISH.}

The remarkable-looking Angler-Fish, disposed on the fishmonger's slab to greatest advantage, its huge gape Angler or distended with a lobster or other attractive Fishing- mouthful, is very frequently the cause of obfrog.

structions on London pavements. Of voracious appetite but sluggish habits, it lies in ambush for the small fish on which it preys, and is said to attract them within reach of its jaws with the aid of the filaments that grow from the dorsal fin-a popular estimate which Cunningham ${ }^{1}$ criticises, more particularly as regards the alleged phosphorescence of the forked extremity of the filament, quoting an interesting fact observed by Mr Lane, that the fish always contrived, by snapping rapidly, to catch that portion of a stick which just touched the filament. This is very different from the old notion of the "rod" catching the young fish and conveying them to the mouth. The most striking character of this fish is perhaps to be found in the huge bulk of its flattened spinous head as contrasted with the attenuated hind-quarters, a van concentration of strength similar to that in the mole. In colour it is dark-brown above, white beneath. Though a slow swimmer, save in the larval stage, the angler is able, with the aid of its arm-like pectoral fins, to walk on the sand after the fashion of gurnards. It spawns in summer, the eggs floating at the surface in great sheets of 20 feet or more in length.

1 Marketable Marine Fishes, p. 338. 


\section{CHAPTER IV. THE WEEVERS.}

These venomous little fishes are a plague on every coast, save that of the United States, where, on the eastern side at any rate, they are unknown. There is in Australian waters a so-called "whiting" which is closely related to these weevers, but it lacks the poisonous spines, gives good sport, and is exceilent for the table.

The Greater Weever is the less formidable, if only that it is not so given to lurking in the sand with its backGreater fin protruding. It is most abundant on the

Weever. southern coasts of these islands, much rarer in the north. Its colour is dark yellow, with lighter lines on the sides, the head streaked or spotted with blue. Of sluggish habits, it feeds at the bottom on cephalopods and small crustaceans. The dorsal spines can inflict a festering wound, but the contact is a chance one; those on the gillcovers, however, are, in both this and the next species, used intentionally, the fish bending head and tail together and suddenly uncoiling, striking the offending object with wonderful precision.

The Lesser Weever is not more than half the size of the last; in colour, too, it is somewhat paler, and there is a

Lesser conspicuous light band on the tail-fin. This

Weever. little fish is a source of constant danger to the netsmen and of annoyance to the amateur; and I have noticed for years that a number are almost invariably hooked from piers in the summer months during the prevalence of an east wind. Without being exactly dangerous, a wound from the gill-spines of this fish may cause many days of intense pain. In the Hebrides this fish is regarded as the male of the sand-eel. ${ }^{1}$

1 Harvie-Brown and Buckley, Fauna of the Outer Hebrides, p. 189. 


\section{CHAPTER V. THE MACKEREL FAMILY.}

Of somewhat less importance in this country than with some Continental nations, the present family furnishes at any rate one important food-fish. All the members of this group are rapid swimmers, seeking their food at, or near, the surface. This has been connected by some authorities with the well-known difficulty of keeping their flesh from rapid deterioration. Nor, with the important exception of the tunny, can their flesh be regarded as particularly suitable for purposes of canning.

The type of this family, the beautiful blue-and-silvery Mackerel, is one of the most abundant and familiar fishes Mackerel. of our seas, in which, however, its goings and Mackerel. comings appear almost the result of caprice, and still occasion a considerable amount of confusion.

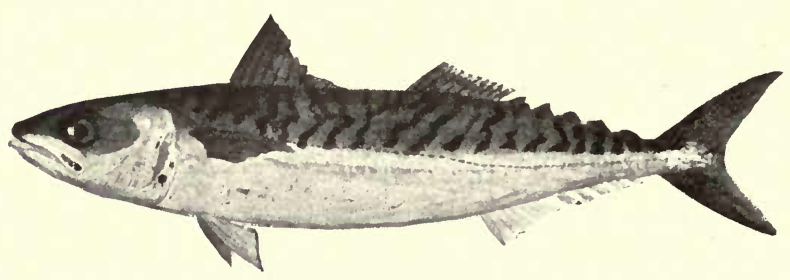

The most familiar form of this fish has the belly silvery, with purple reflections, and deep bands down the sides; but there is a not uncommon form having numerous spots on the back. For the rest, the mackerel is an elegant tapering fish, the tail-fin large and deeply forked, and having small keels above it. There are also a number of finlets above and beneath the tail end of the body. Besides undertaking migrations of considerable extent, which, yet unexplained, are believed to depend largely on temperature, the mackerel performs two regular seasonal 
movements, from deep to shallow water, and vice vers $\hat{A}$, the deeper water being affected in winter; but as the fish is found in any quantity on parts of the east coast at certain seasons only, there is still good reason, for all that has been said to the contrary, to suspect an extensive migrational movement along shore. In Bournemouth Bay, for instance, where the fishery is somewhat irregular, mackerel are taken only between the middle of June and the end of October. The spawning-time appears to be late in June; anyhow, I have found the males with milt early in that month, but they were spent by the beginning of August. The mackerel which are caught during June and the first days of July are rarely over a pound in weight, but the larger "hook" mackerel of August weigh three times as much. They are very powerful swimmers, and their first instinct on being hooked is to sheer wildly to right and left in the endeavour to shake out the hook. I have often known them, indeed, to fray the gut against the keel of the boat. The food of the mackerel consists largely of the fry of herring and other fishes, also of medusæ, small crustaceans, and the like. In the early summer it pursues the fry in large shoals close to the surface, at which time the fishermen catch it in drift-nets or on baits trailed at the surface ; but later in the year, about August as a rule, the shoals break up and the mackerel go to the bottom, when they are caught in the trawl and on ground-lines. The fishermen have an idea that these fish are blind towards the end of winter, being in fact unable to perceive the bait; but Cunningham ${ }^{1}$ offers an explanation of this in their probable absence at that season from the inshore grounds where such hand-lining is practised. The blindness is supposed to be the result of sickness, a fatty film covering the eye.

The darker, heavier Coly Mackerel can only be regarded as a wanderer from the Mediterranean to our southern

1 Marketable Marine Fishes, p. 316. 
shores. In it we find the beginnings of the breastplate of large scales more characteristic of the bonitoes. In Spanish colour, it resembles the common species, being, or Coly however, distinguished by the blotches on the Mackerel. underparts. As its appearances on our shores are irregular, and its flesh deteriorates even more rapidly than that of the other, it is of no commercial importance.

[The Plain Bonito is another straggler to our seas. It has the scaly breastplate more conspicuous than in the last.]

The most important fish in the Mediterranean, the Tunny is of irregular occurrence on our coasts, though not uncom-

Tunny. mon as far north as the western lochs of Scotland, ${ }^{1}$ where it is known as the "Mackrelsture." Tunnies of 9 feet in length and $900 \mathrm{lbs}$. in weight have been captured in British waters; but the fish grows to twice the size in the Mediterranean. I have seen them in the market at Naples weighing probably rooo lbs. Tunny is a favourite article of food with the Italians; and I was regaled with it in one form or another every day without fail for over three months, the least disagreeable way of serving it being as a roast with green peas, the least agreeable being when soused in olive oil and sent to table in a dish that has been first rubbed with a head of garlic. In colour, the tunny is very deep blue, lighter on the scaly breastplate. The tail is well keeled.

In the Albicore, otherwise Long-finned Tunny, we have a smaller fish, distinguished by the great length of the Albicore. pointed pectoral fins, which, in examples of large size, may exceed one-third the length of the fish. It is this fish that ocean travellers observe over the bow of steamers or in the wake of sailing ships, generally harassing the flying-fish. I have watched then (some

1 Harvie-Brown and Buckley, Fauna of the Outer Hebrides, p. 188. 
fully 4 feet in length, so far as it was possible to judge) at this work in the Indian Ocean, mostly about three hundred miles south-east of Aden. The largest recorded from British waters was less than 3 feet; and the occurrence of this fish, mostly on the south-west coast, is very irregular.

Another wanderer to our waters is the ocean-going Bonito, which does not in these parts exceed a length of

Bonito.

3 feet and a weight of ro lbs. The pectoral fin is short, the breastplate embraces a con. siderable portion of the back and sides, and there are a number of curved blue bands along the sides.

The Belted Bonito is an allied form which has, at irregular intervals, been taken on our south-west coast of a Belted length of 2 feet and a weight of $6 \mathrm{lbs}$. It is Bonito or distinguished by a number of broad vertical Pelamid. bands, crossed by other bands, curved and lateral. The habits of all these fishes so resemble those of the mackerel that it is a saving of space to omit any individual account.

As the boon companion of sharks, it is only natural that a good deal, both true and untrue, should have been written Remora at all times about the remarkable little Remora. or Sucking- It has only been taken in British waters at fish.

long intervals, and as it was always in the company of sharks, indebted to them, moreover, for its introduction to British waters, its admission to the present list is at least open to criticism. It is included, however, for the sake of the interesting evidence it affords of Nature's ways to different ends. In no sense of the word is it to be regarded as a parasite, the name bestowed on it by the ancients, as it never preys on the great fish whose company it keeps for various reasons-among them being, if we may so presume on its secrets, the advantages of free 
and easy locomotion, protection from the above-mentioned ravenous bonito and albicore that scour the surface of the waters day and night, and possibly some crumbs that fall from the host's jaws. The shark's part of the profit has not hitherto been explained, but I am inclined to think, from the examination of a number of small sharks which I caught in a Queensland river, some with one or more remoras attached, others without, that the fish may rid its host of the parasites that bore into its hide. The sucker with which this fish attaches itself to sharks or ships is a modified fin, and is situated on the back of the head. Contrary to rule, the back of this fish (which passes most of its life with its belly to the light) is of lighter hue than the lower surface. The largest remora I ever handled weighed just over 3 lbs., but one or two out of the ten existing species run much larger. The power of suction even in small examples is very great, and, even after death, it is difficult to remove one without injury, the best way being to seize it by the head, gently but firmly, and push it forward. It will then slide to the edge.

\section{CHAPTER VI. THE CORYPHENES AND THEIR ALLIES.}

The five fishes belonging to this group are of slight importance, and need only be mentioned. Ray's Bream is

Ray's a flattened blue fish, not unlike a bream in

Bream. appearance, with a continuous dorsal fin and a curious oblique cleft in the mouth. It is rare in our waters, where, however, it has been taken to a weight of over 4 lbs. In Irish waters it is known as the "Henfish." 
Another occasional wanderer to our waters is the many coloured Opah (otherwise "Sunfish" or "King-fish"), a handsome green-and-red fish, with silvery spots.

Opah. The lateral line takes a remarkable upward curve above the pectoral, and the head ends in a kind of beak. The skin is exceedingly thick. A specimen of I 90 lbs. weight was recently taken from the North Sea.

[The Black-fish, as Couch calls it, and the allied Centrolophus britannicus, are small and rare fish on our coasts, of which little seems to be known. Another rarity in British waters is Luvarus imperialis, one of which, weighing I $20 \mathrm{lbs}$., is recorded from Cornish waters. It has a bright red band along the side, the back being dark, the belly white, fins bright red. Both dorsal and anal fins extend only a short way from the tail, the foreparts of either margin being finless.]

\section{CHAPTER VII. THE HORSE-MACKERELS AND THEIR ALLIES.}

[It is convenient to include in this group not alone the horse-mackerels proper, but also members of a number of families that fall naturally in this place-such apparently distinct types as the dory, sword-fish, and hairtails.]

The only fish of the family that occurs in our seas in any numbers is the typical Scad or Horse-mackerel, shoals Scad or of which visit our south-west coast in summerHorse- time, though I have more often found it in mackerel. company with the mackerel, joining in keen pursuit of the "mackerel-midge" and other fry. I have taken as many as a dozen in a morning when drift-lining 
for mackerel, but never when sailing under canvas, though there is of course no reason why fish of habits so closely resembling those of the mackerel should not be taken in this fashion. The scad is known to the Italians as cantatore (the singer), owing to a peculiar grunting which, like the gurnards, it is said to utter when removed from the water. I must confess never to have noticed this myself, but it seems a matter of common observation. This fish may be distinguished by its long, low, dorsal fin, as well as by the bony plates along the lateral line. In colour, it is bluish grey above, white beneath. As food it is not to be recommended. It is still more capricious in its wanderings than the mackerel. During the early days of July in the present year (I897), tens of thousands were netted off Bournemouth (locally confused with pilchards), where they are often not seen for years together. My boatman took one this August (1897) off Mevagissey, weighing close on 3 lbs.

With the exception perhaps of the wonderful remora, few fish have been the theme of more downright nonsense than that other friend and ally of the shark, Pilot-fish. the Pilot-fish. As in the former case, we find all, or apparently all, the advantage on the side of the weaker, though, as these arrangements are generally mutual throughout vertebrate and invertebrate nature, man not excepted, it is probable that the shark derives some advantage that has so far escaped our notice. The wellseasoned story about the pilot warning the shark against the snare of the baited hook is as incredible as its fondness, alleged of old, for sailors in danger of running aground. I have myself seen a 20 -foot shark hooked the moment after one of its two attendant pilots had swum round the hook. This was in about $x 7^{\circ} \mathrm{S}$., and the bait was the half of a smaller shark that I had caught a few moments before. The pilot made a leisurely survey of the bait, found it apparently not to its own taste, and the 
minute afterwards the monster rolled lazily towards it and engulfed bait, chain, and all, but the hook came away. When such a shark is caught and hauled aboard, both pilots and remoras soon attach themselves, doubtless for the sake of protection, to the ship. The pilot-fish is in colour of a steely blue, having a number of dark bands down the sides, and occasionally one on the tail.

[The Black Pilot and Derbio have been recorded once each in our waters. The former, also known as the Snipnosed mullet or "Rudder-fish," is of American origin, and the solitary British example was found off the Cornish coast in a broken wooden case (!). The Derbio, or Glaucus, is a small green fish.]

In the Boar-fish we have a remarkable form, rarely exceeding a length of 7 inches, and being laterally flattened Boar-fish or like the more familiar dory. It is very roughCuckoo. skinned, to which, as well as to the prominent snout, may be due the trivial name. It is also, I believe, said to grunt on being captured and removed from the water; but here again, as in the case of the scad, I have not been favoured with a performance, as we used to net dozens in the little estuary north of Leghorn, and I never heard a sound from them. It is a bright-red fish, the fins being long and spinous, the mouth small and tubular. It occurs chiefly on the south-west coast.

The John Dory, one of the ugliest and most delicate of British table fishes, is too familiar on the fishmonger's slab to need much by way of description. John Dory. The body is flattened, the skin smooth, the dorsal fin tipped with long filaments. The colour is a deep brown, there being also a number of lighter bands and a single black spot with a light rim on either side. These spots are associated by tradition with the finger and thumb of St Peter; hence, according to some etymologists, 
the name is a corruption of the Italian word gianitore (gatekeeper). Cunningham ${ }^{1}$ gives an interesting picture of how the Dory, which is so depressed laterally as to foreshorten to the merest line, stalks small fishes; and I have repeatedly had the opportunity of observing this in the clear water beneath Bournemouth pier, where several dories take up their quarters each summer. The tragedy was continuous. First, the sand-eels harassed the "mack-

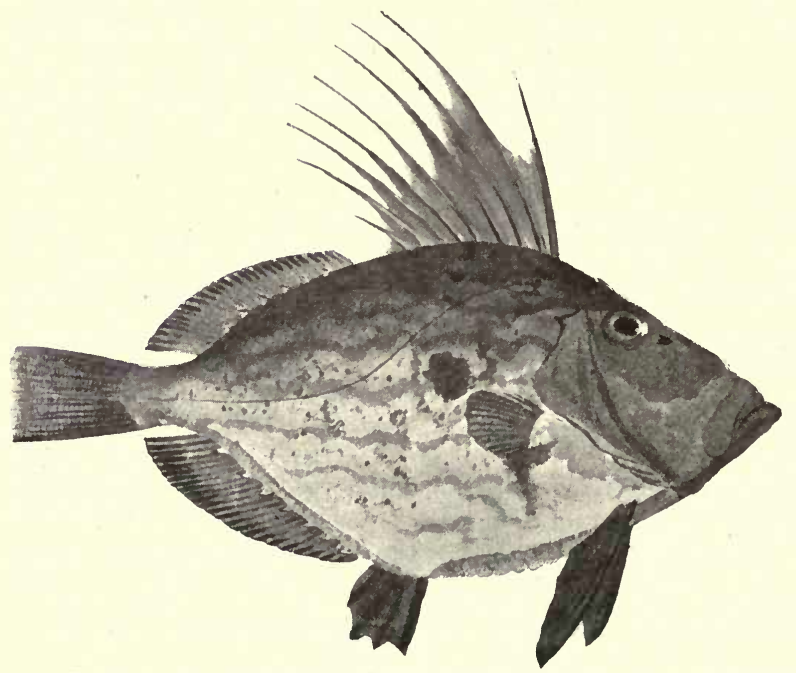

erel-midge"; then a pollack would dash out from the piles, miss the agile launce, and have to content itself with a small sand-smelt; lastly, a more leisurely dory would rise slowly from the depths, and, approaching end on, would quickly catch several sand-eels in its tube-like, mobile mouth. The dory is to some extent, and within limits not satisfactorily fixed, a migratory fish. It appears to spawn at the end of summer, and occurs as far north 
at any rate as the Moray Firth. ${ }^{1}$ Its greatest weight is about $18 \mathrm{lbs}$. , but the average would be nearer $5 \mathrm{lbs}$.

Easily recognised from all other living fishes by the curious sword-like growth on the snout, from which it Sword-fish. derives its name, the Sword-fish, which grows to a length of at least ro feet, is occasionally entangled in the mackerel nets on our south-west coast, and, more rarely, farther north. Another conspicuous feature of this fish is the high dorsal fin, particularly noticeable when, as not seldom happens, the sword-fish is observed basking at the surface. It is endowed with great strength and activity, and is known to attack with its only weapon both whales and ships.

The Maigre, practically the Jew - fish of Australian waters, is a large and handsome fish, growing to a weight Maigre or of near $400 \mathrm{lbs}$. We used to fish for its anSciæna. tarctic equivalent with a live bait weighing as much as a pound. In British seas, it is taken only casually in the mackerel-nets. In colour, dark grey, with metallic reflections, above, white beneath.

The Hairtail that occasionally visits our coasts hails from the West Indies. Examples, the largest of which Hairtail or had a length of $2 \mathrm{~T} / 2$ feet, have from time Blade-fish. to time been taken on the south-west coast. The tail, lacking the usual fin, tapers to a point.

The Scabbard-fish is the famous "Frost-fish," for which such prices are paid in New Zealand, on the shores of scabbard- which it is cast up in winter-time. It has fish. also occurred in our seas about a dozen times. It is a band-like fish with a long dorsal fin and a small fin at the end of the tail. (The "scabbard-fish," figured on p. 26I of the 'Royal Natural History,' would appear to

${ }^{1}$ Harvie-Brown and Buckley, Fauna of Sutherland, p. 262. 
be a Hairtail of some kind.) These occurrences have been confined to the coasts of Devon and Cornwall, and there seems to be some probability of a single Irish example. The length of specimens taken in British waters has been under 6 feet, nor does it anywhere appear to exceed this.

\section{CHAPTER VIII. THE GARFISH AND FLYING-FISH.}

This group finds a different place in every succeeding scheme. For the purposes of the present elementary work, however, it may be introduced here.

The well-known silvery-and-green eel-like Garfish, though excellent eating, is the object of a ridiculous prejudice, the Garfish or outcome of the green colour of its bones. The Guardfish. roof of the mouth is, as I have often had occasion to know, extremely hard. When hooked, this fish has a curious habit, also observed in sharks, of making straight

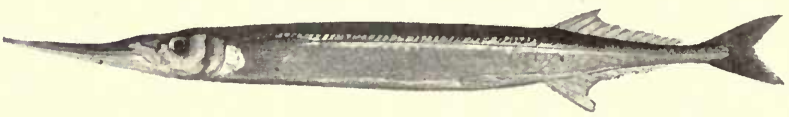

for the surface, even leaping into the air in its attempts to shake out the hook. Its food consists of small fish, which are pursued with long leaps at the surface. It is also characterised by a strong, unpleasant odour, peculiarly its own. From the great length of its beak it is known as the "Long Nose," while its arrival and departure with the mackerel has obtained for it the local title of "Mackerel guide." The migrations of this fish are as yet imperfectly understood, all we know being that it is absent from our coast in winter. 
Not unlike the last, the Saury Pike is a much smaller species. It is distinguished from small garfish of its own Saury Pike size by the presence of finlets behind the or Skipper. dorsal and anal fins, its smaller teeth, and its bluer colour. As in the garfish, the young skipper has the lower jaw much longer than in the adult; and, also like the garfish, its eggs are attached one to the other by long filaments.

The beautiful blue-and-silver Flying-fish, in which the pectoral fins are developed into wings, finds its way into Flying-fish. our waters, if ever, at long intervals only ; indeed some caution is necessary in accepting its recorded occurrences. In the first place, its action at the surface is, especially when seen at some little distance, not unlike that of the last, and might easily deceive those

- who had never seen the real flying-fish. As regards the examples cast up on the beach, it must be borne in mind that few South Sea curios are brought over in greater numbers, and dried specimens, being easily blown about, might, and doubtless do, get lost over the side in the confusion of packing as the ship is getting near the British coast. At the same time, there seems to be little doubt of the occurrence of living examples on our south-west coast.

\section{CHAPTER IX. THE GOBIES AND SUCKERS.}

\section{The Gobies.}

There appears to be some confusion as to the precise nomenclature of these little fishes, and the following is offered as an approximate list of British species. The male guards the eggs, which are deposited in shells fixed 
in the sand. The gobies are credited with the power of changing colour when pursued-a phenomenon, however, that I have not witnessed.

The Black Goby, largest of our gobies (and also known as the "Rock-Goby"), is common in rock-pools on most

†Black parts of our coasts, clinging with its fins in

Goby. one typical position to the rock. It also frequents brackish, even fresh, water, and its food consists of small fishes and vegetable matter. In colour it is dull brown, having white blotches on the sides. The tail is not forked. This goby breeds in June.

The "Polewig," as the Spotted Goby is often called, is abundant in the estuary of the Thames, in fact all round

Spotted our coasts. A very small fish, it is quick

Goby. to escape when disturbed. It feeds on crustaceans. In colour it is dark brown, with numerous spots.

The small Paganellus is very dark in hue, with some reddish shades on the dorsal and anal fins. It is said Paganellus. by Day to occur in both rocky and sandy localities, and to breed in May or June.

One of our smallest gobies, the Two-spotted Goby, has a conspicuous black spot above the pectoral fin, and a Two-spot- second on the tail. According to Harvieted Goby. Brown and Buckley, this species is found breeding in the neighbourhood of mussel-beds, its eggs being deposited in the shell of that mollusc.

There is, however, a still smaller species in the shape of White the White Goby, the length of which is $I / 2$ Goby. inch. This little fish is thought to spawn once and die; and if this is correct, its life lasts but a

1 Fauna of the Outer Hebrides, p. 194. 
year, and it is one of the only European cases of what is termed an "annual vertebrate."

†The Four- A small species occurring in brackish spotted Goby. water.

Nilsson's A small and rare semi-transparent deepGoby. water goby, having dark spots on the jaw and fins.

Parnell's This goby has light bands on the dorsal Goby. fin, dark on the caudal.

The Gemmeous Dragonet is a beautiful smooth-skinned species, the male being orange and blue in colour, with red Gemmeous and lilac markings, and having the dorsal fin Dragonet. yellow with lilac bands, with a long ray. The duller female, known as the "Dusky Skulpin," is brown, with various spots and blotches, and lacking the long dorsal ray. The mouth is pointed, its opening being of small size; and the food consists chiefly of molluses.

[The Spotted Dragonet, a deep-water species, has been once dredged near the Hebrides. There are black spots on the fins, sometimes on the body.]

\section{The SuCkers.}

Among the ugly fish of the sea none can perhaps bid against the Lumpsucker for sheer repulsiveness of exterior,

Lumpsucker or

Cockpaidle. with its slimy skin and rows of tubercles, the skin almost enveloping the front dorsal fin. It grows to a weight of $20 \mathrm{lbs}$., the colour of the male being normally red, that of the female blue. The young, which are of a bright green, are often taken in the salmon-nets. The eggs, also reddish, are deposited among the rocks, and are jealously guarded by the 
male, though, according to M'Intosh, ${ }^{1}$ they are often uncovered at low tide and devoured by rats and crows. The ventral fins form in this fish an adhesive disc, by the aid of which it attaches itself to rocks. It preys on smaller fishes, and is said in its turn to be much eaten by seals.

The little Sea-snail, which does not exceed a length of 6 inches, has the same modification of the ventral fins, but is without scales or tubercles. It is light Sea-snail. brown, with darker bands. Cunningham ${ }^{2}$ says that the spawn has frequently been mistaken for that of the herring.

A smaller and more active fish than the last, Montagu's Sucker is of similar habits and appearance, only more Montagu's yellow, and marked with dark spots. As in Sucker. all these fish, the normal colouring is subject to much variation. This species is common in the Hebrides (Harvie-Brown and Buckley).

We now come to a small group of three fishes having the sucker between the ventral fins, not to any extent Cornish formed by them. They also lack the spinous Sucker. dorsal fin. These, of which the Cornish Sucker is typical, are thus distinct from the foregoing, and are included in the present chapter only conditionally and for convenience. The oval sucking-disc is divided into two portions, the hinder part having a free edge of thick skin. In colour this species is red above, lighter beneath, but subject to much variety. This little fish, which rarely exceeds a length of 4 inches, is common on all our rocky coasts. It feeds on crustaceans and breeds in spring, depositing the eggs in empty shells.

The Connemara and Doubly-spotted suckers are similar in habits. The first, which has a shorter dorsal fin, is red

1 Life-Histories of British Food-Fishes, p. 15.

2 Marketable Marine Fishes, p. 351. 
with light oval spots. The second, which does not exceed a length of 2 inches, is red above, pink below, and marked with a few light vertical bands. The male guards the eggs.

\section{CHAPTER X. THE BLENNIES AND BAND- FISHES.}

\section{The Blennies.}

From the absence of scales the Shanny is also known as the "Smooth Blenny." In colour, it is yellowish, with

Shanny. black spots. Its food apparently consists of small crustaceans and regetable matter. The shanny spawns on the bottom in the summer.

We have in the Gattorugine a far larger species, easily recognised by the fringed tentacle over the eye, the pro-

Gatto- portionate length of this appendage being aprugine. parently subject to variation. In colour, the gattorugine is greyish brown with vertical bands, the fins edged with yellow or white.

The Butterfly Blenny, also known as the "Eyed" Blenny, may be recognised by the large black whiteButterfly rimmed spot on the first dorsal fin. In Blenny. colour it is grey, having half-a-dozen dark vertical bands. Like the last, it has a tentacle over the eye. It seems almost confined to the south-west coast.

Montagu's Blenny, smallest of all those of British Montagu's habitat, rarely exceeds the length of 3 inches, Blenny. and is covered with conspicuous white spots. Between the eyes is a fold of skin with a fringe of 
tentacles, which the fish appears able to erect at will. Like the rest of the group, it is a most active fish, making endless attempts to leap over the side of any vessel in which it may be confined.

The somewhat larger Yarrell's Blenny, which has been recorded to a length of 7 inches, is distinguished from the Yarrell's foregoing by the presence of small scales. In Blenny. colour it is brown, with dark bands, the latter being sometimes absent. On the head are four tentacles. This species appears common on every part of the coast, and is either dredged or taken in the crab-pots.

The elongated Butterfish grows to a length of near I2 inches, the dorsal fin being continuous with the tail and Gunnel or ventral, its base marked by black, white-edged Butterfish. spots. There are no tentacles on the head of this blenny. According to Cunningham, ${ }^{1}$ these fish were seen by $\mathrm{Mr}$ Holt to be spawning at the St Andrews aquarium in February, the parents taking turns in rolling the eggs into a ball, coiling their bodies round the mass. This blenny is found on every part of the coast, and the male is known to mount guard over the eggs.

The most interesting, however, of the group is unquestionably the Viviparous Blenny. The young, as many as Viviparous 300 in number and $1 / 2$ inch in length, ${ }^{2}$ are Blenny. born early in the year, and there appears to be some evidence in favour of a second brood. This blenny, which seems, unlike the rest, least in evidence on our south-west coast, grows to a length of 24 inches. It is of an olive-brown colour, the body being marked with arched bands. The dorsal fin, which has a deep notch just before the tail, is continuous.

1 Marketable Marine Fishes, p. 344.

$2 \mathrm{M}$ 'Intosh and Masterman (Life-Histories, p. 13) gives the length as 2 inches, and points out that it is proportionately great. 
The Wolf-fish, largest of our blennies, is the muchmaligned "Stone-biter" of the Baltic fishermen, who de-

wolf- clare that it is of fierce disposition. It is

fish. certainly not a very attractive creature, but, as in the case of the dory, appearance does not go for much, and the "Cat-fish," another of its names, is good eating. It grows to a length of at least 6 feet, and is grey, with a row of black bands and small black spots. A fish of cold seas, it is rarest on our southern coast, being chiefly known among the isles of Scotland; only a few examples are mentioned from Irish waters. There are no throat-fins; the tail-fin is small but distinct. The teeth of this blenny, which are, I suspect, more formidable than its character, are long and curved, and it feeds on all manner of shell-fish, whelks more particularly.

[The Sharp-tailed Lumpenus ${ }^{1}$ was once trawled (1884) off the Carr Lightship.]

\section{The Band-Fishes.}

[The three species of this group which have wandered occasionally to British waters are the Red Band-fish, the Deal-fish, and Banks's Oar-fish. The first of these, a small deep-water fish that rarely exceeds a length of 2 feet, is occasionally hooked, more often thrown ashore in gales. It is compressed in form; red, with yellow markings. The eyes and teeth are conspicuously large. The tail-fin is absent.

The Deal-fish, which grows to a length of 9 or to feet, the largest British example having measured rather over 7 feet, is taken at long intervals in the stake-nets on the northern coasts. It is silvery in colour; and the tail-fin, raised above the line of the body, has several long rays. There is no ventral fin.

1 I include this on the authority of M'Intosh and Masterman (LifeHistories, p. 223). 
[Banks's Oar-fish, an elongated silvery form, the longest British example of which measured $15 \mathrm{I} / 2$ feet, has a remarkable process of the dorsal fin, which gives the impression of a crest. The pelvic fins are mere filaments. When this deep-sea form is thrown ashore, the long flattened body breaks at the least touch. One at least of the dozen odd British examples has been referred to an allied form, R. grillii.]

\section{CHAPTER XI. THE ATHERINES AND GREY MULLETS.}

I. The Atherines.

The Atherine, the so-called "Sand-smelt," is common along just those parts of our south coast where the true t Atherine salmonoid smelt is wanting. Hence, no doubt, the confusion; for when seen side by side the two are distinct enough, the latter being at once recognised by its soft dorsal and adipose fins, as well as by the numererous sharp teeth with which the mouth is lined. On the Hampshire coast the little atherine, which rarely measures more than 6 inches, is particularly abundant. It spawns in summer, and I have hooked dozens full of roe in June. These fish are attracted by a bait in motion, and few better baits can be found than a fragment of atherine! This fish is an excellent bait for turbot. In colour the atherine is brown or green along the back, and has a broad silver band, with purple reflections, on the sides, the fish being semi-transparent. The above length is generally supposed to be slightly exceeded by atherines from the Irish coast.

[ + Boier's Atherine, a smaller fish with relatively larger eye, is by many regarded as a variety, by others as the young, of the common form.] 


\section{The Grey Mullets.}

This is one of the handsomest and wariest of our seafish, wandering up some of our rivers, notably up the Grey or Sussex Arun. In colour it is silvery, with Thin-lipped dark bands, the metallic lustre fading very Mullet. rapidly after death. Having no teeth, a defect in its digestive arrangements which is in part compensated by the presence of a gizzard-like arrangement in the

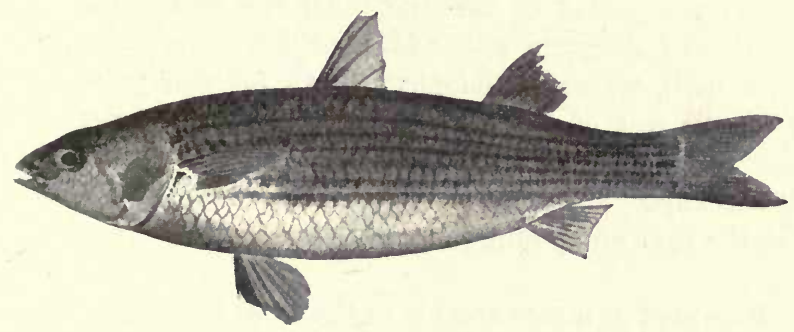

stomach, this fish feeds entirely on small soft substances, among which are various weeds. To varieties of this fish are now ascribed more than one of the so-called British species. According to some authorities, the grey mullet spawns twice in the year, but this appears very doubtful.

The other distinct British form is more gregarious than the last, and also attains to a greater weight. I have taken Lesser Grey this species in the Mediterranean weighing

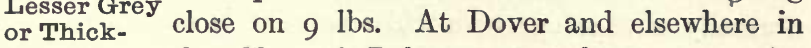
lipped the Channel I have seen the two species Mullet. swimming together. This would appear to be the commoner species on the Devonshire coast; indeed it is the only species that Cunningham has ever observed at Plymouth. 


\section{CHAPTER XII. THE STICKLEBACKS.}

The little grey and golden Stickleback, with the three (sometimes four) spines in the dorsal fin, is familiar in most of our streams. In place of scales, it is + Common clad in bony plates, and the variations to which
or Threespined it is subject in the number of these plates, as Stickle- in that of the spines, has been the basis for
back.

a number of species, which might be more properly regarded as varieties. All the sticklebacks are capable of living in either fresh or salt water; and they have been, wrongly, thought to live for one year only. Like the rest of the group, this stickleback constructs a nest towards the middle of spring, the male, which assumes at this important season patches of red, subsequently guarding the eggs and young from intruders.

Regarded as a sore trouble in the trout-stream, the Tenspined Stickleback, or "Tinker," is widely, though locally, + Ten- distributed throughout these islands, frequent-

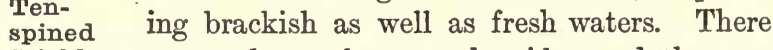
Stickle- are no bony plates on the sides, and the norback. mal colour, which is subject to considerable variation, is greenish-brown, with black spots, belly and sides silvery. In the breeding season the male, at any rate, changes to a deep black.

The larger Fifteen-spined Stickleback, or "Bottlenose," normally olive-colour with white patches, is said to change $\dagger$ Fifteen- hue when excited. In these islands this species spined is described by most writers as exclusively Stickle- marine, but it has been observed to enter back. some streams in northern Continental countries. It is therefore probable that it has similar tastes with us, but has chanced to escape observation in our rivers. This species has a long attenuated body and 
pointed snout. It is pugnacious and greedy as the rest, feeding on similar small worms and larvæ, and building a nest of seaweeds, in which the polygamous male presently mounts guard over the eggs.

[We may here conveniently consider that small and remarkable form the Bellows- or Trumpet-fish, which has been taken in our waters about half-a-dozen times. Viewed from above, it has the compressed appearance of the dory; from below, the bony plates and spinous edge give the impression of a knife-blade. This fish, which does not exceed 6 or 7 inches in length, is of a pink hue; belly silver. The bellows-fish has a beak like the last, the mouth being small and toothless. The body is covered with small spinous scales, and there is no lateral line. One spine of the first dorsal fin is long and serrated.]

\section{CHAPTER XIII. THE WRASSES.}

The fishes comprised in this group are all characterised by thick lips, mostly having brilliant colouring and strong teeth adapted to crushing. They frequent weed-covered rocks, take almost any bait, and are, for all the ancients accorded them high praise, the poorest of eating. I have observed all our species, I believe, and several more on the Italian coast; and the largest members of the group I ever saw were the blue gropers of Australia, which are hooked weighing as much as $100 \mathrm{lbs}$.

One of the commonest of our wrasses, which I have caught Striped off Dartmouth weighing over 2 lbs., is the Wrasse or Striped Wrasse, or "Cook" (locally, "Carp"), Cook.

a red-and-yellow fish with blue bands in the male, the female being distinguished by black marks near 
the tail. It is more abundant in the Channel than farther north, and seems to grow to a length of 13 inches (Day).

Like the last, the greenish Ballan, with blue spots on the body and red lines on the face, is subject to several Ballan or varieties. I have taken this wrasse on the Comber. Cornish coast weighing near $5 \mathrm{lbs}$., and it is said to grow to a weight of 8 lbs. Like all the wrasses, it frequents weed-covered rocks, and feeds largely on hermitand other crabs.

More gregarious than the foregoing, the small Connor, also known as Baillon's Wrasse, has bright red or yellow Connor or bands on the face, white rings on the tail-fin, Goldsinny. and black spots on the anal fin. Its greatest length would appear not to exceed 9 inches, and it occurs on all parts of the coast.

Equally common on the coasts of England and Ireland, though somewhat less so off that of Scotland, the small Pink Brame Pink Brame, which does not exceed a length of or Jago's 6 inches, is the least esteemed of a worthless Goldsinny. family. It has a distinguishing black blotch on the red dorsal fin.

One of our largest wrasses, the Scale-rayed Wrasse, is easily distinguished by the rows of scales on the dorsal scale-rayed fin, to which it owes its trivial name. In Wrasse. colour it is of a reddish orange, with or without blue spots on the sides.

Rock-Cook or Small-

The Rock-Cook is a small and uncommon mouthed Wrasse. species, of a brown hue, with yellow shading, having yellow lines and blue bands on the head.

The Rainbow Wrasse, another small species, is even 
more brilliantly coloured than the rest, in which particular it is subject to considerable sexual and other variation.

Rainbow It is difficult to say whether red, purple, green,

Wrasse. or yellow predominates; and there is usually a large dark spot on the dorsal fin, sometimes a second on the pectoral. Like most wrasses, it has a peculiarity of the air-bladder that causes it to float if flung in the water as soon as it is taken off the hook. I have in this way thrown back many wrasses, ranging in weight from 3 ounces to as many pounds, and they invariably floundered helpless at the surface.

\section{CHAPTER XIV. THE COD FAMILY.}

Of this important group of food-fishes we have a number of representatives-one only, the burbot or eel-pout, inhabiting fresh waters. They are cold-water fish, distinguished for the most part by soft fins, smooth skin, and a "beard" or fleshy barbel, not always present, on the lower jaw. The eyes and mouth are large.

The Cod, type of the family, is too well known to need

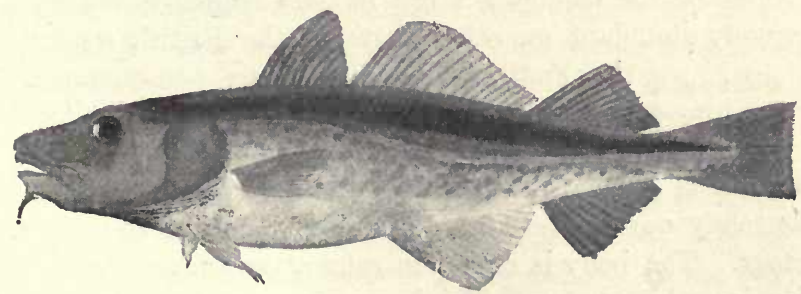

minute description, being a large-headed, tapering, greenish cod. brown fish with distinct white lateral line, upper jaw longer than the lower, and the family barbel. Codlings, as the young are called, are 
more yellow in hue, and often spotted with brick-red. This fish occurs on all our coasts, and seems to approach the land early in the year for spawning purposes. It feeds on the ground, the barbel, like the tongue of snakes, helping it to find and investigate the crustaceans on which it preys. Cunningham gives an interesting account of the observations recorded by Sars. The cod grows to a weight of $80 \mathrm{lbs}$.

This almost equally familiar fish has the lateral line black instead of white, the barbel shorter, and a conspicuHaddock. ous black blotch on either side, which shares with that on the dory the honour of association with the apostle Peter. In our waters, at any rate, the haddock is a smaller fish than the last, rarely exceeding a weight of $20 \mathrm{lbs}$, averaging nearer $5 \mathrm{lbs}$. On the coast of Iceland, however, I understand that haddock are caught of such enormous weight as to be useless for curing purposes. Like the cod, this species feeds mostly on shell-fish, though Cunningham ${ }^{1}$ mentions a case of haddocks gorged with herring-spawn. The haddock seems to hug the land throughout the winter months, and spawns in spring.

One of the commonest fish in the Channel, and almost equally abundant on other parts of the British coast, is Pout or the Pout, a fish with many names, among Whiting- which may be mentioned "Bib," "Blain," and pout. "Pouting." It grows in our waters to a weight of $4 \mathrm{lbs}$, though it is more often caught weighing as many ounces, few fish taking the hook at so early a stage. The body is deep; in colour, brown, with vertical bands; white below. The barbel is present on the lower jaw, and there is usually a black spot on the pectoral fin. Fond of rocks, sunken wrecks, and like "marks," these fish wander but little from place to place, and I have

1 Marketable Marine Fishes, p. 152. 
often found it possible in the course of a couple of tides to empty a spot of its large pout.

[The Norway Pout has apparently been added to the British fauna recently. It is distinguished by the pointed snout, large eye, and projecting lower jaw. According to Harvie-Brown and Buckley, ${ }^{1}$ it is not uncommon in Kilbrannan Sound.]

In the smaller Poor Cod we find the body narrower, the eye larger, and the lateral line less curved. There Poor Cod are no vertical bands. It has the family or Power. barbel. This fish occurs all round these islands.

Most familiar after the cod, the Silver Whiting is remarkable for the delicate flavour that makes it invaluable

Silver to convalescents, though it deteriorates almost

Whiting. with the rapidity of mackerel. More elongated than the foregoing, this species lacks the barbel. In colour, it is silvery, having the lateral line black, as also a spot on the pectoral fin. The mouth is large, the teeth small and numerous, and very sharp; the food consisting of sand-eels, worms, crustaceans, and the like. Essentially a sand-fish, it moves from place to place much more than the pout, and seems to undertake movements of considerable extent to and from the deep water. It is recorded to the weight of 4 lbs., but the average is very much below this. The whiting spawns about May. With reference to its migrations, it occurs to me as of interest to mention that $I$ have noticed for years at Bournemouth a spring inshoring of small silver whiting, measuring about 3 inches, early in May, after which there are few or no whiting in the bay until the larger fish put in an appearance late in July.

Rarely seen at the fishmonger's, owing to the little esteem in which it is held as food and the rapidity with which its

1 Fauna of the Outer Hebrides, p. 203. 
flesh deteriorates, the Pollack is a handsome green fish, with protruding lower jaw and no barbel. This fish-which is Pollack or taken in the Channel, as on the Scottish and Lythe. Irish coasts, to a weight of 25 lbs.-lurks during the day in the darker pools among the rocks; but after sunset, and for an hour either side of sunrise, it comes to the surface, where it either chases the sand-eels, or, as I have repeatedly watched it, gambols in a manner that, unless its object be the riddance of its body from some

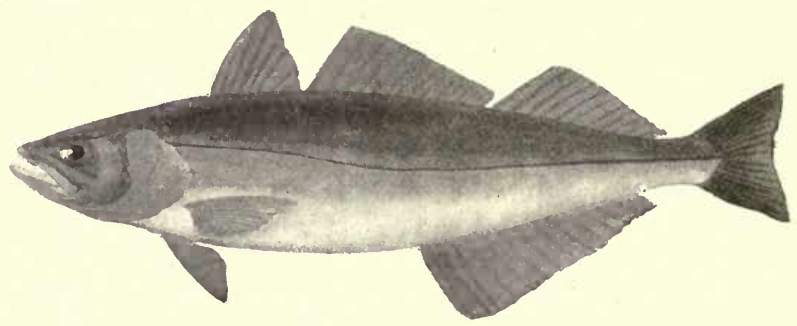

unwelcome parasite, can only be regarded as wanton sport. When hooked, this fish at once heads for the bottom, and the angler tries, at any cost, to keep it from the rocks. It is often taken coiled up in a crab-pot; and its fondness for the neighbourhood of these baited pots is so well known that pollack-fishers ask no better moorings than the corks on the line of the pot. Pollack taken on the sand are not only lighter in colour, but usually exhibit light patches soon after death.

Why the Coal-fish should ever have been confused with the pollack, seeing their many points of difference, is not Coal-fish easy to understand; but the fact remains that or Saith. they have been confused. This fish, which grows to, if anything, a heavier weight than the pollack, may be readily distinguished by the presence of a small barbel, and the more abrupt division between the greenish grey of the back and the silvery white of the belly. The 
lower jaw also protrudes less. The habits and food seem, indeed, to bear considerable resemblance to those of the pollack, but the present species is said to spawn somewhat later. It is also known as the "green cod," and the young go by the name of "podleys." 1

Another species without the barbel is the little Poutassou, which is known as Couch's whiting. The general colour Poutassou. is brown, and there is a yellow band on either side the nearly straight lateral line. Nowhere very common, this fish occurs seasonally on every part of the British coast.

As an example of the more voracious gadoids, a greater offender by far than the pollack, we may take the formid-

Hake. able Hake, which is caught in the pilchard-nets weighing over $20 \mathrm{lbs}$. It differs from the foregoing mainly in the presence of but two dorsal fins; it has no barbel, and the teeth are large. Of elongated form, its scales are large and rough; and its colour is dark grey above, silvery beneath. It chases the pilchards on our south-west coast, the herring and mackerel farther east, causing irreparable damage among the nets, most of its raids being perpetrated at night.

Another very large member of the group, which reaches a weight of upwards of roo lbs., the Ling is dark grey on

Ling. the back, lighter on the head and belly. It is yet more elongate than the last, the skin being much smoother, fins soft and narrow, upper jaw protruding beyond the lower. Essentially a ground-fish, wherein it differs from the hake, it feeds almost exclusively on the small fish that inhabit those depths. It spawns in summer.

The Burbot, our only fresh-water form of cod, is much 1 M'Intosh and Masterman, Life-Histories, p. 209. 
like the ling in appearance, but the scales are rougher and the teeth smaller. The burbot rarely exceeds, in our rivers Burbot or at least, a weight of $3 \mathrm{lbs}$, and its colour is Eel-pout. yellowish, with dark spots and blotches. Its distribution in these islands is confined, singularly enough, to the east side of England, being absent. or apparently so, from both Scotland and Ireland. It is even locally distributed in the limited area mentioned, occurring only in the Ouse, Cam, and Trent, as well as in a few smaller streams in Yorkshire, Staffordshire, and Durham. A fish of somewhat singular habits, it lurks during the greater part of the day among the stones (hence "Rabbit-fish"), feeding chiefly at night on small fishes and insects. It is accounted a great trouble in a trout- or salmon-river, and seems to thrive equally well in river, stream, lake, or pond, evincing a preference for clear deep water, where, according to Seeley, ${ }^{1}$ its colour is usually paler. It spawns in the spring.

In the Fork-beard, we find the ventral fin modified Fork- into a long forked ray. The barbel is present,

beard. and the skin is extremely smooth. This fish rarely exceeds a length of 2 feet, and is of a dark colour, with black margins to the yellow fins.

In the "Tadpole-fish," as the Lesser Fork-beard is sometimes called, the barbel and first dorsal fin are both small.

Lesser The fish, which has a strong unpleasant smell, Fork- attains a maximum length of $\mathrm{I}$ foot, and is beard. uniformly brown, with purple reflections. Its food consists of small fishes, and it spawns in summer.

In the northern Torsk, known locally as "Cat-fish," we observe, among other characters, a rounded Torsk. body, thick smooth skin, and one dorsal fin only ; in colour, it is of a deep grey, with yellow on the fins.

${ }^{1}$ Fresh-water Fishes of Europe, p. 85. 
It is taken in more northern waters of a length of at least 3 feet and a weight of $5 \circ \mathrm{lbs}$., but examples taken off our north coasts - it does not occur in the south - average nearer ${ }_{5} \mathrm{lbs}$. It seems uncertain whether this fish should find a place in the Irish list.

In the three rocklings we have shore-fishes that feed, mostly at night, on small fish and crustaceans, lurking. Three- during the day among the stones, and frebearded quently getting left behind in shallow rockRockling. pools by the receding tide. The largest of them, the Three-bearded Rockling, is a light-brown fish with black spots, and has two barbels on the upper and one on the lower lip. It appears to attain a length of 20 inches, but the largest I ever hooked, off Hastings pier, measured just 9 inches. This fish, locally known as the "Three-bearded Gade," spawns in summer. It is its young that are known as "Mackerel-midge"; they are silvery and without spots, and a favourite food of herring, mackerel, and other surface-feeding fish.

The Four-bearded Rockling has one barbel more than the last, the upper jaw carrying three of these appendages, Four- the lower one. It is brown, and has no spots bearded of any kind. The small dorsal fin of this fish Rockling. is observed to vibrate rapidly, not unlike that of the pipe-fishes. Like the other rocklings, it is a favourite in the marine aquarium. It spawns in summer.

Yet one more "beard," five in all, has the Five-bearded Rockling, four on the upper and the usual single one on Five- the lower jaw. The body, which is of a unibearded form brown or stone colour, is unspotted. This Rockling. fish is known down in Cornwall as the "Brown Whistler," the reason of which sobriquet I was never able to learn. It frequents shallow water, feeds on small crustaceans, mostly at night, and in summer deposits its eggs 
in a nest of seaweed. Conger-fishers know from experience that there are few better baits for the eel than a rockling of any species and about 5 inches in length. This might at first give rise to surprise at the rockling choosing the same time as the larger fish to be abroad; but it is to be remembered that, as pike-fishers have known all time, predatory fish have a special weakness for sickly or wounded fishes, and it does not by any means follow that the rocklings, acceptable though they be when impaled on the hook, form the conger's natural food.

\section{CHAPTER XV. THE SAND-EELS AND ALLIED FORMS.}

The five fishes that compose this group are, for all the external dissimilarity, somewhat closely allied to the cod family. With the true eels they have nothing in common; both their appearance and their action in the water are quite distinct.

The most familiar at many of our watering-places is the small silvery Launce, which attains a length of over I

foot, but is more commonly found measuring
less than half. In colour it is bright green, with a silvery band on the sides and a black spot on the head; and it may be further distinguished by the projecting, horny-tipped lower jaw and the two sharp teeth in the upper. Throughout the summer months these little fish forgather at the surface, often in company with the next and with sand-smelts, feeding on floating fry and other organisms. They are bold and pugnacious, and when they are minded to take every baited hook, the atherines seem to know that they stand no chance, 
and, as I have often observed on Bournemouth pier, hold aloof, or pick up what they may lower down. There seems to be some doubt as to the exact spawning-time. According to Cunningham, the next species is known to deposit its spawn in the month of July; and this, taken in conjunction with the fact that the larvæ of the present species were got at St Andrews in March of a size corresponding with that of other larvæ, less closely identified, taken in August, leaves room for two hypotheses - either that the present species spawns in winter, or that one or both may spawn twice in the year.

The Lesser Launce, known as the "Wriggle," differs but slightly from small examples of the last, the lower Lesser jaw being relatively shorter and the two upper

Launce. teeth being absent. In colour it closely resembles the last, though somewhat lighter. The food and habits are also similar, both species being fond of burrowing in the wet sand above low-water mark, from which they are often "scraped" by moonlight, a favourite diversion in the Channel Islands. Bearing in mind the limitation mentioned under the head of rocklings, it is worth mentioning that the sand-eels are the best bait for almost every fish in our seas, so that it is quite possible that they have a brisk time of it.

$\left[\right.$ Day $^{1}$ only admitted the third sand-eel to our fauna conditionally, as it is a deep-water form and very rare in our waters. The Smooth Sand-launce, as it is called, is a very small species, toothless, and practically without scales.]

[The Bearded Ophidium, or Snake-fish, which has only been recorded once in our seas, is said to reach a length of ro inches, has two barbels on the lower jaw, and is brown, the fins having a black margin.] 
[Drummond's Echiodon, which has been taken in our seas on one or two occasions, is one of a group of small semi-parasitic fishes that shelter in the folds of large medusæ and holothurians. It appears not to exceed a length of 12 inches; and is light brown in colour, having a tapering tail, a continuous fringe of fins, and no scales.]

[Coryphcenoides rupestris, which may be placed after the sand-eels, is a small and spinous silvery fish, the body tapering to a pointed tail, the head disproportionately large. Some allied species, all of which inhabit great depths, exceed a length of 2 feet, but the limits of our form are not known.]

\section{CHAPTER XVI. THE FLAT-FISH.}

These are the most interesting anatomically, and, with the single exception perhaps of the herring family, the most important commercially, of all our sea-fish, differing from the rest in their compressed form, the different colouring of either side, and the twisted head, in which the eyes are on the same side. Hence the fishermen distinguish the rest as "round-fish," though it must be confessed that their classification is lenient, since, in many parts at any rate, the skates and rays, cartilaginous fishes with no resemblance to the present group, are included under the category of "flat-fish." These fish dwell in the sand, burying themselves in it, especially in cold weather, all but the eyes; but on warm evenings they will rise to the surface, and I have known several instances of their taking a spinning bait a few feet only from the top. With the exception of a single sharp spine over the 
ventral fin (not always present), these fish are soft to handle, though this spine sometimes gets in the way when they are being taken from the hook. Most of them are smooth, though the dab is rough-skinned, and the turbot and flounder are covered with tubercles. In speaking of "right-sided" or "left-sided" flat-fish, it must be remembered that few families in the fish world are subject to a greater number of aberrant forms. What is meant is that, normally, a right-sided flat-fish, as the plaice, has the eyes and colour on the right side, the fish being held with its tail to the observer and the ventral fin to the ground. A comparison with any round-fish will show that what appears as the back of these fish is in reality one of its sides, while the edges of the flat-fish are really their back and belly. As already said, exceptions are numerous, and we constantly come across examples with both sides coloured, known as "double" examples; others that should be coloured on the right side are found to be coloured on the left, and vice versa. These latter are called "reversed" examples. The mouth of flat-fish is, as a rule, exceedingly small, and they mostly feed on worms and other soft food, which they suck from the sand. The females are larger and more numerous than the males.

The turbot and brill, with three or four more of less importance, have the eyes and colour on the left side, and their mouth is large.

The first of these, the Turbot, is a familiar fish, in which tubercles take the place of scales. These tubercles are Turbot. confined to the coloured side, the colour being brown or stone-grey. This fish, which has been recorded to a weight of over $20 \mathrm{lbs}$., feeds on small fishes, among them being sand-eels and atherines, and crustaceans. Though a ground-fish, taken on the long line or in the trawl, I have observed small examples clinging to the piles of Bournemouth pier within a couple of feet 
of the surface. The turbot spawns in summer, and appears to hug the coast at that season.

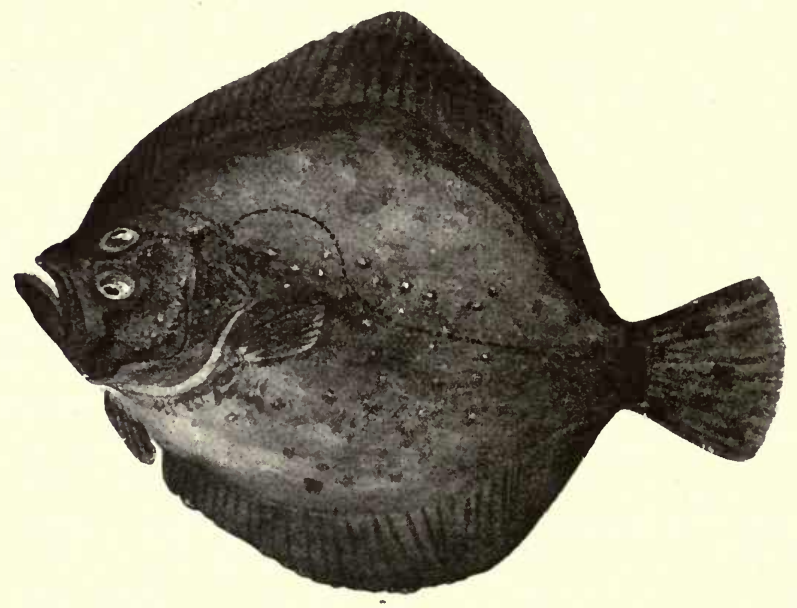

In the Brill or "Kite," the tubercles of the turbot give place to the usual scales, which are small in size. This is

Brill. a much smaller fish, rarely exceeding a weight of ro lbs. Its food and spawning-time correspond with those of the turbot.

The smaller Megrim, which grows to a length of 20 inches, is lighter in colour than the foregoing, and there Megrim or are sometimes dark spots on the white side, Whiff. though these are the exception. The skin is very rough to the touch. This species appears to spawn in spring.

The most remarkable feature about the Scald-fish, described by Couch under the name of "Megrim," is Scald-fish. the exceedingly delicate skin, which with its large scales peels off at the least touch. It is to the singular appearance of these fish when removed from the trawl that the name, sometimes rendered "Scald 
back," has reference. In colour, this fish is of a pale brown; white on the right side, or beneath, as it would be called; and its greatest length is given as 8 inches. It spawns in spring.

The Topknot, commonly known as "Browny," is a rough-scaled fish, smooth on the uncoloured side. It Topknot. appears to be common on all our sandy in early spring.

Another unimportant member of the group, the Onespotted Topknot, which is not known to exceed a length One-spotted of 5 inches, is of reddish hue, having a single Topknot. dark spot on the back and sometimes several fainter spots. The right, or under, side is rough. This fish is further characterised by the long dorsal ray.

The third and smallest of the topknots, the Norwegian Topknot, of which a mature example has been taken measNorwegian uring little over 3 inches, is smoother both Topknot. above and below than the last; and has not the elongated dorsal ray. It is said to spawn about April.

All the remaining flat-fishes of our seas have the eyes and colour on the right side. The halibut and long rough dab present certain points in common.

In the Halibut, largest of our flat-fishes, which is taken in our seas weighing as much as Ioo lbs., we find Halibut. the skin smooth and the right side dark brown in colour. The mouth is large and the teeth are pointed, the food of this species consisting largely of ground-fish, crustaceans, and molluses. Though this is to be regarded as a marketable fish, the flesh is coarse when compared, at any rate, with that of the sole or turbot. According to Cunningham, the halibut spawns in the 
summer months, "from April to August." It should be remembered that in some parts of Scotland this fish is known as the "Turbot."

The Long Rough Dab is common on the more northern coasts of Great Britain and Ireland. As in the preceding, Long the mouth is large and armed with pointed Rough teeth, the food of this species consisting chiefly Dab. of crustaceans and small fishes. This fish, the colour of which is usually uniform greyish brown, is rougher to the touch than the halibut. It spawns in March and April.

In the same group with the Plaice are comprised most of the familiar flat-fishes, all having the eyes on the right

†Plaice. side. The scales of the body are small and emthe only spine being that before the ventral fin, which

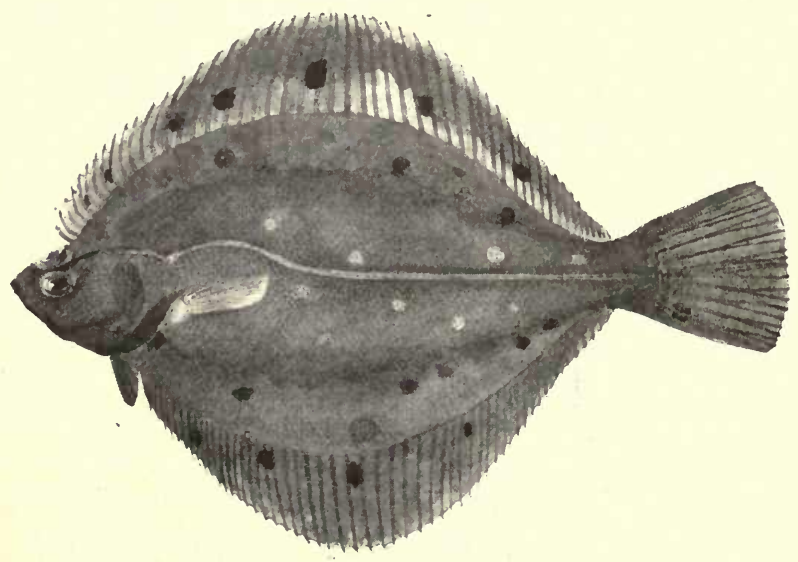

this fish has in common with the next. The coloured side is deep brown, covered with orange spots; the lateral line is straight, and there is a bony ridge on the head. Such 
are the main characters of this common and important fish, which grows to a weight of over ro lbs., though the fish trawled nowadays in the home waters average nearer 2 lbs. The teeth are flat, enabling the plaice to crush the shellfish on which it feeds; these teeth are more developed on the left, or "blind," side, and the mouth is of small size and situated at the end of the snout. The plaice is found in brackish waters. I have caught large numbers in the estuaries of rivers running into the Baltic, a sea that is itself little more than brackish; and Seeley ${ }^{1}$ mentions its occurrence in some rivers in the south of Spain. The plaice spawns between January and March; its eggs are large, and float at the surface. The young, as those of all the flat-fish, swim in their earliest stage like those of "round" fish, the eyes being on either side of the head, until, in the course of a few weeks, the left eye works round or through the margin of the head, taking its place beside the other, and leaving only a minute black dot to indicate its former position. By this time the little fish has taken to the bottom, and swims on its side, the twist in the head, which brings the dorsal fin along the line of the face, being simultaneous.

In the smaller Dab we have a rough-skinned fish of light-brown hue with dark spots. It is found, often Dab or in brackish estuaries, on every part of our Smear Dab. coasts, where it spawns'in April or May. Its food seems to be almost confined to small crustaceans.

The Flounder may be regarded as a sea-fish that has made its way up rivers or taken to a partially fresh-water habitat. Flounder According to Cunningham, ${ }^{2}$ it does not shed or Fluke. its spawn in fresh water, invariably returning to the sea to breed. He alludes to a curious belief current among the fishermen, to the effect that the flounder carries

1 Fresh-water Fishes of Europe, p. 88.

2 Marketable Marine Fishes, p. 229. 
its eggs on its back, the so-called eggs being in reality tumours. The colour of the flounder, which is observed to vary according to locality, is usually of a dark brown, with darker mottlings; and the fish has tubercles, mostly along the lateral line. The eyes are close together, somewhat above the level of the head, though left-eyed flounders are not uncommon. The teeth of the flounder are conical, most developed on the left side, and its food appears to consist largely of worms and molluses. It spawns in March or April.

The Lemon-Sole is occasionally sold by the fishmonger as "Sole," but the difference between it and the true sole is

Lemon- so striking that it is fair to suppose that his Sole. customer makes the purchase with her eyes open. It is also known as the "Mary Sole," and Cunningham suggests a better name in "Lemon-Dab." Oval in shape, this fish is so smooth to the touch as to seem slimy, and in colour it is yellow with dark markings. The eyes are normally on the right side. The spawning-time of the lemon-sole appears to vary on different parts of the coast, April being the month on the south-west coast, June and July in the North Sea. This fish is widely distributed in British seas, though its movements in Scottish waters would seem to be somewhat uncertain. It feeds on crustaceans.

The last of the plaice group, the Witch, is a less familiar form, pale brown in colour, with some dusky marks on the Pole Dab left side, longer in body than the plaice, and or witch. having a rough skin. Like the preceding, it lacks the spine found before the anal fin of the plaice and dab. The lateral line is almost straight. The food consists of worms, spawn, and other soft matter, and it appears to spawn in summer. It is also known as the Pole-flounder.

In the concluding group of flat-fishes we have the most 
important of all, the Common Sole. The mouth of the sole is more distorted than that of any of the foregoing; the eyes, on the right side, are minute; the t Sole. lower side of the head is without scales, and there are filaments at the edge of the snout. All the teeth are on the left side of the small twisted mouth. In colour the fish is very deep brown, white on the left side. The maximum weight of this fish may be placed approximately at $9 \mathrm{lbs}$; Cunningham, whose monograph on this fish is one of our most important works on ichthyology, gives the average length as between 12 and I8 inches. There would appear to be a falling off of late years in the supply of soles from British seas, the fishermen being compelled to reap the harvest, which soon spoils, farther and farther from home. This fish prefers a muddy bottom, and seeks its soft food chiefly at night. According to Seeley, ${ }^{1}$ it is capable of developing marked characters in some rivers.

The greatest length to which the Sand Sole, also known from its colour as the "Lemon-sole" (a title to which it

Sand or has certainly a better right than the "Mary French Sole" aforementioned), is known to attain is Sole. not above 14 inches, its colour being lemonyellow, with or without dark blotches, and usually a black spot on the pectoral fin. There are filaments on the snout and round the dilated edge of the nostril on the blind side.

The "Bastard Sole," as the Thickback is sometimes called, is taken in deep water, where it grows to a length Thickback. of $8 \mathrm{r} / 2$ inches. The colour is reddish brown, with vertical dark bands. The pectoral fins are very small.

The smallest member of the family, the Solenette, that never exceeds a length of 5 inches, has so often been

1 Fresh-water Fishes of Europe, p. 88. 
regarded by the trawling men-so, at least, they averas the young of the common sole, as to have gained Solenette. thereby some fame which would not otherwise have belonged to it. In colour this fish is of a yellowish grey, having numerous small dark spots, as well as black lines at intervals on the fins.

\section{CHAPTER XVII. THE EELS.}

Of eels we have, besides the murry (a straggler), two, the fresh-water eel and the conger. The eel-pout and sand-eel are of course distinct. The female of both our eels is always the larger, and the so-called species of river eel are only the different sexes. Considerable mystery surrounded the breeding of both eel and conger, and only lately has the difficulty been solved by Italian biologists.

The Common Eel, its small scales embedded so as to give the impression of a scaleless fish, is one of our most

Eel. familiar fishes. In colour it is green or brown above, yellow or white beneath; the upper jaw protrudes ; the eyes and teeth are of small size. The female - the so called "Sharp-nosed" eel-exceeds a length of 3 feet; the male-the "Broad-nosed" eel of some authors - has not been recorded as measuring quite 20 inches. like the flounder, this fish descends in autumn to spawn in the sea, and it seems certain that it dies after spawning, as the adult fish are not seen reascending the rivers like the elvers at the end of winter. I have taken numbers of females in August off the east breakwater at Hastings, which are known to work westward along the rocky foreshore from Rye Harbour. Elvers, as the young are called, are also known to cross fields of damp 
grass, and are capable of climbing almost perpendicular stone banks. The so-called "Silver" Eels appear to be merely those which are observed just before the breeding season. According to Cunningham, the growth of the eel in fresh water is not rapid, several years, apparently the normal span of eel-life, having to elapse ere the elvers will be ready in their turn to descend to the sea and spawn. The larvæ of both eel and conger have been identified, the latter (known as "Morris") in British waters, the former hitherto only on the north coast of Sicily, where Professor Grassi has found the larvæ of the eel to be abysmal-dwelling Leptocephali. The eel is capable of surviving extremes of temperature, and there are instances on record in which they have been thawed back to activity, though in very hard weather these fish are known to lie torpid in the mud. Besides the spawning journey, eels living in tidal waters go down to the salt each tide and feed on garbage. One of the most recent and most lucid summaries of eeldevelopment will be found in M'Intosh and Masterman on the 'Life-Histories of British Marine Food-Fishes' (pp. 434-460).

The large marine Conger, a fish of almost cosmopolitan range, is found in our seas to a weight of more than Ioo lbs. In colour it is dark brown to black

Conger. above, white beneath, and having white spots along the lateral line. There have been attempts to distinguish two species of conger in our seas, and the fishermen speak vaguely of the black and white "kinds," which are merely colour races from deep or shallow water. The conger has relatively large head and eyes, the upper jaw is long, the dorsal fin is continuous and has a black margin, and the body is devoid of scales. Widely distributed in our seas, the conger is, owing to the rocky nature of its habitat, found in greater numbers on the west than on the east side of these islands. It feeds cliefly at night, only the smaller examples weighing 6 or 8 lbs., 
taking the hook in the daytime. The food of the larger fish seems to consist mainly of lobsters and cuttlefish, and they are also partial to a medium-sized rockling. The breeding of the conger has been much studied of late years. The eggs are apparently deposited in summer, and I recollect Mr Dunn of Mevagissey telling me some years ago that in his opinion a number of ripe females would gather in a bunch, while a small male would swim round, impregnating the ova as they fell. This was, however, mere theory. It seems in any case probable that both sexes die after the first spawning. Upwards of eight millions of eggs have been counted in a fish measuring about 5 feet. Besides her greater length, the female may be distinguished by her more pointed snout and by the more complete absence of colour from the belly.

[The Murry, or Muræna, of the Mediterranean seems to have wandered to our seas on one or two occasions, as Day mentions an example of over 4 feet. The body is without scales; the nostrils are tubular, and there are pores on the jaws. In colour it is brown, with or without yellow spots.]

\section{CHAPTER XVIII. THE HERRING FAMILY.}

This is, commercially at any rate, the most important group of food-fishes. They are all surface-feeders, and are therefore taken for the most part in drift-nets, that float like walls near the top of the water. All our herrings are small fish, as we have none of the giant members of the family, such as the tarpon of Mexico, or other giant herrings of the Queensland coast. The members of this family are silvery fishes with large thin scales; and they lack the lateral line. 
Most familiar of them all is the Herring, which has been cured in a variety of ways for centuries, involving a traffic tHerring. of such magnitude that more than one ConAges from no other source. The herring reaches a length of about $\mathrm{I} 7$ inches in the north, $121 / 4$ inches in the southern waters (Cunningham). In the Baltic I noticed that all the herrings were invariably small. Our best herrings come from the east coast of Scotland. Unlike the eels, the males are said to have slightly the advantage both in size and numbers. The chief characters of the herring are the large thin scales, absence of lateral line, and keeled belly. The teeth of this fish are minute, and its food consists of small floating organisms. The water is filtered through gill-rakers, the function of which is not unlike that of the baleen in whales; and this mode of feeding is characteristic of the family. The migrations of the herring are even now imperfectly understood. It was formerly thought to perform journeys of great duration, and the older writers went to the trouble of describing those pilgrimages to and from the arctic seas with an attention to detail that did credit to their imagination. The later theory, however, is that they simply move to and from the deeper water in search of warmth or food. The spawning-time appears to extend over the greater portion of the year according to locality, but it is not probable that the same fish spawns twice in the year. The eggs, unlike those of our other food-fishes, sink to the bottom, where they adhere to stones and are devoured wholesale by cod, haddock, and other groundfish. $^{1}$ Cunningham ${ }^{2}$ gives a most interesting account of the spawning of the various races of herring and the development of the larvæ. The so-called "Whitebait," formerly regarded as a distinct species, is now known to consist of the fry of herrings and sprats, the herrings pre-

${ }^{1} \mathrm{M}$ 'Intosh and Masterman, Life-Histories of the British Marine Food-Fishes, p. 15.

2 Marketable Marine Fishes, pp. 151-163. 
ponderating in summer, the sprats in winter. Other fry are usually found in the dish, especially those of flat-fish, gurnards, and sand-eels. As already mentioned, these fish are mostly taken for the market in the drift-net, as they comparatively seldom find their way into the trawl. In some parts there is a regular spring hook-fishery for herring, when they will take bare hooks jigged among the shoal.

The smaller Sprat differs from the herring in several important particulars, as, for example, in the serrated edge of the belly, the origin of the dorsal fin lying

Sprat. nearer the tail, and absence of teeth. In colour, the sprat is grey and silver. It spawns on our south-west coast between January and April; on the Scottish coast from April to July (Cunningham). The egg, unlike that of the herring, floats. The young fish enter largely, as already pointed out, into the composition of "Whitebait," especially in winter. At a still earlier stage they are the "Brit," much harassed by gulls and mackerel.

Another important fish, characterised by a rounded body, keel-edged belly, large scales, dorsal fin farther forPilchard ward than in either of the foregoing, and the or Sardine. presence of small teeth in the jaws, is the Pilchard. In colour, this fish is deep green above, shading to silver below. When one considers the vexed question of the identity of the pilchard and sardine, memory recalls the school exercises in elementary logic: "All pilchards are sardines, but all sardines are not pilchards"; the fact being that, for the inferior brands at all events, young herrings and sprats are also pressed into the service. The true sardine is, however, a young pilchard. Although the British pilchard-fishery is practically confined to the south-west coast, it is not to be supposed that this fish does not occur farther east. I have myself met with it 
at Bournemouth ${ }^{1}$ and Ventnor; and I believe it occurs at irregular intervals in the herring-nets of the North Sea. It spawns in July and August.

Connected by many honest fishmongers with the salmon, a parallel case with those of the atherine and lemon-dab, t Allis Shad. the Shad certainly resembles that fish in its anadromous tendencies, as it invariably enters some rivers, the Thames and Severn among them, to spawn. It grows to a weight of at least $8 \mathrm{lbs}$; and its colour is pale-green, shading to silver on the belly, and having a dark-green spot at the shoulder, as well as some smaller dark spots on the sides. The edge of the belly is serrated like that of the sprat. There is a transparent eyelid ; the teeth are small and the gill-rakers very numerous. The shad feeds on small fishes, crustaceans (Cunningham), and vegetable substances (Seeley), and is occasionally hooked off Deal. It spawns in May and June.

The Twaite Shad is a smaller fish of similar habits. Its † Twaite weight has not been known to exceed 2 lbs.

shad. This species has the gill-rakers shorter and fewer than in the last. The spots on the body are also as a rule more numerous.

Chiefly known in this country in the preserved state, the delicate little Anchovy is thought to occur in autumn, Anchovy. sometimes in considerable numbers, on most parts of our coast, particularly down in the west. Whether its abundance is at any time sufficient to warrant a regular fishery has not yet been determined. Custom rules strong in these matters, and it is not probable that the fishermen would turn their attention to a hitherto neglected fish without very good reasons. This is the smallest member of the family, and in colour it is,

1 The fish commonly known at Bournemouth as the pilchard is the scad! 
like the rest, green and silver. The projecting snout, giving the impression of a miniature shark, is sufficient to distinguish it from the rest, and the deep cleft of the mouth is also characteristic. The edge of the belly is smooth. The anchovy is not known to spawn on our coasts, but in the Mediterranean it deposits its floating eggs in the summer months.

\section{CHAPTER XIX. THE CARP FAMILY.}

Of greatest importance to the angler, to whom they are collectively known as "Coarse fish," the fishes composing the present group are but little eaten in these islands, though in general use on the Continent. They are all inhabitants of fresh water, several thriving best in lakes without outlet. In most, we find the scales of large size, the mouth without teeth; in some, the jaws are furnished with barbels, differing slightly in appearance, probably in function as well, from those of the cods. These fish spawn in the summer months, the close-time in this country lasting, with local variations, from March 15 th to June $15^{\text {th }}$. Several of the commoner species are known to interbreed.

That typical pond-fish, the Carp, was introduced from the Continent, it would appear, a couple of centuries ago, and is now widely distributed in our rivers and

*Carp. lakes, though it appears to be exceedingly rare (if indeed present) in Scotland, and of local occurrence only in Ireland. In colour, the carp is generally between green and bronze, the scales having a black margin, and the fins having yellow and violet reflections; but the colours are subject to some variation. The growth of this fish is, according to Seeley, ${ }^{1}$ rapid, as a carp

1 Fresh-water Fishes of Europe, p. 97. 
of six years may weigh anything between $4 \mathrm{lbs}$. and ro lbs.; and the largest carp ever recorded in England (Petersfield) weighed $24 \mathrm{lbs}$., and had scales the size of florins. The carp has four barbels, two on either jaw, those on the lower being longer than the others. It is for the most part a vegetablefeeder, but also consumes large quantities of the larvæ, which it routs up from the muddy bottom. Though a long-lived fish, and also capable of surviving some time out of water, the carp is somewhat susceptible to sudden

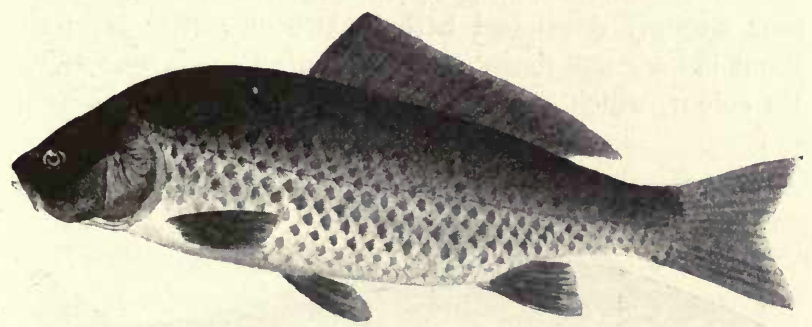

changes of temperature; and in very cold weather numbers of these fish are known to burrow in company, not unlike, though under opposite conditions, the mud-fish of the East. The breeding-time is in summer, and as many as 750,000 (Seeley) of the small green eggs have been taken from a Io-lbs. fish. The carp breeds freely with the two species that follow. It is said to utter sounds not unlike a grunt. The large size of the scales in our carp is nothing to what is observed in a Continental variety, which has enormous scales arranged in rows.

The Continental Crucian Carp is, together with the goldfish, without barbels on the jaws. A small fish,

${ }^{*}$ Crucian rarely exceeding a weight of $\mathrm{I} / 2 \mathrm{lb}$., it has

Carp. done well in the Thames and others of our rivers. It is somewhat deeper for its length than the common carp; in colour, it is greenish above, bronze on the sides. 
[*Golden Carp or "Goldfish," which came originally from China and Japan, are known chiefly in the strictly domesticated state in glass bowls, though they also thrive, under somewhat more natural conditions, in the heated waters of mill-dams.]

Absent from both Scotland and Ireland, the Barbel, which reaches a weight of at least $\mathrm{I}_{5} \mathrm{lbs}$. in the vicinity

* Barbel. of Thames weirs, is more in evidence in the streams of the east side of England. It has four strongly developed barbels, two on either jaw; the snout is long and fleshy, and the upper lip is very thick. Its colour, which varies somewhat in the breeding-season,

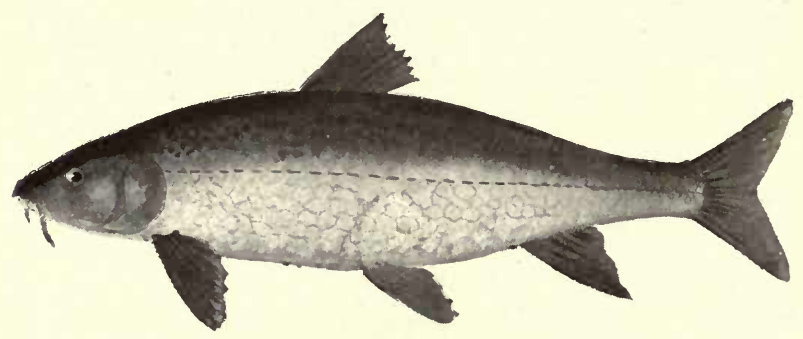

is normally green above, white beneath; the lower fins red. It is not fastidious in the choice of food, living largely on vegetable substances, but also devouring small fishes, molluses, and animal droppings. It spawns in May and June, and is not one of the most fertile of the group. Like the carp, it is hardy, and stands removal from the water well. It is little esteemed as food in this country, and the roe is actually regarded as poisonous.

The Gudgeon, one of the smallest of the family, rarely exceeds a weight of $\mathrm{x} / 4 \mathrm{lb}$., though, according to Day, ${ }^{1}$ Pennant mentions one of $1 / 2 \mathrm{lb}$., "which some modern

1 British Fishes, ii. 174. 
authors have doubled"! (Unless this be a misprint for doubted, one is inclined to envy the said "modern authors" *Gudgeon. their inventive power.) In colour the gudgeon is some shade of grey, having dark blotches along the lateral line. It has only two barbels. Thriving equally in still or running water, with a preference perhaps for the latter, this is the fish of the Seine. In England it is widely distributed; but its occurrence in Scotland seems doubtful, and in Ireland it is extremely local. Its food consists chiefly of insects and their larvæ, but it is also suspected, not wholly without reason, of consuming fishspawn. It spawns in the month of June.

One of the angler's favourite fishes, the Roach is found in most suitable waters, still or running, in Great Britain,

* Roach. but is absent from Ireland, its place being supplied, so far as sport goes, by its near ally the rudd. In colour, this fish is dark blue, or green, above, lighter on the sides, and silver beneath; lower fins, red.

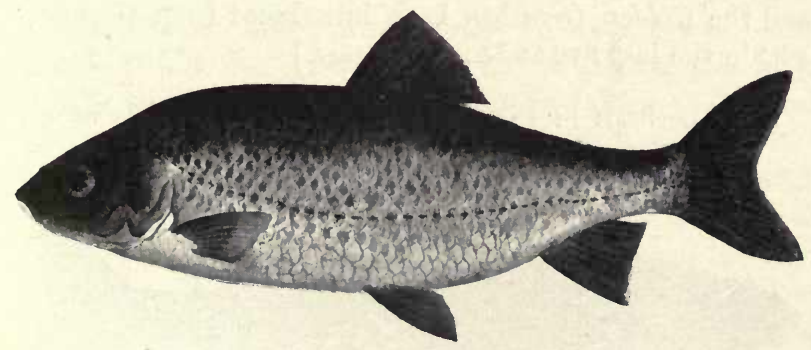

According to Seeley, the scales become rough in the spawning-season. The roach grows to a weight of at least $3 \mathrm{lbs}$. , but one of half that weight is nowadays considered a trophy from most waters. Its food consists of insects and molluscs, possibly also of some weedy matter; and it is generally accounted by anglers in this country an exceptionally wary fish. This, however, must be the result 
of over-fishing, for few fishes were, as I remember them, easier to capture in the Baltic rivers. Though traditionally free from disease, the roach is subject to the attacks of a number of parasites.

From the last the somewhat similar Rudd, which replaces it in Ireland, may be readily distinguished by its deeper * Rudd or body, position of the dorsal fin (nearer the Red-eye. tail), and the presence of more red about the eye and fins. Easiest of recollection, however, is the fact that the upper lip of this fish is horny and rigid, whereas that of the roach can be pulled forward. The rudd, which grows to a weight in these islands of $3 \mathrm{lbs}$., rises freely to the fly in parts of Norfolk, at Slapton Ley in Devon, and in many Irish waters, but does not occur in many of the largest rivers of the south of England. It is a very "bony" fish, and not much esteemed as food. It feeds on insects, and, in captivity at all events, will take, so, Alderman Newlyn of Bournemouth tells me, small minnows.

[The Ide is included by some writers in the British list; and the Golden Orfe has been introduced from Germany within the last five-and-twenty years.]

Save perhaps in the extreme west, the Chub is widely

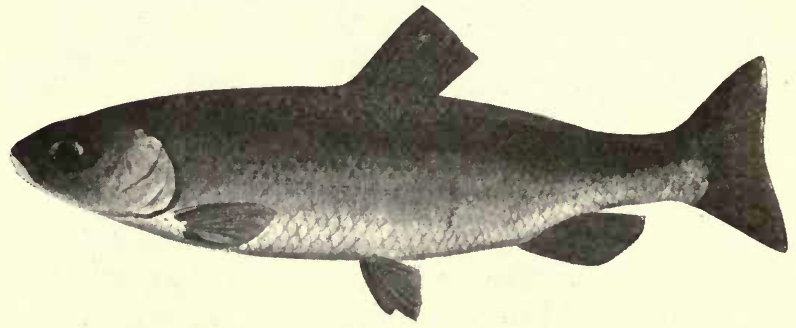

distributed in England, in the southern two-thirds of Scotland, and in the whole of Ireland. Its most

* Chub. characteristic feature is the great breadth of the head, which has a pink shade, the general colour of the 
fish being dark green on the back, with some red at the base of the fins, and white beneath. Its greatest weight is about $7 \mathrm{lbs}$. The chub feeds on small fishes, crayfish (Seeley), frogs, and water-voles. It spawns in May.

Like some others of the coarse fish, the Dace is absent from Scotland and Ireland, though widely distributed in * Dace or England. It is a fish of running waters, and Graining. grows in this country to a weight of $\mathrm{I}$ lb. A more tapering fish than the foregoing, it is silvery blue throughout, and has little or no red on the fins. The "graining" is, more properly, to be regarded as a variety, in which the head is smaller and the fins longer. The food of the dace consists of insects and vegetable matter, and it spawns in May or June.

Rarely, if ever, exceeding a length of 7 inches, and more commonly measuring less than 4 inches, the Minnow is

* Minnow. found in every part of England, in all but the extreme north of Scotland, and in most counties in Ireland, into which country, however, it was introduced within the present century. In colour, this little fish is dark green, with black patches along the lateral line, which is interrupted about half-way, the breast-fins being tinged with red. The colours of this fish change rapidly according to circumstances, owing to two layers of superimposed pigment-cells that lie just beneath the skin (Seeley). The minnows are gregarious by habit, and catholic in their feeding. They are also endowed with a fatal curiosity that prompts them to congregate over a net in which are tied fragments of red wool, a habit I have also found in sand-smelts. The spawning-time is in May and June.

The mud-loving Tench, in which the small scales are so embedded as to make it as slippery to the touch as an eel, thrives well in stagnant waters, but to appreciate the beauty 
of a large example in good condition it should be placed for forty-eight hours in running water, after which it

* Tench. looks a different fish. There are small barbels at the corner of the mouth. The dorsal-fin is without spines, the lips are fleshy, and the tail-fin is large and not forked. The colour of the tench is usually a dark shade of green, white beneath. Its greatest weight in these islands is rather over $5 \mathrm{lbs}$. It is more tenacious

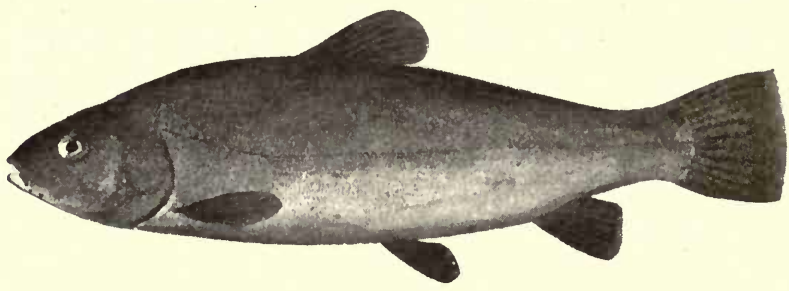

of life than any of the foregoing, surviving many hours out of water. Every writer on the subject has noticed, and most have criticised, the reputed healing powers of this fish. These remain not proven. The tench feeds on insects, aquatic plants, and mud, and the spawning-season lasts through the summer. Fond of stagnant water, but thriving equally in rivers, the tench is widely distributed in England, more locally in Scotland and Ireland, in which latter country many regard it as not indigenous.

One of the most familiar of our coarse fish, the Bream is captured in our rivers and lakes to a weight of nearly $\mathrm{I} 2$

* Bream. lbs., and bream of 7 lbs. are by no means uncommon in the Broads. These large Norfolk bream are much used as bait for the crab-pots on the coast. Deep for its length, the bream is of silvery hue throughout, save for a tinge of red on the fins. The lower lobe of the tail is slightly longer than the upper, the reverse of that in sharks. The bream thrives equally in still or running waters, preferring the latter with a 
muddy bottom. It feeds on worms and insects, and spawns in May or June. It is poor as an article of food.

Distinguished from the preceding by the greater amount of red on the body and fins, as well as by the shorter anal

* Bream- fin, longer scales, and equal tail-lobes, the flat or small and solitary Bream-flat, which rarely White exceeds a weight of $\mathrm{r}$ lb., is found more Bream. particularly in the eastern rivers of England, and is common in many parts of Ireland.

The small Bleak, the greatest length of which is not much more than 7 inches, is common in the Thames and * Bleak. Lea, as well as many other waters, both still and running, of England, but is absent from Scotland and Ireland. In colour, it is blue on the back and sides, silver below; and the scales have, like those of the mackerel-midge, long been used in the manufacture of artificial pearls. This fish is infested with a tapeworm, often longer than the fish itself. It feeds, near the surface in warm weather, on insects, and spawns in May and June.

That small mud-fish, the Loach, which does not often exceed a length of 4 inches, has no fewer than six barbels, all on the upper jaw. In colour, the loach is

* Loach. dark green along the back, yellow on the sides, and grey below, spotted and streaked with dark brown. During the day this little fish hides at the bottom, lurking beneath the stones, from which it may be dislodged in a half-stunned condition by a smart blow on the stone. Unlike the foregoing coarse fish, it dies almost immediately on removal from the water. It feeds on insects, worms, and spawn, sometimes on vegetable matter, and spawns in March and April. It appears to be widely distributed throughout these islands. 
The Spinous Loach is a still smaller species, its greatest length in these islands being no more than 3 inches. Like

* Spinous the last, it has six barbels, all on the upper Loach. jaw; but it is easily distinguished by the erectile bifid spine beneath each eye. In colour the spinous loach is yellow, having rows of black spots along the back and sides. It seems to be far rarer in England than the last, and its occurrence in either Scotland or Ireland appears open to doubt. In habits it is said to resemble the last.

\section{CHAPTER XX. THE SALMON FAMILY.}

The salmonoid fishes are now, as ever, a bone of contention among ichthyologists, some of whom recognise as many as sixty European species, while others refer all under less than half-a-dozen typical groups, as the salmon, trout, char, grayling, and the rest. For the purposes of a small introductory work like the present, in which economy of space is an ever-present necessity, it will be sufficient to glance briefly at the typical species, mentioning such varieties as are of importance.

Though termed in angling lore the "king of fishes," the Salmon, with his kind, comes undeniably low in the scale. Of this well-known fish, the features easiest to † Salmon. identify are the hooked jaws, the small adipose fin on the back not far from the tail, the X-shaped black spots-red after the fish has passed some time in fresh water-and the pink colour of the flesh. The remarkable hook that develops in old breeding males on the lower jaw is regarded by Smitt as no more than the result of irritation from frequent blows. ${ }^{1}$ The salmon is caught in our

1 A History of Scandinavian Fishes, p. 855 fn. 
waters to a weight of at least 60 lbs., though fish of between $20 \mathrm{lbs}$. and $40 \mathrm{lbs}$. are far more common. An anadromous fish, the salmon repairs regularly to fresh water for spawning purposes; and of so-called salmon-rivers there are several that have become justly famous, as the Hampshire Avon, the Severn, the Tay, Shannon, and others. It is even said that the fish will return by preference to their native river, the females first, the old males next, the young fish last $;^{1}$ and this view is at all events borne out, so far at least as the order of arrival is concerned, by the experience of the nets-men of the Hampshire Stour and Avon. I have visited the fishery at Mudeford on many occasions during the past few years, and have invariably found the catches during February and March to be few, but most of them picked fish of over $20 \mathrm{lbs}$. in weight, whereas at the end of April they would look for larger numbers of small fish. The present year (1897) has been one of the worst for a long time, the fish having been both later and fewer than for ten years at least. There is a variety of names, differing according to locality, for salmon at various stages, the chief being "parr" or "smolt," the name for the young fish ; "peal" or "grilse," those that enter fresh water for the first time since they left it ; and "slat," "kelt," "baggit" (female), or "kipper" (male), the spent fish. The salmon spawns in the majority of our rivers rather before Christmas, the fertilised eggs being deposited in a heap of gravel. Salmon-roe is a deadly and illegal bait for the fish themselves. The males fight desperately before and during the spawning-time. This fish is said to leap perpendicularly almost a dozen feet ${ }^{2}$ out of the water; and it is assisted over waterfalls of considerable height with ladders specially

1 Seeley, Fresh-water Fishes of Europe, p. 275.

2 Day (British and Irish Salmonidæ, p. 73) quotes a number of conflicting authorities on the record leap of salmon, according to whom the perpendicular distance ranges from 16 feet (Landmark) to no more than 6 or 7 (Scrope). 
made for the purpose. As already mentioned, reddish spots and lines make their appearance after the fish has been some time in fresh water, and it is also noticed that the steel blue of the fresh-run fish becomes much dulled under the same influence. Although these fish spend a considerable portion of the year in salt water, being in fact regarded by many as sea-fish, it is interesting to learn that fish-culturists have succeeded in hatching the spawn of land-locked salmon, the product being fertile. Of the food of the salmon, either in fresh or salt water, little seems to have been satisfactorily ascertained. It is thought by some not to feed very much during its stay in rivers; but this view is not easily reconciled with the greediness with which the fish will seize a mass of fur and feather that bears no resemblance to any living creature. Besides the attacks of a grey fungus, saprolegnia, which breaks out in patches on the adipose fin and body, there is a high rate of mortality among the kelts after the first spawning.

Salmon-fishing, with both net and rod, is subject to rigorous legislation, there being a close-time on most rivers of at least three months in the year, and of fortyeight hours each week during the fishing. The Tweed closes for only two months and a-half.

The common brown Trout of our rivers, which is regarded by many as no more than a variety of the salmon,

* Trout. is a familiar form, its colour being silvery green or brown with spots, some $\mathrm{X}$-shaped, but mostly circular, of black or red. In colour, as in size, however, the trout is subject to greater variety than perhaps any other fish. The famous Thames trout grows to a weight of nearly $20 \mathrm{lbs}$., but the average from most rivers may be placed at about $\mathrm{x} / 2 \mathrm{lb}$., a fish of $5 \mathrm{lbs}$. being exceptional. The trout is a long-lived fish. Its food consists of small fishes and different stages of insect life; it roots up the larvæ, and rises at the fly. It spawns 
some time between the end of October and January, in consequence of which want of uniformity local boards, vested with the necessary powers, exercise considerable

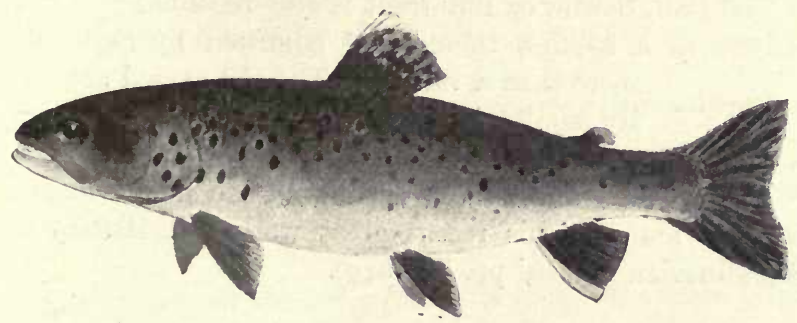

ingenuity in modifying the fence-months to suit the requirements of each river, with more or less success.

The following varieties probably connect $S$. salar and S. fario :-

* Gillaroo of many Irish loughs and the Shannon. recognised by the muscular thickness of the stomach.

$+S$. argenteus. - One of the rarest sea-trouts of our coast, having an extra ray in the dorsal and ventral fins.

*S. nigripinnis. - A small lake-trout, found in parts of Wales and Ireland (Lough Melvin).

$+S$. gallivensis. - A Galway sea-trout.

*Lochleven Trout.-Occurring in several Scottish lochs, also in Windermere and other English lakes.

+Orkney Trout, of which there are two races.

+Grey Trout.-A migratory species of the Forth, Trent, and Ouse.

Great Lake-Trout of Derwentwater and some other British and Irish lakes.

The Sea-Trout is found in various parts of the coast, mostly perhaps in the north. It grows to a length of 3 t Sea-Trout. feet, and bears a strong resemblance to the salmon, save for the occasional absence of the $\mathrm{X}$-spots. In habits it is also similar, only it feeds more 
regularly when in fresh water. It is generally accepted as a constant species.

The Peal, Sewin, or Bull-trout is also regarded by most writers as a species, though not admitted by Smitt as

† Sewin. more than a variety. The last-named authority admits, in fact, but two British species, a salmon (S. salar, S. fario, \&c.) and a char ( $S$. salvelinus, $S$. alpinus, \&c.), and a mass of information and evidence is to be found in his recent great work ('A History of Scandinavian Fishes,' pp. 827-9r9).

Of our Chars there are also half-a-dozen local races, varieties, all of them delicate fish of nocturnal habits, * Char. requiring still deep water, and not sufficiently hardy to bear much transplanting. The Char of Windermere never exceeds a length of 12 inches. In colour it is deep green above, the belly and ventral fins being red. The so-called Torgoch, S. colii, S. killinensis, dc., are nowadays no longer seriously regarded as more than races or variations.

Already mentioned incidentally in connection with the atherine, the Smelt has the distinguishing adipose fin of the + Smelt or tribe, and is of a light-green colour, silvery

Sparling. beneath, with a silver band on the sides. In length it rarely exceeds 12 inches. Its characteristic smell has been compared by different writers with that of violets, cucumber, and other substances less fragrant. Like the salmon, it ascends the tidal reaches of rivers for spawning purposes. It appears to be absent from the Irish coast. This fish has a large mouth armed with sharp teeth, and its food consists of small fishes, insects, and crustaceans. It spawns in spring and early summer, having a preference for shedding its spawn in stormy weather. 
Another fish inhabiting British lakes, Ullswater, Bala, and Loch Lomond among them, the Powan grows to a * Powan or weight of 4 lbs. In colour it is dark blue Gwiniad. above, silvery beneath. Large shoals of this fish approach the shores of the lakes in summer.

The Vendace occurs in at least one Scottish loch. Far smaller than the last, it rarely exceeds a *Vendace. length of 9 inches. It spawns in November, the female being the larger fish.

The Pollan, on the other hand, is found in certain Irish loughs (Neagh, Corrib, \&c.) and the Shannon, and grows

*Pollan. to an average length of 6 inches. Unlike the preceding, it is occasionally taken with the fly, though the greater number are netted. It feeds on small fishes and molluses; and spawns in winter among the rocks.

[Coregonus oxyrhynchus, the "Houting" of Dutchmen, is supposed to occur in some of our eastern and southern estuaries along with the smelts. It has a long fleshy snout, and grows to a length of at least 20 inches. It can only be regarded as a wanderer to our waters.]

The Grayling is an elegant fish, on the sporting qualities of which there is much difference of opinion, and may *Grayling. be distinguished from the rest of the family by the many-rayed first dorsal fin. Like the smelt, it has a peculiar odour. This solitary fish, fond of clear running water, is particularly rapid in its movements. In colour it is usually of a pale brown, silvery below, with black spots on the head and body and light on the fins, the latter exhibiting red bands in the spawning-time. The colours are subject to variation according to season. The food of the grayling is generally supposed to consist largely of small fishes and molluses, as it is said 
not to rise very freely to the fly until the early autumn. The grayling grows to a weight of at least 4 lbs., among our more celebrated grayling-rivers being the Trent, Severn, Wye, Teme, and Yorkshire Ouse. It is not indigenous to Scotland, but has been introduced into that country; nor does it occur in Ireland. It spawns early in the year, April or May being the usual time.

[The Argentine is a scarce and unimportant little fish, of which not much appears to be known. It occurs in our northern waters, where it is occasionally hooked close inshore. In length it rarely exceeds ro inches.]

\section{[Argyropelecus hemigymnus and Maurolicus pennantii} are two small and insignificant deep-water forms which are usually placed either immediately before or after the salmon group. Their chief interest lies in the presence along the body of round spots, sometimes raised, the object of which has been supposed to be luminosity - a theory based on the great depth at which these little creatures pass their lives, as well as on the identification of light-giving pores in a similar Atlantic form. The former is the merest straggler to the deeper waters round these islands, but the latter is not uncommon.]

\section{CHAPTER XXI. THE PIKE.}

Angling writers have had a great deal to say about the Pike, which they are pleased to term the "Fresh-water "Pike, or Shark"; and it is familiar in most of our rivers Jack. and lakes, thriving equally well, so live food be abundant, in still or running water. There appear to be no pike in Sutherland. Many tales have been told of 
monster pike, but it is safe to say that it grows to a weight of $60 \mathrm{lbs}$., though one of half that weight is, so far as the British Islands of to-day go, a fine fish indeed. In colour the pike is dark brown to green above, lighter on the sides, and white beneath, marbled all over with yellow spots and bands. It is a voracious fish, consuming great

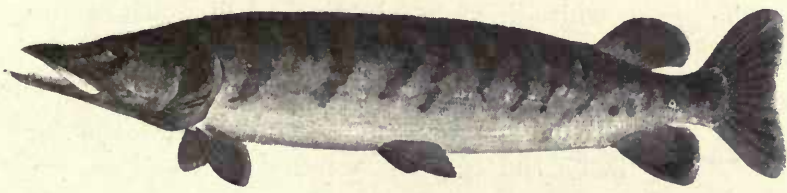

quantities of its own kind and other fish, as well as of voles, waterfowl, and frogs. Although a very active fish when on the feed, it is fond of basking at the surface. It is easily recognised by the projecting lower jaw, and the position of the dorsal fin back near the tail, the latter being forked. The pike spawns in March or April.

\section{CHAPTER XXII. THE PIPE-FISHES.}

In this order we find the gill-openings exceedingly small, the British family having but one dorsal fin, which, rotated with a peculiar and rapid action, appears to be the chief organ of locomotion, their swimming being for the most part performed in a vertical position. The male has, as a rule, a pouch for the reception of the eggs, which he carries until hatched.

The Broad-nosed Pipe-fish is an eel-like species, the body having raised ridges, the tail, with a fan-shaped fin, being a continuation of the lateral line, the snout tapering to 
a point. In colour this fish, which grows to a length of at least 12 inches, is dark brown with lighter spots. It is Broad- found on most parts of our coasts, being nosed confused in some localities with the young Pipe-fish. of the garfish.

Greater Pipe-fish.-A striped, deep-water species.

The green, white-lined Straight-nosed Pipe-fish of about the same size is also found round our coasts, though in Straightnosed Pipe-fish. somewhat deeper water than the last. The tail of this species is pointed, and the male lacks the egg-pouch found in the last.

The largest of British Pipe-fishes, the Sea-adder, grows to a length of over 2 feet, and is common in the Snake- majority of our estuaries, where it is accused Pipe-fish of "stinging." Certainly, those who have or Sea- never seen a real snake might possibly mistake adder. this for one-hence, no doubt, the superstition. In colour this harmless fish is dark brown with bluish-white bands and a purplish stripe on the face. The male has no pouch, but retains the eggs in a fold of skin.

In the smallest of all, the Worm Pipe-fish, we have a species not exceeding a length of 9 inches, and in colour Worm of a dark green or brown, with white lines Pipe-fish. and spots. Like the rest, it appears generally distributed on our coasts. According to Couch, this species keeps almost entirely to the ground.

A familiar object in the aquarium, the remarkable Seahorse occurs sparingly on all our coasts. It has a mailed sea-horse. body, with lateral ridges, also a tubular snout sea-horse. and the family egg-pouch. The pointed tail is prehensile, and the sea-horse is fond of winding it round stems of weed or other support. The body, which is covered with spines, is black, with white dots and bands; and the greatest length of the species is about 4 inches. 


\section{CHAPTER XXIII. THE FILE-FISHES.}

In this order, the bones of the body are not completely hardened. The gill-openings are small, and in one family the jaws terminate in a kind of beak.

The name of the curious and unprepossessing File-fish has reference to the serrated edge of the dorsal spine, as File-fish or well as to the manner in which the fish can Trigger- elevate it at will. It is by no means common fish. in British seas, where it has been taken measuring 16 inches. Its colour is yellowish.

[An allied species is thought to have been taken at Polperro.]

Not unlike the hideous and poisonous Australian "Toadfish," our Globe-fish, which is taken at irregular intervals Globe-fish. in these waters, has the same unpleasant habit of distending its body when irritated, as well as the same reputation for tenacity of life. The blue of the back presents a sharp contrast with the white of the sides and belly, the latter being covered with star-shaped spines. The jaws terminate in a beak.

The huge basking Short Sunfish is not uncommon in our seas, where it has been taken weighing as much as 5 cwt.

Short and measuring fully 5 feet. I have seen the

Sunfish. dorsal fin of this fish cruising about off the Lizard. It is known at times to display great activity, and even to leap out of the water. It feeds on small crustaceans.

The rarer Oblong Sunfish has smoother skin and is less Oblong deep in the body. The dorsal and anal fins

Sunfish. lie farther back than in the last. It does not bask. 


\section{CHAPTER XXIV. THE ARCTIC CHIM ARA.}

For a group quite distinct, and placed in some classifications at a considerable distance from them, the chimæArctic roids certainly bear extraordinary superficial Chimæra. resemblance to the sharks, having the same cartilaginous skeleton, the same "claspers"; and, like them, lacking the air-bladder, and depositing the egg in a "purse." The Arctic Chimæra is found in our northern waters to a length of 4 feet, which is almost the maximum length attained by any existing member of the group. The fishermen know it as the "Rabbit-fish" or "King of the Herrings." The body of this fish is long, and, in the adult, smooth; the snout soft and slightly upturned; the tail tapering to a whip-like extremity; the dorsal fin long, and having a sharp spine. The head is furnished with pores and a spine-like crest; the four gill-slits have but one external opening. The internal resemblances to the sharks are also remarkable, but these lie without the province of the present account. The chimæra is a carnivorous fish, herrings being its favourite food.

\section{CHAPTER XXV. THE STURGEON.}

It seems that, in spite of some inclination on the part of writers to include a second, but one member of this family † Sturgeon. wanders to our estuaries. The Sturgeon is a † Sturgeon. ganoid fish, having quadrate scales of true bone capped with enamel. Bony plates are also disposed in rows along the body. The distinguishing features of the sturgeon are the longer upper lobe of the heterocercal tail, the elongated snout with four barbels, and the small 
toothless mouth beneath the snout, the single gill-opening. bony plates or shields on the head, and cartilaginous skeleton. The breathing-spiracle is present, as in sharks. The sturgeon is only a wanderer to British rivers, the Thames and Severn among them, which it doubtless enters for the purpose of depositing its spawn. Examples of over Io feet in length and $500 \mathrm{lbs}$. weight have been taken in British waters. In colour, this fish is reddish or bluish grey along the back and sides, white beneath. It spawns early in the year. The food of our Sturgeon consists of mud and of the worms and molluses contained in it. The flesh has a faint pink tinge, and there is a good deal of fat. It is not bad eating, but rather coarse, and rarely fetches anything more than a very low price in the market. Enormous shoals of sturgeon make their way up Russian rivers from the Caspian, their most valuable products being the roe, which is made into caviare, and the air-bladder, which makes isinglass of the first quality. In this country it is a royal fish, belonging to the Crown.

\section{CHAPTER XXVI. THE SHARKS AND RAYS.}

British seas contain representatives of five out of the nine existing families of sharks, some of formidable dimensions, others of mischievous habits, the latter being in our waters of small size and comparatively harmless. It seems probable, indeed, that the vermin will increase in these parts, a result contributed to by the cutting of the Suez Canal and the rapid growth of our seaport towns; for nothing is so likely to attract sharks in from the ocean as the presence of more offal and sewage in the shallower water, as an example of which we have the enormous increase of sharks in Sydney Harbour during the past 
twenty years. The Suez Canal has already admitted two new sharks to European waters, though they have not as yet been observed west of Gibraltar.

\section{The Sharks.}

These cartilaginous fishes have the body tapering, the tail with the upper lobe the larger, the snout pointed or shovel-shaped, breathing-spiracles on the head behind the eyes, the mouth, usually crescentic, beneath the head. The eyes have a movable, nictitating membrane. The teeth, the formation of which differs from that in teleostean fishes in a manner that need not be particularised here, lie in rows, the hinder ready to take the place of those in front. The skin within the mouth is rough like that without, which lacks scales. The lateral gill-openings are usually five, sometimes six or seven, in number. The eye has, in some, a closing membrane not found in other fishes. By these features, as well as by the presence of claspers at the vent, and several internal peculiarities (as the absence of airbladder, a spiral valve in the intestine, and the nature of the optic nerves, which last are not transverse or decussate, as in bony fishes), sharks are not difficult to distinguish. They are all of carnivorous tastes, though several, as our Basking Shark and the Port Jackson Shark, are quite inoffensive. In reproduction, they are mostly oviparous, many depositing their eggs in oblong receptacles of a horny substance, known as "purses." The hammerhead, the porbeagle, the tope, and the smooth hound bring forth their young alive.

One of the handsomest of British sharks, the Blue Shark, is plentiful on the Cornish coast every summer, where nets Blue are ruined and long lines torn to shreds. I

Shark. have hooked small examples of 20 or $30 \mathrm{lbs}$. on the rod, but sharks of this species have been taken in the nets of twice the weight and at least 6 feet in length. 
When hooked, this shark not infrequently comes to the surface to shake out the hook, failing which, it revolves in the water with great rapidity, the line scoring into the roughly granulated skin and tying the fish in a knot. This shark is deep blue above, lighter on the pointed

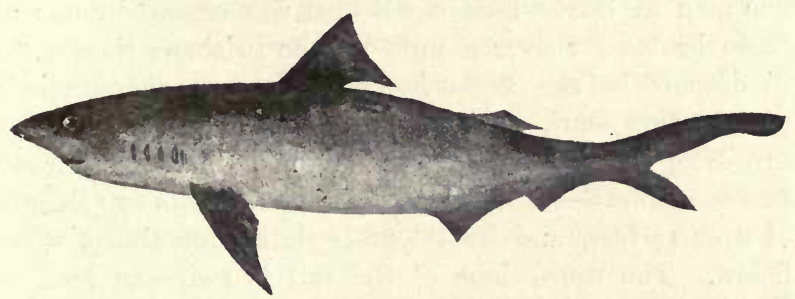

snout, white beneath. The upper lobe of the tail is notched; the eye has the usual nictitant membrane; but the spiracle, so characteristic of many members of the family, is absent. It feeds on mackerel, pilchards, and ground-fish. This shark is supposed to deposit its eggcases in winter when absent from our shores.

The Tope, more familiar on our coasts, and known locally as the "Silver Dog" or "Rig"-the "School"

Tope. Shark of Australian seas-occurs along the south and east coasts. I have caught them at Bournemouth over 4 feet in length, as they feed at midwater, and are fond of following up the hook and seizing a whiting already hooked. This shark, which is grey above and white beneath, grows to a length of over 6 feet, and is slender in form. The eye has a nictitating membrane, and a small spiracle is present. The teeth, in three rows, are triangular and serrated. When fresh caught, this shark has, like the porbeagle, a rank smell. It is viviparous, extruding one or two score of young at midsummer. One of 5 feet 4 inches, and weighing nearly $5 \circ \mathrm{lbs}$., was taken this summer in the mackerelnets off Deal. 
From the true sharks we come to the Hammerhead, one of the most remarkable of living fishes, a rare visitor to Hammer- British waters, but exceedingly numerous on head. the other side of the world, where it is regarded as one of the most dangerous; and I know of one man at least whose small boat was chased by one of these brutes for over a mile up the Brisbane river until in despair he ran her ashore. The most characteristic part of this shark is the hammer-shaped head, the large eye lying at either end and having a nictitating membrane. Spiracles are absent. This fish grows to a length of over 12 feet, and its colour is dark grey above, white below. The upper lobe of the tail is twice as long as the lower. This shark is viviparous, the young being born in autumn. It is also known as the "Balance-fish."

Another group of small ground-sharks is chiefly interesting for the distinction existing before birth between the

Smooth two species that compose it. As some doubt

Hound. exists, indeed, as to whether the second of these, Mustela lavis, is to be regarded as a British fish, it is convenient to consider the two under the same trivial name of Smooth Hound. The difference alluded to is that in this doubtful British subject-which is, like its commoner congener, viviparous - there is a placental connection between the unborn young and its parent, this connection being absent in the other. The latter, which is also known as the "Ray-mouthed Dog," is of frequent occurrence on our coasts, examples of 4 feet being taken on the ground-lines. In colour it is grey, with indistinct white spots. The food of this species is said to consist of crustaceans.

The Porbeagle, the type of another group, belongs to a Porbeagle. genus of which our seas contain no other going, but the eye has no nictitating membrane, and the 
spiracle is either minute or wanting altogether. This fish may be further recognised by the deep body and wide gillopenings, the pores on the snout, and the pit on the tail-fin. In colour, it is deep grey or brown above, white beneath. It has been taken on every part of our coasts, mostly, however, in the south-west, and of a length of over Io feet. I never knew it seize a hooked fish like the blue shark, but it will often take a large bait intended for pollack; and I have caught several in this way, one of them weighing $23 \mathrm{lbs}$, , on the rod. It is viviparous, according to authorities on the subject, though there seems some little uncertainty as to the breeding season.

In that remarkable form, the Thresher, known even at some distance by the disproportionate length of the Fox-Shark notched upper tail-lobe, which may exceed or Thresher. that of the head and body together, we have one of the commonest of British sharks, which has outside of these seas a distribution that is practically cosmopolitan. With the tail, this shark grows to a length of $I_{5}$ feet, and its colour is bluish grey above, white beneath. The eyes are small and round, and there is no nictitant membrane. Spiracle, if present at all, very minute. The teeth of this species are small and triangular, and their size has caused stay-at-home naturalists to denounce the stories of this shark attacking whales. Those who prefer gathering their natural history at home are always free to do so, and are also free to disbelieve others who, not necessarily in the mantle of Munchausen, travel abroad with their eyes open. At any rate I certainly saw on one occasion on the coast of Queensland two of these sharks attacking a whale of some kind, for we steamed so near that the resounding blows with which the assailants fell on the whale were distinctly heard by those on board, while the captain's glasses left no doubt as to the identity of the long-tailed fishes that leapt in the air to fall again and again on the whale's back. The conjectured presence 
of the saw-fish below the surface rests on somewhat circumstantial evidence, the theory being, that but for some forbidding presence of that nature the whale would have the sense to sink to a depth where the attacks of the small threshers would be of slight account. In our seas this shark feeds largely on the mackerel and pilchards. It occurs there all the year round, but is most in evidence in the summer months. It is oviparous, depositing "purses." The leaping power of this fish is extraordinary; and I had on one occasion this summer two or three (one eaught in the nets the same evening measured 8 feet 5 inches from tip to tip) jumping quite their own length out of the water close to my boat and not half a mile from the end of Bournemouth pier.

The largest, as well as the most innocuous, of our sharks, however, is the Basking Shark, or "Sail-fish," also known Basking as the "Sunfish," which occurs with us chiefly Shark. on the Irish coast, growing to a length of between 30 and 40 feet, yet so gentle and unsuspecting as to allow a noose to be slipped over its tail. In colour, this huge fish is dark green to black above, white or yellow beneath; above the snout is a stain of reddish brown. The first dorsal fin is large, and when the fish is basking at the surface is held erect like a sail. The gill-openings are wide and furnished with gill-rakers, the function being, as in the baleen of whales, to filter the water, retaining the minute organisms on which this, one of the largest of living fishes, contrives to nourish itself, parallel to the largest of living mammals The eye is small and without nictitant membrane; and the spiracles are also minute. The tail, the sides of which are keeled, has both lobes distinct, and there is a pit at its base. Attempts have been made to distinguish as species more than one aberrant form of this shark.

The normal number of gill-openings in the sharks is, 
as has already been mentioned, five; but in the present comb-toothed species, which has no near ally in our seas, Six-gilled we find the number of gill-openings to be Shark. six-indeed there are two allied species in the Mediterranean with seven. The large and fierce Six-gilled Shark has been taken on our coasts to the length of nearly 30 feet. The single dorsal fin, situate far back over the anal, is without spines. The eye is large, and devoid of nictitant membrane. The spiracles are small, and lie low down on the neck. The mouth is without labial fold, and the teeth are not equally developed in either jaw, several series being in use together. In colour this shark is uniform grey.

In the dog-fishes we have an important group of groundsharks, mostly of small size, and feeding on crustaceans and carrion.

One of the most familiar of these, a fish that grows to a length of at least 4 feet, possibly more, is the spotted

Nurse. Nurse, also known as "Bounce" or "Cat-fish." In colour this dog-fish is reddish brown on the back and sides, and covered with large dark spots, lower surface white. The eye is without nictitant membrane; the spiracles are of moderate size. I have taken this fish of a length of nearly 3 feet on the rod, and have invariably found it show a tendency to wind itself round my arm, by no means a pleasant sensation, as the skin is very rough, so much so that it is an efficient substitute for emery-paper. This is more eaten than most of our sharks and dog-fish. It feeds, chiefly at night, on crustaceans. It is oviparous, the "purses" being deposited in the autumn. I have observed on the nostrils of this fish folds similar to those alluded to by Mr Dunn in the blackmouthed dog-fish, and denoting in all probability smelling powers of a high order.

The most remarkable property in the allied Row Hound, 
"Huss," or "Lesser Spotted Dog-fish," and one mentioned by Day and since verified by myself on many occasions, is

Rough

Hound or Row Hound. that when first caught and placed in the basket with pollack and other fish, its touch discolours the latter, the points of contact being indicated by white patches. It is somewhat commoner on our coasts than the last, preferring deeper water. A smaller species, it rarely exceeds a length of $3 \mathrm{~T} / 2$ feet. In colour and markings, however, it strongly resembles the last, the spots being smaller, less blurred, and more numerous. It is oviparous, depositing its "purses" in autumn.

The Black-mouthed Dog-fish is not common in British seas, where it grows to a length of 3 or 4 feet. In colour Black- it is greyish, having three rows of black mouthed white-edged spots along the sides. The snout Dog-fish. is pointed, and secretes a viscid matter; the tail has serrated processes; the skin is very rough throughout. The inside of the mouth, which has a fold of skin, is black. The eye is large, and there are spiracles. This shark deposits "purses" devoid of the usual filaments. Mr Dunn of Mevagissey, a most accurate observer of seafish, has remarked on the presence of curious reticulated organs above and below the snout of this species.

[Centrina salviani, a Mediterranean form, has been trawled on one occasion at least off the Cornish coast. It grows to a length of nearly 6 feet. The eye is large and without nictitant membrane, and over it is a distinct ridge. The spiracle is large, the gill-openings narrow, and the mouth small. In colour this dog-fish is uniform dark brown.]

One of the commonest of our smaller members of the shark tribe is the Spur-dog or Picked Dog, a gregarious, fish-eating species, found on every part of the British and 
Irish coasts. It grows, according to Day, to a length of 4 feet, and is easily recognised by the sharp spine before Spur-dog or each dorsal fin. The teeth of this dog-fish are Picked Dog. somewhat peculiar, being small and having the inner edge the sharpest. The eyes are large, as also are the spiracles behind them; and there is no nictitating

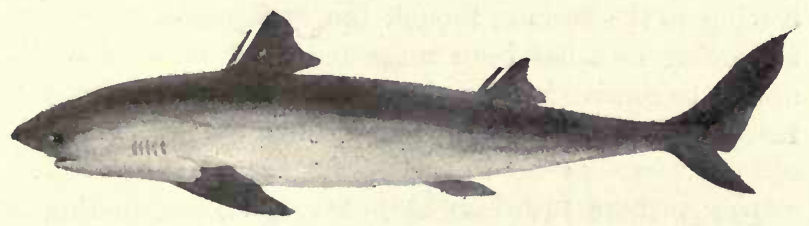

membrane. In colouring this fish is grey above, white on the belly, occasionally dashed with faint yellow, and in young examples having some white spots. In certain internal characters, this and the following sharks agree somewhat closely with the rays. This fish is viviparous, and seems to breed at various seasons.

A large allied species, growing to a length of ${ }_{5} 5$ feet at least, the Greenland Shark is another of the whale's most Greenland formidable enemies. As its name implies, it Shark. is an inhabitant of the colder northern seas, only visiting the Scottish, and still more rarely the English, coast at irregular intervals. The colour of this fish is grey, lighter beneath; and its chief peculiarities are that the body is covered with small tubercles, and the fins are very small, the dorsal fins having no spines. The teeth in the lower jaw show the peculiarity noticed in those of the last, and they lie in six rows. This shark is viviparous, and is said to produce three or four young only at a birth.

The entire body of the large Spinous Shark, which grows to a length of over 8 feet, is covered with round tubercles. Like the last, it has all the fins of small size, 
and the dorsal is spineless. In colour it is dark grey, with touches of red on the sides and belly, and the lateral

spinous line distinctly white. The lower lobe of the

shark. tail-fin is very insignificant. The eye is large, and has no nuctitating membrane; the spiracle is small. The teeth lie in several rows, only one of which is functional. In habits, this shark is a ground-species, rarely coming to the surface, though the existence of a distinct swimming race has been suggested; and its food would appear to consist largely of crustaceans. The majority of recorded British examples were captured west of Plymouth.

In the Monk Fish we find so strange a combination of the external characters of the foregoing and following Angel or groups, that it may be regarded in a measure Monk Fish. as the connecting link between the two, though its place is, strictly speaking, with the sharks. It is common on all our sandy coasts, particularly in the northern waters, though the Channel furnishes a large number to the trawlers; and I recollect measuring one of a few inches over 4 feet and weighing nearly 50 lbs., which was trawled off West Bournemouth in the month of August 1896 . It is rarely taken in the winter months, stray examples being, however, thrown ashore at that season in heavy gales, which makes it probable that the monk retires during the cold weather a few miles only from land. In colour this shark is usually dark brown or grey, with numerous blotches, lighter beneath. The dorsal fins, which lie back near the tail, are without spines, and there is no anal fin, the pectorals being very large, but not joining the head, as in the rays. There are a number of tubercles over the skin, but their distribution differs. Before the nostrils, next the mouth, is a loose process of skin. The lateral gill-openings are large, as also the crescent-shaped spiracles. The eyes lie far apart and somewhat beneath the surface of the head, being in fact included in the skin. This fish grows to a length of over 
7 feet. Its food consists largely of flat-fish. In reproduction it is viviparous, producing a score of young at a birth, it is said, in July (Couch). Among the many other names by which it is known are "Shark-Ray" and "Mongrel Skate," having allusion to its affinities to both groups ; "Fiddle-fish," in reference to its shape; and "Kingston," a Sussex name the meaning of which I was never able to trace.

\section{The Rays.}

In this, the second subdivision of the sub-order, we find a number of characters distinct from those of sharks. In the first place, the body is flattened; the tail is slender and whip-like, with or without a notched spine; the pectoral fins are enormously developed, the dorsal fins, if present, lie on the tail, the anal fin is absent. The mouth is beneath the fish, but farther back than in sharks; the teeth flat and adapted for crushing; the gillopenings, five in number, lie, with the mouth, on the under surface. Large spiracles are present behind the eyes, which are without nictitating membrane, but have in most cases a fringed eyelid. As aiready mentioned, the spiny dog-fishes have strong affinities with the present group, and should indeed be considered with them. With this reservation, however, it is convenient in an introductory work to adhere to the older division of sharks and rays. They deposit their eggs in the same kind of "purses" as some of the sharks, but these have no filaments, as, for example, those of the nurse. Mr Dunn of Mevagissey tells me that they have, in place of these, an adhesive matter that keeps them fast to weeds and stones.

The typical family and genus embrace nearly a dozen Common British species. One of the most familiar Skate. and largest is the Common Skate, otherwise "Grey Skate," "Blue Skate," or "Tinker," in which the 
sexual differences extend to the teeth, in addition to the usual smoothness of skin observed in the females; and the male is further distinguished by a patch of tubercles on the pectoral fins. In colour, this skate is pale grey with black spots, the under surface nearly white, also speckled with black. On the tail are two spineless dorsal fins and three rows of tubercles. This skate grows to a length of over 6 feet, a breadth of over 5 feet, and a weight of between $5_{50}$ and $200 \mathrm{lbs}$. It feeds largely on whitings and crustaceans, and deposits its "purses," devoid of tendrils, in early summer.

Another skate of similar habits is the common Thornback or "Maid," which grows in our waters to a length of over Thornback. 3 feet, and is trawled or hooked in moderately deep water. In colour it is brown, sometimes mottled, above, white beneath. The sexes differ in the

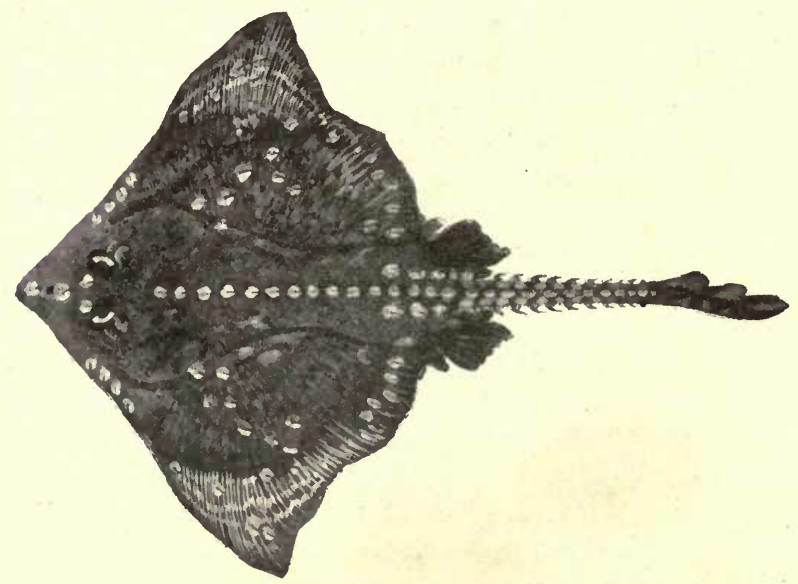

same particulars as those of the skate, the teeth of the male being pointed, those of the female flat. The upper surface of the thornback is, as the name implies, covered at intervals with curved spines that point towards the tail. 
This fish is said to feed not only on flat-fish and crustaceans, but also on such surface or mid-water forms as shad and herrings. The "purses" of this species are deposited in summer.

The deeper water furnishes the rarer Long-nosed Skate, which has a long shovel-shaped snout with which to dig up Long- the flat-fish, its favourite food. It is grey on nosed both surfaces, with or without spots and streaks.

Skate. On the lower surface of the tail there is a series of spines. The skin of this species is granulated and rough to the touch, but lacks the larger tubercles. Like the rest, the long-nosed skate is oviparous.

[The Flapper Skate of Day is regarded by many naturalists, Couch among them, as a variety only. Günther considers it a hybrid between the common skate and some other species.]

The largest of our rays, the Sharp-nosed Ray, also known variously as the "Burton Skate," "White Skate," or "Mavis Sharp- Skate," is taken to a weight of $500 \mathrm{lbs}$., its nosed Ray. greatest length being given at between 7 and 8 feet. As in all rays, distinguished from the skates proper, the lower surface is spotless white, the edge of the pectoral fin being sometimes, though not invariably, shaded with black. On the tail and pectoral fin, also behind the eyes, are rows of spines. The edge of the snout is undulated as far as the pectoral fin.

A deep-water species, caught chiefly in the summer months, the Shagreen Ray, "Dun Cow," or "French Shagreen Ray" grows to a length of 3 feet, and is Ray. more common on the east coast than in the Channel. The skin of this species is roughly granulated, and there are two rows of large spines along the disc and round the eyes. In colour this ray is light brown above, pure white below, the edge of the disc being often of darker hue than the rest. 
Found in shallow water, the Homelyn, "Spotted Ray," or "Taily" attains a length of 4 feet. The upper surface is rough, and there are rows of compressed Homelyn. spines along the back, and in males upon the head. The tail is somewhat flattened, and has three rows of spines. The spiracles are very large. The colour of this ray is brown with black spots. The lower surface is smooth and white. It feeds like the rest on fish and crustaceans, and extrudes its "purses" towards the end of summer.

The Starry Ray is taken chiefly in Scotch waters, the name having reference to the star-like radiating spines Starry Ray. with which the body is thickly covered. In to the thornback, though the spots are often absent. It is trawled chiefly in the late summer and autumn.

The "Small-eyed Ray," as the Painted Ray is often called, is a moderately large species, inhabiting shallow

Painted water, and abundant in the Channel. It is

Ray. more eaten perhaps than most other rays. The colouring is varied, as implied in the trivial name, but is usually some shade of marbled grey above with dashes of white and yellow; the lower surface, in accordance with the unvarying rule in true rays, spotless white. The teeth of this species are flatter than in the last.

The Cornish trawls generally bring up in summer-time a large sprinkling of Sand Rays, or "Owls," which seem in

Sandy or Cuckoo Ray. winter to retire to the deeper untrawled water outside. This species attains an average length of 3 feet, large examples weighing $20 \mathrm{lbs}$. In colour the upper surface is brown, spotted and marbled with yellow. The mouth is arched, and the teeth, which lie in sixty or seventy rows, are curved and pointed.

[In some systems the Cuckoo Ray is separated as a 
smaller species, having a large black spot with yellow centre at the shoulder, other yellow spots occasionally surrounding it.]

In the Torpedo, otherwise "Cramp-fish" or "Numbfish," which is not uncommon in our deeper waters, we come

Torpedo. to another type, the distinguishing feature of which is the presence of electric organs in the sides of the head, these organs taking the form of between four and five hundred hexagonal prisms of cells containing a gelatinous substance. This power of giving electric shocks ceases with life. The British species grows to a length of 5 feet, with an accompanying breadth of upwards of a yard. The body is plump and without tubercles. The dorsal fins, the first of which is about twice the size of the second, are spineless, and situate on the tail. The eyes, behind which lie oval spiracles devoid of fringe, are small and embedded. The crescent-shaped mouth is not very large, the teeth being curved, pointed, and movable in their sockets. The colour of this species varies from dull red or brown to black. It feeds on fishes of considerable size, examples of which have been recovered intact from its inside.

[The Marbled Torpedo, a Mediterranean species having a fringe of tentacles round the spiracle, is included by some writers in the British list.]

One of the most formidable and indeed commonest of our rays is the Sting-Ray, or "Fireflaire," which has an almost cosmopolitan range, and is taken in sting-Ray. British seas to a weight of $80 \mathrm{lbs}$. This mud-loving fish is recognised by the serrated spine (6 or 8 inches long in large examples) with which the whiplike tail is armed. This weapon, which is liable to injury, can be replaced after accident, if not indeed periodically. The tail has a fold on the lower surface and a ridge above. The body is either smooth or sparsely covered with 
tubercles. In colour, the sting-ray is generally of a uniform reddish brown, rarely marbled or spotted. The tailspine is capable of inflicting serious wounds, but it seems uncertain whether their severity is due merely to laceration, or whether there is in addition any active poison at work.

The Eagle-Ray and Ox-Ray are among the largest of living fishes, growing, in tropical seas at any rate, to the Eagle-Ray. enormous weight of upwards of rooo lbs. In amples, between 2 and 3 feet in length, have been captured. The tail of the eagle-ray is, like that of the sting-ray, armed with a serrated spine as a rule; but this spine is sometimes wanting, and in some examples, on the other hand, there is a second. The tail itself is whip-like, and bears a small fin before the spine. This ray is exceedingly broad, the wing-like appearance of the pectoral fins having doubtless suggested the trivial name. Its colour is greenish brown above, white beneath, the tail being in many examples almost black. The teeth are broad, and lie in seven rows. This fish is generally described as viviparous, but Couch gives an account of its "purse," which he described as of large size and marked with lines and spots.

[The Ox-Ray, likewise a wanderer only to our seas, is the "Devil-fish" of the West Indies, which is distinguished

Ox-Ray. by the "horns" before the eyes, fleshy processes which the fish can coil and unfurl at will. The long and tapering tail, which is three times the length of the body, is covered with tubercles and armed with a serrated spine. The gape of the mouth is enormous, and the teeth lie in 150 rows. It has been suggested that the retractile "horns" may be of service in setting up a current and bringing food to the mouth. But one example (Irish) is recorded from our seas.] 


\section{THE LOWEST VERTEBRATES}





\section{THE LOWEST VERTEBRATES.}

\section{LAMPREYS AND HAG-FISHES.}

THE great sub-kingdom of the Vertebrates, to the consideration of which the present volume is restricted, draws its lowest subjects from the ranks of these small and remarkable creatures, which, presumably from a consideration of their watery habitat, it was formerly the custom to include among fishes-a habit that has taken such deep root that one group still retains the title of hag-fishes. The distinctive features of this class are the absence of jaws, the single opening of the nostrils, and the curious pouch-like character of the gills, which are without arches. The skeleton is cartilaginous, and the skull is closely joined to the vertebral column.

\section{The Lampreys.}

Of the true lampreys we have three forms. The largest of these, the Sea-Lamprey, is an inhabitant of salt water, t Sea- but enters many of our rivers, the Severn

Lamprey. among them, for breeding purposes. It grows to a length of about 3 feet and a weight of $5 \mathrm{lbs}$., and its colour is usually some shade of grey or green, spotted with black. The young, which remain for some years in fresh water, their growth being very gradual, are toothless and 
practically blind. The members of this group have seven gill-slits; and the mouth, a mere slit when closed, opens as a circular orifice, having suctorial lips and a flexible disc. This lamprey is much esteemed as food, and is caught in wicker baskets specially constructed and placed in the mud. Like the rest, it is carnivorous, rasping the sides of living fishes, to which it adheres for the purpose, with its hard teeth. It enters English rivers to spawn in the spring.

The commoner Lampern was till recently regarded as a fresh-water form, but later investigations have estabtLampern lished its presence in the sea, and it is now or River- regarded, like the last, as an anadromous Lamprey. form. It differs in its smaller size, rarely exceeding a length of I $_{5}$ inches, as well as in the bluish colour and absence of spots. It spawns in rivers having a stony bed, the eggs being deposited in furrows excavated by the lamperns themselves; and it is thought to die after spawning. Its food consists of the flesh of living and dead fish, worms, and insects. Its chief use is as bait in the cod-fishery.

The smallest of the three, the Mud-Lamprey, familiarly known as the "Pride," does not exceed a length of ro † Mud- inches. Like the last, it is, chiefly on account Lamprey. of its toughness, an excellent bait for some sea-fish. Beyond its supposed residence in salt water and invariable ascent of rivers for spawning, after which ordeal it is supposed to die, little has been recorded of the life-history of this form, the most interesting discovery being that of its larva, which was long regarded as a distinct species.

\section{The Hag-Fish.}

In the singular Hag-fish we have a true parasite, for the "Borer," as it is called, is most commonly taken from the 
bodies of cod into which it has eaten its way. A more repulsive animal could not be easily imagined, for it is Hag-fish blind, the mouth without lips and having four or Glutin- barbels; the abdomen with rows of sacs that ous Hag. secrete a quantity of slime. There is but one opening to the internal gill-pouches. This form inhabits our deeper northern waters. 



\section{APPENDIX I.}

\section{MATERIALS FOR A BIBLIOGRAPHY OF BOOKS ON THE BRITISH VERTEBRATE FAUNA.}

[This list has for the most part undergone revision by the publishers. In the case of works out of print (o.p.) the price is usually omitted.]

\section{INDEX TO COUNTIES AND DISTRICTS.}

$$
\text { ( } g=\text { general. } \quad b=\text { birds. } \quad m=\text { mammals. })
$$

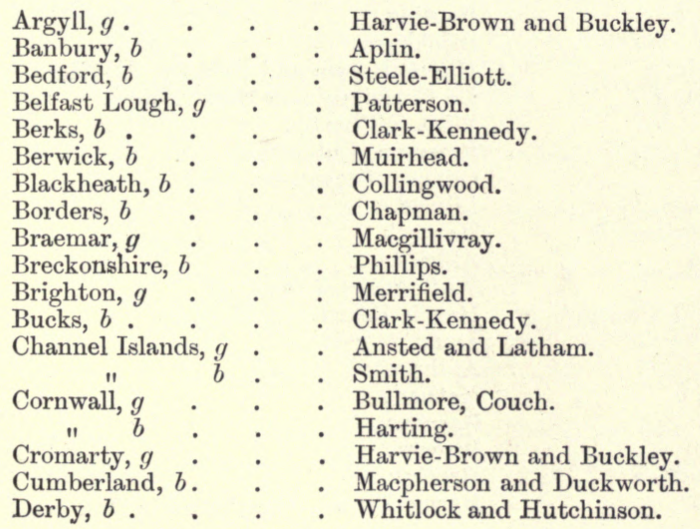




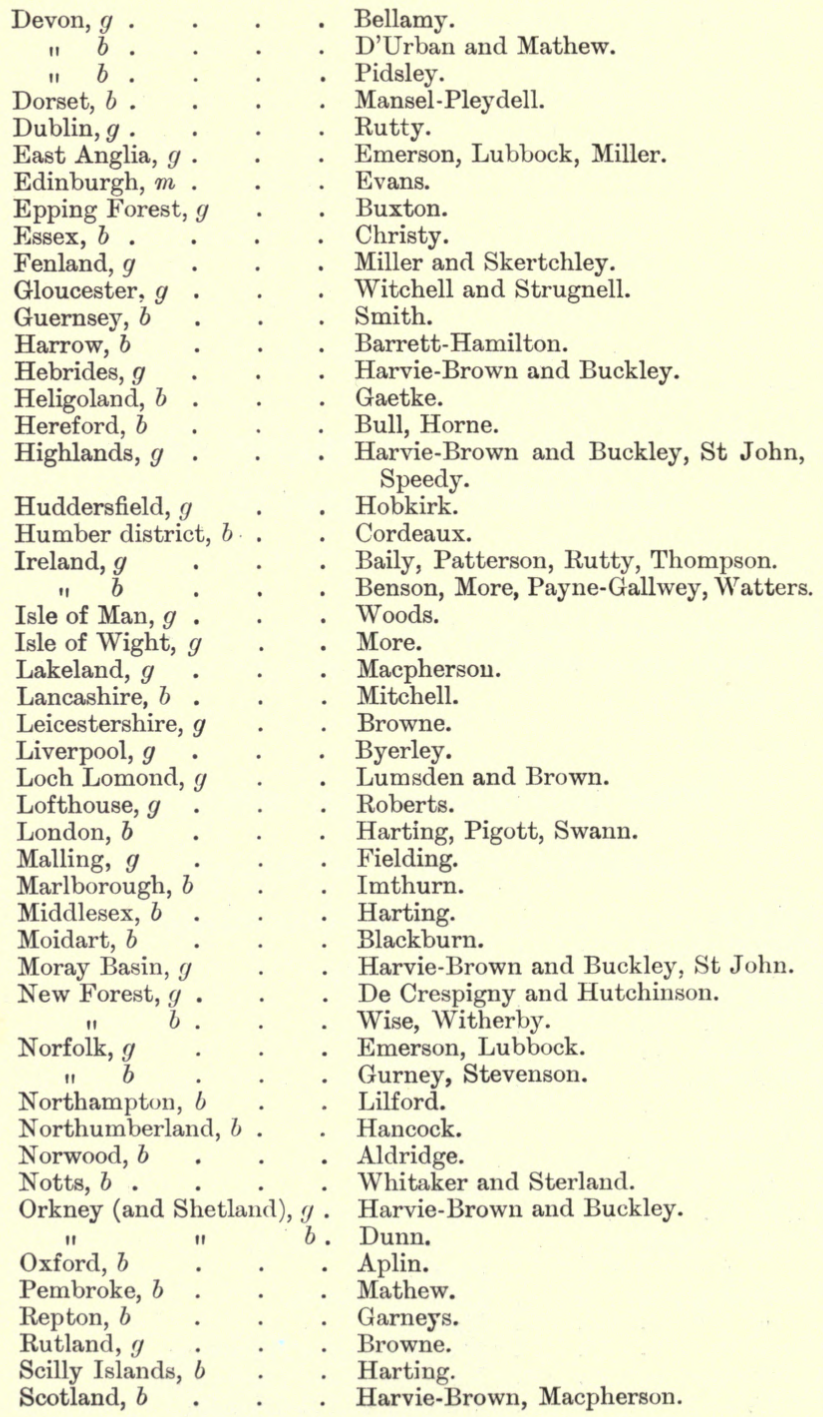




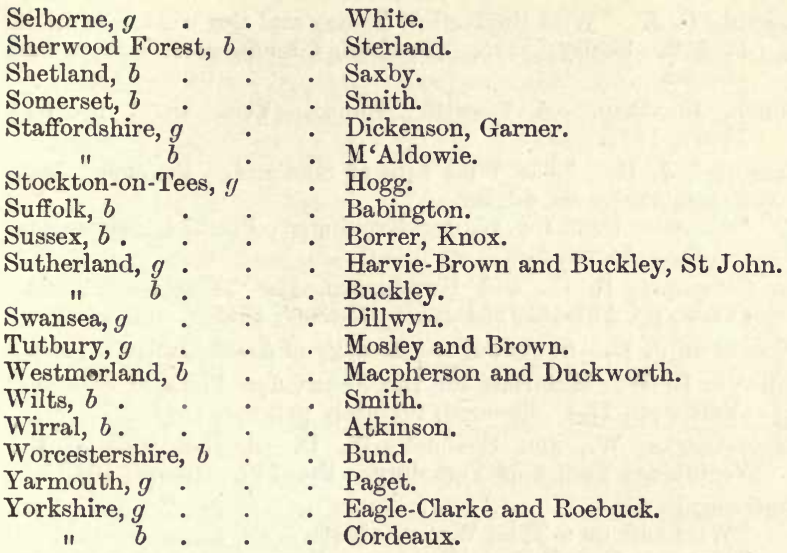

Books are in one volumc and $8 v 0$, unless otherwise stated. ${ }^{*}=$ illustrated.

\section{GENERAL.}

Ansted, D. T., and Latham, R. G. The Channel Islands. (Vert., pp. 188-196.) W. H. Allen, 3rd ed., 1893.

Atkinson, Rev. J. C.-

* Sketches in Natural History, with an Essay on Reason and Instinct. Pp. 338. Routledge, 1865.

* Forty Years in a Moorland Parish. Pp. 465. Macmillan, 1892. 5s.

Baily, W. H. Rambles on the Irish Coast. (Vert., pp. 58-69.) Dublin, 1886.

Bellamy, J. C. *The Natural History of South Devon. Pp. 441. Plymouth, 1839.

Browne, Montagu. *The Vertebrate Animals of Leicestershire and Rutland. 1889. $£ 1,1$ s.

Bullmore, W. K. Cornish Fauna. Pp. 64. Truro, 1867.

Buxton, E. N. *Epping Forest. (Vert., pp. 71-101.) Stanford, 1897. 18.

Byerley, I. The Fauna of Liverpool. (Vert., pp. 34.) 1856.

Collingwood, Cuthbert. The Fauna of Blackheath and its Vicinity. (Pt. 1, Vert., pp. 46.) Clowes, 1859. 
Cornish, G. J. * Wild England of To-day and the Wild Life in it.

P. 310. Seeley, 1895. [Seafowl, salmon, deer, osprey, \&c.] 12 s. $6 \mathrm{~d}$.

Couch, Jonathan. A Cornish Fauna. (Vert., Pt. 1, pp. 63.) Truro, 1838.

Crawford, J. H. *The Wild Life of Scotland. Pp. 280. Macqueen, 1896 . 8 s. 6 d. net.

*Summer Days for Winter Evenings. Pp. 274. Macqueen, 1897. 8s. 6d. net.

De Crespigny, R. C., and Hutchinson, H. *The New Forest. (Vert., pp. 151-165, 204-265.) Murray, 1895.

Dickenson, J. H. Sketch of the Zoology of Staffordshire. 1798.

Dillwyn, L. W. Materials for the Fauna and Flora of Swansea.

(Vert., pp. 17.) Swansea, privately printed, 1848.

Eagle-Clarke, W., and Roebuck, W. D. A Handbook of the Vertebrate Fauna of Yorkshire. Pp. 149. Reeve, 1849.

Emerson, R. H.-

* Wild Life on a Tidal Water. Nutt. $£ 3,3$ s.

* Pictures from Life in Field and Fen. Nutt. Fol., £5, 5s. and $\mathfrak{f} 1,2 \mathrm{~s}$.

* On English Lagoons. £1, 1s. and 7s. 6d.

*Birds, Beasts, and Fishes of the Norfolk Broadland. Pp. 396. Nutt, 1895.

Fielding, Rev. C. H. Memories of Malling and its Valley (with lists of Kent Vertebrates). West Malling, 1893.

Fraser, Rev. R. W. * ${ }^{*}$ Seaside Divinity. (Vert., pp. 317-377.) Hogg, 1861.

Garner, R. *The Natural History of the County of Stafford. (Vert., pp. 241-298.) Van Voorst, 1844.

Graham, P. Anderson. All the Year with Nature. Pp. 237. Smith, Elder, 1893. 5 s.

Green, Rev. G. C. * Collections and Recollections of Natural History and Sport. Pp. 221. Reeve, 1886. 7s. 6d.

Harvie-Brown, J. A., and Buckley, T. E.-

*A Vertebrate Fauna of Sutherland, Caithness, and West Cromarty. Pp. 354, 2 vols. Douglas, 1887. O.p.

A Vertebrate Fauna of the Outer Hebrides. Pp. 387, 2 vols. Douglas, 1889. O.p.

*A Vertebrate Fauna of the Orkney Islands. Pp. 338. Douglas, 1891. 30s.

*A Fauna of Argyll and the Inner Hebrides. Pp. 262. Douglas, 1892. $30 \mathrm{~s}$.

* A Fauna of the Moray Basin. Pp. 615, 2 vols. Douglas, 1896. 60s. [In vol. ii. Extinct Vert., pp. 50, by $\mathrm{Dr}$ Traquair.]

Hobkirk, C. C. P. Huddersfield: its History and Natural History. (List of mammals and birds, pp. 138-145.) Ward Lock, 1859. 
Hogg, John. On the Natural History of the Vicinity of Stocktonon-Tees. (Vert., pp. 18.) Stockton, 1827.

Idle, C. Hints on Shooting and Fishing. Pp. 293. Longmans, 1855. O.p.

Jefferies, Richard-

Wild Life in a Southern County. Pp. 316. Smith, Elder, 1879,7 s. 6 d. 1897,6 s.

Nature near London. Pp. 242. Chatto \& Windus, 1883. 6s. and 2s. $6 \mathrm{~d}$.

The Life of the Fields. Pp. 262. Chatto \& Windus, 1884. $6 \mathrm{~s}$. and $2 \mathrm{~s}$. $6 \mathrm{~d}$.

The Open Air. Pp. 270. Chatto \& Windus, 1885. 6s. and 2s. $6 \mathrm{~d}$.

Round About a Great Estate. Pp. 204. Smith, Elder (latest ed.), 1894. $5 \mathrm{~s}$.

The Amateur Poacher. Pp. 240. Smith, Elder, 1896. 5s.

Jesse, Ed. Gleanings in Natural History. (Vert. passim.) Pp. 945 (3 series). Murray, 1835-36.

Knight, F. A. -

* By Leafy Ways.

The Rambles of a Dominie. Wells Gardner, 1891. 5s.

* By Moorland and Sea. Stock, 1893. 5s.

Knox, A. E. *Autumns on the Spey. Pp. 171. Vun Voorst, 1872. [Deer, eagles, owls, \&c.] 6s.

Lubbock, Rev. R. Observations on the Fauna of Norfolk, and more particularly on the District of the Broads. Pp. 156. Jarrold, 1845.

2nd ed. [ed. T. Southwell], pp. 239. 1879.

Lumsden, J., and Brown, A. A Guide to the Natural History of Loch Lomond and Neighbourhood. Pp. 103. Glasgow, 1895.

Macgillivray, W. The Natural History of Deeside and Braemar. Pp. 507. [Ed. E. Lankester.] 1855.

Macpherson, Rev. H. A. *A Vertebrate Fauna of Lakeland. Pp. 552. Douglas, 1892. 30s. [Preface by R. S. Ferguson: excellent chapters on extinct mammals, bird-fowling, \&c.]

Maxwell, Right Hon. Sir Herbert, Bart., M.P. Memories of the Months. (Vert. passim.) Pp. 300. Arnold, 1897. 6s.

Merrifield, Mrs. A Sketch of the Natural History of Brighton and its Vicinity. (Vert., pp. 161-180.) Brighton, 1860.

Miller, S. H., and Skertchley, S. B. T. The Fenland, Past and Present. (Vert., pp. 354-400.) Longmans. O.p.

More, A. G. Outlines of the Natural History of the Isle of Wight. (Vert., pp. 1-36.) Spottiswoode, 1860.

Mosley, Sir O., and Brown, E. The Natural History of Tutbury. (Vert., pp. 102.) Van Voorst, 1863.

Mudie, Robert. The British Naturalist. 1st ed., pp. 380. Whittaker, 1830.

2nd ed., pp. 763 (2 vols.) Orr, 1835. 
Paget, C. J. and J. Sketch of the Natural History of Yarmouth and its Neighbourhood. (Vert., pp. 1-18.) Yarmouth, 1834.

Patterson, R. Lloyd. The Birds, Fishes, and Cetacea commonly frequenting Belfast Lough. Pp. 267. Bogue, 1880.

Pennant, Thomas. British Zoology.

1st ed., fol. 1766.

2nd ed. (2 vols.) Pp. 754. 1768. [Mammals and birds.]

3rd ed. (4 vols. Vert., pp. 1565, vols. i.-iii.) 1812.

Roberts, G. Topography and Natural History of Lofthouse and its Neighbourhood. (2 vols.) (Vert. passim, i. 111-388; ii. 87-170.) Leeds, 1882.

Rutty, John. An Essay towards the Natural History of the County of Dublin. (Vert., i. 263-370.) (2 vols.) Dublin, 1772.

St John, Charles -

A Tour in Sutherlandslire.

2nd ed. * (2 vols. $),$ pp. 706. Douglas, 1884. 21s. [Appendix by Harvie-Brown and Buckley.]

* Wild Sports and Natural History of the Highlands. 1st ed. Natural History and Sport in Moray.

Shand, A. Innes. *Mountain, Stream, and Covert. Pp. 334. Seeley, 1897.

"Son of the Marshes"-

Forest Tithes. Pp. 208. Smith, Elder, 1893. 5s.

Nature Studies. Smith, Elder, 1893. 5s.

Forest, Field, and Fell. Lawrence \& Bullen, 1893. 3s. 6d.

Woodland, Moor, and Stream. Pp. 224. Smith, Elder, 1896. $5 \mathrm{~s}$.

Speedy, T. Sport in the Highlands and Lowlands of Scotland with Rod and Gun. Pp. 444. Blackwood, 1884. 15s.

Thomas, E. The Woodland Life. Pp. 234. Blackwood, 1897. 6s.

Thompson, W. The Natural History of Ireland. (4 vols.) (Vert., pp. 1543.) Reeve, 1849-56. £3, 3s.

Turton, W. British Fauna (containing a compendium of the Zoology of the British Isles). (Vert., pp. 1-117.) 12mo. Swansea, 1807.

Tutt, J. W. * Woodside, Burnside, Hillside, and Marsh. Pp. 241. (Vert. passim.) Sonnenschein, 1894.

Walsingham, Lord, Sir R. Payne-Gallwey, and others. * Shooting. Longmans ["Badminton Library"]. (2 vols.) (Nat. Hist. passim.) £1, 1s.

White, Gilbert. Natural History and Antiquities of Selborne.

*White, 1789. 4to, pp. 468 [3 illust.]

* White, 1802. Large 8vo, pp. 692 [2 vols. in one].

* White, 1813. 4to [2 vols.], pp. 888.

* Arch., Longman, \&c., 1822. [2 vols.] pp. 715 [orig. text].

* Rivington, \&c., 1825. Large 8vo, pp. 714 [orig. text].

Constable, 1829. 12mo, pp. 343. [Ed. Jardine in "Constable's Miscellany."] 
White, Gilbert-

*Hailes, 1833. 12mo, pp. 316. 「Arranged for young persons by Lady Dover.]

* Chambers, 1833. Small 8vo, pp. 356. [Notes by Capt. T. Brown.]

*Orr \& Smith, 1836. Small 8vo, pp. 418. [Ed. Ed. Blyth : chap. by Mudie.]

*Arch., Longman, \&c., 1837. Pp. 640. [Ed. E. T. Bennett: excellent notes.]

* S.P.C.K., 1842. 8vo, pp. 328. [This is Lady Dover's 1833 ed. with extra notes and illust.]

* Harper, 1843. $12 \mathrm{mo}$, pp. 335.

*Van Voorst, 1843. Pp. 398. [Ed. L. Jenyns.] 7s. 6d.

* Bohn, 1851. Pp. 416. [Jardine's ed., with notes by Edward Jesse.]

*Routledge, 1854. 8vo, pp. 428. [Ed. J. G. Wood.]

* Bell \& Daldy, 1862. 12mo, pp. 426. [Notes embodied in the letters.]

*Macmillan, 1875. Royal 8vo, pp: 591. [Ed. Frank Buckland.] O.p.

[Ditto, 1876. In 2 vols. 4to, pp. 601, £4, 4s. ; and a cheaper 1 vol. ed. in $1880,6 \mathrm{~s}$.

Van Voorst, 1877. 2 vols. 4to, pp. 917. [Ed. Thomas Bell.] $£ 1,11$ s. 6 d.

* Chatto \& Windus, 1878. Pp. 348. [Ed. Brown.] 2s.

* Routledge, 1880. 8vo, pp. 475. [The Jardine ed.]

Scott, 1887. Pp. 366. ["Camelot Series": pref. by Richard Jefferies, who speaks of "the little Surrey parish of Selborne."]

Routledge, 1886. Pp. 160. ["World Library": ed. H. R. Haweis.] 6d.

* Sonnenschein, 1890. Pp. 583. [Ed. J. E. Harting: additional letters.]

Routledge, 1891. Pp. 475. ["Sir John Lubbock's Hundred Books: the Jardine text and notes, with short intro. by Lubbock.]

Blackie, 1895. Pp. 252.

* Macmillan, 1895. 2 vols., pp. 422. [The Buckland text, with 17 pp. introd. by John Burroughs.] 10s. 6d.

The following undated on title:-

*Warne, pp. 470. ["Chandos Library": ed. Christopher Davies.]

Cassell. 2 vols. 120, pp. 334. ["National Library": ed. H. Morley.] 3d.

While I was making a list of editions of this classic a complete bibliography was announced in book form. I intended to give the various editions somewhat in extenso, because, in spite of the modern habit of "smart" naturalists, who sneer at the "slipshod work of poor old Gilbert White," much interest must always attach to the reappearances of a book that has already been issued in something over five-and-twenty different editions, by almost all the leading publishers, and with at least three naturalists of repute figuring in the list of editors. I abandoned the attempt, however, and the above is the unfinished result. 
Wilson, Dr Andrew. Leaves from a Naturalist's Notebook. Pp. 255. Chatto \& Windus, 1882. 2s. 6 d.

Witchell, C. A., and Strugnell, W. B. [and other contributors]. *The Fauna and Flora of Gloucestershire. (Vert., pp. 166.) Stroud Press, 1892.

Wood, Theodore. * The Farmer's Friends and Foes: a Popular Treatise on the various Animals which affect British Agriculture beneficially or injuriously. Sonnenschein. 3s. 6d.

Woods, G. An Account . . . of the Isle of Man. ["On Manx Zoology," pp. 24-29.] Blackwood, 1811.

\section{MAMMALS.}

Bell, Thomas. * British Quadrupeds (and Cetacea). Van Voorst. 24s. O.p.

1st ed., 1837.

2nd ed., 1874. Pp. 476 (with other authors). $£ 1,6$ s.

Evans, W. * Mammalian Fauna of the Edinburgh District. Fol., 1892.

Everitt, N. *Ferrets. Pp. 209. A. \& C. Black, 1897. 3s. 6d.

Harting, J. E. * Extinct British Animals. Pp. 258. Trübner, 1880.

Jefferies, Richard. Red-Deer. Pp. 207. Longmans, 1884.

*2nd ed., pp. 248 . Longmans, 1892. 3s. 6d.

Lydekker, R. *A Handbook to the British Mammalia. Pp. 339. W. H. Allen, 1895. [Excellent chapter on Ancient Mammals.]

Macgillivray, W. * A History of British Quadrupeds. [Naturalist's Library.] 1843. O.p.

Macpherson, Rev. H. A., and others-

* Red Deer. Pp. 330. Longmans ["Fur and Feather Series": ed. Alfred Watson], 1896. 5s.

*The Hare. Pp. 274. Longmans ["Fur and Feather Series": ed. Alfred Watson], 1896. 5s.

Millais, J. G. * British Deer and their Horns. Pp. 224. Sotheran, 1897. £4, 4s.

Southwell, T. * The Seals and Whales of the British Seas. Pp. 128. Jarrold, 1881.

Storer, Rev. J. *The Wild White Cattle of Great Britain. Pp. 384. [Ed. J. Storer.] Cassell, 1879. 21s.

Whitaker, Joseph. . A Descriptive List of the Deer Parks and Paddocks of England. Pp. 190. Ballantyne, 1892. 


\section{BIRDS.}

Adams, H. G.-

* Our Feathered Families. Hogg.

1. The Birds of Prey. Pp. 320.

2. Game and Water Birds. Pp. 345 .

* Favourite Song-Birds. Pp. 192. Groombridge, 1881. 3s.6d. Adamson, C. M. -

Sunday Natural History Scraps. Pp. 98. Newcastle, 1879. [More especially about birds.]

* Studies of Birds. 1881. [ 40 sketches, 1 autotype, chiefly waders and waterfowl : no letterpress.]

* Some more Scraps about Birds. Pp. 273. 1880-81.

*Another Book of Scraps. 1882. [Letterpress pp. 56;36 f.p. sketches.]

* Some more Illustrations of Wild Birds. Gurney \& Jackson, 1887. [24 tinted drawings: no letterpress : mostly waterfowl.] O.p.

Aitkinson, W. Wirral Notes. Bolton, 1897. 1s.

Albin, E.-

* A Natural History of English Song-Birds. Pp. 110. Lowndes, 1779.

*A Natural History of Birds. Pp. 290. (3 vols. 4to.) Innys, 1838. [Includes the "Batt or Fluttermouse."]

Aldridge, W. "A Gossip on the Wild Birds of Norwood and Crystal Palace District. Pp. 109. Norwood, 1885.

Aplin, F. C., B. d'O., and O. V. A List of the Birds of the Banbury District. Pp. 29. Banbury, 1882.

Aplin, O. V. The Birds of Oxfordshire. Pp. 217. Clarendon Press, 1889.

Arnold, E. L. Bird Life in England. Pp. 325. Chatto \& Windus, 1887. 6s. [Grouse-moors, sea-fowl, crows, ducks, \&e.]

Atkinson, J. A Compendium of the Ornithology of Great Britain (with a reference to the Anatomy and Physiology of Birds). (2 vols.) Hurst, 1820.

Babington, Churchill. *Catalogue of the Birds of Suffolk. Pp. 281. Van Voorst, 1884-86. 10s. 6d.

Barrett-Hamilton, G. E. H. Harrow Birds. Pp. 50. Harrow School, 1892.

Benson, Rev. C. W. * Our Irish Song-Birds. Pp. 189. Hodges, 1886.

Bewick, T. *A History of British Birds. Pp. 781 (2 vols.) Newcastle, 1821.

Blackburn, Mrs H.-

* Birds drawn from Nature. Glasgow, 1868. [45 col. plates.]

* Birds from Moidart and elsewhere. Pp. 200. Douglas, 1895. 15s. 
Bladen, W. W. Stray Notes on Birds. 1884.

Bolton. * British Song-Birds. (2 vols.) 1824.

Booth, E. T.-

Catalogue of the Cases of Birds in the Dyke Road Museum (Brighton). - Pp. 219. Brighton, 1876.

* Rough Notes on the Birds observed during Twenty Years' Shooting in the British Islands. (3 vols. fol.) Porter, 1881-87.

Borrer, W. *The Birds of Sussex. Pp. 385. Porter, 1891. 15s. net.

Buckley, T. E. Birds of East Sutherland. Pp. 152. Glasgow Natural Hist. Soc., 1882.

Bull, H. G. Notes on the Birds of Herefordshire. Pp. 274. Hereford, 1888.

Bund, J. W. Willis. A List of the Birds of Worcestershire and the adjoining Counties. Pp. 53. Worcester, 1891. [Tables faced by notes of occurrences of rare visitors.]

Butler, A. G.-

*British Birds' Eggs. 1886. £1, 10s.

${ }^{*}$ British Birds with their Nests and Eggs. (4to.) Brumby \& Clarke, 1896, \&c. (In progress.) Weekly, 6d.

Chapman, Abel-

* Bird-Life of the Borders. Pp. 300. Cox. 12s. 6d.

* First Lessons in the Art of Wildfowling. Pp. 270. Cox, 1896.

Christy, Miller-

* The Birds of Essex. Pp. 302. Chelmsford, 1890.

A Catalogue of Local Lists of British Birds. Pp. 42. [Under Counties.] Porter, 1891. 2s. net.

Clark-Kennedy, A. W. M. *The Birds of Berkshire and Buckinghamshire. Pp. $226 . \quad$ Eton, 1868.

Clement, Lewis ("Wildfowler"). *Modern Wildfowling. Cox, 1895. 10s. 6d.

Cordeaux, John. Birds of the Humber District. Pp. 231. Van Voorst, 1872.

Cornish, C. J. *Nights with an Old Gunner (chiefly birds). Pp. 307. Seeley, 1897. 6s.

Crichton, A. W. A Naturalist's Ramble to the Orcades. P . 132. Van Voorst, 1872. O.p.

Dixon, Charles-

Rural Bird Life. Pp. 374. Longmans, 1880. O.p.

* Our Rarer Birds. Pp. 373. Bentley, 1888.

* Stray Feathers from many Birds. Pp. 231. W. H. Allen, 1890.

* Annals of Bird Life. Pp. 352. Chapman \& Hall, 1890. 7s. $6 \mathrm{~d}$.

Idle Hours with Nature. Pp. 278. Chapman \& Hall, 1891. 6s. The Birds of our Rambles. Pp. 249. Chapman \& Hall, 1891. 7s. 6d. [Field, wood, coast, \&c.] 
Dixon, Charles-

The Migration of Birds. Pp. 300. Chapman \& Hall, 1892. $6 \mathrm{~s}$.

*The Nests and Eggs of British Birds. Pp. 371. Chapman \& Hall, 1893. 6s.

* Game Birds and Wild Fowl of the British Isles. Pp. 468. Chapman \& Hall, 1893. 18s.

* The Nests and Eggs of Non-Indigenous British Birds. Pp. 368. Chapman \& Hall, 1894. $6 \mathrm{~s}$.

The Migration of British Birds. Pp. 320. Chapman \& Hall, 1895. 7s. 6d.

* British Sea-Birds. Pp. 295. Bliss, Sands, 1896. 10s. 6d.

The Migration of Birds. Pp. 426. Horace Cox, 1897.

* Our Favourite Song-Birds. Pp. 287. Lawrence \& Bullen, 1897. 7s. 6d.

Doubleday, Henry. A Nomenclature of British Birds. Wesley, 1836.

Dunn, R. The Ornithologist's Guide to the Islands of Orkney and Shetland. Pp. 128. Hull, 1837.

D'Urban and Mathew. *The Birds of Devon. Pp. 546. Porter, 1892. 18s. 6d. net.

Eyton, T. C. *A History of the Rarer British Birds. Pp. 168. Longmans, $1836 . \quad$ O.p.

Fowler, W. Warde-

*A Year with the Birds. Pp. 266. Macmillan, 1889. (3rd ed.) [The 1st and 2nd eds. contain a list of birds of Oxfordshire.] 3s. 6d.

*Tales of the Birds. Pp. 210. Macmillan, 1889. (2nd ed.) 3 s. 6 d.

The Marsh Warbler (A. palustris) in Oxfordshire, \&c. Pp. 29. Oxford, 1893.

Summer Studies of Birds and Books. Pp. 288. Macmillan, 1895. [Marsh-warbler, wagtails, song of birds, \&c.] $6 \mathrm{~s}$.

Fulcher, F. A. $\quad{ }^{*}$ The Birds of Our Islands. Melrose, 1897.

Gaetke, H. Heligoland as an Ornithological Observatory. Pp. 600. Douglas, 1895. 30s.

[A detailed acconnt of nearly 400 species observed by the author during fifty years of residence on the island. Prefaced by chapters on the causes, direction, altitude, and velocity of bird-migration.]

Garneys, W. Birds of Repton. 1881.

Gordon, W. J. * Our Country's Birds, and How to Know Them.

Pp. 152. Day, 1892. 6s. [Col. illust. of every species.]

Gosse, P. H. * Popular British Ornithology. Pp. 320. Reeve, 1853.

Gould, John-

* The Birds of Great Britain (5 vols. fol.) Sotheran, 1873. $£ 75$.

An Introduction to the Birds of Great Britain. Pp. 135. Taylor \& Francis. 5s. 6d. 
Graham, H. D. * Birds of Iona and Mull. Pp. 296. Douglas, 1890. £1, 1s.

Gurney, J. H. A Catalogue of the Birds of Norfolk. Pp. 4\%.

Wertheimer, 1884. [285 species.]

Gurney, J. H., \& Son. A Catalogue of a Collection of British Birds. Porter, 1892. 1s. 3d.

Hancock, J. Catalogue of Birds of Northumberland and Durham. Williams, $1874.15 \mathrm{~s}$.

Harting, J. E.-

The Birds of Middlesex. Pp. 279. Van Voorst, 1866. O.p.

*Essays on Sport and Natural History. Pp. 463. Cox. 10s. $6 \mathrm{~d}$.

Hints on Shore-Shooting. Pp. 88. Van Voorst, 1871. [With a chapter on skinning.] 3s. $6 \mathrm{~d}$.

A Handbook of British Birds. Pp. 198. Van Voorst, 1879. 7s. 6 d.

Our Summer Migrants. Pp. 343. Sonnenschein, 1889. [An account of the migratory birds which pass the summer in the British Islands.]

* Sketches of Bird Life. Pp. 292. W. H. Allen, 1883.

Harvie-Brown, J. A. *The Capercaillie in Scotland. Pp. 173. Douglas, 1879 . $8 \mathrm{~s} .6 \mathrm{~d}$.

Harvie-Brown, J. A., and Cordeaux, J., \&c. Report on the Migration of Birds. Edinburgh, 1880-81. [Maps, \&c.]

Hayes, C. * Portraits of British Birds. Pp. 120. 1808.

Headley, F. W. * The Structure and Life of Birds. Pp. 406. Macmillan, 1895. 7s. $6 \mathrm{~d}$.

Hewitson, W. C. ${ }^{*}$ Coloured Illustrations of Eggs of British Birds. (2 vols.) Van Voorst, $1856 . £ 3,3$ s.

Horne, George. An Authenticated List of the Birds of Herefordshire. Pp. 24. Hereford, 1889.

Hubbard, Hon. Rose. Ornamental Waterfowl. (A practical manual on the acclimatisation of the swimming birds.) Pp. 208. Simpkin, 1888.

Hudson, W. H. -

*Lost British Birds. Pp. 32. (Soc. Prot. Birds.) [Crane, capercaillie, avocet, bittern, \&c.]

Birds in a Village (and other papers). Pp. 232. Chapman \& Hall, 1893.7 s. 6 d.

${ }^{*}$ British Birds. Pp. 382. Longmans, 1896. 7s. 6d. [A chapter on anatomy and classification by F. Beddard.]

Hunt, J. * British Ornithology. (3 vols.) Norwich, 1815. (Containing portraits of all the British Birds.)

Imthurn, E. F. Birds of Marlborough. Pp. 117. Marlborough, 1870.

Irby, Lt.-Col. L. H. British Birds ! Key List. Porter. 1st ed., pp. 58. 1888. 2s. net.

2nd ed., pp. 69. 1892. [With an index.] 2s. net. 
Jefferies, Richard-

*'The Gamekeeper at Home. Pp. 221. Smith, Elder, 1879. 10s. 6d. Later edition, 1896 . $5 \mathrm{~s}$.

*Field and Hedgerow. Longmans ["Silver Library"]. 3s. 6d. Johns, Rev. C. A. * British Birds and their Haunts. Pp. 626. S.P.C.K., 1867. 78. $6 \mathrm{~d}$.

Johnson, T. B. The Gamekeeper's Directory. Pp. 194. Piper, 1851. [Instructions for the preservation of game.]

Jones, T. Rymer. *The Natural History of Birds, a Popular Introduction to Ornithology. Pp. 576. S.P.C.K., 1867. [British passim.]

Kearton, R. -

*Birds' Nests, Eggs, and Egg-Collecting. Pp. 96. Cassell, 1896. Is.

*British Birds' Nests: how, where, and when to find and identify them (introd. by R. B. Sharpe). Pp. 368. Cassell, 1895.

Klein, E. *The Etiology and Pathology of Grouse Disease. Pp. 130. Macmillan, 1892. 7s. net.

Knox, A. E.-

Ornithological Rambles in Sussex. Pp. 250. Van Voorst, 1849. 7s. 6d. [Letters and systematic catalogue.] O.p.

* Game Birds and Wild Fowl : their Friends and their Foes. Pp. 264. Van Voorst, 1850. [A chapter on four-footed vermin.] O.p.

Lee, Oswin A. J. * Among British Birds and their Nesting Haunts. Illustrated by the Camera. In parts. Douglas, 1896, \&c. 10s. 6d. per part.

Lewin, W. *The Birds of Great Britain. (8 vols.) 1795. [In English and French.]

Lilford, Lord-

* Coloured Figures of the Birds of the British Islands. (4 vols.) Porter, 1885 . $£ 7,12 \mathrm{~s} . \quad$ O. $p$.

* Birds of Northamptonshire. Pp. 706. Porter, 1895. (2 vols.) $£ 2,2$ s. net.

M'Aldowie, A. M. The Birds of Staffordshire. Pp. 151. Stoke, 1893.

Macgillivray, W.-

*Descriptions of the Rapacious Birds of Great Britain. Pp. 482. Edinburgh, 1836.

* A History of British Birds (indigenous and migratory). Scott. 1st ed., 1837. (5 vols.) Pp. 3290. 2nd ed., 1846. Pp. 548.

Macpherson, Rev. H. A., and Duckworth, W. The Birds of Cumberland. Pp. 206. Carlisle, 1886. [Critically studied, including some notes on the Birds of Westmorland.]

Macpherson, Rev. H. A.-

The Visitation of Pallas's Sand-Grouse to Scotland in 1888. Pp. 38. [A map.] Porter, 1889. 
Macpherson, Rev. H. A.-

An Introduction to the Study of British Birds. Pp. 120. 1890.

Macpherson, Rev. H. A., and others-

*The Partridge. Pp. 284. Longmans ["Fur and Feather Series": ed. Alfred Watson], 1893. 5s.

*The Grouse. Pp. 302. Longmans ["Fur and Feather Series": ed. Alfred Watson], 1894. 5s.

*The Pheasant. Pp. 276. Longmans ["Fur and Feather Series": ed. Alfred Watson], 1895. 5s.

Mansell-Pleydell, J. C. The Birds of Dorsetshire, a Contribution to the Natural History of the County. Pp. 179. Porter, 1888. 7s. 6 d. net.

Masefield, J. R. B. *Wild Bird Protection and Nesting Boxes. Pp. 130. Leeds, 1897. 6s.

Mathew, Rev. M. A. * The Birds of Pembrokeshire and its Islands. Pp. 131. Porter. $£ 1,1$ s. and 10s. 6d.

Meyer, H. L. ${ }^{*}$ Coloured Illustrations of British Birds and their Eggs. (7 vols.) Pp. 1501. Willis \& Sotheran, 1857.

Millais, J. G. * Game Birds and Shooting Sketches. Pp. 72 (fol.) Sotheran, 1892.

Mitchell, F. S. The Birds of Lancashire. Gurney \& Jackson. 1st ed. 1885 . O.p.

2nd ed. (Ed. Howard Saunders.) Pp. 271. 1892. 10s. 6d.

Montagu, G. Dictionary of British Birds (ed. Newman). Sonnenschein, $1889.7 \mathrm{~s} .6 \mathrm{~d}$.

Moore, Capt. G. P. British Birds, systematically arranged in five tables, showing the comparative distribution and periodical migrations, and giving an outline of the geographical range of 376 species.

More, A. G. A. List of Irish Birds. Pp. 32. Dublin, 1885.

Morris, B. R. * British Game Birds and Wild Fowl. Pp. 252 (4to). Groombridge, 1855.

Morris, Rev. F. O.-

*A History of British Birds. (6 vols.) Pp. 2050. Groombridge, 1866 . $£ 6,6 \mathrm{~s}$.

*A Natural History of the Nests and Eggs of British Birds (4th ed. Tegetmeier). 3 vols. Nimmo, 1896.

Mosley, S. L. *A History of British Birds, their Nests and Eggs. Huddersfield, 1881, \&c. (in progress). Vols. 1 and 2, £2, 16s. 6d. [Plumage of male, female, immature, varieties of eggs, \&c.]

Mossop, Rev. J. A Synopsis of British Land Birds in Verse and Prose. Pp. 259. Jackson, 1841.

Mudie, R.-

*The Feathered Tribes of the British Islands. Pp. 770 (2 vols.) Bohn, 3rd ed., 1841.

*The Natural History of Birds. Pp. 408 (12mo). Orr \& Smith, 1834. 
Muirhead, G. *The Birds of Berwickshire. Pp. 1002 (2 vols.) Douglas, 1889-95. 30s. [Game birds, heron, bittern, folklore, \&c.]

Napier, C. O. G. The Food, Use, and Beauty of British Birds. Pp. 88. Groombridge, 1865. [An essay accompanied by a catalogue of all the British Birds, \&c.]

Payne-Gallwey, Sir R.-

* The Fowler in Ireland. Pp. 503. Van Voorst, 1882. £1, 1s.

* Letters to Young Shooters (3rd series). Pp. 630. Longmans, 1896.

Phillips, E. C. The Birds of Breconshire. Pp. 45. West, 1882. Pidsley, W. E. H. The Birds of Devonshire. Pp. 194. Gibbings, 1891.

Pigott, T. D. London Birds and London Insects. (Birds, pp. 121.) Porter, 1892. [Farnes, Shetlands, \&c.] 6s. 6d.

Poynting, F. *Eggs of British Birds; with an Account of their Breeding Habits : Limicola. Pp. 253. Porter, 1897. £5.

Robinson, Phil. ${ }^{*}$ Birds of the Wave and Woodland. Pp. 224. Isbister, 1894.

Rodd, E. H.-

A List of British Birds, as a Guide to the Ornithology of Cornwall. Penzance.

1 st ed. 1864 .

2nd ed. Pp. 51. 1869.

[Ed. J. E. Harting.] The Birds of Cornwall and the Scilly Isles. Pp. 320. Trübner, 1886.

Salvin, F. H., and Brodrick, W. Faloonry in the British Isles. Pp. 171. Van Voorst. £3; 2nd ed. 1870, £2, 2s.

Saunders, Howard. * Manual of British Birds. Pp. 754. Gurney \& Jackson, 1889 . $£ 1,1$ s.

Saxby, H. L. $\quad{ }^{*}$ Birds of Shetland. 1874. $£ 1,18$.

Seebohm, Henry-

${ }^{*}$ A History of British Birds. Pp. 1898. (4 vols.) (With col. illust. of their eggs.) Porter, 1883-85. $£ 6,6 \mathrm{~s}$.

Geographical Distribution of British Birds. Porter, 1893. $7 \mathrm{~s} .6 \mathrm{~d}$.

Sharpe, R. Bowdler. * British Birds. (4 vols.) Allen's Naturalist's Library, 1895-97.

Slaney, Rev. R. A. * An Outline of the Smaller British Birds. Pp. 143. Longman, 1832. O.p.

Smith, Rev. A. C. The Birds of Wiltshire. Pp. 558. Porter, 1887. 10s. net.

Smith, Cecil-

The Birds of Somersetshire. Pp. 643. Van Voorst, 1869. 7s. $6 \mathrm{~d}$.

The Birds of Guernsey and the Neighbouring Islands. Pp. 223. Porter, 1879. 3s. 6d. 
"Son of the Marshes." *The Wild-Fowl and Sea-Fowl of Great Britain. Pp. 326. Chapman \& Hall, 1895. 14s.

Sowerby, J. G. * Rooks and their Neighbours. Pp. 169. Gay \& Bird, 2nd ed., 1895.

Stanley, Rev. E. Familiar History of British Birds, their Nature, Habits, and Instincts. Parker.

3rd ed., 1840, 2 vols., pp. 564. 7s.

*4th ed., 1848, pp. 480 . 7s.

*5th ed. Longmans, 1880 . Pp. 420. 6s.

*New ed. Pp. 420. 1896. 3s. 6d.

Steele-Elliott, J. The Vertebrate Fauna of Bedfordshire. Pp. 24. 1897. Private.

Sterland, W. J. * Birds of Sherwood Forest. Reeve, 1881. 7s. 6 d.

Stevenson, H. The Birds of Norfolk. Pp. 1326. Van Voorst. 31 s. $6 \mathrm{~d}$.

Vols. i. and ii., 1866-70. O.p.

Gurney \& Jackson. Vol. iii. (cont. T. Southwell), 1890. Pp. 432.

Stewart, H. E. * The Birds of Our Country. Pp. 397. Digby, Long, 1897.

Swainson, Rev. C. Provincial Names and Folklore of British Birds. Pp. 243.

Swann, H. Kirke-

A Concise Handbook of British Birds. Pp. 210. Wheldon, 1896. 3s. 6d.

The Birds of London. Sonnenschein. 2s.

Nature in Acadie.

Swaysland, W. * Familiar Wild Birds. Pp. 160. Cassell, 1883. 12s. 6d. [A chapter on eggs and egg-collecting by $R$. Kearton.]

Tegetmeier, W. B. * Pallas's Sand Grouse: its history, habits, food, and migrations, \&c. Pp. 23. Cox, 1888.

Watson, John (and others). Ornithology in its relation to Agriculture and Horticulture. Pp. 220. W. H. Allen, 1893.

Watters, J. J. The Natural History of the Birds of Ireland. Pp. 299. Dublin, 1853.

Whitlock, F. B., and Hutchinson, A. S. ${ }^{*}$ Birds of Derbyshire. Pp. 239. Bemrose, 1893. 10s. 6d.

Whitaker, J., and Sterland, W. J. Descriptive List of the Birds of Nottinghamshire. (Vert., pp. 71.) 1879.

Witherby, H. F. * Forest Birds, their Haunts and Habits. Pp. 98. Kegan Paul. [Green woodpecker, tree-creeper, nuthatch, \&c.] 
Willughby, Francis. Ornithology. (In 3 books.) Martyn. [Ed. John Ray.]

Lat. ed., 1676, pp. 311.

Eng. ed., 1678, pp. 447. [Chaps. on trapping, falconry, \&c.]

Wise, J. R. The New Forest. (Birds, pp. 258-276, 307-318.) Gibbings, 5th ed., 1895.

Wood, C. T. The Ornithological Guide. Pp. 240. Whittaker, 1835.

Wood, Neville-

British Song-Birds, being Popular Descriptions and Anecdotes of the Choristers of the Groves. Pp. 441. Parker, 1836.

The Ornithologist's Text-Book. Pp. 232. Parker, 1836. [Extracts and reviews.]

Wright, M. O. * Bird Craft. Pp. 305. Macmillan, 1895. 12s. 6 d. net.

Wright, M. O., and Elliot Coues. *Citizen Bird. Pp. 428. Macmillan, 1897. 6s.

Wyatt, C. W. * British Birds, being Coloured Illustrations of all the Species of Passerine Birds resident in the British Isles (with some notes in reference to their plumage). Ff. 25. (4to.) Wesley, 1894.

Yarrell, W. * British Birds. (3 vols.) 1st ed., 1843, pp. 1722 and a supp. O.p.

2nd ed., 1845, pp. 1893. O.p.

3rd ed., 1856, pp. 1995. O.p.

4th ed., 1884-85, pp. 2355. [Vols. i. ii., ed. Newton ; vols. iii. iv., ed. Saunders.]

\section{REPTILES.}

Bateman, Rev. G. C. *The Vivarium. Pp. 424. Upcott Gill, 1897. 7s. $6 \mathrm{~d}$.

Bell, T. *A History of British Reptiles. Van Voorst. 1st ed., pp. 142, 1839 . O.p. 2nd ed., pp. 159, 1849 . 12s.

Cooke, M. C. * Our Reptiles.

1st ed. (Hardwicke), pp. 199, 1865. 6s.

2nd ed. (W. H. Allen), pp. 200.

Hopley, Catherine, C. * British Reptiles and Batrachians. Pp. 94. Sonnenschein, 1893. 1s. 


\section{FISHES.}

Aflalo, F. G. ${ }^{*}$ Sea-Fish. Pp. 258 (Nat. Hist., chap. ii. and passim). Lawrence \& Bullen ["The Angler's Library"], 1897. 5s.

"Bickerdyke, John." *Wild Sports in Ireland. Pp. 234 (passim). Gill, 1897. 6s.

"Bickerdyke, John," and others. * "Sea-fishing. Pp. 513. Longmans ["Badminton Library"], 1895. 10s. 6d.

Brabazon, Wallop. * The Deep-Sea and Coast Fisheries of Ireland. Pp. 111. Dublin, 1848.

Brown, W. *The Natural History of the Salmon. Pp. 136. Glasgow, 1862.

Buckland, F. T.-

*Fish-Hatching. Pp. 268. Tinsley, 1863. 5s.

* Natural History of British Fishes. Pp. 407. S.P.C.K.

Cholmondeley-Pennell, H., and others-

*Fishing. Longmans ["Badminton Library"]. (2 vols.) 1893. (6th ed.) $£ 1,1$ s.

* The Angler-Naturalist. Routledge, 1884. 3s. 6d.

Couch, Jonathan. *A History of the Fishes of the British Islands. (4 vols.) Bell, 1878. £4, $4 \mathrm{~s}$.

Cunningham, J. *The Edible Marine Fishes of Great Britain. Pp. 368. Macmillan, 1896. 7s. 6d. net.

Davies, Rev. E. W. L. Our Sea-Fish and Sea-Food. Pp. 128. Leadenhall Press, 1887.

Day, Francis-

* The Fishes of Great Britain and Ireland. (2 vols.) Pp. 724. Horace Cox, 1880-84. £2, 2s.

* British and Irish Salmonidx. Pp. 298. Cox, 1887. £1, 1s.

Dean, Bashford. *Fishes, Living and Fossil. Pp. 283. Macmillan, 1895. 10s. $6 \mathrm{~d}$.

Fraser, Alexander. Natural History of the Salmon, Herrings, Cod, \&c.

2nd ed., pp. 132. Inverness, 1833.

Hamilton, R. *British Fishes. (2 vols.) W. H. Allen, 1876. 9s.

Holdsworth, E. W. H. Sea-Fisheries. Pp. 202. Stanford, 1877. 3 s. $6 \mathrm{~d}$.

Houghton, Rev. W. * British Fresh-water Fishes. (2 vols.) Pp. 202 (fol.) Mackenzie, 1879. £3, 3s.

Jardine, Alfred. * Pike and Perch. Pp. 200. Lawrence \& Bullen ["The Angler's Library "], 1897. 5s. 
M'Intosh, W. C.-

*The Marine Invertebrates and Fishes of St Andrews. (Fishes, pp. 168-186.) Black, 1875.

M'Intosh, W. C., and Masterman, A. T. *The Life-Histories of the British Marine Food-Fishes. Pp. 516. Cambridge University Press, 1897. $£ 1,1$ s.

Maitland, Sir J. R. *The History of Howietoun [Fish-Culture]. Pp. 278 (4to). Howietoun, 1887.

Mitchell, J. M. * The Herring : its Natural History and National Importance. Pp. 372. Longmans, 1864.

Wheeley, C. H. ${ }^{*}$ Coarse Fish. Pp. 268 (Nat. Hist. passim). Lawrence \& Bullen ["The Angler's Library "], 1897. 5s.

Wilcocks, J. C. *The Sea Fisherman. Pp. 298 (Nat. Hist. passim). Longmans (4th ed.), 1884. $6 \mathrm{~s}$.

Yarrell, W.-

*A History of British Fishes. Van Voorst.

1st ed. (2 vols. and 2 suppls.) Pp. 1000. 1836. £2, 15s. 6d. 2nd ed. (2 vols. and 1 suppl.) Pp. 1122. 1841.

3rd ed. (By Sir J. Richardson.) 2 vols., pp. 1345. 1859. $£ 3,3 \mathrm{~s}$.

* On the Growth of Salmon in Fresh Water (fol.) 1839. O.p. Young, A. Salmon-Fisheries. Pp. 98. Stanford, 187\%. 2s. 6d. 


\section{APPENDIX II.}

\section{A LIST OF NATURAL HISTORY SOCIETIES AND FIELD-CLUBS IN THE UNITED KINGDOM,}

With their Secretaries.

[IN the hope of making this account of some interest, I addressed a letter to the secretary of every society in the following list. Either many of the letters miscarried, or the gentlemen addressed were too occupied for outside correspondence. A second whip brought the number of answers up to a considerable proportion of the whole, and there I was constrained to stop. I offer the complete list at my disposal, with some of the information, varying in detail, against each, that my letters evoked. Naturalists wishing detailed information on the fauna of certain districts will, it is hoped, find some secretary in the under-mentioned able and willing to assist them. The date of foundation and present strength are given for those interested in the history and development of the Field-Club movement. As changes in the constitution and secretaryship of these Field Clubs are constantly happening, I think it desirable to refer the reader to two annual publications in which such information is brought up to date, the "Year-Book of Scientific Societies' (Griffin) and the 'Naturalist's Directory' (Upcott Gill).

The following abbreviations have been used below: $\mathrm{A}=$ Antiquarian ; Ar. = Archæological ; F.C. = Field Club ; M. = Microscopical (or Microscopists'); N.H. = Natural History ; Ns'.= Naturalists'; P.=Philosophical ; Publications in italic and annual unless marked otherwise; S.=Society ; Sc. =Scientific.]

Date of foundation in round brackets; number of members in square brackets.

Aberdeen Working Men's N.H. and Sc.S. Accrington Ns'.S. 
Andersonian Ns'.S., Glasgow. (1885.) [180.] Library. Annals. Field ornithology, botany, marine biology, \&c. A. D. Brownlie, 20 Jardine Street, and C. Cunningham, 110 Garthland Drive, Dennistoun.

Anstruther : East Fife Ns'.S.

Armagh N.H. and P.S. (1850.) [260.] Library. H. A. Gray, The Mall.

Ayr N.H.S.

Barnsley Ns'. and Sc.S. (1867.) [103.] Publications occasional only. H. Wade, 10 Pitt Street.

Bath N.H. and A.S. (1855.) Proceedings. Rev. W. W. Martin, 49 Pulteney Street.

Bedford N.H.S. (1889.) [25.] Chiefly microscopical work. Library. H. Darrington, St Loyes.

Belfast Ns'.F.C.

Berwickshire Ns'.C.

Birmingham (see Midland Union) $\left\{\begin{array}{l}\text { M. and Ns'. Union. } \\ \text { N.H. and P.S. }\end{array}\right.$

Birmingham M. and Ns'. Union. (1880.) [50.] Ornithology and conchology. John Collins, Temperance Institute.

Bradford Ns'. and M.S. (1875.) [50.] Diary of N.H. Observations (irregularly). B. Spencer, 33 Carlisle Terrace, Manningham.

Bridgend District Ns'.S., Glamorgan. (1897.) H. J. Randall, jun., 3 Molton Street.

Brighouse and Rastrick N.H.S.

Brighton and Sussex N.H. and P.S. (1853.) [182.] Library. E. A. Pankhurst, 12 Clifton Road, and J. C. Clark, 64 Middle Street.

Bristol Ns'.S. (1862.) [160.] Biological, entomological, and other sections. Proceedings (the vol. for 1896 included papers on "Summer Visitors to the Neighbourhood," \&c.) Theodore Fisher, M.D., 25 Pembroke Road, Clifton.

British F.C. Huddersfield. (1896.) [260, and 200 Assoc.] The Naturalists' Journal (monthly). W. E. L. Watton, 54 Towngate, Newsome.

British Ornithologists' Union. (1858.) [337, with honorary and foreign members.] The Ibis (ed. P. L. Sclater and Howard Saunders). Osbert Salvin, 10 Chandos Street, Cavendish Square.

Buchan F.C., Peterhead. (1887.) [180.] Transactions. (Papers published: Muirhead's Birds of Methlick and Tarves; Arbuthnot's Fishes of the Peterhead Coast; Serle's Avifauna of Buchan, \&c.) J. F. Tocher.

Burton-on-Trent N.H.S.

Cambridge Practical Ns'.S. (1883.) [707.] Objects : the study of practical N.H. as bearing on agriculture, \&c. ; the promotion of correspondence among the members; and the publication of local faunas. The Ns'. Chronicle and Practical Naturalist (2s. 6d. per ann.) Albert H. Waters, 48 Devonshire Road.

Canterbury. See East Kent.

Caradoc and Severn Valley F.C., Shrewsbury. (1893.) [185.] 
Transactions (an index of the first four vols. in preparation) and Record of Bare Facts. Rev. J. H. Painter, St George's, Wellington.

Cardiff Ns'.S. Transactions. (A paper by Professor W. N. Parker on the Objects of the Biological and Geological Section.) Walter Cook, 98 St Mary Street.

Carlisle Sc. and Literary S. and F.Ns'.C. (1876.) [120.] Formerly affiliated to the Cumberland and Westmoreland Assoc. for the Advancement of Literature and Science, which ceased to exist two years ago. Maintained the museum until taken over by the Corporation in 1893 . J. Percival Wheatley, 27 Aglionby Street.

Channel Islands. See Guernsey.

Chester S. of N. Science and Literature. (1871, by Charles Kingsley.) [560.] Zoological, microscopical, and other sections. Museum and library. G. R. Griffith, 30 Hough Green, and G. P. Miln, Milnholme, Brook Lane.

Chichester and West Sussex N.H.S. (Dormant.)

Cirencester: Leaholme College Nature S. (1896.) [54.] E. J. E. Creese.

Clifton College Sc.S. (1869.) [70.] A section takes charge of each branch, the ornithological section recording arrivals and departures of migratory birds. Transactions (irregularly). Museum. J. T. Stephen, 34 College Road, Clifton.

Cork Ns'.F.C. (1892.) [70.] The Irish Naturalist (6d. monthly). E. Brooke-Hughes, 3 Frankfield Terrace.

Cotteswold Ns'.F.C., Gloucester. (1846.) [100.] Proceedings (a part annually ; 3 parts to the vol.) A History of the Origin of the Club and an Epitome of forty-one years' Proccedings, by W. C. Lucy.

Coventry: Cow Lane Young Men's F.C.

Croydon M. and N.H.C. (1870.) [230.] Transactions. Zoological, microscopical, and other sub-committees. R. F. Grundy, 112 Lower Addiscombe Road.

Darlington and Teesdale Ns'F.C. (1891.) [60.] Objects: to compile correct lists for the district, and to discourage the extermination of rare plants and animals. G. Best.

Denshaw Parish Botanical and F.Ns'.S. (1893.) [30.] Mainly botany. Isaac Gartside.

Derby N.H.S.

Devizes. See Wiltshire.

Dorset N.H. and A.F.C., Dorchester. (1875.) [350.] Proccedings. Nelson M. Richardson, Montevideo, Chickerell, nr. Weymouth.

Douglas : Insular N.H.S.

Dover F.C. and N.H.S.

Dublin Ns'.F.C. [200.] (Transactions pub. in the Irish Naturalist.) Professor T. Johnston, Science and Art Museum.

Dudley and Midland Geol. S. Museum. W. Madeley, Coalbournbrook, Stourbridge, and H. Johnson, Trindle Street, Dudley.

Dulwich College N.H.S.

Dumfriesshire and Galloway N.H.S. 
Dundee $\left\{\begin{array}{l}\text { Dundee's Ns'.S. } \\ \text { East of Scotland Union of Ns'. Societies. }\end{array}\right.$

Ealing N. Science and M.S. (1877.) [160.] Report and Proceedings (in last vol. a catalogue, with observations of Birds of the Brent Valley). Anthony Belt, The Cedars, Uxbridge Road. Eastbourne N.H.S.

East Kent N.H.S., Canterbury. (1857.) [83.] South Eastern Naturalist (monthly). Stephen Horsley, St Peter's House.

Edinburgh. See also Scottish N.H.S. Pentland F.C. and F.Ns'S. (1869.) [180.] Transactions (since 1882). A committee of experts has undertaken to work up the fauna and flora of the county, and it is proposed later to work up those of the Lothians. A. B. Steele, 5 Brighton Terrace, Joppa.

Elland Ns'.S.

Epsom College N.H.S. [80.] Ornithological, entomological, and other sections. T. L. Drapes.

Essex F.C. (1880.) [350.] The Essex Naturalist (quarterly). Hon. Sec. and Curator, W. Cole, Buckhurst Hill, Essex.

Felstead School Sc.S. (Essex.) (1877.) [51, with honorary.] Iibrary and museum. Zoological, photographic, and other sections. Report (biennial). Rev. E. Jepp.

Folkestone N.H.S.

Glasgow (see also Andersonian): N.H.S. of Glasgow. (1850.) [300, with Assoc.] Proceedings and Transactions. Library. Research, microscopic, and other committees. S. M. Wellwood, 128 St Vincent Street, and R. D. Wilkie, 302 Langside Road.

Gloucester. See Cotteswold.

Greenock N.H.S. (1878.) G. W. Niven, 23 Newton Street.

Grimsby and District Ns'.S. (1897.) [40.] Members note the rarer fish (Chimcera, \&c.) landed at the market. Arthur Smith, 75 Newmarket Street.

Guernsey S. of N. Science and Local Research. (1882.) [100.] Transactions. (Papers chiefly entomological and botanical.) W. Sharpe, The Corne.

Halifax Sc.S. and Geological F.C. [130.] The Halifax Naturalist (bi-monthly). C. E. Fox, Burnley Road, and Arthur Crabtree, West Hill.

Hampshire F.C., Southampton. [250.] (Rule 20: "That the Club discourage the practice of removing and rooting up rare plants from characteristic localities, and the extermination of rare birds.") W. Dale, 5 Sussex Place, Southampton.

Harrogate F. Ns'. and Camera C. (1884.) [60.] A museum of strictly local interest is contemplated. Among publications by members are: Birds of Harrogate and District by Riley Fortune, and Flora by J. Farrah. Riley Fortune, Leamd House.

Haslemere N.H.S.

Hastings and St Leonards N.H.S. (1893.) Meetings at the Museum, Brassey Inst. Microseopes, \&c., for use of members. Lending library. E. Connold, 1 Cambridge Gardens. 
Hereford. See Woolhope.

Hertfordshire N.H.S. and F.C., Watford. (1875.) [230.] Transactions (in parts ; one vol. to two years : papers have appeared in these on the fauna of the county by the late H. Seebohm, J. E. Harting, and other well-known naturalists). J. Hopkinson, The Grange, St Albans, and W. R. Carter, Amesbury, Watford.

Holmesdale N.H.C. Reigate. (1857.) [87.] Chief work, recording local fauna and flora. Proceedings (triennial : papers have appeared on The Nesting of the Kentish Plover; Birds that nest around Reigate; A Summer Holiday in Cornwall and the Scilly Islands; Nesting of the Norfolk Plover; \&c.) A. J. Crosfield, Carr End, Reigate.

Huddersfield. See British F.C.

Hull Sc. and F.Ns'.C. (1875.) [120.] Recorders for Zoclogy, \&c. Library. F. W. Fierke and T. Sheppard, 78 Sherburn Street.

Isle of Man N.H. and A.S. [150.] Zoological, microscopic, and other sections. Sends one delegate to the annual meeting of the British Association. H. Shortridge Clarke.

Kingston: Tiffins Boys' School N.H.S. (1892.) [40.] B. G. Cooper.

Kirkcaldy Ns'.S.

Lambeth F.C. and Sc.S., Newington Butts, S.E. (1872.) [44.] Library. H. Wilson, 14 Melbourne Square, Brixton.

Lancaster F.N.S.

Leeds $\left\{\begin{array}{l}\text { Ns'.C. } \\ \text { Yorkshire Ns'. Union. }\end{array}\right.$

Lewes and East Sussex N.H.S.

Limerick F.C. (1892.) [110.] Journal (vol. 1, 1897 : chiefly historical). F. Neale, Laurel Hill Avenue.

Lincolnshire Ns'. Union. Objects: to investigate the fauna and flora of the county. Sections of vertebrate zoology, entomology, \&c. Museum. Rev. E. A. Woodruffe-Peacock, Cadney, Brigg.

Linnæan S., Burlington House, Piccadilly. (1788.) . E. Harting.

London. See also British Ornithologists' Union, Battersea, Croydon, Ealing, Lambeth, Linnæan S., North Middlesex, St Dunstan's, Selborne S., S. for Protection of Birds, West Kent and Zoological S.

City of London N.H.S.

North London N.H.S., Dalston Lane. (1885.) [59.] Founded by the "Grocers' Co. School Sc.S." Objects : to popularise natural history and encourage young members. During 1897 papers were read on " Over-collecting," "British Corvidae," \&c. Lawrence Tremayne, 51 Buckley Road, Brondesbury.

South London N.H.S.

Ludlow N. Science S.

Maidstone and Mid-Kent N.H.S.

Manchester $\left\{\begin{array}{l}\text { F.Ns'.S. } \\ \text { Grammar School N.H.S. }\end{array}\right.$

Marlborough College N.H.S. (1864.) [310.] Objects : catalogu- 
ing the fauna of the district, and recording habits and dates of appearance of birds. Report. President: E. Meyrick, Elmswood.

Midland Union of N.H.S., Birmingham (Mason's College), formerly published the now defunct Midland Naturalist. A. Henham.

Newbury District F.C. (1870.) [75.] Transactions (4 vols., 1870-95, have appeared). G. J. Watts, Donnington.

Newcastle-on-Tyne N.H.S.

Northamptonshire N.H.S., Northampton. Transactions (quarterly: papers have appeared : Notes on the Birds of Northamptonshire; The Mammals of Northamptonshire, \&c.) H. N. Dixon, Wickham House, and G. S. Emson, East Park.

North Kent. See Woolwich.

North Middlesex F.C. (1896.) [15.] A fauna of the district is being collected. Journal (monthly, 1d.) H. R. Creighton, 28 Ferme Park Road, N.

Norwich and Norfolk Ns'.S.

Nottingham Ns'.S.

Old Kilpatrick Ns'. and A.S. (1887.) [31.] David Andrew, Gavinburn Schoolhouse.

Oxfordshire N.H.S. and F.C. [202.] Mrs V. H. Veley, 22 Norham Road.

Paisley Ns'.S.

Penzance N.H.S.

Perthshire S. of N. Science, Perth. (1867.) [320.] Has established and maintains the Natural History Museum (free to the public), one hall of which is devoted to a general type collection, the rest to collections representing the natural history of Perthshire and the basin of the Tay. Transactions and Proceedings. S. T. Ellison, 56 South Methven Street.

Peterborough N.H. and Ar.S. (1871.) [175.] Museum and library. J. W. Bodger, 18 Cowgate Park.

Peterhead. See Buchan.

Plymouth $\left\{\begin{array}{l}\text { Devon and Cornwall N.H.S. } \\ \text { Marine Biological Association. }\end{array}\right.$

Portsmouth and Gosport N. Science S.

Reading N.H.S. (1881.) [40.] Chiefly entomology. Library. Report (irregularly). F. W. Leslie, Haydn Villa.

Reigate. See Holmesdale.

Richmond (Yorks) Ns'.F.C.

Ripon Ns'.C. (1882.) [100.] Museum and library. B. M. Smith, The Museum.

Rochester Ns'.F.C.

Rugby School N.H.S. (1867.) [300, a limited number active.] Report, with lists of observations of the seven sections: zoological section chiefly interested in the vivarium managed by Mr H. L. Highton. W. N. Wilson.

St Dunstan's F.C. and N.H.S. (1896.) [24.] Publishes Notes and Records in the Parochial Magazine. Basil W. Martin, 16 Hampstead Hill Gardens.

St Helens and District Ns'.S. (1897.) [50.] W. Webster, 35 Church Street. 
Scarborough F.Ns'.S. (1889.) [70.] List of local fauna in preparation. Museum and library. R. J. Fryer, 3 Ramshill Road, and E. R. Cross, 96 Westborough.

Scottish N.H.S., Edinburgh. (1881.) [170, besides hon. fellows, \&c.] Each branch has a referee to identify specimens, \&c. (Zoolog. section, J. Arthur Thomson.) Heber H. Brown, 50 Dick Place, Grange.

Selborne S., 20 Hanover Square. [3000.] Objects : to protect wild birds, animals, \&c., and promote the study of natural history. Nature Notes (monthly). A. J. Western.

Sheffield Ns'.C. (1871.) [100.] Report. C. Bradshaw, Weston Park Museum.

Shrewsbury. See Caradoc and Severn Valley.

Society for the Protection of Birds. (1889.) [15,000 members; 2500 associates; over 150 branches, at home and abroad.] Object: to protect by precept and example against the indiscriminate destruction of birds. Report and Leaflets. Mrs F. E. Lemon, Hillerest, Redhill.

South - Eastern Union of Sc. Societies, Tunbridge Wells. G. Abbott, 2 Owen's Road.

Southampton. See Hampshire.

Southport S. of N. Science. (1890.) [109.] D. E. Benson, Queenwood, Lansdowne Road.

Stirling N.H. and Ar.S. (1879.) [90.] The birds of the district have been worked, the collection being shown at the Smith Inst: D. B. Morris, 3 Snowdon Place.

Teign Ns'F.C. (1859.) [120, limited to this number.] Report of Proceedings. P. F. S. Amery, Druid, Ashburton.

Thirsk N.H.S.

Torquay N.H.S. (1844.) [220.] Museum and circulating and reference library. Alex. Somervail.

Tunbridge Wells N.H. and P.S. (1855.) [82, and 65 associates.] Report. E. G. Gilbert, 32 The Pantiles.

Wakefield Ns'.S. W. Rushforth, Horbury.

Warrington F.C. (1884.) [54.] In close association with the museum. Objects : to compile a Warrington flora and prevent the eradication of rare plants; to collect information relative to local drift-boulders; to form a collection representing the natural history of the district. A. J. Jolley, Froghall Lane.

Warwickshire N.H. and Ar.S. (1836.) [30.] The society issued reports annually for fifty years, but its income is now devoted to keeping up the museum, in which the avi-fauna is represented by over 3000 specimens. S. S. Stanley, 3 Regent Grove, Leamington, and J. Galloway, Jury Street, Warwick.

Warwickshire Ns'. and Ar.F.C. (1854.) [94.] Report of Proceedings. S. S. Stanley.

Weardale Ns'.F.C.

West Kent N.H.M. and Photographic S. (1857.) [80.] Stanley Edwards, Kidbrooke Lodge, Blackheath, and H. F. Witherby, 1 Eliot Place, Blackheath. 
NATURAL HISTORY SOCIETIES AND FIELD-CLUBS. 467

Wiltshire Ar. and N.H.S., Devizes. (1853.) [350.] Magazine (29 vols. published). David Owen, Devizes.

Wincanton F.C. (1889.) [36.] Report and Supplements. G. Sweetman.

Winchester College N.H.S.

Wolverhampton Ns'.F.C. (1894.) [24.] Lists of local fauna, \&c., in preparation. J. Darby, Stonely House.

Woolhope Ns'.F.C., Hereford. (1851.) [200.] Transactions (biennial). Library (with Transactions since 1866 and pamphlets published previously). T. Hutchinson, Aylstone Hill.

Woolwich Polytechnic N.H.S. (late North Kent). (1884.) [50.] Chiefly entomology and mollusea. H. J. Webb, 3 Gunning Street, Plumstead.

York and District F.Ns'.S. (1886.) [42.] Chiefly entomology and zoology. R. Dutton, Phœnix House, Fishergate.

Zoological Society, 3 Hanover Square. Library. Gardens at Regent's Park. Over 3000 Fellows, Corresponding Members, \&c. P. L. Sclater. 



\section{N D E X.}

(Fn. = footnote.)

Abramis, 335.

acadica, 295.

Acanthias, 338.

A cantholabrus, 332.

A canthopterygii, 326.

Acanthyllis, 118 .

acarne, 327, 346.

Accentor, Alpine, 114, 148.

Accentor, 114.

Hedge, 147.

Accentorino, 114.

Accipiter, 120.

Accipitres, 120.

accipitrinus, 119.

Acclimatisation, 15.

Acerina, 326.

Acipenser, 337.

Acipenserida, 337.

Acredula, 114.

Acrocephalus, 113.

Actinopterygii, 326.

aculeatus, 331.

acuminata, 127.

acus, 337.

acuta, 123.

acutus, 30.

adamsi, 131.

Adder, 37, 301, 304.

Aden, 357.

Aëdon, 113.

Egialites, 126, 295.

aglefinus, 332.

agyptus, 118.

oxquoreus, 337.

arruginosus, 120.

asalon, 121.

Ageloeus, 295.

agilis, 301.

Agonus, 328.

agrestis, 29.

Ailsa Craig, 221.

Air-bladder, 322 .

Alauda, 118, 295.

Alaudida, 118.

alba (Ardea), 121.

" (Ciconia), 122

" (Motacilla), 115.

" Raia), 339.

Albatross, Black-browed, 129, 285.

albellus, 124.

albeola, 123.

albicilla, 120.

albicollis, 295.

Albicore, 328, 356.

albifrons, 122.

albirostris, 30.

Alburnus, 335.

Alca, 130.

Alcedinida, 119.

Alcedo, 119.

Alcidae, 130.

Alectorides, 125.

alle, 130.

'Allen's Naturalist's Library,'10, 24, 53, 77.

Allis Shad, 334, 399. Alopias, 338. 
alosa, 334.

alpestris, 118.

alpina, 127.

Alpine Accentor, 114, 148.

" Chough, 187.

" Hare, 24, 81.

" Swift, 118, 191.

alpinus, 336, 412.

aluco, 119.

Amber, 90.

Ambergris, 50, 89.

America, North, 17, 42, 97, 295.

'American Naturalist' (quoted), 9. americana, 123.

americanus, 119.

Ammodytes, 333.

Ampelida, 115.

Ampelis, 115.

Amphibians, 311-316.

amphibius, 29.

Anacanthini, 332.

Anadromous fishes, 319 .

anoestheta, 128.

Anarrhicas, 331.

Anas, 123.

Anatida, 122.

Anchovy, 334, 399.

Angel Fish, 339, 428.

Angler-fish, 328, 352.

anglica, 128.

anglorum, 130.

Anguida, 301.

Anguilla, 334.

Anguis, 301.

Anous, 129.

Anser, 122.

Anseres, 122.

Anthus, 115.

antiquorum, 337.

aper, 329.

Aphia, 330.

apiaster, 119.

apivorus, 121.

Apteryx, 204.

apus, 118.

aquaticus (Acrocephalus), 114.

$$
" \quad \text { (Cinclus), } 114 .
$$

Aquila, 120.

aquila (Myliobatis), 339.

" (Scicena), 329.

arborea, 118.

Arctic Chimæra, 337, 418.

arctica, 130.

arcticus (Colymbus), 131.

Ardea, 121.
Ardeida, 121.

Ardetta, 121.

Area of the British Islands, 2.

arenaria, 127.

argentatus, 129.

argenteus, $335,411$.

Argentina, 336.

Argentine, 336, 414.

Argyllshire, 46, 51, 243.

Argyropelecus, 336, 414.

Armed Bullhead, 351.

" Gurnard, 328.

Arnoglossus, 333.

arquata, 128.

Arun, 199, 373.

Arundel, 342.

arvensis, 118.

ascanii, 331.

asiatica, 295.

Asio, 119.

asio, 295.

Ass, 15.

Astur, 120.

ater, 114.

Athene, 119.

Atherina, 331.

Atherine, 331, 372.

" Boier's, 331, 372.

Atherinida, 331.

Atlantic, 17, 101.

atra, 125.

atricapilla (Muscicapa), 115.

atrigularis, 112.

(Sylvia), 113.

Auk, Great, 9

" Little, 130, 291.

auratus (Colaptes), 296.

" ' (Pagrus), 327.

auritus (Plecotus), 27.

" (Podicipes), 131.

Australia, 2, 4, 15, 31, 44, 49, 57,

$62,76,82,138,170,185,191$,

$223,228,244,272,279,287$,

$299,300,305,324,344,345$ fin.,

$346,349,353,363,375,417$, 421 .

australis, 29.

'Autumns on the Spey' (quoted), 149.

A uxis, 328.

avellanarius, 28.

Avocet, 126, 266.

avocetta, 126.

Avon (Gloucester), 303.

" (Hants), 217, 409.

Awe, Loch, 64 .

Axillary Bream, 327, 346. 
Badger, 28, 37, 49, 57-60.

bailloni, 125.

Baillon's Crake, 125, 257.

Bala, 413 .

Wrasse, 376.

Baloena, 29.

Balanida, 29.

Baloenoptera, 29.

"Balauce Fish," 422.

Balearica, 295.

Baleen, 87.

Balistes, 337.

Ballan, 331, 376.

"Ballard," 345.

Baltic, 65, 90, 172, 231, 233, 241, $265,281,340,343,348,349$, $371,391,397,404$.

Banbury, 146.

"Band-fish, Red, 331, 371.

Banffshire, 178.

banksii, 331.

Banks's Oar-fish, 331, 372.

"Barbarian Haddies," 345 .

Barbastelle, 27, 35.

barbastellus, 27.

barbatulus, 335.

barbatum, 333 .

barbatus, 327.

Barbel, 335, 402.

Barbus, 335.

Barnacles, 290.

Barrett-Hamilton, Mr (quoted), 140.

Barrington, Mr (quoted), 75.

Bartramia, 127.

Bartram's Sandpiper, 127, 273.

Basking Shark, 338, 424.

Bass, 326, 341.

Bass Rock, 3, 221.

bassana, 121.

Basse, Stone, 326, 343.

Bastard Sole, 393.

Bat, Bechstein's, 27, 34.

" Daubenton's, 27, 35.

" Great, 33.

" Greater Horseshoe, 27, 36.

" Hairy-armed, 27, 33.

" Lesser'Horseshoe, 27, 36.

" Long-eared, 27, 35.

" Mouse-coloured, 27, 34.

" Natterer's, 27, 34.

" Particoloured, 27, $34 \mathrm{fn}$.

" Rough-legged, 27, $34 \mathrm{fn}$.

" Whiskered, 27, 35.

Bath, 146.

batis, 339.

Bats, 24, 31-36.
Beachy Head, 4, 6.

Bear, 9.

Bearded Ophidinm, 333, 385.

" Reedling, 6, 10, 14, 114, 150.

Tit, 150.

Beaver, 9, 18:

bechsteini, 27.

Bechstein's Bat, 27, 34.

Bedfordshire, 50.

Beech-Marten, 24, 52.

Bee-eater, 119, 200.

Behring Sea, 63.

(1) Blue-tailed, 295.

belgica, 128.

Bell (quoted), 24, 25, 35, 36, 56, $69,311$.

Bellows-fish, 331, 375.

Belone, 329.

Beluga, 93.

Bergylt, 327, 347.

Bernicla, 122.

berus, 301.

Berwickshire, 225 fn., 231 fn., $232 \mathrm{fn}$.

bervicki, 122.

Bexley, 73, 135, 160, 163.

biarmicus, 114.

" Bib," 378.

Bibliography, 441.

bicolor, 296.

bidens, 30.

bifasciata, 117.

Bill of birds, 102, 106.

bimaculatus, 330.

Bird-catchers, 12.

Birds, 95-296.

" books on, 98 .

" of prey, 209.

il Perching, 132-189.

'Birds of Berwickshire' (quoted), 14 fn., 225 fn., 231 fn., 232 fn.

'Birds of Guernsey' (quoted), 14 fn.

Birdsnesting, 107.

Bison, 10.

Bittern, American, 121, 229.

" Common, 10, 14, 121, 227.

" Little, 121, 226.

bjorkna, 335.

"Black Cock," 252.

"Black Curlew," 229.

"Black Eagle," 212.

"Black Fish" (Cetacean), 92.

"1 (Fish), 329, 359.

"Black Grebe," 294.

"Black Pilot," 329, 361. 
Black Redstart, 113, 138. " Sea-Bream, 346.

Blackbird, 111, 112, 135 .

"Black-brim," 346 .

Black-browed Albatross, 129, 285.

Blackcap, 113, 143.

"Black-headed Bunting," 117, 178.

Black-mouthed Dog-fish, 338, 426.

Black-throated Thrush, 112, 134.

Black-winged Stilt, 126, 266.

Blade-fish, 363.

Blain, 378 .

Bleak, 335, 407.

Blenniida, 330.

Blennius, 330.

blennoides, 333.

Blenny, Butterfly, 330, 369.

" "Eyed," 369.

" Montagu's, 330, 369.

" Smooth, 369.

" Viviparous, 331, 370.

"Yarrell's, 331, 370.

Blind Worm, 303.

Blubber, 88.

Blue Hare, 29, 81.

" Shark, 338, 420.

"Blue Skate," 429.

Blue-tailed Bee-eater, 295.

Bluethroat, Red-spotted, 113, 138. 138.

" White-spotted, 113,

Boar, 9, 18, 50 .

Boar-fish, 329, 361 .

bogaraveo, 327.

Bognor, 281.

Bogue, 327, 346.

Boier's Atherine, 331, 372.

Bonito, 328, 357.

" Belted, 328, 357.

" Plain, 328, 356.

Books on birds, 98 .

hoïps, 29.

Booth, Mr (quoted), 222.

borealis (Balonoptera), 29.

"Borer," 438.

(Numenius), 128.

boscas, 123.

Boscombe, 15.

Botaurus, 121.

Bottlenose, 30, 91, 93.

"Bottlenose," 374.

Boulenger, Mr (quoted), 326.

"Bounce," 425.

Bournemouth 7, 15, 67, 141, 160, $192,219,234,289,302,345$, $355,360,362,379,385,387$, $399,404,421,424,428$.
Box, 327.

boyeri, 331.

brachydactyla, 118.

brachyrhynchus, 122.

Brama, 328.

brama, 335.

Brambling, 116, 173.

Brame, Pink, 332, 376.

Bream, 335, 406.

" -flat, 335, 407.

" Axillary, 327, 346.

" Black Sea, 346 .

" Couch's (Couch's Sea Bream), 327, 347.

" Pandora, 346.

" Ray's, 328, 358 .

" Sea, 327, 345.

" Spanish, 327, 346.

" White, 407.

brenta, 122.

Brighton, 189, 221.

Brill, 333, 388.

Brisbane River, 422.

"Brit," 398.

britannicus, 359.

'British and Irish Salmonidæ,' (quoted), $409 \mathrm{fn}$.

'British Birds' (quoted), 141.

"British" birds, 17, 34, 100.

'British Deer and their Horns' (quoted), 69, 80, 85, 86.

'British Fishes' (quoted), 350, 385,402 .

British Islands, area of, 2.

$$
\text { " " climate of, 2, } 18 .
$$

" coast-line of, 2

'British Mammals' (quoted), 10, 53, 77.

'British Reptiles' (quoted), 300.

Broad-nosed Pipe-fish, 337, 415.

Broads, Norfolk, 6, 45, 60, 150 , $211,217,223,226,293,406$.

" Brock," 57.

"Brocket," 84.

brosme, 333.

Brosmius, 333.

" Brown Whistler," 383.

"Browny," 389.

bruennichi, 130.

bubalis, 327.

Bubo, 120.

bubulcus, 121.

Buckland, 157.

Buckland, Frank, (quoted), 43 , 348.

Buckley, T. E. (quoted), 53, 59, $60,64,65,73,305,340,342$, 
345, 353 fn., 356 fn., 363 fn., Cam, 382.

$366,368,379$.

Buffaloes, 15.

Bufo, 312.

Bufonida, 312.

Building, effects of, 14 .

Buitenzoorg, 10.

"Bulgarian Haddies," 345.

Bullinch, 108, 116, 175.

Bullhead, Armed, 351.

$$
\text { " Norway, 327, } 349 .
$$

Bull-trout, 412.

Bulweria, 130.

Bulwer's Petrel, 130, 287.

Bunting, Black-headed, 117, 178.

" Cirl, 117, 178.

" Corn, 117, 177.

" Lapland, 117, 178.

" Little, 117, 178.

" Ortolan, 117, 178.

" Reed, 117, 178 .

" Rustic, 117, 178.

" Snow, 117, 178.

" Yellow, 117, 177.

"Bunting Lark," 177.

Burbot, 332, 381.

"Burton Skate," 431.

Bustard, Great, 9, 125, 260.

" Little, 125, 260.

" Macqueen's, 125, 260.

" Butcher-birds," 164.

Buteo, 120, 295.

Butler, Colonel (quoted), 214.

Butterfish, 370.

Butterfly Blenny, 330, 369.

Buxton, Sir T. F., 10.

Buzzard, African, 295.

" Common, 14, 120, 211.

" Honey, 121, 214.

" Rough-legged, 120, 211.

cabrilla, 326.

Caccabis, 124.

Cachalot, 30, 89, 91.

carvileus, 114, 295.

corsia, 114.

Cage-birds, 15.

"Ca'ing Whale," 92.

Caithness, 200, 242, 246.

calamita, 312.

calandra, 295.

calendula, 296.

Calcarius, 117.

Calidris, 127.

calidris, 128.

Callionymido, 330.

Callionymus, 330.

cambricus, 335 .

Cambridgeshire, 285.

Camels, 15.

campestris, 115.

candicans, 121.

candidus, 126.

canescens, 128.

canicula, 338.

Canida, 28.

Canis, 28.

Cannabina, 116.

cannabina, 116.

canorus, 119.

Cantharus, 327.

cantiaca, 128.

cantiana, 126.

canus, 129:

canutus, 127.

Cape Pigeon, 295.

capensis (Daption), 295.

" (Pycnonotus), 296.

'Capercaillie in Scotland' (quoted), 251.

Capercailzie, 10, 14, 15, 98, 104, $125,251$.

capito, 331.

caprea, 29.

Capreolus, 29.

Caprimulgida, 118.

Caprimulgus, 118.

capriscus, 337.

Capros, 329.

Caradoc and Severn Valley, 'F. C.

Record '(quoted), 176.

Carangida, 329.

Caranx, 329.

carbo, 121.

Carcharias, 338.

Carchariido, 338.

Carduelis, 116.

Carelophus, 331.

Carnivora, 28, 46-66.

carolina, 295.

carolinensis, 123.

Carp, 15, 335, 400.

" Crucian, 401.

" Golden, 402.

"Carp," 375.

carpio, 335.

Carrington, Miss, 12 fn., 171.

Carron, Loch, 342.

caryocatactes, 117.

casarca, 122.

caspia, 128.

Caspian Plover, 295.

Caspian, The, 419. 
Cat, 15.

Chiffchaff, 113, 145.

Cat, Wild, 8, 16, 18, 24, 25, 28, 46-48.

Catadromous fishes, 319.

Cataphracti, 328.

cataphractum, 328.

cataphractus, 328.

catarrhactes, 129.

"Cat-fish,"'371, 382, 425.

Cattle, 15.

catulus, 338.

catus, 28.

caudacuta, 118.

Caudata, 312.

caudata, 114.

caudatus, 329.

cavirostris, 30.

Celtic names, 8.

cenchris, 121.

Centrina, 338, 426

Centriscida, 331.

Centriscus, 331.

centrodontus, 327.

Centrolabrus, 332.

Centrolophus, 329, 359.

Centronotus, 331.

Cephaloptera, 339.

cephalus, 335 .

Cepola, 331.

Cepolida, 331.

cernium, 326.

cernua, 326.

Certhia, 115.

Certhiidae, 115.

Cervida, 29.

cervinus, 115.

Cervus, 29.

Cetacea, 29.

Cetaceans, 24, 86.

Ceylon, 306.

Chad, 345.

Chatodontida, 326.

Chaffinch, 104, 116, 172.

Chameleon, 314.

Channel, English, 93, 145, 150, $172,201,210,219,279,342$, $345,350,351,373,376,378$, $380,428,431,432$.

Channel Islands, 3, 14, 71, 187, 385.

Char, 1, 336, 412.

Charadriido, 126.

Charadrius, 126.

Charlton, 4.

chelo, 331.

Chen, 122.

Cheshire, 81.

Chimæra, Arctic, 337, 418.

Chimora, 337.

Chimarida, 337.

China, 402.

Chiroptera, 27.

Chiselhurst, 137.

chloris, 116.

chloropus, 125.

Chondrostei, 337.

Chough, 10, 118, 187, 279.

$$
\text { " Alpine, } 187 .
$$

Christchurch, 7, 15, 99, 217, 265.

chrysoetus, 120.

Chrysomitris, 116.

Chub, 6, 335, 404.

cicerellus, 333.

Ciconia, 122.

Ciconiida, 122.

cimbria, 333.

Cinclidae, 114.

Cinclus, 114.

cinclus, 114.

cineraceus, 120.

cinerea (Ardea), 121.

" (Perdix), 124.

" (Sylvia), 113.

cinereus, 122.

circia, 123.

circularis, 339.

Circus, 120.

Cirl Bunting, 117, 178.

cirlus, 117.

citrinella, 117.

Clarke, Mr Eagle- (quoted), 54, $216,238$.

clavata, 339 .

Clifton, 303.

Climate of the British Islands, 2, 18.

Clupea, 334.

Clupeido, 334.

clupeoides, 336.

Clyde, 343.

clypeata, 123.

Coal-fish, 64, 332, 380.

"Coarse Fish," 400.

Cobitis, 335.

Coccothraustes, 116.

Coccystes, 119.

Coccyzus, 119.

Cock-paidle, 367.

Cod, 91, 332, 377.

" Poor, 332, 379.

" Power, 332, 379.

Codling, 377.

coelebs, 116. 
colestis, 127.

colchicus, 124.

colias, 328.

colii, 336, 412.

collaris, 114.

Collectors, 12.

collurio, 115.

Colonsay, 287.

Colubridae, 301.

Colubriformes, 301.

Columba, 124.

Columbo, 124.

Columbidae, 124.

columbina, 130.

Coly Mackerel, 355.

Colymbida, 131.

Colymbus, 131.

Comber, 376.

communis (Coturnix), 124.

" (Grus), 125.

" (Phocana), 30.

" (Turtur), 124.

Conger, 5, 334, 395.

Conger, 334.

Connor, 332, 376.

Conway Bridge, 64 .

"CCook," 375.

Coot, 103, 111, 125, 259.

Coracias, 119.

Coraciida, 119.

Coral-fishes, 344.

corax, 117.

Cordeaux, Mr, 230.

Coregonus, 336, 413.

Coregonus, 336.

Coris, 332.

Cormorant, 5, 121, 219.

Corn-bunting, 117, 177.

Corncrake, 104, 197 fn., 256.

cornix, 117.

cornubica, 338.

cornuta, 122.

Cornwall, 5, 17 fn., 38, 64, 107, $137,140,143,158,161,187,189$, $195,221,229,278,280,282,283$, $284,287,291,292,343,346,347$, $359,361,364,376,383,420,426$, 432.

corone, 117.

Coronella, 301.

Corrib, 413.

Corvida, 117, 184.

Corvus, 117.

Coryphanidae, 328.

Coryphanoides, 333, 386.

Coryphenes, 358.

Cosmonetta, 123.
Cottidoe, 327.

Cottus, 327.

Cottus, Four-horned, 327, 349.

Coturnix, 124.

Couch, Mr (quoted), 346, 359, 388, 416, 429, 431, 434.

Couch's Sea-Bream, 327, 347.

" Whiting, 381.

Courser, Cream-coloured, 126, 261.

Coventry, Earl of (quoted), $51 \mathrm{fn}$.

Crake, Baillon's, 125, 257.

" Carolina, 295.

" Corn, 104, 197 fn., 256.

" Little, 125, 257.

" Spotted, $125,257$.

Cramp-fish, 433.

Crane, 125, 260.

" Crowned, 295.

" Demoiselle, 125, 260.

Cray, 143, 258.

Crayfish, 61 .

Crayford, 138.

crecca, 123.

Creeper, Tree, 103, 115, 153, 156. " Wall, 115, 156.

Crenilabrus, 332.

crepidatus, 129

Crex, 125.

"Cricket-teal," 239.

cristata (Alauda), 118.

" (Cystophora), 28.

" (Fuligula), 123.

" (Molge), 312.

cristatus (Parus), 114.

" (Podicipes), 131.

" (Regulus), 113.

Croonan, 349.

Crossbill, 102, 117, 176.

" Parrot, 117 fn., 177.

" Two-barred, 117, 177.

Crossopus, 27.

Crow, Carrion, 117, 183.

" Hooded, 117, 183.

" Royston, 183.

Crystallogobius, 330.

Ctenolabrus, 332.

" Cuckoo," 361.

Cuckoo, 98, 103, 104, 109, 119, $197 \mathrm{fn} ., 201$.

Cuckoo, Black-billed, 205.

" Great Spotted, 119, 204.

" Gurnard, 350.

" Ray, 432.

" Yellow-billed, 119, 205.

Cuculida, 119.

cucullatus, 124.

Cuculus, 119. 
cuculus, 327.

" Culterneb," 291.

Cultivation, effects of, 14 .

Cumberland, 169, 255.

cuniculus, 29.

Cunningham, $\mathrm{Mr}$ (quoted), 324, 344 , 347, 349, 351, 352, 355, 362, $368,370,373,378,385,389,391$, 392, 393, 395, 397, 398, 399.

Curlew, 106, 128, 275.

" Black, 229 ,

" Eskimo, 128, 276.

" Stone, 125, 261.

curonica, 126.

"Curre," 239.

curruca, 113.

Cursorius, 126.

curvirostra, 117.

Cushat, 244.

Cuttle, 87.

Cuvier's Whale, 30, 92.

Cyanecula, 113.

cyaneus, 120.

Cyclopterus, 330.

Cygnus, 122.

cynoglossus, 334.

Cyprinido, 335.

Cyprinus, 335.

Cypselidae, 118.

Cypselus, 118.

Cystophora, 28.

Cyttidae, 329.

Dab, 334, 391.

" Lemon, 392.

" Long Rough, 334, 390.

" Pole, 334, 392.

" Smear, 391.

Dabchick, 294.

Dace, 335, 405.

"Daddy long-legs," 39.

Dafila, 123.

dama, 29.

Daption, 295.

Dartford Heath, 137, 142, 144, $155,156,160,192$.

Dartmouth, 375 .

'Das Thierleben der österr-ungar Tiefebenen' (quoted), 62.

dasycneme, 27.

daubentoni, 27.

Daubenton's Bat, 27, 35.

Daulias, 113.

Day, Dr (quoted). 343, 350, 366, $376,385,396,402,409$ fn., 426, $427,431$.

Deal, 399, 421.
Deal-fish, 331, 371.

decandolii, 330.

De Crespigny and Hutchinson (quoted), 85 .

decumanus, 29.

Deer, Fallow, 15, 17, 29, 85.

" Red, 17, 29, 83.

" Roe, 8, 17, 29, 85 .

Delphinapterus, 30.

Delphinida, 30.

Delphinus, 30.

delphis, 30, $91 \mathrm{fn}$.

Dendrocopus, 118, 296.

dentatus, 333 .

Dentex, 326, 343.

Dentex, 326.

Derbio, 329, 361.

Derwentwater, 411.

'Descriptive List of the Deer Parks and Paddocks of England' (quoted), 83.

deserti, 112.

desertorum, 295

" Devil-fish," 434.

Devon, 83, 140, 146, 158, 187, 226 , 238, 283, 304, 343, 364, 373, 404.

De Winton (quoted), 74 .

Dingo, 10, 15, 49, 62 .

Diomedea, 129.

Dipper, 114, 148. " Black-bellied, 114, 149.

Discoboli, 330.

discolor, 27.

discors, 123.

" Diver," 219.

Diver, Black-throated, 131, 292.

" Great Northern, 131, 292.

" Red-throated, 131, 292.

" White-billed, 131, 292.

"Yellow-billed, 292 .

Diving Ducks, 239-244.

Dixon, Mr (quoted), 105, 202.

Doberan, 146.

Dodman, the, 91 .

Dog-fish, Black-mouthed, 338, 426.

" Lesser Spotted, 426.

Dogs, 11, 15, 32 fn., 57.

Dolphin, 30, 93.

" Bottle-nosed, 30, 94.

" White-beaked, 30, 94 .

" White-sided, 30, 94.

domesticus, 116.

Dormouse, 8, 24, 25, 28, 69 .

Dorset, 280.

Dory, John, 329, 361.

Dotterel, 5, 15, 101, 126, 263.

" Ringed, 261. 
dougalli, 128.

Dove, Ring, 108, 175, 244.

" Rock, 124, 245.

" Stock, 124, 245.

" Turtle, 124, 246.

Dover, 41, 157, 160, 181, 280, 373. draco, 328.

Dragonet, Gemmeous, 272 fn., $330,367$.

" Spotted, 330, 367.

Draining, effects of, 14.

“ Drumming ” of Snipe, 268.

Drummond's Echiodon, 333, 386.

Dublin, 217.

Duck, Buffel-headed, 123, 241.

" Eider, 123, 241.

" " King, 123, 241.

" " Steller's, 123, 242.

" Ferruginous, 123, 240.

" Harlequin, 123, 241.

" Long-tailed, 123, 241.

" Ruddy Sheld, 235.

" Sheld, 235.

" Tufted, 123, 240.

" "White-eyed," 240.

" Wild, 123, 236.

ductor, 329.

" Dunbird," 239.

" Dun cow," 431.

" Dung-bird," 284.

Dungeness, 6 .

Dunlin, 106, 127, 270.

Dunn, Mr Matthias (quoted), 396, $425,426,429$.

Durham, 195, 382.

Dusky Serranus, 326, 343.

" Skulpin, 272 fn., 367.

Eagle, Black, 212.

" Golden, 120, 212.

" Spotted, 120, 211.

" White-tailed, 120, 213.

L’arbóg, 8.

East Anglia, 249, 260, 272, 278.

eburnea, 129.

Ecaudata, 312.

Ecclesbourne, 286.

kicheneis, 328.

Echidnas, 38.

kichinorhinus, 339.

Echiodon, Drummond's, 333, 386.

Ectopistes, 295.

Eddystone, the, 16.

Eel, 53, 98, 319, 334, 394.

" Broad-nosed, 394.

" Conger, 5, 334, 395.

" Pout, 382.
Eel, Sharp-nosed, 394.

" Silver, 395.

Eggs of birds, 109.

" of reptiles, 300 .

Egret, Little, 121, 226.

Eider, 241.

" King, 241.

" Steller's, 242.

Elanus, 295.

elaphus, 29.

Elasmobranchii, 338.

Elbe, 287.

elegans, 116.

Elvers, 394.

Emberiza, 117.

Emberizina, 117.

Emu, 103.

encrascicholus, 334.

'Encyclopædia of Sport' (quoted), $51 \mathrm{fn}$.

Engraulis, 334.

Enniskillen, 177.

enucleator, 116.

eperlanus, 336.

epops, 119.

Erinaceida, 27.

Erinaceus, 27.

Erithacus, 113.

Ermine, 53.

erminea, 28.

"Erne," 213.

erythrina, 117.

erythrinus, 327.

erythrophthalmus, 335.

esculenta, 312.

Esocidee, 336.

Esox, 336.

Essex, 5, 138, 163, 191, 210.

Eton College, 233.

Eudromias, 126.

europaes (Pyrrhula), 116

" (Talpa), 27.

europaeus (Caprimulgus), 118.

" (Erinaceus), 27.

" (Lepus), 29.

excubitor, 115.

Exocoetus, 329.

exoletus, 332.

Extermination of species, 11, 25.

'Extinct British Animals' (quoted). $9,24$.

Extinct mammals, 9 .

Eye in fish, 322.

faber, 329 .

Fairlight Glen, 304.

falcinellus, 122. 
Falco, 121.

Falcon, Greenland, 121, 215.

" Gyr, 215.

" Icelaud, 121, 215.

" Peregrine, 121, 215.

" Red-footed, 121, 216.

Falconidae, 120.

Fallow-deer, 15, 17, 29, 85.

familiaris, 115 .

fario, 335, 411, 412.

Farmers, 12, 47, 48, 50, 75, 97, 210.

Farne Islands, 3, 241, 277, 278.

Faroë Islands, 285.

Father-Lasher, 327, 348.

'Fauna of Argyle' (quoted), 47, $59,60,64,65,80,305$.

'Fauna of Sutherland' (quoted), 345,363 .

'Fauna of the Outer Hebrides' (quoted), 73, 340, 353, 356, 366, 379.

Feathers, 101.

Felido, 28.

Felis, 28.

Felpham, 76.

Fen Country, 6, 14, 49, 54, 60, 162, 208, 223, 275 .

ferina, 123.

ferox, 336.

Ferrets, 16, 53.

ferrugineus, 295.

ferrum-equinum, 27.

"Fiddle-fish," 429.

'Field,' the (quoted), 25, 44, $55 \mathrm{fn}$., 77, 163, 200, 203, 214, 290.

Fieldfare, 112, 132, 134.

Field-mouse, Long-tailed, 25, 75 . " " Short-tailed, 77.

i Vole, 29, 77.

Field-work, need for, 19.

Fierasfer, 333.

Fifteen-spined Stickleback, 331, 374.

File-tish, 337, 417.

Finches, 116, 168-175.

Finners, 91.

Fins, 320.

inta, 334.

Firecrest, 113, 145.

"Fireflare, 433.

Fish, definition of a, 320 .

Fisher, Major (quoted), 47.

Fishes, 317-434.

Fishing-frog, 352.

Flamborough Head, 245.

Flamingo, 98, 122, 230. flammea, 119.

"Flapper Skate," 430.

Flat fish, 5, 322, 386.

flava, 115.

flavescens, 330.

flavicollis, 29.

flavipes, 128.

flavirostris, 116.

flesus, 334.

Flight of birds, 104.

Floods, Foxes in, 49.

" Mole in, 41.

Florence, 200.

Flounder, 92, 319, 334, 391.

$$
\text { " Pole, } 392 .
$$

Fluke, 391.

fluviatilis (Gobio), 335.

" (Perca), 326.

" (Podicipes), 131.

" (Sterna), 128.

Flycatcher, Pied, 115, 165.

" Red-breasted, 115, 165.

" Red-eyed, 295.

" Spotted, 115, 165.

Flying-fish, 329, 365.

fodiens, 27.

Food of birds, 106.

" of fishes, 323.

Foot in birds, 103.

Fork-beard, Greater, 333, 382.

" " Lesser, 333, 382.

Fork-tailed Petrel, 286.

Forth, 245, 411.

Foumart, 52.

Fowlsheugh, 291.

Fox, 11, 17, 18, 25, 28, 37, 48-51, 60,78 .

Fox-Shark, 338, 423.

fragilis (Anguis), 301.

Fratercula, 130.

"French Ray," 431.

'Fresh-water Fishes of Europe,' (quoted), 382, 391, 393, 400, 409.

Fresh-water Shark, 414.

Fringilla, 116.

Fringillido, 116.

Fringillino, 116.

Frog, Common, 6, 312, 313.

" Edible, 15, 312, 313.

Frogs, 61 .

"Frost-fish," 363.

frugilegus, 117.

Fulica, 125.

Fulicarioe, 125.

fulicarius, 126.

fuliginosa, 128.

Fuligula, 123. 
fullonica, 339.

Fulmar Petrel, 106, 130, 287.

Fulmarus, 130.

Fulton, Dr (quoted), 350.

fulvus (Charadrius), 126.

" (Gyps), 120.

funerea, 119.

"Furze-chat," 144.

fusca, 124.

fuscicollis, 127.

fuscus (Larus), 129.

" (Totanus), 128.

Fyfe, Lord, 10.

Gade, Three-bearded, 383.

Gadida, 332.

Gadus, 332.

Gadwall, 123, 237.

Gaetke, Dr, 3, 105.

galactodes, 113.

galbula, 115.

galerita, 330.

Galeus, 338.

gallicus, 126.

Gallino, 124.

Gallinago, 127.

Gallinula, 125.

gallinula, 127.

Gallinule, Martinique, 295.

gallivensis, 335, 411.

Galloway, 71, 187, 350 .

Galway Sea-trout, 335, 411.

Game Birds, 37, 97, 109, 247-255.

'Game Birds' (quoted), 109 fn., 255.

Gamekeepers, 11, 12.

Ganges, 94.

Gannet, 5, 102, 121, 221.

Gaper, 343.

Garfish, 329, 364.

Garganey, 123, 239.

Garrulus, 118.

garrulus (Ampelis), 115. " (C'oracias), 119.

garzetta, 121.

Gasterosteidae, 331.

Gasterosteus, 331.

gattorugine, 330.

Gattorugine, 330, 369.

Gavia, 128.

Gecinus, 118.

Gemmeous Dragonet, 272 fn., 330, 367.

'Geographical Distribution of Animals' (quoted), 8.

Germany, North, 107, 186, 187.

germo, 328.
Gibraltar, 420.

gigas, 326.

Gillaroo, 335, 411.

Gilthead, 327, 347.

giornce, 339.

Girella, 324.

giu, 120.

glacialis (Colymbus), 131.

" (Fulmarus), 130.

" (Harelda), 123.

gladiator, 30 .

gladius, 329.

glandarius (Coccystes), 119. " (Garrulus), 118.

glareola, 127.

Glareolido, 125.

Glareolus, 125.

glareolus, 29.

glauca, 329.

glaucion, 123.

Glaucus, 361.

glaucus (Carcharias), 338.

" (Lamus), 129.

Globe-fish, 337, 417.

Globicephalus, 30.

Glutinous Hag, 439.

Goat, 15.

"Goat-sucker," 191.

Gobiesocidae, 330.

Gobiidue, 329.

Gobio, 335.

gobio, 327.

Gobius, 329.

Goby, Black, 329, 366.

" Four-spotted, 330, 367.

" Nilsson's, 330, 367.

" Parnell's, 330, 367.

I Rock, 366.

" Spotted, 329, 366.

" Two-spotted, 330, 366.

"White, 330, 366.

Godwit, Bar-tailed, 128, 274.

" Black-tailed, 128, 275.

Goldcrest, 113, 144.

"Golden Back," 315 .

Golden Eye, 123, 240.

Golden Orfe, 404.

Golden Oriole, 13, 109, 115, 162.

Goldfinch, 108, 109, 116, 169.

Goldfish, 402.

Goldsinny, 376.

Goodwood, 4.

Jago's, 376.

Goosander, 102, 124, 243.

Goose, Bean, 122, 231.

" Bernicle, 122, 233.

" Brent, 122, 232. 
Goose, Grey lag, 122, 231.

" Laughing, 232.

" Red-breasted, 122, 232.

" Pink-footed, 122, 232.

" Snow, 122, 232.

" White-fronted, 122. 232.

Gordon-Cumming, 10.

Goshawk, 120, 213.

" American, 213.

gouanii, 330.

Gourneau, 349.

Grackle, Rustic, 295.

Gracula, 295.

graculus (Phalacrocorax), 121.

" (Pyrrhocorax), 118.

Graining, 405.

Grampus, 30, 92.

Grampus, 30.

Grassi, Professor, 395.

grayi, 336.

Grayling, 336, 413.

Great Auk, 9.

Great Bat, 33.

Great Grey Shrike, 104, 115, 163.

Great Lake Trout, 336, 411.

Greater Horseshoe Bat, 27, 36.

Greater Pipe-fish, 337, 416.

Grebe, Black, 294.

" Eared, 131, 294.

" Great Crested, 101, 103, 131, 293.

" Little, 101, 131, 294.

" Pied-billed, 295.

" Red-necked, 131, 293.

" Slavonian, 131, 294.

"Green Cod," 381.

"Green Linnet," 169.

Greenfinch, 116, 168.

Greenland, 174, 233, 348.

" Falcon, 121, 215.

" Shark, 339, 427.

" Whale, 90.

Greenshank, 128, 274.

gregarius, 126.

"Grey," 57.

"Grey Hen," 252.

Grey Shrike, 115.

"Grey Skate," 429.

"Grey Trout," 335, 411.

grillii, 331, 372.

griseigena, 131.

griseus (Grampus), 30.

" (Macrorhamphus), 127.

" (Notidanus), 338.

" (Nycticorax), 121.

" (Puffinus), 130. grisola, 115.

gronlandica, 28.

Grosbeak, Pine, 116, 176.

" Scarlet, 117, 175.

Grouse, Black, 125, 252.

" Red, 1, 6, 17, 18, 98, 125, 254.

Willow, 254.

Gruidae, 125.

Grus, 125.

grylle, 130.

grypus, 28.

Guardfish, 364.

Gudgeon, 6, 335, 402.

Guillemot, 5, 110, 130, 204, 289.

" Black, 130, 291.

" Brünnich's, 130, 291.

I Ringed, 289.

Guinea Pig, 15.

Gulf Stream, 2, 89.

Gull, Black-headed, 129, 281.

" Bonaparte's, 129, 282.

" Common, 129, 279.

Glaucous, 129, 282.

GreatBlack-backed, 129, 282. " " -headed, 129,281.

Herring, 129, 280.

Iceland, 129, 282.

Ivory, 129, 283.

Laughing, 281.

" Lesser Black-backed, 129, 282.

" Little, 129, 282.

" Mediterranean Blackheaded, 129, 281.

" Ross's 129, 283.

" Sabine's, 129, 283.

Gulls, 279-284.

Gunnel, 331, 370.

gunnellus, 331.

Günther, Dr (quoted), 431.

Gurnard, Armed, 328.

" Beaked, 351.

" Cuckoo, 350.

" Grey, 327, 350 .

" Lanthorn, 327, 351.

" Long-finned, 351.

" Red, 327, 350.

" Sapphirine, 327, 350.

gurnardus, $32 \pi$.

Streaked, 327, 350.

Gwiniad, 413.

Gymnodontes, 337.

Gyps, 120.

Gyr Falcon, 215.

Habitat of Fishes, 325. 
Haddlock, 332, 378.

Hamatopus, 126.

hositata, 130.

Hag-fish, 438.

Hairtail, 329, 363.

Hairy-armed Bat, 27, 33.

Hake, 332, 381.

Haliaëtus, 120.

haliaëtus, 121.

Halibut, 333, 389.

Halichoerus, 28.

Hammerhead, 338, 420, 422.

Hampshire, 4, 35, 43, 76, 99, 107 , $140,172,191,216,217,225,235$, $238,262,263,265,267,270,289$, $372,409$.

Hanoverian Rat, 16, 72.

Hare, Alpine, 24, 81.

" Blue, 29, 81 .

" Common, 11, 17, 29, 78.

"Irish, 25, 81 .

" Varying, 81.

Harelda, 123.

harengus, 334.

Harrier, Hen, 14, 120, 210.

" Marsh, 120, 210.

If Montagu's, 120, 210.

Harris, Cornwallis, 10.

'Harrow Birds' (quoted), 140.

Hart, Mr, 99.

Harting, Mr J. E. (quoted), 7 fn., $8,9,24,38,39,45$ fn., 55 fn., $70,81,165,214,230$.

Harvest-Mouse, 8.

Harvie-Brown, Mr J. A. (quoted), $47,53,59,60,64,65,73,80$, $251,274,305,340,344,345,353$, $356,363,366,368,379$.

Hastings, 280, 286, 304, 394.

Hawfinch, 116, 169.

Hazel-Hen, 254.

Hebrides, 3, 45, 47, 53, 55, 65, 73, $75,83,132,137,144,163,164$, $181,191,231,237,238,239,241$, $247,252,263,274,275,277,286$, 287, 291, 292, 353, 367, 368.

"Hedge-Accentor," 147.

Hedgehog, 27, 37-39, 41, 50, 58.

Hedge-Sparrow, 19, 109, 114, 147. ielena, 334.

Heligoland, 3.

'Heligoland as an Ornithological Observatory,' 3.

Helodromas, 109.

helvetica, 126.

hemigymnus, 336, 414.

Hemipode, Andalusian, 295.
"Hen-fish," 358.

Hengistbury Head, 219, 289.

Herodiones, 121.

Heron, 98, 103, 105, 121, 223.

" Buff-backed, 121, 226.

" Great White, 121, 226.

" Night, 121, 226.

" Purple, 121, 226.

" Squacco, 121, 226.

Herring, 334, 397.

" Gull, 129, 280.

Hertfordshire, 304.

hiaticula, 126.

Hibernating, 32.

hibernicus, 73.

Highgate, 178.

Highlands, 6, 11, 41, 50, 51, 54, 59, $69,81,83,142,145,153,159$, $160,166,210,212,217,242,243$, $245,255,315$.

"Hilling" of Ruffs, 272.

Himantopus, 126.

Hippocampus, 337.

Hippoglossoides, 334.

Hippoglossus, 333.

hipposiderus, 27.

hirtensis, 114.

Hirundinido, 116.

Hirundo, 116.

hirundo, 327.

hispida, 28.

'History of Scandinavian Fishes, A' (quoted), 408, 412.

histrionica, 123.

Hobby, 32, 121, 216.

Hog, 15.

Holocanthus, 326, 344.

Holocephali, 337.

Holt, Mr (quoted), 370.

Holyhead, 8.

Holy Island, 232.

Homelyn, 432.

Honey Buzzard, 121.

Hoopoe, 119, 200.

Hopley, Miss (quoted), 300.

Horses, 15.

hortensis, 113.

hortulana, 117.

hortulanus, 116.

Hound, Fox, 48-50.

" Otter, 18.

" Row, 338, 426.

" Smooth, 338, 420, 422.

"Houting," 413.

Hudson, Mr W. H. (quoted), 141.

Humpback Whale, $29,91$.

"Huss," 426. 
hybrida, 128.

Hydrochelidon, 128.

hyperboreus (Chen), 122.

Hyperoödon, 30.

(Phalaropus), 126.

Hypolais, 113.

hypoleucus, 127.

Ibididae, 122.

Ibis, Glossy, 122, 229.

"Ice-Bird," 199.

Iceland, $31 \mathrm{fn} ., 378$.

ichthyaëtus, 129.

icterina, 113.

icterus, 295.

ictinus, 120.

Ide, 404.

Identification of Birds, 110.

ignavus, 120.

ignicapillis, 113.

iliacus, 112.

imperialis, 329, 359.

India, 31, 50.

Indian Ocean, 357.

Insectivora, 27, 37-46.

interpres, 126.

Irish Fauna, 8, 24, 25, $55 \mathrm{fn}$.

" Hare, 25, 81.

"Names, 8, 40.

isabellina, 112.

islandus, 121.

Isle de Bourbon, 167.

Isle of Man, 3, 245, 291.

Isle of Wight, $3,6,144,164,289$, 290,340 .

ispida, 119.

Italy, 13, 344, 375 .

Iyngince, 119.

Iynx, 119.

Jack, 414.

Jackdaw, 111, 117, 182.

"Jack-Hurry," 284.

Jack-Snipe, 127, 269.

Jago's Goldsinny, 376.

Japan, 402.

Java, 10.

Jay, 14, 104, 118, 185.

Jefferies, Richard (quoted), 1.

Jesse, Mr (quoted), 12.

Jew-fish, 363.

julis, 332.

Jura, 59, 305.

Kea, 107.

Kent, 4, 107, 143, 161, 162, 190, 192, 197, 206, 217, 258.
Kerguelen, $31 \mathrm{fn}$.

Kestrel, 32, 104, 121, 217.

"I Lesser, 121, 217.

Keulemanns, Mr (quoted), 101.

Kilbrannan Sound, 379.

Kilkenny, 51.

"Killer," the, 92.

killinensis, 336, 412.

"Kingfish," 359.

Kingfisher, 98, 111, 119, 197. " Belted, 200.

"King of the Breams," 346 .

"King of the Herrings," 418.

"Kingston," 429.

"Kite," 388.

Kite, 14, 104, 120, 214.

" Black, 120, 214.

" Black-winged, 295.

" Swallow-tailed, 214.

Kittiwake, 129, 283.

" Knobber," 83.

Knot, 127, 271.

'Knowledge' (quoted), 208.

Knurrhahn, 349.

Labrax, 326.

Labrida, 331, 332.

Labrus, 331.

Lacerta, 301.

Lacertida, 301.

Lacertilia, 301.

Ladybird, 26.

Laemargus, 339.

laevis (Coronella), 301.

" (Mustela), 422.

" (Rhombus), 333.

Lagenorhynchus, 30 .

lagocephalus, 337.

Lagopus, 125.

lagopus, 120.

Lake Country, $47,59,74,81,83$, 263.

Lamna, 338.

Lamnidae, 338.

Lampern, 438.

lampetriformis, 331.

Lamprey, Mud, 438.

" River, 438.

il Sea, 437.

Lampris, 328.

Lancashire, 265.

lanceolatus, 333.

Landmark, Herr (quoted), $409 \mathrm{fn}$.

Landrail, 125, 256.

Land's End, 282, 289.

Laniidla, 115.

Lanius, 115. 
Lanthorn Gurnard, 327, 351. Lapland Bunting, 117, 178.

lapponica, 128.

lapponicus, 117.

Lapwing, 104, 126, 264.

Larida, 128. Sociable, 126, 265.

Larinoe, 129.

Lark, Calandra, 295.

" Crested, 118, 189.

" Sand, 261.

" Shore, 118, 189.

" Short-toed, 118, 189.

" Sky, 103, 118, 188.

" White-winged, 118, 189.

" Wood, 118, 188.

Larus, 129.

lascaris, 334.

Lascelles, Hon. Gerald (quoted), $6 \mathrm{fn}$., 85 .

Lateral Line in Fish, 322.

laterna, 333.

"Laughing Goose," 232.

" Laughing Gull," 281.

Launce, 333, 384.

" Lesser, 333, 385.

" Smooth, 333, 385.

"Laverock," 188.

Lea, 407.

"Leather grub," 39.

Le Court, 41.

Leghorn, 272, 346, 361.

Leicestershire, 51, 147.

leisleri, 27.

Lemon Dab, 392.

" Sole, 334, 392.

lentiginosus, 121.

Lepadogaster, 330.

Lepidopus, 329.

Leporida, 29.

Leptocephali, 395.

lepturus, 329.

Lepus, 29.

Lesser Horseshoe Bat, 27, 36.

Lesser Redpoll, 116, 174.

'Letters to Young Shooters' (quoted), 269.

leucas, 30.

Leuciscus, 335.

leucopsis, 122.

leucoptera, 128.

leucopterus, 129.

leucorodia, 122.

leucorrhoa, 130.

levenensis, 335.

Lichia, 329.

'Life-Histories of British Food-
Fishes' (quoted), 368, 370, 371

fn., 381, 395, 397.

'Life of the Fields' (quoted), 1.

Ligurinus, 116.

Lilford, Lord, 185, 209.

limanda, 334.

limandoides, 334.

Limicola, 127.

Limicoloe, 125-128.

Limosa, 128.

linaria, 116.

Lincolnshire, 281.

lineata, 327.

lineatus, 327.

Ling, 332, 381.

Linnæus, 86.

Jinnet, 116, 140, 173.

"Lintie," 173.

Linton, 285.

Liparis, 330.

Little Auk, 130, 291.

Littlehampton, 199, $220 \mathrm{fn}$.

Liverpool, 17.

livia, 124.

Lizard, the, $61,345,417$.

" Common, 301, 302.

" Green, 302.

" Sand, 301, 302.

Lizards, 111, 302, 303.

Loach, 335, 407.

" Spinous, 335, 408.

"Lobster," 54.

Local names, 8 .

Lochaber, 46.

Lochleven Trout, 335, 411.

Locustella, 114.

Lomond, Loch, 252, 413.

London, 165, 169, 181, 281.

"Iong Nose," 364.

Long-eared Bat, 27, 35.

longicauda, 127.

Lophius, 328.

Lophobranchii, 337.

Lord Londesborough's Snake, 306.

Lota, 332.

Lowestoft, 228.

Lowlands, 41.

Loxia, 117.

lucidus, 335.

lucius, 336.

lugubris, 115.

Lulworth, 144, 280, 288, 342 .

lumbriciformis, 337 .

Lumpenus, Sharp-tailed, 331, 371.

Lumpenus, 331.

Lumpsucker, 330, 367.

lumpus, 330. 
luna, 328.

Lundy Island, 3, 187, 221, 286, 287, 292.

lupus (Anarrhicas), 331.

" (Labrax), 326.

luscinia, 113.

luscinioides, 114.

luscus, 332.

lutea, 334.

Lutra, 28.

Luvarus, 329, 359.

Lydlekker, Mr (quoted), 10, 24, 40, $53,77$.

lyra (Callionymus), 330.

" (Trigla), 327.

Lythe, 380.

Machetes, 127.

M'Intosh, Prof. (quoted), 368, 370 , 371 fn., 381, 395, 397.

Mackerel, 322, 328, 354.

" Coly, 355.

" "Guide," 364.

" Horse, 359.

" Midge, 383.

" Spanish, 328, 356.

"Mackrelsture," 356.

Macpherson, Rev. H. A. (quotell), 246.

macqueeni, 125.

Macqueen's Bustard, 125, 260. macrocephalus, 30.

Macrorhamphus, 127.

macrura, 128.

Macrurida, 333.

macularius, 295.

maculata (Raia), 339.

" (Tringa), 127.

maculatus (Callionymus), 330. " (Labrus), 331.

Madagascar, 31.

magna, 295.

Magpie, 14, 104, 109, 112, 117 , 184.

" Maid," 430.

Maigre, 329, 363.

major (Dendrocopus), 118.

" (Gallinago), 127.

" (Lanius), 115.

" (Parus), 114.

" (Puffinus), 130.

Mallard, 236.

malleus, 338.

Mammals, 25-94.

" Bell on our, 24.

" Difficulties of observing our, 23.
Mammals, Extinct, 9.

" Lydekker on our, 24.

" Scant literature on our, 23.

Man. See Isle of Man.

Maori Rat, 72.

Mareca, 123.

marila, 123.

marinus, 129.

Market Drayton, 62.

'Marketable Marine Fishes' (quoted), 344, 349, 350, 352, 355, $362,368,370,378,391,397$.

Marten, Beech, 52 .

$$
\text { " Pine, 10, 18, 25, 28, } 51 .
$$

1" Stone, 52.

"Marten Cat," 51.

Martes, 28.

Martin, 116, 167.

" Purple, 295.

" Sand, 1]6, 168.

martinicus, 295.

martius, 296.

maruetta, 125.

Mary Sole, 392.

Massachusetts, 97.

Masterman, Mr (quoted), $370 \mathrm{fn}$., $371 \mathrm{fn}, 381,395,397$.

Maurolicus, 336, 414.

"Mavis Skate," 431.

maxima, 338.

maximus (Rhombus), 333.

Maxwell, Sir Herbert (quoted), 7 fn., 25 fn., 40 fn., $47,58,71,77$, 164, 185 fn., 252 fn., 265, 305.

"May-bird," 275.

Mealy Redpoll, 116, 174.

Mecklenburg, 138, 146, 186, 199, 294.

Mediterranean, 42, 343, 346, 355, $356,373,396,400,425,426,433$.

Megaptera, 29.

megastoma, 333.

Megrim, 333, 388.

melanocephala, 117.

melanocephalus, 129.

melanope, 115.

melanophrys, 129.

melanostomus, 338 .

melas, 30.

melba, 118.

Meles, 28.

melops, 332.

Melvin, Lough, 411.

Merganser, Hooded, 124, 244.

" Rerl-breasted, 124, 243.

merganser, 124. 
Mergulus, 130.

Mergus, 124.

merlangus, 332.

Merlin, 98, 121, 217.

Merluccius, 332.

Meropidae, 119.

Merops, 119, 295.

merula, 112.

Mesoplodon, 30.

Mevagissey, 91, 346, 360, 396, 426, 429.

Mexico, 396.

Michelet (quoted), 167.

microcellata, 339.

microcephalus (Lamargus), 339.

Microtus, 29. (Pleuronectes), 334.

Middlesex, 143, 176.

Middleton, 47.

migrans, 120.

Migration of birds, 105.

" $\quad$ fishes, 324

migratorius, 295.

miliaria, 117.

Millais, Mr J. G. (quoted), 69, 80, $85,86,109,255$.

Miller's Thumb, 327, 347.

Milvus, 120.

Minnow, 335, 405.

minor (Dendrocopus), 118.

" (Lanius), 115.

minuta (Ardetta), 121.

" (Sterna), 128.

" (Tringa), 127.

minutilla, 127.

minutus (Gadus), 332.

" (Gobius), 329.

" (Larus), 129:

" (Mus), 29.

" (Sorex), 27.

mixtus, 331.

Mocking Bird, 26.

modularis, 114.

mola, 337.

Mole, 8, 27, 39-43.

Molge, 312.

mollissima, 123.

Molva, 332.

monedula, 117.

"Mongrel Skate," 429.

Monk Fish, 428.

monoceros, 30.

Monodon, 30.

monstrosa, 337.

montagui, 330.

Montagu's Blenuy, 330, 369.
Montagu's Harrier, 120, 210.

montanus, 116. Sucker, $330,368$.

Monticola, 112.

montifringilla, 116.

Moorhen, 61, 125, 225, 257.

Moray Firth, 363.

morinellus, 126.

Morocco, 201.

morrhua, 332.

"Morris," 395.

Morse, 66.

Motacilla, 115.

Motacillido, 115.

Motella, 333.

"Mother Carey's Chickens," 286.

"Moudiewarp," 41.

Moulting, 101, 300.

"Mountain Finch," 173.

Mountain Hare, 6.

"Mountain Linnet," 175.

'Mountains of California, The' (quoted), 149.

Mouse, Common, 29, 73.

" Harvest, 29, 74.

" Long-tailed Field, 25, 75.

" Short-tailed Field, 77.

"Wood, 29, 75.

i Yellow-necked, 29, 74.

Mouse-coloured Bat, 27, 34.

Mouth and Teeth of Fish, 321.

Mudeford, 409.

Mugil, 331.

Mugilida, 331.

Muir, Mr (quoted), 149.

Muirhead, Mr (quoted), 14, 225

fn., 231 fn. $232 \mathrm{fn}$.

Mull, 83, 305.

Mull of Kintyre, 349.

Mullet, Grey, 322, 373.

" Red, 327, 344.

" Thick-lipped, 331, 373.

" Thin-lipped, 331, 373.

Mullida, 327.

Mullus, 327.

Muroena , 334, 396.

Ir uranidue, 334.

muraria, 115.

Muridae, 29.

murinus, 27.

"Murr," 280.

Murry, 334, 396.

Mus, 29.

Muscardinus, 28.

Muscicapa, 115.

Muscicapida, 115.

musculus (Balanoptera), 29. 
musculus (Mus), 29.

musicus (CYynus), 122. " (Turdus), 112.

Musk Rat, 18.

Mustela, 28, 422 .

mustela, 333.

Mustelidoe, 28.

Mustelus, 338.

mutus, 125.

Myliobatidoe, 339.

Myliobatis, 339.

Myna, 295.

Myoxidce, 28.

mystacinus, 27.

noevia (Aquila), 120.

" (Locustella), 114.

Nansen, 66.

Naples, 356.

Narwhal, 30, 93.

natrix, 301.

nattereri, 27.

Natterer's Bat, 27, 34.

Natterjack, 312, 315.

Naucrates, 329.

Neagh, Lough, 413.

Needles, The, 284.

Nemachilus, 335.

Neophron, 120.

Nerophis, 337.

Nests, 107.

Newcastle, 193.

New Forest, 6, 34, 67, 78, 83, 85, $86,151,154,203,253,268,299$, $305,306$.

'New Forest, The' (quoted), 85.

New South Wales, 4.

Newlyn, Alderman (quoted), 404.

Newt, Common, 312, 316.

" Great Water, 312, 316.

" Palmated, 312, 316.

" Smooth, 316.

Newts, 315, 316.

New Zealand, 13, 23, 26, 72, 107, 170,363 .

niger, 329.

Nightingale, 7, 26, 98, 103, 104, $113,140$.

Nightjar, 97, 98, 102, 103, 109, $118,191$.

" Egyptian, 118, 193.

nigra (Ciconia), 122.

Egyptian, 118, 193.

" (Hydrochelidon), 128.

" (OEdemia), 124.

nigricollis, 131.

nigripinnis, 335, 411. nilssoni, 330 .

nisoria, 113.

nisus, 120.

nivalis, 117.

nobiliana, 339.

noctua, 119.

noctula, 27, 33.

Noctule, 27, 33.

Noddy, 129, 279.

Norfolk, 174, 210, 229, 237, 242, 270, 282, 287, 294, 404, 406.

Norfolk Broads, $6,45,60,150,211$, $217,223,226,293,406$.

North Sea, 359, 392, 399.

Northamptonshire, 209.

Northumberland, 174, 205, 214, 273.

norvegicus (Sebastes), 327.

" (Zeugopterus), 333.

Norway Bullhead, 327, 349.

" Haddock, 347.

" Pout, 332, 379.

" Rat, 16, 72.

Norwegian fjords, 65 .

Notidanidoe, 338. Topknot, 333, 389.

Notidanus, 338.

Notts, 193, 240.

Nucifraga, 117.

" Numb-fish," 433.

Numenius, 128.

"Nun," 242.

Nurse, 338, 425.

Nutcracker, 117, 184.

Nuthatch, 114, 153.

Nyctala, 119, 295.

Nyciea, 119.

Nycticorax, 121.

nyroca, 123.

Oar-Fish, Banks's, 331, 372.

Oblong Sunfish, 337, 417.

obscura, 327.

obscurus (Anthus), 115.

$$
\text { " (Puffinus), } 130 .
$$

oceanicus, 130.

Oceanites, 130.

Oceanodroma, 130.

ocellaris, 330.

ochropus (IIelodromas), 109.

$$
\text { " (Totanus) } 127 .
$$

Odontoglossae, 122.

Edemia, 124.

OEdicnemida, 125.

Edicnemus, 125.

onanthe, 112.

onas, 124. 
Estrelata, 130.

old Wife, 327, 346.

olivaceus, 295.

olor, 122.

Opah, 328, 359.

Ophidia, 301.

Ophidiida, 333.

ophidion, 337.

Ophidium, Bearded, 333, 385.

Ophidium, 333.

Orca, 30.

orcadensis, 335.

Orcynus, 328.

Orfe, 404.

Oriole, Golden, 13, 109, 115, 162.

Oriolidae, 115.

Oriolus, 115.

Orkney Trout, 335, 411.

Orkneys, 2, 3, 90, 94, 137, 172, 205, $209,234,241,263,275,291$.

Ormerod, Miss, 12 fn.

orphea, 113.

Orphean Warbler, 113, 142.

Orthagoriscus, 337.

Ortolan Bunting, 117, 178.

Osmerus, 336.

Osprey, 121, 217.

ostralegus, 126.

Ostrich, 103.

Otilidae, 125.

Otis, 125.

Otocorys, 118.

Otter, 17, 18, 25, 28, 57, 60-63.

Otus, 119.

Ouse, 382, 411, 414.

Ousel, Ring, 6, 112, 132, 135.

" Water, 148.

'Outdoor Life in England' (quoted), 47.

owenii, 327 .

Owl, Barn, 119, 205.

" Eagle, 120, 209.

" Hawk, 119, 209.

" Little, 119, 208.

" Long-eared, 119, 207.

" Saw-whet, 295.

" Scops, 120, 209.

" Short-eared, 6, 119, 207.

" Snowy, 119, 209.

" Tawny, 119, 208.

" Tengmalm's, 119, 208.

Owls, 6, 32, 103, 119, 205-209.

"Owls," 432.

" Ox-bird," 270.

Oxen, 15.

" Wild, 15, 24.

Oxfordshire, 47, 187. oxyrhynchus (Coregonus), 336, 413.

(Raia), 339.

Oyster-catcher, 126, 266.

Paganellus, 330, 366.

paganellus, 330.

Pagellus, 327, 346.

Pagham, 4.

Pagophila, 129.

Pagrus, 327.

Pallas's Grey Shrike, 115, 163.

" Sand-grouse, 106, 124, 246.

palloni, 332 .

palmata, 312.

palumbarius, 120.

palumbus, 124.

palustris (Acrocephalus), 114.

" (Parus), 114.

Pammelas, 329.

Pandion, 121.

Pandora, 327, 346.

Panurida, 114.

Panurus, 114.

paradoxus, 124.

parasiticus, 129.

Paridae, 114.

Parkstone, 7.

parnelli, 330 .

Particoloured Bat, 27, 34 fn.

Partridge, 56, 98, 124, 249.

" Freuch, 249.

Parus, 114. Freuch, 249.

parva (Muscicapa), 115.

" (Porzana), 125.

parvulus, 114.

Passer, 116.

Passeres, 112-118.

pastinaca, 339.

Pastor, 117.

“Pastor, Rose-coloured," 180.

pavonina, 295.

Payne-Gallwey, Sir R. (quoted), 32 fn., 230, 269.

Peak Country, 51.

Peal, 412.

Pediculati, 328.

Peewit, 264.

pelagica, 130.

Pelamid, 357.

Pelamys, 328.

pelamys, 328.

Pelecanida, 121.

Pelias, 301.

Pelican, 219. 
pellucida, 330.

Pembrokeshire, 221.

penelope, 123.

Penn pond, 225.

Pennant (quoted), 402.

pennantii, 336, 414 .

Perca, 326.

Perch, 6, 326, 340.

Perches and Sea-Breams, 340-347.

Perching Birds, 132-189.

Percidae, 326.

perciformis, 329 .

percnopterus, 120.

Perdix, 124.

Peregrine, 104, 121, 215, 264.

peregrinus, 121.

perisii, 336.

Peristethus, 328.

Pernis, 121.

perspicillata, 124.

Perthshire, 173.

Petersfield, 401.

Petrel, Bulwer's, 130, 287.

" Capped, 130, 287.

" Fork-tailed, 286.

" Fulmar, 106, 130, 287.

" Leach's, 130, 286.

" Storm, 130, 286.

" Wilson's, 130, 287.

Petroïca, $] 38$.

Pevensey, 4.

phocopus, 128.

Phalacrocorax, 121.

Phalarope, American, 295.

" Grey, 101, 126, 266.

" Red-necked, 101, 126, 267.

Phalaropus, 126, 295.

Phasianide, 124.

Phasianus, 124.

Pheasant, 15, 17, 98, 109, 124, 247.

philadelphia, 129.

philippinus, 295

Phoca, 28.

Phocaena, 30.

Phocidae, 28.

phoniceus, 295.

Phoenicopterida, 122.

Phoenicopterus, 122.

phonicuv'us, 113.

pholis, 330.

phoxinus, 335.

phragmitis, 114.

Phycis, 333.

Phylloscopus, 113.

Physeter, 30.

Physeterida, 30. l'hysostomi, 334.

Pica, 117.

Picarice, 118.

Picidae, 118.

Picina, 118.

Picked Dog, 426.

pictus, 330.

Picus, 296.

Pigeon, Cape, 295.

" Passenger, 295.

"Wood, 124, 128, 244.

Pike, 6, 336, 414.

" Saury, 329, 365.

pilaris, 112.

Pilchard, 334, 398.

pilchardus, 334 .

Pilot, Black, 329, 361.

Pilot-fish, 329, 360.

" -whale, 92.

Pine Grosbeak, 116.

" Marten, 10, 18, 25, 28, 51.

Pink Brame, 332, 376.

Pintail, 123, 237.

Pipe-fish, Broad-nosed, 337, 415.

" Greater, 337, 416.

" Snake, 337, 416.

" Straight-nosed, 337, 416.

" Worm, 337, 416.

“Piper," 327, 351.

Pipistrelle, 27, 33.

pipistrellus, 27.

Pipit, Meadow, 115, 160.

" Red-throated, 115, 161.

" Richard's, 115, 161.

" Rock, 115, 161.

" Tawny, 115, 161.

" Tree, 115, 159.

" Water, 115, 161.

Pipits, 159-161.

Pisa, 156.

piscatorius, 328.

Pisces, 326.

Plaice, 334, 390.

Plain Bonito, 328, 356.

Platalea, 122.

Plataleido, 122.

Platessa, 334.

platyrhynchus, 127.

Plecotus, 27.

Plectognathi, 337.

Plectrophenax, 117.

Plegadis, 122.

Pleuronectes, 334.

Pleuronectida, 333.

Plover, Caspian, 295.

" Golden, 126, 263.

" Green, 264. 
Plover, Grey, 126, 263.

"Kentish, 126, 262.

"Killdeer, 126, 263.

" Lesser Golden, 126, 263.

" Little Ringed, 126, 262.

" "Norfolk," 261.

" Ringed, 126, 261.

pluvialis, 126.

Plymouth, 187, 242, 344, 373, 428. Pochard, 123, 239.

" Red-crested, 123, 240. podiceps, 295.

Podicipedida, 131.

Podicipes, 131.

Podilymbus, 295.

"Podleys," 381.

Pogge, 328, 351.

Polar fowl, 3, 283, 291, 292.

Pole Dab, 334, 392.

" Flounder, 392.

Polecat, 8, 10, 25, 28, 52, 53, 55 .

Polewig, 366.

Polish Swan, 234.

pollachius, 332.

Pollack, 5, 332, 380.

Pollan, 336, 413.

pollan, 336.

Polperro, 417.

Polruan, 280.

Polyprion, 326.

pomatorhinus, 129.

pomeranus, 115.

pompilus, 329.

Poole, 140, 157, 234, 239.

Poor Cod, 332, 379.

Pope, 326, 342.

Porbeagle, 338, 420, 422.

Perphyrio, 295.

Porpoise, 30, 92, 93.

" Round-headed, 30, 92.

Port Jackson Shark, 223, 420.

Porzana, 125, 295.

Pottinger, Sir H. (quoted), 252.

Poultry, 15, 50.

Pout, 332, 378.

" Norway, 332, 379.

" Pout," 39.

Poutassou, 332, 381.

poutassou, 332.

Pouting, 378.

Powan, 336, 413.

Power Cod, 332, 379.

pratensis (Anthus), 115.

" (Crex), 125.

Pratincola, 112.

pratincola, 125.

Pratiucole, 125, 261. presbyter, 331.

Preservation of Gamie, 17, 47, 97.

"Pride," 438.

Pristiurus, 338.

Procellaria, 130.

Procellariidae, 130.

Progne, 295.

proregulus, 113.

Protection of fauna, 17, 25, 97.

Ptarmigan, 6, 101, 125, 255.

Pterocletes, 124.

Pteroclidoe, 124.

Pteropus, $31 \mathrm{fn}$.

pubescens, 296.

Puffin, 5, 111, 130, 291.

Puffinus, 130.

pugnax, 127.

punctatus (Zeugopterus), 333.

pungitus, 331.

Purple Heron, 121, 226.

" Sandpiper, 127, 271.

purpurea (Ardea), 121.

pusilla, 117. (Progne), 295.

putorius, 28.

Pycnonotus, 296.

Pygopodes, 130.

Pyrrhocorax, 118.

Pyrrhula, 116.

quadricornis, 327.

quadrimaculatus, 330.

Quail, 6, 124, 250.

Queensland, 172, 228, 358, 396, 423.

Querquedula, 123.

Rabbit, 25 fn., 29, 50, 52, 55, 61, 82.

"Rabbit-Fish," 382, 418.

radiata, 339 .

Raia, 339.

raii (Brama), 328.

" Motacilla), 115.

Raiidae, 339.

Rail, Land, 125, 256.

" Water, 125, 257.

Rails and Crakes, 256-259.

Rainbow Wrasse, 332, 377.

"Rain-Goose," 292.

Rallida, 125.

ralloides, 121.

Rallus, 125.

Ramsgate, 182.

Rana, 312.

Raniceps, 333.

Ranid $2,312$. 
raninus, 333.

Rat, Black, 10, 16, 29, 71 .

" Brown, 16, 29, 72.

" Hanover, 16, 72.

" Musk, 18.

I" Norway, 16, 72 .

Rats, 56, 67, 71-73.

Ratton, 71.

rattus, 29.

Raven, 104, 117, 182.

Ray, Eagle, 339, 434.

" French, 431.

" Homelyn, 339, 432.

" $\mathrm{Ox}, 339,434$.

" Painted, 339, 432.

" Sandy, 339, 432 .

" Shagreen, 339, 431.

" Sharp-nosed, 431.

" Starry, 339, 432.

" Sting, 339, 433.

" Ray-mouthed Dog," 422.

Ray's Bream, 328, 358.

Razorbill, 130, 288.

Recurvirostra, 126.

Red Band-fish, 331, 371.

" Deer, 17, 29, 83.

" Gurnard. 327, 350.

" Mullet, 327, 344.

" Sea, 100, 277.

Redbreast, 106, 113, 138.

Redpoll, Lesser, 116, 174.

" Mealy, 116, 174.

Redshank, 15, 128, 274. " Spotted, 128, 274.

Redstart, 113, 137 .

" Black, 113, 138.

Redwing, 112, 134.

"Red Eye," 404.

"Reed Pheasant," 150.

"Reed Sparrow," 178.

Reedling, Bearded, 6, 10, 14, 114, 150.

Reeve, 272.

Regalecus, 331.

Regulus, 113, 296.

Reindeer, 9.

religiosa, 295 .

Remora, 328, 357.

remora, 328.

Reproduction of fishes, 324 .

Reptile, definition of, 299.

Respiration in fishes, 323.

Rhina, 339.

Rhinida, 339.

Rhinolophida, 27.

Rhinolophus, 27.

Rhodostethia, 129.
Rhombus, 333.

Rhytina, 9.

richardi, 115.

Richmond Park, 144, 160, 225.

ridibundus, 129.

" Rig," 421.

Ring Dove, 108, 175, 244.

it Ousel, 6, 112, 132, 135.

Ringed Dotterel, 261.

" Guillemot, 289.

" Plover, 126, 261.

" Snake, 301, 306.

Ringwood, 140, 147.

riparia, 116.

Rissa, 129.

Risso's Grampus, 30, 93.

Roach, 335, 403.

Robin, 106.

" American, 135.

rochei, 328.

Rock-cook, 332, 376.

" Goby, 366.

Rockling, Three-bearded, 333, 383.

" Five-bearded, 333, 383.

Rockyll, 3. Four-bearded, 333, 383.

Rodentia, 28.

Rodents, 25, 66-82.

Roebuck, Mr (quoted), 47, 54, 59, 71, 238 .

Roedeer, 8, 17, 29, 85.

Roller, 119, 200.

Rome, 342 .

" Abyssinian, 200.

Rook, 12, 117, 180.

Roosevelt, Mr, 10.

Rorqual, Common, 29, 91.

" Lesser, 29, 91.

" Rudolphi's, 29, 91.

" Sibbald's, 29, 91.

rosea, 129.

roseus (Pastor), 117.

" (Phoenicopterus), 122.

rosmarus, 28.

Ross, 242, 340, 342.

Rostock, 348 .

Rostocker Heide, 186.

rostrata, 29.

rostratus, 30.

"Rosy Bullfinch," 175.

Rough-legged Bat, $27,34 \mathrm{fn}$.

'Rough Notes' (quoted), 222.

Round-headed Porpoise, 30, 92.

Row Hound, 426.

'Royal Natural History,' The (quoted), 363.

rubecula, 113. 
rubescens, 331.

rubetra, 112.

rubicola, 112.

Rudd, 335, 404.

"Rudder-fish," 361.

rufa, 124.

rufescens (Cannabina), 116.

$$
\text { " (Tryngites), } 127 .
$$

Ruff, $6,10,14,101,127,272$. (Fish), 342.

muficollis (Bernicla), 122.

" (Caprimulgus), 118. rufina, 123.

rufus, 113.

Rugby School N.H.S. (Secretary quoted), 181.

mupestris (Coryphanoides), 333, 386.

\section{" (Ctenolabrus), 332.}

'Rural Bird Life' (quoted), 202. Ruskin, Mr (quoted), 13.

Russia, 282.

rustica (Emberiza), 117.

" (Hirundo), 116.

"I Pica), 117.

rusticula, 127.

Ruticilla, 113.

rutilus, 335.

Rye Harbour, 394.

Sabine's Gull, 129, 283. sabinii, 129 . Snipe, 269.

"Sail-fish," 424.

St Alban's Head, 289.

St Andrews, 370, 385.

St Hilaire, 33,36 .

St Kilda, 3, 286, 287.

Saith, 380. Wren, 114, 155

Salamandrida, 312.

salar, 335, 411, 412.

Salmo, 335.

Salmon, 64, 90, 335, 408.

Salmon Trout, 336.

Salmonida, 335.

salvelinus, 336, 412.

salviani, 338, 426.

Salvin, Mr (quoted), 219.

Sand-eel, 353.

Sanderling, 127, 272.

Sandpiper, Bartram's, 127, 273.

Bonaparte's, 127, 270.

" Bonapartes, 127, 270.

" Buff-breasted, 127, 272.

" Common, 127, 273.

" Curlew, 127, 271.
Sandpiper, Green, 127, 273.

Marsh, 295.

Pectoral, 127, 270.

Purple, 127, 271.

Sharp-tailed, 127, 270.

Solitary, 128, 273.

Spotted, 295.

Wood, 127, 273.

Sand-smelt, 372

Sapphirine Gurnard, 327, 350.

sarda, 328.

Sardine, 398.

Sark, 71 .

Sars, Prof. (quoted), 378.

Saunders, Mr Howard (quoted), $99,101,195,210,211,214,226$, 230, 234, 240, 256, 263, 268, 279. saurus, 329.

Saury Pike, 329, 365.

Sawtish, 424.

saxatilis, 112.

Saxicola, 112.

Scabbard-fish, 329, 363.

Scad, 329, 359.

"Scaldback," 388.

Scald-fish, 333, 388.

Scale-rayed Wrasse, 332, 376.

Scales of Fish, 320.

scandiaca, 119.

Scandinavia, 175, 247, 251, 254, 267, 270.

Scarlet Grosbeak, 117, 175.

"Scart," 221.

Scaup, 123, 240.

Scent, 51 fn.

schoeniclus, 117.

School Shark, 421.

Sciæna, 363.

Sciana, 329.

Scianida, 329.

Scilly Islands, 1, 3, 263, 278, 286, 292.

Sciurida, 28.

Sciurus, 28.

Sclerodermi, 337.

Scolephagus, 295.

Scolopacida, 126.

Scolopax, 127.

scolopax (Centriscus), 331.

Scomber, 328. (Edicnemus), 125.

scomber, 328.

Scomberidae, 328.

Scombresocida, 329.

Scombresox, 329.

Scops, 120, 295.

Scorponidae, 327. 
scorpius, 327.

Scoter, Black, 124, 242.

" Surf, 124, 242.

" Velvet, 124, 242.

scoticus, 125.

Scotton, 281.

Scrope (quoted), 409.

Scylliida, 338.

Scyllium, 338.

Sea-Adder, 416.

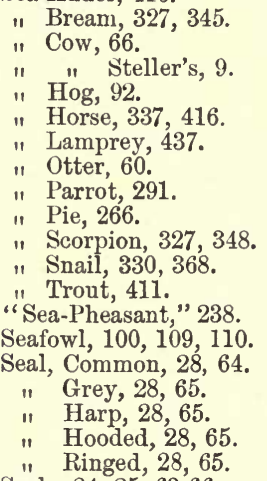

Seals, 24, 25, 63-66.

Sebastes, 327.

Seebohm, Mr (quoted), 13.

"Seed-bird," 159.

Seeley, Mr (quoted), 382, 391, 393, 399, 400, 401, 403, 405, 409.

segetum, 122.

Seine, 403.

Selache, 338.

Selachii, 338.

'Selborne,' White's (quoted), 43, 133.

septentrionalis, 131.

Serin, 116, 170.

Serinus, 116, 295.

Serotine, 27, 33.

serotinus, 27, 33 .

Serranus, Dusky, 326, 343.

Serranus, 326.

$$
\text { " Smooth, 326, 343. }
$$

scrrator, 124.

Severn, 65, 342, 399, 409, 414, 419, 437.

Sewin, 412.

Shad, Allis, 334, 399.

" Twaite, 334, 399.

Shag, 121, 220.

Shakespeare Cliff, 6 .
Shannon, 409, 411, 413.

Shanny, 330, 369.

Shark, Basking, 338, 424.

" Blue, 338, 420.

" Fox, 338, 423 .

" Greenland, 339, 427.

" Porbeagle, 338, 420-422.

" Six-gilled, 338, 425.

" Spinous, 339, 427.

"Shark-ray," 429.

Sharpe, Dr Bowdler (quoted), 174, 181, 209.

Sharp-tailed Lumpenus, 331, 371.

Shearwater, Dusky, 130, 288.

$\begin{array}{ll}" & \text { Great, 130, } 288 . \\ \text { " } & \text { Manx, 130, } 287 . \\ \text { " Sooty, 130, } 288 .\end{array}$

Sheep, 15. Sooty, 130, 288.

Sheld-duck, 122, 235, 243. " Ruddy, 122, 235.

Sherwood Forest, 182.

Shetlands, 3, 172, 173, 177, 178, 181, 191, 205, 209, 213, 241, 254, $261,263,271,275,284,287,291$, 292.

Short Sunfish, 337, 417.

Short-eared Ow], 6, 119, 207.

Shoveller, 123, 229, 238.

Shrew, Common, 27, 44.

" Lesser, 27, 43, 45.

" Water, 27, 45.

Shrews, 8, 26, 43-46.

Shrike, Great Grey, 104, 115, 163.

" Lesser Grey, 115, 163.

" Pallas's Grey, 115, 163.

" Red-backed, 115, 163.

I" Woodchat, 115, 164.

Shropshire, 176.

"Shufflewing," 147.

sibbaldi, 29.

Siberian birds, 13, 134, 191, 263, 270.

sibilatrix, 113.

sibirica, 118.

sibiricus, 112.

Sicily, 395.

Silver Dog, 421.

" Whiting, 379 .

Siphonostoma, 337.

Siskin, 98, 116, 169.

Sitta, 114.

Sittida, 114.

Six-gilled Shark, 338, 425.

Skate, Common, 339, 429.

" Flapper, 430.

" Long-nosed, 339, 431.

" Sharp-nosed, 339, 431. 
Skipler, 365.

Skula, Arctic, 285.

" Common, 103, 129, 284

" Long-tailed, 129, 285.

" Pomatorhine, 129, 284.

" Richardson's, 129, 285.

". Skye, 144.

Skylark, 105, 118, 188.

Slapton Ley, 404.

Sloughing of Reptiles, 300 .

Slow-worm, 301, 303.

"Small-eyed Ray," 432.

Small-mouthed Wrasse, 376.

Smear-dab, 391.

Smelt, Sand, 372.

" True, 336, 412.

Smew, 124, 242.

Smith, Mr C. (quoted), 14.

Smitt, Herr (quoted), 408, 412.

Smooth Hound, 338, 420, 422.

" Serranus, 326, 343.

" Snake, 301, 307.

Snake, Common, 306.

" Fish, 385.

" Pipe-fish, 337, 416.

" Ringed, 301, 306.

" Smooth, 301, 307.

Snakes, 6, 8, 304-307.

Snipe, Common, 6, 32 fn., 127, $247,269$.

Double, 268.

Great, 127, 268.

Half, 269.

Jack, 127, 269.

Red-breasted, 127, 269.

Sabine's, 269.

Solitary, 268.

Summer, 273.

"Snip-nosed Mullet," 361.

Societies for protecting Birds, 97.

Solan Goose, 221.

Sole, 334, 393.

" "Bastard," 393.

" French, 393,

" Lemon, 334, 392.

" Mary, 392.

" Sand, 334, 393.

Solea, 334 .

solitarius, 128.

Solenette, 334, 394.

Solway, 278.

Somateria, 123.

Somerset, 83, 177, 210, 260, 304.

Sorex, 27.

Soricidoe, 27.

Sonthampton, 342.

Southbourne-on-Sea, 15.
Southwell, Mr (quoted), $145 \mathrm{fn}$., 230.

Spain, 391.

Spallanzani, 32.

Spanish Bream, 327, 346.

" Mackerel, 328, 356.

Sparidoe, 327.

Sparling, 412.

Sparrow, Hedge, 19, 109, 114, 147.

" House, 108, 110, 116, 170.

" Tree, 110, 116, 172.

" White-throated, 295.

Sparrow-Hawk, 120, 213.

Spatula, 123.

"Spayad," 84.

spectabilis, 123.

Speedy, Mr T. (quoted), 12, 47, 58.

Spermaceti, 89.

Sphyroena, 336.

spinachia, 331.

Spinacidae, 338.

spinosus, 339.

Spinous Loach, 335, 408.

" Shark, 339, 427.

spinus, 116.

spipoletta, 115.

Spoonbill, 122, 229, 238.

Sport, Animals preserverl for, 17, $18,48,50$.

'Sport in the Highlands' (quoted), 12,58 .

"Spotted Ray," 432.

Sprat, 334, 398.

smattus, 334.

Spur Dog, 338, 426.

Squatarola, 126.

squatina, 339.

Squirrel, 28, 52, 67-69.

Staffordshire, 382.

stagnatilis, 295.

stapazina, 112.

Starling, 104, 117, 134, 179.

" Meadow, 295.

11 Red-winged, 295.

" Rose-coloured, 117, 180.

Steele-Elliott, Mr J. (quoted), 213.

Steganopodes, 121.

stellaris, 121.

stelleri, 123.

Stercorariince, 129.

Stercorarius, 129.

Sterna, 128.

Sternina, 128.

Sternoptychida, 336 .

Stickleback, Fifteen-spined, 331, 374. 
Stickleback, Ten-spined, 331, 374. surmuletus, 327.

" Three-spined, 331, Surmullet, 327. $374 . \quad$ Surnia, 119.

Stilt, Black-winged, 126, $266^{\circ}$.

Surrey, 162, 197, $252 \mathrm{fn}$.

Sting-fish, 348.

Sting-Ray, 339, 433.

Stint, American, 127, 271.

" Little, 127, 270.

" Temminek's, 127, 271.

Stoat, 25, 28, 32, 53, 81 .

Stockton-on-Tees, 71.

stolidus, 129.

stomachichus, 335.

Stone Basse, 326, 343.

" Curlew, 125, ¿61.

" Marten, 52.

"Stone-biter," 371.

Stonechat, 112, 137.

Stonehaven, 291.

Stonehenge, 260.

Stork, Black, 122, 229.

" White, 122, 229.

Stornoway, 344.

Stour (Hampshire), 76, 217, 409.

Sussex, 4, 76, 146, 161, 176, 189, $262,270,286,373,429$.

Sutherland, 178, 231, 243, 414.

Swallow, 97, 98, 105, 112, 116, $165,166$.

Swallow, Tree, 296.

Swan, Bewick's, 122, 234.

" Mute, 122, 233.

1" Polish, 234.

" Whistling, 234.

" Whooper, 122, 234.

Swanage, 219.

Swift, 112, 118, 165, 190.

" Alpine, 118, 191.

" Needle-tailed, 118, 191.

Sword-fish, 329, 363.

Sydney, 72, 304, 419.

sylvatica, 28, 295.

sylvaticus, 29.

Sylvia, 113.

Stradling, Dr A. (quoted), 300, 304, 305, 306.

strepera, 123.

streperus, 113.

Strepsilas, 126.

striata, 127.

Striges, 119.

Strigida, 119.

Striped Wrasse, 331, 375.

Strix, 119.

Stromateidae, 329.

Sturgeon, 337, 418.

sturio, 337.

Sturnella, 295.

Sturnida, 117.

Sturnus, 117.

subarquata, 127.

subbuteo, 121.

Sucker, Connemara, 330, 368.

" Cornish, 330, 368.

" Double-spotted, 330, 368.

"Montagu's, 330, 368 .

Sucking-fish, 357.

suecica, 113.

Suez Canal, 419, 420.

Suffolk, 53, 214.

Suinart, Loch, 64 .

Sula, 121.

Sumatra, 87.

Sunfish, Oblong, 337, 417.

" Short, 337, 417.

"Sunfish," 359, 424.

Sylviinae, 113.

Syngnathidae, 337.

Syngnathus, 337.

Synotus, 27.

Syrnium, 119.

Syrrhaptes, 124.

Tachycineta, 296.

Tadorna, 122.

" Tadpole-Fish," 382.

Tail of birds, 103.

"Taily," 432.

Talpa, 27.

Talpida, 27.

tarda, 125.

Tarpon, 396.

Taunton, 146.

taxus, 28.

Tay, 409 .

Taylor's 'Half-Hours in the Green Lanes' (quoted), 320.

Teal, 123, 238.

" American Green-winged, 123, 238.

" Blue-winged, 123, 238.

Teleostomi, 326.

Teme, 414.

temmincki, 127.

temporaria, 312.

tencea, 335 .

Tench, 335, 405.

tengmalmi, 119.

superciliosus, 113.

Tern, Arctic, 128, 277. 
Tern, Black, 128, 278.

" Caspian, 128, 277.

" Common, 128, 276.

" Gull-billed, 128, 277.

" Little, 13, 128, 277.

" Roseate, 128, 278.

" Sandwich, 128, 277.

" Scopoli's Sooty, 128, 277.

" Sooty, 128. 277.

"Whiskered, 128, 279.

"White-winged Black, 128, 278.

Terns, 276-279.

Tetrao, 125.

Tetraonida, 125.

tetrax, 125.

tetrix, 125 .

Tetrodon, 337.

Thames, The, 64, 65, 136, 144, $158,163,178,199,233,238$, $254,277,279,342,349,366$, $399,401,402,407,410,419$.

Thickback, 334, 393.

"Thick-knee," 261.

Thornback, 339, 430.

"'Three-bearded Gade," 383.

Thresher Shark, 423.

Thrush, Black-throated, 112, 134. Gold-vented, 296.

Holm, $132 \mathrm{fn}$.

Mistle, 112, 132.

Rock, 112, 136.

Siberian, 112, 135.

Song, 104, 112, 132, 134.

Storm, 132.

White's, 112, 135.

Thrushes, 132-142.

Thymallus, 336.

Thynnus, 328.

thynnus, 328.

Tiber, The, 342.

Tichodroma, 115.

'Times,' the (quoted), 13 fn., 67 fn.

timidus, 29.

Timor Sea, 300.

Tinca, 335.

"Tinker," 374, 429.

tinnunculus, 121.

Tit, Bearded, 150.

" Blue, 114, 153.

1" Bottle, 151.

" Coal, 114, 152.

" Continental Coal, 152.

" " Long-tailed, 151.

" Crested, 114, 153.

" Great, 114, 151.
Tit, Long-tailed, 114, 151.

" Marsh, 114, 152.

tithys, 113.

"Titlark," 160.

Titmice, 150-153.

"Titterel," 275.

Toad, Common, 6, 89, 312, 314.

" "Cornish," 315 .

Toad-fish, 417.

tobianus, 333.

Tope, 338, 420, 421.

Topknot, 333, 389.

torda, 130.

" $\quad$ One-spotted, 333, 389

Torgoch, 336, 412.

Torpedinida, 339 .

Torpedo, 339.

Torpedo, 339, 433.

torquata, 112.

Torquay, 280.

torquilla, 119.

Torsk, 333, 382.

Totanus, 127, 295.

Trachinida, 328.

Trachinus, 328.

trachurus, 329.

Trachypterido, 331.

Trachypterus, 331.

Tree-Creeper, 103, 115, 153, 156.

" Pipit, 115, 159.

" Sparrow, 110, 116, 172.

Trent, 382, 411, 414.

Trichechidoe, 28.

Trichechus, 28.

Trichiurido, 329.

Trichiurus, 329.

tricirrata, 333.

tricolor, 326, 344.

tridactyla, 129.

Trigger-fish, 417.

Trigla, 327.

Tringa, 127.

trivialis, 115.

trochilus, 113.

Troglodytes, 114.

Troglodytid $\propto, 114$.

troile, 130.

Tropidonotus, 301.

Trout, 1, 335, 410.

Trumpet-fish, 375 .

truncatus, 337.

trutta, 336.

Trygon, 339.

Trygonide, 339.

Tryngites, 127. 
Tub-fish, 351.

Tubinares, 130.

Tunny, 328, 356.

" Long-finned, 356.

Turbot, 333, 387.

"Turbot," 390.

Turdidoe, 112-114.

Turdinoe, 112, 132.

turdoides, 113.

Turdus, 112.

Turnix, 295.

Turnstone, 126, 266.

Tursio, 30.

Turtle Dove, 124, 246.

"Turtle Dove," 291.

Turtles, 16, $17 \mathrm{fn}$.

Turtur, 124.

Tuscany, ]07, 157.

Twaite Shad, 334, 399.

Tweed, 410.

Twigmore, 281.

Twite, 116, 175.

typhle, 337.

Ullswater, 413.

undata, 113.

Ungulata, 29.

unimaculatus, 333.

United States, 353.

Upupa, 119.

Upupidae, 119.

urbica, 116.

Uria, 130.

urogallus, 125.

vandesius, 336.

Vanellus, 126.

variegata, 334.

varius, 112.

Vendace, 336, 413.

Ventnor, 399.

Vermin, 9, 37, 39, 58, 66, 71.

'Vertebrate Fauna of Bedford-

shire' (quoted), 215.

Vertebrates, the lowest, 437-439.

Vespertilio, 27.

Vespertilionida, 27.

vespertinus, 121.

Vesperugo, 27.

villosus, 296.

Viper, 6, 304.

vipera, 328.

Viperidee, 301.

Viperiformes, 301.

virens, 332.

Vireo, 295.

virgo, 125. viridis, 118

viscivorus, 112.

'Visitation of Pallas's Sand-

Grouse' (quoted), 246.

vitulina, 28.

vivipara (Lacerta), 301.

viviparus, 331.

vocifera, 126.

Voice of birds, 103.

Vole, Bank, 29, 78.

" Field, 29, 77.

" Red Field, 78.

" Water, 29, 56, 76.

Voles, 8, 25 fn., 55, 66, 76-78. volitans, 329.

Von Mosjvar (quoted), 62.

vulgaris (Acanthias), 338.

(Anguilla), 334.

(Barbus), 335.

(Belone), 329.

(Box), 327.

(Bufo), 312.

(Buteo), 120.

(Coccothraustes), 116.

(Conger), 334.

(Dentex), 326.

(Galeus), 338.

(Hippoglossus), 333.

(Leuciscus), 335.

(Liparis), 330.

(Lota), 332.

(Lutra), 28.

(Merluccius), 332.

(Molge), 312.

Molva), 332.

(Mustela), 28.

(Mustelus), 338.

(Pagrus), 327.

(Sciurus), 28.

(Solea), 334.

(Sorex), 27.

(Sturnus), 117.

(Thymallus), 336.

(Tinca), 335.

(Vanellus), 126.

vulpes (Alopias), 338.

" (Canis), 28.

Vulture, Egyptian, 120, 210.

Vulturida, 120.

$$
\text { " Griffon, 120, } 210 .
$$

Waders, 5, 109, 260-276.

Wagtail, 97 .

" Blue-headed, 115, 159.

" Grey, 115, 158.

" Pied, 115, 157.

" Water, 157. 
Wagtail, White, 115, 158.

" Yellow, 115, 159.

Wagtails, the, 157-159.

Wallace, $\operatorname{Dr} A$. R. (quoted), 8, 149 .

Wall-creeper, 115, 156.

Walmer, 206.

Walney Island, 3.

Walrus, 28, 63, 66 .

Warbler, Aquatic, 114, 146.

Barred, 113, 144.

Blackcap, 113.

Dartford, 113, 144.

Garden, 113, 143.

Grasshopper, 114, 147.

Great Reed, 113, 146.

Icterine, 113, 146.

Marsh, 114, 146.

Orphean, 113, 142.

Pallas's Willow, 113, 145.

Reed, 113, 146.

Rufous, 113, 146.

Savi's, 14, 114, 147.

Sedge, 104, 114, 147.

Yellow-browed, 113, 145 .

Warblers, 142-147.

Waterfowl, 99, 102, 103, 105.

Water-hen, 257.

" ousel, 148.

" pipit, 115, 161.

" rail, 125, 257.

" rat, 76 .

" shrew, 27, 45 .

" vole, 29, 56, 76 .

" wagtail, 157.

Waxwing, 115, 164.

Weasel, 8, 19, $25 \mathrm{fn} ., 28,41,55-56$.

Weever, Greater, $328,353$.

" Lesser, 328, 353.

West Indies, 363, 434.

Weymouth, 234, 287.

Whale, Cuvier's, 30, 92.

" Greenland, 90.

" Humpback, 29, 91.

" Right, 90.

" Southern, 29, 90.

" Sowerby's, 30, 91.

" Sperm, 91.

" Whalebone, 90.

" White, 30, 93.

"Whale-feed," 87.

Whalebone, 87, 88.

Whales, 86-92.

Wheatear, 112, 136.

$\begin{array}{ll}\text { " } & \text { Black-throated, 112, } \\ & 136 . \\ \text { " } & \text { Desert, 112, 136. } \\ \text { Isabelline, 112, 136. }\end{array}$

Whiff, 388.

Whimbrel, 15, 128, 275.

Whinchat, 106, 112, 137.

Whiskered Bat, 27, 35 .

"Whistling Swan," 234.

Whitaker, $\operatorname{Mr}$ (quoted), 83 .

White, Gilbert (quoted), 33, 37, $43,107$.

"Whitebait," 397, 398.

White Bream, 407.

" Goby, 330, 366.

" Whale, 30, 93.

"White Skate," 431.

Whitethroat, 56, 104, 113, 142.

" Lesser, 113, 142.

Whiting, 5, 332, 379.

" Couch's, 381.

" Pout, 378.

"Whittret," 56.

Whooper, 122.

Wigeon, 123, 237.

" American, 123, 237.

Wight. See Isle of Wight.

Wigtownshire, 58.

Wild Cat, $8,16,18,24,25,28$, 46-48.

Wild Cattle, 15, 24.

Willow Grouse, 254.

." Wren, 113, 145.

Wilson, Mr W. N. (quoted), 181.

wilsoni, 295.

Wincanton Field Club Proceedings (quoted), 260.

Winchester, 56, 164.

Windermere, 411.

"Windhover," 217.

Witch, 392.

Witherby, Mr (quoted), $6 \mathrm{fn}$., 208.

Wolf, 9, 14.

Wolf-fish, 331, 371.

wolfi, 113.

Wood Sandpiper, 127, 273.

" Wren, 113, 145.

Woodchat, 115, 164.

Woodcock, 6, $32 \mathrm{fn}$., 102, 105, 127, $144,247,267$.

"Woodcock Owl," 207.

“Woodcock Pilot," 144.

Woodlark, 118, 188.

Wood-mouse, 29, 75 .

Woodpecker, Black, 296.

$\begin{array}{ll}\text { " } & \text { Downy, } 296 . \\ \text { Golden-winged, } 296 . \\ \text { Great Spotted, 102, } \\ \text { " } \quad \text { 103, 118, 193. } \\ \text { " } \quad \text { Hairy, 103, 118, } 195 .\end{array}$


Woodpecker, Lesser Spotted, 118, "Yaffle," 195.

194.

Wood-pigeon, 108, 124, 244.

Worm Pipe-fish, 337, 416.

Wrasse, Baillon's, 376 .

" Rainbow, $332,377$.

" $\quad$ Scale-rayed, 332, 376.

" Small-mouthed, 376.

" Striped, 331, 375.

"Wreck-fish," 343.

Wren, 98, 114, 155.

" Ruby-crowned, 296.

" St Kilda, 114, 155.

" Willow, 113, 145.

" Wood, 113, 145.

"Wriggle," 385.

"Writing Lark," 177.

Wryneck, 119, 197.

Wye, 414.

Xema, 129.

Xiphias, 329.

Xiphiidoe, 329.

Yarrell's Blenny, 331, 370.

Yellow Ammer or Hammer, 104, $117,177$.

11 -necked Mouse, 29, 74.

Yellowshank, 128, 274.

Yorkshire, 47, 54, 59, 71, 81, 140, $143,144,145,175,201,210,211$, $216,217,226,232,238,254,274$, 287, 382, 414.

'Yorkshire Vertebrata' (quoted), $47,54,59,216,238$.

Zebus, 18.

Zeugopterus, 333.

Zeus, 329.

Ziphius, 30.

Zoarces, 331.

Zonotrichia, 295 .

'Zoologist, The' (quoted), 24, 38 fn., 45 fn., 55 fn., 75,145 fn.

Zygoena 338.

THE END. 



